\title{
PROCEDIMENTO PARA ESTUDO DA ESCOLHA MODAL EM VIAGENS REALIZADAS POR ESTUDANTES DE INSTITUIÇÕES DE ENSINO MÉDIO, MEDIADO PELA PSICOLOGIA SOCIAL
}

\section{ÂNGELA BEATRIZ SOUZA BERTAZZO}

TESE DE DOUTORADO EM TRANSPORTES DEPARTAMENTO DE ENGENHARIA CIVIL E AMBIENTAL 
UNIVERSIDADE DE BRASÍLIA

FACULDADE DE TECNOLOGIA

DEPARTAMENTO DE ENGENHARIA CIVIL E AMBIENTAL

PROCEDIMENTO PARA ESTUDO DA ESCOLHA MODAL EM VIAGENS REALIZADAS POR ESTUDANTES DE INSTITUIÇÕES DE ENSINO MÉDIO, MEDIADO PELA PSICOLOGIA SOCIAL

ÂNGELA BEATRIZ SOUZA BERTAZZO

ORIENTADORA: MARIA ALICE PRUDÊNCIO JACQUES

TESE DE DOUTORADO EM TRANSPORTES

PUBLICAÇÃO T. D - 01/2016

BRASÍLIA/DF: FEVEREIRO - 2016 
UNIVERSIDADE DE BRASÍLIA

FACULDADE DE TECNOLOGIA

DEPARTAMENTO DE ENGENHARIA CIVIL E AMBIENTAL

\section{PROCEDIMENTO PARA ESTUDO DA ESCOLHA MODAL EM VIAGENS REALIZADAS POR ESTUDANTES DE INSTITUIÇÕES DE ENSINO MÉDIO, MEDIADO PELA PSICOLOGIA SOCIAL}

\section{ÂNGELA BEATRIZ SOUZA BERTAZZO}

TESE SUBMETIDA AO DEPARTAMENTO DE ENGENHARIA CIVIL E AMBIENTAL DA FACULDADE DE TECNOLOGIA DA UNIVERSIDADE DE BRASÍLIA COMO PARTE DOS REQUISITOS NECESSÁRIOS PARA A OBTENÇÃO DO GRAU DE DOUTOR EM TRANSPORTES.

Profa. Maria Alice Prudêncio Jacques PhD (ENC-UnB)

(Orientadora)

Prof. Pastor Willy Gonzáles Taco Dr. (ENC-UnB)

(Examinador Interno)

Prof: Paulo César Marques da Silva PhD (ENC-UnB)

(Examinador Interno)

Profa- Cira Souza Pitombo Dr. (EESC - USP)

(Examinadora Externo)

Prof. Hartmut Günther PhD (PSTO - UnB)

(Examinador Externo)

BRASÍLIA/DF, 29 DE FEVEREIRO DE 2016. 
FICHA CATALOGRÁFICA

\begin{tabular}{l}
\hline BERTAZZO, ÂNGELA BEATRIZ SOUZA \\
Procedimento para estudo da escolha modal em viagens realizadas por estudantes de \\
instituições de ensino médio, mediado pela psicologia social. [Distrito Federal] 2016. \\
xvii, 347p., 210 x 297 mm (ENC/FT/UnB, Doutor, Transportes, 2016). \\
Tese de doutorado - Universidade de Brasília. Faculdade de Tecnologia. \\
$\begin{array}{ll}\text { Departamento de Engenharia Civil e Ambiental. } \\
\text { 1.Escolha Modal } & \text { 2.Instituições de Ensino Médio } \\
\text { 3. Planejamento de Transportes } & \text { 4. Modelos de Escolhas Discreta } \\
\text { I. ENC/FT/UnB } & \end{array}$ \\
\hline
\end{tabular}

\section{REFERÊNCIA BIBLIOGRÁFICA}

BERTAZZO, A. B. S. (2016). Procedimento para estudo da escolha modal em viagens realizadas por estudantes de instituições de ensino médio, mediado pela psicologia social. Tese de doutorado em Transportes, 2016, Departamento de Engenharia Civil e Ambiental, Universidade de Brasília, Brasília, DF, 347p.

\section{CESSÃO DE DIREITOS}

AUTOR: Ângela Beatriz Souza Bertazzo.

TÍTULO: Procedimento para estudo da escolha modal em viagens realizadas por estudantes de instituições de ensino médio, mediado pela psicologia social.

GRAU: Doutor

ANO: 2016

É concedida à Universidade de Brasília permissão para reproduzir cópias desta tese e para emprestar ou vender tais cópias somente para propósitos acadêmicos e científicos. A autora reserva outros direitos de publicação e nenhuma parte desta tese pode ser reproduzida sem autorização por escrito da autora.

Ângela Beatriz Souza Bertazzo

SQN 104 bl. J ap. 404

70733-100 Brasília - DF - Brasil

angela.bertazzo@hotmail.com 


\section{DEDICATÓRIA}

"Àquele que é poderoso para tudo muito mais..." Ef. 3:20a 


\section{AGRADECIMENTOS}

Em primeiro lugar, agradeço a Deus, por nos dar vida, sempre. À família que compreendeu minhas ausências. Ao André, esposo que esteve sempre presente e que me deu suporte nas horas mais difíceis. Ao meu filho e querida nora, pelos incentivos. À minha mãe, pelo apoio constante. À irmã Arlene, sempre disponível, pelas revisões, tantas. Aos primos Línive e André, que me acompanharam na coleta de dados. Pelas orações fiéis da Fátima e Bete, acreditando em mim.

À minha orientadora, Profa. Maria Alice Prudêncio Jacques, que me fez gostar de ser pesquisadora, suportou meus deslizes e, com paciência, me conduziu à concretização desta tese. Aos professores da UnB que participaram das bancas parciais, ou em disciplinas, ajudando a dar foco no trabalho: Paulo Cesar, Pastor, Günther, Michele, Fabiana, Zé Augusto, Adelaida, Claudio Torres, Laros e Pasqualli. À Profa. Cira, que foi mais que revisora, dando valiosas contribuições.

Aos colegas do PPGT e Psicologia, que foram mais que colegas, cooperando, dando palpite, ou simplesmente dobrando e grampeando papeis: Ingrid Luiza Neto, Edwin e Wesley, Luciany, Janeth Lanque, Yvonne, Graziele, Zuleide, Gisele, Patrícia, e às secretárias Lucinete, Camilla. À Profa. Rosa, Prof. Günther, e colegas Ingrid e Zuleide pela revisão dos instrumentos de pesquisa. Aos amigos que aceitaram participar das aplicações de testes pilotos dos instrumentos de pesquisa.

Agradeço imensamente às direções, coordenações e professores das escolas participantes, ou, de alguma forma, envolvidas no estudo: Ana, Ivan, Dora, Gilbert, Carmênio, André, Felinto e Ticiane, do CEM Setor Leste; Marcão, do COC; Vanessa, Luciana, Dirlei, Creusa, Larissa e Amaranta, do CEM Paulo Freire; Augusto, do CEM Setor Oeste; Irmã Lourdes, do Colégio Notre Dame. 


\section{RESUMO}

\section{PROCEDIMENTO PARA ESTUDO DA ESCOLHA MODAL EM VIAGENS REALIZADAS POR ESTUDANTES DE INSTITUIÇÕES DE ENISNO MÉDIO, MEDIADO PELA PSICOLOGIA SOCIAL}

Dentre as teorias da psicologia social, a Teoria do Comportamento Planejado (TCP) propõe que a escolha modal seja analisada como processo racional. Isto é, postula que essa escolha é afetada pela Atitude, Norma Social e Controle Percebido do tomador de decisão, mediados pela sua intenção em realizar uma determinada escolha. Considera, ainda, que esses fatores psicológicos resultam de crenças subjacentes.

O presente estudo desenvolveu um procedimento para a caracterização do padrão de viagens dos estudantes e identificação dos atributos intervenientes na escolha modal, baseado na TCP, para aplicação em Instituições de Ensino Médio - IEMs. Foram testados vários tipos de modelagem para a análise dos dados, com destaque para: i) o uso de Modelos Lineares Generalizados (MLGs) e estimação por quase-verossimilhança, nas relações entre as crenças e dimensões psicológicas, e intenção comportamental; ii) na análise do comportamento, o uso de Modelos Híbridos de Escolha Discreta (MHEDs), integrados com variáveis latentes.

A validade do procedimento foi testada em três IEMs em Brasília. Sete modos de transportes integraram as análises descritivas: A pé, Automóvel Carona, Bicicleta, Metrô, Transporte Escolar, Ônibus, e Automóvel da Família. Apenas os dois últimos modos foram incluídos nos processos de modelagem, para dados coletados em duas IEMs públicas. Na relação das crenças com as dimensões psicológicas, foram significativas, tanto para o modo Automóvel, quanto para o modo Ônibus, a opinião dos grupos de referência, pais e amigos, e a percepção de segurança. Nas modelagens da intenção, a TCP foi confirmada, tendo sido pontuais as ocorrências significativas para as variáveis sociodemográficas. Nas modelagens do comportamento, apenas a Intenção e o Comportamento Passado responderam pela probabilidade de escolha dos modos. A hipótese sobre a interação da opinião dos alunos e seus respectivos pais/responsáveis sobre a escolha modal não pode ser refutada. Entretanto, sua confirmação não se deu para todos os casos analisados. Essa situação pode ter sido provocada pela limitação das amostras disponíveis para a realização do teste da hipótese.

Palavras chaves: Escolha modal; Instituições de Ensino Médio; Teoria do Comportamento Planejado; Modelos Híbridos de Escolha Discreta; Modelos Lineares Generalizados 


\section{ABSTRACT \\ PROCEEDING FOR MODAL CHOICE STUDIES AMONG HIGH SCHOOL'S STUDENTS, THROUG A SOCIAL PSYCHOLOGY APPROACH}

Among the theories of social psychology, the Theory of Planned Behavior (TPB) proposes that the modal choice comes from a rational process. This means that the modal choice is affected by decision makers' psychological factors such as Attitude, Social Norm and Perceived Control, related to a given transportation mode, and their underlying beliefs, mediated by Intention.

This study proposes a procedure for the description of students' travel pattern and identification of factors involved in their modal choices, based on the TPB, for use in high schools communities. Various types of modeling for data analysis were tested, especially: $i$ ) the use of Generalized Linear Models (GLMs), with quasi-likelihood estimation, for linear relationships of salient beliefs and psychological factors, and behavior intention modelling; ii) in behavior analysis, the use of Hybrid Models of Discrete Choice (MHEDs), integrated with latent variables was adopted.

The procedure had its applicability tested for three high schools in Brasilia. Seven transport modes were considered for descriptive analysis: Walking, Ridership, Bicycle, Subway, Public Bus Services, School Buses and Car. Only car and public bus services were considered for modelling analysis and for public high schools only. With respect to the beliefs versus psychological factors, the beliefs that were significant for both car and bus modes were the referent groups, parents and friends, and the perception of security. For the Intention modelling, the TPB conceptual framework fitted data. Only few sociodemographic factors were statistically significant. In modelling behavior, only the Intention and Past Behavior accounted for the probability of mode selection. The test of hypothesis about the interaction of the opinion between students and their parents on the modal choice could not be refuted. However, it was not confirmed for all cases studied, probably due to sample size restrictions.

Key-words: Modal Choice; High Schools; Theory of Planned Behavior; Hybrid Choice Models; Generalized Linear Models. 


\section{SUMÁRIO}

1. INTRODUÇÃ

1.1 QUESTÕES DE PESQUISA ...........................................................................20

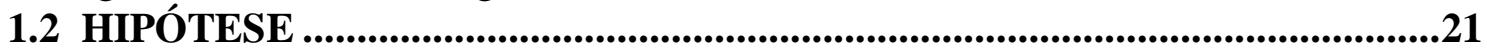

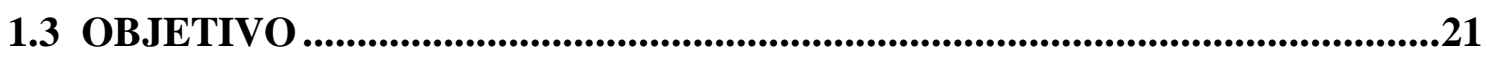

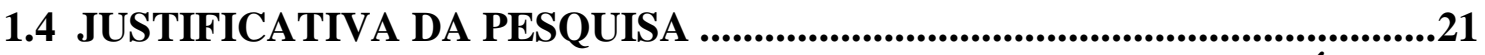

1.4.1 ESTUDO DAS ESCOLHAS MODAIS NOS CONTEXTOS DAS ÁREAS

ESCOLARES. .21

1.4.2 ESPECIFICAÇÃO ADEQUADA DE PROGRAMAS DE

GERENCIAMENTO DA MOBILIDADE. . .22

1.4.3 MOTIVAÇÃO PARA A INCLUSÃO DE ESTRATÉGIAS DE GM NA APROVAÇÃO DE NOVOS ESTABELECIMENTOS ESCOLARES...............23

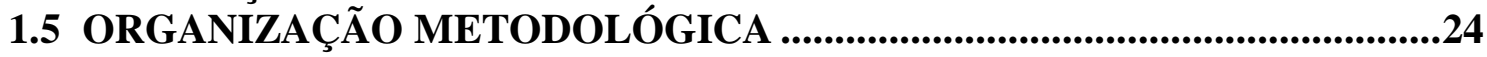

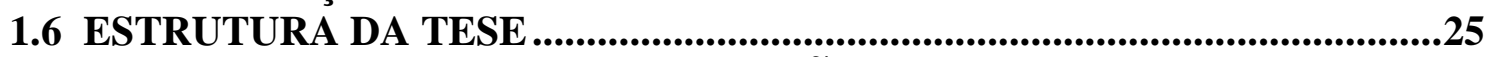

2. ESCOLHA MODAL EM INSTITUIÇÕES DE ENSINO ..................... 27

2.1 GENERALIDADES SOBRE A ESCOLHA MODAL ..................................27

2.1.1 CLASSIFICAÇÃO DOS ESTUDOS SOBRE A ESCOLHA MODAL.......28

2.1.2 ATRIBUTOS UTILIZADOS EM ESTUDOS DE ESCOLHA MODAL ...29

2.2 A ESCOLHA MODAL EM ÁREAS ESCOLARES .......................................30

2.2.1 CLASSIFICAÇÃO DAS VIAGENS POR MOTIVO ESTUDO ..................31

2.2.2 ESPECIFICIDADES DAS ÁREAS ESCOLARES BRASILEIRAS...........32

2.3 ESTUDOS DA ESCOLHA MODAL EM INSTITUIÇÕES DE ENSINO .........34

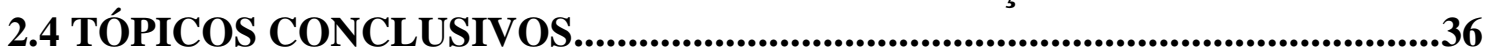

3. TEORIAS RELACIONADAS A MUDANÇAS NO

COMPORTAMENTO ............................................................................. 38

3.1 ABORDAGENS SOBRE PROCESSOS DECISÓRIOS ....................................38

3.2 A ATITUDE COMO PREDITORA DO COMPORTAMENTO ........................39

3.3 TEORIAS SOBRE MUDANÇAS COMPORTAMENTAIS.................................40

3.4 TEORIA DO COMPORTAMENTO PLANEJADO ........................................42

3.4.1 OPERACIONALIZAÇÃO DA TEORIA DO COMPORTAMENTO

PLANEJADO 44

3.4.2 TEORIA DO VALOR DA EXPECTÂNCIA .................................................44

3.5 CRÍTICAS À TCP E OUTRAS TEORIAS COGNITIVAS ...............................45

3.6 TÓPICOS CONCLUSIVOS.........................................................................48

4. TÉCNICAS ANALÍTICAS PARA ESTUDOS COMPORTAMENTAIS SOBRE A ESCOLHA MODAL ...................................................52

4.1 TÉCNICAS EXPLORATÓRIAS QUALITATIVAS ........................................55

4.2 ANÁLISE FATORIAL EXPLORATÓRIA ...................................................56

4.3 MODELOS DE REGRESSÃO LINEAR MÚLTIPLA .......................................58

4.4 MODELOS LINEARES GENERALIZADOS ...................................................60

4.5 MODELOS POR EQUAÇÕES ESTRUTURAIS ..............................................62

4.6 MODELOS DE ESCOLHA DISCRETA ..............................................................65

4.7 MODELOS HÍBRIDOS DE ESCOLHA DISCRETA ...........................................68

4.7.1 EQUAÇÕES ESTRUTURAIS NO MODELO DE VARIÁVEL LATENTE

DO ICVL ............................................................................................................71

4.7.2 EQUAÇÕES ESTRUTURAIS NO MODELO DE ESCOLHA DO ICVL 71 
4.7.3 EQUAÇÕES DE MEDIDA NO MODELO DE VARIÁVEL LATENTE

DO ICVL . .71

4.7.4 EQUAÇÕES DE MEDIDA NO MODELO DE ESCOLHA DO ICVL .....71

4.8 TÓPICOS CONCLUSIVOS.

5. DESENVOLVIMENTO DE PROCEDIMENTO PARA IDENTIFICAÇÃO DE ATRIBUTOS INTERVENIENTES NO COMPORTAMENTO DE ESCOLHA MODAL ..................................... 73

5.1 ATIVIDADES PRELIMINARES ..................................................................74

5.2 CONTATO INICIAL COM AS IEMS ............................................................74

5.3 OBSERVAÇÃO DA ENTRADA E SAÍDA DOS TURNOS ..................................76

5.4 ABORDAGEM QUALITATIVA EXPLORATÓRIA ............................................78

5.4.1 APLICAÇÃO DA TÉCNICA DE GRUPOS FOCAIS ……………………....78

5.4.2 ANÁLISE DAS INFORMAÇÕES OBTIDAS …………………………….....79

5.5 ABORDAGEM QUANTITATIVA EXPLORATÓRIA.......................................80

5.5.1 ELABORAÇÃ̃O E APLICAÇÃ̃O DO QUESTIONÁRIO ...............................

5.5.2 OBTENÇÃ̃O DAS VARIÁVEIS DERIVADAS DO ENDEREÇAMENTO

5.5.3 TRATAMENTO PRELIMINAR DA BASE DE DADOS .............................87

5.5.4 ANÁLISES DAS INFORMAÇÕES ..............................................................89

5.6 ABORDAGEM QUANTITATIVA PREDITIVA ..................................................89

5.6.1 TESTES NA BASE DE DADOS.....................................................................89

5.6.2 MODELAGENS....................................................................................93

5.7 PROCEDIMENTO PROPOSTO ...............................................................98

5.7.1 ETAPA 1 - ATIVIDADES INICIAIS .........................................................99

5.7.2 ETAPA 2 - DESCRIÇÃO DO CONTEXTO AMBIENTAL DA IEM ......99

5.7.3 ETAPA 3 - LEVANTAMENTO DAS CRENÇAS SALIENTES................99

5.7.4 ETAPA 4 - ELABORAÇÃO E APLICAÇÃO DO QUESTIONÁRIO ..100

5.7.5 ETAPA 5 - ELABORAÇÃO DO PERFIL DE MOBILIDADE DA

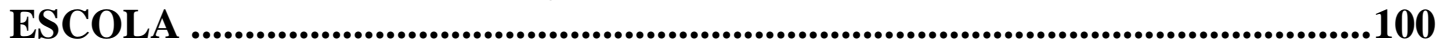

5.8 TÓPICOS CONCLUSIVOS........................................................................102

6. APLICAÇÃO DO PROCEDIMENTO - PARTE 1 ........................... 104

6.1 ETAPA 1 - ATIVIDADES INICIAIS......................................................104

6.2 ETAPA 2 - DESCRIÇÃO DO CONTEXTO AMBIENTAL DAS IEMS .......106

6.3 ETAPA 3 - LEVANTAMENTO DAS CRENÇAS SALIENTES ………..........109

6.3.1 PERCEPÇÕES GERAIS ........................................................................111

6.3.2 SÍNTESE DAS PERCEPÇÕES RELATADAS EM GRUPO FOCAL NA

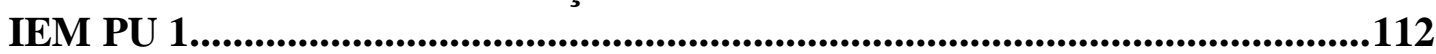

6.3.3 SÍNTESE DAS PERCEPÇÕES RELATADAS NOS GRUPOS FOCAIS

NA IEM PU 2.................................................................................................113

6.3.4 SÍNTESE DAS PERCEPÇÕES RELATADAS EM GRUPO FOCAL NA

IEM PR 1..............................................................................................114

6.3.5 PRINCIPAIS CRENÇAS IDENTIFICADAS...........................................115

6.5 ETAPA 5 - ELABORAÇÃO DO PERFIL DE MOBILIDADE DAS IEMs ...120

6.5.1 TRATAMENTO PRELIMINAR DA BASE DE DADOS ...........................120

6.5.2 AGRUPAMENTO DAS LOCALIDADES DE RESIDÊNCIA

INFORMADAS..............................................................................................122

6.5.3 PERFIL DA MOBILIDADE NA IEM PU 1 ..................................................124

6.5.4 PERFIL DA MOBILIDADE NA IEM PU 2 ...................................................129

6.5.5 PERFIL DA MOBILIDADE NA IEM PR 1 ................................................134 
6.6 TÓPICOS CONCLUSIVOS...........................................................................136

7. APLICAÇÃO DO PROCEDIMENTO - PARTE 2 ........................... 140

7.1 TRATAMENTO PRELIMINAR DA BASE DE DADOS..................................140

7.2 ANÁLISE EXPLORATÓRIA DAS CRENÇAS .................................................142

7.2.1 ANÁLISE FATORIAL EXPLORATÓRIA DAS CRENÇAS.....................143

7.2.3 ANÁLISE DOS CONSTRUTOS DA TCP X CRENÇAS............................146

7.3 MODELAGEM DA INTENÇÃO ............................................................................162

7.4 MODELAGEM DO COMPORTAMENTO .......................................................172

7.4.1 MODELAGEM DO COMPORTAMENTO POR MODO - MODELOS

BINÁRIOS ....................................................................................................173

7.4.2 MODELAGEM DA INTERAÇÃO ENTRE PAIS E ALUNOS...................180

7.5 TÓPICOS CONCLUSIVOS..................................................................183

8. CONCLUSÕES E RECOMENDAÇÕES ........................................... 186

8.1 DO ALCANCE DO OBJETIVO DA PESQUISA ……........................................186

8.2 DO MODELO TEÓRICO ADOTADO .......................................................189

8.3 LIMITAÇÕES DO ESTUDO ...............................................................................189

8.3.1 AMOSTRAGEM.........................................................................................189

8.3.2 ADAPTAÇÃO DA LINGUAGEM AO ADOLESCENTE .........................190

8.3.3 VIESES OBSERVADOS ..............................................................................190

8.4 RESULTADOS DOS GRUPOS FOCAIS.......................................................191

8.5 RESULTADOS DOS PERFIS DE MOBILDADE ............................................191

8.6 RESULTADOS DO ESTUDO EXPLORATÓRIO DAS CRENÇAS.................192

8.7 RESULTADOS DAS MODELAGENS DA INTENÇÃO ………….....................197

8.8 RESULTADOS DAS MODELAGENS DO COMPORTAMENTO .................199

8.8.1 RESULTADO DO TESTE SOBRE A INTERAÇÃO DE OPINIÃO

ENTRE PAIS/RESPONSÁ VEIS E ALUNOS NA ESCOLHA MODAL ..........199

8.9 RECOMENDAÇÕES PARA TRABALHOS FUTUROS...................................201

REFERÊNCIAS BIBLIOGRÁFICAS ............................................ 203

APÊNDICES ..................................................................................... 212

APÊNDICE A - Tabela de revisão de estudos sobre a escolha modal em

Instituições de Ensino.

APÊNDICE B- Termos de Consentimento Livre e Esclarecido (autorização dos pais para participação dos filhos, para pais participantes, para filhos

participantes) ...............................................................................................................220

APÊNDICE C - Questionário Institucional ...........................................................224

APÊNDICE D - Roteiro para avaliação do contexto físico das IEMs......................226

APÊNDICE E - Questionário para participação de pais na etapa de grupos focais

229

APÊNDICE F - Planejamento e protocolo do grupo focal ........................................233

APÊNDICE G - Questionário disponibilizado aos alunos na etapa de grupos focais

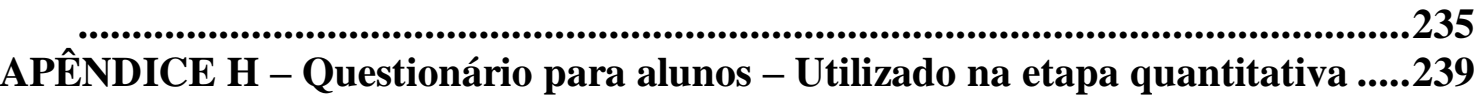

APÊNDICE I - Questionário para pais - Utilizado na etapa quantitativa ............247

APÊNDICE J - Descrição das variáveis utilizadas nas abordagens quantitativas

nos questionários para alunos ...............................................................................255

APÊNDICE K - Descrição das variáveis utilizadas nas abordagens quantitativas

nos questionários para pais ...............................................................................277

APÊNDICE $L$ - Elenco de crenças para os modos de transporte considerados

viáveis na opinião dos alunos e pais/responsáveis. ..............................................300 
APÊNDICE M - Notas sobre a Densidade Demográfica......................................308

APÊNDICE N - Estatísticas descritivas e testes de normalidade para variáveis participantes das etapas de modelagem na IEM PU1 ................................310

APÊNDICE O - Estatísticas descritivas e testes de normalidade para variáveis participantes das etapas de modelagem na IEM PU2

APÊNDICE P - Gráficos CURE para modelagens de crenças para o modo

Automóvel da Família na IEM PU1.

APÊNDICE Q - Gráficos CURE para modelagens de crenças para o modo Ônibus na IEM PU1

APÊNDICE R - Gráficos CURE para modelagens da Intenção na IEM PU1 .....344

APÊNDICE S - Gráficos de resíduos para modelagens da Intenção na IEM PU2 


\section{LISTA DE ABREVIATURAS}

CEP - Código de Endereçamento Postal

CFA - Análise Fatorial Exploratória

GM - Gerenciamento da Mobilidade

EFA - Análise Fatorial Exploratória

HCM - Hybrid Choice Models

ICLV - Integrated Choice and Latent Variable Model

IEF - Instituição de Ensino Fundamental

IEM - Instituição de Ensino Médio

IEM PR - Instituição de Ensino Médio Privada

IEM PU - Instituição de Ensino Médio Pública

IES - Instituição de Ensino Superior

MACML - Maximum Approximated Composite Marginal Likelihood

MAN - Modelo de Ativação da Norma

MED - Modelos de Escolha Discreta

MEE - Modelagem por Equações Estruturais

MEP - Modelo de Elaboração da Probabilidade

MHED - Modelos Híbridos de Escolha Discreta

MM - Mobility Management

MNL - Modelo logit Multinomial

MQO - Método dos Mínimos Quadrados Ordinários

MRLM - Modelo de Regressão Linear Múltipla

PGM - Programa de Gerenciamento da Mobilidade

PGV - Polo Gerador de Viagens

TCI - Teoria do Comportamento Interpessoal

TCP - Teoria do Comportamento Planejado

TDM - Travel Demand Management

TE - Transporte Escolar

TP - Transporte Público

TAR - Teoria da Ação Racional 


\section{LISTA DE FIGURAS}

Figura 1.1: Organização metodológica e estrutura da tese ............................................26

Figura 3.1: Estrutura dos modelos TAR e TCP (acrescentando o Controle Percebido) ....43

Figura 3.2: Modelo teórico de decisão do aluno por modo de transporte em viagens escolares a ser estudado.

Figura 3.3: Modelo teórico da influência conjunta de pais e alunos no processo de decisão por modo de transporte em viagens de escolares a ser estudado....................................51

Figura 4.1: Exemplo de uma análise de diagrama de caminhos aplicado à TCP..............54

Figura 4.2: Exemplo de e gráfico de resíduos acumulados CURE ................................62

Figura 4.3: Modelo de escolha de utilidade aleatória (tipo a).......................................69

Figura 4.4: Modelo de escolha com indicadores incluídos diretamente na utilidade (tipo b).

Figura 4.5: Estimação sequencial: análise fatorial seguida de um modelo de escolha (tipo

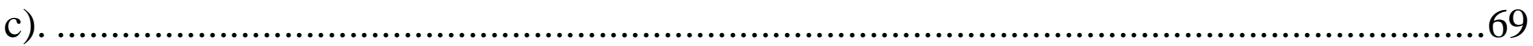

Figura 4.6: Modelo de escolha com atributos latentes (tipo d) ....................................69

Figura 4.7: Modelo integrado de escolha e variável latente (tipo e). ...............................70

Figura 5.1: Etapas metodológicas abordadas no Capítulo 5 ........................................73

Figura 5.2: Impacto do tamanho da amostra sobre o poder para vários níveis de alfa $(0,01$;

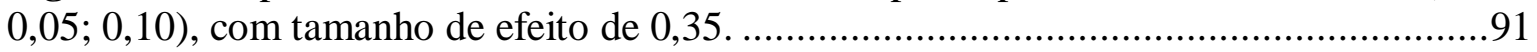

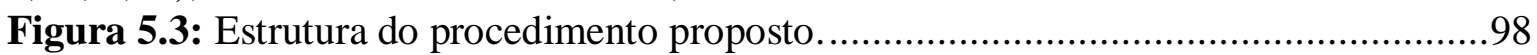

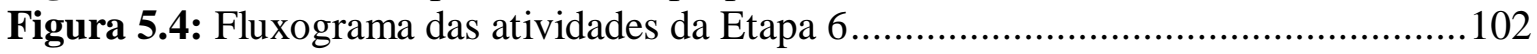

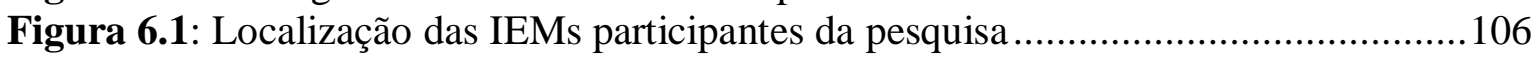

Figura 6.2: Agrupamento das localidades de residência em setores ..............................123

Figura 6.3: Distribuição das localidades de residência dos alunos - IEM PU 1 ..............125

Figura 6.4: Distribuição das localidades de residência dos alunos - IEM PU 2 .............130

Figura 6.5: Distribuição de localidades de residência dos alunos - IEM PR 1 .................135

Figura 7.1: Estrutura dos modelos dos construtos da TCP x crenças salientes, por modo.

Figura 7.2: Diagrama de caminhos dos modelos de variável latente (modelos tipo ii) para a intenção por modo.

Figura 7.3: Estrutura do modelo final da intenção para o modo Automóvel da Família na IEM PU 1

Figura 7.4: Estrutura do modelo final da intenção para o modo Automóvel da Família na

IEM PU 2

Figura 7.5: Estrutura do modelo final da intenção para o modo Ônibus na IEM PU $1 \ldots .170$ Figura 7.6: Estrutura do modelo final da intenção para o modo Ônibus na IEM PU 2....171

Figura 7.7: Estrutura dos modelos binários estudados sobre o comportamento de escolha do modo, por IEM e por modo, pra amostra "alunos geral".

Figura 7.8: Estrutura do modelo final para escolha do modo Automóvel da Família na ida

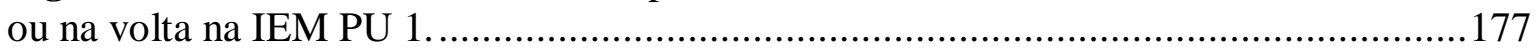

Figura 7.9: Estrutura do modelo final para escolha do modo Automóvel da Família na ida

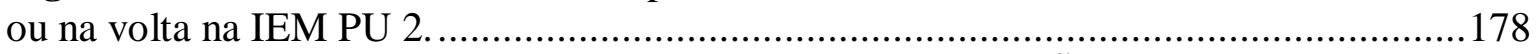

Figura 7.10: Estrutura do modelo final para escolha do modo Õnibus, na ida ou na volta

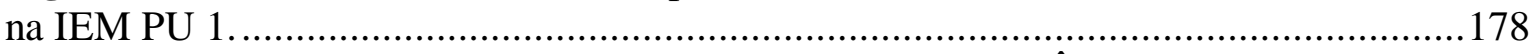
Figura 7.11: Estrutura do modelo final para escolha do modo Ônibus na ida ou na volta na

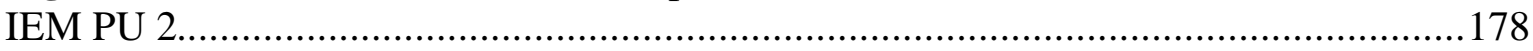

Figura 7.12: Estrutura dos modelos binários estudados sobre a interação da opinião dos alunos e pais/responsáveis na escolha modal, para amostras integradas IEMPU 1 e IEM PU 2. 
Figura 7.13: Estrutura dos modelos finais da interação entre alunos e pais/responsáveis para o modo Automóvel da Família, para as duas IEMs, na ida e na volta.

Figura 7.14: Estrutura dos modelos finais da interação entre alunos e pais/responsáveis para o modo Ônibus, para as duas IEMs, na ida e na volta. 


\section{LISTA DE TABELAS}

Tabela 2. 1: Comparação dos dados obtidos por Preferência Revelada e Declarada .........29

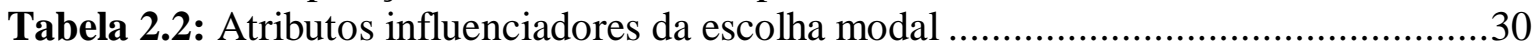

Tabela 2.3: Classificação das viagens por motivo estudo................................................31

Tabela 2.4: Óbitos por acidentes de transporte de crianças e adolescentes no Brasil em

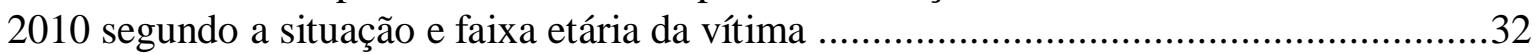

Tabela 2.5: Estudos revisados com experimentos de intervenção na escolha modal ..........35

Tabela 3.1: Comparativo de modelos teóricos para mudanças comportamentais pela mudança de atitude

Tabela 3.2: Resultados de Elliott et al.(2005) na validação do uso da Teoria da Expectância para medir construtos da TCP.

Tabela 3.3: Classificação de comportamentos planejados impulsivos e habituais. .46

Tabela 4 .1: Itens para medida direta de avaliação dos construtos da TCP em estudo sobre a escolha modal - exemplo para modo Ônibus. ..............................................................53

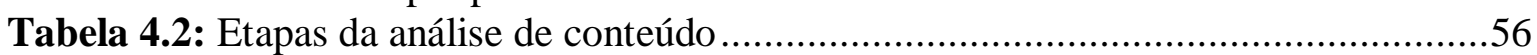

Tabela 4.3: Análise comparativa dos métodos de obtenção dos escores fatoriais ..............57

Tabela 4.4: Índices para avaliação do ajuste de modelos MEE .....................................65

Tabela 4.5: Modelos de escolha e sua integração com variáveis latentes........................69

Tabela 5.1: Indicadores físicos da IEM e seu contexto físico ..........................................77

Tabela 5.2: Atributos influenciadores da escolha modal nas viagens à escola ..................83

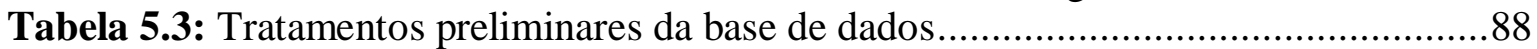

Tabela 5.4: Testes univariados para avaliação da normalidade .....................................91

Tabela 5.5: Instrumentos desenvolvidos para a aplicação do procedimento .....................99

Tabela 5.6: Técnicas de modelagem por grupo e propósito.......................................... 101

Tabela 6.1: Participação das IEMs de Brasília na aplicação das etapas do procedimento

Tabela 6.2: Características das IEMs participantes da pesquisa ................................... 108

Tabela 6.3: Elenco de crenças para os modos de transporte considerados viáveis na

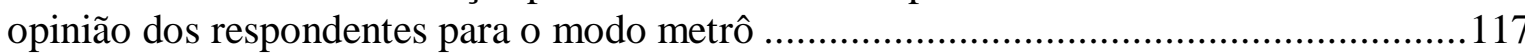

Tabela 6.4: Frequência temática nas afirmativas de crenças por modo e grupo de

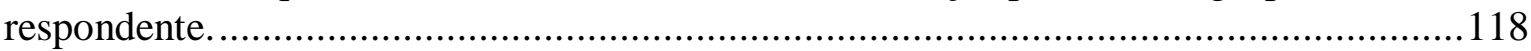

Tabela 6.5: Dados populacionais e amostrais das IEMs participantes ..........................120

Tabela 6.6: Amostras resultante do tratamento $\mathrm{T} 1 \mathrm{de}$ casos ausentes ............................122

Tabela 6.7: Características médias das localidades dos respondentes na amostra "alunos

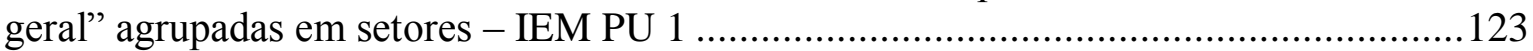

Tabela 6.8: Estatísticas univariadas - para IEM PU1 ................................................. 124

Tabela 6.9: Modo ida/ volta e frequência de uso na amostra "alunos geral"- IEM PU 1126

Tabela 6.10: Opções de mudança de modo na ida, amostra "alunos geral" - IEM PU 1.127

Tabela 6.11: Escolha modal na ida e variáveis sociodemográficas - IEM PU 1............128

Tabela 6.12: Estatísticas univariadas - IEM PU 2 …................................................. 130

Tabela 6.13: Modo ida/volta e frequência de uso na amostra "alunos geral"-IEM PU 2131

Tabela 6.14: Opção de mudança de modo na amostra "alunos geral" - IEM PU 2 .........131

Tabela 6.15: Escolha modal na ida e variáveis sociodemográficas - IEM PU 2 ..............133

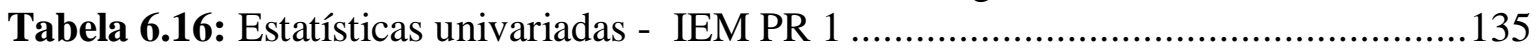

Tabela 7.1: Repostas por modo depois do tratamento T2 de dados ausentes ..................141

Tabela 7.2: Comparação modos utilizado atualmente x opinião por modo ...................... 142

Tabela 7.3: Matriz pattern AFE crenças por modo - amostra "alunos geral" - IEM PU1144

Tabela 7.4: Matriz pattern AFE crenças por modo - amostra "alunos geral" - IEM PU2144

Tabela 7.5: Composição de itens para medida direta dos construtos ............................. 147

Tabela 7.6: Consistência dos itens por modo na IEM PU 1 ....................................... 147 
Tabela 7.7: Consistência dos itens por modo na IEM PU 2

Tabela 7.8: Modelos GLM para construto Atitude x crenças salientes, modo Automóvel da Família, IEM PU1, amostra "alunos geral"

Tabela 7.9: Modelos GLM para construto Norma Social $x$ crenças salientes, modo "Automóvel da Família", IEM PU1, amostra "alunos geral"

Tabela 7.10: Modelos GLM para construto Controle Percebido x crenças salientes, modo Automóvel da Família, IEM PU1, amostra "alunos geral".

Tabela 7.11: Modelos GLM para construto Intenção x crenças salientes, modo Automóvel da Família, IEM PU1, amostra "alunos geral".

Tabela 7.12: Modelos GLM para construto Atitude x crenças salientes, modo Ônibus, IEM PU1, amostra "alunos geral"

Tabela 7.13: Modelos GLM para construto Norma Social x crenças salientes, modo Onibus, IEM PU1, amostra "alunos geral"

Tabela 7.14: Modelos GLM para construto Controle Percebido x crenças salientes, modo

Ônibus, IEM PU1, amostra "alunos geral"

Tabela 7.15: Modelos GLM para construto Intenção x crenças salientes, modo Ônibus, IEM PU1, amostra "alunos geral"

Tabela 7.16: Comparação dos ganhos pela inclusão dos itens de força de crença "e" e produto "bxe" ao conteúdo de crença "b"

Tabela 7.17: Modelagem Intenção no modo Automóvel da Família, na IEM PU 1, amostra "alunos geral"

Tabela 7.18: Modelagem Intenção no modo Ônibus, na IEM PU 1, amostra "alunos geral"

Tabela 7.19: Modelagem Intenção no modo Automóvel da Família, na IEM PU 2, amostra "alunos geral".....

Tabela 7.20: Modelagem Intenção no modo Ônibus, na IEM PU 2, amostra "alunos geral"

Tabela 7.21: Escolha do modo na IEM PU 1, amostra "alunos geral".

Tabela 7.22: Escolha do modo na IEM PU 2, amostra "alunos geral".

Tabela 7.23: Teste de poder para amostras pareadas resultantes do tratamento $\mathrm{T} 2$

Tabela 7.24: Modelos para o teste da interação da opinião de pais/responsáveis e alunos, para as amostras integradas IEM PU 1 e IEM PU 2

Tabela 8.1: Resumo das técnicas de modelagens utilizadas nos modelos finais mais significativos na aplicação do procedimento em IEMs de Brasília

Tabela 8.2: Ocorrência das relações significativas das crenças com construtos da TCP para o modo Automóvel da Família na IEM PU1

Tabela 8.3: Ocorrência das relações significativas das crenças com construtos da TCP para o modo Ônibus na IEM PU1

Tabela 8.4: Melhores modelos MLG para os construtos da TCP obtidos a partir das crenças, na IEM PU1, para amostra "alunos geral".

Tabela 8.5: Sugestões de Intervenção de GM nas IEMs estudadas

Tabela 8.6: Melhores modelos MLG para os antecedentes da intenção, para modos Automóvel da Família e Ônibus, nas duas IEMs, para amostra "alunos geral". 198

Tabela 8.7: Modelos sobre o comportamento da escolha modal obtidos nas IEMs estudadas. 


\section{INTRODUÇÃO}

Mesmo que novas tecnologias amenizem os problemas ambientais relacionados ao transporte motorizado, como poluição do ar e ruído, a demanda por mais espaço público para o automóvel não parece ter limites e, portanto, continua a agravar esses problemas. A sustentabilidade nos transportes não é mais uma questão de modismo. Wee (2007) comenta que as últimas quatro décadas imprimiram grandes desafios na relação transporte e meio ambiente, a ponto desta relação ser reconhecida como o foco principal das políticas públicas para o meio urbano. A promoção do transporte sustentável é um desafio a ser vencido na definição e implementação de políticas públicas. A Política Nacional de Mobilidade Urbana (Brasil, 2012) é um exemplo de política de promoção do transporte sustentável.

Melhorar a mobilidade urbana pode requerer novos paradigmas e estratégias de gestão que integrem de diferentes modos de transporte. A promoção do transporte sustentável deve tornar perceptível a cada indivíduo envolvido alternativas viáveis ao uso do automóvel particular. As propostas de intervenção do uso do modo de transporte (ou menor uso do automóvel), visam às viagens cotidianas em geral, relacionadas a comunidades de usuários de empresas em geral ou a comunidades específicas, tais como as comunidades escolares.

No caso das comunidades escolares, o uso do automóvel individual para conduzir crianças e adolescentes à escola tem comprometido a segurança nas áreas escolares. Os conflitos nessas áreas atingem o grupo mais vulnerável no trânsito, crianças e adolescentes optantes de modos não motorizados, pedestres e ciclistas. Mesmo visando melhorias qualitativas do ambiente urbano e da segurança da comunidade envolvida, as estratégias que visam a redução do uso do automóvel individual não parecem ser facilmente aceitas pela população alvo dessas propostas. As pessoas envolvidas ainda mantêm um padrão insustentável de viagens, mesmo perante melhorias da oferta de modos de transporte alternativos ao automóvel e a realização de campanhas para um comportamento próambiental (Klöckner e Friedrichsmeier, 2011). É necessário, portanto, compreender quais características implicam na manutenção desses padrões para propor intervenções eficazes. 
O estudo da escolha modal é o cerne dos estudos de promoção da mobilidade sustentável. O estudo do impacto da escolha modal nos sistemas de transportes não é uma abordagem nova. A escolha modal é parte integrante dos modelos tradicionais de transporte (Ortúzar e Willumsen, 2011). A modelagem mais frequente utiliza Modelos de Escolha Discreta MED, onde importa a escolha individual de uma opção entre várias disponíveis (ou possíveis), ou seja, uma abordagem multimodal. Nos modelos MED, a escolha modal é realizada em consequência das preferências individuais, onde o indivíduo escolhe a alternativa que lhe propicie maiores benefícios (ou utilidade), a partir de um conjunto finito de alternativas à sua disposição (Ben-Akiva et al., 2003).

Estudos sobre a escolha modal têm indicado a ampliação da análise dos atributos influenciadores da decisão da escolha modal (como em Zhou, 2012; Curtis e Perkins, 2006; Ben-Akiva et al., 1999; entre outros), para além das características específicas do modo e da viagem ou características sociodemográficas dos usuários. Esses atributos podem estar ligados a situações psicológicas dos usuários e também ao contexto urbano onde ocorrem as viagens.

Apenas as características do modo e características sociodemográficas do indivíduo (hard information) eram incluídos como variáveis explicativas nos modelos tradicionais de escolha discreta - MEDs, por limitações metodológicas. A incorporação de variáveis psicológicas (soft information) às preferências individuais motivou a adaptação das modelagens tradicionais e o desenvolvimento de Modelos Híbridos de Escolha Discreta - MHED. Tal classe de modelos pretende explicar melhor o comportamento de escolha individual, bem como a heterogeneidade populacional (Ben-Akiva et al., 2002; Kamargianni et al., 2015).

Às teorias psicológicas cognitivas do final do século XX, dentre as quais as pesquisas sobre a atitude, são atribuídos os méritos por impulsionar as mudanças nas modelagens da decisão (Ben-Akiva et al., 2002), na expectativa de influenciar as mudanças comportamentais. Essas teorias identificam o processo de decisão como um processo racional, sendo o processo da escolha modal um exemplo dessa racionalidade (Bamberg et al., 2003). Os construtos psicológicos subjacentes às decisões racionais (por exemplo, a atitude) têm como antecedentes as crenças salientes, conceitos elementares sobre os 
comportamentos. Os construtos, por sua vez, são influenciadores tanto da intenção de se comportar de determinada maneira, como da realização do comportamento em si (Ajzen, 1991).

No caso dos usuários dos modos de transporte serem estudantes, principalmente aqueles de Instituições de Ensino Médio - IEMs, as preferências individuais na escolha modal podem ter considerações diferenciadas: i) oriundas da decisão autônoma do estudante (Kamargianni et al., 2015); ou ii) oriundas de um compartilhamento de decisão entre alunos e seus respectivos pais (Yarlagadda e Srinivasan, 2008).

Frente aos conflitos cotidianos observados nas áreas escolares, é relativamente raro encontrar no Brasil, e mesmo em outros países, estudos da escolha modal referente às áreas escolares que considerem: i) um amplo espectro de atributos de decisão, incluindo dimensões psicossociais; ii) a abordagem simultânea de diferentes modos viáveis do ponto de vista do usuário; iii) as considerações sobre a limitada autonomia das escolhas modais para esses estudantes. Esta lacuna aponta a demanda tanto por pesquisas exploratórias quanto metodológicas, aplicadas a diferentes contextos, tal como o brasileiro.

\subsection{QUESTÕES DE PESQUISA}

Cada comunidade escolar é uma população potencial para implantação de medidas que visem a mobilidade sustentável. Assim, a forma de abordagem do estudo da escolha modal que forneça subsídios à adequação dessas medidas, deve ser adaptada às características e peculiaridades de cada comunidade, visando potencializar a aceitabilidade das medidas. Perante as lacunas de pesquisa apontadas acima, e as considerações sobre as especificidades das comunidades escolares, e das Instituições de Ensino Médio em particular, algumas questões de pesquisa foram elencadas, as quais pretendem ser respondidas por este estudo:

1- Como identificar adequadamente os atributos influenciadores do comportamento da escolha de modos de transporte por parte dos usuários das Instituições de Ensino Médio -IEMs? 
2- $\quad$ Como verificar se o comportamento de escolha do modo de transporte para chegar ou sair da IEM é compartilhado entre estudantes e pais para a realização efetiva dos deslocamentos?

\subsection{HIPÓTESE}

O procedimento proposto permite a identificação dos atributos influenciadores do comportamento de escolha modal no transporte de estudantes para chegar ou sair das IEMs, levando em conta que esse comportamento pode ser afetado por dimensões psicossociais dos alunos e, de modo conjunto, por dimensões psicossociais de seus pais/responsáveis.

\subsection{OBJETIVO}

O objetivo geral do presente estudo é desenvolver um procedimento para a identificação dos atributos intervenientes no comportamento de escolha modal para o transporte de estudantes nas viagens para chegar e/ou sair das Instituições de Ensino Médio, considerando, inclusive, dimensões psicológicas e sociais dos pais/responsáveis e dos alunos.

\section{$1.4 \quad$ JUSTIFICATIVA DA PESQUISA}

A presente pesquisa se justifica, considerando os seguintes aspectos: i) necessidade de estudar a escolha modal nos contextos das áreas escolares; ii) subsídio à adequada especificação de Programas de Gerenciamento da Mobilidade - PGMs; iii) necessidade de motivar a inclusão de estratégias de GM na aprovação de novos estabelecimentos escolares.

\subsubsection{ESTUDO DAS ESCOLHAS MODAIS NOS CONTEXTOS DAS ÁREAS ESCOLARES}

O ambiente escolar/acadêmico é também um ambiente "aprendente", com uma comunidade disposta a mudanças. Estudos apontam que a prática multimodal na fase escolar pode desencadear comportamentos mais sustentáveis na vida adulta (Cairns, 
2000), aumentando o potencial propagador dos comportamentos pró-ambientais pela vivência escolar sustentável.

No Brasil, a faixa etária de alunos que frequentam o ensino médio (15 a 18 anos) é formada por adolescentes que transitam entre a mobilidade autônoma progressiva (uso do transporte público, caminhar ou usar a bicicleta em seus deslocamentos) e a dependência pela tutoria dos pais em seus deslocamentos cotidianos (deslocamentos motorizados por automóvel). Assim, o desenvolvimento, divulgação e reflexão sobre os estudos da escolha modal em contextos escolares pode incentivar a prática multimodal na vida escolar, visando comportamentos de escolha modal sustentáveis na idade adulta.

\subsubsection{ESPECIFICAÇÃO ADEQUADA DE PROGRAMAS DE GERENCIAMENTO DA MOBILIDADE}

O Gerenciamento da Mobilidade - GM é um conjunto de medidas que visam a redução do uso do automóvel particular e a promoção de modos coletivos e não motorizados em viagens cotidianas. A partir do entendimento de como se dão as decisões pelos modos de transporte, pode-se elaborar um conjunto de estratégias sistematizadas e customizadas a partir das preferências da comunidade escolar, para a diminuição do uso do automóvel (Cairns et al., 2004). A esse conjunto de estratégias sistematizadas para o atendimento de uma comunidade específica dá-se o nome de Programa de Gerenciamento da Mobilidade - PGM. A escola é um ambiente propício para a aplicação de Programas de Gerenciamento da Mobilidade, com a criação de estratégias alternativas ao uso do automóvel particular adequadamente delineadas para as condições de mobilidade, e com potencial de aceitação pela comunidade escolar.

Os PGMs e suas estratégias se baseiam na comparação de contrapartidas (trade off) das características das opções modais. São necessários, portanto, estudos que referenciem adequadamente os atributos influenciadores da decisão na escolha modal, a partir de uma abordagem multimodal, e na consideração das opções tidas como viáveis para aqueles que realizam a escolha modal.

Tanto a comunidade escolar quanto o órgão de gerenciamento do trânsito na localidade são interessados na elaboração de um PGM. A necessidade da sua elaboração pode vir 
de: i) uma exigência do órgão gerenciador de trânsito, coercitivamente como forma de compensação em processos de licenciamento para a implantação da escola; ii) uma iniciativa do órgão gerenciador de trânsito, demandando adesão da comunidade escolar, na proposição da melhoria do tráfego local e sustentabilidade da mobilidade; iii) uma iniciativa da direção da escola, na proposição pela melhoria e sustentabilidade da mobilidade dos estudantes; iv) uma iniciativa de instituições/pessoas externas à comunidade escolar, ou não vinculadas ao órgão de gerenciamento do trânsito. Nas inciativas que demandam a adesão voluntária de toda a comunidade escolar, itens (ii) e (iv), a preocupação maior deve ser por motivar e envolver a direção e a coordenação da escola que, se devidamente comprometida com o PGM, pode facilitar o acesso e participação dos estudantes e de seus pais/responsáveis.

\subsubsection{MOTIVAÇÃO PARA A INCLUSÃO DE ESTRATÉGIAS DE GM NA APROVAÇÃO DE NOVOS ESTABELECIMENTOS ESCOLARES}

A implantação de Instituições de Ensino Médio - IEMs no Brasil, como em diferentes países, é considerada como atividade impactante, classificada como Polo Gerador de Viagens (DENATRAN, 2001; TRB, 2010). Por isso passa por um processo de análise de implantação diferenciado. O foco tradicional do processo de análise de impacto do PGV é assegurar que a oferta da infraestrutura esteja em equilíbrio com a demanda projetada. Para este tipo de instituições, as exigências são geralmente dirigidas ao atendimento do modo automóvel, como estacionamentos, áreas de embarque e desembarque, além de acessos adequados ao sistema viário (Bertazzo e Jacques, 2010), reforçando o uso desse modo.

$\mathrm{Na}$ análise de impacto, entretanto, o melhor seria que, antes dos empreendimentos serem implantados, fosse previsto um menor uso do automóvel junto a instituições de ensino para os deslocamentos cotidianos vinculados a esse PGV. A análise do impacto decorrente da implantação do empreendimento indicaria, pela proposta de diminuição do uso do automóvel, uma melhoria qualitativa da área de implantação (Bertazzo e Jacques, 2010). Na prática, pela observação do cotidiano nas áreas escolares no Brasil, nos horários de entrada e saída de alunos, conclui-se que, em geral, esta preocupação não tem sido considerada no planejamento desses empreendimentos. 
As práticas de aprovação de PGVs tradicionalmente não envolvem estratégias de Gerenciamento da Mobilidade - GM e, portanto, não levam em conta metas de deslocamento sustentáveis. Miranda et al. (2009) pesquisaram as barreiras para a implantação de planos de mobilidade junto aos gestores de transportes de uma cidade no interior de São Paulo, e observaram que "apesar de alguns técnicos/gestores de transporte defenderem o transporte não-motorizado e o transporte público como alternativas ideais para a cidade, a prioridade de ação ainda é voltada para o modo motorizado individual".

A inserção de conceitos de mobilidade sustentável aos processos de aprovação de PGVs pode demandar que as viagens geradas sejam realizadas por meio de modos alternativos ao automóvel. Na definição de alternativas eficazes, entretanto, é importante que os atributos que afetam o comportamento dos usuários de cada tipo de empreendimento na escolha do seu modo de transporte sejam devidamente compreendidos. A análise da escolha modal é, portanto, fundamental para a proposição de medidas de GM que sejam integradas aos processos de análise de PGV.

\subsection{ORGANIZAÇÃO METODOLÓGICA}

O presente estudo foi desenvolvido segundo as etapas metodológicas descritas abaixo e sintetizadas na Figura 1.1.

Etapa 1: Revisão das teorias e práticas ligadas aos seguintes temas: escolha modal em instituições de ensino e processos de decisão com vistas às mudanças comportamentais. O produto obtido nesta etapa foi a identificação de um modelo teórico de suporte ao desenvolvimento da pesquisa.

Etapa 2: Planejamento da coleta de dados, com a elaboração das estratégias, ferramentas e procedimentos de coleta e tratamento de dados, incluindo a seleção das IEMs que serão envolvidas nas atividades das Etapas 3 a 6. Foram desenvolvidos dois tipos de coleta de dados:

a) Grupos focais para identificação do elenco dos atributos intervenientes na decisão da escolha modal em nível de crenças salientes; 
b) Questionários para coleta de dados sobre a influência dos atributos intervenientes identificados sobre a intenção comportamental;

Etapa 3: Elaboração de procedimento para pesquisa exploratória junto a usuários de IEMs com diferentes escolhas modais. Incluiu o primeiro tipo de coleta de dados, cujos resultados produziram um elenco das crenças salientes nas decisões do modo de transporte, contextualizados ambiental e culturalmente, sob o ponto de vista do aluno e de seus pais/responsáveis, quanto à disponibilidade, aceitabilidade e viabilidade.

Etapa 4: Elaboração de procedimento para a pesquisa de abordagem preditiva. Visou identificar a influência das crenças salientes (identificadas na Etapa 3) e de outros atributos (indicados teoricamente ou referenciados na literatura) sobre a escolha modal de estudantes em suas viagens cotidianas. Envolveu o segundo tipo de coleta de dados, com a aplicação de questionários a uma amostra significativa de alunos. A análise dos dados resultantes dessa coleta de dados utilizou as técnicas analíticas previstas na revisão teórica (Etapa 1) para a análise dos efeitos dos diferentes atributos sobre a escolha modal. O produto obtido nesta etapa foi a identificação do impacto dos atributos pesquisados sobre a escolha modal.

Etapa 5: Sistematização da proposta de procedimento para identificação dos atributos intervenientes sobre a escolha modal em IEMs a partir dos resultados das Etapas 3 e 4.

Etapa 6: A validade do procedimento proposto na Etapa 5 foi testada em IEMs localizadas no Distrito Federal, de modo a verificar a sua eficácia. Essa aplicação permitiu, também, a verificação das hipóteses de pesquisa.

Etapa 7: Relato das conclusões e recomendações sobre a utilização do procedimento desenvolvido em relação às realidades estudadas e desdobramentos futuros.

\subsection{ESTRUTURA DA TESE}

A tese se estrutura em oito capítulos, conforme apresentado na Figura 1.1. Após este capítulo introdutório serão apresentadas as revisões teóricas sobre a escolha modal e instituições de ensino - Capítulo 2, as teorias para a mudança comportamental - Capítulo 
3, e as técnicas analíticas para estudos comportamentais de escolha modal - Capítulo 4. $\mathrm{Na}$ sequência, o Capítulo 5 apresenta o desenvolvimento do procedimento para a identificação dos atributos intervenientes da escolha modal em IEMs. Os Capítulos 6 e 7 apresentam o teste do procedimento proposto em IEMs no DF, descrevendo, respectivamente, os procedimentos qualitativos e descritivos desenvolvidos na abordagem exploratória e os testes e modelagens estatísticas desenvolvidos na abordagem preditiva. O Capítulo 8 apresenta as conclusões e recomendações para futuras pesquisas.

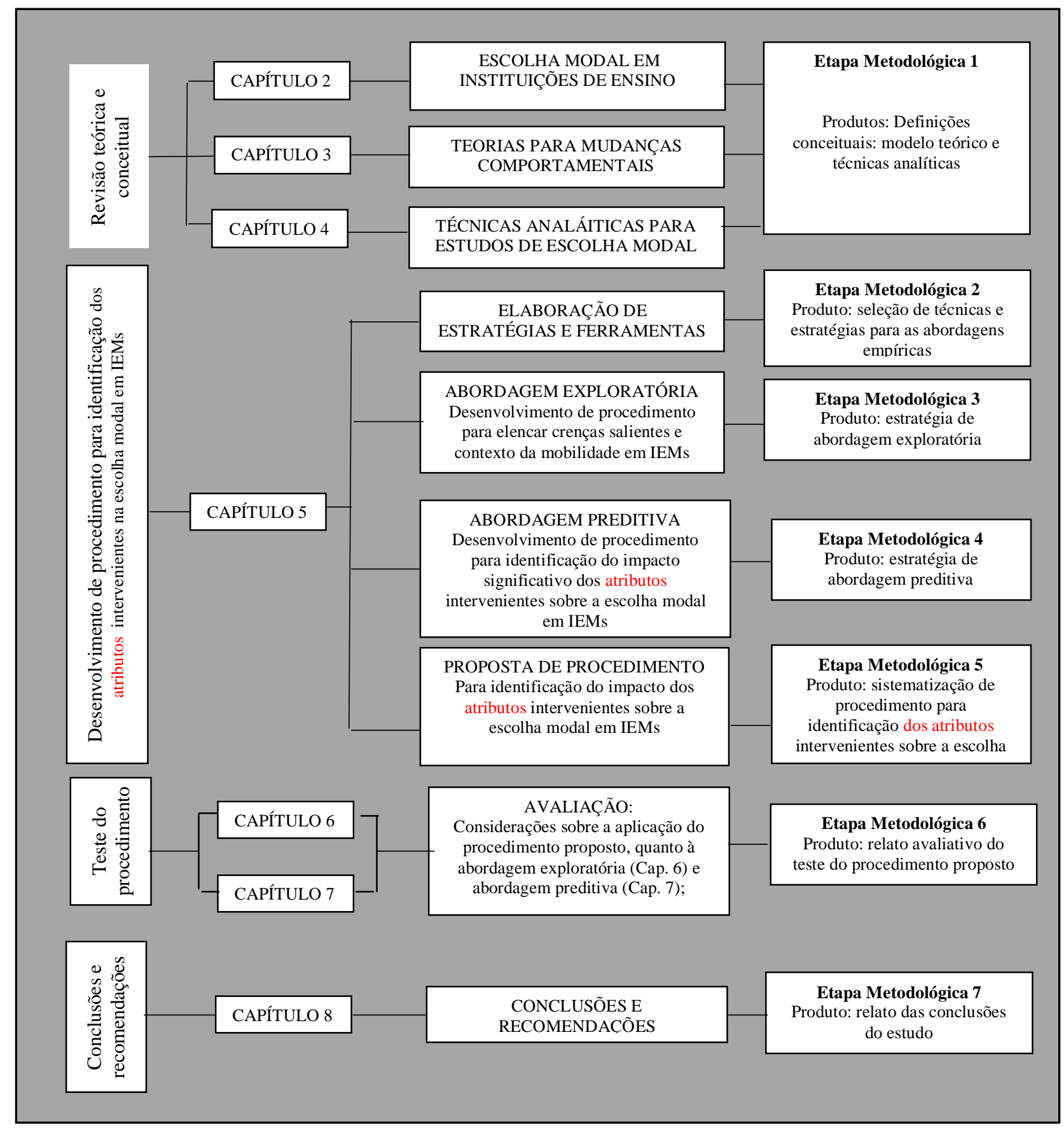




\section{ESCOLHA MODAL EM INSTITUIÇÕES DE ENSINO}

Neste capítulo, são apresentados os conceitos de suporte ao estudo da escolha modal em Instituições de Ensino. Inicialmente são abordadas generalidades sobre o tema, a relação da escolha modal e as áreas escolares. Em seguida, é apresentada uma revisão da literatura sobre a escolha modal, aplicada a instituições de ensino. Nos tópicos conclusivos, são apresentadas as oportunidades de contribuição da presente pesquisa, perante o panorama teórico revisado.

\subsection{GENERALIDADES SOBRE A ESCOLHA MODAL}

O estudo da escolha modal não é um objeto novo de pesquisa. Desde a década de 1960, os estudos sobre a escolha modal integram as pesquisas de planejamento de transporte (Ortúzar e Willumsen, 2011), tanto com abordagens agregadas ou desagregadas, a partir das preferências individuais. A modelagem mais comum nos estudos tradicionais de escolha modal é a utilização de Modelos de Escolha Discreta - MED. Esses modelos supõem que os usuários, promotores da escolha: i) tenham acesso a modos alternativos de transporte, com condições comparáveis de operação, acessibilidade, custo, etc.; ii) detenham todas as condições de informação, além de capacidade física e financeira para realizar as escolhas entre os modos de transporte disponíveis.

Os atributos influenciadores das escolhas modais na abordagem tradicional frequentemente se restringiam ao que se chamava de informação menos flexível (hard information): i) atributos do modo (custo/tarifa; conforto; tempo de viagem; origem/destino; etc.) e ii) características sociodemográficas do indivíduo (gênero, idade, renda, etc.) (Ben-Akiva et al., 2002; Kamargianni et al., 2015).

Outra abordagem para os estudos de escolha modal está vinculada aos estudos sobre o comportamento de viagens, ou travel behavior (para uma revisão, ver Curtis e Perkins, 2006). Para Lee-Gosselin e Pas (1997), o travel behaviour ampliou a análise da escolha modal, preocupado em entender e explicar como diferentes composições de regulações, valores pessoais e morais levam a mudanças no comportamento de viagens. Segundo esses autores, as análises incluem "contextos ambientais, socioeconômicos, demográficos e tecnológicos, do tipo bottom-up". Ou seja, a abordagem é totalmente desagregada, onde 
é necessário conhecer a variedade de contextos nos quais os usuários tomam suas decisões, como as informações contribuem para sua efetivação, e por que realizam suas escolhas.

Os chamados Modelos Híbridos de Escolha Discreta - MHED, incorporam aos MEDs as variáveis psicológicas, chamadas de dados flexíveis (soft information), aproximando a abordagem tradicional da abordagem do travel behavior. Essa adaptação responde por uma melhor especificação dos modelos e, assim, uma melhor interpretação da heterogeneidade populacional no comportamento das escolhas individuais (Ben-Akiva et al., 2002; Kamargianni et al., 2015).

Tanto para os modelos MEDs quanto os MHEDs o conceito da utilidade da opção modal é o cerne das modelagens: uma opção terá maior probabilidade de ser escolhida se, comparativamente às alternativas disponíveis, for percebida como aquela que trará maiores benefícios (ou utilidade) para quem toma a decisão. Cada alternativa tem, portanto, sua atratividade representada por uma função de utilidade específica. A utilidade não é um atributo observado ou medido diretamente. Tal qual um indicador, a utilidade é uma variável latente, pois é definida pela composição dos vários atributos observáveis diretamente e que influenciam a escolha da alternativa relacionada àquela utilidade.

\subsubsection{CLASSIFICAÇÃO DOS ESTUDOS SOBRE A ESCOLHA MODAL}

Podem-se reunir os estudos sobre a escolha modal em dois grandes grupos, segundo o tipo de dados a partir dos quais são realizadas as análises (Ben-Akiva et al., 2003):

i) estudos que coletam informações a partir da observação direta das escolhas ou relato individual sobre as decisões passadas. É chamada de Preferência Revelada (Revealed Preference);

ii) estudos que coletam informações a partir de respostas à apresentação de cenários hipotéticos. Desta forma são afirmativas da intenção de se comportar de determinada maneira. É chamada de Preferência Declarada (Stated Preference). 
A Preferência Declarada ajuda o planejador a avaliar situações ainda não disponíveis aos usuários, economizando recursos. Muitos estudos têm utilizado a Preferência Declarada para avaliar a disponibilização de uma nova tecnologia (como em Chen e Chao, 2011). A comparação das vantagens e desvantagens dos dois tipos de dados utilizados para avaliar a escolha modal é apresentada na Tabela 2.1.

Tabela 2. 1: Comparação dos dados obtidos por Preferência Revelada e Declarada

\begin{tabular}{|c|c|c|}
\hline & Preferência Revelada & Preferência Declarada \\
\hline Preferência & $\begin{array}{l}\text { Comportamento de escolha referente } \\
\text { ao comportamento atual; } \\
\text { Comportamento congruente com o } \\
\text { comportamento atual; } \\
\text { Restrições pessoais ou de contexto } \\
\text { são consideradas. }\end{array}$ & $\begin{array}{l}\text { Afirmações de preferência para } \\
\text { cenários hipotéticos; } \\
\text { O comportamento declarado pode } \\
\text { não ser congruente com o atual; } \\
\text { Restrições pessoais ou de contexto } \\
\text { podem não ser consideradas. }\end{array}$ \\
\hline Alternativas & $\begin{array}{l}\text { Alternativas atuais; } \\
\text { Não são observadas preferências a } \\
\text { alternativas não disponíveis. }\end{array}$ & $\begin{array}{l}\text { Alternativas geradas pelo analista; } \\
\text { Podem ser observadas preferências } \\
\text { por alternativas não disponíveis } \\
\text { atualmente. }\end{array}$ \\
\hline $\begin{array}{l}\text { Conjunto de escolhas } \\
\text { individuais }\end{array}$ & Pode ser ambíguo em vários casos. & $\begin{array}{l}\text { É especificado antecipadamente pelo } \\
\text { analista. }\end{array}$ \\
\hline Atributos & $\begin{array}{l}\text { Pode incluir erros de medida; } \\
\text { Atributos correlacionados; } \\
\text { Os valores ou limites dos atributos } \\
\text { são limitados. }\end{array}$ & $\begin{array}{l}\text { Não inclui erros de medida; } \\
\text { A multicolinearidade pode ser } \\
\text { evitada pelo delineamento } \\
\text { experimental; } \\
\text { Os valores ou limites dos atributos } \\
\text { podem ser estendidos pelo analista. }\end{array}$ \\
\hline Número de Respostas & $\begin{array}{l}\text { É sempre difícil para obter múltiplas } \\
\text { respostas de cada indivíduo. }\end{array}$ & $\begin{array}{l}\text { Questionamentos repetitivos são } \\
\text { facilmente aplicados. }\end{array}$ \\
\hline Tipos de preferência & Somente uma escolha é observada. & $\begin{array}{l}\text { Diferentes formatos de preferência } \\
\text { são disponíveis (como a } \\
\text { hierarquização, a classificação e as } \\
\text { correspondências). }\end{array}$ \\
\hline
\end{tabular}

Fonte: Adaptado de Ben-Akiva et al. (2003).

\subsubsection{ATRIBUTOS UTILIZADOS EM ESTUDOS DE ESCOLHA MODAL}

Os atributos utilizados em estudos da escolha modal foram revisados em Zhou (2012), e agrupados em seis grupos de atributos influenciadores da escolha modal. A Tabela 2.2 apresenta esses grupos. Nem todos os atributos podem ser facilmente medidos na prática, como conforto, conveniência, segurança, proteção, seguridade, entre outros (Ortúzar e Willumsen, 2011). Os atributos do modo (Grupo 2) e os dados socioeconômicos (Grupo 4) foram explorados largamente pelos modelos tradicionais de transportes (Lee-Gosselin e Pas, 1997). O Grupo 1 se origina de uma série de estudos que pretendem explicar a escolha modal pelo ambiente construído, também bastante explorado na literatura (para revisão, ver Ewing e Cervero, 2001). O Grupo 3 envolve políticas públicas e sua avaliação 
é mais comum em estudos "antes" e "depois" da implantação de determinada medida de Gerenciamento da Demanda - GM ou TDM.

Tabela 2.2: Atributos influenciadores da escolha modal

\begin{tabular}{|c|c|c|}
\hline & Grupos & Descrição \\
\hline \multirow[b]{2}{*}{$\stackrel{8}{\Sigma}$} & Grupo 1 & $\begin{array}{l}\text { Elementos do meio ambiente físico e da forma urbana, como a densidade } \\
\text { populacional, a miscigenação do uso do solo, topografia, disponibilidade de } \\
\text { infraestrutura, a conectividade de rede multimodal. }\end{array}$ \\
\hline & Grupo 2 & $\begin{array}{l}\text { Atributos específicos do modo, como componentes do tempo de viagem, } \\
\text { componentes monetários do custo da viagem, custo de estacionamento, } \\
\text { regularidade do serviço, confiabilidade no tempo da viagem, disponibilidade, } \\
\text { acesso, conveniência, conforto, privacidade, liberdade, segurança. }\end{array}$ \\
\hline ఏे & Grupo 3 & $\begin{array}{l}\text { Presença de medidas de gerenciamento da demanda (TDM), como: i) a taxação ou } \\
\text { restrição de estacionamentos; ii) o uso de campanhas informativas contra o uso do } \\
\text { automóvel; iii) a promoção do uso do 'vale transporte'. }\end{array}$ \\
\hline \multirow{3}{*}{ 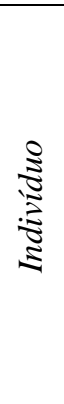 } & Grupo 4 & $\begin{array}{l}\text { Características' pessoais do indivíduo que realiza a viagem, como profissão, estado } \\
\text { civil, sexo, idade, renda, responsabilidades cotidianas, propriedade ou } \\
\text { disponibilidade de veículo e ser licenciado para dirigir, estrutura familiar, como a } \\
\text { presença de crianças pequenas. }\end{array}$ \\
\hline & Grupo 5 & $\begin{array}{l}\text { Características da viagem, como o tempo de viagem, o período de realização da } \\
\text { viagem, o propósito da viagem, a distância da viagem, a origem e o destino da } \\
\text { viagem, se é realizada pelo indivíduo sozinho ou acompanhado. }\end{array}$ \\
\hline & Grupo 6 & $\begin{array}{l}\text { Dimensões psicológicas como o hábito, atitude, conscientização sobre a saúde, o } \\
\text { meio ambiente, familiaridade aos modos alternativos ao automóvel e o apego } \\
\text { inconsciente ao uso do automóvel. }\end{array}$ \\
\hline
\end{tabular}

Recentemente tem crescido o envolvimento de pesquisadores com os atributos do Grupo 6, em adição aos Grupos 2, 4 e 5. A introdução dos atributos desse grupo, em conjunto com os atributos dos demais grupos nos estudos de escolha modal, tem contribuído para uma melhor explicação dos processos de decisão por modo de transporte (Ben-Akiva et al., 2002; Kamargianni et al., 2015). Tal abordagem foi impulsionada pelos estudos de psicologia social sobre a atitude, como os que resultaram na Teoria do Comportamento Planejado - TCP (Ajzen 1991) e na teoria do Modelo de Ativação da Norma - MAN (Bamberg et al., 2003). Destas, a mais utilizada para explicar a escolha modal é a Teoria do Comportamento Planejado - TCP (Bamberg et al., 2003; Bamberg e Schimidt, 2003). Estas teorias e os atributos da escolha modal serão devidamente apresentados no Capítulo 3 desta tese.

\subsection{A ESCOLHA MODAL EM ÁREAS ESCOLARES}

As áreas escolares merecem atenção especial dos estudos da escolha modal. Os conceitos e atitudes formados na idade escolar, a percepção da mobilidade nas áreas escolares, e os modos utilizados para viabilizar a chegada ou saída da escola parecem impactar outras 
fases da vida. Crianças que realizam a maior parte de seus deslocamentos de carro tendem a continuar com tal comportamento na vida adulta, e a ser mais relutantes ao uso de modos alternativos ao automóvel. Schlossberg et al.(2006) e McMillan (2005) ampliam a preocupação com este tipo de estudo acrescentando razões por que deveríamos nos preocupar em estudar as viagens escolares. São elas: i) a escolha pelo modo automóvel tem reduzido a oportunidade de realização de atividade física através dos deslocamentos escolares rotineiros; ii) os condutores das crianças também comprometem suas rotinas diárias pelo envolvimento em congestionamentos; iii) crianças e adolescentes, como pedestres e ciclistas, integram o grupo mais vulnerável do trânsito. As áreas escolares, portanto, deveriam ser foco de ações consistentes para a promoção da segurança desses usuários.

\subsubsection{CLASSIFICAÇÃO DAS VIAGENS POR MOTIVO ESTUDO}

As classificações das viagens por motivo estudo diferem com relação à atuação do indivíduo que realiza a viagem e com relação à teoria subjacente à classificação. Podem ser consideradas viagens pendulares (commute trips) (Litman, 2010), pois se realizam de forma cotidiana e programada na base domiciliar com antecedência. De acordo com a teoria do travel behaviour, as viagens pendulares ainda podem ser divididas como obrigatórias (mandatory trips), quando referidas aos próprios estudantes, por serem predominantes no diário de viagens (Ewing et al., 2004; Fujii, 2003), ou como viagens de manutenção (maintenance trips) (Curtis e Perkins, 2006; Golob et al., 1995), quando referidas aos adultos que conduzem os estudantes. Nas viagens de manutenção, observase a importância dessas viagens no diário de viagens dos adultos, impactando as demais atividades do dia. Uma síntese sobre as classificações encontradas na literatura é apresentada na Tabela 2.3.

Tabela 2.3: Classificação das viagens por motivo estudo

\begin{tabular}{clc}
\hline Classificação & \multicolumn{1}{c}{ Característica } & Foco da abordagem \\
\hline Commute Trips & Rotina da comunidade alvo. & $\begin{array}{l}\text { Programas de redução das } \\
\text { viagens pendulares. }\end{array}$ \\
\hline Mandatory Trips & Prioridade nos diários de viagens. & $\begin{array}{l}\text { Planejamento antecipado das } \\
\text { viagens (planos de viagem). }\end{array}$ \\
\hline Maintenance Trips & $\begin{array}{l}\text { Viagens de subsistência - viagens dos alunos } \\
\text { e funcionários das escolas; } \\
\text { Viagens de manutenção - viagens dos adultos } \\
\text { que conduzem os alunos. }\end{array}$ & $\begin{array}{c}\text { Modelos baseados em } \\
\text { atividades. }\end{array}$ \\
\hline
\end{tabular}

Fonte: Adaptado de Golob et al.(1995); Fujii (2003); Ewing et al.(2004); Curtis e Perkins (2006); Litman, (2010). 


\subsubsection{ESPECIFICIDADES DAS ÁREAS ESCOLARES BRASILEIRAS}

O Manual de Sinalização de Áreas Escolares do DENATRAN (2000) preconiza a prioridade de tratamento das áreas vizinhas às escolas, em relação à segurança viária. $\mathrm{O}$ manual prevê a realização de diagnóstico multimodal, principalmente vinculado à segurança de pedestres, como a verificação da iluminação noturna nas rotas mais utilizadas. Com relação ao uso dos transportes públicos e às integrações a pé até os pontos de embarque/desembarque, ainda há carência de especificação. O manual não explicita distâncias aceitáveis às redes de transporte público em relação ao nível escolar, nem que tratamentos são indicados para esses percursos. A atratividade ou repulsão dos escolares a modos de transporte alternativos ao automóvel pode estar associada a este percurso a pé, além das características próprias do modo.

No Brasil, e em Brasília em particular, não existem dados disponíveis e consistentes relacionando especificamente os acidentes de trânsito com estudantes no caminho da escola. Entretanto, as estatísticas sobre a mortalidade de crianças e adolescentes em acidentes de transporte no Brasil dão indícios de como esta população está sendo afetada pela falta de segurança nos seus contextos cotidianos. Waiselfisz (2012) aponta que 27,2\% das mortes entre crianças e adolescentes no Brasil são decorrentes de acidentes de transporte. Entre as vítimas com idade entre 1 e 14 anos, a "maior incidência acontece quando transitam a pé pelas ruas" (Waiselfisz, 2012). A Tabela 2.4 apresenta os percentuais de vítimas entre crianças e adolescentes em acidentes de transporte no Brasil, por faixa etária e segundo a situação, ou modo em uso, no momento do acidente.

Tabela 2.4: Óbitos por acidentes de transporte de crianças e adolescentes no Brasil em 2010 segundo a situação e faixa etária da vítima

\begin{tabular}{ccccccc}
\hline \multirow{2}{*}{ Situação } & \multicolumn{7}{c}{ Percentuais por faixa etária } \\
\cline { 2 - 7 } & $\mathbf{1}$ & $\mathbf{1 ~ a ~ 4}$ & $\mathbf{5 - 9}$ & $\mathbf{1 0 - 1 4}$ & $\mathbf{1 5 - 1 9}$ & Total \\
\hline Pedestre & 19,4 & 44 & 41,9 & 31,1 & 12,2 & 20,9 \\
\hline Bicicleta & 0,8 & 1,3 & 3,7 & 8,9 & 2,5 & 3,4 \\
\hline Motocicleta & 8,1 & 3,3 & 4,0 & 13,7 & 38,8 & 27,8 \\
\hline Automóvel & 40,3 & 23,4 & 25,7 & 19,7 & 19,3 & 20,9 \\
\hline Veíc.carga & 0,8 & 2,6 & 2,8 & 2,5 & 1,9 & 2,1 \\
\hline Onibus & 1,6 & 0,9 & 1,2 & 0,8 & 0,2 & 0,5 \\
\hline Outros & 29,0 & 24,5 & 20,6 & 23,4 & 25,0 & 24,4 \\
\hline Total & 100 & 100 & 100 & 100 & 100 & 100 \\
\hline
\end{tabular}

Fonte: Waiselfisz (2012). 
A segurança pessoal, além da segurança viária, nos percursos entre a residência e a escola, também parece afetar a forma de deslocamento casa/escola. Rosa (2010), em um estudo sobre a escolha modal de estudantes para Instituições de Ensino Fundamental - IEFs na cidade de São Carlos/SP, aponta que em média os usuários dos modos a pé e bicicleta percebem as áreas escolares como menos seguras do que os usuários de automóveis e ônibus. Nesse estudo foram abordados os seguintes itens: i) segurança para usar o modo a pé e bicicleta; ii) preocupação em ser assediado no caminho para a escola; iii) preocupação com o roubo da bicicleta. Tais resultados corroboram os obtidos em outros países, como em Lang et al.(2011), Shokoohi et al. (2012) e Sidharthan et al. (2010) que apontam que a presença de ambientes hostis nas áreas escolares propicia o uso do automóvel particular.

As viagens alvo da presente pesquisa são por motivo estudo, com origem ou destino nas Instituições de Ensino Médio - IEM, e realizadas nos períodos de início e final de turno e em dias úteis. As viagens a estudo são viagens bem programadas e, de modo análogo às viagens a trabalho, elas se repetem cotidianamente, em contextos bem semelhantes (Bertazzo e Jacques, 2010; Bertazzo et al., 2012). Miranda et al. (2014) apontam que "o impacto gerado pelas operações de embarque e desembarque (E/D) dos estudantes junto às IEMs brasileiras, nos horários de entrada e saída dos turnos, pode ser considerado o efeito adverso mais significativo decorrente da implantação deste tipo de PGV [Instituições de Ensino Médio]”.

Nas pesquisas brasileiras não se espera encontrar alunos de IEMs condutores de automóveis, pela restrição legal para tal, a não ser entre alunos fora da idade escolar padrão, em programas de Educação de Jovens e Adultos. Tal observação diferencia os estudos brasileiros dos estudos americanos e canadenses. Entretanto, deve-se considerar que o adulto que conduz um aluno à escola também realiza viagens por motivo estudo, mas de forma diferenciada para a importância dessas viagens no seu plano diário de viagens. Miranda et al. (2014), em estudo em Brasília, apontaram que os veículos conduzindo alunos apresentavam baixa ocupação veicular, com maior média observada na entrada dos turnos e em IEMs públicas, com ocupação de apenas 1,22 alunos por veículo (neste estudo, os condutores observados não eram alunos). Ou seja, a prática de compartilhamento de veículos, automóvel carona, não é um modo popular para a condução de escolares. 


\subsection{ESTUDOS DA ESCOLHA MODAL EM INSTITUIÇÕES DE ENSINO}

Na revisão da literatura sobre a escolha modal em instituições de ensino, foram analisadas diferentes publicações, com foco nos últimos doze anos. A síntese desta revisão é apresentada no Apêndice A. Ela evidencia a importância dada ao tema no período, principalmente nos últimos cinco anos (65\% dos trabalhos revisados). Grande ênfase é dada à segurança dos estudantes nos seus deslocamentos cotidianos, à promoção da saúde e à realização de atividade física em decorrência da sua escolha modal nas viagens por motivo estudo.

A geografia dos estudos é bem diversificada. A maioria (32 estudos) foi realizada em países desenvolvidos, na América do Norte, Europa e Japão. Entretanto, também inclui pesquisas desenvolvidas em países em desenvolvimento, como no Brasil (8) e Peru (1) na América do Sul, e países do Oriente Médio (4), da Oceania (5), da Ásia (3) e da África (1). A maior parte dos estudos se concentra nas Instituições de Ensino Fundamental (34). Os modos estudados mais frequentes são o transporte ativo, ou não motorizado.

São diversos os métodos de análise da escolha modal. A modelagem mais frequente é através de modelos logit multinomial, mas também inclui modelos mais requintados como o logit aninhado (nested) e o mixed logit, Equações Estruturais, Análise Fatorial Exploratória - EFA e modelos integrados de escolha modal e variável latente (modelos ICLV). A maior parte dos estudos utiliza dados referentes a um único período de tempo (estudos do tipo cross-section), sendo raros os estudos longitudinais que levam em conta dados de vários períodos de tempo, como é o caso do realizado por McDonald (2007).

Na revisão, foram encontrados estudos baseados em coletas de dados mais amplas como censos, pesquisas domiciliares, ou pesquisas nacionais sobre a mobilidade. Tais estudos, envolvendo amostras acima de 2000 indivíduos, possibilitou análises estatísticas requintadas (como em Karmargianni et al., 2015). Outra abordagem é apresentada em quatro(4) estudos revisados que propõem a avaliação de experimentos de intervenção na escolha modal de estudantes. Um resumo desses estudos é apresentado na Tabela 2.5. Os resultados desses estudos são promissores, indicando que a correta especificação dos atributos influenciadores da escolha modal pode compor estratégias eficazes para motivar 
a escolha de modos diferentes daqueles atualmente utilizados, visando a mobilidade sustentável.

Tabela 2.5: Estudos revisados com experimentos de intervenção na escolha modal

\begin{tabular}{lcl}
\hline \multicolumn{1}{c}{ Estudo } & $\begin{array}{c}\text { Nível da } \\
\text { Instituição de } \\
\text { Ensino }\end{array}$ & \multicolumn{1}{c}{ Tipo do experimento } \\
\hline Bamberg et al., 2003 & IESs & $\begin{array}{l}\text { Avaliação da repartição modal dos participantes, antes } \\
\text { e depois da distribuição de bilhete para uso do } \\
\text { transporte público no período do experimento. }\end{array}$ \\
\hline Cairns et al, 2004 & IEFs e IEMs & $\begin{array}{l}\text { Avaliação da repartição modal dos participantes, antes } \\
\text { e depois da elaboração de planos de viagem. }\end{array}$ \\
\hline Fujii e Taniguchi, 2005 & IEFs & $\begin{array}{l}\text { Avaliação da repartição modal dos participantes, e da } \\
\text { emissâo de CO } \text { COn }_{2} \text { nas viagens escolares, antes e depois } \\
\text { da elaboração de planos de viagem. }\end{array}$ \\
\hline Srinoongvikraiet al.,2010 & IESs & $\begin{array}{l}\text { Avaliação da repartição modal dos participantes, antes } \\
\text { e depois da oferta de diferentes incentivos para uso do } \\
\text { transporte público no período do experimento. }\end{array}$ \\
\hline
\end{tabular}

Das características ambientais em relação à escolha modal, predominam os estudos realizados nos EUA, e destacam-se os seguintes atributos: i) a distância casa-escola (26 estudos); ii) as condições da via e da calçada (08 estudos, sendo dois no Brasil e dois nos EUA); iii) o clima (07 estudos, sendo quatro nos EUA e três na Europa); iv) a forma urbana (04 estudos, sendo dois nos EUA); v) o uso do solo (04 estudos, sendo três nos EUA); vi) a densidade (03 estudos, sendo dois nos EUA).

A análise cruzada entre a opinião de pais e alunos para a escolha modal é apontada como importante em diversos estudos. Este compartilhamento de opinião é melhor relatado em estudos em Instituições de Ensino Fundamental (Zhu, 2007; Sanches et al., 2010; Carver et al., 2013, entre outros) do que em estudos em Instituições de Ensino Médio (Zwerts e Wets, 2006; Yalargadda e Srinivasan, 2008; Alemu e Tsutsumi, 2011, Karmargianni et al., 2015). Karmargianni et al., 2015, propõem que não haja o compartilhamento de opinião entre os alunos e seus respectivos pais/responsáveis.

Os estudos revisados propõem algumas hipóteses sobre a relação das variáveis sociodemográficas e a escolha modal. Quanto ao gênero, espera-se que as meninas utilizem mais automóveis para as viagens escolares (Zwerts e Wets, 2006; Fox et al., 2012). Quanto à idade, espera-se que alunos de maior idade utilizem menos o automóvel (Zhu, 2007; Yalargadda e Srinivasan, 2008). Quanto à renda, alunos de famílias com maior renda usariam mais o automóvel (Wilson et al. 2010, Sidharthan et al., 2010, 
Shokoohi et al., 2012, Haque et al.,2013, Danaf et al., 2014,). Quanto à distância (McDonald, 2007; Shokoohi et al., 2012), alunos morando mais longe, e em áreas periféricas e de menor urbanização (Whalen et al., 2013; Carver et al., 2013), usariam mais o modo automóvel. Alunos que residem e estudam em áreas mais densas tendem a caminhar mais (Zhu, 2007; Yoon et al.,2011; Ermagum et al., 2013).

A revisão da literatura realizada sobre a escolha modal em Instituições de Ensino aponta, também, que o Brasil ainda carece de estudos abrangentes sobre o tema, que incluam: i) abordagens multimodais; ii) diferentes técnicas de abordagem; iii) avaliação da eficiência das estratégias de GM para a melhoria qualitativa dos deslocamentos compulsórios cotidianos de crianças e adolescentes. O presente estudo pretende contribuir para o entendimento da escolha modal, incluindo as abordagens apontadas nos itens "i" e "ii".

\subsection{TÓPICOS CONCLUSIVOS}

É necessária a identificação da percepção social da mobilidade dos indivíduos envolvidos, os motivos e contextos dessa decisão, para que alguma redução de uso do automóvel ou a troca do seu uso por modos alternativos de fato aconteça. Ou seja, a proposição de alternativas ao uso do automóvel deve ser adaptada às especificidades da população alvo. Tais motivações indicam a necessidade de incluir dimensões psicológicas (Atributos do Grupo 6 de Zhou, 2012) aos atributos tradicionais da escolha modal. As dimensões psicológicas se propõem a explicar o processo decisório de forma desagregada e sob o foco dos usuários do transporte. Para a análise da escolha modal, a modelagem que inclua as dimensões psicológicas com o uso de MHEDs é um enfoque promissor no planejamento de transportes, trazendo contribuições mais precisas sobre a heterogeneidade populacional e sobre os atributos influenciadores da escolha modal.

A literatura revisada traz muitos exemplos de estudos que, em localidades diferentes, analisam a escolha modal. A maioria tem objetivos na promoção de modos alternativos ao automóvel, principalmente modos não motorizados. As instituições de ensino médio têm sido menos exploradas nos estudos, mas constituem um segmento interessante para pesquisa, imediatamente anterior à idade de motorização, no caso brasileiro. Em nível nacional, a revisão da literatura apresentou oportunidade de pesquisa, no aprofundamento do estudo da escolha modal em áreas escolares a partir de abordagens multimodais. 
O contexto escolar das IEMs no Brasil apresenta características que devem ser consideradas para pesquisa sobre a mobilidade de seus usuários, em contraste ou semelhança aos estudos revisados:

a) O impedimento legal de conduzir veículos motorizados antes dos 18 anos, diferente de países com estudos sobre escolha modal bem referenciados na literatura, como EUA e Canadá;

b) a mobilização de pais/responsáveis na viabilização das viagens escolares pela condução de seus filhos para e da IEM;

c) a necessidade de realização de estudos multimodais para as áreas escolares;

d) os efeitos adversos do uso predominante do automóvel nas operações de embarque e desembarque nos horários de entrada e saída dos turnos, que têm implicações para a segurança viária nas imediações da IEM;

e) a segurança pessoal, derivada da percepção de um contexto seguro para a mobilidade, parece influenciar a escolha modal em escolas. Deve ser avaliado, como apontado por Rosa (2010), como os contextos e as percepções de segurança influenciam a escolha modal nas áreas escolares.

Tais considerações apontam que há a necessidade de realização de etapa exploratória de pesquisa, segundo um procedimento bem definido e devidamente fundamentado, na qual sejam observadas: i) as características de contexto das áreas escolares; ii) as questões gerais sobre a percepção dos usuários na escolha modal; iii) e como pais e alunos compartilham suas decisões sobre a escolha do modo de transporte. 


\section{TEORIAS RELACIONADAS A MUDANÇAS NO COMPORTAMENTO}

Para a presente pesquisa, busca-se analisar a escolha modal em nível do usuário da IEM (estudantes ou pais/responsáveis), envolvido na decisão de como realizar a viagem de/para a IEM. O entendimento dos processos decisórios subjacentes às escolhas modais torna-se fundamental para o prosseguimento do estudo. A decisão é um comportamento observável, mas nem sempre estão acessíveis seus antecedentes. E, ainda, interessa compreender se existe potencialidade de mudança comportamental, com foco na mobilidade sustentável. Este capítulo revisa as teorias relacionadas a mudanças no comportamento, aplicadas à escolha modal, culminando no modelo teórico proposto para o estudo da escolha modal dos usuários das IEMs.

\subsection{ABORDAGENS SOBRE PROCESSOS DECISÓRIOS}

Os processos decisórios envolvem algum rito de planejamento na busca pela otimização de tempo e energia. Tais processos têm sido estudados em diferentes campos do conhecimento. Em administração de processos, o interesse está em modelar processos confiáveis e críticos para a tomada de decisão que minimizem os riscos de prejuízos. Em gerenciamento empresarial, a tomada de decisão é geralmente analisada considerando a existência de uma racionalidade limitada e a necessidade de se trabalhar com um modelo simplificado da realidade (Shimizu, 2010).

A abordagem da psicologia social é mais abrangente que as anteriores, indicando que a investigação sobre os processos decisórios possa envolver, além das limitações situacionais, as restrições cognitivas e a flexibilidade do tomador de decisões perante circunstâncias adversas (Montgomery, 1994). O processo de tomada de decisão é precedido por um deliberado processamento de informação, que pode incluir escolhas estratégicas, a busca por informação, a análise das alternativas existentes e a seleção ou construção de alternativas (Gärling e Axhausen, 2003). Bamberg et al. (2003) afirmam que a escolha modal é "fundamentalmente uma decisão racional" e existe um amplo espectro de condições pelas quais o indivíduo faz a sua escolha. 
Uma meta frequente nas pesquisas da psicologia social relacionadas aos processos decisórios é promover a mudança comportamental (Petty e Wegener, 1998). Salienta-se que a mudança comportamental deve ser proposta com cuidado, pois não se trata de qualquer mudança. Segundo Collier et al. (2010), a mudança deve ser realizada para “consolidar e reforçar a opção pela direção desejada e sustentável no tempo. (...) A mudança se baseia nos incentivos e motivações pessoais, que podem incluir benefícios financeiros, normas sociais ou apenas um atributo de percepção do bem para a realização de uma ação positiva”.

Os estudos sobre a atitude vêm delinear os possíveis determinantes do comportamento (como, por exemplo, a decisão pela escolha modal). Embora não haja um consenso de que as atitudes sejam boas preditoras do comportamento, pode-se dizer que as decisões comportamentais são influenciadas pelas atitudes. Atitudes são 'tendências psicológicas expressas pela avaliação de uma entidade específica (objeto, pessoa ou comportamento), com certo grau de aprovação ou desaprovação" (Eagly e Chaiken, 1998).

As atitudes refletem "as crenças sobre as consequências do comportamento, ou crença sobre o objeto (belief $-b$ ), e os valores atribuídos a essas consequências, ou força da crença (evaluation - e)” (Ajzen, 1991; Neto, 2014). Na formulação da atitude pelas crenças comportamentais é adotada a Teoria da Expectância (Fishbein e Ajzen,1975), que tem sido empregada em estudos aplicados, como o de Elliott et al.(2005). Esta teoria considera simultaneamente as crenças sobre o objeto e os valores atribuídos a elas (bxe).

\subsection{A ATITUDE COMO PREDITORA DO COMPORTAMENTO}

A atitude é construída com base em três componentes: cognitivo, afetivo e comportamental. Estes componentes são adquiridos em diferentes estágios no processo de tomada de decisão, compondo uma resposta avaliativa perante um objeto, influenciando a decisão e a mudança comportamental. A formação da atitude é um processo desenvolvido a partir da generalização de associações mais elementares, do acúmulo de experiências ou de informações recebidas.

A mudança de atitude pode envolver uma mudança radical de posição (polarização). $O$ simples contato com valores distintos já ajuda a criar novas atitudes, pré-disposições para 
um comportamento diferenciado, ampliando o leque de posições aceitáveis e podendo até influenciar futuras mudanças de comportamento.

Pode existir forte relação entre atitude e comportamento quando as atitudes são baseadas em experiências diretas, ou quando o comportamento relativo à atitude estudada tem consequências importantes para a pessoa. Da mesma forma, pessoas com baixo auto monitoramento confiam mais em suas atitudes e são por elas guiadas (Torres, 2011).

\subsection{TEORIAS SOBRE MUDANÇAS COMPORTAMENTAIS}

São diversas as teorias da psicologia que estudam as mudanças comportamentais a partir de mudanças atitudinais. Nesta seção, serão revisados alguns modelos teóricos sobre mudanças comportamentais referenciados na literatura sobre a escolha modal: o Modelo de Elaboração da Probabilidade, o Modelo de Ativação da Norma, a Teoria da Ação Racional, a Teoria do Comportamento Planejado e a Teoria do Comportamento Interpessoal. A influência do hábito sobre a mudança de comportamento é apresentada no final da seção.

Nesses modelos, a atitude é abordada pelo seu viés cognitivo de forma que a mudança de atitude se processe racionalmente, ou seja, o comportamento é influenciado pela atitude na comparação dos benefícios/prejuízos (não apenas econômicos) ou custos de cada alternativa. São conhecidas algumas aplicações dessas teorias para estudos de transportes (Bamberg e Schimidt, 2003; Fujii e Taniguchi, 2005a; Egmond e Bruel, 2007; Thorgersen, 2007; Collier et al., 2010; Rye et al., 2011, entre outros). Para essa abordagem são raros os trabalhos no contexto nacional, como revisado no capítulo anterior.

Cada modelo teórico explicará melhor um ou outro fenômeno dependendo do contexto social da proposição de mudança, das variáveis que compõem o modelo, e da aplicação pretendida para os resultados da pesquisa. A Tabela 3.1 apresenta um comparativo dos modelos teóricos analisados. 
Tabela 3.1: Comparativo de modelos teóricos para mudanças comportamentais pela mudança de atitude

\begin{tabular}{|c|c|c|c|}
\hline Modelo Teórico & Contexto & Variáveis & Aplicação \\
\hline \multirow{2}{*}{$\begin{array}{l}\text { MEP - Modelo } \\
\text { de Elaboração } \\
\text { da } \\
\text { Probabilidade }\end{array}$} & \multirow{2}{*}{$\begin{array}{l}\quad \text { Mudança da } \\
\text { atitude por grande } \\
\text { esforço cognitivo. }\end{array}$} & $\begin{array}{l}\text { Persuasão pela rota central - os indivíduos, } \\
\text { ao ter contato com a nova informação, a } \\
\text { consideram importante e atêm-se a ela. } \\
\text { O que importa é a qualidade do argumento. } \\
\text { Produz uma mudança de atitude que é mais } \\
\text { duradoura e mais resistente a futuras } \\
\text { mudanças. }\end{array}$ & $\begin{array}{l}\text { Campanhas } \\
\text { educativas. }\end{array}$ \\
\hline & & $\begin{array}{l}\text { Persuasão pela rota periférica - a mudança } \\
\text { de atitude é resultado de uma elaboração mais } \\
\text { displicente da informação, dependendo mais } \\
\text { da quantidade de informação a que o } \\
\text { indivíduo foi exposto do que da qualidade } \\
\text { desta informação. }\end{array}$ & $\begin{array}{l}\text { Campanhas de } \\
\text { marketing de } \\
\text { transporte. }\end{array}$ \\
\hline $\begin{array}{l}\text { MAN - Modelo } \\
\text { de Ativação da } \\
\text { Norma }\end{array}$ & $\begin{array}{l}\text { Mudança de } \\
\text { atitude por } \\
\text { constrangimento } \\
\text { moral (evitar } \\
\text { prejuízos a outras } \\
\text { pessoas). }\end{array}$ & $\begin{array}{l}\text { Norma Pessoal - o sentimento de obrigação } \\
\text { moral de agir de certa maneira. É ativada pelas } \\
\text { variáveis: } \\
\text { Norma Social; } \\
\text { Percepção de Controle sobre o } \\
\text { Comportamento; } \\
\text { Percepção das Consequências Adversas; } \\
\text { Percepção de Responsabilidade. }\end{array}$ & $\begin{array}{l}\text { Comportamentos } \\
\text { altruísticos. }\end{array}$ \\
\hline $\begin{array}{l}\text { TRA - Teoria } \\
\text { da Ação } \\
\text { Racional }\end{array}$ & $\begin{array}{l}\text { Mudança da } \\
\text { atitude pelo viés } \\
\text { cognitivo. } \\
\text { Modelo Geral. }\end{array}$ & $\begin{array}{l}\text { Relação preliminar entre a norma social e a } \\
\text { atitude positiva com relação ao } \\
\text { comportamento, indicando uma intenção } \\
\text { comportamental. }\end{array}$ & $\begin{array}{l}\text { Escolha deliberada; } \\
\text { Limitação: não } \\
\text { modela o controle } \\
\text { sobre o } \\
\text { comportamento. }\end{array}$ \\
\hline $\begin{array}{c}\text { TCP }- \\
\text { Teoria do } \\
\text { Comportamento } \\
\text { Planejado }\end{array}$ & $\begin{array}{l}\text { Mudança da } \\
\text { atitude pelo viés } \\
\text { cognitivo. } \\
\text { Modelo Geral. }\end{array}$ & $\begin{array}{l}\text { Variáveis modeladas: } \\
\text { Atitude para com o comportamento; } \\
\text { Norma Social; } \\
\text { Controle Percebido do Comportamento; } \\
\text { Mediados pela Intenção de } \\
\text { Comportamento na decisão pela realização } \\
\text { do comportamento. }\end{array}$ & $\begin{array}{c}\text { Escolhas } \\
\text { deliberadas. }\end{array}$ \\
\hline $\begin{array}{c}\text { TCI - } \\
\text { Teoria do } \\
\text { Comportamento } \\
\text { Interpessoal }\end{array}$ & $\begin{array}{l}\text { Mudança da } \\
\text { atitude pelo viés } \\
\text { cognitivo e pela } \\
\text { força do hábito. }\end{array}$ & $\begin{array}{l}\text { A intenção do comportamento é formada } \\
\text { pelas seguintes variáveis: } \\
\text { Norma Pessoal; } \\
\text { Crenças Comportamentais; } \\
\text { Crenças de Controle; } \\
\text { Crenças de funções; } \\
\text { Afeto; } \\
\text { Hábito. }\end{array}$ & $\begin{array}{l}\text { Escolhas } \\
\text { deliberadas ou } \\
\text { habituais. }\end{array}$ \\
\hline
\end{tabular}

O Modelo de Elaboração da Probabilidade - MEP tenta explicar o processo de mudança da atitude e a força das atitudes resultantes deste processo. $\mathrm{O}$ foco é uma probabilidade contínua definida como o tanto que a pessoa está motivada e apta para acessar o objeto da atitude e selecionar as informações relevantes (Petty e Wegener, 1998). Vários estudos empíricos têm relatado a validade do modelo MEP para a predição da escolha de modos de transporte sustentável (como em Zhou, 2012; Huneck et al., 2001) desde que implique em algum tipo de obrigação moral, como os comportamentos pró-ambientais. 
O Modelo de Ativação da Norma - MAN foi desenvolvido por Schwartz em 1977 e se preocupa em modelar como as pessoas são guiadas a decidirem-se baseadas mais em uma obrigação moral, e menos por uma intenção comportamental (Bamberg e Schimidt, 2003). As normas sociais são "regras e padrões que são compreendidos pelos membros do grupo, e que guiam ou constrangem o comportamento social sem a força da lei" (Cialdini e Trost, 1998). As normas sociais são valorizadas dentro da cultura local e lhe dão identidade.

O uso desta teoria para previsão de comportamentos pró-ambientais implica em "assumir que as pessoas têm uma regra geral de valor orientado para o bem estar dos outros (altruísmo), ou seja, são motivadas para prevenir prejuízos a outros" (Bamberg e Schimidt, 2003). A relevância do modelo é restrita ao comportamento moral.

Klöckner e Friedrichsmeier (2011) e Bamberg e Schimidt (2003), apresentaram crítica ao uso exclusivo do modelo MAN, pois a relação entre a norma pessoal e o comportamento parece ser melhor explicada se mediada pela intenção do comportamento, como postulado pela Teoria da Ação Racional e pela Teoria do Comportamento Planejado, apresentadas na seção 3.4 .

As bases da Teoria do Comportamento Interpessoal são tratadas na seção 3.5.

\subsection{TEORIA DO COMPORTAMENTO PLANEJADO}

Dentre as teorias que estudam a mudança de comportamento pelo viés cognitivo da atitude, a Teoria da Ação Racional e sua sucessora, a Teoria do Comportamento Planejado, são, de longe, as teorias mais utilizadas para explicar o comportamento da escolha modal (Fujii e Taniguchi, 2005a; Thorgersen, 2007; Collier et al., 2010; Gärling e Axhausen, 2003, para uma revisão).

Proposta por Fishbein e Ajzen (1975), a Teoria da Ação Racional - TAR procura explicar a forma como são construídas as decisões comportamentais pelo viés cognitivo. A teoria propõe que a presença de uma atitude positiva com relação a um comportamento tende a aumentar a probabilidade de que o indivíduo aja conforme aquele comportamento, se existir uma norma social (referente à percepção do que as pessoas que são importantes 
para o indivíduo pensam que o indivíduo deve fazer) que o apoie, formalizando o processo por uma intenção comportamental (Torres, 2012).

Em 1991, Ajzen acrescenta à estrutura da Teoria da Ação Racional a variável controle percebido do comportamento, criando a Teoria do Comportamento Planejado - TCP. O controle sobre o comportamento é observado considerando as crenças sobre a presença ou ausência de elementos que podem promover ou dificultar o desempenho de determinado comportamento (Torres, 2011).

Segundo Ajzen (1991), este desenvolvimento foi necessário para que se pudessem modelar comportamentos nos quais o indivíduo tivesse controle parcial sobre ele. $\mathrm{O}$ comportamento será mais bem realizado se, além do controle para a sua realização, o indivíduo estiver motivado a realizá-lo (Ajzen, 1991). A Figura 3.1 apresenta o esquema geral (a representação não inclui a semântica do diagrama de caminhos) da formulação da Teoria do Comportamento Planejado- TCP, a partir da Teoria da Ação Racional - TAR. De acordo com a TCP, portanto, a intenção de realizar o comportamento é resultante da interação de três construtos - atitude, norma social e controle percebido - e que a intenção faz a mediação entre esses construtos e o comportamento, acrescido da liberdade de execução do comportamento (influência direta do controle percebido sobre o comportamento).

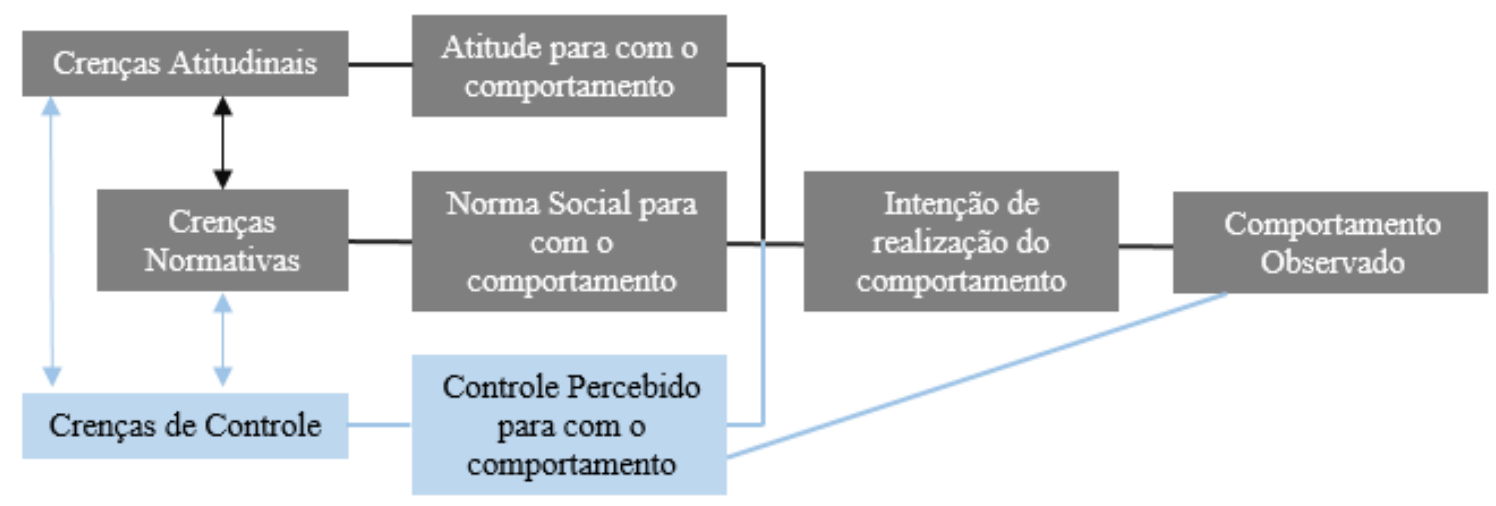




\subsubsection{OPERACIONALIZAÇÃO DA TEORIA DO COMPORTAMENTO PLANEJADO}

Os construtos da TCP não podem ser diretamente observados. São considerados construtos latentes. Seus efeitos, entretanto, podem ser avaliados por meio de medidas proxies (Bhat e Dubey, 2014), que são índices ou fatores obtidos pela composição de itens específicos respondidos pelo indivíduo. Ajzen (2000) propõe um questionário modelo, com a redação de itens específicos, chamados de medidas diretas dos construtos. Cada construto que compõe a TCP (Atitude, Norma Social, Controle Percebido e Intenção) deve ser avaliado pelo indivíduo respondente por escalas de medida. Construídos os índices para cada construto pela composição de seus itens específicos, a intenção e o comportamento podem ser modelados por meio de técnicas multivariadas, como, por exemplo, os modelos desenvolvidos por Elliott et al.(2005).

\subsubsection{TEORIA DO VALOR DA EXPECTÂNCIA}

Alternativamente às medidas diretas dos construtos, podem-se avaliar os construtos da TCP através das crenças salientes dos indivíduos ligadas ao comportamento estudado. As crenças salientes devem ser obtidas através de técnicas qualitativas aplicadas a grupos de respondentes da população alvo. Estes devem ser motivados a expressar sua opinião livre sobre o comportamento em estudo, referenciada aos resultados decorrentes do comportamento (vantagens, desvantagens e outros aspectos associados), às pessoas de referência (possíveis influenciadores na decisão comportamental), e aos elementos de controle sobre o comportamento (Ajzen, 2000).

Fishbein e Ajzen (1975) e Ajzen (2000), e estudos aplicados como os de Elliott et al. (2005) e Neto (2014), indicam o uso da Teoria do Valor da Expectância para a obtenção do impacto de cada crença saliente sobre os construtos da TCP - atitude, norma social e controle percebido. Cada crença é avaliada quanto ao seu conteúdo (belief - b) e quanto à força da crença (evaluation - e). A formulação do Valor da Expectância produz um escore para cada item pela multiplicação das duas medidas " $b_{i}$ ”, relativa à crença sobre o objeto do indivíduo "i”, e "e e" relativa à avaliação dos atributos do objeto, ou força da crença do indivíduo “i” (Fishbein e Ajzen, 1975; Eagly e Chaiken, 1998; Elliott et al., 2005). De acordo com essa teoria, cada construto é obtido pela Equação 3.1. 


$$
\text { Construto }=\sum_{i=1}^{n} b_{i} \cdot e_{i}
$$

Em estudo mais recente, Elliott et al. (2005) analisaram a validade do uso da Teoria do Valor da Expectância para explicar os construtos da TCP referentes à intenção de condutores de veículos em obedecer à velocidade limite das vias. Para essa avaliação foi utilizada a técnica de análise por regressão hierárquica, onde, no Passo 1, os construtos foram avaliados com base somente no valor do objeto das crenças $\left(b_{i}\right)$; no Passo 2, foram incluídos no modelo os escores relativos à força das crenças $\left(e_{i}\right)$; no passo final (Passo 3 ), o valor da expectância de cada crença foi incorporado. Os resultados da análise são apresentados na Tabela 3.2. Observa-se que o acréscimo da variância explicada devido ao termo de interação $\left(b_{i} X e_{i}\right)$ ficou entre $2 \%$ e $4 \%$. Os autores do estudo consideraram o acréscimo importante, embora pequeno, indicando que o uso do valor da expectância no uso da TCP é apropriado.

Tabela 3.2: Resultados de Elliott et al.(2005) na validação do uso da Teoria da Expectância para medir construtos da TCP.

\begin{tabular}{|c|c|c|c|c|c|}
\hline \multirow[b]{2}{*}{ Crença/construto } & \multirow[b]{2}{*}{ Passo } & \multicolumn{2}{|c|}{ Previsão do construto } & \multicolumn{2}{|c|}{ Previsão da intenção } \\
\hline & & $R^{2}$ & $\begin{array}{c}\text { Mudança } \\
R^{2}\end{array}$ & $R^{2}$ & Mudança $R^{2}$ \\
\hline \multirow{3}{*}{ Crenças referente à Atitude } & 1 & 0,31 & - & 0,31 & - \\
\hline & 2 & 0,39 & 0,08 & 0,37 & 0,06 \\
\hline & 3 & 0,42 & 0,03 & 0,41 & 0,04 \\
\hline \multirow{3}{*}{ Crenças referente à Norma Social } & 1 & 0,41 & - & 0,30 & - \\
\hline & 2 & 0,41 & 0.00 & 0,31 & 0,01 \\
\hline & 3 & 0,42 & 0,02 & 0,33 & 0,02 \\
\hline \multirow{3}{*}{$\begin{array}{c}\text { Crenças referente ao Controle } \\
\text { Percebido }\end{array}$} & 1 & 0,14 & - & 0,11 & - \\
\hline & 2 & 0,39 & 0,25 & 0,36 & 0,25 \\
\hline & 3 & 0,42 & 0,03 & 0,38 & 0,02 \\
\hline
\end{tabular}

Fonte: Adaptado de Elliott et al. (2005).

\subsection{CRÍTICAS À TCP E OUTRAS TEORIAS COGNITIVAS}

Gollwitzer (1993) apresentou uma proposta complementar à definição da TCP. Ele propõe que a intenção necessita de um plano para ser implementada (goal intention). Sua proposta foi testada com sucesso por Fujii (2003) e Fujii e Taniguchi (2005a), indicando que o processo de decisão é racionalmente estruturado, apresentando uma forma de operacionalização da intenção comportamental. A elaboração desse plano também contribui para fazer com que o processo seja mais deliberativo que repetitivo, provocando 
rompimento do processo habitual necessário para a efetivação da mudança comportamental.

As críticas à Teoria do Comportamento Planejado, e também à Teoria da Ação Racional, foram compiladas em Egmond e Bruel (2007), com os argumentos relacionados aos contextos culturais (influência do grupo sobre as decisões individuais), à influência dos hábitos e rotinas sobre a decisão racional e à influência das respostas emocionais e afetivas que podem confundir a deliberação cognitiva.

Paralelamente à TCP, a Teoria do Comportamento Interpessoal (TCI) introduziu a modelagem do hábito como explicação para a inércia da mudança de opção modal. Foi desenvolvida por Triandis em 1977, onde a abordagem do hábito se dava pela força do comportamento passado sobre o comportamento futuro. É o aspecto da teoria TCI que tem sido mais explorado nos estudos de escolha modal.

O hábito pode ser definido como um desempenho repetido de sequências de comportamentos (combinação do modo, destino, hora de partida, dia da semana, rota, por exemplo). É presumido que "o custo de procurar e construir novas alternativas é geralmente muito alto e os ganhos associados com as novas alternativas muito incertos" (Gärling e Axhausen, 2003).

O estudo de Triandis pela TCI aponta existir uma relação recíproca de como o comportamento passado ou hábito determina um comportamento: "quanto maior o determinante do hábito, menor o determinante da intenção, e vice versa" (Gärling e Axhausen, 2003). Os mesmos autores propuseram uma classificação de comportamentos, na interpretação da TCI, apresentada na Tabela 3.3.

Tabela 3.3: Classificação de comportamentos planejados impulsivos e habituais.

\begin{tabular}{c|cc}
\hline & Nenhuma ou pouca deliberação & Muita deliberação \\
\hline Nenhuma intenção formada & Comportamento habitual & -- \\
\hline Intenção formada & Comportamento impulsivo & Comportamento planejado \\
\hline
\end{tabular}
Fonte: Gärling e Axhausen (2003).

Bamberg e Schmidt (2003) estudaram as viagens de 321 estudantes na Universidade de Giessen, Alemanha, e concluíram que, "no caso de escolha modal, para um comportamento repetido no cotidiano, o ato comportamental não é definido apenas por 
atos controlados e conscientes, mas influenciados por processos mais automáticos, habituais". Verplanken et al. (1994) propõem que o hábito seja incluído nos modelos de predição da escolha modal, para que possa captar o elemento de estabilidade de decisão, ou a inércia por buscar novas alternativas.

Segundo a teoria do TCI, na primeira escolha, o processo deliberativo ou a intenção comportamental dominará o processo decisório. Porém, à medida que a mesma decisão pelo modo de transporte se repete dia após dia, o processo se torna menos racional, do tipo rotineiro (script-based). A justificativa para o interesse na modelagem do hábito paralelo a variáveis de deliberação deriva da consideração de que, se de fato a escolha modal for não deliberada, será menos eficiente a utilização de argumentos racionais (ou eles podem até ser descartados) para influenciar a escolha de modos de transporte mais sustentáveis (Gärling e Axhausen, 2003).

As dificuldades na mensuração do hábito são diversas. Primeiramente, quanto à necessidade de se observar as escolhas modais, ou se outras características da viagem são habituais, em séries históricas com os mesmos indivíduos. Alguns indicadores tradicionais envolvem os quilômetros viajados por ano, as viagens de transporte público nas últimas duas semanas, a posse do carro, a posse de vale transporte, ou qual a hora de partida se repete mais frequentemente.

Outra característica do hábito é de que é um processo de aprendizagem que se adapta mediante as consequências das escolhas individuais no passado e que podem ser melhoradas no futuro (Gärling e Axhausen, 2003, e Verplanken et al.,1994). A aprendizagem pressupõe, também, a ideia que o hábito não é restrito a um contexto comportamental em particular, mas à possibilidade de repeti-lo em outros contextos. Vários estudos recentes (Eriksson et al., 2008; Fujii e Kitamura, 2003) têm apontado a necessidade de uma intervenção que rompa os processos habituais, tornando o processo decisório mais deliberativo e suscetível às campanhas educativas pró- ambientais.

Verplanken et al. (1994), Bamberg et al. (2003), e Cristo (2013) consideram que a Medida de Frequência Auto Relatada do Comportamento Passado (Self Reported Frequancy of Past Behavior) é um bom indicador do comportamento passado, mas não para o hábito. Na proposição de uma medida mais acurada do hábito, Verplanken et al. (1994) propõem 
que o hábito seja avaliado por uma medida independente, a Medida de RespostaFrequência do Hábito (Response Frequency Measure of Habit).

Por esta medida, a presença do hábito deve ser informada pela frequência de respostas aproximadamente impulsivas a uma sequência de situações rotineiras (como por exemplo: “suponha que você vá à praia com alguns amigos, qual modo utilizaria?”). Essa medida considera o hábito como uma generalização, em vez de específico para um objetivo ou viagem (Cristo, 2013).

A solicitação para que o indivíduo faça uma escolha rápida de modo de transporte para a realização do seu deslocamento nas situações apresentadas pressupõe que o indivíduo responda perante um estímulo global, sem muita deliberação, tal como esperado que aconteça nos processos habituais (script-based). A frequência de escolha de determinado modo perante diversas situações apresentadas é considerada a medida da existência do hábito na utilização de certo modo de transporte, como por exemplo o automóvel.

Medida de Resposta-Frequência do Hábito foi utilizada por Bamberg et al. (2003) em estudos sobre a escolha modal. No Brasil, essa medida foi traduzida e adaptada para o estudo da utilização do transporte público por Cristo (2013). Nesta tradução, Cristo (2013) comenta que a medida deve ser adaptada para as situações e população envolvida no estudo.

\subsection{TÓPICOS CONCLUSIVOS}

As teorias relacionadas às mudanças de comportamento, principalmente aquelas derivadas da psicologia social, apresentam escopo teórico importante sobre as tomadas de decisão. Cada teoria revisada contribui para a compreensão e direcionamento de estratégias que visem à diminuição do uso do automóvel. Pelo modelo MEP, e por todos os modelos que envolvem processos cognitivos, pode-se deduzir que é preciso fornecer informações qualificadas (adequadas e convincentes) e que tenham importância para o indivíduo (rota central) sobre as opções de transportes alternativas ao uso do automóvel, para que o indivíduo cogite a possibilidade de mudar seu modo de transporte. 
O modelo MAN envolve comunidades influenciadas por códigos morais fortes, onde a cultura e costumes locais promovem um comportamento padronizado pelas crenças morais. Sempre que os Programas de Gerenciamento da Mobilidade envolverem pessoas com certa dependência social, como é o caso das crianças, adolescentes e idosos, a observação da norma subjetiva deverá integrar a estrutura conceitual, analisando-se a influência e controle exercido pelas pessoas 'tutoras' na intenção de comportamento do indivíduo. É possível que se encontrem diferenças entre a influência do grupo social (norma) na intenção comportamental de pais e alunos das IEMs. Entretanto o modelo TCP também modela esta influência.

A Teoria da Ação Racional (TAR) e do Comportamento Planejado (TCP) são as teorias mais referenciadas em estudos econômicos e de transportes. As aplicações disponíveis na literatura utilizam procedimentos para promover a mudança do comportamento de viagens incluindo os seguintes elementos: i) a motivação e a provisão de informação personalizada, direcionada à construção de uma atitude positiva em relação ao modo alternativo; ii) a formulação de planos de viagens, visando modificar a intenção comportamental para o uso de modos alternativos ao automóvel; iii) e suporte institucional, no sentido de promover a aceitação do modo alternativo pela comunidade atingida pelo plano, ou seja, mudar a norma social.

A Teoria do Comportamento Interpessoal (TCI), e seus desdobramentos com relação ao hábito, propõe a crítica às teorias anteriores e aponta a necessidade de incluir nos estudos de escolha modal os processos habituais. Se as conclusões da pesquisa pretendem subsidiar programas de mudanças comportamentais (escolha de modos mais sustentáveis), como o desenvolvimento de um PGM para uma dada IEM que seja considerado aceitável e viável pelos usuários da instituição, é importante prever a necessidade de romper escolhas habituais.

Perante a revisão teórica apresentada, propõe-se que na identificação de atributos intervenientes na escolha modal em IEMs sejam avaliadas a influência de variáveis sociodemográficas (Grupos 1, 2, 4 e 5 de Zhou, 2012) e a influência das seguintes dimensões psicológicas (Grupo 6 de Zhou, 2012): i) atitude; ii) norma social; iii) percepção de controle sobre o comportamento; iv) hábito; v) comportamento passado. A influência das variáveis sociodemográficas, do hábito e do comportamento passado deve 
ser avaliada tanto com relação à intenção, quanto ao comportamento, conforme estudo de Bamberg et al. (2003).

A Figura 3.2 apresenta o modelo teórico de decisão do aluno por modo de transporte que será estudado na tese. Como proposto nas hipóteses de trabalho, deve ser também avaliada a influência conjunta de pais e alunos na decisão do modo de transporte a ser utilizado pelo aluno. Essa avaliação será feita de acordo com o modelo apresentado na Figura 3.3. As Figuras 3.2 e 3.3 não estão representadas de acordo com a semântica do diagrama de caminhos (path analysis).

A eleição da Teoria do Comportamento Planejado - TCP como estrutura teórica básica para o entendimento dos atributos intervenientes na escolha modal permite que o estudo proposto inclua as dimensões psicológicas como antecedentes da escolha modal, corroborando com Zhou (2012). Espera-se que o presente estudo possa subsidiar a formulação de PGMs em IEMs. Com a preocupação de desenvolver um procedimento baseado na opinião da comunidade escolar envolvida (suas crenças e opiniões sobre os modos considerados viáveis), espera-se, ainda, que as medidas futuras tenham maior adequação e adesão por parte dos usuários. Tal adesão, porém, não será testada no presente estudo.

Muito indicado na bibliografia estudada é o caráter da multimodalidade. Assim, os atributos intervenientes devem ser analisados tanto para com o uso do automóvel particular, quanto para com o uso de modos alternativos ao automóvel. Propõe-se que uma análise empírica seja conduzida tanto para elencar as crenças que orientam os comportamentos nas escolhas modais em IEMs, como para avaliar a força dos atributos elencados (atitude, norma social, percepção de controle sobre o comportamento, comportamento passado e hábito) sobre a decisão por modo de transporte em IEMs. 


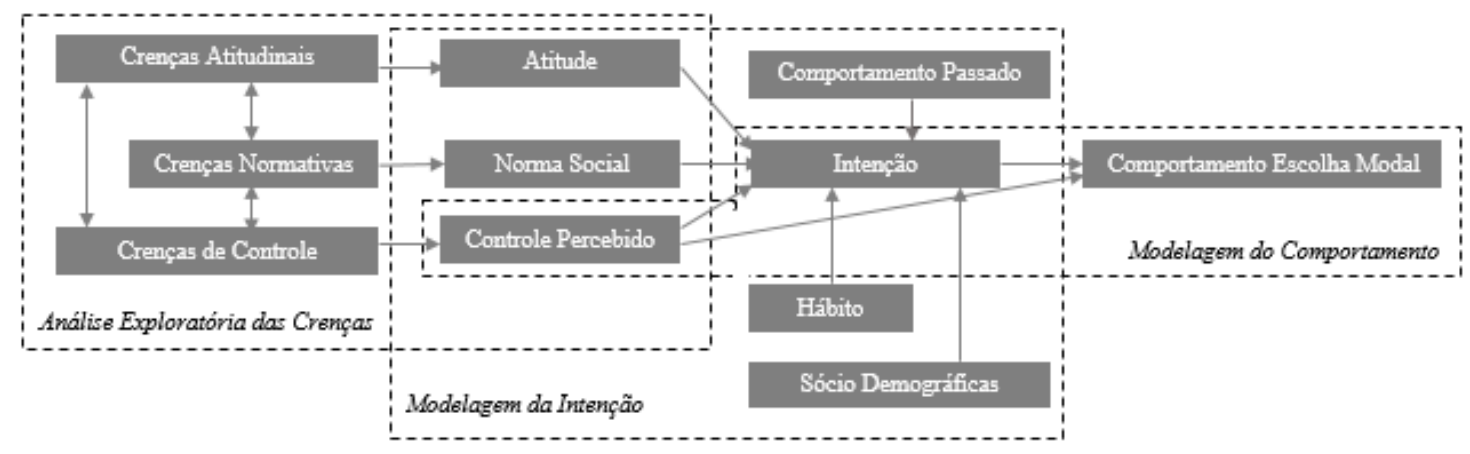

Figura 3.2: Modelo teórico de decisão do aluno por modo de transporte em viagens escolares a ser estudado.

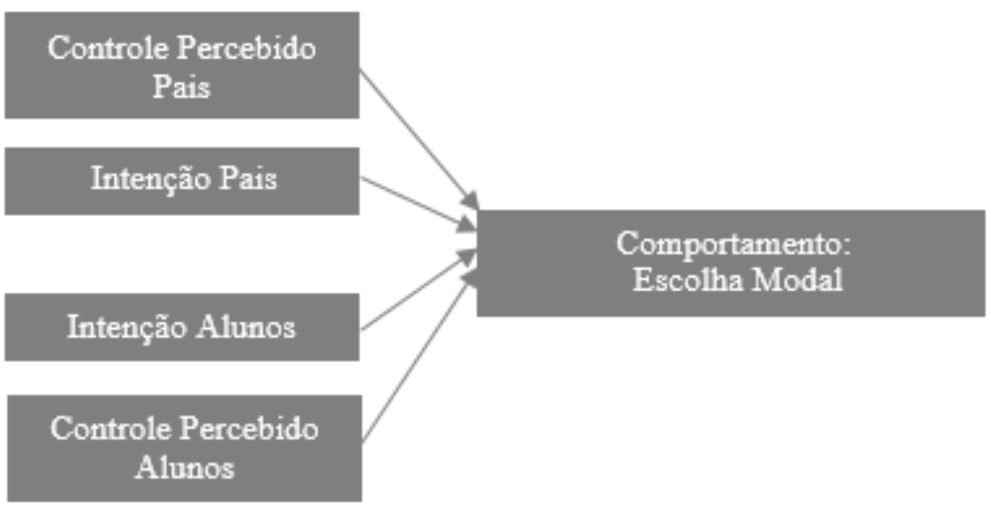

Figura 3.3: Modelo teórico da influência conjunta de pais e alunos no processo de decisão por modo de transporte em viagens de escolares a ser estudado. 


\section{TÉCNICAS ANALÍTICAS PARA ESTUDOS COMPORTAMENTAIS SOBRE A ESCOLHA MODAL}

Para empreender estudos comportamentais sobre a escolha modal é necessário compreender os tipos de técnicas analíticas que viabilizam os testes empíricos sobre as teorias formuladas. Em geral, os estudos comportamentais envolvem características observáveis do modo e dos usuários (por exemplo, sociodemográficas), usadas largamente para previsões e, fundamentalmente, características psicológicas e atributos do modo que não são observados diretamente. Os conceitos psicológicos, chamados de construtos psicológicos, como a atitude, norma social, hábito, etc., integrantes das teorias comportamentais são de difícil (ou impossível) mensuração direta (Ortúzar e Willumsen, 2011). Esses conceitos abstratos são chamados de variáveis ou atributos latentes (Babbie, 2013). Estes elementos são inferidos por itens de medição.

Experimentos controlados podem identificar tais construtos em nível individual, ou para pequenos grupos (Eagly e Chaiken, 1998). A identificação dos construtos para certa população de forma ampla necessita de instrumentos de medida, chamados de escalas, para efetivar a mensuração (indireta) (Babbie, 2013). As escalas não são apenas aplicadas a questionários com questões sistematizadas. Elas são ligadas a questões formuladas para revelar os construtos, ou variáveis latentes, que se deseja estudar (Babbie, 2013). As respostas à escala, e seus respectivos escores, são consideradas variáveis manifestas ou observadas, servindo de indicadores do construto latente subjacente que se acredita que as variáveis representem (Babbie, 2013).

As escalas são guiadas por teorias e devem ser validadas empiricamente. Ajzen (2000) sugere o uso de escalas adjetivas bipolares e escalas likert para medir construtos da TCP. Um exemplo do uso dessas escalas é apresentado na Tabela 4.1, do estudo de Bamberg et al.(2003). Elaborado de acordo com as orientações de Ajzen (2000) para estudos guiados pela Teoria do Comportamento Planejado - TCP, o questionário foi utilizado para analisar o processo decisório na escolha modal entre estudantes universitários em uma universidade na Alemanha. Além disso, o estudo também avaliou a influência do comportamento passado e do hábito nas escolhas modais. 
Tabela 4 .1: Itens para medida direta de avaliação dos construtos da TCP em estudo sobre a escolha modal - exemplo para modo Ônibus.

\begin{tabular}{|c|c|c|}
\hline Construto & Item & Escala \\
\hline \multirow{2}{*}{ Atitude } & $\begin{array}{l}\text { Para você, usar o ônibus da próxima vez que você for ou voltar } \\
\text { da escola seria: (Ruim/Bom); }\end{array}$ & Bipolar \\
\hline & $\begin{array}{l}\text { Para você, usar o ônibus da próxima vez que você for ou voltar } \\
\text { da escola seria: (Agradável/Desagradável); }\end{array}$ & Bipolar \\
\hline \multirow{2}{*}{ Norma Social } & $\begin{array}{l}\text { A maioria das pessoas importantes para você aprovaria sua } \\
\text { opção de usar o ônibus da próxima vez que você for ou voltar da } \\
\text { escola. (Concordo, Discordo); }\end{array}$ & Likert \\
\hline & $\begin{array}{l}\text { A maioria das pessoas importantes para você acha que deveria } \\
\text { usar o ônibus da próxima vez que você for ou voltar da escola; } \\
\text { (Concordo, Discordo); }\end{array}$ & Likert \\
\hline \multirow{2}{*}{ Controle Percebido } & $\begin{array}{l}\text { Para você, usar o ônibus da próxima vez que for ou voltar da } \\
\text { escola seria: (Fácil/Difícil); }\end{array}$ & Bipolar \\
\hline & $\begin{array}{l}\text { A chance de você usar o ônibus da próxima vez que for ou voltar } \\
\text { da escola é (Forte/Fraca); }\end{array}$ & Bipolar \\
\hline \multirow{2}{*}{ Intenção } & $\begin{array}{l}\text { Sua intenção de usar o ônibus da próxima vez que for ou voltar } \\
\text { da escola é (Forte; Fraca); }\end{array}$ & Bipolar \\
\hline & $\begin{array}{l}\text { Você pretende usar o ônibus da próxima vez que for ou voltar da } \\
\text { escola. (Concordo/Discordo); }\end{array}$ & Likert \\
\hline
\end{tabular}

Fonte: Adaptado de Bamberg et al. (2003).

Nos modelos matemáticos de representação do comportamento, é importante distinguir entre dois tipos de variáveis, de acordo com Babbie (2013) e Hair et al. (2009):

a) Variáveis exógenas - também conhecidas como variáveis independentes, influenciam, ou causam flutuações nas variáveis latentes, mas não são explicadas pelos modelos;

b) Variáveis endógenas - são influenciadas pelas variáveis exógenas, diretamente ou indiretamente. São as variáveis consideradas dependentes, latentes ou observáveis, e sua categorização é crítica para a escolha da técnica analítica a ser utilizada. Suas flutuações são explicadas pelo modelo. Todas as variáveis endógenas devem estar incluídas na especificação do modelo.

As relações entre variáveis em estudo nas análises multivariadas podem ser representadas e analisadas por diagramas de caminhos (path analysis). O diagrama de caminhos é uma representação gráfica do "modelo de relação causal para o entendimento das relações entre variáveis" obtido por análises de regressão (Babbie, 2013). Diferentes conjuntos de relações podem ser analisados de forma simultânea na análise de caminhos (Hair et al., 2009). A Figura 4.1 traz um exemplo da representação por diagrama de caminhos, aplicado à Teoria do comportamento Planejado - TCP. 
Os retângulos indicam as variáveis observadas, ou medidas empiricamente, e as elipses, as variáveis latentes (Pilatti e Laros, 2007). As setas unidirecionais com linhas contínuas entre as elipses representam as relações de causa e efeito entre as variáveis latentes, chamadas de equações estruturais. As linhas contínuas entre os retângulos e as elipses (em algumas representações aparecem tracejadas, como em Ben-Akiva et al., 2002) representam as relações entre as variáveis observáveis e as latentes, como as cargas fatoriais dos indicadores na formação das variáveis latentes. São as equações de medida. As linhas com setas nas duas pontas (bidirecionais) representam a correlação ou covariância entre duas variáveis

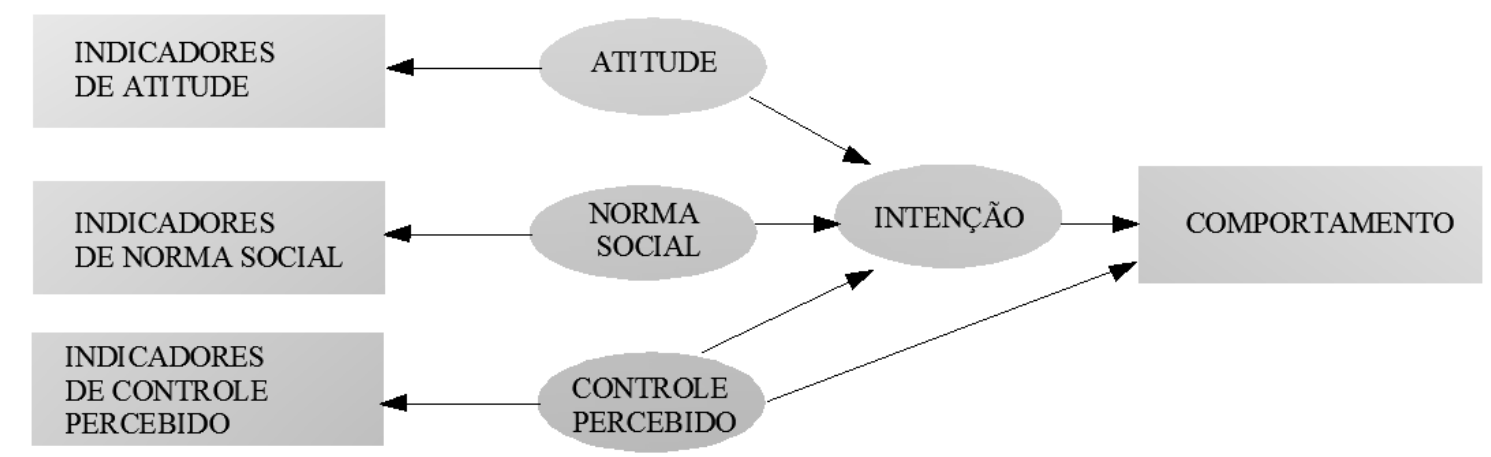

Para operar com variáveis latentes como representantes dos construtos psicológicos a serem estudados, é necessário que os modelos matemáticos considerem que as variáveis não são medidas diretamente, mas através de uma composição de indicadores ou itens manifestos. As técnicas de análises entre variáveis observadas e latentes são diversas, envolvendo análises multivariadas, com análises algébricas complexas (Babbie, 2013).

Nas seções que seguem, são revisadas algumas técnicas analíticas, consideradas pertinentes à proposição do presente estudo, referenciadas na literatura revisada no Capítulo 2. Todas as técnicas apresentadas foram utilizadas no presente estudo. A técnica de Modelos de Regressão Linear Múltipla, descrita na seção 4.3, sendo uma técnica mais simples e de análise dos resultados bem referenciada na literatura, foi considerada preliminarmente como técnica a ser utilizada para a modelagem da análise exploratória das crenças e da modelagem da intenção, descritos nos Capítulos 5 e 6. Porém, a verificação da falta de normalidade, pressuposto desse tipo de modelos, levou ao uso de Modelos Lineares Generalizados. Sua descrição, entretanto, foi mantida como referência 
para análises futuras semelhantes, em amostras com identificação de normalidade nos dados.

\subsection{TÉCNICAS EXPLORATÓRIAS QUALITATIVAS}

Mesmo que a teoria de guia do estudo (por exemplo, a TCP) preconize uma escala validada de medida dos construtos envolvidos, uma abordagem qualitativa deve preceder as análises quantitativas. O objetivo é obter um melhor entendimento e adequada especificação do comportamento que se deseje estudar. As recomendações de Ajzen (1991 e 2000) são de que esta etapa sirva para contextualizar o comportamento a ser estudado e para explicitar as crenças antecedentes dos construtos envolvidos no comportamento.

Para a operacionalização da TCP, segundo Ajzen (1991 e 2000), a etapa qualitativa deve prever manifestação direta de amostra da população a ser estudada e formulação de questões abertas sobre: i) a avaliação de resultados - vantagens e desvantagens, simpatias ou aversões para com o comportamento pesquisado; ii) as pessoas de referência social pessoas ou grupos que aprovam ou desaprovam a realização ou não de determinado comportamento; iii) as dimensões de controle - elementos que tornam a realização do comportamento mais fácil, ou mais difícil, que permitem ou impedem a realização do comportamento.

Para abordagens exploratórias qualitativas, uma das técnicas bem referenciadas na literatura é o uso de Grupos Focais (como utilizado em Lang et al., 2011 e Rocha e Feitas, 2007). Esta técnica permite uma elaboração rápida da percepção geral do comportamento em estudo e a obtenção das crenças salientes subjacentes a ela. A técnica de grupos focais permite ainda: i) identificar as diferentes opiniões expressas e vivenciadas pelos usuários envolvidos (Medeiros e Nodari, 2011); ii) aprender como os participantes interpretam a realidade (Dias, 2000); iii) gerar novas ideias ou hipóteses, estimulando o pensamento do pesquisador (Dias, 2000); vi) acelerar a compreensão do fenômeno de maneira geral, pois a "sinergia entre os participantes leva a resultados que ultrapassam a soma das partes individuais" (Dias, 2000). 
Para sistematização das informações dos grupos focais, é empregada a técnica de análise de conteúdo (Bardin, 2009; Babbie, 2013). De acordo com Bardin (2009), a análise de conteúdo é "um conjunto de técnicas de investigação que, através de uma descrição objetiva, sistemática e quantitativa do conteúdo manifesto das comunicações, tem por finalidade a interpretação destas mesmas comunicações”. Silva e Assis (2010) sintetizaram as etapas envolvidas na técnica de análise de conteúdo, apresentadas na Tabela 4.2.

Tabela 4.2: Etapas da análise de conteúdo

\begin{tabular}{cc}
\hline Etapa & Estratégia \\
\hline Pré-análise & Sistematização das ideias iniciais em categorias. \\
\hline Exploração do Material & Reanálise do texto através das categorias. \\
\hline Tratamento dos resultados & $\begin{array}{c}\text { Trata da inferência e interpretação dos resultados categorizados. } \\
\text { Deve-se submeter as categorias sistematizadas a operações } \\
\text { estatísticas, ressaltando as informações obtidas. }\end{array}$ \\
\hline
\end{tabular}

Fonte: Silva e Assis (2010).

\subsection{ANÁLISE FATORIAL EXPLORATÓRIA}

No modelo de análise fatorial, o interesse básico é de redução do número de variáveis a serem analisadas (Pasqualli, 2012). A análise envolve a identificação do padrão de correlação ou covariância da matriz de um conjunto de variáveis observadas, no intuito de gerar informação sobre um conceito ou construto latente subjacente, também chamado de fator (Babbie, 2013). O fator se torna representante dos itens que agrupa. Para cada item observado diretamente, ou variável observada diretamente, deverá ser identificada uma carga fatorial relativa a um caminho de regressão (diagrama de caminhos), para a composição do fator subjacente.

DiStefano et al.(2009) afirmam que os resultados da análise fatorial são sensíveis ao método de obtenção das cargas ou escores fatoriais. A Tabela 4.3 apresenta uma análise comparativa de alguns métodos de obtenção dos escores fatoriais. O método mais simples para a obtenção dos fatores é a soma ou média das cargas dos itens, sempre utilizando dois ou mais itens por construto ou fator (Fisbein e Ajsen, 1975). Apesar de fácil operacionalização e interpretação, não são tão exatos, tratando igualmente itens medidos em métricas diferentes. O resultado são fatores, ou índices, com limitada confiabilidade, se os itens que os compõem têm muita variabilidade de medida entre si. 
Tabela 4.3: Análise comparativa dos métodos de obtenção dos escores fatoriais

\begin{tabular}{|c|c|c|c|}
\hline Método & Procedimento & Vantagens & Considerações \\
\hline \multicolumn{4}{|c|}{ Métodos não Refinados } \\
\hline $\begin{array}{l}\text { Soma acima de } \\
\text { um valor de } \\
\text { corte }\end{array}$ & $\begin{array}{l}\text { Soma das cargas dos itens } \\
\text { que compõe o fator } \\
\text { (cargas negativas são } \\
\text { subtraídas na criação do } \\
\text { escore). } \\
\text { Pode-se aplicar um valor } \\
\text { de corte, somando-se } \\
\text { apenas os itens acima } \\
\text { deste valor (p.e. } 0.30) .\end{array}$ & $\begin{array}{l}\text { Escores médios podem } \\
\text { ser calculados para } \\
\text { manter a mesma métrica } \\
\text { da escala }(*) \text {; fácil de } \\
\text { calcular e interpretar; } \\
\text { para estudos posteriores, } \\
\text { a soma preserva a } \\
\text { variação presente nos } \\
\text { dados. }\end{array}$ & $\begin{array}{l}\text { Dá igual peso a todos os } \\
\text { itens. } \\
\text { Um valor de corte maior } \\
\text { resulta em menos } \\
\text { variáveis incluídas; } \\
\text { valor menor pode incluir } \\
\text { variáveis com relações } \\
\text { fracas com o fator. }\end{array}$ \\
\hline $\begin{array}{c}\text { Soma com } \\
\text { valores padrão }\end{array}$ & $\begin{array}{l}\text { Padronizar as cargas } \\
\text { fatoriais antes de somar. } \\
\text { Pode ser aplicado um valor } \\
\text { de corte. }\end{array}$ & $\begin{array}{l}\text { Útil para variáveis bem } \\
\text { diferentes em termos de } \\
\text { desvio padrão. Senão, a } \\
\text { soma sem padronização é } \\
\text { mais fácil de computar. }\end{array}$ & $\begin{array}{l}\text { Nenhuma ponderação é } \\
\text { dada a itens com } \\
\text { maiores cargas. }\end{array}$ \\
\hline $\begin{array}{c}\text { Soma } \\
\text { ponderada }\end{array}$ & $\begin{array}{l}\text { Multiplicar a carga fatorial } \\
\text { pelo peso e depois somar. } \\
\text { Pode ser aplicado um valor } \\
\text { de corte. }\end{array}$ & $\begin{array}{l}\text { Reconhece a força (ou a } \\
\text { fraqueza) dos itens; } \\
\text { Itens com maiores cargas } \\
\text { têm maior efeito no fator. }\end{array}$ & $\begin{array}{l}\text { Se as diferenças nas } \\
\text { cargas fatoriais forem } \\
\text { devido ao método de } \\
\text { extração de fatores ou } \\
\text { rotação, é melhor usar a } \\
\text { soma. }\end{array}$ \\
\hline
\end{tabular}

(*) O cálculo de escores médios pode ser feito para todos os métodos "não refinados". Os escores médios podem ser úteis para comparações entre fatores que possuem número diferente de itens.

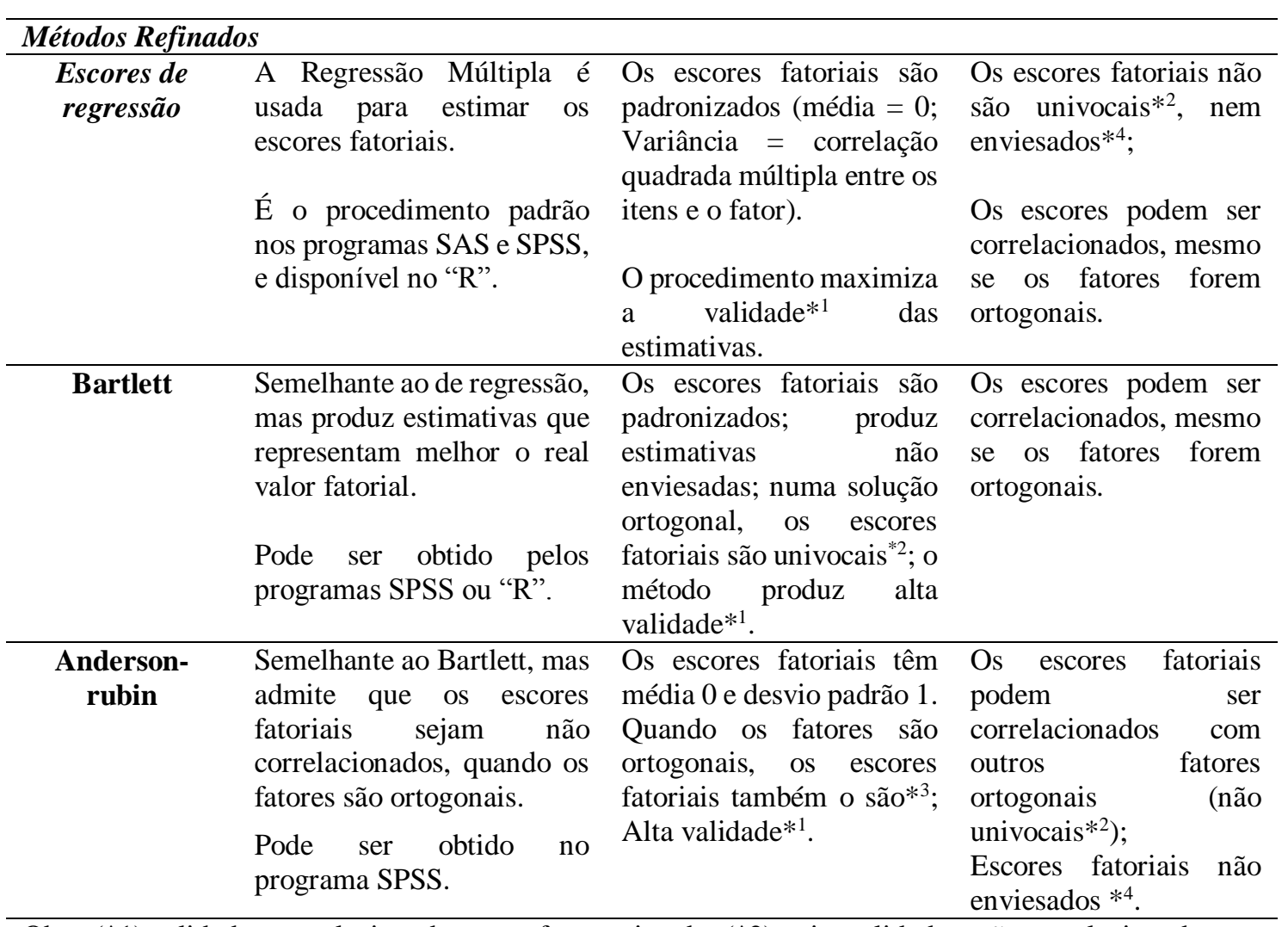

Obs.: (*1) validade - correlacionado com o fator estimado; $(* 2)$ univocalidade - não correlacionado com outros fatores ortogonais; $(* 3)$ exatidão correlacional - não correlacionado com escores fatoriais de outros fatores ortogonais; $(* 4)$ estimativa não enviesada dos parâmetros de escores fatoriais.

Fonte: Adaptado de DiStefano et al. (2009). 
Alternativamente, os métodos refinados, de maior exigência computacional, propõem a estandardização dos itens medidos, considerando a comunalidade e a unicidade entre itens e fatores (DiStefano et al.,2009). Os princípios da análise fatorial são, segundo Pasqualli (2012): i) a parcimônia, em que vários itens podem ser melhor expressos em termos de poucos fatores comuns; ii) a causalidade do fator, onde se pressupõe que a existência do fator comum é a causa da relação entre as variáveis empíricas; iii) a relação linear entre as variáveis.

O modelo de análise fatorial pode ser de dois tipos: i) Análise Fatorial Exploratória AFE; e ii) Análise Fatorial Confirmatória - AFC. Na primeira, "as relações entre as variáveis observadas e latentes são desconhecidas ou incertas", e o pesquisador quer determinar "como e até que ponto as variáveis observadas estão relacionadas aos fatores subjacentes” (Byrne, 2010). Já para a Análise Fatorial Confirmatória - AFC, o analista já deve ter de antemão alguma informação sobre a estrutura latente entre variáveis que deseja testar (Byrne, 2010). A AFC faz parte do grupo de modelos chamados de Modelos de Equações Estruturais, descritos na seção 4.4.

\subsection{MODELOS DE REGRESSÃO LINEAR MÚLTIPLA}

Preliminarmente, a operação com modelos MRLM requer: i) amostra com tamanho (n) suficiente para a consideração da significância $(\alpha)$ e poder ( $\beta$-1) adotados; ii) a utilização de uma única variável métrica como variável dependente; iii) que o número de observações seja maior que o número de variáveis envolvidas no modelo; iv) a inexistência de casos ausentes ou casos extremos; v) variabilidade suficiente nos valores das variáveis envolvidas; vi) que o modelo seja corretamente especificado (coerência teórica) (Tabachnick e Fidel, 2007).

A forma funcional dos modelos MRLM é dada pela Equação 4.1. Quando a variável explicativa $X_{i}$ varia em uma unidade, e todo o resto permanece constante, o valor de $\beta_{i}$ indica a variação no valor médio de $\mathrm{Y}, \mathrm{E}(\mathrm{Y})$, e devido à variação unitária de $\mathrm{X}_{\mathrm{i}}$.

$$
Y=\beta_{0}+\sum_{i=1}^{m} \beta_{i} X_{i}+\epsilon
$$


Em que:

$Y=$ variável dependente;

$X_{i}=$ variável independente (variável observada);

$m=$ número de variáveis independentes do modelo;

$\beta_{0}$ e $\beta_{i}=$ parâmetros do modelo;

$\varepsilon=$ erro estocástico.

Os pressupostos para o uso de modelos MRLM são (Gujarati, 2004): i) o modelo de regressão é linear nos parâmetros; ii) os valores dos parâmetros $\beta_{\mathrm{i}}$ das variáveis independentes (coeficientes parciais de regressão) são fixos em amostragens repetidas; iii) o valor médio do erro $\varepsilon$ é igual a zero; iv) a variância de $\varepsilon$ é constante (homocedasticidade); v) não há colinearidade exata entre as variáveis independentes vi) o termo de erro estocástico $\varepsilon$ é normalmente distribuído.

O método de estimação dos modelos de regressão múltipla é o método dos mínimos quadrados ordinários (MQO). A verificação do grau de ajuste dos modelos de regressão linear múltipla é feita, em geral, a partir de: i) o nível de explicação do modelo ( $\left.\mathrm{R}^{2}\right)$; ii) a significância do modelo (razão F); iii) o sinal e a significância dos coeficientes do modelo (p-valor); iv) a conferência dos pressupostos quanto aos erros, pela plotagem dos resíduos (Hair et al., 2009). A interpretação dos modelos de regressão linear múltipla é que os parâmetros estimados $\left(\beta_{i}\right)$ indiquem que, quando a variável independente muda em uma unidade, a variável dependente muda na proporção do valor do parâmetro (AmirAlavifar e Anuar, 2012).

O passo final da análise de regressão linear múltipla é verificar se o modelo significativo encontrado representa a população a partir da qual a amostra considerada foi extraída (validação do modelo). Em alguns casos, pode ser interessante verificar se o modelo pode ser aplicado para outras populações em situação análoga (possibilidade de transferência do modelo). A validação pode ocorrer, a partir da coleta de dados em uma nova amostra, de duas formas: i) utilizar o modelo original estimado e calcular o seu ajuste preditivo para a nova amostra (analisar a diferença entre os valores estimados pelo modelo e os valores observados na nova amostra); ou ii) estimar um novo modelo pela nova amostra e comparar a nova equação com a equação original, quanto ao sinal e significância das variáveis incluídas no modelo, o tamanho e a importância relativa das variáveis e a precisão preditiva. 
Outra técnica, citada por Hair et al. (2009) é a validação particionada, dividindo-se a amostra original em duas sub amostras, uma para a calibração do modelo e outra para a validação. $\mathrm{Na}$ impossibilidade de coletar uma nova amostra, a validação pode ser realizada com a técnica denominada "validação cruzada", onde sub amostras são retiradas sequencialmente e modeladas. Os erros de estimativa são determinados para os valores não incluídos em cada sub amostra e, posteriormente, acumulados para a determinação de diferentes medidas de ajuste, como utilizado por Costa (2013).

\subsection{MODELOS LINEARES GENERALIZADOS}

Nem sempre as variáveis de interesse dos estudos de escolha modal são bem explicadas pelos modelos MRLM (Custódio e Barbin, 2005). Para se atingir a homogeneidade da variância (homocedasticidade), transformações nas variáveis são requeridas, segundo o tipo de assimetria e achatamento da distribuição da variável em estudo. Hair et al.(2009) apontam vários tipos de possibilidades de transformação, como a inversa da variável, a raiz quadrada, arco seno, entre outras. Quando as transformações não atingem o seu objetivo, outra classe de modelos deve ser desenvolvida: os Modelos Lineares Generalizados - MLG.

Essa classe de modelos possibilita um "leque de opções para a distribuição da variável resposta", dentro da família exponencial de distribuições, bem como flexibiliza "a relação funcional da variável resposta e o preditor linear" (Paula, 2013). À família exponencial pertencem as distribuições normal, binomial, Poisson, Gamma, normal inversa, geométrica e binomial negativa (Hardin e Hilbe, 2001). É necessário especificar três elementos para operar modelos MLG: i) um componente aleatório (Y e sua distribuição de probabilidade); ii) um componente sistemático; e iii) uma função de ligação entre esses componentes (Cunto e Nodari, 2011).

A especificação da distribuição de probabilidade para escolher o tipo de modelo MLG a utilizar depende de conhecimento prévio do fenômeno (análise não exploratória) (Chan, 2015). Quando não se sabe ao certo se a distribuição pertence à família exponencial, podese utilizar os modelos de quase-verossimilhança, aceitando, inclusive, dados correlacionados (Paula, 2013). É necessário especificar apenas a relação entre a média e a variância (Amaral e Cordeiro, 2003). A estimação dos modelos, neste caso, utiliza a 
função de Log-quase-verossimilhança, que é uma aproximação da estimação de verossimilhança (para detalhes ver Hardin e Hilbe, 2001; Paula, 2003; Chan, 2015). Para a quase verossimilhança, o ajuste do modelo deve ser avaliado pela análise de resíduos (Amaral e Cordeiro, 2003).

Antes de proceder à análise de resíduos, os resultados devem ser analisados quanto à significância das variáveis e o sinal e a magnitude dos parâmetros associados às variáveis significativas, verificando se são compatíveis com a teoria. Em seguida, procede-se à análise da significância do modelo através dos resíduos. São várias as análises de resíduos para os modelos MLG. Dentre elas serão aqui consideradas a análise do desvio residual (residual deviance), o pseudo - $\mathrm{R}^{2}$ e o Cure Plot. O desvio residual informa o "incremento para o desvio total devido a cada observação" (Hardin e Hilbe, 2001). Ele deve ser pequeno, para indicar que o modelo é bom, explicando bem os dados, se aproximando de uma distribuição Chi-quadrada, com $\mathrm{K}+1$ graus de liberdade (em que K é o número de variáveis explicativas do modelo). Isto é, a hipótese nula é a de que o modelo tem um ajuste adequado. Assim, se o p-valor do desvio residual for maior que o p-crítico (para $\alpha=95 \%$, p-valor $=0,05$ ), então a hipótese nula não é rejeitada e o ajuste do modelo pode ser considerado adequado.

Hardin e Hilbe (2001) apresentam várias medidas de ajuste da qualidade do modelo, dentre as quais o pseudo - $\mathrm{R}^{2}$, desenvolvido por Efrom, e dado pela equação 4.2.

$$
R_{\text {Efron }}^{2}=1-\frac{\sum_{i=1}^{n}\left(Y_{i}-\widehat{Y_{l}}\right)^{2}}{\sum_{i=1}^{n}\left(Y_{i}-\bar{Y}\right)^{2}}
$$

Em que, $Y_{i}$ e $\hat{Y}_{i}$ são, respectivamente, os valores observados e estimados para o elemento “i”, enquanto $\bar{Y}$ é a média dos valores observados.

Outra análise de resíduos é realizada por meio de gráficos de resíduos acumulados versus a variável de interesse, também chamados de gráficos CURE. Um bom gráfico CURE deve oscilar em torno do zero, e não extrapolar as bandas (Hauer, 2004). Para construir um gráfico $C U R E$, deve-se seguir o procedimento detalhado por Hauer (2004): 
a) Ordenar os $\mathrm{n}$ resíduos, na ordem crescente da variável de interesse, e numerálos consecutivamente;

b) Calcular o valor de cada resíduo n elevado ao quadrado;

c) Fazer $\hat{\sigma}^{2}(n)$ igual à soma acumulada dos resíduos ao quadrado de $1 \mathrm{a} n$, e calcular $\sigma^{*}$ por meio da equação 4.3 ;

$$
\sigma^{*}=\widehat{\sigma}(n) \sqrt{1-\frac{\hat{\sigma}^{2}(n)}{\sigma^{2}(n)}}
$$

d) Acrescentar ao gráfico CURE, limites iguais a $\mp 2 \sigma^{*}(n)$.

A Figura 4.2 traz um exemplo de um gráfico CURE.

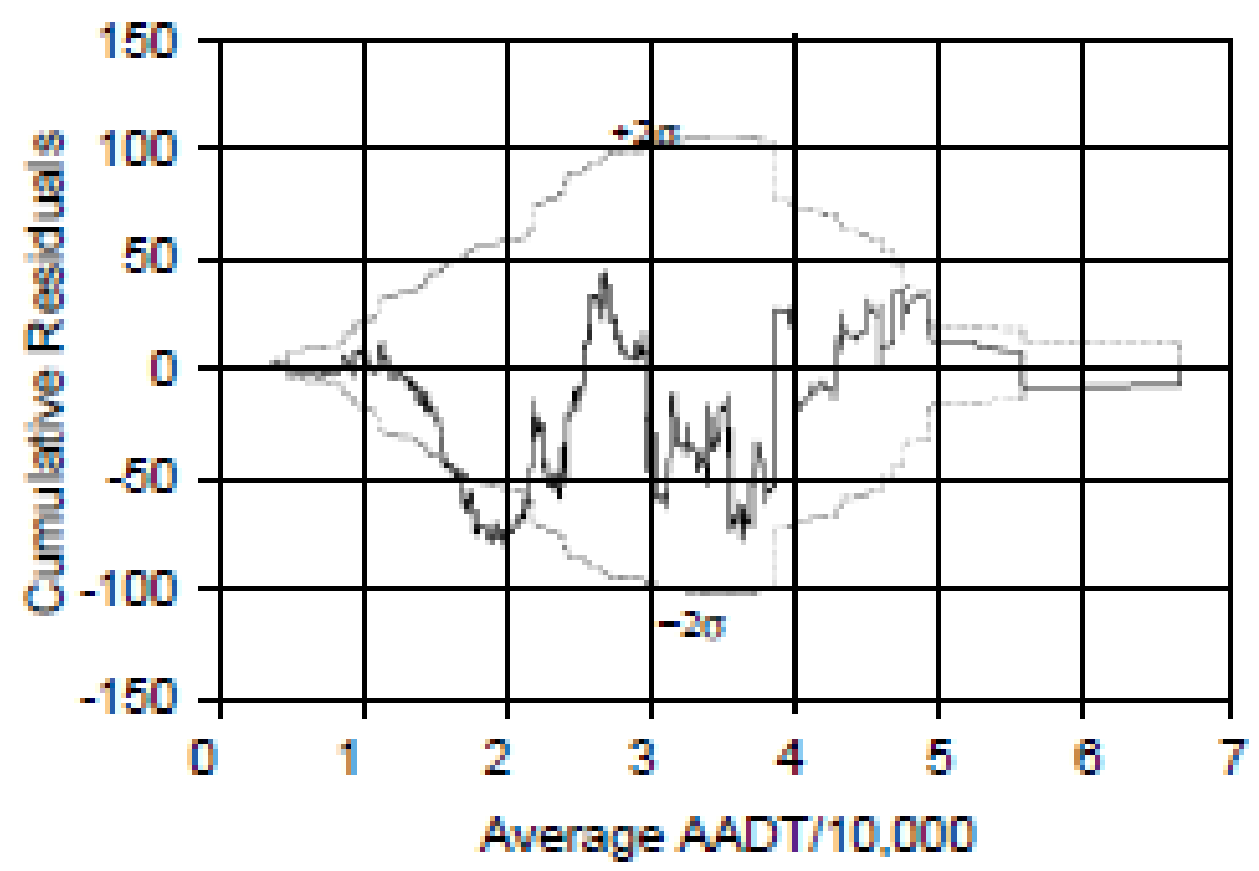

Fonte: Hauer (2004).

\subsection{MODELOS POR EQUAÇÕES ESTRUTURAIS}

A Modelagem por Equações Estruturais - MEEs é uma metodologia de análise multivariada de dados que não apenas descreve os dados empíricos, mas propõe inferências sobre hipóteses teóricas que o pesquisador pressuponha sobre os dados ou fenômenos. Ela é especialmente importante para o teste de teorias que envolvem múltiplas 
equações com relações de dependência, uma vez que permite tratar simultaneamente uma série dessas relações (Hair et al., 2009).

Byrne (2010) resume a diferença das MEEs e as outras técnicas de análise multivariada em quatro aspectos: i) está apoiada na abordagem confirmatória, e não exploratória, apesar desta abordagem também ser possível; ii) os MEEs podem explicitar estimativas da variância do parâmetro do erro de medida; iii) os MEEs podem incorporar na análise tanto variáveis observáveis (empíricas) quanto não observadas (latentes); iv) MEE é o método de análise multivariada de fácil aplicação para modelagem de relações entre diferentes variáveis e para estimações pontuais ou intervalares de efeitos indiretos.

Segundo Muthén (1993), a Modelagem por Equações Estruturais - MEE é realizada em duas partes: i) Modelo de medida (measurement model $-M M$ ), onde as medidas diretas (variáveis observadas) geram os construtos (variáveis não observadas ou latentes); ii) Modelo estrutural (structure model $-S M$ ), onde os construtos ou medidas diretas geram outras variáveis latentes. Parte importante da MEE é a identificação do modelo teórico que deverá ser testado como hipótese do pesquisador. Entende-se que para um mesmo conjunto de dados existam infinitos modelos, mais ou menos ajustados. Este é um processo complexo, que se propõe a verificar quando "existe ou não um único conjunto de parâmetros que é consistente com os dados" (Byrne, 2010). Se esse único conjunto existir, o modelo é considerado identificado, pode ser testado e os parâmetros podem ser estimados. Se o modelo não for identificado, tem-se a indicação de que "os parâmetros são decorrência da arbitrariedade, implicando, assim, que diferentes valores dos parâmetros definem o mesmo modelo" (Byrne, 2010).

Uma das regras para a definição do modelo, segundo Thompson (2005), é que o número de parâmetros a serem estimados deve ser igual ou menor que o número de graus de liberdade disponíveis. O método de cálculo dos graus de liberdade é expresso na Equação 4.4 .

$$
G L=\frac{[p(p+1)]}{2}-N P A R
$$

Em que:

$G L=$ graus de liberdade;

$p=$ total de pontos da matriz de covariância ou correlações;

NPAR = número de parâmetros do modelo; 
A Análise Fatorial Confirmatória - AFC é um tipo de MEE, cujo objetivo é testar diferentes configurações de modelos para obter um modelo que interprete e descreva os dados com menor número de parâmetros (AmirAlavifar e Anuar, 2012). O uso da AFC deve ser usado como uma técnica "desconfirmatória" (Kline, 2011). Se os modelos concorrentes não forem melhores que o modelo hipotético, aceita-se o modelo hipotético identificado como uma boa explicação dos dados. A representação gráfica dos modelos é realizada por meio de diagramas de caminhos. O modelo especificado no diagrama implica em uma estrutura de médias e covariâncias que podem ser comparadas às médias e covariâncias da amostra (Nachtigall et al., 2003). Para a identificação do modelo de equações estruturais é necessária a análise de elementos não redundantes e graus de liberdade maior que zero.

Para o uso da MEE deve-se: i) empregar amostra compatível, pelo menos 5 observações por variável e erro; ii) usar vários itens (2 ou 3) para mensurar um construto; iii) considerar os pressupostos dos métodos de estimação; iv) ter sempre uma teoria guia para a construção do modelo a ser testado; v) verificar se existe razão teórica suficiente para testar um modelo com erros correlacionados; vi) considerar teoricamente a direção dos caminhos presentes nos diagramas dos modelos, prezando pela parcimônia (Byrne, 2010).

Os métodos de estimação são variados e impõem restrições à modelagem, conforme seus pressupostos. Os métodos dos mínimos quadrados ordinários (MQO) e o da Máxima Verossimilhança (ML) exigem que as variáveis sejam contínuas e com distribuição normal multivariada (Nachtigall et al., 2003). Os métodos de mínimos quadrados ponderados (WLS), o método assintótico isento de pressupostos de distribuição (ADF) e a Verossimilhança Marginal Composta (CML) são alternativas à ausência da normalidade, mas necessitam de grandes amostras, por volta de 2000 respondentes, para obter respostas satisfatórias, raramente acessíveis em estudos de construtos psicológicos (Nachtigall et al., 2003; Kamargianni et al., 2015).

MacCallum e Austin (2000) afirmam que a normalidade multivariada não se aplica às variáveis exógenas (observadas). A Tabela 4.4 resume os índices de ajuste dos modelos MEE referenciados na literatura e seus respectivos critérios de aceitação de um bom ajuste de modelo. O ajuste do modelo deve ser indicado por, pelo menos, três ou quatro índices de ajuste, sendo um índice incremental, um índice absoluto e um da má qualidade do 
ajuste. No teste da teoria através da AFC, busca-se comparar modelos rivais, visando identificar o que apresente melhor ajuste, maior parcimônia e menos resíduos. Alterações de melhoria de 0,01 nos indicadores serão consideradas uma melhoria significativa em prol do modelo de maior escore (Thompson, 2005).

Tabela 4.4: Índices para avaliação do ajuste de modelos MEE

\begin{tabular}{|c|c|}
\hline Índice & Critério de bom ajuste \\
\hline \multicolumn{2}{|l|}{ Índices de adequação absoluta } \\
\hline Chi-quadrado $(\mathbf{p}<0,05)$, sendo gl - graus de liberdade ${ }^{1}$ & $\frac{\chi}{g l}^{2} \leq 5$ \\
\hline MFI (McDonald Fit Index) & Maior, melhor. \\
\hline \multicolumn{2}{|c|}{ Comparação do $X^{2}$ de modelos independentes com $\chi^{2}$ do modelo em teste -testes incrementais } \\
\hline NFI (Normed Fit Index) & $\geq 0,95$ (variando de 0 a 1$)$ \\
\hline NNFI (Non-Normed Fit Index) & $\geq 0,95$ (variando de 0 a 1 ). \\
\hline IFI (Incremental Fit Index) & $\geq 0,95$ (variando de 0 a 1$)$ \\
\hline RFI (Relative Fit Index) & $\geq 0,95$ (variando de 0 a 1$)$. \\
\hline CFI (Comparative Fit Index) & $\geq 0,95$ (variando de 0 a 1$)$ \\
\hline TLI (Tucker-Lewis Index) & $\geq 0,95$ (variando de 0 a 1$)$ \\
\hline RMSEA (Root Mean Square Error of aproximation) & $\begin{array}{l}\text { Valor }<0,05 \text { ou } 0,06 \text { - bom ajuste; } \\
0,08<\text { Valor }<0,1 \text { - ajuste medíocre; } \\
\text { Valor }>0,1 \text { - ajuste pobre. }\end{array}$ \\
\hline \multicolumn{2}{|l|}{ Índices relativos à proporção da variância explicada } \\
\hline GFI (Goodness of Fit Index) & Perto de 1 (variando de 0 a 1 ). \\
\hline AGFI (Adjusted Goodness of Fit Index) & Perto de 1 (variando de 0 a 1 ). \\
\hline \multicolumn{2}{|l|}{ Índices relativos à parcimônia do modelo testado } \\
\hline PGFI (Parcimony Goodness of fil index) & $\geq 0,50$ \\
\hline AIC (Akaike Information Criterion ) & Quanto menor, melhor. \\
\hline CAIC (Consistent Akaike Information Criterion) & Quanto menor, melhor. \\
\hline \multicolumn{2}{|c|}{ Índices baseados em resíduos - testes da má qualidade do modelo } \\
\hline RMR (Root Mean Square Residual) & Valor 0 indica um ajuste perfeito. \\
\hline SRMR (Standardized Root Mean Square Residual & $\leq 0,05$ (variando de 0 a 1$)$ \\
\hline \multicolumn{2}{|c|}{ Notas: 1 - no AMOS SPSS, $\chi^{2}$ é representado pelo indicador CMIN e gl por df. } \\
\hline \multicolumn{2}{|c|}{$\begin{array}{l}\text { Fonte: Adaptado de: Gärling e Fujii (2002); Thompson (2005); Tabachnick e Fidel (2007); Pilati e Laros, } \\
\text { (2007); Campbell et al. (2008); Hair et al.(2009); Byrne (2010); Kline (2011). }\end{array}$} \\
\hline
\end{tabular}

Os Modelos de Equações Estruturais - MEEs trabalham amplamente com a estimação de modelos de variáveis latentes e variáveis contínuas (Ben-Akiva et al.,2002), podendo incluir variáveis que sejam, ao mesmo tempo, dependentes e explicativas do modelo (Byrne, 2010). Quando a variável dependente é de natureza discreta, o uso de MEEs, entretanto, resulta em estimações inconsistentes (Ben-Akiva et al.,2002).

\subsection{MODELOS DE ESCOLHA DISCRETA}

Os Modelos de Escolha Discreta - MED são a classe de modelos adequada à modelagem de variáveis discretas. Eles consideram que, a partir das diferenças individuais, haverá uma probabilidade da decisão cair em determinada classe de escolha. Neste caso, o modo 
escolhido. A análise de escolhas discretas é aplicada para modelar situações de comportamento em que uma decisão é realizada a partir de um conjunto finito de alternativas discretas, mutuamente exclusivas e coletivamente exaustivas. A modelagem baseia-se na escolha da alternativa que propicia maior utilidade ao tomador de decisão, dentre todas as alternativas disponíveis (Ben-Akiva et al.,2003).

O Modelo Logit Multinomial - MNL é o modelo clássico do tipo MED (Ben-Akiva et al.,2003), e é dado pela forma funcional mostrada nas Equações 4.5 a 4.7. O modelo assume que a utilidade da alternativa $i$ para um indivíduo $q\left(\mathrm{U}_{\mathrm{iq}}\right)$ é composta por um componente determinístico $\left(V_{i q}\right)$ e por um componente aleatório, desconhecido do pesquisador $\left(\varepsilon i_{q}\right)$, apresentado na Equação 4.5.

$$
\mathrm{U}_{i q}=\mathrm{V}_{i q}+\varepsilon_{i q}
$$

A parte determinística do modelo, $\mathrm{V}_{i q}$, representa a utilidade, ou a atratividade, atribuída pelo indivíduo $q$ à alternativa $i$, sendo definida por um vetor de atributos para alternativa $i$, como percebido pelo indivíduo $q$, (atributos do usuário e das viagens realizadas), em que $\beta_{0 i}$ é uma constante atribuída à alternativa $i$. A Equação 4.6 apresenta a formulação linear para a utilidade, porém ela pode assumir formas não lineares (Ben-Akiva et al., 2013)

$$
\mathrm{V}_{i q}=\beta_{0 i}+\beta \mathrm{x}_{i n}
$$

O componente aleatório $\varepsilon_{i q}$ representa os erros na habilidade do modelador de representar todos os elementos que influenciam a utilidade de uma alternativa para um indivíduo, e segue três pressupostos: (i) todos os erros são independentes e igualmente distribuídos (IID) com a distribuição de Gumbel; (ii) o modelo mantém a homogeneidade de resposta aos atributos das alternativas entre indivíduos; (iii) a estrutura de variância de erros para cada alternativa é idêntica para todos os indivíduos (Bhat, 2000). O primeiro pressuposto leva à dedução do modelo MNL (Equação 4.7).

$$
P_{i q}=\frac{e^{V i q}}{\sum_{i=1}^{J} e^{V i q}}
$$


Em que:

$\mathrm{P}_{i q}=$ probabilidade da alternativa $i$ ser escolhida pelo indivíduo $q$;

$e=$ função exponencial;

$\mathrm{V}_{i q}=$ componente determinístico da utilidade da alternativa $i$, para o indivíduo $q$;

$\mathrm{J}=$ número de alternativas.

No modelo MNL, as estimativas são apresentadas em grupos de comparação em pares de níveis de resposta (ou alternativas) para a variável dependente. Uma das alternativas é considerada categoria de referência, e as demais alternativas são comparadas a esta referência. Em estudos que implicam o gerenciamento da mobilidade, o foco é comparar o uso do modo automóvel (categoria de referência) com modos alternativos, de forma a identificar as utilidades dos modos alternativos na escolha modal em comparação com a utilidade do automóvel.

A avaliação da qualidade de ajuste dos modelos MNL é realizada por diferentes indicadores, como apresentados por Hair et al. (2009): i) teste de significância do modelo - teste de Chi-quadrado sobre as diferenças no logaritmo da verossimilhança (-2LL); ii) valores "pseudo" $\mathrm{R}^{2}$ - indicador semelhante ao $\mathrm{R}^{2}$ da regressão linear, variando de 0,0 a 1,0. Valores próximos de 1,0 indicam um ajuste perfeito; iii) Teste Wald da significância dos coeficientes - testa se o coeficiente logístico é diferente de zero. A interpretação se dá ao comparar p-valor ao seu valor crítico; iv) interpretação dos coeficientes - o coeficiente da equação (beta) reflete a variação do logaritmo de "y" para uma unidade de mudança em x, permanecendo as demais variáveis constantes. Um coeficiente positivo indica que "maiores valores da variável leva a um incremento na probabilidade predita, mas não por uma quantidade fixa" (Hendrikx, 2002); v) sinal dos coeficientes (no termo determinístico $V_{i q}$ na Equação 4.3) - avaliação da relação entre variável dependente e independente negativa ou positiva; vi) magnitude da relação - avaliação pelo coeficiente exponenciado (na Equação 4.4), de quanto a probabilidade mudará dada uma variação de uma unidade da variável independente (dado pela variação percentual na variável dependente, igual ao coeficiente exponenciado menos 1, vezes 100).

Outra interpretação dos resultados no modelo MNL é a razão de chance (odds ratio). É um número real que indica a razão da probabilidade de um evento acontecer sobre a probabilidade do mesmo evento não acontecer. Para eventos raros, de frequência menor que $10 \%$, o conceito se aproxima do risco relativo - comparação percentual das 
probabilidades (ou riscos). Quando o odds ratio é maior que 1, ele indica um efeito positivo, enquanto valores entre 0 e 1 indicam efeitos negativos. Para alternância entre efeitos positivos e negativos, basta calcular o seu inverso (Long, 1997).

\subsection{MODELOS HÍBRIDOS DE ESCOLHA DISCRETA}

O modelo MED tradicional se baseia na teoria da utilidade aleatória, também chamado Modelo de Escolha de Utilidade Aleatória, como é o caso do Modelo Logit Multinomial - MNL (ver Figura 4.3). Esses modelos não modelam explicitamente a formação de atitudes e percepções (Ben-Akiva et al., 2002). Na tentativa de melhor explicar as escolhas observadas, incluindo nos MEDs a análise das variáveis psicossociais, pesquisadores desenvolveram os chamados modelos híbridos de escolha discreta MHEDs (Hybrid Choice Models - HCMs) (Ben-Akiva et al.,2002; Temme et al., 2008; Kamargianni et al., 2015).

Ben-Akiva et al. (2002) revisaram as formulações dos MHED mais recentes, apresentadas sinteticamente nas Figuras 4.3 a 4.6 (de acordo com a semântica de diagrama de caminhos) e Tabela 4.5. Segundo os autores, as tentativas dos tipos "a" a "c" não eximiram as inconsistências de estimação: “i) [na modelagem tipo "a”] a omissão de variáveis latentes importantes pode levar a especificação inadequada do modelo e a estimação inconsistente dos parâmetros; ii) o uso direto dos indicadores, [modelagem tipo 'b"] no modelo de escolha é inadequado, pois são altamente dependentes do tipo de linguagem utilizada nas questões de pesquisa e, desta forma, não disponíveis para a previsão; iii) a abordagem em dois estágios [modelagem tipo "c"] sem ser integrado, leva a erros de medida e resultados de estimativas inconsistentes. Sendo integrado é consistente, mas com estimativas ineficientes. A integração (não necessariamente usando pacotes de estimação prontos) pode, da mesma forma, realizar a modelagem simultânea; iv) O modelo de escolha e a variável latente sem os indicadores [modelagem tipo 'd"] é restritiva, já que as variáveis, atributos latentes das alternativas, são específicas das alternativas de escolha, e não variam entre os respondentes".

Nas suas formulações mais recentes, tipo "e" na Tabela 4.5, os modelos híbridos que explicitamente modelam as variáveis latentes dos atributos psicossociais são denominados Modelos Integrados de Escolha e Variável Latente (Integrated Choice and 
Latent Variable Model - ICLV) (Temme et al., 2008; Figura 4.6: Modelo de escolha Bhat e Dubey, 2014). Nesses modelos, tem-se dois com atributos latentes (tipo d) componentes: um modelo de escolha discreta e um modelo de variável latente. As variáveis latentes que influenciam o processo de escolha são estimadas de forma integrada, não acumulando erros de estimação (Ben-Akiva et al.,2002; Temme et al., 2008; Kamargianni et al., 2015), como apresentado na Figura 4.7.

Tabela 4.5: Modelos de escolha e sua integração com variáveis latentes

\begin{tabular}{|c|c|c|}
\hline Tipo & Estratégia & Figura \\
\hline$a$ & Modelo de escolha tradicional & 4.3 \\
\hline b & Inclusão das dimensões psicológicas diretamente na função utilidade & 4.4 \\
\hline$c$ & $\begin{array}{l}\text { Realizar uma análise fatorial dos indicadores e depois inserir os fatores obtidos na } \\
\text { função utilidade }\end{array}$ & 4.5 \\
\hline$d$ & $\begin{array}{l}\text { Realizar uma inferência dos atributos latentes das alternativas (os atributos são } \\
\text { relativos à alternativa e não variam conforme o respondente) a partir dos dados de } \\
\text { escolha e incluir na função utilidade; }\end{array}$ & 4.6 \\
\hline$e$ & $\begin{array}{l}\text { Os dados psicométricos das variáveis latentes são modelados de forma integrada com } \\
\text { o modelo de escolha discreta e incluídos na função utilidade. }\end{array}$ & 4.7 \\
\hline
\end{tabular}

Fonte: Ben-Akiva et al.(2002), adaptado.

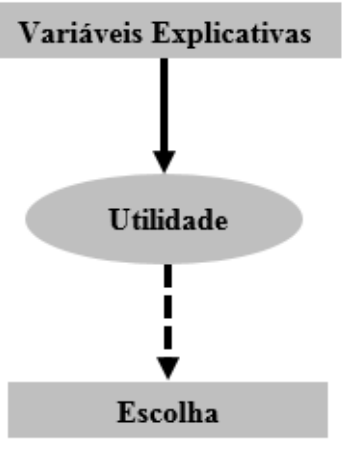

Figura 4.3: Modelo de escolha de utilidade aleatória (tipo a).

Fonte: Ben-Akiva et al.(2002).

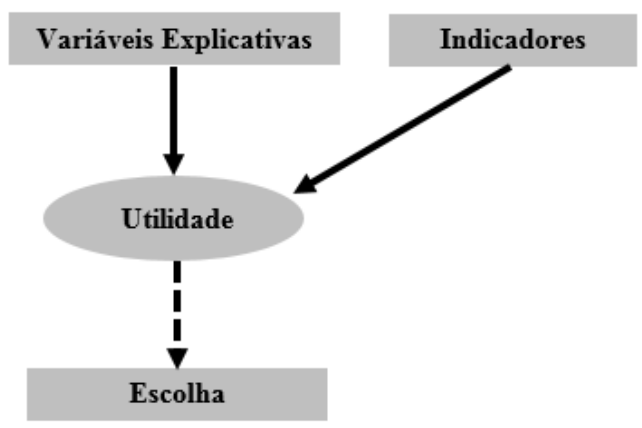

Figura 4.4: Modelo de escolha com indicadores incluídos diretamente na utilidade (tipo b).

Fonte: Ben-Akiva et al.(2002).

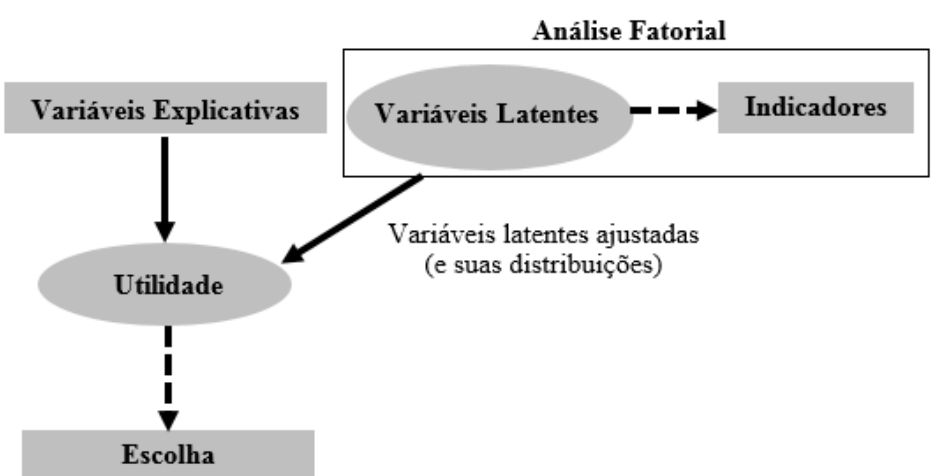

Figura 4.5: Estimação sequencial: análise fatorial seguida de um modelo de escolha (tipo c).

Fonte: Ben-Akiva et al.(2002).

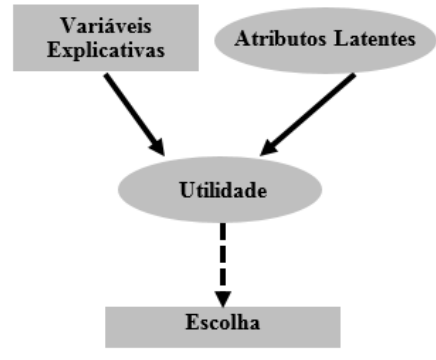

Figura 4.6: Modelo de escolha com atributos latentes (tipo d)

Fonte: Ben-Akiva et al.(2002). 


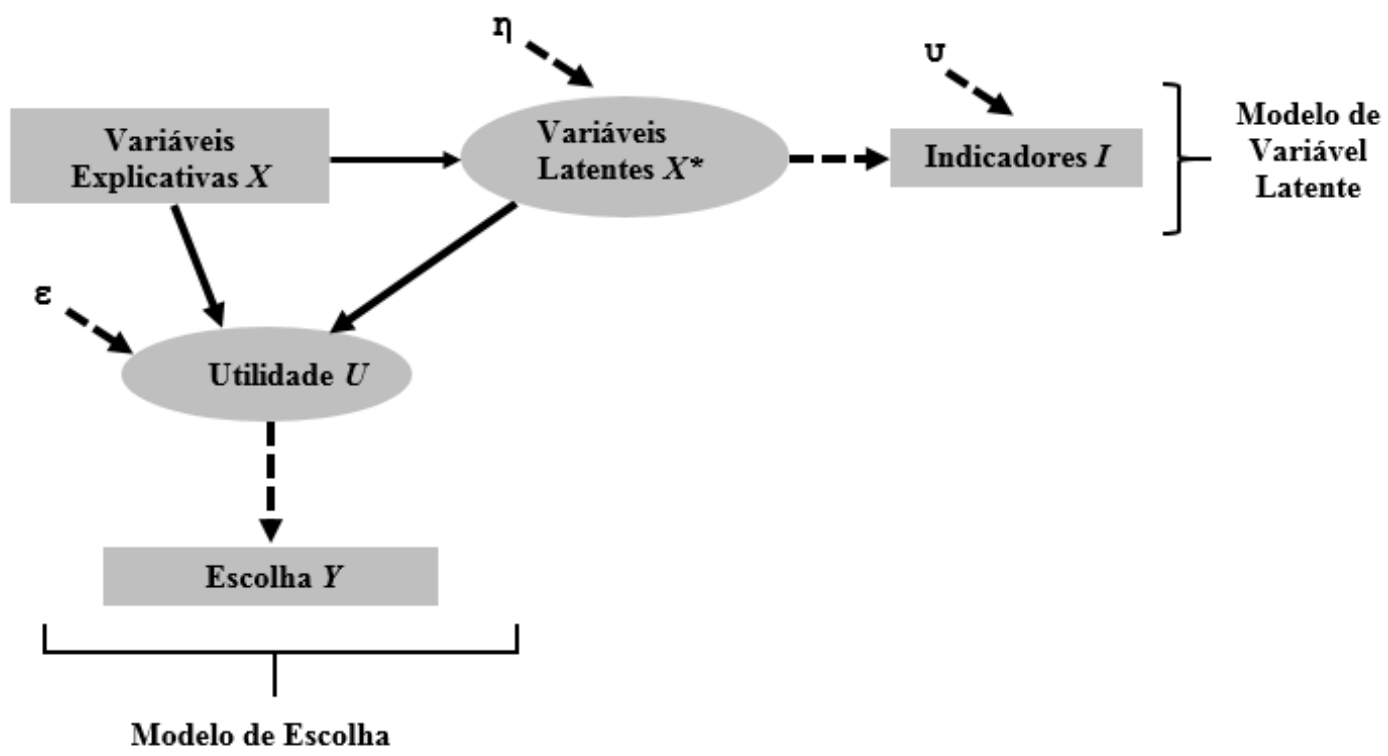

Fonte: Ben-Akiva et al.(2002).

O modelo ICLV apresentado na Figura 4.7 utiliza dados psicométricos "explicitamente para modelar atitudes e percepções e suas influências nas escolhas" (Ben-Akiva et al., 2002). E ainda, "a metodologia requer a estimação de um modelo de diferentes equações integradas, entre um modelo de escolha discreta e um modelo de variável latente, ambos com equações estruturais e de medida. O modelo é estimado simultaneamente utilizando a máxima verossimilhança, na qual sua função inclui integrais complexas de várias dimensões". O modelo é dividido em duas partes, o modelo de escolha discreta e o modelo de variável latente. Cada parte consiste em uma ou mais equações estruturais e uma ou mais equações de medida. O modelo será especificado nas seções a seguir, adotando a seguinte notação:

X - variáveis observáveis explicativas;

X* - variáveis latentes explicativas;

I - indicadores de $X^{*}$ (itens do questionário);

$\mathbf{U}_{\mathbf{i}}$ - utilidade da alternativa $\mathrm{i}$;

$\mathrm{V}$ - vetor de utilidades;

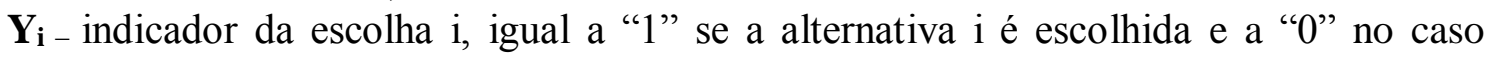
contrário;

$\mathrm{Y}$ - vetor dos indicadores de escolha;

$\alpha, \beta, \gamma$ - parâmetros a serem estimados;

$\eta, \varepsilon, U-$ termos de erros aleatórios;

$\Sigma, \sigma$ - covariância dos termos de erros aleatórios;

$\mathrm{D}$ - distribuição genérica;

$\mathrm{h}(),. \mathrm{v}(),. \mathrm{g}($.$) - funções não definidas.$ 


\subsubsection{EQUAÇÕES ESTRUTURAIS NO MODELO DE VARIÁVEL LATENTE DO ICVL}

O modelo de variável latente terá uma equação estrutural para cada variável latente. É necessário estimar a distribuição das variáveis latentes dadas as variáveis explicativas $\mathrm{X}$ : $\mathrm{f}_{1}\left(\mathrm{X}^{*} \mid \mathrm{X} ; \curlyvee, \Sigma_{\eta}\right)$, como na Equação 4.8.

$$
X^{*}=h(X, \gamma)+\eta \text { e } \eta \sim D\left(0, \Sigma_{\eta}\right)
$$

\subsubsection{EQUAÇÕES ESTRUTURAIS NO MODELO DE ESCOLHA DO ICVL}

No modelo de escolha discreta é necessário estimar a distribuição das utilidades:

$\mathrm{f}_{2}\left(\mathrm{U} \mid \mathrm{X}, \mathrm{X}^{*}, \beta, \Sigma_{\varepsilon}\right)$, como na Equação 4.9.

$$
U=V\left(X, X^{*} ; \beta\right)+\varepsilon \text { e } \varepsilon \sim D\left(0, \Sigma_{\epsilon}\right)
$$

\subsubsection{EQUAÇÕES DE MEDIDA NO MODELO DE VARIÁVEL LATENTE DO ICVL}

No modelo de variável latente, é necessária a distribuição dos indicadores condicionais aos valores das variáveis latentes. Haverá uma equação para cada indicador: $\mathrm{f}_{3}\left(\mathrm{I} \mid \mathrm{X}, \mathrm{X}^{*} ; \alpha, \Sigma_{\mathrm{v}}\right)$, como na Equação 4.10.

$$
I=g\left(X, X^{*} ; \alpha\right)+v e v \sim D\left(0, \Sigma_{v}\right)
$$

\subsubsection{EQUAÇÕES DE MEDIDA NO MODELO DE ESCOLHA DO ICVL}

No modelo de escolha, é necessário expressar a escolha como função das utilidades. Por exemplo, na equação 4.11:

$$
Y_{i}=\left\{\begin{array}{c}
1, \text { se } U_{i}=\max _{j}\left\{U_{j}\right\} \\
0, \text { nos demais }
\end{array}\right.
$$


A probabilidade de escolha é derivada da distribuição do termo de erro, $\varepsilon$ (IID Gumbel para o MNL), e condicional tanto às variáveis explicativas observáveis quanto às variáveis explicativas latentes, $\mathrm{P}\left(\mathrm{Y} \mid \mathrm{X}, \mathrm{X}^{*} ; \beta, \Sigma_{\varepsilon}\right)$, como na Equação 4.12. Em geral, as mesmas regras aplicadas aos modelos de variáveis latentes tradicionais e aos MEDs são aplicadas aos modelos ICLV (Ben-Akiva et al., 2002).

$$
P\left(Y_{i}=1 \mid X, X * ; \beta\right)=\frac{e^{V_{i}}}{\sum_{J \epsilon C} e^{V_{i}}}
$$

\subsection{TÓPICOS CONCLUSIVOS}

Neste capítulo, foram analisadas as técnicas analíticas ligadas aos estudos comportamentais na escolha modal, mais referenciadas na literatura revisada no Capítulo 2. Essas técnicas incluem desde modelos mais populares, como a análise fatorial, até modelos de requinte computacional, como o ICLV. Os modelos teóricos apresentados no final do Capítulo 3 envolvem, como variáveis exógenas, tanto variáveis observáveis diretamente, quanto variáveis latentes. As variáveis endógenas, ou dependentes, também pertencem a diferentes categorias, como variáveis numéricas contínuas, binárias e categóricas.

Para que se dê prosseguimento ao presente estudo, é necessária: i) a realização das etapas metodológicas para definição das estratégias de coletas de dados; ii) a definição do procedimento de estudo da escolha modal em IEMs, integrando os modelos teóricos apresentados nas Figuras 3.2 e 3.3 e realizando as etapas metodológicas propostas no Capítulo 1; iii) a definição dos aplicativos computacionais disponíveis e necessários à aplicação da técnica analítica mais adequada para a análise proposta. 


\section{DESENVOLVIMENTO DE PROCEDIMENTO PARA IDENTIFICAÇÃO DE ATRIBUTOS INTERVENIENTES NO COMPORTAMENTO DE ESCOLHA MODAL}

Este capítulo descreve as atividades desenvolvidas que permitiram a definição de um procedimento para a identificação de atributos intervenientes no comportamento de escolha modal em Instituições de Ensino Médio. A realização das etapas metodológicas 2, 3 e 4, como salientado na Figura 5.1, permitiu o desenvolvimento de proposta de procedimento (Etapa 5), cujo teste aplicativo é apresentado nos Capítulos 6 e 7, para IEMs em Brasília. No texto a seguir, para cada etapa metodológica realizada, são detalhadas as ações realizadas e os suportes de técnicas referenciadas na literatura para operacionalizar cada ação.

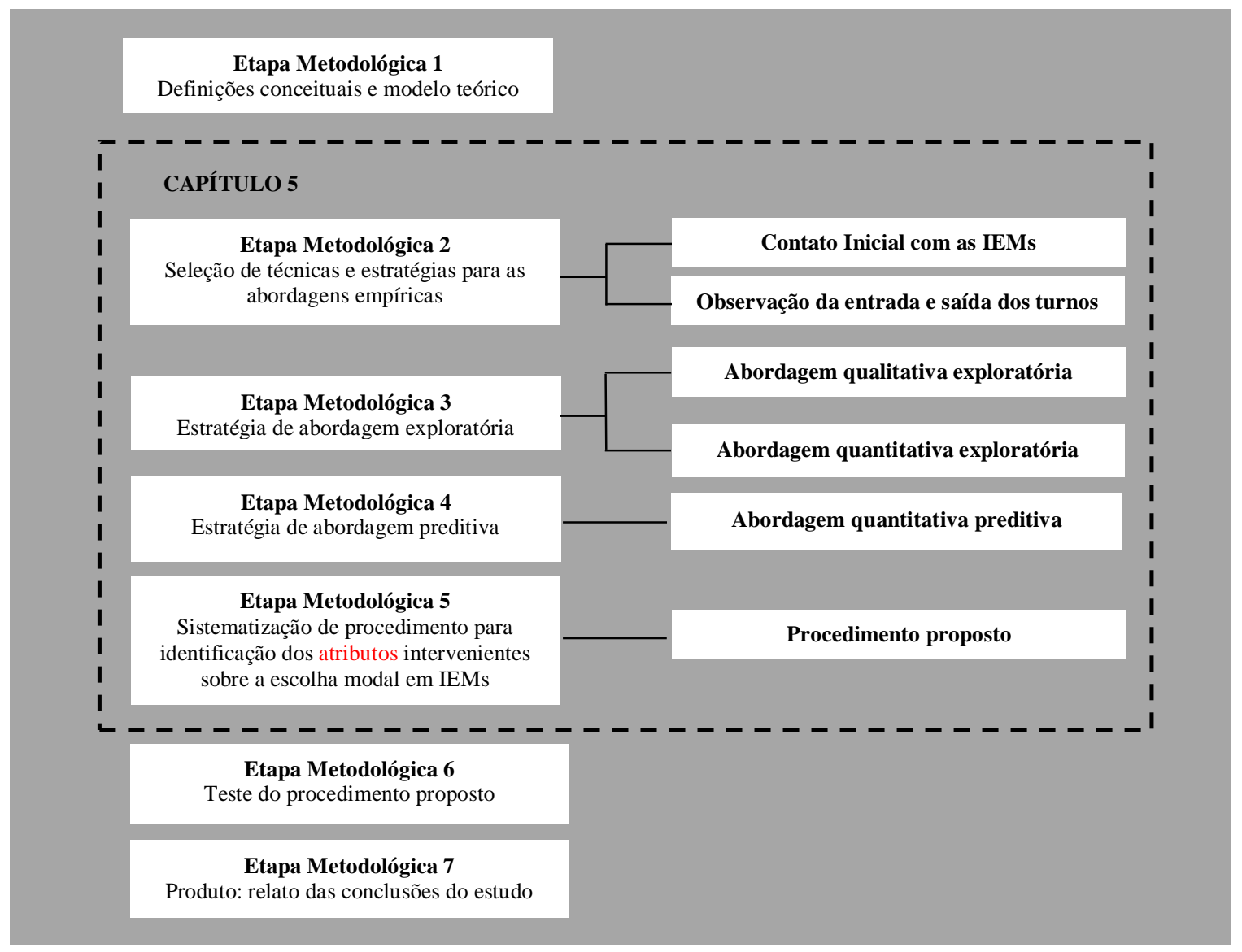




\subsection{ATIVIDADES PRELIMINARES}

O planejamento preliminar da pesquisa visou à determinação dos recursos necessários ao procedimento empírico, o que inclui, também, a adoção das medidas necessárias à aprovação prévia pelo Comitê de Ética em Pesquisa - CEP. Pela Resolução n. 196/96 do Conselho Nacional de Saúde, o envolvimento de menores de 18 anos na pesquisa é um indicativo da necessidade de revisão ética com relação à metodologia e abordagens da coleta de dados. A pesquisa com alunos de IEMs, portanto, deve ter anuência de Comitê de Ética em Pesquisa, e sua participação autorizada por pais e/ou responsáveis. Os modelos dos Termos de Consentimento Livre Esclarecido - TCLE (autorização dos pais para participação dos filhos, para pais participantes, para filhos participantes) são apresentados no Apêndice B.

No roteiro inicial para revisão ética, foram indicados os indivíduos a serem envolvidos na pesquisa, e prováveis riscos éticos subjacentes à metodologia proposta: i) a direção da escola, bem como professores e funcionários (estes de forma excepcional), para a autorização, acompanhamento da pesquisa e acolhimento dos resultados da pesquisa, além do retorno à comunidade participante; ii) os alunos participantes; iii) os pais/ responsáveis dos alunos participantes.

No intuito de dar visibilidade ao tema e motivar a comunidade escolar, foi criado um Blog (gmescolas.blogspot.com.br>), com publicações de temas correlatos à pesquisa como PGMs de outras localidades, envolvimento de IEMs com o tema mobilidade e as atividades do grupo de pesquisa da UnB. Também foi adotado o codinome de pesquisa "ESCOLA + VERDE", facilitando a identificação da pesquisa, com mais de 800 visualizações (visitas ao blog) no período de coleta de dados.

\subsection{CONTATO INICIAL COM AS IEMS}

O contato inicial com a direção da IEM foi o passo crítico para o desenvolvimento das demais etapas de pesquisa. Teve como objetivo comprometer a direção da escola com o andamento da pesquisa e obter autorização formal para realização do trabalho, necessária à autorização do Comitê de Ética. 
Ao mesmo tempo em que se pretendia envolver as IEMs, pretendia-se não influenciar (enviesar) as respostas da comunidade escolar na pesquisa. Os contatos iniciais não envolveram, portanto, palestras a alunos ou eventos sobre o tema. Outro objetivo do contato inicial foi identificar o tamanho da população alvo, pelo número de matrículas por turno/turma. Inicialmente foram previstas duas estratégias: i) pesquisar todos os alunos da IEM, caso preferencial para escolas com matrículas no ensino médio por turno inferior a 200 estudantes; ii) selecionar, para a pesquisa, uma amostra representativa da população de estudantes, a ser adotada em escolas com número elevado de estudantes por turno.

Entretanto, pela organização dos turnos de duas das escolas envolvidas, decidiu-se considerar apenas as turmas de $1^{\mathrm{a}}$ série. Além de facilitar a coleta de dados em um mesmo turno, o envolvimento apenas dos alunos de $1^{\mathrm{a}}$ série apresentou os seguintes benefícios: i) nesta série os alunos têm menor comprometimento de tempo escolar com as provas para ingresso nas universidades (ENEM, PAS e Vestibular) e, portanto, maior disponibilidade para participar da pesquisa; ii) a mudança do ensino fundamental para a $1^{a}$ série do ensino médio implica, muitas vezes, na mudança de escola, favorecendo uma reflexão de pais e alunos sobre como realizar as novas viagens escolares.

Das seis IEMs contatadas inicialmente, apenas três assinaram o termo de participação. Em todas as IEMs participantes utilizou-se o envolvimento apenas de alunos da $1^{\mathrm{a}}$ série. A estratégia possibilitou, além das vantagens já expostas, a realização de dois períodos de coleta de dados nas escolas públicas participantes $\left(2^{\circ} / 2014\right.$ e $\left.1^{\circ} / 2015\right)$, minimizando os efeitos de um ano atípico pela realização da Copa e greves de rodoviários em Brasília. Os detalhes sobre a população alvo e a população pesquisada nos dois períodos de coleta de dados serão apresentados no Capítulo 6.

Foram propostas e aplicadas com sucesso dois tipos de estratégias para o contato inicial com a IEM:

a) Entrevista com a Direção - encontro de sensibilização sobre o tema, inquerindo sobre os problemas de mobilidade vivenciados pela comunidade escolar. Também foram levantadas experiências prévias de GM na comunidade escolar, como iniciativas para uso de bicicletas, presença do batalhão escolar nas travessias de pedestres, etc. 
$\mathrm{Na}$ entrevista, foram obtidos os dados do Questionário Institucional, apresentado no Apêndice C, com informações cadastrais da IEM, como endereço físico e virtual dos contatos da IEM, número de alunos matriculados por série e turma, número de vagas de estacionamento, etc.

b) Questionário Institucional - Nas situações em que o encontro com a direção teve restrições de tempo, ou quando as informações não se encontravam disponíveis, o questionário institucional foi entregue para ser respondido e posteriormente coletado.

Integraram a pesquisa duas escolas públicas e uma privada. Nas duas IEMs públicas foram realizados dois períodos de coleta de dados. Para tal, foram necessários contatos adicionais com a direção/coordenação, e elaboradas cartas de apresentação adicionais, panfletos de sensibilização sobre o tema e divulgação do blog, criado pela pesquisadora (ver seção 5.1). Em uma das IEMs participantes, a direção indicou o envolvimento de professores (área de sociologia e história) para acompanhamento da pesquisa. Embora desejável, principalmente para o desenvolvimento futuro de um Plano de Gerenciamento da Mobilidade - PGM para a escola, tal envolvimento não surtiu o efeito desejado. $\mathrm{O}$ cronograma pedagógico das disciplinas indicadas já estava comprometido pelo final de atividades do ano letivo, e os professores dessas disciplinas apenas acompanharam timidamente as atividades de pesquisa.

\subsection{OBSERVAÇÃO DA ENTRADA E SAÍdA DOS TURNOS}

Antes de pesquisar a opinião dos alunos sobre sua mobilidade, foi necessário conhecer o contexto onde ela ocorria. A observação das operações de entrada e saída dos turnos visou promover as percepções sobre: i) a mobilidade cotidiana da IEM; ii) as relações espaciais do campus com o entorno; iii) a forma e a densidade de utilização dos modos de transporte na entrada e saída dos turnos.

Foram realizadas visitas às IEMs participantes nos horários de entrada e saída dos turnos pesquisados, manhã ou tarde, observando-se os conflitos nas operações de embarque e desembarque das viagens individuais motorizadas (Automóvel da Família, Automóvel Carona e Transporte Escolar). Também foram percorridos a pé os trajetos até os terminais 
mais próximos de ônibus e metrô. A Tabela 5.1 apresenta os itens do contexto físico da IEM registrados nas observações.

Tabela 5.1: Indicadores físicos da IEM e seu contexto físico

\begin{tabular}{|c|c|c|}
\hline Indicador & Grupo*** & Descrição \\
\hline Matrículas* & E & $\begin{array}{l}\text { Total de matrículas do ensino médio na IEM, ou apenas no } 1^{\circ} \text { ano } \\
\text { (conforme a coleta de dados). }\end{array}$ \\
\hline Área construída* & E & Área construída da IEM. \\
\hline $\begin{array}{c}\text { Estacionamento } \\
\text { interno* }\end{array}$ & $\mathrm{E}$ & Total de vagas de estacionamento internas à IEM. \\
\hline $\begin{array}{c}\text { Estacionamento } \\
\text { externo* }\end{array}$ & E & $\begin{array}{l}\text { Total estimado de vagas de estacionamento público nas } \\
\text { adjacências à IEM, incluindo ao longo do meio fio lindeiro. }\end{array}$ \\
\hline Distância casalescola & A & $\begin{array}{l}\text { Distância euclidiana do portão de acesso até o centroide do setor } \\
\text { censitário da residência do respondente. }\end{array}$ \\
\hline $\begin{array}{l}\text { Densidade na } \\
\text { localidade de } \\
\text { residência }\end{array}$ & A & $\begin{array}{l}\text { Cálculo do número de habitantes por } \mathrm{Km}^{2} \text { no setor censitário da } \\
\text { localidade de residência do aluno. }\end{array}$ \\
\hline Uso do solo & $\mathrm{E}$ & $\begin{array}{l}\text { Categorização do tipo de uso do solo, por análise de imagens } \\
\text { georreferenciadas e visitas ao local, num raio de } 500 \text { metros ao } \\
\text { redor da IEM: residencial; comercial/serviços; institucional; } \\
\text { misto (mais de } 30 \% \text { de presença de área para o segundo uso do } \\
\text { solo). }\end{array}$ \\
\hline $\begin{array}{l}\text { Acessibilidade à rede } \\
\text { de TP por ônibus }\end{array}$ & $\mathrm{E}$ & $\begin{array}{l}\text { Distância euclidiana em metros, medida por georreferenciamento, } \\
\text { do portão de acesso até o ponto de ônibus mais próximo, se } \\
\text { disponível. }\end{array}$ \\
\hline $\begin{array}{l}\text { Acessibilidade à rede } \\
\text { de TP por metrô }\end{array}$ & $\mathrm{E}$ & $\begin{array}{l}\text { Distância euclidiana em metros, medida por georreferenciamento, } \\
\text { do portão de acesso até o ponto de metrô mais próximo, se } \\
\text { disponível. }\end{array}$ \\
\hline Ciclovias & $\mathrm{E}$ & $\begin{array}{l}\text { Variável binária ( } 1 \text { ou } 0 \text { ). Existência (valor } 1 \text { ) de ciclovias a } \\
\text { menos de } 50 \mathrm{~m} \text { da escola. }\end{array}$ \\
\hline Apoio ciclo & $\mathrm{E}$ & $\begin{array}{l}\text { Variável binária ( } 1 \text { ou } 0) \text {. Existência (valor } 1) \text { de apoio para } \\
\text { ciclistas (bicicletários; duchas etc.). }\end{array}$ \\
\hline E/D automóveis & $\mathrm{E}$ & $\begin{array}{l}\text { Variável binária ( } 1 \text { ou } 0 \text { ). Existência (valor } 1 \text { ) de espaço (baias, } \\
\text { etc.) para a operação de embarque e desembarque em automóveis. }\end{array}$ \\
\hline $\begin{array}{l}\text { E/D p/transporte } \\
\text { escolar }\end{array}$ & E & $\begin{array}{l}\text { Variável binária (1 ou 0). Existência (valor 1) de espaço (baias, } \\
\text { etc.) para a operação de embarque e desembarque do transporte } \\
\text { escolar. }\end{array}$ \\
\hline Segurança viária & $\mathrm{E}$ & $\begin{array}{l}\text { Índice da existência de recursos de segurança viária num raio de } \\
50 \mathrm{~m} \text { dos portões de acesso, tais como: semáforos para pedestres; } \\
\text { faixas de segurança; controladores eletrônicos de velocidade; } \\
\text { quebra-molas. Considerando } 01 \text { ponto para cada um dos itens. }\end{array}$ \\
\hline Calçadas & E & $\begin{array}{l}\text { Variável binária ( } 1 \text { ou 0). Existência (valor } 1 \text { ) de calçadas em bom } \\
\text { estado de pavimentação e conservação num raio de } 2000 \text { metros } \\
\text { do portão de acesso. }\end{array}$ \\
\hline \multicolumn{3}{|c|}{$\begin{array}{l}\text { Obs.: * itens incluídos no questionário institucional (Apêndice C); } \\
\text { ** Grupo } \mathrm{A} \text { - variáveis diretamente relacionadas com os alunos - obtidas pelo questionário } \\
\text { abordado na seção } 4.5 .1 \text { e Apêndice } \mathrm{H} \text {; } \\
\text { Grupo } \mathrm{E} \text { - variáveis representando características da IEM. }\end{array}$} \\
\hline
\end{tabular}

Nessas observações, foi importante cuidar para que alunos não fossem fotografados (indicação ética da Secretaria Estadual de Educação), quando utilizado este recurso na coleta de dados. As observações possibilitaram a construção ou escolha de variáveis sobre o uso do solo, com potencial para explicar a utilização dos principais modos de transporte 
para cada IEM. As variáveis diretamente associadas à condição específica do aluno (Grupo A) foram consideradas na elaboração dos modelos. Já as variáveis que representam características da IEM (Grupo E) foram utilizadas nas análises posteriores aos modelos. Para suporte à coleta das informações integrantes dos indicadores apresentados na Tabela 5.1, foi elaborado um roteiro para avaliação do contexto físico das IEMs, apresentado no Apêndice D.

\subsection{ABORDAGEM QUALITATIVA EXPLORATÓRIA}

A primeira investigação da opinião dos alunos se deu de forma qualitativa. O objetivo era obter uma visão geral da percepção da mobilidade pela comunidade escolar e obter um elenco de crenças salientes sobre o comportamento da escolha modal. Conforme indicado na literatura de operacionalização da Teoria do Comportamento Planejado - TCP (Ajzen, 1991 e 2000), as crenças salientes são os antecedentes dos construtos psicológicos que influenciam a escolha modal. As crenças salientes são opiniões relevantes para cada indivíduo, alunos e/ou seus pais, sobre determinado comportamento, por exemplo, usar ou não o ônibus em determinadas circunstâncias para chegar à escola. Elas são os antecedentes das atitudes, norma social e controle percebido, de acordo com a Teoria do Comportamento Planejado - TCP. Tais crenças integrarão o instrumento de avaliação da opinião de alunos e seus pais sobre a mobilidade local.

No planejamento da abordagem qualitativa exploratória, foram seguidas as recomendações de Ajzen (1991) apresentadas na seção 4.1, para a obtenção das crenças sobre o comportamento estudado, na formulação de questões abertas sobre: i) a avaliação de resultados - vantagens e desvantagens, simpatias ou aversões para com o comportamento pesquisado; ii) as pessoas de referência social - pessoas ou grupos que aprovam ou desaprovam a realização ou não de determinado comportamento; iii) as dimensões de controle - elementos que tornam a realização do comportamento mais fácil, ou mais difícil, que permitem ou impedem a realização do comportamento.

\subsubsection{APLICAÇÃO DA TÉCNICA DE GRUPOS FOCAIS}

Foram organizadas reuniões de grupos focais nas três IEMs participantes, nos horários de intervalo dos turnos, com duração máxima de 20 minutos. A seleção dos participantes do 
grupo focal buscou: i) ser representativa de todas as turmas da população envolvida; ii) priorizar alunos líderes de agremiações estudantis e representantes de turma; iii) contar com participantes da administração da escola. Apesar de convidadas, apenas em uma IEM participante a direção/coordenação da escola participou dos grupos focais.

Pretendia-se, incialmente, que os pais participassem presencialmente dos grupos focais (como em Lang et al., 2011). Entretanto tal pretensão foi desestimulada pelas coordenações de todas as três IEMs participantes. A participação dos pais foi mediada, então, por um questionário com questões abertas e uma carta de apresentação, enviados para casa e devolvidos respondidos na reunião, através dos alunos (modelo apresentado no Apêndice E). Para que os alunos convidados participassem do grupo focal, termos TCLE (Apêndice B) foram enviados aos pais, e entregues assinados na reunião. Para que a reunião tivesse duração controlada, foi prevista no planejamento dos grupos focais a elaboração de roteiro ou protocolo de moderação (Apêndice F). O roteiro deveria apresentar a proposta das questões para discussão, mas com flexibilidade para absorver as demandas de discussões dos participantes (Dias, 2000).

Além do roteiro, foi elaborado um questionário impresso para os alunos participantes (Apêndice G), semelhante ao questionário enviado aos pais, com o objetivo de racionalizar o tempo disponível, concentrando-se nos itens de interesse. O roteiro da reunião, bem como os questionários enviados aos pais e disponibilizados aos alunos presentes, foram elaborados para facilitar a coleta das informações vinculadas ao uso da teoria TCP, às crenças salientes por construto (atitude, norma social e controle percebido), bem como aos aspectos gerais da mobilidade. O tamanho do grupo focal foi estimado entre o mínimo de 6 e máximo de 25 pessoas (Dias, 2000). As reuniões foram registradas por escrito, por, pelo menos, um observador pesquisador, além do moderador, e depois comparados os registros obtidos para a composição de um relatório síntese.

\subsubsection{ANÁLISE DAS INFORMAÇÕES OBTIDAS}

As reuniões de grupo focal foram ricas no entendimento da mobilidade local. Para sistematização das informações dos grupos focais, uma análise de conteúdo (Bardin, 2009; Babbie, 2013) foi realizada a partir dos relatórios sínteses, representativo da manifestação livre dos participantes. Nas escolas com dois turnos, apenas um relatório 
síntese foi gerado para a escola. Na análise de conteúdo foram identificadas a frequência dos temas citados, sua magnitude ou importância (por exemplo, o relato de assaltos no caminho até a parada de ônibus foi falado por apenas um dos presentes, mas considerado crítico por todos), e as consequências para a rotina escolar (por exemplo, diminuição dos tempos de aula nos turnos pela ocorrência de greve dos rodoviários).

A sistematização das informações seguiu os seguintes critérios: i) agrupamento de respostas para pais ou alunos; ii) agrupamento de respostas por questão do roteiro da reunião; iii) indicação dos modos de transporte mais citados e avaliados; iv) agrupamento de respostas mais citadas para cada modo de transporte; v) agrupamento por temas amplos e/ou críticos. Os registros foram, em seguida, redigidos na forma de crenças (afirmativas sobre a mobilidade local segundo os modos de transporte indicados). O objetivo da redação na forma de crenças é permitir que as afirmativas possam ser incluídas no instrumento de avaliação quantitativa das abordagens descritas nas próximas seções, de forma compatível com o uso da teoria TCP (Ajzen, 1991 e 2000).

Seguindo as orientações de Günther (2003), foram tomados cuidados na redação das afirmativas de crenças, tais como: i) utilizar linguagem objetiva e acessível, sem o uso de gírias ou verbetes (mesmo que esses sejam mais acessíveis aos adolescentes, como por exemplo, 'dar um rolé', ao invés de 'perambular pela cidade'); ii) não abordar dois comportamentos numa mesma afirmativa (por exemplo, 'é mais seguro caminhar da escola ao ponto de ônibus, do que do ponto de ônibus até minha casa'). Em situações comparativas, foram criadas duas afirmações, uma para cada comportamento; iii) utilizar tanto itens autorreferentes (como "moro muito longe da escola para usar bicicleta"), como heterorreferentes (como "é vantajoso caminhar até a escola"); iv) utilizar parte dos itens com redação invertida (como por exemplo, afirmativa positiva "é seguro usar metrô para ir ou voltar da escola", ou negativa "não é seguro esperar pelo metrô nas estações nos horários de ida e volta da escola"). Os resultados da abordagem qualitativa exploratória aplicada às IEMs participantes do estudo são apresentados no Capítulo 6.

\subsection{ABORDAGEM QUANTITATIVA EXPLORATÓRIA}

O objetivo da abordagem quantitativa exploratória é obter escores para a população escolar, como a partição modal, as distâncias médias viajadas, entre outros. Além disso, 
é oportuno testar a validade das opiniões obtidas nos grupos focais com um número reduzido de participantes, agora ampliados para a população alvo. Entretanto, a organização de uma coleta de dados baseada em questionários é exaustiva tanto para os aplicadores da pesquisa quanto para o envolvimento da população alvo. Em algumas IEMs, por restrições peculiares à escola, como a organização do calendário escolar e aplicação de simulados, a coleta de informações com questionários a todos os alunos pode ser prejudicada.

A aplicação de questionários foi otimizada de forma a dar conta da obtenção de dados tanto para a abordagem quantitativa exploratória quanto para a abordagem quantitativa preditiva. Nas três IEMs participantes da pesquisa, foram realizados esforços para que as etapas quantitativas, exploratória e preditiva, fossem realizadas de modo a testar a opinião obtida nos grupos focais, agora em termos populacionais. A abordagem adotada para o questionário é a de um estudo do tipo Preferência Revelada e, à semelhança do contexto relatado por Bamberg et al.(2003), com restrições para a realização de um novo período de coleta de dados com a população alvo. Por essa razão, a informação sobre o comportamento atual (escolha do modo de transporte) foi obtida no mesmo instrumento e período de coleta que os demais construtos da TCP.

\subsubsection{ELABORAÇÃO E APLICAÇÃO DO QUESTIONÁRIO}

Para esta etapa, foram utilizados questionários impressos com questões fechadas e questões abertas sobre características individuais ou do domicílio. As questões incluídas no questionário fazem parte de um dos seguintes grupos de questões ligadas ao levantamento de: i) condição sociodemográfica do pai ou aluno; ii) aspectos psicológicos (variáveis da TCP) envolvidos na avaliação de cada modo por pai/aluno; iii) hábito; iv) comportamento passado; e v) o comportamento adotado no dia da pesquisa para ir ou voltar da escola. O uso de ferramentas eletrônicas (como em Zhou, 2012; Whalen et al., 2013) para obtenção das opiniões de pais e alunos não foi permitida pelas coordenações das IEMs participantes.

O roteiro apresentado em Ajzen (2000) e utilizado por Elliott et al. (2003) foi seguido para a organização do questionário, no que diz respeito aos aspectos psicológicos. Cada crença saliente obtida nos grupos focais foi escrita na forma de dois itens avaliados por 
uma escala adjetiva bipolar de cinco pontos: um item sobre o conteúdo da crença, ou crença sobre o objeto (belief - $b$ ) e um item sobre a avaliação dos atributos do objeto, ou força da crença (evaluation - $e$ ).

A abordagem aos pais e aos alunos foi diferenciada, segundo as conclusões da etapa qualitativa (crenças salientes identificadas e modos principais utilizados), com adaptação de linguagem para adolescentes na versão de alunos. Uma codificação (numeração do questionário dos pais) foi empregada para a vinculação/ pareamento da resposta do aluno e seu respectivo pai.

Os itens para compor as medidas diretas dos construtos - atitude, norma social, controle percebido e intenção - foram elaborados segundo as recomendações apresentadas por Ajzen (2000) e Bamberg et al. (2003). Os itens foram medidos por escalas adjetivas bipolares (por exemplo, bom "1", “2”, “3”, “4”, “5” ruim) ou likert (1 -discordo totalmente; 2 - discordo; 3 - nem concordo, nem discordo; 4 - concordo; 5 - concordo totalmente). Em todas as medidas foi mantido o ponto neutro (valor “3”).

As escalas bipolares e likert, para medição dos itens e composição dos construtos, são consideradas de natureza ordinal e não métricas contínuas (Gujarati, 2004). Segundo Muthén (1984) deve-se ter atenção quanto à generalização do uso dessas escalas, especialmente quanto à utilização das medidas ordinais das escalas como variáveis contínuas. Deve-se utilizar sempre mais de 3 pontos na medição (não usar intervalos muito grandes entre os pontos) e a interpretação deve ser cuidadosa. Há um claro ordenamento entre as categorias, mas não se pode afirmar que a categoria de valor 1 (por exemplo, "discordo totalmente") equivale à metade da categoria de valor 2 (por exemplo, "nem concordo, nem discordo").

A avaliação dos construtos psicológicos da TCP, hábito e comportamento passado propostos por Ajzen (2000) e testada em países europeus e EUA como em Bamberg et al. (2003), entretanto, necessitou de adaptação de linguagem e contexto. A partir de uma tradução inicial dos questionários fonte, o texto foi avaliado por quatro pesquisadores envolvidos com pesquisas da TCP e fluentes na língua original do questionário e em português. A revisão da tradução foi seguida de uma revisão ortográfica e semântica. 
Como referido anteriormente, além dos itens da TCP, buscou-se incluir variáveis sociodemográficas no estudo. A literatura revisada traz inúmeros exemplos de investigação da influência das variáveis sociodemográficas e características locacionais na escolha modal, que podem ser incluídos no questionário. Van-Ristell (2011) fez uma revisão dos atributos influenciadores da escolha modal nas viagens de crianças à escola, resumidos na Tabela 5.2.

Tabela 5.2: Atributos influenciadores da escolha modal nas viagens à escola

\begin{tabular}{|c|c|c|}
\hline Categoria & Subcategoria & Características \\
\hline \multirow{11}{*}{ Individuais } & \multirow{3}{*}{ Criança } & Idade \\
\hline & & Gênero \\
\hline & & Grupo Étnico \\
\hline & \multirow{4}{*}{ Pais } & Atitude \\
\hline & & Tipo de emprego \\
\hline & & Educação \\
\hline & & Renda \\
\hline & \multirow{4}{*}{ Lar } & Posse de automóvel \\
\hline & & Número de licenças para dirigir \\
\hline & & Presença de crianças menores \\
\hline & & Horas de trabalho \\
\hline \multirow{9}{*}{ Ambientais } & \multirow{5}{*}{ Vizinhança da escola } & Percepção de segurança \\
\hline & & Nível de tráfego local \\
\hline & & Cultura \\
\hline & & Uso do solo \\
\hline & & Densidade na localidade da escola \\
\hline & \multirow{2}{*}{ Vizinhança da residência } & Distância casa/ escola \\
\hline & & Densidade na localidade de residência \\
\hline & \multirow{2}{*}{ Ambiente Natural } & Clima \\
\hline & & Topografia \\
\hline \multirow{7}{*}{ Institucionais } & \multirow{2}{*}{ Escola } & Tamanho, tipo e qualidade \\
\hline & & Currículo \\
\hline & \multirow{5}{*}{ Política } & Matérias e influências \\
\hline & & Planos de viagens para escolas \\
\hline & & Ônibus escolares institucionais \\
\hline & & Transporte casa-escola gratuito \\
\hline & & Escolha da escola \\
\hline
\end{tabular}

Fonte: Adaptado de Van-Ristell (2011).

A lista de Van-Ristell (2011) guiou a escolha dos indicadores. Dos atributos individuais, foram inseridas nos questionários para alunos questões sobre idade, gênero e turma. No questionário para pais, foram incluídas questões sobre idade do pai/responsável respondente, número de horas trabalhadas por quem acompanha o aluno na escola, número de automóveis, número de licenças para dirigir e presença de menores no domicílio. 
O questionário dos alunos não incluiu questões sobre características do domicílio do aluno. Porém, considerando a necessidade de incluir tais atributos no estudo, algumas informações foram inferidas por georreferenciamento, com base no endereçamento CEP, compatibilizado com a base de dados censitária (IBGE, 2010). Foram elas: i) a distância casa/escola; ii) a densidade na localidade de residência; iii) renda média domiciliar (proxy de renda, correspondente à média do setor censitário do CEP informado); iv) a disponibilidade de automóvel na residência (alternativo ao item do questionário dos pais). A seção 5.5.2 e Apêndice $\mathrm{J}$ descrevem mais detalhadamente a obtenção dessas variáveis. Não foram considerados relevantes os itens relativos ao grupo étnico e tipo de emprego.

Como o presente estudo não pretende comparar instituições entre si, mas, a partir das características de cada IEM, compreender como se dá a escolha modal em cada comunidade, os atributos institucionais, da vizinhança da escola e ambiente natural não foram incluídos no questionário, por se manterem constantes entre os indivíduos de uma mesma IEM. As características da vizinhança da escola, levantadas pelos indicadores descritos na Tabela 5.1, foram utilizadas apenas para a discussão dos resultados em cada IEM.

Na formatação final do questionário, os itens de composição das crenças e medidas diretas dos construtos da TCP tiveram ordem sorteada, mas foram agrupados por modo de transporte. O formato final do questionário incluiu uma página para cada modo considerado viável na etapa de grupos focais. Ao total, sete modos de transporte (A pé, Automóvel Carona, Transporte Escolar, Automóvel da Família, Metrô, Ônibus e Bicicleta), todos considerados viáveis pelos participantes dos grupos focais na etapa anterior, foram incluídos. A ordem de aparição de cada modo de transporte também foi sorteada na composição do questionário. Uma última seção (“todos os modos”) propunha uma avaliação de hábito, comportamento passado e variáveis sociodemográficas (como sugerido em Günther, 2003).

Para medir o hábito, foi utilizada a tradução livre da Medida de Resposta-Frequência do Hábito (Verplanken et al.,1994; Cristo, 2013). Cristo (2013) salienta que os itens da medida do hábito proposta por Verplanken et al. (1994) não são padronizados, devendo ser adaptados para cada contexto de pesquisa, neste caso, a rotina dos adolescentes. Para 
a medida do Comportamento Passado, foi utilizada a Medida de Frequência Auto Relatada do Comportamento Passado (Bamberg et al., 2003; Cristo, 2013).

Finalmente, a medida do comportamento atual observada foi obtida pelos itens que se referem ao modo de transporte usado pelo aluno para chegar na escola e o que ele pretenderia usar na volta para casa, no dia do preenchimento do questionário. A medida do comportamento atual ao mesmo tempo que a da intenção não é o procedimento indicado por Ajzen (2000). Entretanto, as mesmas dificuldades encontradas por Bamberg et al. (2003), que os levaram a adotar essa estratégia de coleta de dados, foram encontradas no presente estudo, justificando seguir a mesma estratégia.

Após a revisão linguística, os questionários foram organizados em versões para pais ou alunos. Um questionário piloto foi primeiramente submetido a seis especialistas em transportes e psicologia social. Em seguida, foi testado quanto à compreensão e organização das questões por três pares de pais e filhos em situação análoga à da pesquisa, mas não pertencentes à população alvo. As versões finais dos questionários para alunos e pais são apresentadas nos Apêndices H e I, respectivamente.

Os questionários para coleta da opinião dos pais/responsáveis foram distribuídos aos alunos em sala de aula, e recolhidos na semana seguinte, quando da aplicação dos questionários aos alunos em geral. No recolhimento foram pareados pais/responsáveis e alunos, pela inserção da numeração do questionário dos pais no questionário do aluno respectivo, e alocados na "amostra pareada" de pais e alunos. Os alunos que não trouxeram o questionário dos pais foram alocados na "amostra alunos geral".

Os questionários foram aplicados diretamente em sala de aula pela pesquisadora ou pesquisadores treinados para a aplicação. A apresentação do questionário incluía breve definição dos objetivos da pesquisa e a explicação de termos não tão familiares aos respondentes (como o verbo 'apoiar' utilizado nos itens normativos). A presença dos alunos em sala de aula facilitou a coleta da opinião dos alunos. O mesmo não aconteceu com os pais, sendo necessária uma intermediação da coordenação da escola para esta coleta, quando os questionários foram enviados aos pais em casa pelos alunos. Esta restrição levou a uma amostra menor de respondentes "alunos pareados" (pais e alunos) do que a coletada dos "alunos em geral". 
À medida que os questionários eram aplicados nas escolas, os procedimentos eram avaliados e adaptados. Na primeira IEM onde foram aplicados os questionários, foi solicitado aos alunos responderem sobre todos os sete modos de transporte do questionário. Observou-se, entretanto, que a pouca experiência dos respondentes com alguns modos levava a uma resistência em responder todo o questionário. Nem todos os alunos podiam ser considerados 'multimodais', ou seja, terem experimentado diferentes modos de transporte nas viagens a estudo e, por esta razão, não tinham opinião formada sobre todos os modos incluídos no questionário.

A partir dessa observação, foi solicitado tanto a pais quanto a alunos, que respondessem apenas sobre três modos de transporte: o que o aluno utilizava atualmente e sobre mais dois, sobre os quais soubesse opinar, positiva ou negativamente. Tal decisão facilitou a obtenção das respostas, tal como sugerido por Günther (2003).

Outra consideração na aplicação dos questionários foi quanto ao formato de pergunta dos itens psicológicos. Em geral, observou-se maior número de manifestações de dúvida sobre como responder as questões/itens que utilizaram a escala adjetiva bipolar como resposta, em relação ao uso da escala de concordância likert. A questão para medida de hábito também gerou dúvidas para os respondentes. Muitos tinham a intenção de responder de forma multimodal aos itens (como por exemplo, usar bicicleta e também o modo a pé para visitar amigos).

Uma possível interpretação para as dúvidas sobre como responder a medida do hábito é que, talvez, os respondentes não tenham sentido seu hábito devidamente representado ao escolher apenas um modo por atividade. A constatação dessas dificuldades na primeira IEM levou à apresentação de esclarecimentos adicionais na fase de apresentação do questionário em sala de aula nas outras escolas.

\subsubsection{OBTENÇÃO DAS VARIÁVEIS DERIVADAS DO ENDEREÇAMENTO}

As respostas dos questionários foram registradas em uma plataforma disponível na ferramenta eletrônica survey monkey, conforme a amostra "alunos geral" ou "pareados". Foi realizado o reordenamento dos itens, por crença/construto/modo de transporte, e obtidas as informações derivadas do CEP do respondente. 
Além das variáveis sociodemográficas informadas diretamente pelos respondentes, como gênero, idade, entre outras, interessava obter informações vinculadas à zona de residência do respondente. O endereço pelo CEP, cruzado com o setor censitário (IBGE, 2010), foi tratado para cada respondente em plataforma GIS - TransCAD 4.5 (Calliper, 2002) e obtidas: i) a distância casa/escola; ii) um proxy de renda, obtido pela informação da renda média familiar do setor censitário; iii) e a densidade da localidade de residência pelo setor censitário do CEP informado. A estratégia de compor a variável renda de forma indireta visou a facilitação da obtenção da informação, embora a obtenção deste proxy seja menos específica (e de menor poder explicativo das diferenças individuais).

Para a análise do modo Automóvel da Família, interessou apontar quais os prováveis respondentes não teriam acesso ao automóvel no domicílio. Como esta questão foi incluída apenas no questionário para os pais e/ou responsáveis, e o resultado da amostragem foi muito baixo, optou-se em obter a informação por um proxy. Esta informação foi obtida pelo cruzamento dos dados censitários de renda domiciliar por localidade (proxy variável RENDA), com os dados de acesso ao automóvel no domicílio por localidade, obtido nas pesquisas de amostragem domiciliar do DF e Região Metropolitana (CODEPLAN, 2014 e CODEPLAN, 2013 respectivamente). A lista e descrição das variáveis analisadas nas abordagens quantitativas para alunos e pais são apresentadas nos Apêndices J e K.

\subsubsection{TRATAMENTO PRELIMINAR DA BASE DE DADOS}

Composta a base de dados com as variáveis de interesse, foram realizados tratamentos preliminares, com uso dos aplicativos Excel (Microsoft, 2013) e IBM SPSS (IBM, 2012), com relação aos dados omissos (missings), dados extremos (outliers), e consistência interna dos itens (ver Tabela 5.3). Na observação dos casos omissos (missings), buscouse verificar se aconteciam ao acaso, ou sob algum viés de interpretação/forma de aplicação do questionário. O percentual de casos omissos foi mapeado por variável e por respondente.

Também foi verificado se existiam casos extremos (outliers), aqueles que possuem valor não usual, ou com características notadamente distintas das outras observações (Hair et al., 2009). Primeiramente, foi verificado se todas as respostas das variáveis quantitativas 
estariam dentro do intervalo de valores de respostas esperadas, por exemplo de 1 a 5 , quando respondidos em escala likert, de 1 a 5.

A análise multivariada dos casos extremos foi realizada pela medida de distância de Mahalanobis ( $\mathrm{D}^{2}$ de Mahalanobis). Esta estatística mede "a distância de cada observação em um espaço multidimensional a partir do centro médio de todas as observações, fornecendo um único valor para cada observação, independentemente do número de variáveis em questão" (Hair et al., 2009). A interpretação da distância de Mahalanobis é dada pela comparação de $\mathrm{D}^{2}$ dividida pelo número de variáveis envolvidas $\left(D^{2} / g l\right)$ ao " $\mathrm{z}$ " crítico, para o nível de significância $(\alpha)$ adotado.

Outro tratamento da base de dados foi avaliar a consistência interna dos itens, quando um determinado conceito, ou construto, é definido por vários itens, como a atitude, e a intenção. Segundo Pasqualli (2012), o teste alfa de Cronbach acima de 0,8 aponta uma boa consistência interna dos itens na formação do construto. Outros autores, como Maroco e Garcia-Marques (2006), aceitam valor a partir de 0,6.

Tabela 5.3: Tratamentos preliminares da base de dados

\begin{tabular}{ll}
\hline \multicolumn{1}{c}{ Ocorrência } & \multicolumn{1}{c}{ Tratamento } \\
\hline Casos Omissos - missings (quando acontecerem & por acaso). Identificar por respondente e variável. \\
\hline Nas VDs & -Eliminar registros com casos omissos ${ }^{* 1}$. \\
\hline <10\% dos registros em VIs & a) Eliminar registros com casos omissos, se n \\
& resultante for suficiente para análise $* 1$ \\
& b) Atribuir algum valor compatível com o estudo, \\
\hline $\mathbf{1 5 \%}$ dos registros em VIs & como a média da variável $* 1 * 2$. \\
\hline Casos extremos - outliers. Identificar registros e avaliar eliminação $* 1 * 2$. \\
\hline
\end{tabular}

Análise Univariada:

a) verificar se os registros estão dentro do intervalo esperado;

b) padronizar registros e comparar ao ' $\mathrm{z}$ ' crítico;

c) plotar em diagramas de caixa e identificar

-Eliminar registros com casos extremos. elementos em destaque.

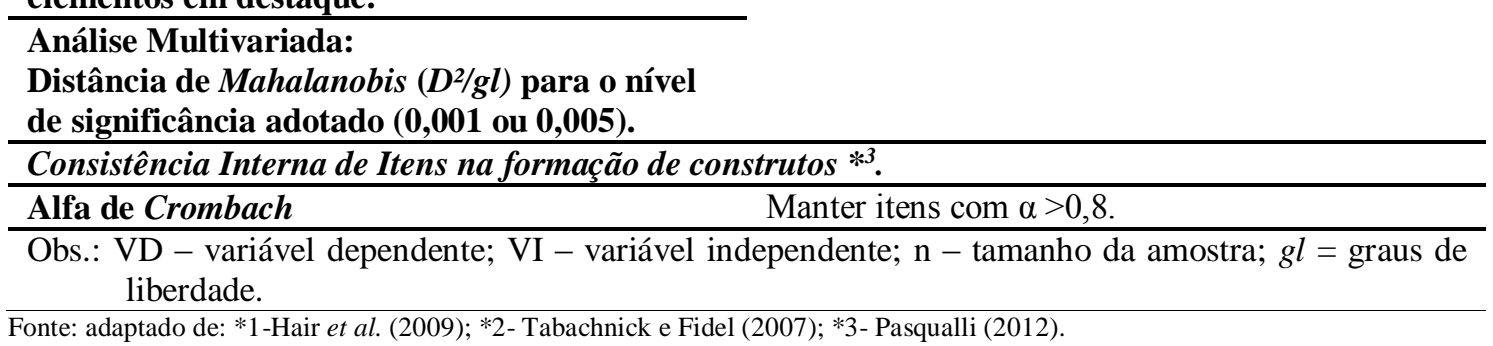




\subsubsection{ANÁLISES DAS INFORMAÇÕES}

A primeira análise de dados foi obtida pelo uso de estatísticas descritivas univariadas. De maneira mais global, procurou-se observar a distribuição proporcional das respostas das variáveis qualitativas e obter medidas representativas das variáveis quantitativas como a média, por exemplo. No caso dos itens medidos por escala bipolar e likert, por serem medidas ordinais foram utilizadas a moda e mediana (Günther, 2003). Para a análise das relações bivariadas entre a escolha modal e as variáveis sociodemográficas, foram elaboradas tabelas de frequência cruzada. Essas relações entre variáveis são indicativos interessantes sobre como a combinação de alguns atributos pode influenciar a escolha modal, por exemplo, a combinação de gênero, distância da escola/casa e a escolha de modos não motorizados.

Após a elaboração das estatísticas descritivas propostas, procedeu-se a uma síntese reflexiva dos resultados observados e as consequentes implicações sobre a escolha modal. Os resultados da abordagem quantitativa exploratória aplicada às IEMs participantes do estudo são apresentadas no Capítulo 6.

\subsection{ABORDAGEM QUANTITATIVA PREDITIVA}

O uso da teoria TCP como base para o estudo da escolha modal implica na investigação inferencial, além da análise exploratória. A condução de técnicas estatísticas de maior poder inferencial, como as modelagens multivariadas, traz grandes contribuições ao entendimento dos fenômenos envolvidos, bem como possibilita a realização de predições (Hair et al., 2009). A investigação inferencial possibilitou avaliar a importância/força das principais crenças salientes e dos construtos da teoria TCP na predição da intenção comportamental e do comportamento observado, bem como da interação de pais e alunos na definição do modo de transporte para ir ou voltar da IEM. Para a condução dessa investigação, levaram-se em conta os modelos teóricos apresentados no Capítulo 3, e as técnicas analíticas apresentadas no Capítulo 4.

\subsubsection{TESTES NA BASE DE DADOS}


Antes de prosseguir com as modelagens, testou-se a base de dados verificando os seguintes critérios: i) coerência do tamanho da amostra com o nível de probabilidade de acerto/erro; ii) e verificação dos pressupostos para análises multivariadas. Algumas técnicas multivariadas são mais rígidas com relação aos pressupostos que outras. Porém é a verificação da presença dos pressupostos que indicará a possibilidade de utilização de uma técnica multivariada ou não. Por exemplo, a não normalidade dos dados, e a heterocedasticidade, impede a utilização de modelos do tipo MRLM, de operacionalização mais popular na literatura. Quando ocorreu a não presença dos pressupostos específicos de cada modelo, foram empregadas modelagens alternativas, menos sensíveis aos pressupostos, como é o caso do MLG.

a) Nível de probabilidade - trata da definição dos níveis de probabilidade para os quais os resultados da pesquisa serão considerados significativos. Eles são relativos aos erros do tipo I $(\alpha)$, que é o risco de rejeitar a hipótese nula $\left(\mathrm{h}_{0}\right)$, quando ela é verdadeira, e do tipo II ( $\beta)$, que é o risco de aceitar a hipótese nula, quando ela é falsa. Como tradicionalmente utilizado em pesquisas de transporte (DNIT, 2006), definiu-se um $\alpha$ de $5 \%$, com grau de confiança de acerto de $95 \%$. Para $\beta$, foi adotado o valor de $20 \%$, com poder $(\beta-1)$ de $80 \%$ de acerto, conforme Hair et al. (2009). O controle da ocorrência de $\alpha$ e $\beta$ se dá pela confluência destes com o tamanho do efeito e o tamanho da amostra (n). O tamanho do efeito indica a discrepância esperada entre as hipóteses nula e alternativa, $\mathrm{h}_{0}$ e $\mathrm{h}_{1}$, respectivamente (Cohen, 1992). Cada estatística tem seu índice próprio de tamanho de efeito (Cohen, 1992). Segundo (Hair et al., 2009), a utilização de um tamanho de efeito médio a pequeno deve ser utilizada, se não houver uma clara definição do tamanho do efeito em questão. A Figura 5.2 apresenta as relações de tamanho da amostra, $\alpha$ e tamanho do efeito fixado em 0,35 e poder sugerido de 0,80 .

b) Teste do pressuposto de normalidade univariada e multivariada - refere-se à forma de distribuição dos dados para uma variável métrica individual e sua correspondência com a distribuição normal (Hair et al., 2009). Pode-se comparar a curtose e a assimetria dos dados observados com a distribuição normal, para avaliação das discrepâncias. Nem todas as análises multivariadas pressupõem distribuições normais. Quando este teste for relevante, como no caso dos Modelos 
de Regressão Linear Múltipla - MRLM, este pressuposto será considerado. A Tabela 5.4 apresenta os testes estatísticos uni variados de normalidade e seus critérios de aceitação para aproximação à distribuição normal. Os dois últimos testes são menos úteis para amostras pequenas (menos de 30 observações), e mais sensíveis para amostras grandes (que excedem 1000 observações). Nos gráficos de resíduos, a observação de não normalidade é indicada quando a maior parte

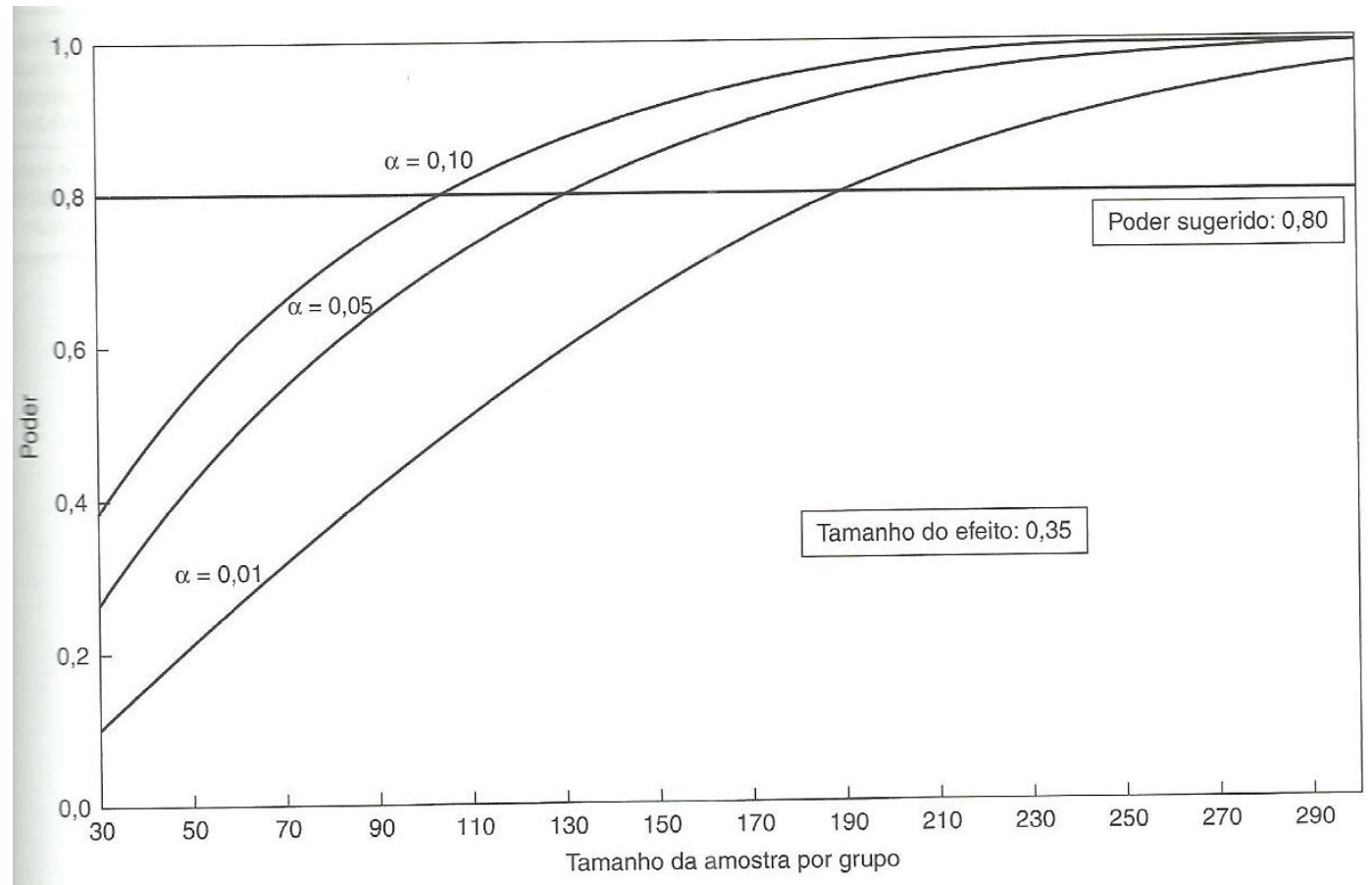

Figura 5.2: Impacto do tamanho da amostra sobre o poder para vários níveis de alfa $(0,01 ; 0,05 ; 0,10)$, com tamanho de efeito de 0,35 .

dos resíduos se concentra acima ou abaixo da linha de zero.

Fonte: Hair et al. (2009).

Tabela 5.4: Testes univariados para avaliação da normalidade

\begin{tabular}{l|cc}
\hline \multicolumn{1}{c}{ TESTE } & INDICADOR & CRITÉRIO \\
\hline Z ASSIMETRIA & $\frac{\text { assimetria }}{\sqrt{6 / n}}$ & $\begin{array}{c}\text { Comparar com z crítico para } \\
\alpha \text { definido. }\end{array}$ \\
\hline Z CURTOSE & $\frac{\text { curtose }}{\sqrt{24 / n}}$ & $\begin{array}{c}\text { Comparar com z crítico para } \\
\alpha \text { definido. }\end{array}$ \\
\hline SHAPIRO-WILK & $W=\frac{b^{2}}{\sum_{i=1}^{n}\left(x_{i}-\bar{x}\right)^{2}}$ & Tabela específica para $n$. \\
\hline $\begin{array}{l}\text { KOLMOGOROV- } \\
\text { SMIRNOV }\end{array}$ & $D=\max \left|F_{o}\left(X_{i}\right)-S_{n}\left(X_{i}\right)\right|$ & Tabela específica para $\alpha$ e $n$.
\end{tabular}

obs.: $\alpha$ - nível de significância; $\mathrm{n}$ - tamanho da amostra; $\mathrm{b}$ - constante a determinar a partir dos dados e tabela; $\mathrm{x}_{\mathrm{i}}$ - cada registro; $\overline{\boldsymbol{x}}$ - média amostral dos registros; $\mathrm{F}_{\mathrm{o}}\left(\mathrm{x}_{\mathrm{i}}\right)$ - proporção esperada de observações menores ou iguais a $x_{i} ; S_{n}\left(x_{i}\right)$ - distribuição de frequências relativas acumuladas observadas de uma amostra aleatória de $n$ observações.

Fonte: Adaptado de Shapiro e Wilk (1965); Siegel e Castellan (2006); Hair et al.(2009). 
c) Teste do pressuposto de linearidade - Este é um pressuposto importante quando se usa a correlação de Pearson (r) como parâmetro de avaliação de modelos, pois a correlação (r) só captura as relações lineares entre as variáveis (Tabachnick e Fidel, 2007). A linearidade é importante para os Modelos de Regressão Linear Múltipla MRLM, porém para outros não. O diagnóstico de não linearidade é dado através de métodos gráficos, como o gráfico de dispersão, para avaliar a linearidade entre pares de variáveis, e gráfico de resíduos. Nos primeiros, a linearidade é dada por uma nuvem aproximadamente oval de pontos.

d) Teste do pressuposto de homocedasticidade - A homocedasticidade trata da relação de dependência entre variáveis. Supõe que as variáveis dependentes exibam níveis iguais de variância ao longo do domínio das variáveis independentes. Esse conceito pode ser aplicado quando as variáveis independentes são métricas ou não (Hair et $a l$. , 2009). Geralmente, a heterocedasticidade (não homocedasticidade) é a consequência de não normalidade em uma ou mais variáveis do conjunto analisado. O teste de Levene é usado para medir a homocedasticidade por variável. Para avaliar a homocedasticidade na matriz de variância/covariância, o teste M de Box é aplicável. Tanto a correção da heterocedasticidade como da não normalidade são realizadas através da transformação de variáveis com verificação posterior do aprimoramento da previsão. As transformações podem ser a raiz quadrada, logaritmo, ou inverso. Estes tratamentos devem ser utilizados quando a técnica demandar o pressuposto de homocedasticidade.

e) Teste do pressuposto de ausência de erros correlacionados - os erros de previsão são encontrados na maioria das modelagens. Geralmente ocorre pela não inclusão no modelo de algum elemento causal. "A tarefa chave do pesquisador não é propriamente a ação corretiva, mas a identificação do efeito não especificado e um meio de representá-lo na análise" (Hair et al., 2009). As técnicas tradicionais de modelagem multivariada como o MRLM são incapazes de acessar ou corrigir os erros de medida. Já os Modelos de Equações Estruturais provêm explicitamente estimações dos parâmetros de variância dos erros (Byrne, 2010).

f) Teste do pressuposto de ausência de singularidade e multicolinearidade - a singularidade indica não haver nenhuma correlação entre a variável dependente e 
as variáveis independentes, o que não é desejável para a regressão. Já a multicolinearidade indica a correlação entre variáveis independentes. Quando ela é alta, pode modificar ou inflacionar os coeficientes, indicando grandes valores de erro padrão (Tabachnick e Fidel, 2007). Para algumas técnicas, a singularidade é pressuposto, porém, como no exemplo da análise fatorial, é desejável a existência de correlações entre as variáveis. Normalmente se calcula a raiz do valor de inflação da variância - VIF para estimar o grau em que o erro padrão aumentou devido à multicolinearidade. A ação corretiva mais comum é deletar uma variável altamente correlacionada ( $\mathrm{r}>$ que 0,80 - Bisquera et al., 2004) com outra, pois seu efeito já está capturado por outra variável.

\subsubsection{MODELAGENS}

Na Teoria do Comportamento Planejado - TCP, pelo menos três análises são relevantes. Elas visam identificar: i) Análise exploratória das crenças - verificando como as crenças determinam os construtos da TCP - Atitude, Norma Social e Controle Percebido do Comportamento; ii) Modelagem da intenção - verificando como os construtos da TCP determinam a intenção comportamental; iii) Modelagem do comportamento - verificando como o controle percebido e a intenção determinam o comportamento atual.

$\mathrm{Na}$ modelagem da intenção, optou-se por incluir variáveis sociodemográficas como variáveis explicativas, bem como medidas do comportamento passado e hábito, apresentado na Figura 3.2. Quando observado que algum grupo dessas variáveis não seja significativo na explicação da intenção, tais grupos foram testados também na relação com o comportamento, como em Bamberg et al. (2003). Nas três modelagens referidas, crenças, intenção e comportamento, apenas a opinião dos alunos foi considerada. Para o teste de uma das hipóteses da pesquisa foi definido um quarto tipo de modelagem, que propõe a consideração conjunta da opinião de pais e filhos na intenção e comportamento por modo de transporte.

a) Análise exploratória das crenças

É esperado que conjuntos de determinadas crenças sejam antecedentes dos construtos da TCP. Na maior parte dos estudos que relacionam crenças a construtos da TCP, a 
categorização das crenças em relação aos construtos que deveria representar é feita intuitivamente (Kamargianni et al., 2015), ou previamente à elaboração do instrumento de medida dos construtos. De fato, a orientação em Ajzen (2000) é o uso de exemplos intuitivos na formulação das crenças por construto. Para verificar a validade da categorização intuitiva proposta por Ajzen (2000), uma análise fatorial exploratória foi conduzida entre todas as crenças na formulação de fatores gerais e comparada à categorização intuitiva proposta. As crenças foram analisadas para cada modo envolvido no estudo.

Na etapa de abordagem qualitativa, cada afirmativa de crença, foi medida em escala likert (discordo totalmente - concordo plenamente), ou adjetiva bipolar (bom/ruim; agradável/desagradável; etc.), com duas medidas para cada crença: do objeto, conteúdo da crença, ou crença sobre o objeto (belief - $b$ ) e a avaliação dos atributos do objeto, ou força da crença (evaluation - $e$ ). A relação das crenças salientes obtidas nos grupos focais com os construtos da TCP, foi testada numa segunda análise, através de modelos lineares.

A Equação 5.1 representa a forma funcional esperada a partir de um Modelo de Regressão Linear Múltipla - MRLM. O mesmo modelo, caso não confirmado os pressupostos do MRLM, deverá ser modelado por MLG, pela quase verossimilhança.

$$
\text { Construto }=\sum\left(b_{i}+e_{i}+b i * e_{i}\right)+\varepsilon_{i}
$$

O modelo da Equação 5.1 foi elaborado a partir dos resultados do trabalho de Elliott et al.(2005), referido no Capítulo 3, para a verificação da relação das variáveis independentes, cada medida de crença $\left(b_{i}\right.$ e $\left.e_{i}\right)$ e os componentes multiplicados das crenças $\left(b_{i} X e_{i}\right)$, com as variáveis independentes - cada construto da TCP - Atitude, Norma Social e Controle Percebido do Comportamento. O objetivo desta análise é verificar se: i) primeiramente uma relação funcional entre os construtos da TCP e as crenças salientes obtidas nos grupos focais; ii) se existem diferenças significativas entre o uso do objeto da crença puro (item $b_{i}$ ), o uso das forças das crenças (item $e_{i}$ ), ou multiplicativo entre elas (Teoria da Expectância).

Nos modelos das relações entre crenças e construtos, os construtos da TCP assumiram os valores correspondentes à média dos escores obtidos nas respostas aos itens do 
questionário ligados a cada variável (itens de medida direta). Essa abordagem é proposta por Fishbein e Ajzen (1975), e vem sendo adotada em diferentes estudos ligados à TCP (por exemplo, Elliott et al., 2003). Para as variáveis de crença, cada valor de crença (b) e da força da crença (e) foi centralizado, ou seja, cada resposta de $b$ ou de $e$ foi transformada, diminuída da média da variável. A transformação das variáveis (rescaling) relativas às crenças não tem efeito nas propriedades correlacionais desejadas para a regressão proposta, porém evita o aporte de altos níveis de multicolinearidade à regressão por causa do termo de interação (Aiken e West, 1991).

A busca por um melhor modelo utilizou o método de modelagem em passos tipo backwards, sendo que o critério de exclusão das variáveis segue dois critérios: i) o nível de probabilidade associada a cada crença, eliminando-se uma a uma, hierarquicamente pelo maior valor de p-valor; ii) manter nos modelos apenas os itens, ou conjunto de itens que contenham o item de conteúdo da crença $\left(\right.$ item $b_{i}$ ). Por exemplo, foi observado que o item ONCCO2, não teve seu correspondente item ONCCE2 incluído no questionário, por erro de revisão do questionário. Nas análises de crença o item ONCCO2 foi eliminado. Da mesma forma, nas modelagens que apresentarem como significativos apenas os itens da força da crença (itens do tipo $e_{i}$ ), ou o item multiplicativo (itens tipo $b_{i} \times e_{i}$ ), estas crenças serão eliminadas da análise. Por fim, a teoria da expectância, por si só, deve ser testada na sua relação com os construtos da TCP, segundo os mesmos critérios de modelagem e ajustes de modelo.

b) Modelagem da intenção comportamental

Segundo a teoria da TCP, a intenção é a variável latente diretamente determinada pela atitude, norma social e percepção de controle, e o antecedente direto do comportamento. Quanto maior a intenção em escolher determinado modo, maior a probabilidade de efetivar esta escolha - comportamento, e vice versa. As intervenções baseadas na intenção são bem referenciadas na literatura e utilizam o planejamento de viagem como forma de motivar a implementação da intenção (Gärling e Fujii, 2002).

A modelagem da intenção pretende ser tratada de duas formas: i) a primeira deve testar se é aplicável o modelo MRLM (ou MLG, caso os pressupostos do MRLM não sejam confirmados), onde as variáveis psicológicas serão representadas pela média dos seus 
itens de medida direta, não deliberadamente como uma variável latente; ii) e por Modelos de Equações Estruturais - MEE, por Análise Fatorial Confirmatória, com especificações detalhadas no Capítulo 4. O objetivo é testar se as duas modelagens conseguem produzir modelos significativos, com resultados semelhantes. Os aplicativos utilizados nas modelagens da intenção foram o "R" e o AMOS (IBM SPSS, 2011), respectivamente.

São propostos modelos para permitir a análise da relação da intenção (variável dependente) com diferentes grupos de variáveis explicativas. São eles: i) todo o conjunto de crenças estudadas; ii) medidas diretas da TCP (atitude, norma social e controle percebido); iii) variáveis sociodemográficas, hábito e comportamento passado. Como a estrutura da modelagem da intenção é tipicamente um modelo de variável latente (a intenção não é observada diretamente, mas através de indicadores), os modelos que modelarem a intenção considerando-a como latente, e cumprindo demais pressupostos da modelagem, serão preferíveis.

c) Modelagem do comportamento

O tipo da variável de medida do comportamento, variável nominal ou categórica, indica que outro grupo de modelagem deve ser utilizado: o grupo de Modelos de Escolhas Discretas - MEDs. Como parte da explicação esperada do comportamento, neste caso a escolha modal nas viagens escolares, é testada a influência dada pelos atributos psicossociais, considerados variáveis latentes por não serem medidos diretamente, a modelagem do comportamento deve envolver uma técnica de modelagem com variáveis latentes integradas ao modelo de escolhas discreta.

A calibração desses modelos requer recursos computacionais relativamente sofisticados para serem utilizados em aplicações práticas, como o procedimento proposto, e, sobretudo, amostra com grande número de observações, incompatível com o porte da maioria das IEMs em Brasília (Brasil, 2013), onde será aplicado o procedimento proposto. Assim, inicialmente, para o estudo do comportamento da escolha modal em uma dada IEM, buscou-se utilizar modelos de estimação sequencial, com a inserção das variáveis psicossociais através das variáveis compostas pelas médias dos itens de medida direta dos construtos, como descrito na seção 4.6 e Figura 4.5 Este tipo de modelagem foi considerado o segundo melhor modelo, atrás apenas dos modelos ICLV, para a 
modelagem de variáveis latentes integrada a modelos de escolha discreta (BahamondeBirke e Ortúzar, 2014).

Para a modelagem do comportamento, a variável dependente toma a forma de variável binária ("1" se escolher o modo e "0" se escolher outro), com modelos separados para a ida ou para a volta. A modelagem é um logit binomial, com o uso da modelagem do tipo hierárquica (como utilizada por Elliott et al., 2005) a ser desenvolvida para cada modo de transporte em particular: i) modelo 1 - a relação da escolha ou não de determinado modo com as médias das medidas diretas dos construtos da TCP, intenção e controle percebido; ii) modelo 2 - acrescentando ao modelo 1 as variáveis sociodemográficas; iii) modelo 3 - acrescentando ao modelo 2 a medida do hábito e o comportamento passado. O aplicativo utilizado para essas modelagens foi o BIOGEME.

d) Modelagem integrada

Dependendo do tamanho da amostra disponível e do acesso às ferramentas computacionais adequadas, deve-se utilizar uma quarta modelagem - Modelagem integrada, integrando os construtos da TCP, intenção e comportamento, através da modelagem por ICLV. Ao invés de se fazer modelagens separadas para os construtos da TCP, a modelagem integrada é um procedimento que pretende diminuir os erros estimados, se comparada às modelagens parciais (AmirAlavifar e Anuar, 2012). Kamargianni et al. (2015) considerou a Modelagem Integrada de Escolha e Variável Latente (Integration of Choice and Latent Variable - ICLV) superior às demais modelagens, por modelar explicitamente o modelo probabilístico de escolha integrado ao modelo de variável latente. Através de uma modelagem integrada espera-se inferir sobre um provável modelo integrado composto pelas variáveis significativas observadas nas modelagens parciais ("b" e "c"). Caso não seja viabilizada a modelagem integrada, a modelagem sequencial (Figura 4.5 na seção 4.7) deve ser utilizada.

e) Modelagem da interação entre pais e alunos.

Até aqui, todas as modelagens se concentraram na opinião dos alunos sobre a escolha modal. A modelagem da interação entre pais e alunos pretende investigar a hipótese complementar do trabalho, em que a decisão pelo modo de transporte para as viagens 
escolares não é uma decisão exclusiva do aluno. As restrições para a repetição das modelagens anteriores ("b" a "d") para as opiniões pareadas entre alunos e seus respectivos pais são a pequena amostra de opiniões pareadas obtida em todas IEMs participantes e apenas para alguns modos. Como apresentado na Figura 3.3, apenas o efeito da intenção comportamental e do controle percebido dos alunos e pais/responsáveis sobre o comportamento observado foi modelado, considerando uma amostra mínima de 26 respondentes, e apenas para os modos Automóvel da Família e Ônibus. O teste da hipótese da interação da opinião sobre a decisão modal entre pais e alunos foi testado à semelhança da modelagem do comportamento (item c).

\subsection{PROCEDIMENTO PROPOSTO}

A partir das etapas metodológicas realizadas com sucesso pode-se construir um procedimento para a identificação dos atributos intervenientes no comportamento de escolha modal nas viagens escolares em Instituições de Ensino Médio. Isto é, o objetivo da tese pode ser alcançado. A Figura 5.3 apresenta o conjunto de etapas integrantes do procedimento proposto.

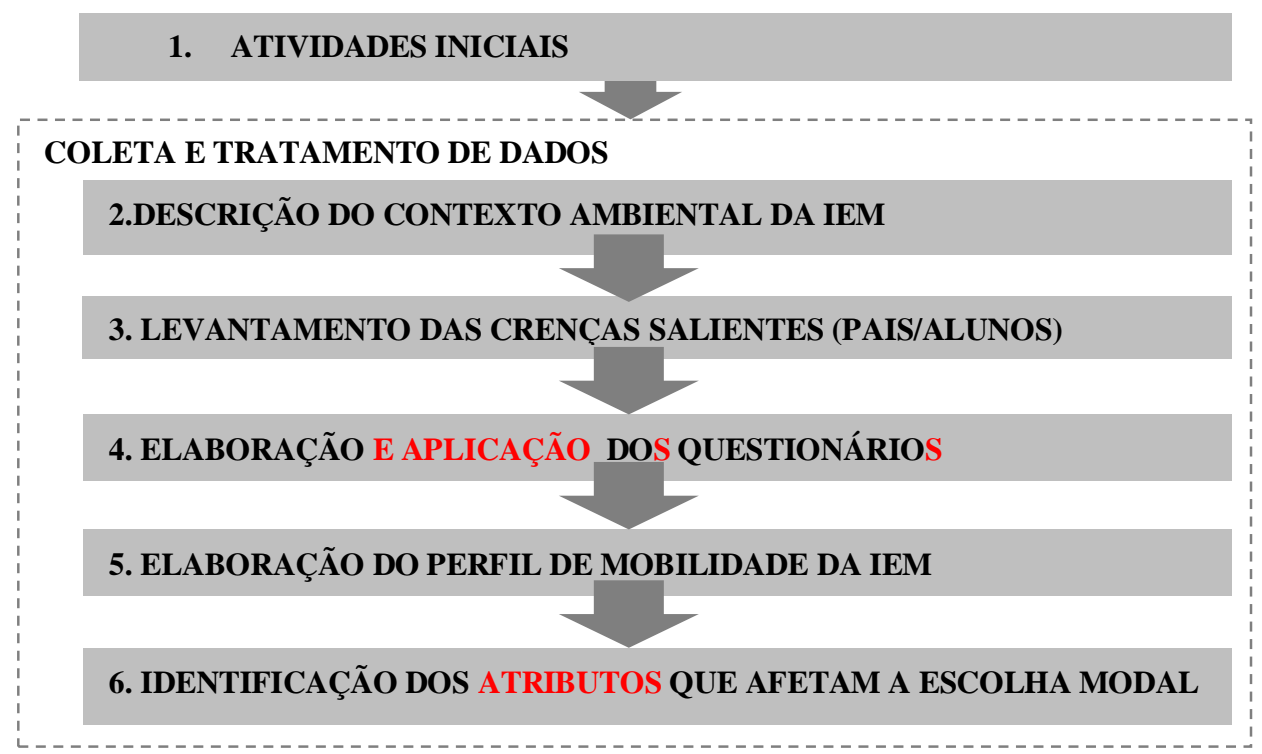

Figura 5.3: Estrutura do procedimento proposto.

As seções a seguir sintetizam cada etapa do procedimento proposto. Para a realização das Etapas 1 a 6 são definidos os instrumentos indicados na Tabela 5.5. A aplicação do procedimento nas três IEMs participantes da pesquisa, especificamente das Etapas 1 a 6, 
é apresentada nos Capítulos 6 e 7. As conclusões da pesquisa e os desdobramentos para pesquisas futuras são apresentados no Capítulo 8.

Tabela 5.5: Instrumentos desenvolvidos para a aplicação do procedimento

\begin{tabular}{clc}
\hline Etapa & \multicolumn{1}{c}{ Instrumento } & Apêndice \\
\hline $\mathbf{0 1}$ & Termos TCLE & $\mathrm{B}$ \\
\hline $\mathbf{0 1}$ & Questionário institucional & $\mathrm{C}$ \\
\hline $\mathbf{0 2}$ & Roteiro para avaliação do contexto físico das IEMs & $\mathrm{D}$ \\
\hline $\mathbf{0 3}$ & Questionário para pais - grupos focais & $\mathrm{E}$ \\
\hline $\mathbf{0 3}$ & Protocolo grupos focais & $\mathrm{F}$ \\
\hline $\mathbf{0 3}$ & Questionário para alunos - grupos focais & $\mathrm{G}$ \\
\hline $\mathbf{0 5}$ & Modelo de questionário para alunos - etapa quantitativa & $\mathrm{H}$ \\
\hline $\mathbf{0 5}$ & Modelo de questionário para pais - etapa quantitativa & $\mathrm{I}$ \\
\hline
\end{tabular}

\subsubsection{ETAPA 1 - ATIVIDADES INICIAIS}

Inclui a elaboração do escopo de pesquisa e seus objetivos, bem como a revisão ética. Os Termos de Consentimento Livre e Esclarecido - TCLE apresentados no Apêndice B são modelos dos termos utilizados na presente pesquisa. Eles devem ser adaptados de acordo com as exigências do Comitê de Ética da região da IEM.

\subsubsection{ETAPA 2 - DESCRIÇÃO DO CONTEXTO AMBIENTAL DA IEM}

Levantar os aspectos gerais da IEM e realizar a descrição do ambiente relacionado às viagens estudadas. O questionário Institucional (Apêndice $\mathrm{C}$ ) deve ser usado como guia. Recomenda-se o levantamento dos indicadores apresentados na Tabela 5.1, conforme instrumento "Roteiro para a avaliação do contexto físico", apresentado no Apêndice D.

\subsubsection{ETAPA 3 - LEVANTAMENTO DAS CRENÇAS SALIENTES}

Levantar elenco de crenças salientes para pais e alunos para cada modo de transporte considerado viável pelo grupo para realização das viagens escolares. Recomenda-se o uso da técnica de grupos focais (Ver Apêndices E, F e G). Uma análise de conteúdo deve sintetizar as opiniões mais frequentes para cada modo viável. O formato final do relato é um elenco de afirmativas de crenças. Cada afirmativa de crença por modo deve originar dois itens (objeto de crença e força da crença), para integrar escala de concordância likert, ou uma escala bipolar adjetiva. 


\subsubsection{ETAPA 4 - ELABORAÇÃO E APLICAÇÃO DO QUESTIONÁRIO}

Elaborar de um instrumento que permita a devida coleta dos dados necessários ao estudo, e os esforços para uma aplicação do questionário que favoreça a qualidade dos dados coletados, garantirá a aplicação das técnicas analíticas propostas nas próximas etapas. A aplicação do procedimento em outras IEMs deve prever as adaptações dos instrumentos dos Apêndices H e I, incluindo três grandes seções. A primeira seção do questionário, sua capa, deve conter: i) a apresentação sucinta da pesquisa e termo de consentimento TCLE; ii) numeração ou codificação do respondente, para o questionário de pais/responsáveis, e espaço para copiar essa numeração/codificação no questionário do aluno, iii) orientações gerais para responder o questionário; iv) anotação de concordância com o TCLE; e v) apenas no questionário dos pais, espaço para informar a data e local para devolução do questionário dos pais/responsável.

$\mathrm{Na}$ segunda seção, cada página deve agrupar as questões por modo. As questões pertencem a três grandes grupos: i) questões relativas às crenças, agrupadas conforme o tipo de escala de resposta (likert, ou adjetiva bipolar; ii) questões referentes às medidas diretas dos construtos, conforme a redação traduzida e testada no presente estudo e apresentada nos Apêndices K e L; iii) questões referentes ao hábito, comportamento passado, sobre a escolha do modo, com diferenciação para viagem de ida ou volta, e desejo e opção de mudança de modo, e sociodemográficas. A redação deve ser a mesma apresentada nos Apêndices K e L, mas coerentes com os modos considerados viáveis. Dentro de cada conjunto os itens devem ter ordem sorteada aleatoriamente. O texto final do questionário deve conter um agradecimento à participação do respondente.

\subsubsection{ETAPA 5 - ELABORAÇÃO DO PERFIL DE MOBILIDADE DA ESCOLA}

Inclui a coleta de dados sobre a mobilidade da comunidade escolar por questionários direcionados a pais/responsáveis e alunos, desenvolvidos na etapa anterior. O tratamento da base de dados e as análises estatísticas descritivas das escolhas modais devem salientar as características mais frequentes, bem como opiniões salientes de pais/responsáveis e alunos. Para efeito de caracterização do perfil de mobilidade da escola, são relevantes as análises dos seguintes itens: partição modal; distâncias médias entre casa/escola; considerações sobre as características sociodemográficas e as escolhas modais; 
considerações sobre opiniões positivas e negativas mais representativas da amostra (frequência, moda, mediana) sobre cada modo de transporte.

\subsubsection{ETAPA 6 - IDENTIFICAÇÃO DOS ATRIBUTOS QUE AFETAM A ESCOLHA MODAL}

Identificar, por meio de diferentes técnicas de modelagem, os principais atributos que afetam a escolha modal, incluindo: i) testes nas bases de dados; ii) testes dos pressupostos das modelagens; iii) grupos de modelos apenas para estudar a opinião de alunos (análise exploratória das crenças, intenção e comportamento, e análise integrada quando a amostra for suficiente para atender os pressupostos do método); iv) grupo de modelos para estudar a opinião pareada entre pais e alunos. A etapa é finalizada com uma discussão dos resultados comparada à literatura revisada, considerando a evolução dos comportamentos estudados. Os modelos a serem desenvolvidos, com as respectivas técnicas de modelagem e propósitos específicos, são apresentados na Tabela 5.6.

Tabela 5.6: Técnicas de modelagem por grupo e propósito.

\begin{tabular}{|c|c|c|c|}
\hline \multicolumn{2}{|c|}{ Grupo } & Propósito & Técnica \\
\hline \multirow{3}{*}{$\begin{array}{c}\text { Opinião de } \\
\text { alunos em geral }\end{array}$} & Crenças & $\begin{array}{l}\text { Identificar crenças significativas aos construtos } \\
\text { TCP, envolvidos na escolha modal. }\end{array}$ & $\begin{array}{l}\text { MRLM/ } \\
\text { MLG }\end{array}$ \\
\hline & Intenção & $\begin{array}{l}\text { Identificar construtos da TCP significativos na } \\
\text { intenção, envolvidos na escolha modal, } \\
\text { incluindo variáveis sociodemográficas, hábito e } \\
\text { comportamento passado. }\end{array}$ & $\begin{array}{l}\text { MEE/ } \\
\text { MRLM/ } \\
\text { MLG }\end{array}$ \\
\hline & Comportamento & $\begin{array}{l}\text { Identificar o efeito da intenção e controle } \\
\text { percebido no comportamento; }\end{array}$ & SEQ/ICLV \\
\hline $\begin{array}{c}\text { Opinião pareada } \\
\text { pais e alunos }\end{array}$ & Comportamento & $\begin{array}{l}\text { Identificar o efeito conjunto da intenção e } \\
\text { controle percebido de pais e alunos no } \\
\text { comportamento; }\end{array}$ & SEQ \\
\hline \multicolumn{4}{|c|}{$\begin{array}{l}\text { Obs.: TCP - Teoria do Comportamento Planejado; MRLM - Modelo de Regressão Linear Múltipla; } \\
\text { MLG - Modelo Linear Generalizado; MEE - Modelo de Equações Estruturais; SEQ - Estimação } \\
\text { integrada sequencial da Análise Fatorial e MNL (Modelo logit Multinomial); ICLV - Modelo } \\
\text { Integrado de escolha e variável latente. }\end{array}$} \\
\hline
\end{tabular}

O fluxograma da Figura 5.4 mostra as atividades gerais a serem realizadas no processo de modelagem para os diferentes propósitos, aplicáveis aos dois grupos amostrais, para a identificação dos atributos intervenientes na escolha modal. 


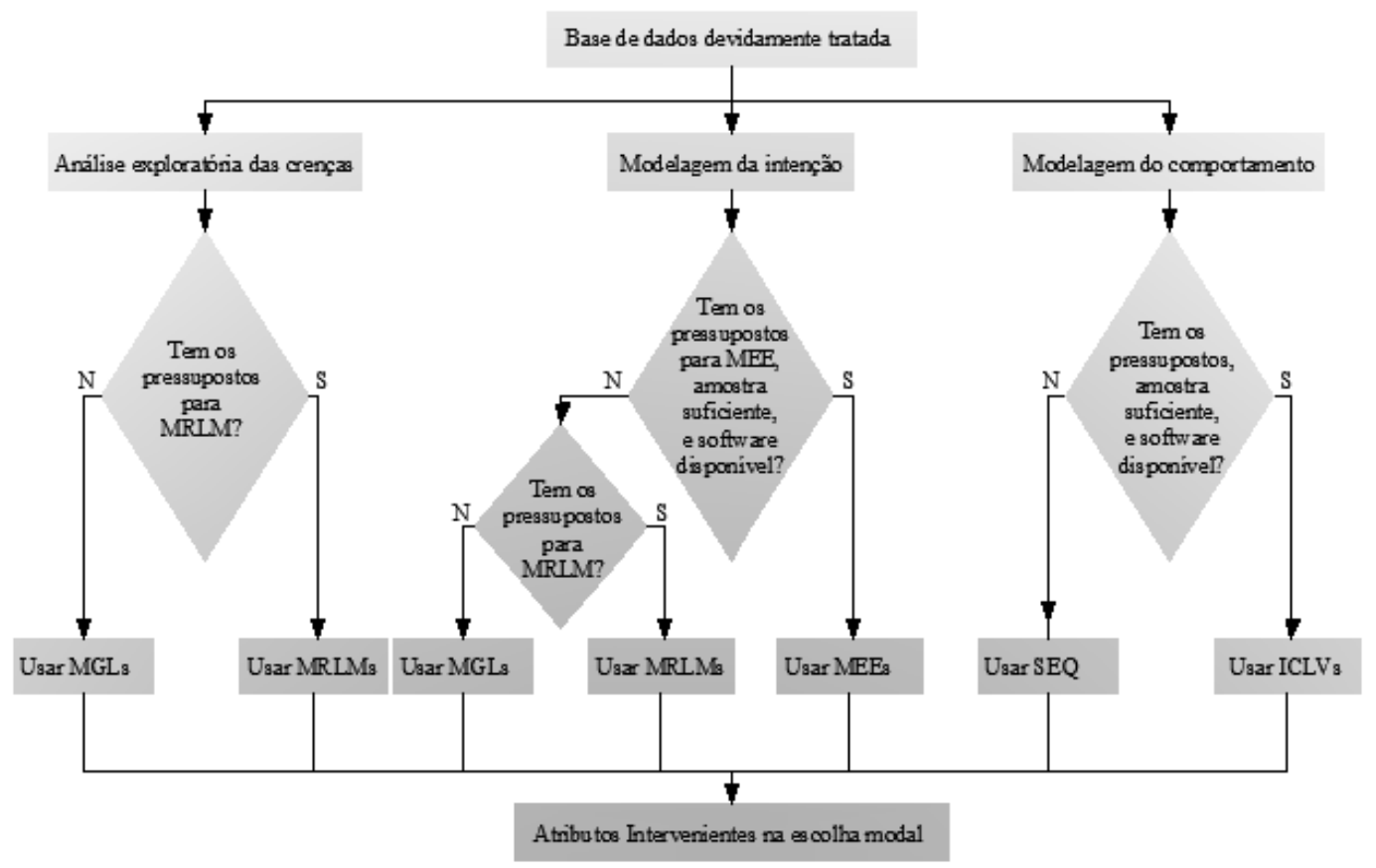

Figura 5.4: Fluxograma das atividades da Etapa 6

\subsection{TÓPICOS CONCLUSIVOS}

A proposta para o estudo do fenômeno da escolha modal nas viagens de e para a escola prevê que esse fenômeno seja investigado em profundidade quanto às motivações para a realização das escolhas modais por meio de testes estatísticos/ teóricos. Porém, pretende ser flexível o suficiente para se adaptar às peculiaridades das IEMs (como matrículas por turno, turnos de aulas, se pública ou privada, localizada em área periférica, rural, ou central), e eficaz para subsidiar proposições viáveis. O procedimento considera cada comunidade escolar uma população definida, com crenças e atributos próprios, e os resultados obtidos pelo procedimento são válidos para cada comunidade. Eles são importantes para fundamentar as estratégias a serem incluídas em futuros PGMs para essas comunidades. A utilização dos resultados para análises agregadas deverá considerar as possíveis diferenças entre as IEMs envolvidas, e o impacto dessas diferenças nos resultados correspondentes.

Uma das maiores barreiras à aplicação do procedimento proposto é a obtenção de tamanhos da amostra suficientes para as modelagens propostas, principalmente de pais interessados. Num contexto de baixo envolvimento/motivação com o tema, a etapa que envolve grupos focais pode ser a primeira ou única fonte de informações sobre a 
mobilidade local. Por isso, esta etapa deve ter realização cuidadosa. Seus resultados já podem indicar sugestões valiosas para subsidiar Programas de Gerenciamento da Mobilidade - PGMs para a comunidade escolar.

As etapas quantitativas se destinam a prover informações mais específicas do que as obtidas nas etapas qualitativas. Sendo essas informações adequadas à população alvo, a sua obtenção aumenta a probabilidade de adesão aos futuros PGMs. O uso das técnicas de modelagem fornece a precisão necessária aos resultados obtidos, mas nem sempre essas técnicas estão acessíveis aos proponentes dos estudos da escolha modal. O desafio de facilitar a obtenção das respostas, tal como sugerido por Günther (2003), deve ser um objetivo a ser seguido na aplicação do procedimento. Sugere-se que a modelagem se paute pela parcimônia, optando-se, quando possível, por modelagens mais simplificadas, ou de maior facilidade de interpretação, e operacionalizadas por programas estatísticos computacionais gratuitos.

O procedimento proposto neste capítulo foi aplicado em três IEMs em Brasília. Os resultados obtidos e as discussões decorrentes dessas aplicações são apresentados nos próximos dois capítulos, Capítulo 6 e 7, para efeito de facilitar a leitura. As conclusões são apresentadas no Capítulo 8. A organização dos capítulos segue a sistematização das etapas do procedimento proposto. 


\section{APLICAÇÃO DO PROCEDIMENTO - PARTE 1}

O procedimento proposto na seção 5.7 do Capítulo 5 contém seis etapas que pretendem ser passíveis de reprodução em estudos semelhantes sobre a escolha modal em IEMs. No presente capítulo, serão apresentados os resultados da aplicação do procedimento em IEMs em Brasília para as Etapas 1 a 5, referidas na Figura 5.3, enquanto no Capítulo 7, os resultados para a Etapa 6. A forma de aplicação das etapas do procedimento nas IEMs participantes é sintetizada na Tabela 6.1. Os resultados e discussões são relatados em sequência por etapas do procedimento, para todas as IEMs participantes e para todos os modos estudados. A não participação da IEM PR 1 na aplicação da Etapa 6 será explicada na seção 6.5.1.

Tabela 6.1: Participação das IEMs de Brasília na aplicação das etapas do procedimento

\begin{tabular}{|c|c|c|c|}
\hline & IEM PU 1 & IEM PU 2 & IEM PR1 \\
\hline $\begin{array}{l}\text { ETAPA } 1 \\
\text { ATIVIDADES INICIAIS }\end{array}$ & Sim & Sim & Sim \\
\hline $\begin{array}{l}\text { ETAPA } 2 \\
\text { DESCRIÇÃO DO CONTEXTO } \\
\text { AMBIENTAL DA IEM }\end{array}$ & Sim & Sim & Sim \\
\hline $\begin{array}{l}\text { ETAPA } 3 \\
\text { LEVANTAMENTO DAS CRENÇAS } \\
\text { SALIENTES }\end{array}$ & Sim & Sim & Sim \\
\hline $\begin{array}{l}\text { ETAPA } 4 \\
\text { ELABORAÇÃO E APLICAÇÃO DOS } \\
\text { QUESTIONÁRIOS }\end{array}$ & \multicolumn{3}{|c|}{ Todas as IEMs em conjunto } \\
\hline $\begin{array}{l}\text { ETAPA } 5 \\
\text { ELABORAÇÃO DO PERFIL DE } \\
\text { MOBILIDADE DA IEM }\end{array}$ & Sim & Sim & Sim \\
\hline $\begin{array}{l}\text { ETAPA } 6 \\
\text { IDENTIFICAÇÃO DOS ATRIBUTOS QUE } \\
\text { AFETAM A ESCOLHA MODAL }\end{array}$ & Sim & Sim & Não \\
\hline
\end{tabular}

\subsection{ETAPA 1 - ATIVIDADES INICIAIS}

Pressupondo que o caráter da Instituição de Ensino Médio - IEM, se público ou privado, poderia interferir na divisão modal observada entre os usuários típicos das IEMs, foi proposto que a pesquisa incluísse tanto IEMs públicas, quanto privadas (Bertazzo e Jacques, 2010). A localização geográfica das IEMs incluídas na pesquisa foi definida como a região do Plano Piloto de Brasília, com 39 instituições com oferta exclusiva ou compartilhada de ensino médio (Brasil, 2013). 
A Rede Escolar Pública Estadual no DF é organizada pela Secretaria de Estado de Ensino em Regionais, que são áreas geográficas de mesma coordenação administrativa das unidades escolares. A Regional do Plano Piloto e Cruzeiro integra todas as unidades públicas ofertantes de ensino médio, totalizando 05 (cinco) Centros de Ensino Médio CEM (oferta exclusiva de ensino médio) e 03 (três) estabelecimentos com oferta compartilhada com ensino fundamental, com matrículas, em dezembro de 2013, de 8.339 alunos (Brasil, 2013). A rede privada é bem maior em número de unidades escolares, incluindo 31 estabelecimentos, sendo que apenas 02 (dois) IEM/campi oferecem exclusivamente o ensino médio. Em dezembro de 2013, as matrículas na rede privada eram de 10.112 alunos (Brasil, 2013). Para integrar a pesquisa foram convidadas por email todas as IEMs do DF cadastradas no censo escolar (Brasil, 2013).

O projeto de pesquisa foi aprovado junto à Secretaria de Estado de Educação para a aplicação junto às IEMs públicas. Também foi encaminhado ao Comitê de Ética em Pesquisa, do Instituto de Ciências Humanas da Universidade de Brasília, para revisão ética, já que se tratava de pesquisa com menores de 18 anos. Na revisão ética, ficaram pendentes os termos de aceite condicionado das IEMs a serem fornecidos pelas direções das IEMs participantes. De todas as IEMs convidadas, oito direções de IEMS manifestaram interesse prévio, e foram visitadas para promoção e condução da pesquisa junto à comunidade escolar. Dessas, apenas três firmaram o aceite condicional, necessário à aprovação da pesquisa pelo Comitê de Ética em Pesquisa, participando das demais etapas propostas da presente pesquisa.

Quanto ao tipo de escola, duas IEMs participantes são públicas e uma é privada. De modo a preservar a identidade das IEMs participantes, neste documento elas serão referidas apenas pelos códigos IEM PU 1 e IEM PU 2 para as duas IEMs públicas, e IEM PR 01 para a IEM privada participante.

A princípio, a escolha das IEMs para integrar a pesquisa foi guiada apenas pela inclusão de IEMs públicas e privadas, localizadas na região do Plano Piloto em Brasília - DF. Nesta Etapa, o maior esforço e tempo foi gasto com a aprovação ética, cuja aprovação implicava nos aceites condicionais de cada instituição que se dispusesse preliminarmente a participar. Como os resultados da aplicação do procedimento são específicos e de interesse de cada comunidade escolar, recomenda-se que, ao aplicar o procedimento, os 
proponentes dos estudos devam obter os aceites éticos condicionados de cada direção escolar de forma antecipada, acelerando a aprovação ética.

\subsection{ETAPA 2 - DESCRIÇÃO DO CONTEXTO AMBIENTAL DAS IEMS}

A Figura 6.1 apresenta a localização das IEMs participantes. Quanto à localização, todas as IEMs participantes estão localizadas no Plano Piloto, com contexto urbano semelhante, em lotes específicos para instalação de instituições, junto à Avenida L2, importante avenida do Plano Piloto, com boa acessibilidade por automóvel e ônibus, localizando-se a leste do Plano Piloto. As adjacências residenciais são as quadras 400, tradicionais em Brasília tanto nos Bairros Asa Sul quanto Asa Norte. Destaca-se, ainda, a presença de dois bairros mais simples, próximos às IEMs participantes, residência de muitos alunos das IEMs públicas. Na Asa Sul, a aproximadamente 2000m a leste da IEM PU 1, observase a presença do bairro Vila Telebrasília. Ao norte, o Varjão dista aproximadamente $3 \mathrm{~km}$ da IEM PU 2. Outra característica é a proximidade do acesso das IEMs na Asa Sul das pontes do Lago Sul, Ponte das Garças, Ponte Honestino Guimarães e JK, por onde passam linhas de ônibus para as localidades a leste, como São Sebastião, Paranoá, Itapoã e Lago Sul.

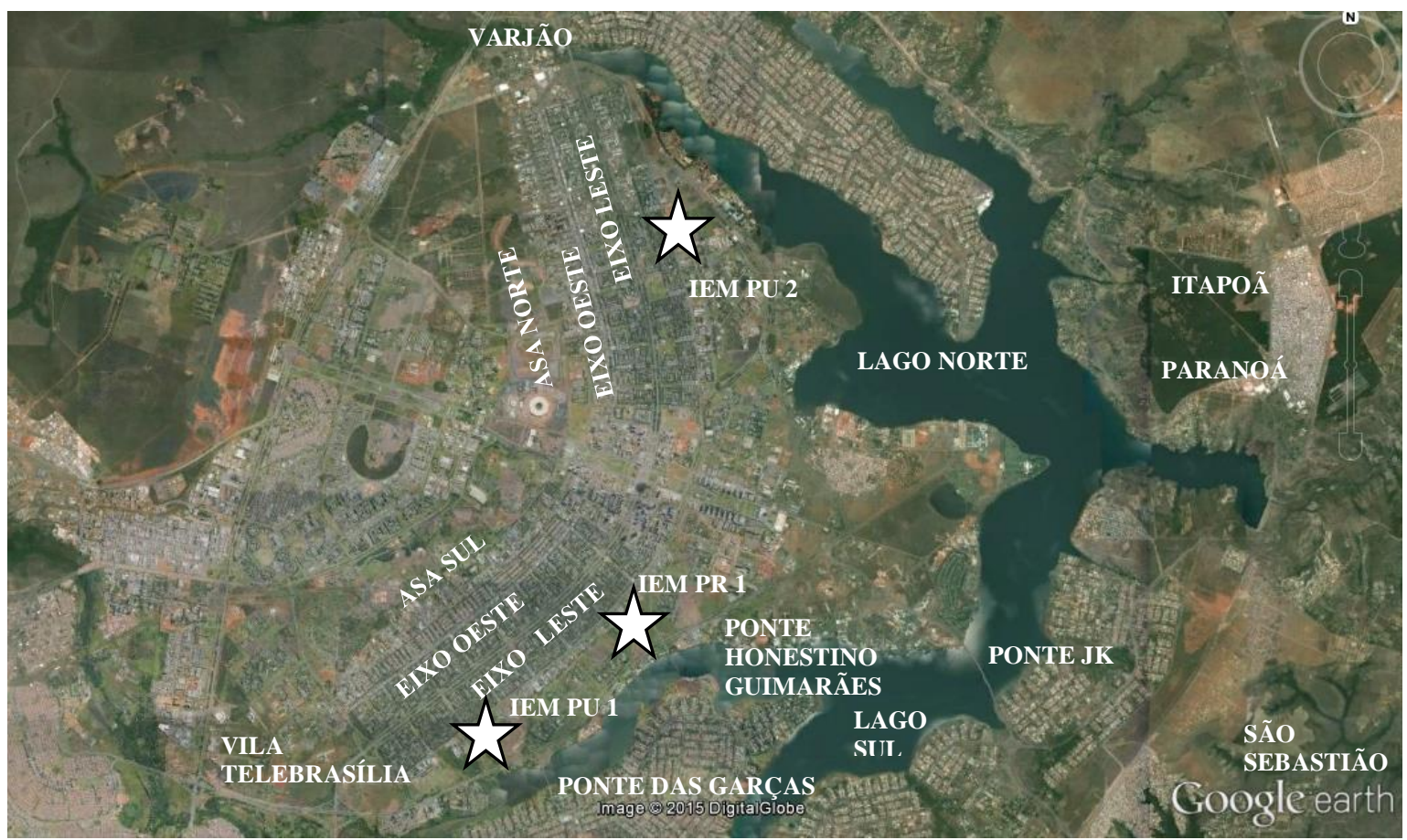

Figura 6.1: Localização das IEMs participantes da pesquisa Fonte: Google Earth. 
É interessante destacar que algumas localidades a norte do Distrito Federal, como Sobradinho e Planaltina, só têm acessibilidade à rede de ônibus em paradas nos Eixinhos Leste e Oeste, no Plano Piloto de Brasília. Assim, para todas as IEMs participantes da pesquisa, os usuários do modo Ônibus que residem nessas localidades têm a necessidade de realizar pelo menos mais $600 \mathrm{~m}$ de caminhada, através das quadras 400 e 200 do Plano Piloto, que os usuários residentes em localidades atendidas por ônibus que passam nas paradas mais próximas das IEMs. Esse trajeto tem boas calçadas e é fortemente arborizado. Para as caminhadas de final do turno vespertino e início da noite, entretanto, a arborização prejudica a iluminação do trajeto.

Conforme previsto na Etapa 2 do procedimento, foram coletados os dados gerais de cada instituição participante, mediante o preenchimento do Questionário Institucional (ver modelo no Apêndice C) e visitas à instituição nos horários de entrada e saída dos turnos, de acordo com o roteiro apresentado na Tabela 5.1 e no Apêndice D. Os dados coletados estão resumidos na Tabela 6.2 .

Os dados apresentados na Tabela 6.2 revelam que as características urbanas (uso do solo, ciclovias, calçadas) e os itens segurança viária e acessibilidade ao transporte público por ônibus são muito semelhantes em todas as três IEMs. Todas estão implantadas em grandes lotes (entre 10 e $60 \mathrm{mil} \mathrm{m}^{2}$ ), áreas construídas semelhantes (entre $3.8 \mathrm{mil} \mathrm{e} 5 \mathrm{mil} \mathrm{m}$ ). A IEM PR 1 tem mais salas de aula, mas também atende o ensino fundamental no mesmo turno e campus utilizado pelo ensino médio. A coleta dos dados da Tabela 6.2 teve por objetivo permitir uma análise contextualizada dos resultados obtidos para cada instituição. Além disso, ao serem incluídas no procedimento proposto, as características das IEMs permitem que na identificação dos atributos contribuintes para a escolha modal para um conjunto de IEMs essas características (variáveis ambientais) sejam investigadas. Ou seja, os atributos intervenientes na escolha modal de cada IEM podem ser ampliados a partir de um estudo comparativo entre diferentes IEMs em que as variáveis ambientais sejam consideradas. 
Tabela 6.2: Características das IEMs participantes da pesquisa

\begin{tabular}{|c|c|c|c|c|c|}
\hline \multicolumn{3}{|c|}{ Características } & IEM PU 01 & IEM PU 02 & IEM PR 01 \\
\hline \multicolumn{3}{|l|}{ Tipo } & Pública & Pública & Privada \\
\hline \multicolumn{3}{|c|}{ Área Terreno } & $57.500,00 \mathrm{~m}^{2}$ & $40.000,00 \mathrm{~m}^{2}$ & $10.350,00 \mathrm{~m}^{2}$ \\
\hline \multicolumn{3}{|c|}{ Área Construída } & $4.879,00 \mathrm{~m}^{2}$ & $4.780,00 \mathrm{~m}^{2}$ & $3.832,00 \mathrm{~m}^{2}$ \\
\hline \multicolumn{3}{|c|}{ Salas de aula } & 24 & 16 & 50 \\
\hline \multicolumn{3}{|c|}{ Vagas p/ estacionamento interno } & 234 & 108 & 37 \\
\hline \multicolumn{3}{|c|}{ Vagas p/ estacionamento externo } & 154 & 46 & 82 \\
\hline \multicolumn{3}{|c|}{ Área de E/D p/ automóveis } & não & sim & sim \\
\hline \multicolumn{3}{|c|}{ Área de E/D p/ Transporte Escolar } & não & não & não \\
\hline \multicolumn{3}{|c|}{ Acessibilidade à rede de $\mathrm{TP}$ ônibus } & $\begin{array}{c}160 \mathrm{~m} \text { sentido Centro/ } \\
\text { Bairro; } \\
136 \mathrm{~m} \text { sentido } \\
\text { Bairro/Centro }\end{array}$ & $\begin{array}{l}94 \mathrm{~m} \text { sentido } \\
\text { Centro/ Bairro; } \\
120 \mathrm{~m} \text { sentido } \\
\text { Bairro/Centro }\end{array}$ & $\begin{array}{l}126 \text { m sentido } \\
\text { Centro/ Bairro; } \\
98 \text { m sentido } \\
\text { Bairro/Centro }\end{array}$ \\
\hline \multicolumn{3}{|c|}{ Acessibilidade à rede de TP metrô } & $820 \mathrm{~m}$ & + de $4000 \mathrm{~m}$ & $854 \mathrm{~m}$ \\
\hline \multicolumn{3}{|c|}{ Ciclovias } & $\operatorname{sim}$ & $\operatorname{sim}$ & $\operatorname{sim}$ \\
\hline \multicolumn{3}{|c|}{ Estacionamento p/ bicicletas } & 10 & 10 & 0 \\
\hline \multicolumn{3}{|c|}{ Apoio Ciclo } & não & não & não \\
\hline \multicolumn{3}{|l|}{ Calçadas } & $\operatorname{sim}$ & $\operatorname{sim}$ & $\operatorname{sim}$ \\
\hline \multicolumn{3}{|c|}{ Segurança Viária*1 } & $\begin{array}{c}02 \text { pontos (Semáforo e } \\
\text { faixa de segurança para } \\
\text { pedestres); }\end{array}$ & $\begin{array}{l}02 \text { pontos } \\
\text { (Semáforo e faixa } \\
\text { de segurança para } \\
\text { pedestres); }\end{array}$ & $\begin{array}{c}02 \text { pontos } \\
\text { (Semáforo e faixa } \\
\text { de segurança para } \\
\text { pedestres); }\end{array}$ \\
\hline \multicolumn{3}{|l|}{ Uso do Solo } & $\begin{array}{c}\text { A oeste }-87 \% \\
\text { residencial e } 13 \% \\
\text { comércio; } \\
\text { A leste }-100 \% \\
\text { institucional. }\end{array}$ & $\begin{array}{c}\text { A oeste }-87 \% \\
\text { residencial e } 13 \% \\
\text { comércio; } \\
\text { A leste }-100 \% \\
\text { institucional. }\end{array}$ & $\begin{array}{c}\text { A oeste }-87 \% \\
\text { residencial e } 13 \% \\
\text { comércio; } \\
\text { A leste }-100 \% \\
\text { institucional. }\end{array}$ \\
\hline \multirow{5}{*}{$\begin{array}{c}\text { Matrículas } \\
\mathbf{1}^{\mathrm{a}} \text { série }\end{array}$} & \multirow{2}{*}{ Manhã } & $1^{0}$ período $^{* 2}$ & -- & $\begin{array}{l}174 \text { alunos } \\
\text { (05 turmas) }\end{array}$ & -- \\
\hline & & $2^{\circ}$ período $*^{2}$ & -- & $\begin{array}{l}182 \text { alunos } \\
\text { (06 turmas) }\end{array}$ & $\begin{array}{l}235 \text { alunos } \\
\text { (05 turmas) }\end{array}$ \\
\hline & \multirow{2}{*}{ Tarde } & $1^{0}$ período $^{* 2}$ & $\begin{array}{l}623 \text { alunos } \\
\text { (17 turmas) }\end{array}$ & $\begin{array}{l}175 \text { alunos } \\
\text { (05 turmas) }\end{array}$ & ( \\
\hline & & $2^{\circ}$ período $^{* 2}$ & $\begin{array}{l}680 \text { alunos } \\
\text { (17 turmas) }\end{array}$ & $\begin{array}{l}175 \text { alunos } \\
\text { (05 turmas) }\end{array}$ & -- \\
\hline & \multicolumn{2}{|c|}{$\begin{array}{l}\text { População pesquisada } \\
\text { total na } 1^{\mathrm{a}} \text { série }\end{array}$} & $\begin{array}{l}1376 \text { alunos } \\
\text { (34 turmas) }\end{array}$ & $\begin{array}{c}706 \text { alunos } \\
\text { (21 turmas) }\end{array}$ & $\begin{array}{l}235 \text { alunos } \\
\text { (05 turmas) }\end{array}$ \\
\hline
\end{tabular}

Obs.: As medidas euclidianas foram medidas por aproximação no Google Earth.

*1 - medida segundo critério apresentado na Tabela 5.1;

*2 - nas duas IEMs públicas foram realizados dois períodos de coleta de dados: o primeiro de outubro a dezembro/2014 e o segundo, de abril a junho/2015.

A IEM PU 1 tem o maior parque de estacionamento (interno e externo), mas não possui área de embarque e desembarque para automóveis como as demais, sendo o estacionamento a própria área de embarque e desembarque. Não foi observada área demarcada exclusiva para embarque e desembarque de transporte escolar em nenhuma IEM pesquisada. Por essas características observadas, espera-se que o maior parque de estacionamento atraia maior número de viagens por automóveis na IEM PU 1. A não demarcação de área de embarque e desembarque exclusiva para o transporte escolar indica que este modo de transporte não tem primazia em relação aos demais modos. 
Assim espera-se encontrar pequeno percentual de usuários desse modo nas IEMs pesquisadas

A acessibilidade ao transporte público por metrô é semelhante para as IEMs ao sul do Plano Piloto (IEM PU 1 e IEM PR 1). Quanto à IEM PU 2, situada no bairro Asa Norte, que não é provido de serviço de metrô, tem uma acessibilidade pobre para esse modo, necessitando de integração com ônibus. Espera-se, portanto, que na IEM localizada na Asa Norte, o uso do modo Metrô seja menor. O uso do transporte público é franqueado aos estudantes residentes no DF, através do Passe Escolar. A gratuidade é um diferencial para a preferência dos modos públicos pelos estudantes em áreas bem atendidas pelas redes públicas de transporte, ônibus e metrô, e apenas dentro do DF. Porém, à época da coleta de dados, a quantidade de viagens/mês e as linhas que o estudante poderia utilizar eram limitadas conforme cadastro prévio, efetuado a partir da matrícula na escola e do comprovante de residência. Mesmo com a restrição, espera-se que a gratuidade do Passe Escolar atraia muitos usuários para este modo, principalmente entre alunos de menor renda familiar.

Igualmente, em todas as IEMs pesquisadas, o apoio ao uso de bicicletas ainda é incipiente (em termos da presença de bicicletários e apoio ao uso da bicicleta). Tal fato indica que a disponibilidade recente de uma rede de ciclovias no Plano Piloto, ainda não foi assimilado como opção de mobilidade nas IEMs pesquisadas. A segurança pública das escolas no DF é realizada pelo Batalhão Escolar da Polícia Militar Estadual. Entretanto, apenas algumas escolas públicas têm efetivo cotidiano do Batalhão. O mais frequente é que sua presença aconteça sob demanda, na ocorrência de delitos, como assaltos ou flagrantes de uso/venda de drogas. Apenas na IEM PU1 foi observada a presença do Batalhão Escolar, durante o período de coleta de dados.

\subsection{ETAPA 3 - LEVANTAMENTO DAS CRENÇAS SALIENTES}

Em todas as IEMs, o levantamento das crenças salientes se deu pela realização de grupos focais com o apoio da equipe pedagógica das escolas. Essa equipe indicou o local para a realização da reunião e forneceu a lista de representantes de turma que seriam convidados a participar. Foi preparado e distribuído aos alunos em sala de aula, e aos pais por intermédio dos alunos, material contendo: carta convite para alunos e pais, termo TCLE 
para pais de autorização da participação dos alunos, termos TCLE para pais e alunos participantes, e questionário para pais (Apêndices B e E). Foi solicitado que o questionário enviado aos pais fosse entregue, junto com os TCLEs, no dia agendado para a reunião do grupo focal na escola.

O roteiro/protocolo (Apêndice F) foi seguido para que todas as reuniões cumprissem o mesmo procedimento. Foi preparada uma apresentação a ser projetada, introduzindo o tema e servindo também para registrar, à vista de todos, as afirmações do grupo à medida que eram feitas pelos seus integrantes. As reuniões foram acompanhadas de, pelo menos, mais um pesquisador para registrar, de forma independente, as respostas do grupo. As reuniões aconteceram em duas etapas: i) breve introdução do tema e distribuição do questionário impresso para alunos (Apêndice G); ii) em seguida, foi realizado debate sobre a mobilidade dos usuários da escola. A pesquisadora introduzia o tema pela pergunta "qual é o maior conflito de mobilidade nos horários de entrada e saída da escola?". Os grupos citavam os itens mais incômodos, e a percepção social das causas ou encaminhamentos necessários.

Depois da pergunta introdutória, as perguntas do questionário impresso foram sistematicamente discutidas. Cada grupo focal definiu o elenco de modos viáveis e disponíveis para a IEM. Em seguida, foram relatadas as principais percepções na realização dos deslocamentos escolares, por modo de transporte. As respostas por escrito nos questionários e registros dos depoimentos orais foram transcritas literalmente, por modo de transporte, grupo respondente (se pais ou alunos), por grupo focal e escola, consoante à pergunta estruturante do debate ou do questionário. As fontes das respostas foram: respostas dos pais por escrito; respostas dos alunos de forma escrita ou a partir dos depoimentos orais.

Alguns respondentes não foram fiéis à estrutura do questionário, respondendo item a item, mas expressando-se livremente, pois as questões eram abertas. Tais respostas foram categorizadas segundo a questão em que melhor se encaixassem: i) se avaliativa, positivamente ou negativamente, para com o modo - atitude (Questões 2 ou 3); ii) se abordasse a pressão social a favor ou contra para a realização da escolha do modo - norma social (Questões 4 ou 5); iii) ou, se revelasse sua capacidade de controle na realização da escolha, como falta de disponibilidade do serviço, desinformação, etc. - Controle 
percebido (Questões 6 ou 7). Outra categorização realizada foi quanto às Questões 6 e 7, referentes às percepções do controle pessoal sobre o comportamento. As afirmativas foram agrupadas em sub categorias, segundo afirmações sobre as características do sistema, sobre o ambiente e sobre limitações pessoais.

Após a transcrição literal, as respostas foram agrupadas pela semântica semelhante. Por exemplo, a palavra insegurança agrupou diversos itens citados como: "é perigoso", "não é seguro", "tenho medo de ser assaltado", etc. Os critérios para agrupamento foram a simplicidade de linguagem, semelhança semântica e variabilidade de percepções. Em seguida, foram realizadas contagens da ocorrência de afirmações por todas as fontes e apontados os temas recorrentes por modo de transporte, grupo respondente (se pais ou alunos), grupo focal e escola. As frequências finais foram conferidas novamente quanto aos registros dos depoimentos orais, verificando se as percepções dos conflitos relevantes se traduziam nas frequências relatadas. Foram selecionadas até quatro afirmativas mais frequentes para cada questão/ aspecto investigado e relatados para cada IEM e grupo focal realizado, e modo considerado.

A maioria das respostas foi traduzida na forma de palavras conceito, como insegurança, falta de iluminação, conforto, etc. As palavras conceito foram transformadas em afirmações indicativas das crenças sobre cada modo de transporte. Os critérios para a elaboração das afirmações foram: simplicidade de linguagem, coerência com os contextos dos depoimentos, não personificação do sujeito da ação, coerência com a teoria. Para cada grupo focal/ escola foi elaborado um relatório resposta, identificando o perfil dos respondentes, as impressões gerais e específicas da reunião e as conclusões sobre as opiniões dos respondentes sobre os modos viáveis e disponíveis nos deslocamentos para ir ou voltar da escola. Os relatórios de cada escola não serão apresentados na íntegra nesta tese, mas sintetizados em percepções gerais, válidas para todas as três IEMs participantes e resultados/características específicas para cada IEM.

\subsubsection{PERCEPÇÕES GERAIS}

Os grupos focais identificaram sete modos como disponíveis/viáveis, tanto para a opinião de alunos, como para pais/responsáveis: automóvel transportando apenas um estudante Automóvel da Família; automóvel transportando dois ou mais estudantes - Automóvel 
Carona; Van ou Ônibus Fretado - Transporte Escolar; Ônibus Público (referido nesse texto somente como modo Ônibus); Metrô; Bicicleta; A pé. O modo Motocicleta apareceu isoladamente em apenas um grupo focal, e na opinião por escrito de apenas dois estudantes, não integrando o elenco de modos a ser estudado.

Mesmo que o metrô não seja um modo de transporte de acesso facilitado para comunidades escolares localizadas na Asa Norte, os participantes nos grupos focais da IEM PU 2 apresentaram a avaliação de disponibilidade/viabilidade desse modo. Uma provável interpretação talvez seja pelo acesso atual integrado com ônibus, pelo Passe Escolar gratuito. Outra possibilidade é o desejo de que a rede de metrô possa ser estendida até a localidade da escola e ser também utilizada pela comunidade escolar.

\subsubsection{SÍNTESE DAS PERCEPÇÕES RELATADAS EM GRUPO FOCAL NA IEM PU 1}

O grupo focal na IEM PU 1 foi realizado em 16/09/2014, no horário estendido de intervalo no turno de aulas da $1^{\mathrm{a}}$ série (vespertino). Teve a participação de 24 representantes (e/ou vice representantes de turma) de 14 das 17 turmas de $1^{\mathrm{a}}$ série em funcionamento. Desses, 10 eram meninos e 14 meninas. Apenas 10 questionários de pais retornaram na reunião de grupos focais, e os participantes trouxeram assinados os termos de TCLE.

No debate, os alunos apresentaram suas impressões gerais sobre a mobilidade urbana junto à IEM. Apresentaram a variedade de modos utilizados e percepções variadas quanto aos modos de transporte para chegar e sair da escola. Os alunos se detiveram a falar sobre os modos mais usados e não extensivamente sobre todos os modos. Os três modos de transporte mais utilizados citados pelos participantes foram Ônibus, Automóvel da Família e Metrô, em ordem de grau de utilização, respectivamente.

A maior preocupação levantada foi com relação ao uso do metrô, principalmente em relação a assaltos no caminho entre a escola e a estação do metrô. Apontaram a falta de policiamento e a deficiência da iluminação, por volta das 18:30hs. Os alunos relataram que se sentiam vulneráveis neste trajeto. Indicaram os aspectos que contribuiriam para essa vulnerabilidade: i) andarem com fones de ouvido e sem atenção; ii) terem dificuldade em se defender; iii) serem facilmente identificados pelo uniforme. Uma proposta do grupo 
na contraposição à falta de segurança foi a ideia de formar grupos e, assim, caminharem juntos até o metrô e não "dar bobeira".

Outro comentário relevante foi com relação ao trânsito, especificamente sobre o comportamento dos motoristas de ônibus. Apontaram que muitos não paravam no ponto de parada quando era para o ingresso de apenas uma pessoa. Outro comportamento de risco é o fato de andarem com o ônibus de porta aberta. Ainda sobre esse serviço, relataram que, para o cadastro do passe escolar, era limitado o uso a certas linhas e horários de interesse. Apontaram que a vantagem do modo Ônibus seria a gratuidade, pelo uso do passe escolar. Sobre o modo Transporte Escolar, relataram ser inadequado, porque, nos veículos desse transporte, os alunos não são obrigados pelos condutores a usar cinto de segurança.

\subsubsection{SÍNTESE DAS PERCEPÇÕES RELATADAS NOS GRUPOS FOCAIS NA IEM PU 2}

Na IEM PU 2, com oferta de ensino médio nos turnos matutino e vespertino, foram realizados dois grupos focais, um em cada turno. Os resultados, porém, estão relatados em conjunto para a IEM. Os dois grupos focais aconteceram no dia 03/09/2014, no horário de intervalo das aulas. Pela manhã, participaram quatro representantes das cinco turmas de $1^{\mathrm{a}}$ série no turno, todos autorizados pelos respectivos TCLE. Desses, dois eram meninas e dois meninos. Três pais retornaram com os questionários respondidos. Pela tarde, participaram seis alunos representantes das seis turmas de $1^{\mathrm{a}}$ série do turno. Apenas um pai retornou o questionário respondido por escrito. O grupo foi composto por três meninos e três meninas.

O serviço de ônibus mereceu atenção com relação à inadequação de horários, não coincidentes com os horários de entrada e saída dos turnos. Os veículos foram classificados como desconfortáveis quanto à lotação, principalmente nos horários de final de tarde, coincidentes com o horário de pico do trânsito da cidade. A espera pelo ônibus menos lotado foi apontada como causa da demora em retornar para casa. A necessidade de caminhar até os "Eixinhos", para destinos ao norte do DF, foi considerada uma impedância ao uso do modo Ônibus e o caminho considerado perigoso, principalmente pela necessidade de utilização de passagens de travessia subterrâneas. 
O uso da bicicleta foi considerado um modo viável para quem mora perto, mas considerado pouco utilizado, ficando o bicicletário da escola ocioso e servindo de banco para sentar. Foi apontado que o serviço público de aluguel de bicicletas (o programa do Banco Itaú está disponível em alguns setores de Brasília) não abrange os arredores da escola, mas poderia ser uma alternativa para os deslocamentos para as atividades com turno estendido. Outra observação foi com relação ao modo Automóvel Carona, confundido com o transporte pirata em carros particulares. $\mathrm{O}$ fato de ter que pagar no transporte pirata o mesmo que no ônibus não gerava atratividade para o modo.

Foram apontados, também, conflitos de segurança viária com relação à travessia da Avenida L2, em frente ao portão da escola. Foi apontado que a largura da faixa de pedestre não comporta os alunos em travessia na saída da escola. Tal fato, em conjunto com o desrespeito dos motoristas ao semáforo de pedestres, tem implicado em atropelamentos no local. Quanto à segurança pessoal, diversas ocorrências de assaltos entre o portão da escola e os pontos de parada de ônibus foram relatadas.

\subsubsection{SÍNTESE DAS PERCEPÇÕES RELATADAS EM GRUPO FOCAL NA IEM PR 1}

Na IEM PR 1, o grupo focal ocorreu no dia 02/09/2014 pela manhã, no turno coincidente com as aulas. Foram convidados os representantes e vice representantes das cinco turmas de $1^{\text {a }}$ série. Teve a efetiva participação de seis alunos, devidamente autorizados pelos seus respectivos TCLEs. Desses, três eram meninos e três, meninas. Apenas três pais retornaram os questionários respondidos.

O metrô foi o modo mais elogiado por alunos, enquanto os pais apontaram falta de confiança neste modo, por causa das panes no sistema. As preocupações ambientais fizeram parte dos discursos e respostas escritas. Os participantes identificaram o uso do automóvel individual como o maior vilão dos problemas ambientais relacionados à mobilidade. Parece haver um consenso de que o uso dos modos coletivos (Ônibus, Metrô e Transporte Escolar) aliviaria a pressão pela dependência dos pais para efetivar os deslocamentos escolares com o uso do automóvel familiar, principalmente nos horários de saída de aulas. 
Foi apontada como desvantagem para o uso do modo Transporte Escolar a necessidade de sair mais cedo de casa para chegar no horário certo na escola, pelas extensas rotas do serviço para a captação dos alunos. As maiores críticas foram com relação à confiabilidade do modo Ônibus (falta de divulgação e/ou cumprimento das tabelas de horários, ou horários não compatíveis com os horários de entrada e saída das escolas), embora seja o modo considerado mais viável. Os participantes também citaram a pouca permeabilidade do sistema (linhas escassas, não vinculadas aos locais de residência dos alunos), o trato grosseiro entre passageiros e motoristas e a vulnerabilidade a assaltos na espera ou no trajeto embarcado.

O reconhecimento do automóvel como rápido parece indicar que sua utilização não coincide com os horários de pico no trânsito da cidade, os quais imputam atrasos substanciais aos deslocamentos, ou que os estudantes não residem em áreas afetadas por congestionamentos nos horários em que estão se deslocando para a escola, ou saindo dela. O modo Automóvel Carona (automóvel utilizado por mais de um aluno) foi citado como elemento potencial de interação entre colegas e socialmente aceitável pelos estudantes. Os pais não apontaram grandes restrições ao uso deste modo, citando inclusive o elemento economia como vantagem.

Os modos não motorizados (A pé e Bicicleta) foram pouco avaliados, indicando pouca familiaridade dos estudantes com esses modos para utilizá-los no dia a dia. Parecem não serem aceitos como modos viáveis pelos familiares (desaprovação). Foram citados apenas como vantagens para a saúde com a atividade física. Uma observação chama a atenção para o modo A pé e também para os modos de transporte público: foi reconhecida a necessidade da realização de algum percurso a pé para os modos Ônibus e Metrô e esse percurso foi referido como o mais inseguro para efeito de assaltos e abordagens de usuários de drogas, principalmente nas Quadras 400 da Asa Sul.

\subsubsection{PRINCIPAIS CRENÇAS IDENTIFICADAS}

A identificação das crenças salientes é a primeira parte da operacionalização da TCP. As recomendações de elaboração das afirmativas de crenças, de acordo com a TCP, e descritas na seção 5.4.2, foram seguidas, e um único elenco de crenças salientes foi compilado (mesma forma e redação) para as três IEMs participantes. Esta síntese foi 
considerada razoável, já que os modos viáveis e as condições ambientais entre as IEMs tinham muitas semelhanças. Cada crença saliente identificada foi escrita sob a forma de dois itens, um para o valor da crença ("b") e outro para a da força da crença ("e"), necessários à análise exploratória das crenças, conforme indicado na seção 5.6.2. O elenco final de afirmativas de crenças para cada modo paralelamente para a opinião de alunos e de pais e responsáveis é apresentado no Apêndice L. Para efeito de exemplo, são apresentadas na Tabela 6.3 as crenças para os dois grupos de respondentes para o modo metrô. A Tabela 6.4 apresenta a frequência temática nas afirmativas de crenças, por modo e por grupo de respondentes.

As opiniões capturadas na forma de crenças não foram tão divergentes entre os grupos de respondentes (alunos e pais/ responsáveis). Dos grupos com opinião de referência sobre o comportamento, tanto para alunos como pais, se destacaram a família e os amigos. $\mathrm{O}$ tema segurança ao utilizar o modo foi um tema bem citado pelos dois grupos de respondentes. Para ser incluído no questionário da etapa quantitativa, esse tema foi dividido em vários contextos, para os modos públicos motorizados, no trecho entre a escola e a parada, na espera, no percurso embarcado e no trecho entre a parada e a casa. 
Tabela 6.3: Elenco de crenças para os modos de transporte considerados viáveis na opinião dos respondentes para o modo metrô

\begin{tabular}{|c|c|c|}
\hline & Opinião dos alunos & Opinião dos pais/responsáveis \\
\hline$b$ & $\begin{array}{l}\text { O metrô é um modo de transporte vantajoso para } \\
\text { quem tem o passe estudantil. } \\
\text { Ter passe estudantil para usar o metrô é } \\
\text { (ruim/bom). }\end{array}$ & $\begin{array}{l}\text { Sem correspondência na opinião dos } \\
\text { pais/responsáveis }\end{array}$ \\
\hline$b$ & $\begin{array}{l}\text { É confortável usar o metrô, mesmo quando se } \\
\text { viaja em pé. } \\
\text { Prezar pelo conforto ao usar o metrô é (ruim/bom). }\end{array}$ & $\begin{array}{l}\text { O metro está lotado nos horários que meu (minha) } \\
\text { filho (a) vai/volta da escola. } \\
\text { Deveríamos nos preocupar com a lotação do metrô } \\
\text { para ir ou voltar da escola } \\
\text { (dificilmente/provavelmente). }\end{array}$ \\
\hline $\begin{array}{l}b \\
e\end{array}$ & $\begin{array}{l}\text { A viagem dentro do metrô não é segura. } \\
\text { Prezar pela segurança ao usar o metrô é } \\
\text { (ruim/bom). }\end{array}$ & $\begin{array}{l}\text { É seguro usar metrô para ir ou voltar da escola. } \\
\text { Prezar pela segurança ao usar o metrô é } \\
\text { (ruim/bom). }\end{array}$ \\
\hline$b$ & $\begin{array}{l}\text { Quem vai para a escola de metrô, chega no horário } \\
\text { certo (concordo/discordo). } \\
\text { Prezar pela pontualidade ao usar o metrô é } \\
\text { (ruim/bom). }\end{array}$ & $\begin{array}{l}\text { Meu (minha) filho(a) chega mais rápido à escola } \\
\text { de metrô(concordo/discordo). } \\
\text { Preocupar-me com o tempo de viagem para ir de } \\
\text { metrô à escola é (ruim/bom). }\end{array}$ \\
\hline$b$ & $\begin{array}{l}\text { Meus pais me incentivam a vir ou voltar da escola } \\
\text { de metrô(concordo/discordo). } \\
\text { Considero o fato de meus pais me incentivarem a } \\
\text { vir ou voltar da escola de metrô como } \\
\text { (negativo/positivo). }\end{array}$ & $\begin{array}{l}\text { A família incentiva que meu (minha) filho(a) use } \\
\text { metrô para ir ou voltar da escola } \\
\text { (concordo/discordo). } \\
\text { Considero o fato de minha família incentivar que } \\
\text { meu (minha) filho(a) use metrô para ir ou voltar } \\
\text { da escola como (negativo/positivo). }\end{array}$ \\
\hline$b$ & $\begin{array}{l}\text { Meus amigos me apoiariam se utilizasse metrô } \\
\text { para ir ou voltar da escola (concordo/discordo). } \\
\text { Considero o fato de meus amigos me apoiarem a } \\
\text { usar metrô para ir/voltar da escola como } \\
\text { (negativo/positivo). }\end{array}$ & $\begin{array}{l}\text { Meus amigos acham uma boa ideia meu (minha) } \\
\text { filho(a) usar metrô para ir ou voltar da escola } \\
\text { (concordo/discordo). } \\
\text { Considero o fato de meus amigos acharem uma } \\
\text { boa ideia meu (minha) filho(a) usar metrô para ir } \\
\text { ou voltar da escola como (negativo/positivo). }\end{array}$ \\
\hline$b$ & $\begin{array}{l}\text { O trecho a pé entre a escola e a estação do metrô é } \\
\text { perigoso(concordo/discordo). } \\
\text { Acho que posso ser agredido no trecho entre a } \\
\text { escola e a estação de metrô (concordo/discordo). }\end{array}$ & $\begin{array}{l}\text { Meu (minha) filho(a) pode ser assaltado no trecho } \\
\text { a pé entre a escola e a estação } \\
\text { (concordo/discordo). } \\
\text { Deveríamos nos preocupar com a segurança no } \\
\text { trecho entre a escola e o metrô } \\
\text { (dificilmente/provavelmente). }\end{array}$ \\
\hline$b$ & $\begin{array}{l}\text { O trecho a pé entre a estação do metrô e a minha } \\
\text { casa é perigoso(concordo/discordo). } \\
\text { Acho que posso ser agredido no trecho entre a } \\
\text { estação de metrô e a minha casa } \\
\text { (concordo/discordo). }\end{array}$ & $\begin{array}{l}\text { Meu (minha) filho(a) pode ser assaltado no trecho } \\
\text { a pé entre a estação e a nossa casa } \\
\text { (concordo/discordo). } \\
\text { Deveríamos nos preocupar com a segurança no } \\
\text { trecho entre a estação do metrô e a nossa casa } \\
\text { (dificilmente/provavelmente). }\end{array}$ \\
\hline$b$ & $\begin{array}{l}\text { Não é seguro esperar pelo metrô nas estações } \\
\text { (concordo/discordo). }\end{array}$ & $\begin{array}{l}\text { Não é seguro esperar pelo metrô nas estações nos } \\
\text { horários de ida/volta da escola } \\
\text { (concordo/discordo). }\end{array}$ \\
\hline$e$ & $\begin{array}{l}\text { Devo prezar pela segurança ao esperar pelo metrô } \\
\text { nas estações (concordo/discordo). }\end{array}$ & $\begin{array}{l}\text { Deveríamos prezar pela segurança ao esperar pelo } \\
\text { metrô nas estações (dificilmente/provavelmente). }\end{array}$ \\
\hline$b$ & Sem correspondência na opinião dos alunos. & $\begin{array}{l}\text { É fácil usar metrô para ir ou voltar da escola } \\
\text { (concordo/discordo). } \\
\text { Preocupar-me com a facilidade do metrô para ir ou } \\
\text { voltar da escola é (ruim/bom). }\end{array}$ \\
\hline$b$ & Sem correspondência na opinião dos alunos. & $\begin{array}{l}\text { Usar metrô para ir ou voltar da escola é possível } \\
\text { para quem mora perto das estações } \\
\text { (concordo/discordo). } \\
\text { Deveríamos considerar a distância entre a estação } \\
\text { e a nossa casa para usar o metrô } \\
\text { (dificilmente/provavelmente). }\end{array}$ \\
\hline
\end{tabular}

Obs.: b - afirmativa sobre o valor da crença; e - afirmativa referente à força da crença. 
Tabela 6.4: Frequência temática nas afirmativas de crenças por modo e grupo de respondente.

\begin{tabular}{|c|c|c|c|c|c|c|c|c|c|c|c|c|c|c|}
\hline MODO & & \multicolumn{2}{|c|}{ 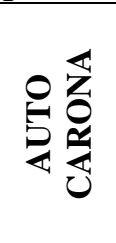 } & \multicolumn{2}{|c|}{ 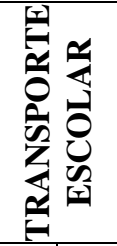 } & \multicolumn{2}{|c|}{ 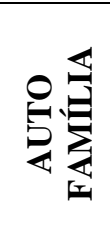 } & \multicolumn{2}{|c|}{ 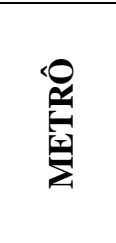 } & \multicolumn{2}{|c|}{ 光 } & \multicolumn{2}{|c|}{ 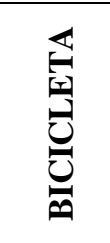 } \\
\hline TEMA / REPONDENTE & $\mathbf{A}$ & $\mathbf{P}$ & $\mathbf{A}$ & $\mathbf{P}$ & $\mathbf{A}$ & $\mathbf{P}$ & $\mathbf{A}$ & $\mathbf{P}$ & $\mathbf{A}$ & $\mathbf{P}$ & $\mathbf{A}$ & $\mathbf{P}$ & $\mathbf{A}$ & $\mathbf{P}$ \\
\hline Agenda/horários & & & $\mathrm{i}$ & $\mathrm{i}$ & & & $\mathrm{i}$ & ii & & & & & & \\
\hline Conforto/comodidade & $\mathrm{i}$ & & & $\mathrm{i}$ & & & & & $\mathrm{i}$ & $\mathrm{i}$ & $\mathrm{i}$ & $\mathrm{i}$ & & \\
\hline Disponibilidade & & & & & $\mathrm{i}$ & $\mathrm{i}$ & & & & & $\mathrm{i}$ & & $\mathrm{i}$ & \\
\hline Distância /condição do trecho & & ii & & & & $\mathrm{i}$ & & & & $\mathrm{i}$ & & & ii & ii \\
\hline Economia & & $\mathrm{i}$ & $\mathrm{i}$ & $\mathrm{i}$ & $\mathrm{i}$ & $\mathrm{i}$ & $\mathrm{i}$ & & & & & & & \\
\hline Facilidade/Vantagens & $\mathrm{i}$ & & $\mathrm{i}$ & & & & & $\mathrm{i}$ & $\mathrm{i}$ & $\mathrm{i}$ & & $\mathrm{i}$ & & \\
\hline Grupos de amizades/vizinhos & & & $\mathrm{i}$ & $\mathrm{i}$ & & & & & & & & & & \\
\hline Iluminação & $\mathrm{i}$ & & & & & & & & & & & & & \\
\hline Preocupações ambientais & & & & $\mathrm{i}$ & & & $\mathrm{i}$ & & & & & & & ii \\
\hline Profissionais/serviço & & & $\mathrm{i}$ & & & $\mathrm{i}$ & & & & & & & & \\
\hline Saúde & $\mathrm{i}$ & $\mathrm{i}$ & & & & & & & & & & & $\mathrm{i}$ & $\mathrm{i}$ \\
\hline Tempo/pontualidade & & & & & ii & $\mathrm{i}$ & $\mathrm{i}$ & & $\mathrm{i}$ & $\mathrm{i}$ & $\mathrm{i}$ & ii & & \\
\hline Trânsito & & & & & & & & $\mathrm{i}$ & & & & & & ii \\
\hline $\begin{array}{l}\text { Grupos de referência: } \\
\text { Opinião dos pais/família }\end{array}$ & $\mathrm{i}$ & $\mathrm{i}$ & $\mathrm{i}$ & $\mathrm{i}$ & $\mathrm{i}$ & $\mathrm{i}$ & $\mathrm{i}$ & $\mathrm{i}$ & $\mathrm{i}$ & $\mathrm{i}$ & $\mathrm{i}$ & $\mathrm{i}$ & $\mathrm{i}$ & $\mathrm{i}$ \\
\hline Opinião de amigos & $\mathrm{i}$ & $\mathrm{i}$ & $\mathrm{i}$ & $\mathrm{i}$ & $\mathrm{i}$ & $\mathrm{i}$ & $\mathrm{i}$ & $\mathrm{i}$ & $\mathrm{i}$ & $\mathrm{i}$ & $\mathrm{i}$ & $\mathrm{i}$ & $\mathrm{i}$ & $\mathrm{i}$ \\
\hline $\begin{array}{l}\text { Segurança: } \\
\text { No trecho a pé entre } \\
\text { escola/parada }\end{array}$ & & & & & & & & & $\mathrm{i}$ & $\mathrm{i}$ & $\mathrm{i}$ & $\mathrm{i}$ & & \\
\hline Na espera & & & & & $\mathrm{i}$ & & & & $\mathrm{i}$ & $\mathrm{i}$ & $\mathrm{i}$ & $\mathrm{i}$ & & \\
\hline No percurso & $\mathrm{i}$ & $\mathrm{i}$ & $\mathrm{i}$ & $\mathrm{i}$ & $\mathrm{i}$ & $\mathrm{i}$ & $\mathrm{i}$ & $\mathrm{i}$ & $\mathrm{i}$ & $\mathrm{i}$ & $\mathrm{i}$ & $\mathrm{i}$ & & $\mathrm{i}$ \\
\hline No trecho a pé entre parada/casa & & & & & & & & & $\mathrm{i}$ & $\mathrm{i}$ & $\mathrm{i}$ & $\mathrm{i}$ & & \\
\hline
\end{tabular}

Obs.: A - Grupo de respondentes alunos; $\mathrm{P}$ - grupo de respondentes pais ou responsáveis; i - o tema aparece apenas uma vez; ii - o tema aparece mais de uma vez.

\subsection{ETAPA 4 - ELABORAÇÃO E APLICAÇÃO DOS QUESTIONÁRIOS}

A elaboração e aplicação de questionários teve como objetivo conferir se a opinião dos grupos focais reproduzia a opinião da população alvo, além de subsidiar as etapas de abordagem quantitativas. Porém, teve dois limitantes: i) as coordenações das IEMs participantes não consideraram adequada, nem viável, a aplicação de questionários virtuais, com o uso, por exemplo, de laboratórios de informática; ii) a restrição orçamentária da pesquisa para a impressão dos questionários.

Perante tal cenário, optou-se por elaborar um único questionário para os estudantes e um outro para os pais/responsáveis, reproduzidos para ser aplicados nas três IEMs participantes. As recomendações de elaboração descritas na seção 4.5.1 foram seguidas e a versão final dos questionários é apresentada nos Apêndices H e I. 
Os questionários impressos (Apêndices H e I) tiveram aplicação iniciada na IEM PU 2 no final de outubro, para alunos em todas as turmas de $1^{\text {a }}$ série, e seus respectivos pais e responsáveis (questionário impresso enviado para casa). Este período, entretanto, apresentou as seguintes limitações para a aplicação dos questionários: i) ser o último período do calendário escolar, onde se concentram as atividades avaliativas e de recuperação; ii) e oferecer pouco espaço para a inclusão das atividades de pesquisa nos períodos de aulas. Este foi, também, o período de ocorrência de diversas greves das empresas de transporte público por ônibus do DF e região do entorno, prejudicando a presença de alunos na escola e/ou a diminuição do tempo de aula dos turnos.

A decisão de incluir todos os modos considerados viáveis pelos respondentes nos grupos focais e a necessidade de incluir duas afirmativas por crença saliente identificada (necessidade para realizar a análise da Teoria da Expectância), tornou o questionário extenso. A estratégia de solicitar que cada indivíduo pesquisado respondesse apenas os itens referentes aos três modos mais familiares e a seção final, sobre todos os modos, pode ter diminuído o estresse do respondente com o tamanho do questionário.

As respostas dos questionários foram classificadas em dois grupos de amostra: "alunos pareados" com seus pais/responsáveis e "alunos geral". Este último grupo envolvia os alunos que participavam da pesquisa, mas que não traziam o questionário dos pais/responsável respondido. As informações sobre os tamanhos da população alvo e amostras por IEM, período de coleta de dados e grupo de classificação da amostra são apresentados na Tabela 6.5.

A taxa de respostas dos pais/responsáveis ao questionário enviado para casa no primeiro período de coleta de dados foi de pouco mais de $1 \%$ na IEM PU 1 e de menos de $8 \%$ na IEM PU 2. Um novo período de aplicação dos questionários nas IEMs públicas foi conduzido de março a maio de 2015 , formado por novos alunos de $1^{\mathrm{a}}$ série, constituindo nova população alvo (considerada semelhante à população inicial para efeito dos objetivos da pesquisa).

Esta nova coleta aumentou o número de respostas na amostra de alunos pareados para mais de 50 respostas. Nas IEMs públicas, a participação dos alunos atingiu mais de $60 \%$, considerada razoável frente às evasões de final de ano e às greves do transporte público 
nos períodos de coleta de dados. Na IEM privada a aplicação dos questionários não foi realizada diretamente pela pesquisadora, mas intermediada pelo coordenador da escola. Os resultados obtidos por esta estratégia para a IEM foram em proporção bem menor, pouco mais de $20 \%$.

Tabela 6.5: Dados populacionais e amostrais das IEMs participantes

\begin{tabular}{|c|c|c|c|c|c|c|c|}
\hline \multirow{3}{*}{ Período } & \multirow{3}{*}{$\begin{array}{l}\text { Matrículas } \\
(\mathbf{N})\end{array}$} & \multicolumn{4}{|c|}{ Grupo Amostral } & \multirow{2}{*}{\multicolumn{2}{|c|}{ Total }} \\
\hline & & \multicolumn{2}{|c|}{$\begin{array}{c}\text { Alunos } \\
\text { pareados }\end{array}$} & \multicolumn{2}{|c|}{$\begin{array}{c}\text { Alunos em } \\
\text { geral }\end{array}$} & & \\
\hline & & n & $\%$ & $n$ & $\%$ & $\mathbf{n}$ & $\%$ \\
\hline \multicolumn{8}{|l|}{ Na IEM PU 1} \\
\hline 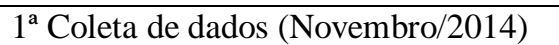 & 623 & 10 & 1.61 & 418 & 67.09 & 418 & 67.26 \\
\hline $2^{\mathrm{a}}$ Coleta de dados(Março-Maio/2015) & 680 & 41 & 6.03 & 426 & 62.65 & 467 & 68.82 \\
\hline Total & 1303 & 51 & 3.91 & 844 & 64.77 & 895 & 68.69 \\
\hline \multicolumn{8}{|l|}{ Na IEM PU 2} \\
\hline $1^{\text {a }}$ Coleta de dados (Outubro/2014) & 356 & 27 & 7.58 & 191 & 53.65 & 218 & 61.24 \\
\hline $2^{\mathrm{a}}$ Coleta de dados (Abril/2015) & 350 & 27 & 7.71 & 191 & 54.57 & 218 & 62.29 \\
\hline Total & 706 & 54 & 7.65 & 382 & 54.11 & 436 & 61.76 \\
\hline \multicolumn{8}{|l|}{ Na IEM PR I } \\
\hline Coleta de dados (Março-Junho/2015) & 235 & 17 & 7,23 & 32 & 13,62 & 49 & 20,85 \\
\hline Total & 235 & 17 & 7,23 & 32 & 13,62 & 49 & 20,85 \\
\hline
\end{tabular}

\subsection{ETAPA 5 - ELABORAÇÃO DO PERFIL DE MOBILIDADE DAS IEMS}

Nas seções que seguem, serão apresentados os perfis de mobilidade para cada IEM. As bases de dados foram tratadas para dados ausentes e casos extremos e para "alunos em geral" e "alunos pareados". O perfil da mobilidade é apresentado através das estatísticas descritivas uni e bivariadas, conforme descrito na seção 5.5.4.

\subsubsection{TRATAMENTO PRELIMINAR DA BASE DE DADOS}

$\mathrm{Na}$ aplicação do questionário elaborado na Etapa 4, as opiniões foram coletadas em separado para cada modo de transporte. A cada respondente era solicitado que opinasse sobre o modo atualmente utilizado para chegar ou sair da escola e, pelo menos, sobre outros dois modos para os quais soubesse. As opiniões foram segmentadas segundo a amostra "alunos pareados" "pais pareados" e "alunos em geral", e verificados os casos extremos e os casos ausentes (missings). Não foram observados dados extremos nas variáveis de estudo. As observações em cada variável pertenciam aos intervalos esperados para cada uma delas. O tratamento de dados ausentes foi realizado seguindo as definições 
da Tabela 5.3, em diferentes etapas, segundo a modelagem proposta, e identificação das variáveis dependentes.

Segundo a Tabela 5.3, as variáveis dependentes em cada modelagem não deveriam receber atribuição de valores para substituir casos ausentes. O primeiro tratamento, T1, teve como objetivo a elaboração do perfil da mobilidade por IEM, e considerou como critério de manutenção do respondente na amostra, ter respostas válidas, tanto para o modo utilizado na ida, quanto para o modo utilizado na volta. Este tratamento é também a base para os demais tratamentos, já que a escolha modal é o cerne do presente estudo e tem implicâncias nas etapas futuras do estudo. Os demais tratamentos serão referenciados à medida que forem necessários para a condução das análises.

Para a elaboração do perfil da mobilidade para cada IEM, tratamento T1, a base de dados envolveu as variáveis comuns a todos modos analisados: i) a escolha do modo na ida e na volta (variáveis dependentes); ii) variáveis complementares à escolha do modo: frequência na ida, frequência na volta, intenção de mudança, opção de mudança; iii) variáveis sociodemográficas: gênero, idade, localidade de residência, distância casaescola, renda familiar, densidade na localidade de residência, disponibilidade de automóvel no domicílio; iv) variáveis de hábito; v) variáveis de comportamento passado. O tratamento T1 incluiu, em sequência:

a) Passo 1 -Eliminação dos respondentes que tivessem dados ausentes nos dois itens da escolha modal: modo na ida e modo na volta. Para os registros de respondentes com dados ausentes remanescentes na ida ou na volta, foi atribuído o valor " 0 ", apenas para consideração nesta etapa de pesquisa;

b) Passo 2 - Atribuição da média - como foi verificado que, para todos os respondentes e variáveis consideradas no tratamento, o valor de dados ausentes não ultrapassava $10 \%$, foi atribuído a eles o valor médio das respostas válidas. No caso das variáveis nominais binárias, foi determinado o percentual de ocorrência dos valores " 1 " e " 0 ", e essa percentagem foi aplicada aos dados ausentes. Por exemplo, se nas respostas válidas $60 \%$ apresentassem valor “1”, então a $60 \%$ dos dados ausentes foi atribuído o valor "1", selecionados aleatoriamente. 
O total de respondentes após o Tratamento T1, considerado para a elaboração do perfil de mobilidade, é apresentado na Tabela 6.6 para as amostras "alunos geral" e alunos pareados". Percebe-se que, para o caso da IEM PR 1, que já tinha um tamanho de amostras bem menor do que o obtido para as demais IEMs, o tamanho das amostras após T1 aponta muita restrição para as análises estatísticas propostas no presente estudo. Assim, esta instituição não será incluída na Etapa 6 do procedimento.

Tabela 6.6: Amostras resultante do tratamento T1 de casos ausentes

\begin{tabular}{c|cccc}
\hline \multirow{2}{*}{ IEM } & \multicolumn{2}{c}{ DADOS BRUTOS } & \multicolumn{2}{c}{ DADOS APÓS T1 } \\
\cline { 2 - 5 } & "alunos geral" & "alunos pareados" & "alunos geral" & "alunos pareados" \\
\hline IEM PU 1 & 844 & 51 & 805 & 48 \\
\hline IEM PU 2 & 382 & 54 & 358 & 52 \\
\hline IEM PR 1 & 32 & 17 & 21 & 11 \\
\hline
\end{tabular}

\subsubsection{AGRUPAMENTO DAS LOCALIDADES DE RESIDÊNCIA INFORMADAS}

$\mathrm{Na}$ transcrição dos dados de endereçamento (via CEP ou diretamente informado pelo respondente), assumiu-se a variedade de localidades informadas e não a divisão política atual do Distrito Federal por Regiões Administrativas. O resultado foram 59 localidades de residência informadas. Para a continuação do estudo, as localidades foram agrupadas em setores, segundo os critérios: i) a orientação geográfica; ii) distância euclidiana ao centro do Plano Piloto (cruzamento dos Eixos Rodoviário e Monumental), em três níveis: até $9 \mathrm{~km}$ (setor central); de 9 a $20 \mathrm{Km}$; e até o limite do Distrito Federal, aproximadamente $35 \mathrm{Km}$; iii) eixo viário principal de ligação das localidades ao Setor Central. Foram identificados oito setores dentro da região do Distrito Federal e três setores das áreas do entorno, no estado de Goiás. A Figura 6.2 apresenta a representação espacial da proposta de agrupamento das localidades de residência em setores.

Como exemplo, a Tabela 6.7 apresenta algumas características médias (renda e distância) das localidades agrupadas nos setores, para a amostra "alunos geral" na IEM PU 1. As localidades com informações em branco referem-se a localidades presentes nos dados das demais IEMs. Observa-se, por esta tabela, que o agrupamento tem alguma relação com a renda familiar, sendo identificado na amostra exemplificada na tabela que quanto maior o afastamento do Setor Central, menor a renda familiar média da localidade. As análises dos perfis de mobilidade por IEM seguirão o agrupamento de setores proposto. 


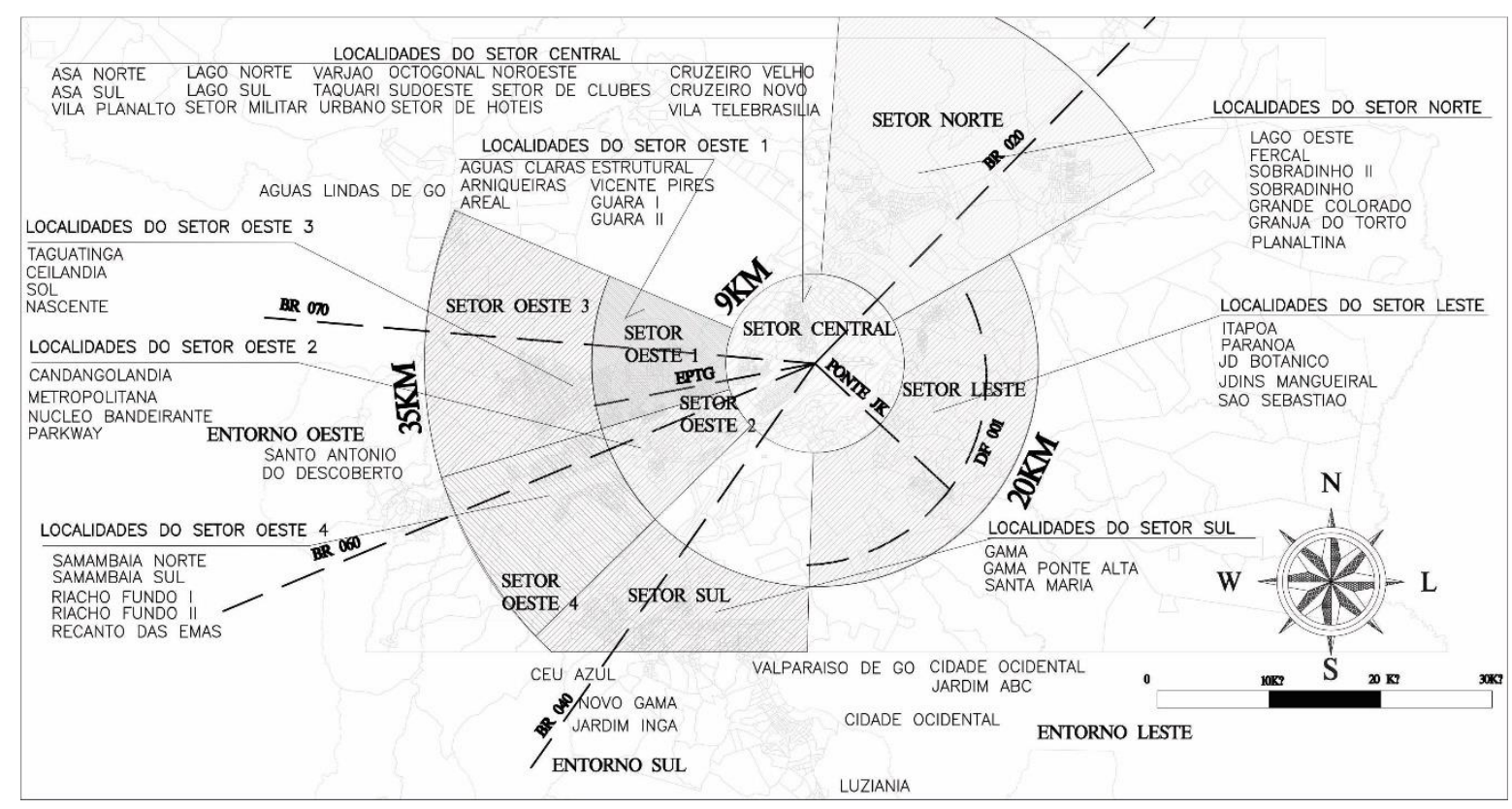

Tabela 6.7: Características médias das localidades dos respondentes na amostra "alunos geral" agrupadas em setores - IEM PU 1

\begin{tabular}{|c|c|c|c|c|c|c|c|}
\hline SETOR & LOCALIDADES & $\begin{array}{l}\text { RENDA } \\
\text { MÉDIA } \\
(\mathbf{R} \$)\end{array}$ & $\begin{array}{l}\text { DISTÂNCIA } \\
\text { MÉDIA (m) }\end{array}$ & SETOR & LOCALIDADES & $\begin{array}{l}\text { RENDA } \\
\text { MÉDIA } \\
(\mathbf{R} \$)\end{array}$ & $\begin{array}{l}\text { DISTÂNCIA } \\
\text { MÉDIA (m) }\end{array}$ \\
\hline \multirow{15}{*}{$\begin{array}{l}\text { SETOR } \\
\text { CENTRAL }\end{array}$} & Asa norte & 7910 & 8715 & \multirow{7}{*}{$\begin{array}{l}\text { SETOR } \\
\text { OESTE } 1 \\
\text { Eixo Viário: } \\
\text { EPTG }\end{array}$} & Águas Claras & 8068 & 12969 \\
\hline & Asa sul & 9344 & 1545 & & Areal & 5589 & 12469 \\
\hline & Cruzeiro Novo & 6445 & 5118 & & Arniqueiras & 6721 & 10993 \\
\hline & Cruzeiro Velho & 6652 & 5724 & & Estrutural & 2081 & 8599 \\
\hline & Lago Norte & 8373 & 14229 & & Guará I & 5554 & 8152 \\
\hline & Lago sul & 8164 & 8025 & & Guará II & 6783 & 8257 \\
\hline & Noroeste & & & & Vicente Pires & 5403 & 13324 \\
\hline & Octogonal & 9252 & 4802 & \multirow{4}{*}{$\begin{array}{l}\text { SETOR } \\
\text { OESTE } 2 \\
\text { Eixos } \\
\text { Viários: } \\
\text { EPIA/EPNB } \\
\text { BR } 060\end{array}$} & $\begin{array}{l}\text { Núcleo } \\
\text { Bandeirante }\end{array}$ & 5485 & 8304 \\
\hline & S. de Clubes & 3958 & 3537 & & Candangolândia & 3554 & 7812 \\
\hline & S. Hotéis/turismo & 3893 & 7802 & & Metropolitana & 7325 & 8999 \\
\hline & Setor Militar U. & 5441 & 7339 & & Parkway & 10109 & 10428 \\
\hline & Sudoeste & 11376 & 7528 & \multirow{2}{*}{$\begin{array}{l}\text { SETOR } \\
\text { OESTE } 3 \\
\text { Eixo Viário: } \\
\text { BR } 070\end{array}$} & Ceilândia & 3154 & 23956 \\
\hline & $\begin{array}{l}\text { Taquari } \\
\text { Varjão }\end{array}$ & 9084 & 14331 & & $\begin{array}{l}\text { Taguatinga } \\
\text { Sol Nascente }\end{array}$ & 4323 & 17204 \\
\hline & Vila Planalto & 3755 & 7532 & \multirow{5}{*}{$\begin{array}{l}\text { SETOR } \\
\text { OESTE } 4 \\
\text { Eixo Viário } \\
\text { BR } 060\end{array}$} & Samambaia Norte & 2758 & 20137 \\
\hline & Vila Telebrasília & 2946 & 2853 & & Samambaia Sul & 2399 & 19296 \\
\hline SETOR SUL & Gama & 3829 & 27113 & & Recanto das Emas & 1689 & 19753 \\
\hline Eixo Viário: & Gama Ponte Alta & 2542 & 26425 & & Riacho Fundo I & 3298 & 13200 \\
\hline BR 040 & Santa Maria & 2451 & 24695 & & Riacho Fundo II & 2056 & 17369 \\
\hline SETOR & Itapoã & 2070 & 16790 & \multirow{6}{*}{$\begin{array}{l}\text { SETOR } \\
\text { NORTE } \\
\text { Eixo Viário: } \\
\text { BR } 020\end{array}$} & Fercal & & \\
\hline LESTE & Jardim Botânico & 8813 & 14386 & & Grande Colorado & & \\
\hline $\begin{array}{l}\text { Eixo } \\
\text { Viários: }\end{array}$ & Jardins Mangueiral & 7302 & 16163 & & Granja do Torto & & \\
\hline Ponte JK & Paranoá & 1832 & 15329 & & Lago Oeste & & \\
\hline DF 001 & São Sebastião & 10516 & 16077 & & Planaltina & 3164 & 34530 \\
\hline & & & & & $\begin{array}{l}\text { Sobradinho } \\
\text { Sobradinho II }\end{array}$ & 6132 & 21987 \\
\hline ENTORNO & Águas Lindas & 1792 & 43016 & \multirow{6}{*}{$\begin{array}{l}\text { ENTORNO } \\
\text { SUL }\end{array}$} & Céu Azul & 2170 & 36919 \\
\hline OESTE & S. A.Descoberto & 1547 & 41354 & & Cidade Ocidental & 1137 & 35137 \\
\hline & & & & & Jardim Ingá & 1376 & 33841 \\
\hline \multirow[t]{3}{*}{$\begin{array}{l}\text { ENTORNO } \\
\text { LESTE }\end{array}$} & \multirow[t]{3}{*}{$\begin{array}{l}\text { Cidade Oc. Jardim } \\
\text { ABC }\end{array}$} & \multirow[t]{3}{*}{1124} & \multirow[t]{3}{*}{34516} & & Luziânia & 1449 & 45550 \\
\hline & & & & & Novo Gama & 1355 & 41331 \\
\hline & & & & & Valparaíso de GO & 1280 & 27107 \\
\hline
\end{tabular}




\subsubsection{PERFIL DA MOBILIDADE NA IEM PU 1}

A Tabela 6.8 apresenta os resultados das estatísticas uni variadas para os dados na IEM PU1. Para as variáveis métricas são apresentadas médias e para as categóricas, as percentagens de ocorrência de cada grupo da variável. As localidades de residência foram agrupadas por setores no DF e entorno, conforme apresentado na Figura 6.2 e Tabela 6.7.

Tabela 6.8: Estatísticas univariadas - para IEM PU1

\begin{tabular}{|c|c|c|c|c|c|}
\hline Amostra & \multicolumn{2}{|c|}{ "alunos em geral" $(\mathrm{n}=805)$} & \multicolumn{3}{|c|}{ "alunos pareados" $(\mathrm{n}=48)$} \\
\hline Gênero & Feminino $55 \%$ & Masculino $45 \%$ & Feminino $65 \%$ & Masculino $35 \%$ & \\
\hline Idade & 15,46 anos & & 14,91 anos & & \\
\hline Distância & $14.926,05 \mathrm{~m}$ & & $14.508,83 \mathrm{~m}$ & & \\
\hline Renda & $\mathrm{R} \$ 5.766,59$ & & $\mathrm{R} \$ 4.721,29$ & & \\
\hline Densidade & $11.995,61 \mathrm{hab} / \mathrm{km}$ & & $10.983,94 \mathrm{hab} /$ & & \\
\hline Disp.Auto. & $85 \% \operatorname{sim} 15 \% \mathrm{n}$ & กão & $98 \% \operatorname{sim} 2 \% 1$ & & \\
\hline Partição moda & l na Ida & & Partição moda & na Ida & \\
\hline$A p e ́$ & Auto carona & T. Escolar & $A p e ́$ & Auto carona & T. Escolar \\
\hline $8 \%$ & $0 \%$ & $6 \%$ & $8 \%$ & $2 \%$ & $8 \%$ \\
\hline AutoFamília & Metrô & Ônibus & Auto Família & Metrô & Ônibus \\
\hline $13 \%$ & $14 \%$ & $59 \%$ & $19 \%$ & $18 \%$ & $54 \%$ \\
\hline Bicicleta & Dados Ausentes & & Bicicleta & Dados Ausentes & \\
\hline $0 \%$ & $0,25 \%$ & & $0 \%$ & $0 \%$ & \\
\hline Partição moda & l na Volta & & Partição moda & na Volta & \\
\hline$A p e ́$ & Auto carona & T. Escolar & $A p e ́$ & Auto carona & T. Escolar \\
\hline $8 \%$ & $1 \%$ & $6 \%$ & $10 \%$ & $0 \%$ & $10 \%$ \\
\hline Auto Família & Metrô & Ônibus & Auto Família & Metrô & Ônibus \\
\hline $18 \%$ & $16 \%$ & $50 \%$ & $19 \%$ & $13 \%$ & $46 \%$ \\
\hline Bicicleta & Dados Ausentes & & Bicicleta & Dados Ausentes & \\
\hline $0 \%$ & $1 \%$ & & $0 \%$ & $2 \%$ & \\
\hline Mesmo modo & na Ida e Volta & $76 \%$ & Mesmo modo 1 & Ida e Volta & $81 \%$ \\
\hline Localidade de & residência (agrupa & ado) & Localidade de & sidência (agrupc & \\
\hline Setor Central & Setor Oeste 1 & Setor Oeste 2 & Setor Central & Setor Oeste 1 & Setor Oeste 2 \\
\hline $23 \%$ & $11 \%$ & $5 \%$ & $23 \%$ & $15 \%$ & $6 \%$ \\
\hline Setor Oeste 3 & Setor Oeste 4 & Setor Leste & Setor Oeste 3 & Setor Oeste 4 & Setor Leste \\
\hline $5 \%$ & $11 \%$ & $22 \%$ & $4 \%$ & $13 \%$ & $17 \%$ \\
\hline Setor Sul & Setor Norte & Entorno Sul & Setor Sul & Setor Norte & Entorno Sul \\
\hline $5 \%$ & $3 \%$ & $7 \%$ & $6 \%$ & $2 \%$ & $4 \%$ \\
\hline $\begin{array}{l}\text { Entorno } \\
\text { Leste }\end{array}$ & Entorno Oeste & D. Ausentes & Entorno Leste & Entorno Oeste & D. Ausentes \\
\hline $2 \%$ & $1 \%$ & $7 \%$ & $4 \%$ & $2 \%$ & $4 \%$ \\
\hline
\end{tabular}

Na comparação das amostras, percebe-se razoável similaridade nas estatísticas obtidas para os dois tipos de amostras. Os alunos respondentes da IEM PU 1 têm as seguintes características: i) são na maioria mulheres; ii) têm por volta de 15 anos; iii) moram a quase $15 \mathrm{~km}$ da escola; iv) têm renda familiar de não mais de $\mathrm{R} \$ 6$ mil; v) moram em áreas relativamente densas (ver Apêndice $M$, para comparação); vi) a maioria tem disponibilidade de uso do automóvel; vii) utilizam amplamente os modos públicos 
motorizados, Ônibus e Metrô, tanto na ida (73\% na amostra em geral e $72 \%$ na amostra pareados), quanto na volta (66\% na amostra em geral e 59\% na amostra pareados); viii) o modo Automóvel da Família também é bastante utilizado (13\% e 19\%, na ida, para alunos em geral e pareados respectivamente; e 18\% e 19\%, na volta, para alunos em geral e pareados, respectivamente); ix) o uso do modo A pé não passa de $10 \%$ e o uso da bicicleta é quase inexistente; $\mathrm{x}$ ) residem majoritariamente nos setores a oeste $(32 \%$ e $38 \%$, para alunos em geral e pareados respectivamente), no Setor Central (23\%), e no Setor Leste (22\% e 17\%, para alunos em geral e pareados respectivamente. A distribuição espacial das localidades de residência, agrupadas em setores, é apresentada na Figura 6.3, para alunos em geral e pareados. Na figura, são apresentadas, também, as percentagens dos estudantes que residem em cada setor para alunos em geral e para alunos pareados (número entre parênteses).

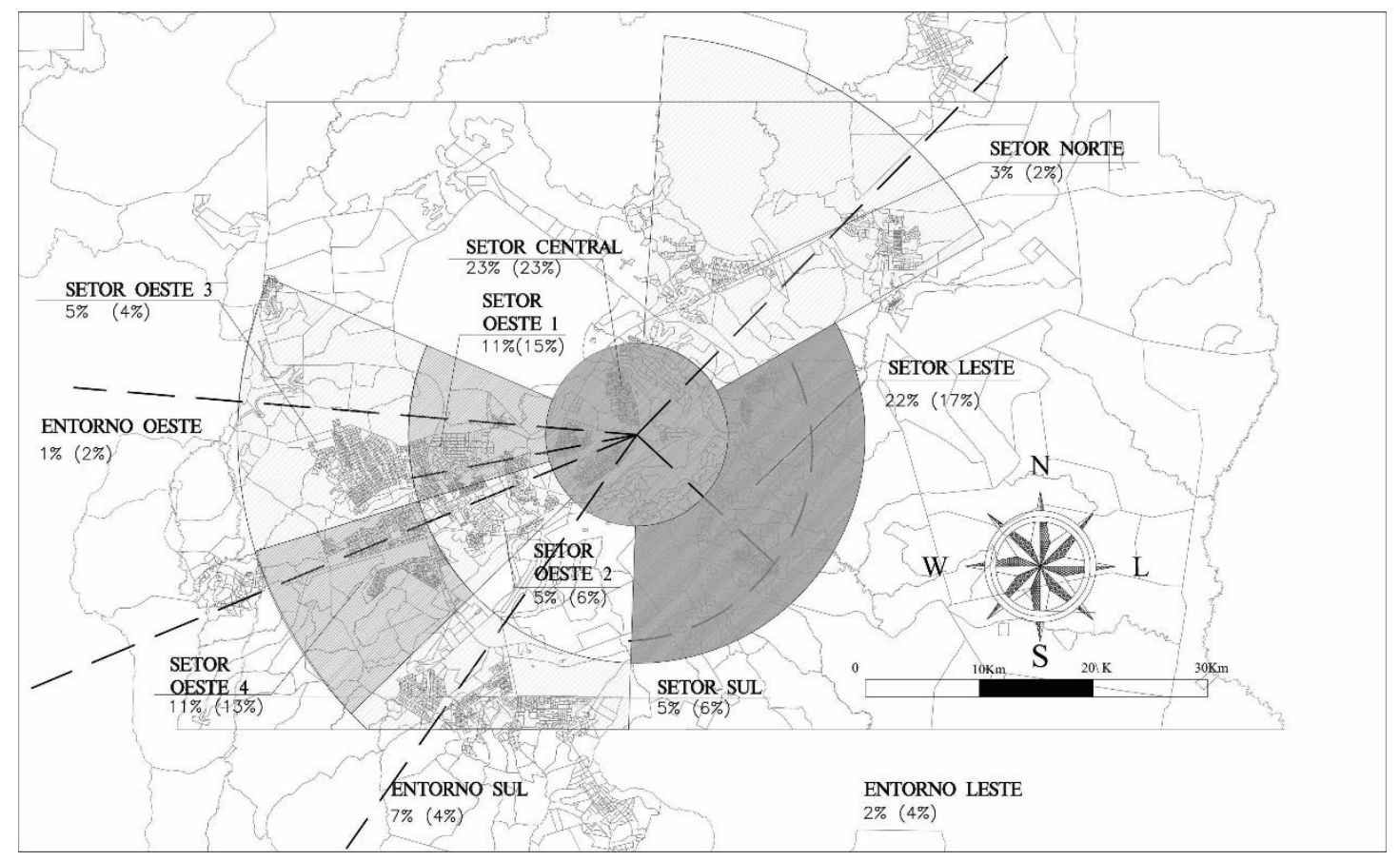

O uso do modo Transporte Escolar é um pouco mais elevado entre os alunos pareados ( $8 \%$ na ida e $10 \%$ na volta) do que entre os alunos em geral (6\% na ida e na volta). A utilização do modo Automóvel Carona é tímida nas duas amostras, não passando de $2 \%$ na amostra de alunos pareados.

A fidelização do uso do mesmo modo na ida e na volta é ligeiramente maior na amostra pareada (5\% a mais), sendo melhor detalhada na Tabela 6.9, pelos valores na diagonal 
principal. Essa característica e as demais estatísticas descritivas bivariadas são apresentadas apenas para a amostra "alunos em geral", considerando as duas amostras bastante semelhantes na partição modal. A frequência de uso do modo (expressa em número de alunos) é apontada tanto para a ida, como para a volta.

Tabela 6.9: Modo ida/ volta e frequência de uso na amostra "alunos geral" - IEM PU 1

\begin{tabular}{|c|c|c|c|c|c|c|c|c|c|c|c|c|c|}
\hline & \multicolumn{9}{|c|}{ MODO VOLTA } & \multicolumn{2}{|c|}{$\begin{array}{c}\text { Uso frequente do } \\
\text { modo na IDA }\end{array}$} \\
\hline & & & $N I$ & A pé & $\begin{array}{c}\text { Auto } \\
\text { carona }\end{array}$ & Bicicleta & Metrô & Ônibus & $\begin{array}{l}\text { Transp. } \\
\text { Escolar }\end{array}$ & \begin{tabular}{|c|} 
Auto \\
Família
\end{tabular} & Total & Sim & Não \\
\hline \multirow{9}{*}{ 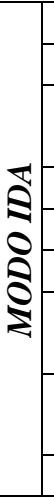 } & \multicolumn{2}{|c|}{$N I$} & $\mathbf{0}$ & 0 & 0 & 0 & 1 & 1 & 0 & 0 & 2 & 2 & 0 \\
\hline & \multicolumn{2}{|c|}{ A pé } & 1 & 48 & 0 & 1 & 2 & 1 & 0 & 10 & 63 & 60 & 3 \\
\hline & \multicolumn{2}{|c|}{$\begin{array}{c}\text { Auto } \\
\text { carona }\end{array}$} & 0 & 0 & 1 & 0 & 0 & 0 & 0 & 1 & 2 & 1 & 1 \\
\hline & \multicolumn{2}{|c|}{ Bicicleta } & 0 & 0 & 0 & 1 & 0 & 0 & 0 & 1 & 2 & 2 & 0 \\
\hline & \multicolumn{2}{|c|}{ Metrô } & 1 & 1 & 1 & 0 & 93 & 9 & 1 & 7 & 113 & 105 & 8 \\
\hline & \multicolumn{2}{|c|}{ Ônibus } & 3 & 7 & 1 & 1 & 25 & 371 & 5 & 58 & 471 & 455 & 16 \\
\hline & \multicolumn{2}{|c|}{$\begin{array}{l}\text { Transp. } \\
\text { Escolar }\end{array}$} & 1 & 0 & 0 & 0 & 1 & 2 & 38 & 7 & 49 & 48 & 1 \\
\hline & \multicolumn{2}{|c|}{$\begin{array}{c}\text { Auto } \\
\text { Família }\end{array}$} & 1 & 5 & 2 & 0 & 9 & 19 & 5 & 62 & 103 & 89 & 14 \\
\hline & \multicolumn{2}{|c|}{ Total } & 7 & 61 & 5 & 3 & 131 & 403 & 49 & 146 & 805 & 762 & 43 \\
\hline \multirow{2}{*}{\multicolumn{2}{|c|}{ 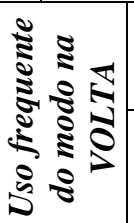 }} & : & 6 & 56 & 4 & 2 & 118 & 377 & 42 & 114 & 719 & & \\
\hline & & 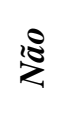 & 1 & 5 & 1 & 1 & 13 & 26 & 7 & 32 & 86 & & \\
\hline
\end{tabular}

As maiores fidelidades de utilização (mesmo modo utilizado nas viagens de ida e volta) estão nos modos coletivos públicos (Metrô $82 \%$ e Ônibus 79\%), seguido do modo A pé (76\%). O fato de dois respondentes comporem viagens de bicicleta com outros modos, na ida ou na volta pode indicar erro de preenchimento, já que este modo (no caso de bicicletas privadas) tem a fidelização por princípio. Descontando os modos Automóvel Carona e Bicicleta, a menor fidelização está entre os usuários do Automóvel da Família. Mais de $60 \%$ dos usuários que escolheram este modo na ida utilizaram outros modos na volta. A maior migração dos usuários do modo Automóvel da Família nas viagens de ida é para o modo Ônibus, cerca de $19 \%$ dessas viagens. O inverso, ou seja, aqueles que foram com o modo Ônibus para a escola e voltaram de Automóvel da Família também é alto, cerca de $12 \%$.

Pelas respostas à questão se o modo de ida ou volta correspondia ao modo de uso frequente, pode-se também inferir pelos dados apresentados na Tabela 6.9 que o 
questionário conseguiu captar os modos mais frequentemente utilizados, tanto na ida, quanto na volta. A Tabela 6.10 apresenta a opção de mudança de modo com relação ao modo atual utilizado na ida, quando a mudança é desejada pelo respondente (a opção de mudança relacionada às viagens de volta não é apresentada uma vez que $76 \%$ dos respondentes usam o mesmo modo na ida e na volta). O Automóvel da Família é a opção de mudança de $44 \%$ dos respondentes que não estão contentes com o modo atualmente utilizado. Destes, os usuários de ônibus (53\%), bicicleta (50\%), e de metrô (41\%) são os usuários de maior potencial para migração para o modo Automóvel da Família. O modo Automóvel Carona é o que atrai a menor percentagem $(0,6 \%)$ dos respondentes que gostariam de mudar de modo. A percentagem de respondentes que não trocaria de modo é de $41 \%$. Os usuários do modo Automóvel da Família e Transporte Escolar são os que manifestaram maior contentamento com o modo utilizado para ir à IEM. O maior descontentamento está entre os usuários de ônibus.

Tabela 6.10: Opções de mudança de modo na ida, amostra "alunos geral" - IEM PU 1 Opção de Mudança

\begin{tabular}{|c|c|c|c|c|c|c|c|c|c|c|c|c|}
\hline & & $\frac{1}{4}$ & 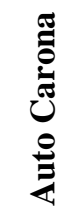 & $\frac{\sqrt[T]{0}}{\frac{0}{e}}$ & 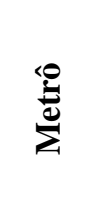 & 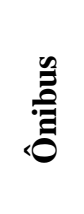 & 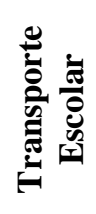 & 严 & 乙 & $\frac{5}{5}$ & 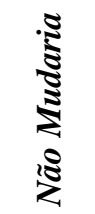 & $\underset{\mathfrak{s}}{\mathfrak{s}}$ \\
\hline \multirow{8}{*}{ 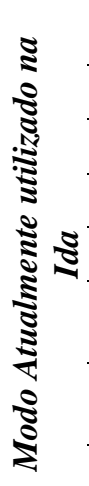 } & A pé & $0.0 \%$ & $0.0 \%$ & $6.0 \%$ & $1.5 \%$ & $6.0 \%$ & $0.0 \%$ & $23.9 \%$ & $0.0 \%$ & $3.0 \%$ & $59.7 \%$ & $100.0 \%$ \\
\hline & Auto Carona & $0.0 \%$ & $0.0 \%$ & $0.0 \%$ & $33.3 \%$ & $0.0 \%$ & $0.0 \%$ & $33.3 \%$ & $0.0 \%$ & $0.0 \%$ & $33.3 \%$ & $100.0 \%$ \\
\hline & Bicicleta & $0.0 \%$ & $0.0 \%$ & $0.0 \%$ & $0.0 \%$ & $0.0 \%$ & $0.0 \%$ & $50.0 \%$ & $0.0 \%$ & $0.0 \%$ & $50.0 \%$ & $100.0 \%$ \\
\hline & Metrô & $0.0 \%$ & $0.0 \%$ & $2.6 \%$ & $0.0 \%$ & $0.9 \%$ & $7.7 \%$ & $41.0 \%$ & $2.6 \%$ & $0.0 \%$ & $45.3 \%$ & $100.0 \%$ \\
\hline & $\hat{O}$ nibus & $1.0 \%$ & $0.8 \%$ & $2.2 \%$ & $5.0 \%$ & $0.0 \%$ & $9.7 \%$ & $52.5 \%$ & $0.6 \%$ & $0.6 \%$ & $27.6 \%$ & $100.0 \%$ \\
\hline & $\begin{array}{c}\text { Transporte } \\
\text { Escolar }\end{array}$ & $1.9 \%$ & $0.0 \%$ & $0.0 \%$ & $5.7 \%$ & $3.8 \%$ & $0.0 \%$ & $28.3 \%$ & $0.0 \%$ & $0.0 \%$ & $60.4 \%$ & $100.0 \%$ \\
\hline & $\begin{array}{l}\text { Auto da } \\
\text { Família }\end{array}$ & $1.8 \%$ & $0.9 \%$ & $3.6 \%$ & $3.6 \%$ & $3.6 \%$ & $8.0 \%$ & $0.0 \%$ & $0.9 \%$ & $1.8 \%$ & $75.9 \%$ & $100.0 \%$ \\
\hline & $N I$ & $0.0 \%$ & $0.0 \%$ & $0.0 \%$ & $0.0 \%$ & $0.0 \%$ & $0.0 \%$ & $0.0 \%$ & $0.0 \%$ & $50.0 \%$ & $50.0 \%$ & $100.0 \%$ \\
\hline
\end{tabular}

São apresentadas, em seguida, algumas relações bivariadas na escolha do modo de transporte. Foram tabulados dados apenas para as viagens de ida, dado que, dos 805 respondentes, 614 (76\%) usaram o mesmo modo na ida e na volta. São apresentadas as seguintes relações: i) a escolha modal por gênero; ii) a escolha modal por idade; iii) e a escolha modal por distância casa/escola; iv) escolha modal por densidade na localidade de residência; v) escolha modal por disponibilidade de automóveis na residência; escolha 
modal por localidade de residência (agrupado). Os resultados são apresentados na Tabela 6.11 .

Tabela 6.11: Escolha modal na ida e variáveis sociodemográficas - IEM PU 1 Modo atualmente utilizado IDA

\begin{tabular}{|c|c|c|c|c|c|c|c|c|c|}
\hline Característica & A pé & $\begin{array}{c}\text { Auto } \\
\text { Carona }\end{array}$ & Bicicleta & Metrô & Ônibus & $\begin{array}{c}\text { Transporte } \\
\text { Escolar }\end{array}$ & $\begin{array}{l}\text { Auto da } \\
\text { Família }\end{array}$ & $N I$ & Total \\
\hline \multicolumn{10}{|c|}{ Quanto ao gênero } \\
\hline Masculino & $9 \%$ & $1 \%$ & $1 \%$ & $16 \%$ & $57 \%$ & $4 \%$ & $12 \%$ & $1 \%$ & $100 \%$ \\
\hline Feminino & $7 \%$ & $0 \%$ & $0 \%$ & $12 \%$ & $59 \%$ & $8 \%$ & $14 \%$ & $0 \%$ & $100 \%$ \\
\hline \multicolumn{10}{|c|}{ Quanto à idade } \\
\hline 13 anos & $0 \%$ & $0 \%$ & $0 \%$ & $0 \%$ & $100 \%$ & $0 \%$ & $0 \%$ & $0 \%$ & $100 \%$ \\
\hline 14 anos & $10 \%$ & $2 \%$ & $1 \%$ & $11 \%$ & $53 \%$ & $9 \%$ & $15 \%$ & $0 \%$ & $100 \%$ \\
\hline 15 anos & $9 \%$ & $0 \%$ & $0 \%$ & $13 \%$ & $56 \%$ & $7 \%$ & $14 \%$ & $1 \%$ & $100 \%$ \\
\hline 16 anos & $5 \%$ & $0 \%$ & $0 \%$ & $15 \%$ & $62 \%$ & $6 \%$ & $11 \%$ & $0 \%$ & $100 \%$ \\
\hline 17 anos & $8 \%$ & $0 \%$ & $0 \%$ & $15 \%$ & $62 \%$ & $3 \%$ & $12 \%$ & $0 \%$ & $100 \%$ \\
\hline 18 anos & $0 \%$ & $0 \%$ & $0 \%$ & $8 \%$ & $92 \%$ & $0 \%$ & $0 \%$ & $0 \%$ & $100 \%$ \\
\hline 19 anos & $100 \%$ & $0 \%$ & $0 \%$ & $0 \%$ & $0 \%$ & $0 \%$ & $0 \%$ & $0 \%$ & $100 \%$ \\
\hline$N I$ & $6 \%$ & $0 \%$ & $0 \%$ & $18 \%$ & $47 \%$ & $12 \%$ & $18 \%$ & $0 \%$ & $100 \%$ \\
\hline \multicolumn{10}{|c|}{ Quanto à distância casa/escola (em metros) } \\
\hline Média & 4.456 & 17.231 & 14.197 & 15.889 & 16.252 & 17.655 & 12.856 & & \\
\hline \multicolumn{10}{|c|}{ Quanto à renda do domicílio (em $R \$$ ) } \\
\hline Média & 7.052 & 2.370 & 6.054 & 5.442 & 5.672 & 4.022 & 6.743 & & \\
\hline \multicolumn{10}{|c|}{ Quanto à densidade na localidade de residência (em hab/Km²) } \\
\hline Média & 9.427 & 12.040 & 9.482 & 16.451 & 10.854 & 16.157 & 11.974 & & \\
\hline \multicolumn{10}{|c|}{ Quanto à disponibilidade de automóveis no domicílio } \\
\hline Não & $13 \%$ & $0 \%$ & $0 \%$ & $5 \%$ & $65 \%$ & $8 \%$ & $9 \%$ & $0 \%$ & $100 \%$ \\
\hline \multirow{2}{*}{\multicolumn{10}{|c|}{ Quanto à localidade de residência }} \\
\hline & & & & & & & & & \\
\hline Setor Central & $28 \%$ & $1 \%$ & $1 \%$ & $2 \%$ & $43 \%$ & $5 \%$ & $21 \%$ & $0 \%$ & $100 \%$ \\
\hline Setor Leste & $2 \%$ & $1 \%$ & $0 \%$ & $1 \%$ & $80 \%$ & $10 \%$ & $7 \%$ & $1 \%$ & $100 \%$ \\
\hline Setor Norte & $5 \%$ & $0 \%$ & $0 \%$ & $0 \%$ & $68 \%$ & $0 \%$ & $27 \%$ & $0 \%$ & $100 \%$ \\
\hline Setor Oeste 1 & $1 \%$ & $0 \%$ & $0 \%$ & $49 \%$ & $30 \%$ & $1 \%$ & $19 \%$ & $0 \%$ & $100 \%$ \\
\hline Setor Oeste 2 & $0 \%$ & $0 \%$ & $0 \%$ & $2 \%$ & $76 \%$ & $10 \%$ & $12 \%$ & $0 \%$ & $100 \%$ \\
\hline Setor Oeste 3 & $0 \%$ & $0 \%$ & $0 \%$ & $72 \%$ & $18 \%$ & $0 \%$ & $8 \%$ & $3 \%$ & $100 \%$ \\
\hline Setor Oeste 4 & $0 \%$ & $0 \%$ & $0 \%$ & $32 \%$ & $64 \%$ & $1 \%$ & $3 \%$ & $0 \%$ & $100 \%$ \\
\hline Setor Sul & $5 \%$ & $2 \%$ & $0 \%$ & $0 \%$ & $83 \%$ & $0 \%$ & $10 \%$ & $0 \%$ & $100 \%$ \\
\hline Entorno Leste & $0 \%$ & $0 \%$ & $0 \%$ & $0 \%$ & $94 \%$ & $0 \%$ & $6 \%$ & $0 \%$ & $100 \%$ \\
\hline Entorno Oeste & $0 \%$ & $0 \%$ & $0 \%$ & $17 \%$ & $83 \%$ & $0 \%$ & $0 \%$ & $0 \%$ & $100 \%$ \\
\hline Entorno Sul & $3 \%$ & $0 \%$ & $2 \%$ & $2 \%$ & $49 \%$ & $29 \%$ & $16 \%$ & $0 \%$ & $100 \%$ \\
\hline$N I$ & $7 \%$ & $0 \%$ & $0 \%$ & $14 \%$ & $62 \%$ & $2 \%$ & $16 \%$ & $0 \%$ & $100 \%$ \\
\hline
\end{tabular}

Quanto ao gênero, os meninos usam mais os modos não motorizados (Bicicleta e A pé), bem como o Metrô e Automóvel Carona. Já as meninas usam mais os modos Transporte 
Escolar, Automóvel da Família e Ônibus. Quanto à idade, excluindo-se a classe de 13 anos, o percentual de usuários dos modos Automóvel da Família e Transporte Escolar diminui com o aumento da idade, enquanto acontece o contrário com o modo Ônibus. Quanto à localidade de residência, e como era esperado, o Setor Central concentra o maior número de viagens a pé. A observação de viagens a pé e de bicicleta vindas do Entorno Sul, distante a mais de $25 \mathrm{~km}$ da escola, pode indicar um erro de preenchimento do questionário, onde o respondente referiu o modo usado para sair de casa e atingir o ponto de ônibus. O Setor Entorno Sul aponta o maior percentual de usuários para o modo Transporte Escolar. Os setores a oeste são bem servidos de metrô, e concentram os maiores percentuais de usuários que chegam na escola por este modo. São mínimas as viagens pelo modo bicicleta no Plano Piloto, onde existe uma boa rede de ciclovias.

\subsubsection{PERFIL DA MOBILIDADE NA IEM PU 2}

A Tabela 6.12 apresenta os resultados das estatísticas univariadas para os dados na IEM PU2, nas amostras "alunos geral" e "alunos pareados" e a Figura 6.4 apresenta a espacialização do agrupamento das ocorrências de localidade de residência para as amostras "alunos geral" e "alunos pareados “. Os valores inseridos em cada setor representam a percentagem dos alunos das amostras "alunos geral" e "alunos pareados" (valor entre parênteses) que residem no setor. Na IEM PU 2, tanto na amostra "alunos geral", como na de "alunos pareados", observa-se que a maioria dos respondentes têm: i) idade média entre 15 e 16 anos; ii) vivem a mais de $10 \mathrm{Km}$ da escola; iii) têm renda domiciliar média inferior a $\mathrm{R} \$ 6500,00$; iv) têm automóvel disponível no domicílio; vii) usam majoritariamente o modo Ônibus e o Automóvel da Família; viii) residem no Setor Central, Setor Norte ou Setor Leste.

As diferenças entre as duas amostras aparecem nas seguintes características: i) na distribuição de gênero (na amostra "alunos geral”, 46\% Feminino e 54\% Masculino, e na amostra "alunos pareados", 62\% Feminino e 38\% Masculino), indicando que um maior número de pais ou responsáveis de meninas decidiu responder ao questionário para pais; ii) na densidade da localidade de residência, os alunos da amostra pareada vivem em lugares mais densos; iii) os alunos da amostra pareada também usam mais o transporte escolar e o modo a pé; e eles não usam carona. 
Tabela 6.12: Estatísticas univariadas - IEM PU 2

\begin{tabular}{|c|c|c|c|c|c|}
\hline Amostra & \multicolumn{2}{|c|}{ "alunos em geral" $(\mathrm{n}=358)$} & \multicolumn{3}{|c|}{ "alunos pareados" $(\mathrm{n}=52)$} \\
\hline Gênero & $46 \%$ Feminino & $54 \%$ Masculino & $62 \%$ Feminino & $38 \%$ Masculino & \\
\hline Idade & 15,67 anos & & 15,56 anos & & \\
\hline Distância & $12.206,64 \mathrm{~m}$ & & $10.301,57 \mathrm{~m}$ & & \\
\hline Renda & $\mathrm{R} \$ 5.052,95$ & & $\mathrm{R} \$ 6.355,98$ & & \\
\hline Densidade & $9.290,70 \mathrm{hab} / \mathrm{km}^{2}$ & & $17.207,47 \mathrm{hab} / \mathrm{k}$ & & \\
\hline Disp.Auto. & $98 \% \operatorname{sim} 2 \%$ nãc & & $98 \% \operatorname{sim} 2 \%$ & & \\
\hline Partição moda & l na Ida & & Partição modal & a Ida & \\
\hline$A p e ́$ & Auto carona & T. Escolar & Apé & Auto carona & T. Escolar \\
\hline $8 \%$ & $2 \%$ & $3 \%$ & $13 \%$ & $0 \%$ & $8 \%$ \\
\hline Auto Família & Metrô & Ônibus & Auto Família & Metrô & Ônibus \\
\hline $28 \%$ & $1 \%$ & $57 \%$ & $33 \%$ & $2 \%$ & $44 \%$ \\
\hline Bicicleta & Dados Ausentes & & Bicicleta & Dados Ausentes & \\
\hline $1 \%$ & $0 \%$ & & $0 \%$ & $0 \%$ & \\
\hline Partição moda & l na Volta & & Partição modal & a Volta & \\
\hline Apé & Auto carona & T. Escolar & Apé & Auto carona & T. Escolar \\
\hline $8 \%$ & $1 \%$ & $3 \%$ & $12 \%$ & $0 \%$ & $6 \%$ \\
\hline Auto Família & Metrô & Ônibus & Auto Família & Metrô & Ônibus \\
\hline $20 \%$ & $2 \%$ & $63 \%$ & $19 \%$ & $2 \%$ & $60 \%$ \\
\hline Bicicleta & Dados Ausentes & & Bicicleta & Dados Ausentes & \\
\hline $1 \%$ & $3 \%$ & & $0 \%$ & $2 \%$ & \\
\hline Mesmo modo 1 & a Ida e Volta & $74 \%$ & Mesmo modo $n$ & Ida e Volta & $75 \%$ \\
\hline Localidade de & residência (agrupc & ado) & Localidade de 1 & sidência (agrupa & \\
\hline Setor Central & Setor Oeste 1 & Setor Oeste 2 & Setor Central & Setor Oeste 1 & Setor Oeste 2 \\
\hline $35 \%$ & $2 \%$ & $0 \%$ & $54 \%$ & $2 \%$ & $0 \%$ \\
\hline Setor Oeste 3 & Setor Oeste 4 & Setor Leste & Setor Oeste 3 & Setor Oeste 4 & Setor Leste \\
\hline $3 \%$ & $5 \%$ & $18 \%$ & $4 \%$ & $4 \%$ & $13 \%$ \\
\hline Setor Sul & Setor Norte & Entorno Sul & Setor Sul & Setor Norte & Entorno Sul \\
\hline $2 \%$ & $21 \%$ & $4 \%$ & $4 \%$ & $15 \%$ & $2 \%$ \\
\hline Entorno Leste & Entorno Oeste & D. Ausentes & Entorno Leste & Entorno Oeste & D. Ausentes \\
\hline $0 \%$ & $0 \%$ & $10 \%$ & $0 \%$ & $2 \%$ & $0 \%$ \\
\hline
\end{tabular}

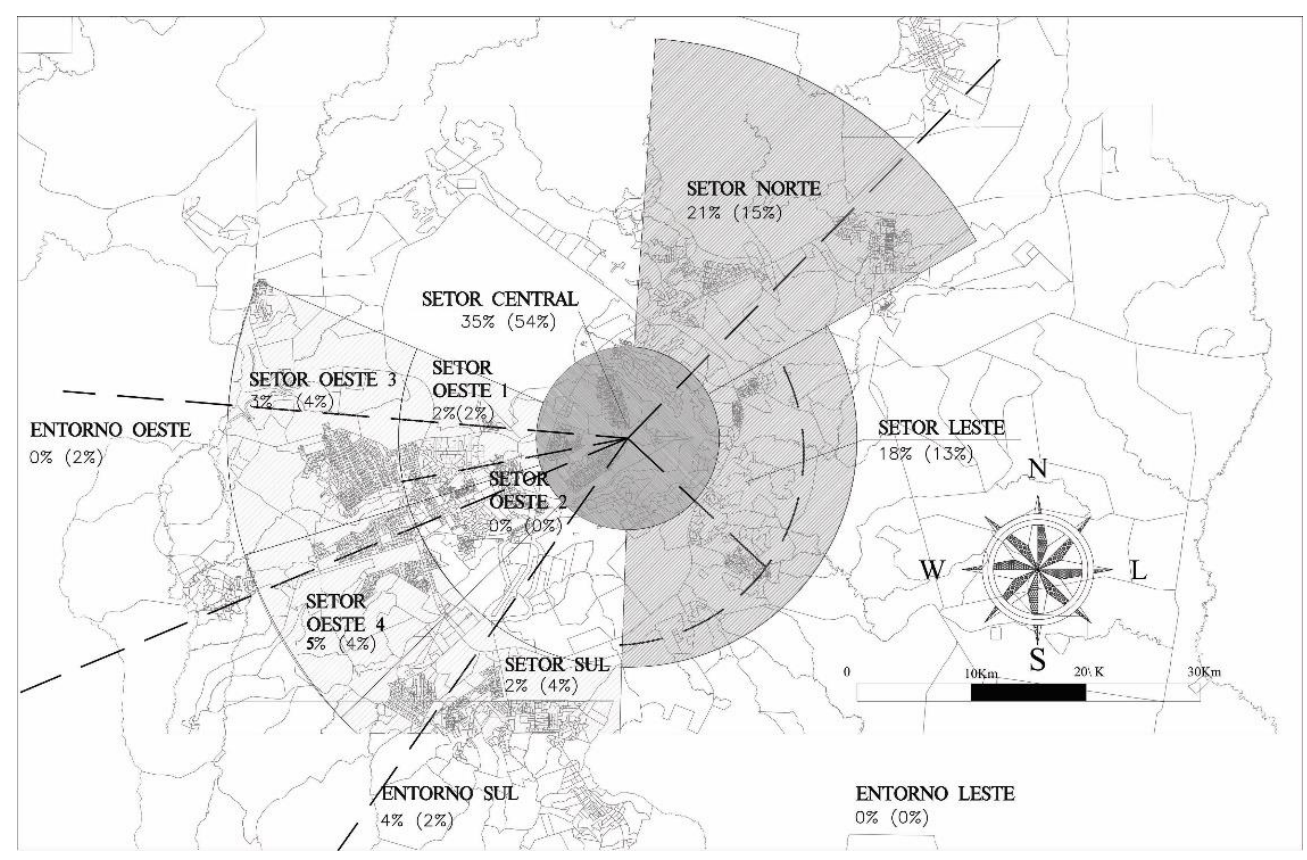


A fidelização na utilização do modo na ida ou na volta se mostrou quase idêntica nas duas amostras "alunos geral" "alunos pareados" e é melhor explicada pelos dados da Tabela 6.13. A Tabela 6.14 apresenta as opções de mudança dos respondentes que se dizem descontentes com o modo atualmente utilizado.

Tabela 6.13: Modo ida/volta e frequência de uso na amostra "alunos geral" - IEM PU 2

\begin{tabular}{|c|c|c|c|c|c|c|c|c|c|c|c|c|c|}
\hline & \multicolumn{9}{|c|}{ MODO VOLTA } & \multicolumn{2}{|c|}{$\begin{array}{c}\text { Uso } \\
\text { frequente do } \\
\text { modo na } \\
\text { IDA }\end{array}$} \\
\hline & & & $N I$ & A pé & \begin{tabular}{|l} 
Auto \\
carona
\end{tabular} & Bicicleta & Metrô & Ônibus & T Escolar & $\begin{array}{c}\text { Auto } \\
\text { Família }\end{array}$ & Total & Não & Sim \\
\hline \multirow{9}{*}{ 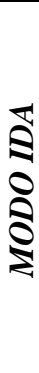 } & $N I$ & & $\mathbf{0}$ & 0 & 0 & 1 & 0 & 0 & 0 & 0 & 1 & 0 & 1 \\
\hline & A pé & & 0 & 22 & 0 & 0 & 1 & 2 & 0 & 3 & 28 & 1 & 27 \\
\hline & \multicolumn{2}{|c|}{ Auto carona } & 1 & 0 & 1 & 0 & 0 & 4 & 0 & 1 & 7 & 2 & 5 \\
\hline & \multicolumn{2}{|c|}{ Bicicleta } & 0 & 0 & 0 & 2 & 0 & 0 & 0 & 1 & 3 & 0 & 3 \\
\hline & \multicolumn{2}{|c|}{ Metrô } & 0 & 0 & 0 & 0 & 3 & 1 & 0 & 0 & 4 & 0 & 4 \\
\hline & \multicolumn{2}{|c|}{ Ônibus } & 5 & 3 & 2 & 0 & 0 & 182 & 1 & 12 & 205 & 4 & 201 \\
\hline & \multicolumn{2}{|c|}{ T. Escolar } & 1 & 1 & 0 & 0 & 0 & 1 & 5 & 2 & 10 & 1 & 9 \\
\hline & \multicolumn{2}{|c|}{ Auto Família } & 2 & 4 & 2 & 0 & 2 & 35 & 4 & 51 & 100 & 13 & 87 \\
\hline & \multicolumn{2}{|c|}{ Total } & 9 & 30 & 5 & 3 & 6 & 225 & 10 & 70 & 358 & 0 & 1 \\
\hline \multirow{2}{*}{\multicolumn{2}{|c|}{ 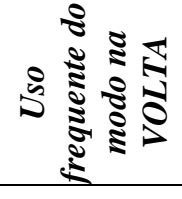 }} & \& & 2 & 4 & 1 & 1 & 1 & 17 & 4 & 17 & 2 & & \\
\hline & & $\stackrel{\Xi}{5}$ & 7 & 26 & 4 & 2 & 5 & 208 & 6 & 53 & 7 & & \\
\hline
\end{tabular}

Obs.: NI - Não informado; T. Escolar - Transporte Escolar.

Tabela 6.14: Opção de mudança de modo na amostra "alunos geral" - IEM PU 2

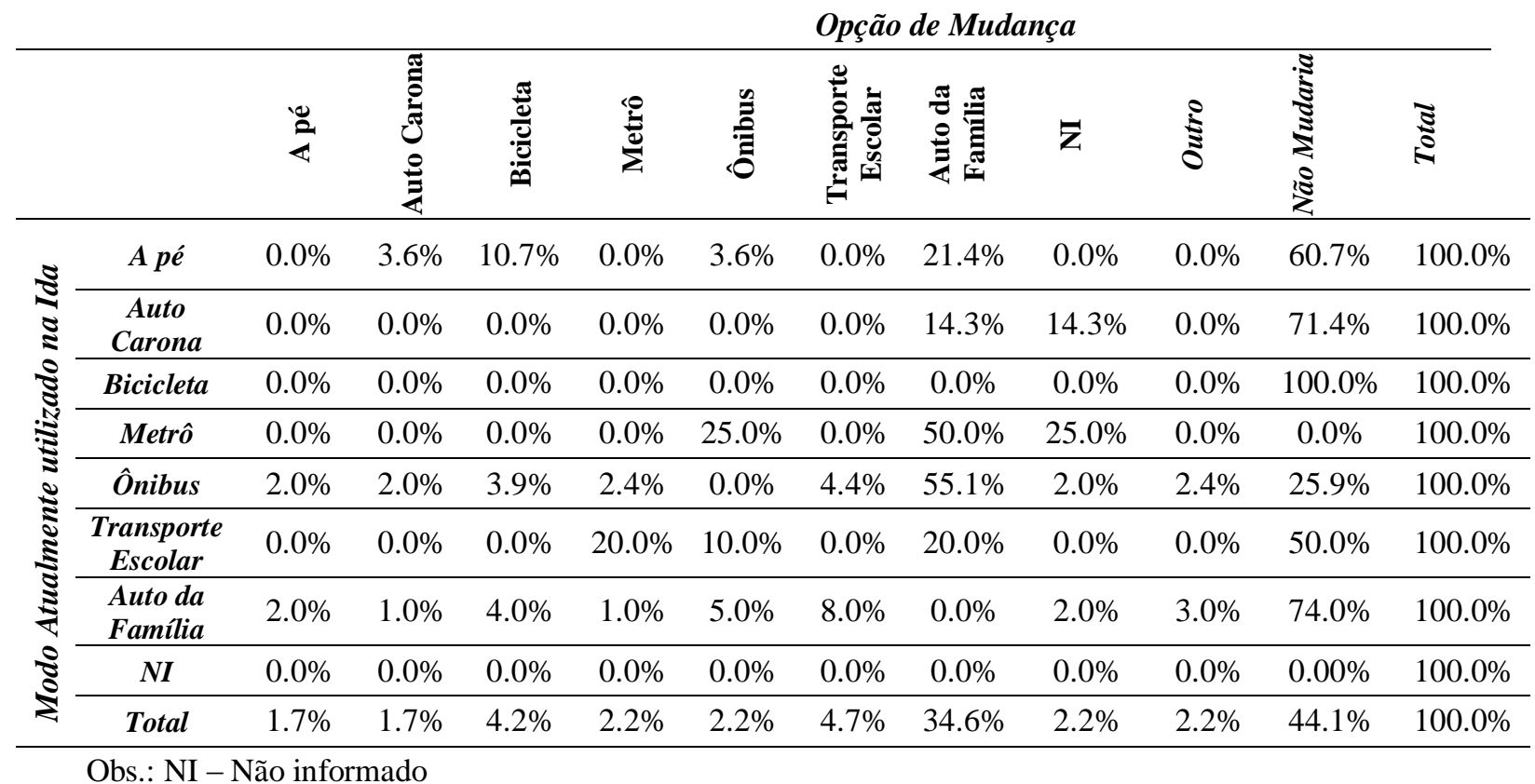


Pela Tabela 6.13, a maior fidelidade de uso do modo na ida e na volta está entre os usuários dos modos Ônibus, A pé e Metrô. Como na IEM PU 1, a amostra desta escola representa os modos mais frequentemente utilizados. Pela Tabela 6.14, percebe-se que, exceto para o ônibus, $50 \%$ ou mais dos usuários dos outros modos estão contentes com o modo atualmente utilizado, o que soma $44,1 \%$ do total de respondentes. O maior percentual de descontentamento é entre os usuários de ônibus $(74,1 \%)$. Os usuários de ônibus $(55,1 \%)$ e metrô (50\%) são os mais propensos a mudar para o automóvel. O modo Automóvel da Família é a opção mais desejada pelos usuários descontentes (34,6\% dos respondentes). Os modos menos atrativos para os descontentes são os modos A pé $(1,7 \%)$ e Automóvel Carona $(1,7 \%)$.

A Tabela 6.15 apresenta algumas relações bivariadas entre o modo na ida com as variáveis sociodemográficas dos respondentes e a localidade de residência. O modo Ônibus é o modo mais utilizado, tanto para meninas, como para meninos. Os meninos caminham mais e usam proporcionalmente mais Transporte Escolar e Automóvel da Família. Quase 90\% dos alunos mais velhos (16 anos ou mais) usam modos motorizados (Metrô, Ônibus e Automóvel da Família). Alunos até 15 anos usam mais o Transporte Escolar do que os mais velhos. Os usuários de transporte escolar têm renda média domiciliar mais baixa, e moram mais longe, como os usuários do modo Metrô.

Os usuários de ônibus têm a segunda menor renda média domiciliar e moram em áreas mais densas. Os que usam o modo bicicleta moram mais perto e vivem em áreas menos densas. Mais de $70 \%$ dos alunos em domicílios considerados como tendo disponibilidade de automóvel declaram não usar o Automóvel da Família para ir à escola. O modo Transporte Escolar é percentualmente mais utilizado por alunos que residem no Setor Oeste 3, Setor Leste e Entorno Sul, e a carona pelos que residem no Setor Norte; $16 \%$ dos residentes no Setor Central vão a pé ou de bicicleta para a escola. 
Tabela 6.15: Escolha modal na ida e variáveis sociodemográficas - IEM PU 2

Modo atualmente utilizado IDA

\begin{tabular}{|c|c|c|c|c|c|c|c|c|c|}
\hline Característica & A pé & $\begin{array}{c}\text { Auto } \\
\text { Carona }\end{array}$ & Bicicleta & Metrô & Ônibus & $\begin{array}{c}\text { Transporte } \\
\text { Escolar }\end{array}$ & $\begin{array}{c}\text { Auto } \\
\text { Família }\end{array}$ & $N I$ & Total \\
\hline & \multicolumn{9}{|c|}{ Quanto ao gênero } \\
\hline Masculino & $10.4 \%$ & $1.6 \%$ & $1.0 \%$ & $.5 \%$ & $51.8 \%$ & $4.1 \%$ & $30.1 \%$ & $.5 \%$ & $100 \%$ \\
\hline \multirow[t]{2}{*}{ Feminino } & $4.8 \%$ & $2.4 \%$ & $.6 \%$ & $1.8 \%$ & $63.6 \%$ & $1.2 \%$ & $25.5 \%$ & $.0 \%$ & $100 \%$ \\
\hline & \multicolumn{9}{|c|}{ Quanto à idade } \\
\hline 13 anos & $0.0 \%$ & $0.0 \%$ & $0.0 \%$ & $0.0 \%$ & $0.0 \%$ & $0.0 \%$ & $100.0 \%$ & $0.0 \%$ & $100 \%$ \\
\hline 14 anos & $0.0 \%$ & $4.5 \%$ & $0.0 \%$ & $0.0 \%$ & $54.5 \%$ & $9.1 \%$ & $31.8 \%$ & $0.0 \%$ & $100 \%$ \\
\hline 15 anos & $9.0 \%$ & $1.9 \%$ & $1.3 \%$ & $0.6 \%$ & $54.2 \%$ & $3.2 \%$ & $29.0 \%$ & $0.6 \%$ & $100 \%$ \\
\hline 16 anos & $7.9 \%$ & $1.0 \%$ & $0.0 \%$ & $2.0 \%$ & $60.4 \%$ & $1.0 \%$ & $27.7 \%$ & $0.0 \%$ & $100 \%$ \\
\hline 17 anos & $7.3 \%$ & $1.8 \%$ & $1.8 \%$ & $0.0 \%$ & $67.3 \%$ & $1.8 \%$ & $20.0 \%$ & $0.0 \%$ & $100 \%$ \\
\hline 18 anos & $0.0 \%$ & $9.1 \%$ & $0.0 \%$ & $0.0 \%$ & $54.5 \%$ & $0.0 \%$ & $36.4 \%$ & $0.0 \%$ & $100 \%$ \\
\hline 19 anos & $0.0 \%$ & $0.0 \%$ & $0.0 \%$ & $0.0 \%$ & $100.0 \%$ & $0.0 \%$ & $0.0 \%$ & $0.0 \%$ & $100 \%$ \\
\hline 20 anos & $0.0 \%$ & $0.0 \%$ & $0.0 \%$ & $50.0 \%$ & $0.0 \%$ & $0.0 \%$ & $50.0 \%$ & $0.0 \%$ & $100 \%$ \\
\hline$N I$ & $20.0 \%$ & $0.0 \%$ & $0.0 \%$ & $0.0 \%$ & $40.0 \%$ & $10.0 \%$ & $30.0 \%$ & $0.0 \%$ & $100 \%$ \\
\hline \multicolumn{10}{|c|}{ Quanto à distância casa/escola (em metros) } \\
\hline Média & 6808.9 & 10282.9 & 2690.4 & 15410.8 & 13097.2 & 14032.1 & 11839.6 & -- & -- \\
\hline \multicolumn{10}{|c|}{ Quanto à renda do domicílio $(e m \boldsymbol{R} \$)$} \\
\hline Média & 7031.6 & 4827.0 & 5066.0 & 7030.0 & 4470.6 & 1942.7 & 5998.8 & -- & -- \\
\hline \multicolumn{10}{|c|}{ Quanto à densidade na localidade de residência (em hab/Km²) } \\
\hline Média & 7129.4 & 6141.8 & 720.3 & 7012.1 & 10597.5 & 10346.0 & 7692.7 & -- & -- \\
\hline \multicolumn{10}{|c|}{ Quanto à disponibilidade de automóveis no domicílio } \\
\hline Não & $0.0 \%$ & $0.0 \%$ & $0.0 \%$ & $0.0 \%$ & $66.7 \%$ & $16.7 \%$ & $16.7 \%$ & 0 & $100 \%$ \\
\hline \multirow[t]{2}{*}{ Sim } & $8.0 \%$ & $2.0 \%$ & $.9 \%$ & $1.1 \%$ & $57.1 \%$ & $2.6 \%$ & $28.1 \%$ & $.3 \%$ & $100 \%$ \\
\hline & \multicolumn{9}{|c|}{ Quanto à localidade de residência } \\
\hline Setor Central & $14.4 \%$ & $1.6 \%$ & $1.6 \%$ & $0.8 \%$ & $53.6 \%$ & $1.6 \%$ & $26.4 \%$ & $0.0 \%$ & $100 \%$ \\
\hline Setor Leste & $1.6 \%$ & $1.6 \%$ & $0.0 \%$ & $0.0 \%$ & $59.4 \%$ & $7.8 \%$ & $28.1 \%$ & $1.6 \%$ & $100 \%$ \\
\hline Setor Norte & $2.7 \%$ & $4.1 \%$ & $1.4 \%$ & $0.0 \%$ & $63.5 \%$ & $1.4 \%$ & $27.0 \%$ & $0.0 \%$ & $100 \%$ \\
\hline Setor Oeste 1 & $0.0 \%$ & $0.0 \%$ & $0.0 \%$ & $33.3 \%$ & $33.3 \%$ & $0.0 \%$ & $33.3 \%$ & $0.0 \%$ & $100 \%$ \\
\hline Setor Oeste 2 & $0.0 \%$ & $0.0 \%$ & $0.0 \%$ & $0.0 \%$ & $0.0 \%$ & $0.0 \%$ & $100.0 \%$ & $0.0 \%$ & $100 \%$ \\
\hline Setor Oeste 3 & $16.7 \%$ & $0.0 \%$ & $0.0 \%$ & $8.3 \%$ & $25.0 \%$ & $8.3 \%$ & $41.7 \%$ & $0.0 \%$ & $100 \%$ \\
\hline Setor Oeste 4 & $5.3 \%$ & $0.0 \%$ & $0.0 \%$ & $0.0 \%$ & $73.7 \%$ & $0.0 \%$ & $21.1 \%$ & $0.0 \%$ & $100 \%$ \\
\hline Setor Sul & $0.0 \%$ & $0.0 \%$ & $0.0 \%$ & $0.0 \%$ & $87.5 \%$ & $0.0 \%$ & $12.5 \%$ & $0.0 \%$ & $100 \%$ \\
\hline Entorno Leste & $0.0 \%$ & $0.0 \%$ & $0.0 \%$ & $0.0 \%$ & $0.0 \%$ & $0.0 \%$ & $0.0 \%$ & $0.0 \%$ & $100 \%$ \\
\hline Entorno Oeste & $0.0 \%$ & $0.0 \%$ & $0.0 \%$ & $0.0 \%$ & $100.0 \%$ & $0.0 \%$ & $0.0 \%$ & $0.0 \%$ & $100 \%$ \\
\hline Entorno Sul & $7.7 \%$ & $0.0 \%$ & $0.0 \%$ & $0.0 \%$ & $69.2 \%$ & $7.7 \%$ & $15.4 \%$ & $0.0 \%$ & $100 \%$ \\
\hline Dado Ausente & $8.6 \%$ & $2.9 \%$ & $0.0 \%$ & $0.0 \%$ & $48.6 \%$ & $0.0 \%$ & $40.0 \%$ & $0.0 \%$ & $100 \%$ \\
\hline
\end{tabular}




\subsubsection{PERFIL DA MOBILIDADE NA IEM PR 1}

A Tabela 6.16 apresenta os resultados das estatísticas uni variadas para os dados na IEM PR 1, e a Figura 6.5 apresenta a espacialização do agrupamento das ocorrências de localidade de residência para as amostras "alunos geral" e "alunos pareados".

As percentagens de respondentes por setor também são apresentadas na Figura 6.5, em que os valores entre parênteses referem-se aos obtidos para a amostra "alunos pareados". O tamanho da amostra tratada reduziu as possibilidades de análises do perfil de mobilidade para a IEM PR 1. Essas análises ficaram limitadas às estatísticas uni variadas, e, por isso, indica-se cautela na utilização dos resultados observados.

Com um público respondente pesquisado preponderantemente formado por meninas, percebe-se que nesta IEM a renda média domiciliar obtida para a amostra "alunos geral" não é superior à da IEM PU1, sendo bastante semelhante à da IEM PU2. Quanto à partição modal, os alunos da IEM PR 1 têm como modo de transporte majoritário o Automóvel da Família. Há uma redução no uso do automóvel para as viagens de volta (apenas na amostra "alunos geral”), com migração para os modos públicos (Ônibus e Metrô).

As duas amostras analisadas apresentam maiores diferenças na distância casa/escola, na densidade de localização da residência, no uso dos modos A pé, Bicicleta e Automóvel Carona, e nas localidades de residência. Nas localidades de residência, a amostra "alunos geral" possui mais residentes do Setor Oeste 1, seguido do Setor Central e Setor Leste. Já a amostra "alunos pareados" é composta majoritariamente por alunos residentes no Setor Central, seguido do Setor Norte, o que pode ser melhor observado na Figura 6.5.

Cabe destacar que, para as duas amostras, o percentual de respondentes que não referiu o local de residência foi bastante elevado (48\% na amostra "alunos geral" e $27 \%$ na amostra “alunos pareados"), sendo muito superior ao observado nas amostras das duas IEMs públicas. 
Tabela 6.16: Estatísticas univariadas - IEM PR 1

\begin{tabular}{|c|c|c|c|c|c|}
\hline Amostra & \multicolumn{2}{|c|}{ "alunos em geral" $(\mathrm{n}=21)$} & \multicolumn{3}{|c|}{ "alunos pareados" $(\mathrm{n}=11)$} \\
\hline Gênero & \multicolumn{2}{|c|}{$90 \%$ Feminino $10 \%$ Masculino } & \multicolumn{3}{|c|}{ 73\% Feminino $27 \%$ Masculino } \\
\hline Idade & \multicolumn{2}{|c|}{15 anos } & \multicolumn{3}{|l|}{15 anos } \\
\hline Distância & \multicolumn{2}{|l|}{$11.953,05 \mathrm{~m}$} & \multicolumn{3}{|l|}{$4.962,54 \mathrm{~m}$} \\
\hline Renda & \multicolumn{2}{|l|}{$\mathrm{R} \$ 6.692,69$} & \multicolumn{3}{|c|}{$\mathrm{R} \$ 8.980,55$} \\
\hline Densidade & \multicolumn{2}{|l|}{$21.098,17 \mathrm{hab} / \mathrm{km}^{2}$} & \multicolumn{3}{|c|}{$6.648,35 \mathrm{hab} / \mathrm{km}^{2}$} \\
\hline Disp.Auto. & \multicolumn{2}{|l|}{$91 \% \operatorname{sim} ; 9 \%$ não } & \multicolumn{3}{|c|}{$100 \% \operatorname{sim} 0 \%$ não } \\
\hline \multicolumn{3}{|c|}{ Partição modal na Ida } & \multicolumn{3}{|c|}{ Partição modal na Ida } \\
\hline Apé & Auto carona & T. Escolar & Apé & Auto carona & T. Escolar \\
\hline $5 \%$ & $0 \%$ & $10 \%$ & $18 \%$ & $18 \%$ & $9 \%$ \\
\hline Auto Família & Metrô & Ônibus & Auto Família & Metrô & Ônibus \\
\hline $81 \%$ & $5 \%$ & $0 \%$ & $36 \%$ & $0 \%$ & $0 \%$ \\
\hline Bicicleta & \multicolumn{2}{|l|}{ Dados Ausentes } & Bicicleta & \multicolumn{2}{|l|}{ Dados Ausentes } \\
\hline $0 \%$ & \multicolumn{2}{|l|}{$0 \%$} & \multicolumn{3}{|c|}{$18 \% \quad 0 \%$} \\
\hline \multicolumn{3}{|c|}{ Partição modal na Volta } & \multicolumn{3}{|c|}{ Partição modal na Volta } \\
\hline Apé & Auto carona & T. Escolar & Apé & Auto carona & T. Escolar \\
\hline $5 \%$ & $10 \%$ & $0 \%$ & $18 \%$ & $0 \%$ & $9 \%$ \\
\hline Auto Família & Metrô & Ônibus & Auto Família & Metrô & Ônibus \\
\hline $62 \%$ & $14 \%$ & $10 \%$ & $36 \%$ & $0 \%$ & $18 \%$ \\
\hline Bicicleta & \multicolumn{2}{|l|}{ Dados Ausentes } & Bicicleta & \multicolumn{2}{|l|}{ Dados Ausentes } \\
\hline $0 \%$ & \multicolumn{2}{|l|}{$0 \%$} & $18 \%$ & $0 \%$ & \\
\hline Mesmo modo $n$ & na Ida e Volta & $62 \%$ & \multicolumn{3}{|c|}{ Mesmo modo na Ida e Volta } \\
\hline \multicolumn{3}{|c|}{ Localidade de residência (agrupado) } & \multicolumn{3}{|c|}{ Localidade de residência (agrupado) } \\
\hline Setor Central & Setor Oeste 1 & Setor Oeste 2 & Setor Central & Setor Oeste 1 & Setor Oeste 2 \\
\hline $10 \%$ & $29 \%$ & $5 \%$ & $64 \%$ & $0 \%$ & $0 \%$ \\
\hline Setor Oeste 3 & Setor Oeste 4 & Setor Leste & Setor Oeste 3 & Setor Oeste 4 & Setor Leste \\
\hline $0 \%$ & $0 \%$ & $10 \%$ & $0 \%$ & $0 \%$ & $0 \%$ \\
\hline Setor Sul & Setor Norte & Entorno Sul & Setor Sul & Setor Norte & Entorno Sul \\
\hline $0 \%$ & $0 \%$ & $0 \%$ & $0 \%$ & $9 \%$ & $0 \%$ \\
\hline Entorno Leste & Entorno Oeste & D. Ausentes & Entorno Leste & Entorno Oeste & D. Ausentes \\
\hline $0 \%$ & $0 \%$ & $48 \%$ & $0 \%$ & $0 \%$ & $27 \%$ \\
\hline
\end{tabular}

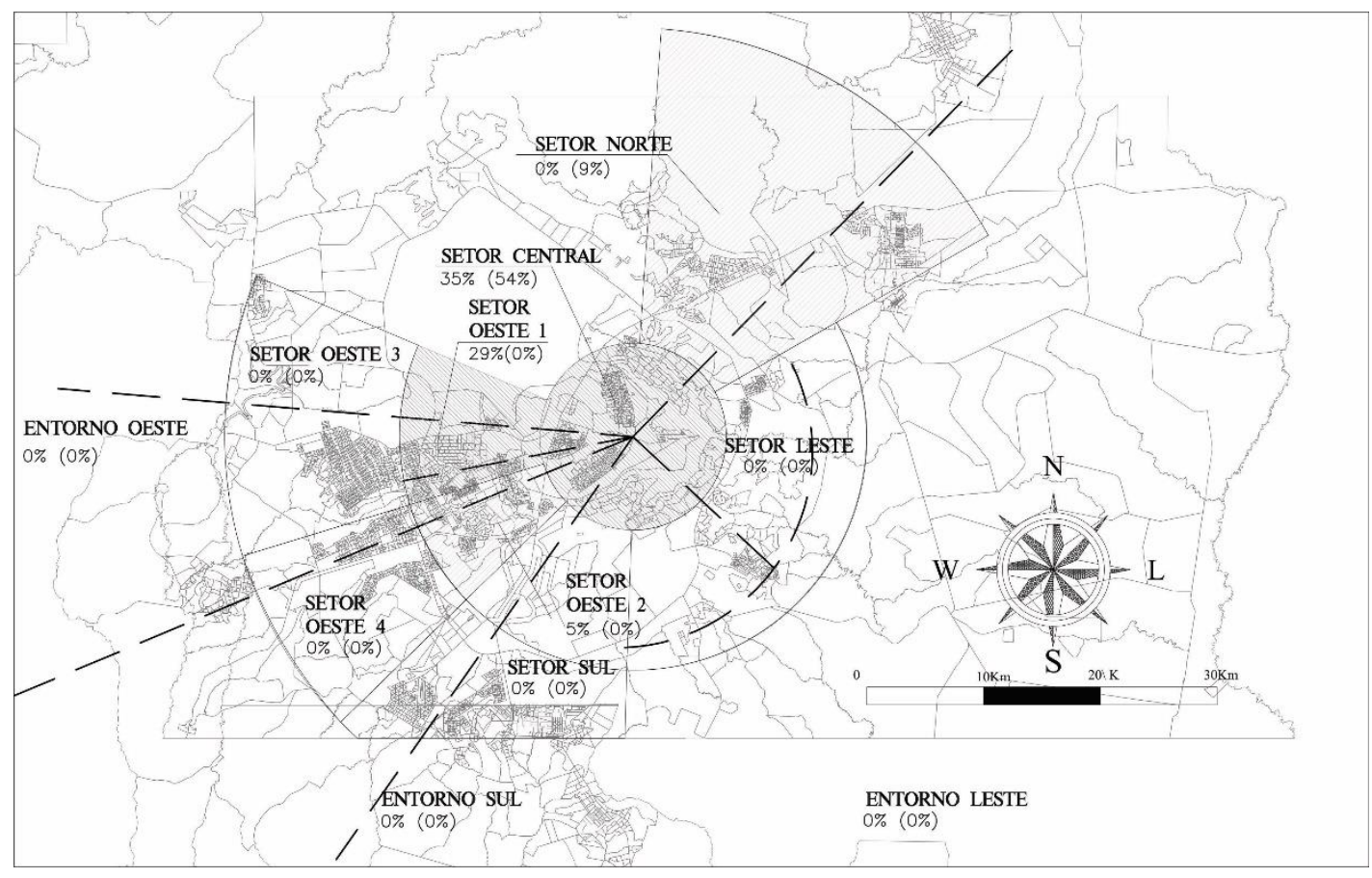

Figura 6.5: Distribuição de localidades de residência dos alunos - IEM PR 1 


\subsection{TÓPICOS CONCLUSIVOS}

O procedimento proposto foi aplicado a três IEMs em Brasília, duas públicas e uma privada. A seleção final das IEMs participantes da pesquisa foi condicionada à aceitação dos termos éticos, e não necessariamente na diversidade das características das IEMs, com características de porte e contexto ambiental que trouxessem variabilidade para a análise dessas características entre instituições. A exceção se deu para a presença ou não do modo Metrô.

A abordagem qualitativa e a análise quantitativa exploratória incluídas no procedimento se mostraram adequadas e eficazes para obtenção do elenco de crenças salientes por modo, bem como descrever os contextos ambientais e os perfis de mobilidade em cada IEM, com destaque para o uso dos grupos focais. Esta técnica viabilizou, no pouco tempo disponibilizado pelas direções nos intervalos de aulas, a obtenção das primeiras impressões da mobilidade da IEM. Grande parte dos pais contatados nessa etapa devolveram suas opiniões, que puderam ser confrontadas com as opiniões dos alunos.

Nas IEMs estudadas, foi identificado pouco interesse para a facilitação de uso dos modos não motorizados, a pé e bicicleta, bem como a promoção dos modos Auto Carona e Transporte Escolar. Essas constatações apontam pouca familiaridade das IEMs com as estratégias de GM. Recomenda-se que, para essas IEMs, os Programas de Gerenciamento da Mobilidade - PGMs incluam etapa motivacional sobre o tema, incluindo discussões sobre o uso do modo motorizado individual versus coletivo e dos modos não motorizados.

A Etapa 3 (levantamento das crenças salientes) foi rica em contribuições para o entendimento da mobilidade local: i) apontando a presença de semelhanças na mobilidade de cada IEM estudada, indicando ser possível a elaboração de um único questionário (Etapa 4), a ser aplicado nas três IEMs para obtenção dos dados necessários às análises das Etapas 5 e 6; ii) possibilitando a identificação do elenco de crenças salientes na escolha do modo de transporte nas viagens escolares, e de quais modos eram considerados viáveis para essas viagens. 
Observações importantes foram coletadas nos grupos focais sob a perspectiva de futura elaboração de PGMs para as IEMs. Dentre elas, destacam-se as seguintes sugestões apresentadas pelos participantes, com vistas a aumentar o uso do transporte público:

a) Para o poder público: melhoria da segurança pública, com a presença de policiais e adaptação da iluminação pública nos percursos de pedestres, especificamente dos que ligam a Avenida L2 e os Eixos Leste e Oeste aos pontos de parada de ônibus ou estações de metrô; adequação do serviço de transporte público por ônibus aos horários de entrada e saída dos turnos; promoção de tratamento cordial dos motoristas e cobradores de ônibus em relação aos alunos; adequação das travessias de pedestres junto aos acessos principais das IEMs;

b) Para as direções das IEMs: melhoria das estruturas de apoio ao uso de modos não motorizados; melhoria da configuração dos acessos de veículos e pedestres nas IEMs, facilitando as operações de embarque e desembarque e diminuindo os conflitos com pedestres;

c) Para campanhas sobre o comportamento de alunos: abordar temas voltados ao aumento da segurança pessoal dos estudantes, tais como realização dos percursos a pé com mais atenção e em estado de alerta; e formação de grupos de alunos com mesma opção modal no turno, no intuito de diminuir o risco de assaltos.

A metodologia adotada para a participação dos pais na pesquisa mostrou-se pouco eficaz, com baixo número de respostas aos questionários preparados para esse segmento de respondentes. Como resultado, as possibilidades de análise para as amostras "alunos pareados" nas três instituições pesquisadas foram bastante diminuídas. Já para as a aplicação de questionários em sala de aula, onde a pesquisadora teve contato direto com os alunos (nas IEMs PU 1 e PU2), os resultados foram bem significativos.

Os tratamentos preliminares na base de dados seguiram os critérios apontados na literatura revisada. Os dados omissos observados foram considerados ao acaso, possibilitando a atribuição de valores significativos para as variáveis consideradas. A redução da amostra pelo tratamento de dados ausentes impactou a obtenção dos dados dos perfis de mobilidade das IEMs participantes, principalmente da IEM PR 1. Tal fato 
pode ser decorrente da falta de acompanhamento da devolução dos questionários de alunos e pais, vetada à pesquisadora e realizada diretamente pelo coordenador da escola. Nesta IEM, foram observadas muitas respostas em branco na última folha do questionário, onde se obtinha a informação do modo atualmente utilizado e das variáveis sociodemográficas, necessárias a várias das análises desenvolvidas.

Os perfis de mobilidade das IEMs públicas se mostraram semelhantes em vários aspectos, principalmente com relação à partição modal, focada nos modos públicos. Já a IEM privada apresentou uso majoritário do modo Automóvel da Família, confirmando a observação de Bertazzo e Jacques (2008). Ressalta-se, entretanto, que no bairro de localização da IEM PU 2 não existe a oferta de metrô. Na comparação entre as partições modais das duas IEMs públicas, verifica-se que a presença do metrô na IEM PU1 não captura, necessariamente, usuários do modo Automóvel da Família, mas sim parte dos usuários do ônibus. Nas duas IEMs públicas os alunos usam majoritariamente o mesmo modo na ida e na volta. A localização da escola, se a norte ou a sul do Plano Piloto, é também um indicativo de atrair mais residentes das áreas a norte ou a sul da escola, o que pode ser observado na comparação das Figuras 6.3 e 6.4. As amostragens foram eficazes na captura dos modos mais frequentemente utilizados.

Os modos pesquisados foram considerados, nas duas IEMs públicas, como os modos mais frequentemente utilizados. Dentre eles, os modos mais utilizados (amostras "alunos geral"), foram, em ordem, Ônibus, Auto Família, Metrô, A pé. Nas duas IEMs públicas o modo Ônibus foi o que apresentou maior descontentamento entre seus usuários, com maior intenção de mudança para o modo Automóvel da Família. Tal fato indica que o serviço deve se adequar melhor às necessidades dos estudantes.

Nas IEMs públicas, para as relações entre gênero e modo utilizado na ida, os meninos preferem os modos não motorizados, a pé e bicicleta. Enquanto as meninas usam mais o ônibus. Para a relação entre idade e modo utilizado na ida, os alunos mais velhos usam mais ônibus, e menos transporte escolar. Sobre as relações de distância, renda e densidade com o modo utilizado na ida, os usuários do transporte escolar têm renda baixa e moram mais longe. As maiores percentagens de uso do transporte escolar ocorrem: para a IEM 
PU 1, no Setor Leste (10\%), Setor Oeste 2 (10\%) e Entorno Sul (29\%); e para a IEM PU 2, no Setor Leste (7,8\%), Setor Oeste 3 (8,3\% e Entorno Sul $(7,7 \%)$.

Os alunos que caminham e usam bicicleta moram mais perto, têm as maiores rendas, e moram em áreas menos densas. Os usuários de ônibus e metrô moram em áreas mais densas, principalmente junto aos setores a oeste, onde as redes de transporte público, por ônibus e metrô, são mais disponíveis. A disponibilidade de automóvel no domicílio, ou a presença de um maior estacionamento na IEM não significam necessariamente um maior uso do modo Automóvel da Família. O uso da bicicleta é bastante baixo (1\% na IEM PU 1, e 1,6\% na IEM PU 2), mesmo nos setores mais próximos das escolas, como no Setor Central que tem, também, uma rede de ciclovias bem consolidada. 


\section{APLICAÇÃO DO PROCEDIMENTO - PARTE 2}

Na continuação do relato dos resultados referente à aplicação do procedimento proposto nas IEMs em Brasília, o presente capítulo apresenta a Etapa 6, relatando resultados e discussões em separado por IEM e por modo de transporte. Essas etapas incluem as modelagens estudadas para a identificação dos atributos que afetam a escolha modal nas IEMs. Apenas as IEMs públicas serão incluídas nas etapas apresentadas neste capítulo, conforme resultados apresentados na seção 6.5.4.

\subsection{TRATAMENTO PRELIMINAR DA BASE DE DADOS}

As opiniões dos alunos e pais/responsáveis foram coletadas pelos questionários, individualmente para cada modo de transporte. A cada respondente era solicitado que respondesse sobre o modo atualmente utilizado para chegar ou sair da escola e, pelo menos, sobre outros dois modos para os quais soubesse dar opinião. O tratamento T1, utilizado para elaboração dos perfis de mobilidade das IEMs, Etapa 5, manteve nas amostras apenas os respondentes que apresentavam respostas válidas para as opções de modo para chegar ou sair da escola (comportamento atual). Em T1 foram tratados os dados comuns a todos os modos de transporte, como as variáveis sociodemográficas, hábito e comportamento passado.

Para a Etapa 6, em cada grupo amostral das IEMs, alunos pareados e alunos em geral, foi realizado um novo tratamento de casos ausentes - T2 a partir dos resultados de $\mathrm{T} 1$, em separado para cada modo de transporte. Não foram observados casos extremos nas amostras em estudo. A segmentação das amostras em T2, necessária à condução das análises propostas na seção 5.6.2, baseou-se nos critérios presentes na Tabela 5.3, e realizado de maneira análoga ao procedimento descrito na seção 6.5.1.

O número e o percentual de respostas por modo de transporte/IEM e grupo amostral são apresentados na Tabela 7.1. A soma total das respostas por modo supera o número total de respondentes, já que cada um deles poderia dar sua opinião para pelo menos três modos diferentes. A redução do número de respondentes decorrente do tratamento T2 da base de dados impactou principalmente as amostras pareadas. Nestas, foi necessário combinar as 
opiniões dos respondentes selecionados via tratamento T2 (aluno e pai/responsável) para cada modo.

Tabela 7.1: Repostas por modo depois do tratamento $\mathrm{T} 2$ de dados ausentes

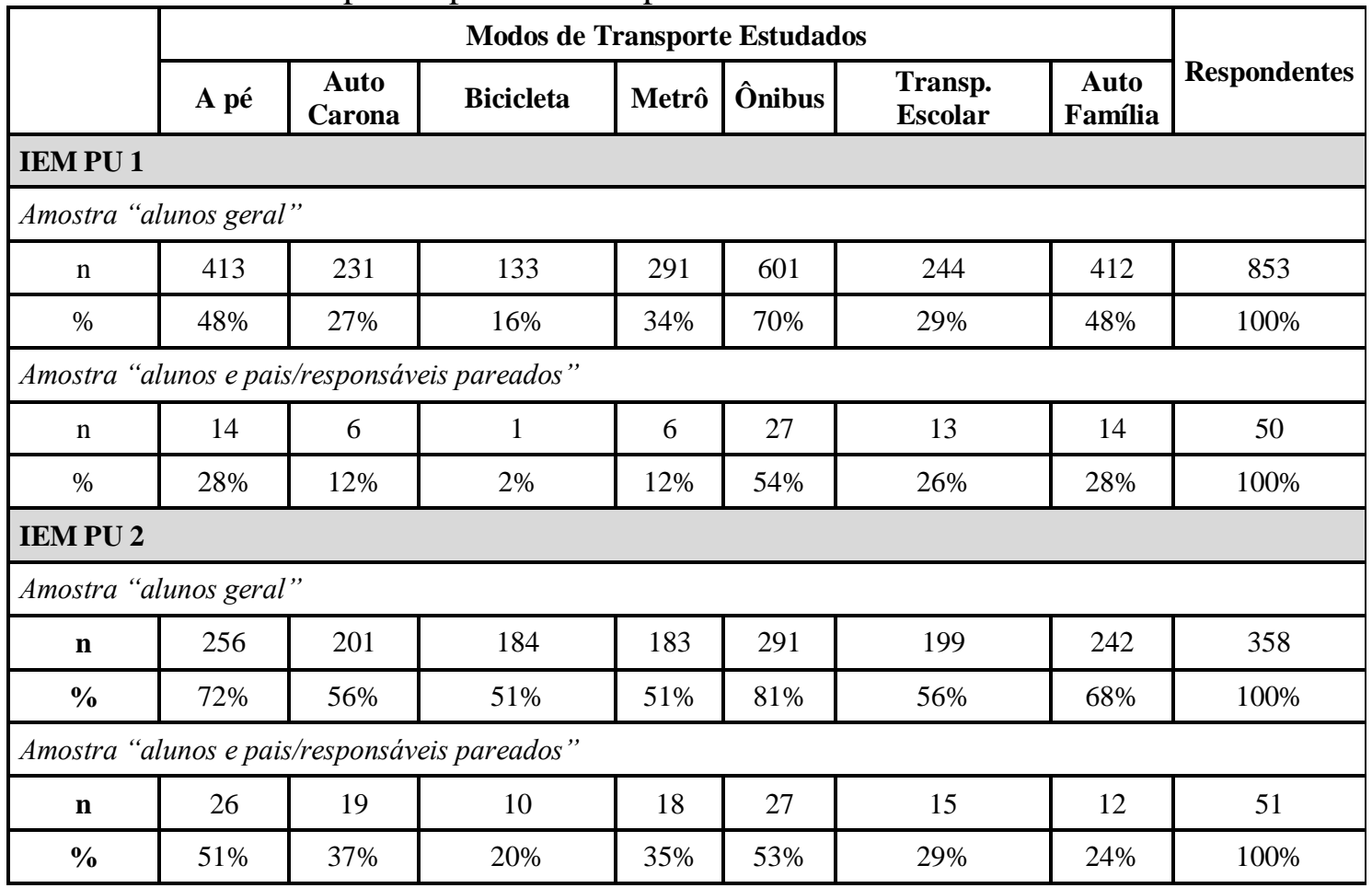

A Tabela 7.2 apresenta a comparação dos percentuais dos modos atuais informados como utilizados na Ida ou na Volta, observados em cada amostra e IEM, com os percentuais de opiniões, respostas observadas por modo. Percebe-se que os dois modos mais utilizados, Ônibus e Automóvel da Família, foram também os mais comentados em todas as amostras, exceto para a amostra de alunos pareados - opinião, onde o modo A pé foi o segundo mais comentado. O terceiro modo mais utilizado e comentado variou entre as amostras, para os modos A pé, Metrô e Automóvel Carona.

No prosseguimento desta etapa, integrarão as análises apenas os dois modos mais utilizados e comentados, tanto para a IEM PU 1 como para a IEM PU 2: modo Ônibus e modo Automóvel da Família”. Os testes nas bases de dados, necessários à confirmação dos pressupostos das modelagens são apresentados junto com os resultados. 
Tabela 7.2: Comparação modos utilizado atualmente $\mathrm{x}$ opinião por modo

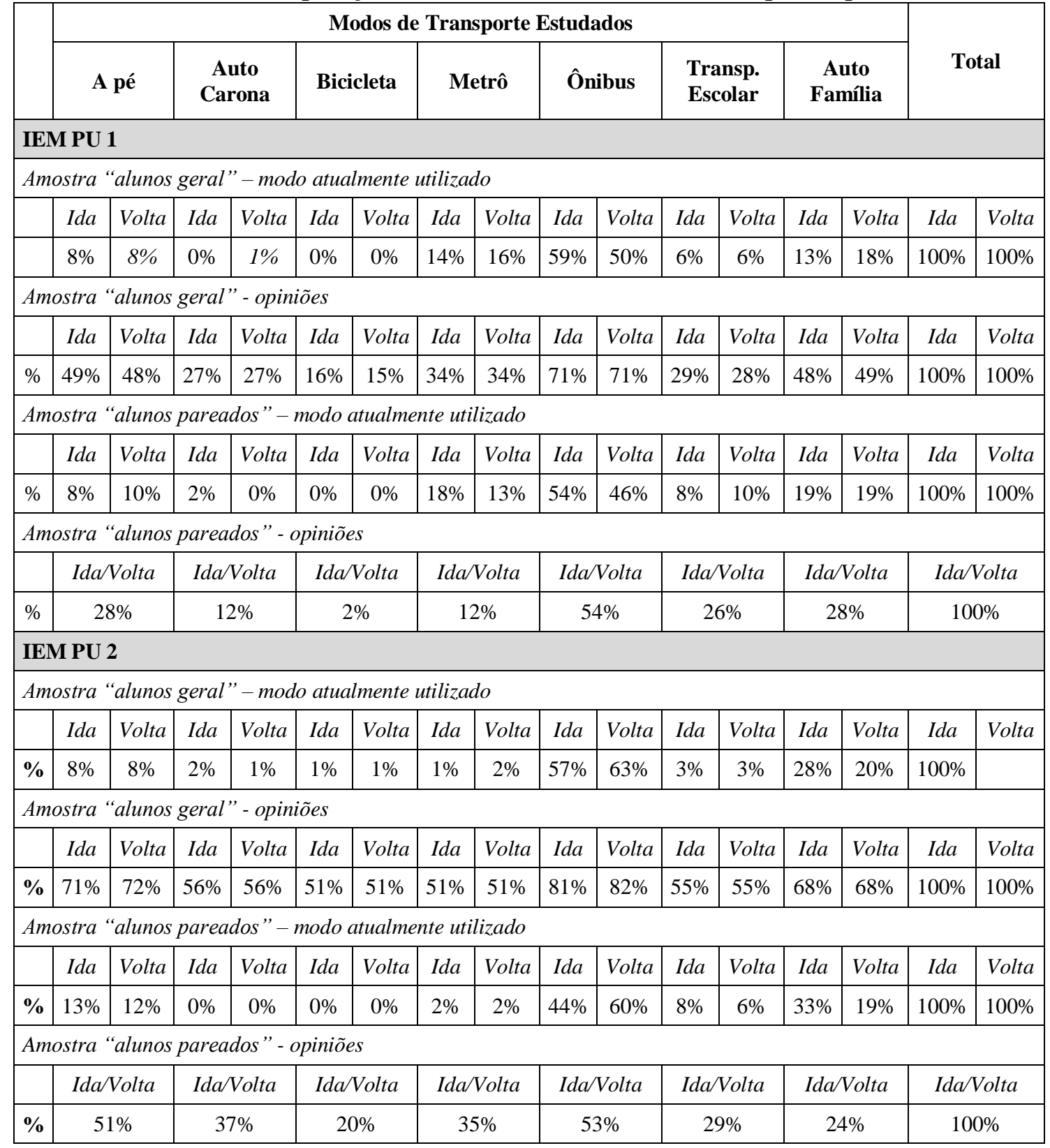

\subsection{ANÁLISE EXPLORATÓRIA DAS CRENÇAS}

$\mathrm{Na}$ Teoria da TCP, as crenças são importantes como antecedentes dos construtos psicológicos. No presente estudo, as crenças salientes para alunos e pais/responsáveis referentes ao uso dos modos considerados viáveis foram obtidas nas reuniões de grupos focais, e testados na população através de questionários. Esta seção pretende analisar se o procedimento adotado e os resultados obtidos são coerentes com a teoria da TCP, que guiou teoricamente o procedimento. 
Os testes univariados dos pressupostos desta etapa precederam o início das análises. O uso de MRLM, como apontado na seção 5.6.1, indicava a necessidade de testar o nível de probabilidade, normalidade, homocedasticidade e linearidade. Para o teste de nível de probabilidade, o menor tamanho da amostra resultante do tratamento T2, com $n=242$ observações para IEM PU 2, modo "auto da família", amostra alunos geral, atende a um $\alpha=0,05$ e poder $=0,80$ e tamanho de efeito $=0,35$.

Para testar a normalidade univariada, foram aplicados os testes Kolmogorov-Smirnov, Shapiro Wilk, $\mathrm{Z}$ assimetria e $\mathrm{Z}$ curtose. Os resultados para as variáveis comuns a todos os modos, como as sociodemográficas, bem como as estatísticas descritivas são apresentadas nos Apêndices N e O, para amostras "alunos geral" e "alunos pareados", e IEM PU 1 e IEM PU2, respectivamente.

Os resultados apresentaram normalidade para poucas variáveis e em apenas um ou dois dos quatro testes realizados. Seguindo a recomendação de Hair et al. (2009), foram testadas transformações de vários tipos (inverso, raiz quadrada, Log, Ln, raiz cúbica e raiz quadrática) e analisadas as normalidades resultantes. Não tendo apresentado resultados razoáveis para a correção da não normalidade (e da heterocedasticidade associada), passou-se a adotar o procedimento GLM, ao invés do MRLM tradicional, conforme indicado na seção 4.4 .

\subsubsection{ANÁLISE FATORIAL EXPLORATÓRIA DAS CRENÇAS}

As crenças obtidas nos grupos focais, e testadas em questionário, foram categorizadas intuitivamente, segundo os construtos da TCP. Para verificar se a categorização foi realizada adequadamente, uma Análise Fatorial Exploratória (ver seção 5.6.2) foi realizada em cada conjunto de objetos das crenças agrupados por modo (apenas com o item 'b", conteúdo da crença). Foram consideradas apenas as amostras "alunos geral", com base no tratamento T2. Para o modo Ônibus, a variável CONCCO2 foi retirada da análise, porque sua correspondente, CONCCE2, por erro na digitação do questionário, não integrou a coleta de dados. Os resultados são apresentados nas Tabelas 7.3 e 7.4, para IEM PU 1 e IEM PU 2, respectivamente. 
Tabela 7.3: Matriz pattern AFE crenças por modo - amostra "alunos geral" - IEM PU1

\begin{tabular}{|c|c|c|c|c|c|}
\hline Modo & Variável & Definição & $\begin{array}{c}\text { Fator } \\
1\end{array}$ & $\begin{array}{c}\text { Fator } \\
\mathbf{2}\end{array}$ & $\begin{array}{c}\text { Fator } \\
\mathbf{3}\end{array}$ \\
\hline \multirow{11}{*}{$\begin{array}{c}\text { ÔNIBUS } \\
n=601\end{array}$} & ONCBO1 & É vantajoso pelo passe estudantil & & 0,599 & \\
\hline & ONCBO2 & Chega atrasado & & & 0,824 \\
\hline & ONCBO3 & Dentro do ônibus não é seguro & 0,599 & & \\
\hline & ONCBO4 & É superlotado & 0,362 & & \\
\hline & ONCNO1 & Incentivo dos pais & & 0,544 & \\
\hline & ONCNO2 & Apoio dos amigos & & 0,508 & \\
\hline & ONCCO1 & Perigo no trecho a pé da escola/ parada & 0,536 & & \\
\hline & ONCCO3 & Não é seguro esperar o ônibus na parada & 0,693 & & \\
\hline & ONCCO4 & Existência de linha direta casa-escola & & 0,328 & \\
\hline & Alfa & & 0,625 & 0,541 & --- \\
\hline & $K M O=0,6$ & Det $=0,389 ;$ Resíduos $>0,05=8 \% ; r^{l, 2}=-0$ & $80 ; r^{2,3}$ & $082 ; r^{l}$ & $-0,213$ \\
\hline \multirow{9}{*}{$\begin{array}{c}\text { AUTO } \\
\text { FAMÍLIA } \\
\text { n=412 }\end{array}$} & AFCBO1 & $\begin{array}{l}\text { Piora o congestionamento } \\
\end{array}$ & & 0,584 & \\
\hline & AFCBO2 & É seguro & & & $-0,425$ \\
\hline & AFCBO3 & Chega no horário certo & & & 0,563 \\
\hline & AFCNO1 & Preferência dos pais em levar de auto & 0,637 & & \\
\hline & AFCNO2 & Apoio dos amigos & 0,454 & & \\
\hline & AFCCO1 & É caro & & 0,432 & \\
\hline & AFCCO2 & Impede realização atividades pós turno & & 0,371 & \\
\hline & Alfa & & 0,429 & 0,435 & 0,319 \\
\hline & \multicolumn{5}{|c|}{$K M O=0,551 ;$ Det $=0,682 ;$ Resíduos $>0,05=4 \% ; r^{1,2}=-0,176 ; r^{2,3}=0,064 ; r^{1,3}=-0,136$} \\
\hline \multicolumn{6}{|c|}{$\begin{array}{l}\text { Obs.: AFE - Análise Fatorial Exploratória; Método de extração - Principal Axis Factoring; Rotação - } \\
\text { Direct Oblimin; Solicitação de } 3 \text { fatores em cada análise. Definições: KMO - Kayser-Meyer-Olkin, } \\
\text { indicador da fatorabilidade da matriz de correlação; Det - Determinante da matriz de correlações; } r^{1,2} \text {, } \\
r^{2,3} \text { e } r^{1,3} \text { - correlações entre os fatores; Alfa - alfa de Cronbach. }\end{array}$} \\
\hline
\end{tabular}

Tabela 7.4: Matriz pattern AFE crenças por modo - amostra "alunos geral" - IEM PU2

\begin{tabular}{|c|c|c|c|c|c|}
\hline Modo & Variável & Definição & Fator 1 & Fator 2 & Fator 3 \\
\hline \multirow{11}{*}{$\begin{array}{c}\text { ÔNIBUS } \\
\mathbf{n}=291\end{array}$} & ONCBO1 & É vantajoso pelo passe estudantil & \multicolumn{3}{|c|}{0,543} \\
\hline & ONCBO2 & Chega atrasado & --- & --- & \multirow[t]{2}{*}{---} \\
\hline & $\mathrm{ONCBO} 3$ & Dentro do ônibus não é seguro & 0,570 & & \\
\hline & ONCBO4 & É superlotado & 0,332 & & \\
\hline & ONCNO1 & Incentivo dos pais & \multicolumn{3}{|c|}{0,657} \\
\hline & ONCNO2 & Apoio dos amigos & \multicolumn{3}{|c|}{0,559} \\
\hline & ONCCO1 & Perigo no trecho a pé da escola/ parada & 0,658 & & 0,621 \\
\hline & ONCCO3 & Não é seguro esperar o ônibus na parada & \multicolumn{3}{|l|}{0,794} \\
\hline & ONCCO4 & Existência de linha direta casa-escola & -- & -- & -- \\
\hline & \multicolumn{2}{|c|}{ Alfa } & 0,656 & 0,589 & --- \\
\hline & \multicolumn{5}{|c|}{$K M O=0,641 ;$ Det $=0,291 ;$ Resíduos $>0,05=13 \% ; r^{1,2}=-0,160 ; r^{2,3}=0,130 ; r^{l, 3}=-0,024$} \\
\hline \multirow{9}{*}{$\begin{array}{c}\text { AUTO } \\
\text { FAMÍLIA } \\
\text { n=242 }\end{array}$} & AFCBO1 & Piora o congestionamento & 0,539 & & \\
\hline & $\mathrm{AFCBO} 2$ & É seguro & & & 0,395 \\
\hline & $\mathrm{AFCBO} 3$ & Chega no horário certo & \multicolumn{3}{|c|}{0,562} \\
\hline & AFCNO1 & Preferência dos pais em levar de auto & & & 0,701 \\
\hline & AFCNO2 & Apoio dos amigos & & & 0,445 \\
\hline & AFCCO1 & É caro & 0,688 & & \\
\hline & $\mathrm{AFCCO} 2$ & Impede realização atividades pós turno & 0,318 & 0,501 & \\
\hline & Alfa & & 0,602 & 0,527 & 0,580 \\
\hline & \multicolumn{5}{|c|}{$K M O=0,651 ;$ Det $=0,398 ;$ Resíduos $>0,05=0 \% ; r^{1,2}=0,178 ; r^{2,3}=-0,070 ; r^{1,3}=0,352$} \\
\hline \multicolumn{6}{|c|}{$\begin{array}{l}\text { Obs.: AFE - Análise Fatorial Exploratória; Método de extração - Principal Axis Factoring; Rotação } \\
\text { - Direct Oblimin; Solicitação de } 3 \text { fatores em cada análise. Definições: KMO - Kayser-Meyer-Olkin, } \\
\text { indicador da fatorabilidade da matriz de correlação; Det - Determinante da matriz de correlações; } r^{l, 2} \text {, } \\
r^{2,3} \text { e } r^{l, 3} \text { - correlações entre os fatores; Alfa - alfa de Cronbach. }\end{array}$} \\
\hline
\end{tabular}


Pelas Tabelas 7.3 e 7.4, observa-se que, ao exigir dos dados o agrupamento em três fatores, as crenças levantadas nos grupos focais se agruparam em fatores com fraca afinidade entre os itens $(0,318<$ alfa $<0,642)$. A fatorabilidade das matrizes, indicada pelos respectivos KMOs, também apresentou valores muito modestos, entre 0,551 e 0,653. A presença de fatores únicos, com apenas um item, representa a fraca associação desse item com os demais. Os agrupamentos não seguiram a classificação intuitiva, sendo difícil de associar semanticamente as crenças ligadas a cada um dos três fatores aos conceitos dos construtos da TCP. O fato do agrupamento dos dados empíricos apontar características semânticas diferentes da teoria precisa ser melhor investigado, já que os resultados modestos da análise fatorial não permitem refutar a teoria, indicando prováveis diferenças culturais ou modificações do comportamento das pessoas ao longo do tempo. Apesar dos modestos resultados, uma possível interpretação dos fatores obtidos, pelos agrupamentos de itens seria:

a) Para o modo Ônibus na IEM PU1 - o Fator 1 agrupou aspectos negativos do uso do modo, como insegurança e superlotação. O Fator 2 agrupou aspectos de incentivo ao uso do modo, como a existência de uma linha direta, ter passe estudantil, bem como a opinião motivadora dos grupos de referência, pais e amigos. O Fator 3, como fator de item único, se refere à pontualidade do serviço de ônibus (ou a falta dela);

b) Para o modo Automóvel da Família na IEM PU 1 - o Fator 1 é um fator de norma social, indicando a influência dos grupos de referência no uso do modo. O Fator 2 agrupa itens de impedância ao uso do modo, como o impacto nos congestionamentos e problemas de agenda. Porém, o item de insegurança (impedância ao uso do modo) integra apenas o Fator 3, que ambiguamente também agrupa o item sobre a pontualidade (incentivo ao uso do modo). Este fator tem também o pior alfa de Crombach;

c) Para o modo Ônibus na IEM PU 2 - o Fator 1 agrupa itens que desmotivam o uso do modo (insegurança e superlotação), à semelhança do Fator 1, modo Ônibus, na IEM PU 1. O Fator 2 é um fator de incentivo ao uso do modo, agrupando a norma social (apoio do amigos e pais), e a facilidade de ter passe estudantil. O Fator 3 é 
ambíguo, pois possui apenas um item, sobre a insegurança entre a escola e a parada, que também participa do Fator 1, com carga fatorial semelhante;

d) Para o modo Automóvel da Família na IEM PU 2 - o Fator 1 tem o mesmo agrupamento do Fator 2, modo Automóvel da Família, da IEM PU 1, indicando itens de impedância ao uso do modo. O Fator 2 é ambíguo, por agrupar item de incentivo ao uso do modo (pontualidade), e o item de restrição de agenda, que seria de impedância ao uso do modo. Já o Fator 3 agrupa itens normativos e de segurança, que favorecem o uso do modo.

Pelos resultados das análises exploratórias das crenças observa-se que as crenças salientes nas duas IEMs devem ser consideradas em conjunto para a previsão dos construtos da TCP, e não em separado pela categorização intuitiva como previsto na Etapa 6 do procedimento proposto. Não obstante, é importante ressaltar que este resultado não pode ser generalizado e que, portanto, essa análise deve ser feita em cada aplicação futura do procedimento proposto.

\subsubsection{ANÁLISE DOS CONSTRUTOS DA TCP X CRENÇAS}

As conclusões das análises fatoriais também indicam a necessidade de realizar procedimento exploratório sobre quais crenças afetam os construtos da TCP. As modelagens visam saber se as crenças obtidas nos grupos focais se relacionam com os construtos da TCP, confirmando a teoria. Se forem observadas relações significativas, essas relações podem subsidiar a elaboração de estratégias de GM, associada a cada crença significativa e construto, num conjunto específico para cada escola. Para as análises dos construtos x crenças, a base de dados gerada a partir do tratamento T2 foi segmentada por modo, no tratamento T3.

Os critérios de eliminação de dados ausentes para a composição de uma sub amostra, por modo e construto, seguiram os critérios adotados nos tratamentos T1 e T2. O tratamento T3 visou possibilitar a retirada de dados ausentes das variáveis consideradas como dependentes nessa análise. Em cada análise, tendo apenas um construto como variável dependente, o tamanho da amostra resultante (n) é o resultado da eliminação das respostas que, em T2, receberam a atribuição da média no lugar dos dados ausentes. Assim, em 
cada caso a variável dependente está livre de dados ausentes, para uma sub- amostra de tamanho $n$ específico. O tamanho da amostra resultante será apresentado em cada análise.

Os itens de medida direta dos construtos foram obtidos por tradução direta do questionário indicado para a aplicação da teoria TCP (Ajzen, 2000; Bamberg et al., 2003). Verificouse a consistência interna dos itens de medida direta na composição dos construtos da TCP pelo teste de alfa de Cronbach, para os construtos Atitude, Norma Social, Controle Percebido e Intenção. Uma síntese das definições dos construtos e a composição de itens por construto utilizado no questionário é apresentada na Tabela 7.5. Os resultados para o alfa de Cronbach e das cargas fatoriais observadas para as medidas diretas dos construtos por modo de transporte são apresentados nas Tabelas 7.6 e 7.7, para IEM PU 1 e IEM PU 2, respectivamente.

Tabela 7.5: Composição de itens para medida direta dos construtos

\begin{tabular}{|c|c|c|c|c|}
\hline & Atitude & Norma Social & Controle Percebido & Intenção \\
\hline $\begin{array}{l}\text { Definição } \\
\text { geral do } \\
\text { construto }\end{array}$ & $\begin{array}{l}\text { Percepção do } \\
\text { conceito geral } \\
\text { sobre a decisão de } \\
\text { usar o modo de } \\
\text { transporte. }\end{array}$ & $\begin{array}{l}\text { Percepção da } \\
\text { pressão social } \\
\text { sobre a decisão de } \\
\text { usar o modo de } \\
\text { transporte. }\end{array}$ & $\begin{array}{l}\text { Percepção sobre a capacidade } \\
\text { e habilidade pessoal de usar o } \\
\text { modo de transporte. }\end{array}$ & $\begin{array}{l}\text { Decisão de usar o } \\
\text { modo de } \\
\text { transporte. }\end{array}$ \\
\hline $\begin{array}{l}\text { Itens de } \\
\text { medida } \\
\text { direta dos } \\
\text { construtos }\end{array}$ & $\begin{array}{l}\text { Agradável ou } \\
\text { desagradável; } \\
\text { Negativo ou } \\
\text { positivo; } \\
\text { Ruim ou bom. }\end{array}$ & $\begin{array}{l}\text { Opinião das } \\
\text { pessoas } \\
\text { importantes; } \\
\text { Opinião das } \\
\text { pessoas próximas; } \\
\text { Opinião das } \\
\text { pessoas que } \\
\text { conhece. }\end{array}$ & $\begin{array}{l}\text { A liberdade de uso do modo; } \\
\text { Dificuldade/facilidade de uso } \\
\text { do modo; } \\
\text { Possibilidade/impossibilidade } \\
\text { de uso do modo. }\end{array}$ & $\begin{array}{l}\text { Pretensão em usar } \\
\text { o modo; } \\
\text { Intenção em usar o } \\
\text { modo; } \\
\text { Intenção de uso do } \\
\text { modo nas próximas } \\
\text { semanas. }\end{array}$ \\
\hline
\end{tabular}

Tabela 7.6: Consistência dos itens por modo na IEM PU 1

\begin{tabular}{|c|c|c|c|c|c|c|c|c|}
\hline & \multicolumn{2}{|c|}{ Atitude } & \multicolumn{2}{|c|}{ Norma Social } & \multicolumn{2}{|c|}{ Controle Percebido } & \multicolumn{2}{|c|}{ Intencão } \\
\hline Modo & Item & $\alpha$ & Item & $\alpha$ & Item & $\alpha$ & Item & $\alpha$ \\
\hline \multirow{3}{*}{$\begin{array}{c}\text { Ônibus } \\
n=600\end{array}$} & ONDAT1 & \multirow{3}{*}{0,810} & ONDNS1 & \multirow{3}{*}{0,628} & ONDCP1 & \multirow{3}{*}{0,706} & ONDIT1 & \multirow{3}{*}{0,782} \\
\hline & ONDAT2 & & ONDNS2 & & ONDCP2 & & ONDIT2 & \\
\hline & ONDAT3 & & ONDNS3 & & ONDCP3 & & ONDIT3 & \\
\hline \multirow{3}{*}{$\begin{array}{c}\text { Auto } \\
\text { Família } \\
n=412\end{array}$} & AFDAT1 & \multirow{3}{*}{0,753} & AFDNS1 & \multirow{3}{*}{0,609} & AFDCP1 & \multirow{3}{*}{0,755} & AFDIT1 & \multirow{3}{*}{0,704} \\
\hline & AFDAT2 & & AFDNS2 & & AFDCP2 & & AFDIT2 & \\
\hline & AFDAT3 & & AFDNS3 & & AFDCP3 & & AFDIT3 & \\
\hline
\end{tabular}

Tabela 7.7: Consistência dos itens por modo na IEM PU 2

\begin{tabular}{|c|c|c|c|c|c|c|c|c|}
\hline & \multicolumn{2}{|c|}{ Atitude } & \multicolumn{2}{|c|}{ Norma Social } & \multicolumn{2}{|c|}{ Controle Percebido } & \multicolumn{2}{|c|}{ Intenção } \\
\hline Modo & Item & $\alpha$ & Item & $\alpha$ & Item & $\alpha$ & Item & $\alpha$ \\
\hline \multirow{3}{*}{$\begin{array}{c}\text { Ônibus } \\
\mathbf{n}=\mathbf{2 9 0}\end{array}$} & ONDAT1 & \multirow{3}{*}{0,711} & ONDNS1 & \multirow{3}{*}{0,566} & ONDCP1 & \multirow{3}{*}{0,697} & ONDIT1 & \multirow{3}{*}{0,694} \\
\hline & ONDAT2 & & ONDNS2 & & ONDCP2 & & ONDIT2 & \\
\hline & ONDAT3 & & ONDNS3 & & ONDCP3 & & ONDIT3 & \\
\hline \multirow{3}{*}{$\begin{array}{c}\text { Auto } \\
\text { Família } \\
\mathrm{n}=\mathbf{2 4 2}\end{array}$} & AFDAT1 & \multirow{3}{*}{0,799} & AFDNS1 & \multirow{3}{*}{0,668} & AFDCP1 & \multirow{3}{*}{0,764} & AFDIT1 & \multirow{3}{*}{0,713} \\
\hline & AFDAT2 & & AFDNS2 & & AFDCP2 & & AFDIT2 & \\
\hline & AFDAT3 & & AFDNS3 & & AFDCP3 & & AFDIT3 & \\
\hline
\end{tabular}


A análise do alfa de Cronbach apresentou valores maiores que 0,5, sendo que a maioria dos agrupamentos (12/16 - 75\%) apresentaram resultados acima ou igual a 0,7. Esses resultados indicam que os itens contribuem uniformemente para a formação de cada construto, medindo semanticamente o mesmo conceito.

Em seguida, foram elaboradas modelagens de caráter exploratório, seguindo o método de análise utilizado por Elliot et al.(2005), descrito na seção 5.6.2, no qual cada conjunto de crenças, tipo "b" - objeto da crença, tipo "e" - força da crença e tipo "b $x$ e" - Teoria da Expectância, entram em sequência na modelagem. Para considerar a Teoria da Expectância, foram calculadas novas variáveis: i) todos os valores das variáveis de crença (objeto e força) foram transformados em valores centralizados (valor observado menos a média da variável); ii) para os valores de expectância, foram criadas variáveis com a interação do objeto da crença " $b$ " e da força da crença " $e$ ", pela multiplicação dos dois itens " $b x e$ ", com valores já centralizados. Nesta etapa, foram consideradas apenas as amostras "alunos geral" por modo e construto, resultantes do tratamento T3. Essas modelagens, entretanto, pela necessidade de intensivo processamento dos dados, foram realizadas apenas para a IEM PU 1. A extensão dessa análise mais detalhada da relação entre as crenças e os construtos da TCP para a IEM PU 2 é sugerida como atividade para trabalhos futuros.

Foi adotado o tipo de modelagem por MLGs, com estimação pelo processo "quaseverossimilhança" já que os a normalidade não foi confirmada nos testes univariados realizados, tanto para as variáveis originais, quanto para as variáveis decorrentes de suas transformações. Cada construto considerado como variável dependente foi representado na modelagem pela média dos seus respectivos itens de medida direta, elaborados de acordo com a teoria (Ajzen, 2000, e DiStefano et al., 2009).

Em todos os modelos, as variáveis explicativas são todas as crenças salientes por modo (crenças do tipo "b" e "e"), com os valores centralizados. Destaca-se que a consideração dos valores das crenças no modo original ou centralizado produz parâmetros idênticos (em magnitude e sinal) no processo de calibração. A única diferença (em função da escala dos valores) é no valor do termo constante. Para cada construto, foram calibrados oito modelos, tendo as crenças como variáveis explicativas: 
a) Modelo $1 \mathrm{~A}$ - modelo inicial contendo todas as variáveis relacionadas ao conteúdo das crenças;

b) Modelo 2A - modelo inicial contendo todas as variáveis relacionadas aos conteúdos e valores das crenças;

c) Modelo 3A - modelo inicial contendo todas as variáveis relacionadas aos conteúdos, valores e produtos dos conteúdos pelos respectivos valores das crenças;

d) Modelo 4A - modelo inicial contendo somente os produtos dos conteúdos pelos respectivos valores das crenças. Esse modelo teve como objetivo verificar o quanto da variabilidade dos construtos é diretamente explicada pela Teoria da Expectância;

e) Modelos 1B, 2B, 3B e 4B - modelos finais obtidos a partir dos respectivos modelos iniciais, aos quais foi aplicado o processo de modelagem tipo backward para a exclusão das variáveis não significativas (remoção, uma a uma, das variáveis não significativas, decrescentemente pelo p-valor). Ou seja, os modelos finais contêm apenas variáveis significativas.

A Figura 7.1 apresenta a estrutura dos modelos dos construtos da TCP $\mathrm{x}$ as crenças salientes, tanto para o modo Ônibus, quanto para o modo Automóvel da Família, elaborados para a IEM PU 1.

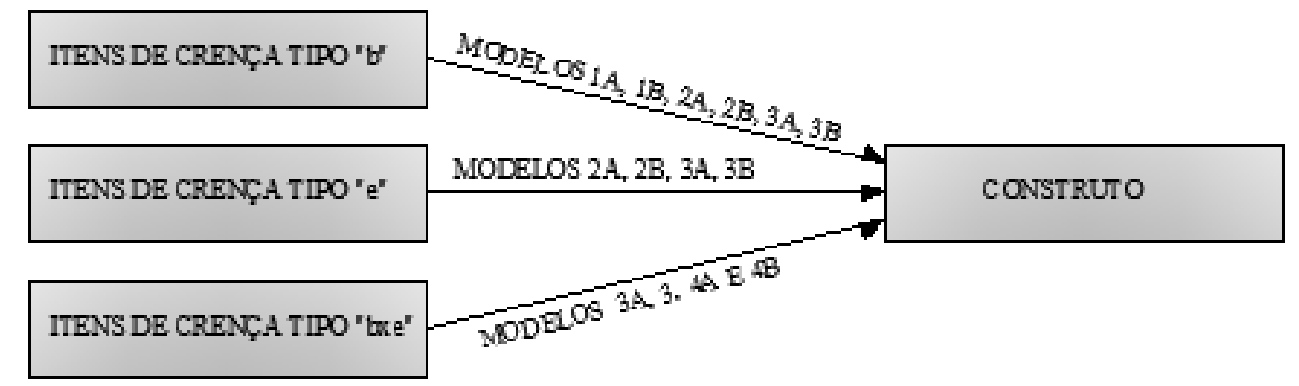

Figura 7.1: Estrutura dos modelos dos construtos da TCP x crenças salientes, por modo.

Obs: Construtos: Atitude, Norma Social, Controle Percebido ou Intenção, em cada modelo estimado; itens tipo "b" - afirmativas de conteúdo das crenças; itens tipo "e" - afirmativas de força das crenças; itens tipo "bxe" - itens referentes à Teoria da Expectância, do produto do conteúdo pela força da crença saliente. 
A análise referente ao grau de ajuste dos modelos calibrados levou em consideração o teste Chi-quadrado, o Pseudo- $\mathrm{R}^{2}$ de Efron e a análise dos resíduos proporcionada pelo gráfico CURE. O tamanho da amostra considerado em cada modelagem é apresentado juntamente com os resultados. O nível de significância adotado foi de 0,10 para remoção de variáveis. Os resultados são apresentados nas Tabelas 7.8 a 7.15. A avaliação gráfica dos resíduos (CURE) está contida nos Apêndices P e Q, para os modos Automóvel da Família e Ônibus, respectivamente.

Destaca-se que a comparação entre os Pseudo- $\mathrm{R}^{2}$, obtidos para os Modelos 1A, 2A, e 3A, visa replicar a análise feita por Elliot et al. (2005). Nela, é investigado o impacto na capacidade do modelo das crenças em explicar cada construto na medida em que são agregadas às variáveis ligadas ao conteúdo das crenças as variáveis referentes aos valores das crenças e aos produtos (conteúdo da crença x valor da crença).

Em geral, e baseado nos resultados do Pseudo- $\mathrm{R}^{2}$, os modelos do tipo 3B, são preferíveis aos modelos 1B, 2B e 4B. Os gráficos CURE (Apêndices P e Q) apresentaram resultados satisfatórios na maioria dos casos, variando em torno do valor "0", e com raros pontos para fora dos limites inferior e superior (+ ou - 2sigma). Em todos os modelos a constante é positiva e significativa.

$\mathrm{Na}$ relação da Atitude com as crenças salientes, para o modo Automóvel da Família, Tabela 7.8, percebe-se que todos os modelos passaram no teste do Chi-quadrado. Comparando-se os modelos 1A, 2A e 3A, percebe-se que o aumento da explicação pelo acréscimo de conjuntos de variáveis é de $31 \%$ e $2 \%$ respectivamente, compatível como estudo de Elliott et al. (2005). Esta observação indica que a inclusão do conjunto de variáveis referentes à força da crença (item "e") e do produto (item "bxe"), aos modelos que consideram apenas os objetos de crença (item “b”) aumenta a explicação da Atitude.

A análise dos modelos contendo somente variáveis significativas (tipo B), obtidos pela retirada sequencial de variáveis não significativas, revela que esses modelos finais têm capacidade explicativa inferior às dos respectivos modelos iniciais, mas seguem o desejável princípio da parcimônia. 
$\mathrm{Na}$ apuração dos modelos 2B e 3B, os resultados são idênticos, com dois conjuntos de crenças significativas. O primeiro refere-se à crença "é seguro", com o item "b" e "e", significativos. O segundo refere-se à crença "apoio dos amigos", também com os dois itens. Os modelos 4A e 4B, apenas com as crenças produto (item "bxe"), têm explicação abaixo de $10 \%$ e apresentam como significativos os produtos relacionados às crenças "usar carro piora o congestionamento", "é seguro" e "impede atividades de pós-turno".

Para o construto Norma Social x crenças salientes para o modo Automóvel da Família, Tabela 7.9, o aumento de explicação entre os modelos $1 \mathrm{~A}, 2 \mathrm{~A}$ e $3 \mathrm{~A}$ é de $5 \%$ e $3 \%$, respectivamente. Nos modelos finais significativos $1 \mathrm{~B}, 2 \mathrm{~B}$ e $3 \mathrm{~B}$, as variáveis significativas são semelhantes entre si, sendo ligadas às crenças: "usar carro piora o congestionamento", "é seguro", "preferência dos pais em trazer de carro", "apoio dos amigos" e "impede atividades de pós turno". Os resultados dos modelos $4 \mathrm{~B}$, diferem dos obtidos para os modelos 1B, $2 \mathrm{~B}$ e $3 \mathrm{~B}$ no que diz respeito ao conjunto de variáveis significativas integrantes do modelo. No modelo 4B as crenças "usar carro piora o congestionamento" e "preferência dos pais em trazer de carro" não são significativas e, no seu lugar, aparece como significativa a crença "é caro". As crenças “é seguro" e "apoio dos amigos" são significativas em todos os modelos ligados ao construto Norma Social.

Para a relação do Controle Percebido x crenças salientes, modo Automóvel da Família, Tabela 7.10, os modelos referentes à Teoria da Expectância, 4A e 4B não são significativos. O incremento de explicação entre os modelos $1 \mathrm{~A}, 2 \mathrm{~A}$ e $3 \mathrm{~A}$ é de $18 \%$ e $1 \%$, respectivamente. Os modelos $2 \mathrm{~B}$ e $3 \mathrm{~B}$ são idênticos, sendo significativas as crenças "preferência dos pais em trazer o carro", "é caro" e "impede atividades de pós-turno". Além dessas crenças, o modelo 1B inclui como significativa a crença "apoio dos amigos".

Nos modelos do construto Intenção x crenças, no modo Automóvel da Família, Tabela 7.11, os modelos 4A e 4B também não são significativos. Os modelos $1 \mathrm{~B}, 2 \mathrm{~B}$ e $3 \mathrm{~B}$ são muito semelhantes entre si, exceto quanto à crença "apoio dos amigos", que é significativa somente no modelo 1B. As crenças "preferência dos pais em trazer de carro", "é caro" e “impede atividades de pós-turno" são significativas nos três modelos.

Na relação da Atitude com as crenças salientes, para o modo Ônibus, pela Tabela 7.12, percebe-se que todos os modelos, exceto os $4 \mathrm{~A}$ e $4 \mathrm{~B}$, passaram no teste do Chi-quadrado. 
$\mathrm{O}$ acréscimo de explicação pelo acréscimo de variáveis nos modelos em sequência 1B, 2B e 3B é de $19 \%$ e 1\%, respectivamente. Muitas crenças do tipo "b" são comuns aos modelos $1 \mathrm{~B}, 2 \mathrm{~B}$ e $3 \mathrm{~B}$, sendo os dois últimos idênticos. São comuns aos três modelos as variáveis significativas ligadas às crenças "vantagem de ter o passe estudantil”, "incentivo dos pais", "superlotado", "é perigoso no trecho a pé escola/parada" e "é inseguro esperar na parada". As duas primeiras crenças apresentam coeficientes positivos (favorecendo a atitude favorável a usar o modo) enquanto as três últimas possuem coeficientes negativos, revelando sua participação na redução da atitude favorável ao uso do modo Ônibus. 
Tabela 7.8: Modelos GLM para construto Atitude x crenças salientes, modo Automóvel da Família, IEM PU1, amostra "alunos geral"

\begin{tabular}{|c|c|c|c|c|c|c|c|c|c|c|c|c|c|c|c|c|c|}
\hline \multirow[b]{2}{*}{ Crença } & \multirow{2}{*}{$\begin{array}{c}n=409 \\
\text { Variável }\end{array}$} & \multicolumn{2}{|c|}{ 1A Inicial } & \multicolumn{2}{|c|}{1 B Final } & \multicolumn{2}{|c|}{$2 A$ Inicial } & \multicolumn{2}{|c|}{2 B Final } & \multicolumn{2}{|c|}{$3 A$ Inicial } & \multicolumn{2}{|c|}{3 B Final } & \multicolumn{2}{|c|}{$4 A$ Inicial } & \multicolumn{2}{|c|}{ AB Final } \\
\hline & & $\beta$ & $p$ & $\beta$ & $p$ & $\beta$ & $p$ & $\beta$ & $p$ & $\beta$ & $p$ & $\beta$ & $p$ & $\beta$ & $p$ & $\beta$ & $p$ \\
\hline & Constante & 3.93 & $<2 \mathrm{e}-16$ & 3.93 & $<2 \mathrm{e}-16$ & 3.93 & $<2 \mathrm{e}-16$ & 3.93 & $<2 \mathrm{e}-16$ & 3.87 & $<2 \mathrm{e}-16$ & 3.93 & $<2 \mathrm{e}-16$ & 3.96 & $<2 \mathrm{e}-16$ & 3.96 & $<2 \mathrm{e}-16$ \\
\hline \multirow{3}{*}{$\begin{array}{l}\text { Usar carro piora } \\
\text { congestionamento }\end{array}$} & CAFCBO1 & 0.04 & 0.29 & & & 0.01 & 0.76 & & & 0.01 & 0.81 & & & & & & \\
\hline & CAFCBE1 & & & & & -0.02 & 0.55 & & & -0.02 & 0.60 & & & & & & \\
\hline & CBO1xCBE1 & & & & & & & & & -0.04 & 0.05 & & & -0.06 & 0.06 & -0.06 & 0.04 \\
\hline \multirow{3}{*}{ É seguro } & CAFCBO2 & 0.29 & 0.00 & 0.30 & 0.00 & 0.10 & 0.01 & 0.14 & 0.00 & 0.10 & 0.02 & 0.14 & 0.00 & & & & \\
\hline & CAFCBE2 & & & & & 0.31 & 0.00 & 0.39 & $<2 \mathrm{e}-16$ & 0.32 & 0.00 & 0.39 & $<2 \mathrm{e}-16$ & & & & \\
\hline & $\mathrm{CBO} 2 \times \mathrm{CBE} 2$ & & & & & & & & & 0.03 & 0.30 & & & -0.15 & 0.00 & -0.16 & 0.00 \\
\hline \multirow{3}{*}{$\begin{array}{l}\text { Costuma chegar } \\
\text { no horário certo }\end{array}$} & CAFCBO3 & -0.07 & 0.04 & -0.07 & 0.05 & -0.04 & 0.22 & & & -0.04 & 0.22 & & & & & & \\
\hline & CAFCBE3 & & & & & 0.09 & 0.01 & & & 0.07 & 0.04 & & & & & & \\
\hline & CBO3xCBE3 & & & & & & & & & -0.03 & 0.31 & & & -0.03 & 0.37 & & \\
\hline \multirow{3}{*}{$\begin{array}{c}\text { Preferência dos } \\
\text { pais em trazer de } \\
\text { carro }\end{array}$} & CAFCNO1 & 0.13 & 0.00 & 0.13 & 0.00 & 0.05 & 0.12 & & & 0.02 & 0.47 & & & & & & \\
\hline & CAFCNE1 & & & & & 0.17 & 0.00 & & & 0.21 & 0.00 & & & & & & \\
\hline & CNO1xCNE1 & & & & & & & & & 0.06 & 0.00 & & & 0.02 & 0.42 & & \\
\hline \multirow{3}{*}{ Apoio dos amigos } & CAFCNO2 & 0.16 & 0.00 & 0.16 & 0.00 & 0.04 & 0.26 & 0.09 & 0.01 & 0.05 & 0.11 & 0.09 & 0.01 & & & & \\
\hline & CAFCNE2 & & & & & 0.13 & 0.00 & 0.21 & 0.00 & 0.12 & 0.00 & 0.21 & 0.00 & & & & \\
\hline & $\mathrm{CNO} 2 \mathrm{xCNE} 2$ & & & & & & & & & 0.00 & 1.00 & & & -0.02 & 0.65 & & \\
\hline \multirow{3}{*}{ É caro } & CAFCCO1 & 0.06 & 0.09 & 0.07 & 0.05 & 0.02 & 0.40 & & & 0.03 & 0.25 & & & & & & \\
\hline & CAFCCE1 & & & & & 0.08 & 0.02 & & & 0.08 & 0.02 & & & & & & \\
\hline & CCO1xCCE1 & & & & & & & & & 0.01 & 0.75 & & & -0.05 & 0.14 & & \\
\hline \multirow{3}{*}{$\begin{array}{l}\text { Impede atividades } \\
\text { de pós turno }\end{array}$} & $\mathrm{CAFCCO} 2$ & 0.00 & 0.97 & & & -0.01 & 0.85 & & & 0.00 & 0.95 & & & & & & \\
\hline & CAFCCE2 & & & & & 0.00 & 0.91 & & & 0.00 & 0.87 & & & & & & \\
\hline & $\mathrm{CCO} 2 \mathrm{xCCE} 2$ & & & & & & & & & 0.01 & 0.43 & & & 0.08 & 0.00 & 0.08 & 0.00 \\
\hline \multicolumn{2}{|c|}{ Teste chi quadrado } & \multicolumn{2}{|c|}{1.00} & \multicolumn{2}{|c|}{1.00} & \multicolumn{2}{|c|}{1.00} & \multicolumn{2}{|c|}{1.00} & \multicolumn{2}{|c|}{1.00} & \multicolumn{2}{|c|}{1.00} & \multicolumn{2}{|c|}{0.96} & \multicolumn{2}{|c|}{0.97} \\
\hline \multicolumn{2}{|c|}{ Pseudo $R^{2}$} & & 24 & & 24 & & 55 & & 47 & & 57 & & 47 & & & & \\
\hline $\begin{array}{l}\text { Obs.: Especificaçãa } \\
\text { itens de crença, tip } \\
\text { para o modo; } 3 \mathrm{~B} F \\
\text { final do processo } b\end{array}$ & $\begin{array}{l}\text { dos modelos: } 1 \\
\text { "b" e "e", para }\end{array}$ & $1-$ entr & da de tod & & de crenç & & ara $0 \mathrm{~m}$ & & nal - $m$ & & 0 pioce & & as $\mathrm{do} \mathrm{n}$ & elo $1 \mathrm{~A}$ & $\mathrm{~A}-\mathrm{ent}$ & as de to & $\begin{array}{l}\text { os os } \\
\text { lizadas, } \\
\text { modelo }\end{array}$ \\
\hline
\end{tabular}


Tabela 7.9: Modelos GLM para construto Norma Social x crenças salientes, modo Automóvel da Família, IEM PU1, amostra "alunos geral”

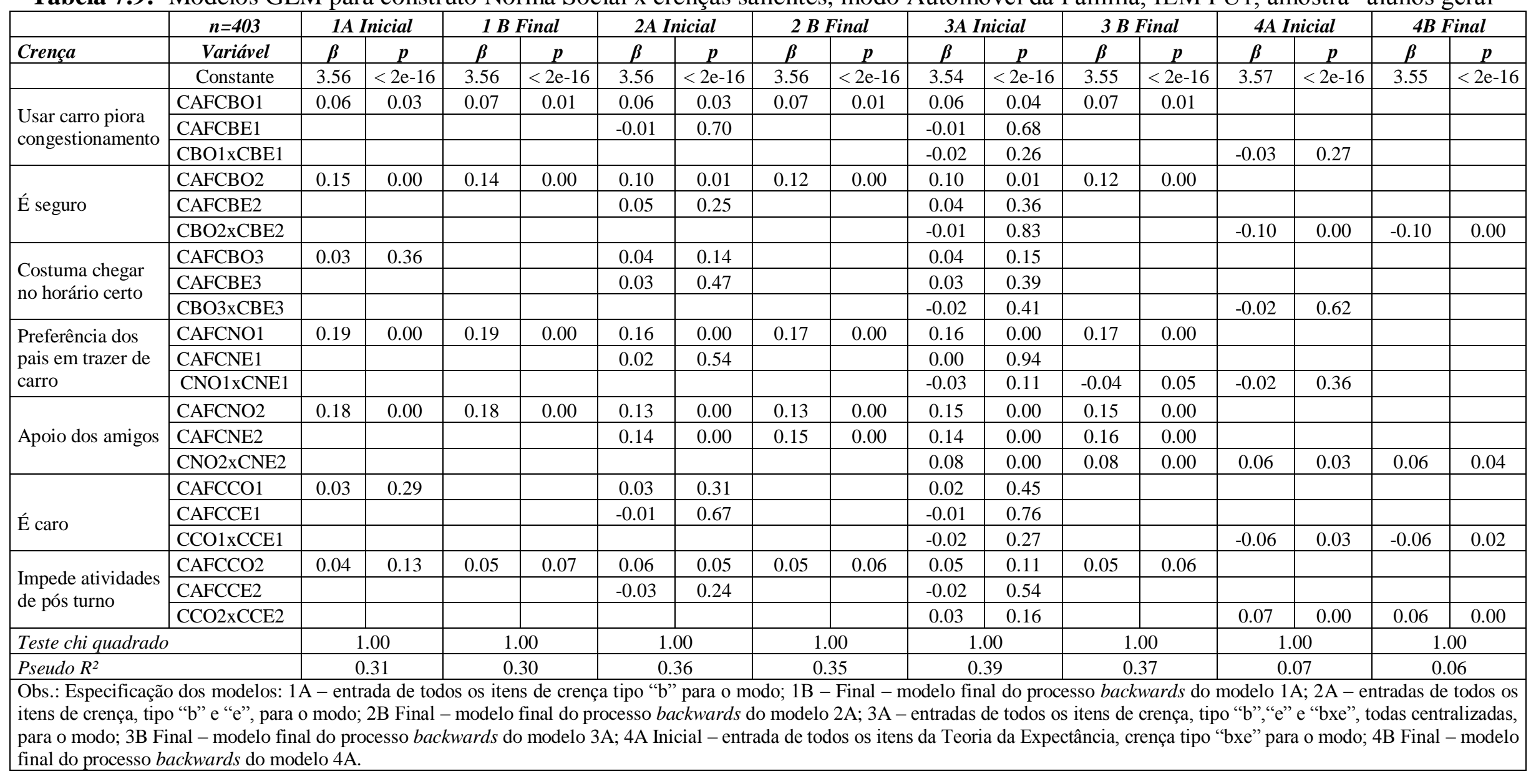


Tabela 7.10: Modelos GLM para Controle Percebido x crenças salientes, modo Automóvel da Família, IEM PU1, amostra "alunos geral"

\begin{tabular}{|c|c|c|c|c|c|c|c|c|c|c|c|c|c|c|c|c|c|}
\hline \multirow{2}{*}{ Crença } & \multirow{2}{*}{$\begin{array}{c}n=407 \\
\text { Variável }\end{array}$} & \multicolumn{2}{|c|}{ 1A Inicial } & \multicolumn{2}{|c|}{1 B Final } & \multicolumn{2}{|c|}{$2 A$ Inicial } & \multicolumn{2}{|c|}{2 B Final } & \multicolumn{2}{|c|}{ 3A Inicial } & \multicolumn{2}{|c|}{3 B Final } & \multicolumn{2}{|c|}{ 4A Inicial } & \multicolumn{2}{|c|}{$4 B$ Final } \\
\hline & & $\beta$ & $p$ & $\beta$ & $p$ & $\beta$ & $p$ & $\beta$ & $p$ & $\beta$ & $p$ & $\beta$ & $p$ & $\beta$ & $p$ & $\beta$ & $p$ \\
\hline & Constante & 3.32 & $<2 \mathrm{e}-16$ & 3.32 & $<2 \mathrm{e}-16$ & 3.32 & $<2 \mathrm{e}-16$ & 3.32 & $<2 \mathrm{e}-16$ & 3.30 & $<2 \mathrm{e}-16$ & 3.32 & $<2 \mathrm{e}-16$ & 3.38 & $<28-16$ & 3.34 & $<2 \mathrm{e}-16$ \\
\hline \multirow{3}{*}{$\begin{array}{l}\text { Usar carro piora } \\
\text { congestionamento }\end{array}$} & CAFCBO1 & -0.03 & 0.45 & & & -0.03 & 0.41 & & & -0.03 & 0.48 & & & & & & \\
\hline & \begin{tabular}{|l|} 
CAFCBE1 \\
\end{tabular} & & & & & 0.01 & 0.74 & & & 0.02 & 0.59 & & & & & & \\
\hline & CBO1xCBE1 & & & & & & & & & -0.04 & 0.15 & & & -0.06 & 0.12 & -0.06 & $0.06^{*}$ \\
\hline \multirow{3}{*}{ É seguro } & CAFCBO2 & 0.07 & 0.22 & & & -0.07 & 0.21 & & & -0.05 & 0.33 & & & & & & \\
\hline & CAFCBE2 & & & & & 0.06 & 0.31 & & & 0.06 & 0.26 & & & & & & \\
\hline & CBO2xCBE2 & & & & & & & & & 0.04 & 0.31 & & & -0.04 & 0.36 & & \\
\hline \multirow{3}{*}{$\begin{array}{l}\text { Costuma chegar } \\
\text { no horário certo }\end{array}$} & CAFCBO3 & 0.03 & 0.44 & & & 0.03 & 0.47 & & & 0.03 & 0.42 & & & & & & \\
\hline & CAFCBE3 & & & & & 0.16 & 0.00 & & & 0.16 & 0.00 & & & & & & \\
\hline & \begin{tabular}{|l|} 
CBO3xCBE3 \\
\end{tabular} & & & & & & & & & -0.03 & 0.41 & & & $\begin{array}{c}-0.01 \\
\end{array}$ & 0.83 & & \\
\hline \multirow{3}{*}{$\begin{array}{c}\text { Preferência dos } \\
\text { pais em trazer de } \\
\text { carro } \\
\end{array}$} & CAFCNO1 & 0.28 & 0.00 & 0.29 & 0.00 & 0.18 & 0.00 & 0.17 & 0.00 & 0.17 & 0.00 & 0.17 & 0.00 & & & & \\
\hline & \begin{tabular}{|l|} 
CAFCNE1 \\
\end{tabular} & & & & & 0.26 & 0.00 & 0.32 & 0.00 & 0.28 & 0.00 & 0.32 & 0.00 & & & & \\
\hline & CNO1xCNE1 & & & & & & & & & 0.02 & 0.42 & & & $\begin{array}{c}-0.03 \\
\end{array}$ & 0.42 & & \\
\hline \multirow{3}{*}{ Apoio dos amigos } & CAFCNO2 & 0.08 & $0.10 *$ & 0.09 & $0,06^{*}$ & -0.04 & 0.35 & & & -0.03 & 0.57 & & & & & & \\
\hline & \begin{tabular}{|l|} 
CAFCNE2 \\
\end{tabular} & & & & & 0.11 & 0.01 & & & 0.10 & 0.04 & & & & & & \\
\hline & CNO2xCNE2 & & & & & & & & & 0.08 & 0.80 & & & -0.01 & 0.71 & & \\
\hline \multirow{3}{*}{ É caro } & CAFCCO1 & -0.08 & $0.07 *$ & -0.08 & $0,05^{*}$ & -0.09 & 0.03 & -0.10 & 0.01 & -0.08 & 0.06 & -0.10 & 0.01 & & & & \\
\hline & CAFCCE1 & & & & & 0.04 & 0.43 & 0.12 & 0.00 & 0.04 & 0.41 & 0.12 & 0.00 & & & & \\
\hline & CCO1xCCE1 & & & & & & & & & 0.01 & 0.68 & & & -0.04 & 0.22 & & \\
\hline \multirow{3}{*}{$\begin{array}{l}\text { Impede atividades } \\
\text { de pós turno }\end{array}$} & CAFCCO2 & 0.07 & $0.08^{*}$ & 0.07 & $0,07 *$ & 0.07 & $0.08^{*}$ & 0.07 & 0.04 & 0.08 & 0.05 & 0.07 & 0.04 & & & & \\
\hline & \begin{tabular}{|l|} 
CAFCCE2 \\
\end{tabular} & & & & & 0.01 & 0.73 & & & 0.01 & 0.70 & & & & & & \\
\hline & CCO2xCCE2 & & & & & & & & & -0.02 & 0.41 & & & 0.03 & 0.32 & & \\
\hline \multicolumn{2}{|c|}{ Teste chi quadrado } & \multicolumn{2}{|c|}{0.44} & \multicolumn{2}{|c|}{0.45} & \multicolumn{2}{|c|}{1.00} & \multicolumn{2}{|c|}{0.99} & \multicolumn{2}{|c|}{1.00} & \multicolumn{2}{|c|}{0.99} & \multicolumn{2}{|c|}{0.01} & \multicolumn{2}{|c|}{0.01} \\
\hline \multicolumn{2}{|l|}{ Pseudo $R^{2}$} & & 17 & & & & & & & 0.2 & & & & 0. & & & \\
\hline
\end{tabular}


Tabela 7.11: Modelos GLM para construto Intenção x crenças salientes, modo Automóvel da Família, IEM PU1, amostra "alunos geral"

\begin{tabular}{|c|c|c|c|c|c|c|c|c|c|c|c|c|c|c|c|c|c|}
\hline \multirow[b]{2}{*}{ Crença } & \multirow{2}{*}{$\begin{array}{c}n=407 \\
\text { Variável }\end{array}$} & \multicolumn{2}{|c|}{$1 A$ Inicial } & \multicolumn{2}{|c|}{1 B Final } & \multicolumn{2}{|c|}{$2 A$ Inicial } & \multicolumn{2}{|c|}{2 B Final } & \multicolumn{2}{|c|}{ 3A Inicial } & \multicolumn{2}{|c|}{3 B Final } & \multicolumn{2}{|c|}{ 4A Inicial } & \multicolumn{2}{|c|}{$4 B$ Final } \\
\hline & & $\beta$ & $p$ & $\beta$ & $p$ & $\beta$ & $p$ & $\beta$ & $p$ & $\beta$ & $p$ & $\beta$ & $p$ & $\beta$ & $p$ & $\beta$ & $p$ \\
\hline & Constante & 3.12 & $<2 \mathrm{e}-16$ & 3.12 & $<2 \mathrm{e}-16$ & 3.12 & $<2 \mathrm{e}-16$ & 3.12 & $<2 \mathrm{e}-16$ & 3.11 & $<2 \mathrm{e}-16$ & 3.12 & $<2 \mathrm{e}-16$ & 3.17 & $<2 \mathrm{e}-16$ & 3.18 & $<2 \mathrm{e}-16$ \\
\hline \multirow{3}{*}{$\begin{array}{l}\text { Usar carro piora } \\
\text { congestionamento }\end{array}$} & CAFCBO1 & -0.04 & 0.36 & ---- & ----- & -0.05 & 0.24 & ---- & ------ & -0.05 & 0.20 & $-\cdots$ & ------ & $-\cdots$ & ----- & $-\cdots$ & ------ \\
\hline & \begin{tabular}{|l|} 
CAFCBE1 \\
\end{tabular} & ------ & $\begin{array}{ll}----- \\
\end{array}$ & ----- & $\begin{array}{ll}---- \\
\end{array}$ & -0.01 & 0.82 & - ---- & - ----- & 0.00 & 0.97 & - ---- & ----- & $\begin{array}{ll}----- \\
\end{array}$ & - ---- & - ----- & $\begin{array}{ll}---- \\
\end{array}$ \\
\hline & \begin{tabular}{|l|} 
CBO1xCBE1 \\
\end{tabular} & $\begin{array}{ll}----- \\
\end{array}$ & $\begin{array}{ll}----- \\
\end{array}$ & $\begin{array}{ll}---- \\
\end{array}$ & $\begin{array}{ll}----- \\
\end{array}$ & $\begin{array}{ll}---- \\
\end{array}$ & $\begin{array}{ll}---- \\
\end{array}$ & $\begin{array}{ll}---- \\
\end{array}$ & $\begin{array}{ll}---- \\
\end{array}$ & -0.06 & 0.03 & $\begin{array}{ll}---- \\
\end{array}$ & $\begin{array}{ll}----- \\
\end{array}$ & -0.08 & 0.03 & -0.08 & 0.02 \\
\hline \multirow{3}{*}{ É seguro } & CAFCBO2 & 0.02 & 0.65 & $\begin{array}{ll}---- \\
-\end{array}$ & $\begin{array}{ll}---- \\
\end{array}$ & -0.08 & 0.12 & $\begin{array}{ll}---- \\
-\end{array}$ & - ---- & -0.08 & 0.13 & $\begin{array}{ll}---- \\
-1\end{array}$ & $\begin{array}{ll}---- \\
\end{array}$ & $\begin{array}{l}----- \\
--1\end{array}$ & $\begin{array}{ll}----- \\
\end{array}$ & $\begin{array}{ll}---- \\
\end{array}$ & $\begin{array}{ll}---- \\
\end{array}$ \\
\hline & CAFCBE2 & $\begin{array}{ll}---- \\
\end{array}$ & $\begin{array}{ll}---- \\
\end{array}$ & $\begin{array}{ll}---- \\
--1\end{array}$ & $\begin{array}{ll}---- \\
\end{array}$ & 0.10 & $0,08^{*}$ & $\begin{array}{ll}---- \\
\end{array}$ & $\begin{array}{ll}---- \\
-1\end{array}$ & 0.10 & $0,07 *$ & $\begin{array}{ll}---- \\
\end{array}$ & $\begin{array}{ll}---- \\
\end{array}$ & $\begin{array}{ll}---- \\
\end{array}$ & $\begin{array}{ll}---- \\
\end{array}$ & $\begin{array}{ll}---- \\
-1\end{array}$ & $\begin{array}{ll}---- \\
\end{array}$ \\
\hline & $\mathrm{CBO} 2 \times \mathrm{CBE} 2$ & ----- & $\begin{array}{ll}---- \\
\end{array}$ & ----- & $\begin{array}{ll}---- \\
\end{array}$ & -ב--- & - ----- & - ---- & - ---- & 0.00 & 0.94 & - ---- & ----- & -0.06 & 0.19 & - ----- & ----- \\
\hline \multirow{3}{*}{$\begin{array}{l}\text { Costuma chegar } \\
\text { no horário certo }\end{array}$} & CAFCBO3 & 0.04 & 0.32 & ----- & ----- & 0.05 & 0.19 & ----- & ----- & 0.06 & 0.13 & $\begin{array}{ll}---- \\
\end{array}$ & ----- & $\begin{array}{l}----- \\
--1\end{array}$ & $\begin{array}{l}----- \\
\end{array}$ & ----- & ----- \\
\hline & \begin{tabular}{|l|} 
CAFCBE3 \\
\end{tabular} & ------ & ----- & ----- & $\begin{array}{l}----- \\
\end{array}$ & 0.74 & 0.11 & ----- & $\begin{array}{l}----- \\
\end{array}$ & 0.06 & 0.19 & $\begin{array}{l}----- \\
\end{array}$ & ----- & $\begin{array}{ll}---- \\
\end{array}$ & $\begin{array}{ll}---- \\
\end{array}$ & $\begin{array}{ll}---- \\
\end{array}$ & $\begin{array}{ll}---- \\
\end{array}$ \\
\hline & \begin{tabular}{|l|} 
CBO3xCBE3 \\
\end{tabular} & $\begin{array}{l}----- \\
\end{array}$ & ------ & $\begin{array}{l}----- \\
\end{array}$ & ------ & - ---- & - & $\begin{array}{l}----- \\
\end{array}$ & $\begin{array}{l}----- \\
-\end{array}$ & -0.03 & 0.43 & $\begin{array}{l}----- \\
-\end{array}$ & ----- & 0.01 & 0.86 & $\begin{array}{l}----- \\
-\end{array}$ & $\begin{array}{l}----- \\
\end{array}$ \\
\hline \multirow{3}{*}{$\begin{array}{l}\text { Preferência dos } \\
\text { pais em trazer de } \\
\text { carro }\end{array}$} & CAFCNO1 & 0.38 & $<2 \mathrm{e}-16$ & 0.39 & $<2 \mathrm{e}-16$ & 0.31 & 0.00 & 0.32 & 0.00 & 0.30 & 0.00 & 0.32 & 0.00 & ----- & ----- & - ---- & ----- \\
\hline & CAFCNE1 & ----- & +----- & ----- & ------ & 0.15 & 0.00 & 0.20 & 0.00 & 0.17 & 0.00 & 0.20 & 0.00 & $\begin{array}{l}----- \\
--1\end{array}$ & - ---- & ----- & - ---- \\
\hline & CNO1xCNE1 & ----- & ----- & ----- & ----- & ------ & ----- & ----- & ----- & 0.02 & 0.48 & ----- & - ----- & 0.00 & 0.87 & ----- & ----- \\
\hline \multirow{3}{*}{ Apoio dos amigos } & CAFCNO2 & 0.12 & 0.01 & 0.12 & 0.01 & 0.03 & 0.53 & ----- & ----- & 0.03 & 0.45 & ----- & $\begin{array}{ll}----- \\
-\end{array}$ & $\begin{array}{ll}---- \\
--1\end{array}$ & $\begin{array}{ll}----- \\
-1\end{array}$ & ----- & ----- \\
\hline & \begin{tabular}{|l|} 
CAFCNE2 \\
\end{tabular} & $\begin{array}{ll}---- \\
-1\end{array}$ & $\begin{array}{ll}---- \\
\end{array}$ & - & $\begin{array}{l}----- \\
\end{array}$ & 0.10 & 0.00 & $\begin{array}{ll}---- \\
--\end{array}$ & $\begin{array}{ll}---- \\
--1\end{array}$ & 0.09 & 0.05 & $\begin{array}{ll}---- \\
--1\end{array}$ & - & - & $\begin{array}{l}----- \\
-1\end{array}$ & $\begin{array}{ll}---- \\
-1\end{array}$ & $\begin{array}{l}---- \\
--1\end{array}$ \\
\hline & CNO2xCNE2 & $\begin{array}{ll}---- \\
\end{array}$ & $\begin{array}{l}---- \\
-\end{array}$ & $\begin{array}{ll}---- \\
\end{array}$ & $\begin{array}{ll}---- \\
\end{array}$ & $\begin{array}{ll}---- \\
-\end{array}$ & $\begin{array}{ll}---- \\
\end{array}$ & $\begin{array}{ll}---- \\
\end{array}$ & $\begin{array}{ll}---- \\
\end{array}$ & -0.02 & 0.43 & $\begin{array}{ll}---- \\
\end{array}$ & ----- & -0.05 & 0.17 & -0.06 & $0,09 *$ \\
\hline \multirow{3}{*}{ É caro } & CAFCCO1 & -0.08 & $0,05^{*}$ & -0.08 & 0.03 & -0.10 & 0.53 & -0.11 & 0.01 & -0.09 & 0.02 & -0.11 & 0.01 & ------ & ------ & ------ & ----- \\
\hline & CAFCCE1 & $\begin{array}{ll}---- \\
\end{array}$ & - ---- & $\begin{array}{ll}---- \\
-\end{array}$ & $\begin{array}{ll}---- \\
\end{array}$ & 0.09 & 0.02 & 0.16 & 0.00 & 0.09 & $0,06^{*}$ & 0.16 & 0.00 & $\begin{array}{ll}----- \\
\end{array}$ & $\begin{array}{ll}----- \\
-1\end{array}$ & $\begin{array}{ll}---- \\
\end{array}$ & $\begin{array}{l}---- \\
\end{array}$ \\
\hline & CCO1xCCE1 & $\begin{array}{ll}---- \\
\end{array}$ & $\begin{array}{ll}---- \\
\end{array}$ & $\begin{array}{ll}---- \\
\end{array}$ & $\begin{array}{ll}---- \\
\end{array}$ & - ----- & - ----- & $\begin{array}{ll}---- \\
\end{array}$ & $\begin{array}{ll}---- \\
\end{array}$ & 0.05 & $0,09 *$ & $\begin{array}{ll}---- \\
\end{array}$ & $\begin{array}{ll}---- \\
\end{array}$ & -0.02 & 0.56 & $\begin{array}{ll}---- \\
\end{array}$ & $\begin{array}{ll}---- \\
\end{array}$ \\
\hline \multirow{3}{*}{$\begin{array}{l}\text { Impede atividades } \\
\text { de pós turno }\end{array}$} & CAFCCO2 & 0.09 & 0.02 & 0.09 & 0.01 & 0.07 & 0.01 & 0.08 & 0.02 & 0.08 & 0.04 & 0.08 & 0.02 & $\begin{array}{ll}---- \\
\end{array}$ & $\begin{array}{ll}----- \\
\end{array}$ & $\begin{array}{ll}---- \\
\end{array}$ & $\begin{array}{ll}---- \\
--1\end{array}$ \\
\hline & \begin{tabular}{|l|} 
CAFCCE2 \\
\end{tabular} & ------ & ------ & ------ & $\begin{array}{ll}----- \\
--1\end{array}$ & 0.04 & 0.04 & $\begin{array}{ll}----- \\
--1\end{array}$ & ----- & 0.04 & 0.24 & $\begin{array}{ll}----- \\
--1\end{array}$ & - ----- & $\begin{array}{ll}---- \\
--9\end{array}$ & $\begin{array}{ll}----- \\
-\end{array}$ & ----- & $\begin{array}{ll}---- \\
\end{array}$ \\
\hline & \begin{tabular}{|l|}
$\mathrm{CCO} 2 \mathrm{xCCE} 2$ \\
\end{tabular} & $\begin{array}{ll}---- \\
\end{array}$ & ------ & $\begin{array}{ll}----- \\
\end{array}$ & ------ & $\begin{array}{ll}---- \\
\end{array}$ & ----- & $\begin{array}{ll}---- \\
\end{array}$ & ------ & 0.00 & 0.91 & $\begin{array}{ll}---- \\
-\end{array}$ & ------ & 0.04 & 0.11 & $\begin{array}{ll}---- \\
\end{array}$ & +----- \\
\hline \multicolumn{2}{|l|}{ Teste chi quadrado } & \multicolumn{2}{|c|}{0.98} & \multicolumn{2}{|c|}{0.98} & \multicolumn{2}{|c|}{0.20} & \multicolumn{2}{|c|}{1.00} & \multicolumn{2}{|c|}{1.00} & \multicolumn{2}{|c|}{1.00} & \multicolumn{2}{|c|}{0.02} & \multicolumn{2}{|c|}{0.02} \\
\hline \multicolumn{2}{|l|}{ Pseudo $R^{2}$} & & 28 & & & & & & & & & & & & & & \\
\hline
\end{tabular}


Tabela 7.12: Modelos GLM para construto Atitude x crenças salientes, modo Ônibus, IEM PU1, amostra "alunos geral"

\begin{tabular}{|c|c|c|c|c|c|c|c|c|c|c|c|c|c|c|c|c|c|}
\hline \multirow[b]{2}{*}{ Crença } & \multirow{2}{*}{$\begin{array}{c}n=562 \\
\text { Variável }\end{array}$} & \multicolumn{2}{|c|}{ 1A Inicial } & \multicolumn{2}{|c|}{1 B Final } & \multicolumn{2}{|c|}{ 2A Inicial } & \multicolumn{2}{|c|}{2 B Final } & \multicolumn{2}{|c|}{ 3A Inicial } & \multicolumn{2}{|c|}{3 B Final } & \multicolumn{2}{|c|}{$4 A$ Inicial } & \multicolumn{2}{|c|}{$4 B$ Final } \\
\hline & & $\beta$ & $p$ & $\beta$ & $p$ & $\beta$ & $p$ & $\beta$ & $p$ & $\beta$ & $p$ & $\beta$ & $p$ & $\beta$ & $p$ & $\beta$ & $p$ \\
\hline & Constante & 3.34 & $<2 \mathrm{e}-16$ & 3.34 & $<2 \mathrm{e}-16$ & 3.34 & $<2 \mathrm{e}-16$ & 3.34 & $<2 \mathrm{e}-16$ & 3.34 & $<2 \mathrm{e}-16$ & 3.34 & $<2 \mathrm{e}-16$ & 3.40 & $<2 \mathrm{e}-16$ & 3.37 & $<2 \mathrm{e}-16$ \\
\hline \multirow{3}{*}{$\begin{array}{c}\text { Vantagem de } \\
\text { ter o passe } \\
\text { estudantil } \\
\end{array}$} & CONCBO1 & 0.15 & 0.00 & 0.15 & 0.00 & 0.09 & 0.02 & 0.13 & 0.00 & 0.09 & 0.03 & 0.13 & 0.00 & & & & \\
\hline & CONCBE1 & & & & & -0.01 & 0.86 & & & 0.03 & 0.46 & & & & & & \\
\hline & CBO1xCBE1 & & & & & & & & & 0.06 & 0.06 & & & -0.03 & 0.52 & & \\
\hline \multirow{3}{*}{$\begin{array}{l}\text { Não Chega } \\
\text { atrasado }\end{array}$} & CONCBO2 & 0.00 & 0.97 & & & -0.03 & 0.32 & & & -0.03 & 0.35 & & & & & & \\
\hline & \begin{tabular}{|l|} 
CONCBE2 \\
\end{tabular} & & & & & 0.07 & 0.04 & & & 0.07 & 0.03 & & & & & & \\
\hline & CBO2xCBE2 & & & & & & & & & 0.03 & 0.11 & & & 0.04 & 0.17 & & \\
\hline \multirow{3}{*}{$\begin{array}{c}\text { Não é seguro } \\
\text { dentro do } \\
\text { ônibus }\end{array}$} & CONCBO3 & -0.10 & 0.01 & -0.10 & 0.01 & -0.04 & 0.22 & & & -0.04 & 0.25 & & & & & & \\
\hline & \begin{tabular}{|l|} 
CONCBE3 \\
\end{tabular} & & & & & -0.05 & 0.13 & & & -0.03 & 0.39 & & & & & & \\
\hline & CBO3xCBE3 & & & & & & & & & -0.05 & 0.04 & & & -0.08 & 0.02 & -0.07 & 0.04 \\
\hline \multirow{3}{*}{ Superlotado } & CONCBO4 & -0.12 & 0.00 & -0.12 & 0.00 & -0.12 & 0.00 & -0.14 & 0.00 & -0.12 & 0.00 & -0.14 & 0.00 & & & & \\
\hline & \begin{tabular}{|l|} 
CONCBE4 \\
\end{tabular} & & & & & 0.01 & 0.62 & & & 0.00 & 0.85 & & & & & & \\
\hline & CBO4xCBE4 & & & & & & & & & 0.04 & $0,09 *$ & 0.04 & 0.07 & 0.05 & 0.17 & & \\
\hline \multirow{3}{*}{ Incentivo pais } & CONCNO1 & 0.34 & $<2 \mathrm{e}-16$ & 0.34 & $<2 \mathrm{e}-16$ & 0.14 & 0.00 & 0.16 & 0.00 & 0.13 & 0.00 & 0.16 & 0.00 & & & & \\
\hline & CONCNE1 & & & & & 0.36 & $<2 \mathrm{e}-16$ & 0.43 & $<2 \mathrm{e}-16$ & 0.36 & $<2 \mathrm{e}-16$ & 0.43 & $<2 \mathrm{e}-16$ & & & & \\
\hline & CNO1xCNE1 & & & & & & & & & -0.01 & 0.73 & & & -0.05 & 0.10 & -0.05 & 0.06 \\
\hline \multirow{3}{*}{ Apoio amigos } & CONCNO2 & 0.09 & 0.02 & 0.09 & 0.02 & -0.01 & 0.69 & & & 0.00 & 0.92 & & & & & & \\
\hline & CONCNE2 & & & & & 0.13 & 0.00 & & & 0.13 & 0.00 & & & & & & \\
\hline & CNO2xCNE2 & & & & & & & & & 0.01 & 0.56 & & & 0.00 & 0.93 & & \\
\hline \multirow{3}{*}{$\begin{array}{l}\text { É perigoso no } \\
\text { trecho a pé } \\
\text { escola/parada }\end{array}$} & CONCCO1 & -0.06 & $0,07 *$ & -0.06 & 0.07 & -0.03 & 0.29 & -0.06 & 0.05 & -0.03 & 0.35 & -0.05 & 0.06 & & & & \\
\hline & CONCCE1 & & & & & -0.02 & 0.55 & & & -0.02 & 0.56 & & & & & & \\
\hline & CCO1xCCE1 & & & & & & & & & -0.03 & 0.12 & & & -0.01 & 0.67 & & \\
\hline \multirow{3}{*}{$\begin{array}{l}\text { É inseguro } \\
\text { esperar na } \\
\text { parada }\end{array}$} & CONCCO3 & -0.11 & 0.01 & -0.11 & 0.01 & -0.08 & 0.02 & -0.10 & 0.00 & -0.08 & 0.03 & -0.10 & 0.00 & & & & \\
\hline & \begin{tabular}{|l|} 
CONCCE3 \\
\end{tabular} & & & & & 0.07 & 0.03 & 0.10 & 0.00 & 0.07 & 0.06 & 0.10 & 0.00 & & & & \\
\hline & CCO3xCCE3 & & & & & & & & & 0.03 & 0.29 & & & 0.03 & 0.44 & & \\
\hline \multirow{3}{*}{$\begin{array}{c}\text { Tem uma linha } \\
\text { direta } \\
\text { casa/escola }\end{array}$} & CONCCO4 & 0.08 & 0.01 & 0.08 & 0.01 & 0.03 & 0.37 & & & 0.02 & 0.58 & & & & & & \\
\hline & CONCCE4 & & & & & 0.06 & 0.06 & & & 0.06 & 0.07 & & & & & & \\
\hline & CCO4xCCE4 & & & & & & & & & -0.02 & 0.36 & & & -0.03 & 0.20 & & \\
\hline \multicolumn{2}{|c|}{ Teste Chi quadrado } & \multicolumn{2}{|c|}{0.97} & \multicolumn{2}{|c|}{0.97} & \multicolumn{2}{|c|}{1.00} & \multicolumn{2}{|c|}{1.00} & & & & & & & & \\
\hline Pseudo- $R^{2}$ & & & & & & & & & & & & & & & & & \\
\hline
\end{tabular}

Obs.: Especificação dos modelos: $1 \mathrm{~A}$ - entrada de todos os itens de crença tipo "b" para o modo; $1 \mathrm{~B}$ - Final - modelo final do processo stepwise backwards do modelo $1 \mathrm{~A} ; 2 \mathrm{~A}$ - entradas de

todos os itens de crença, tipo "b" e "e", para o modo; 2B Final - modelo final do processo stepwise backwards do modelo 2A; 3A - entradas de todos os itens de crença, tipo "b", "e" e "bxe",

todas centralizadas, para o modo; 3B Final - modelo final do processo stepwise backwards do modelo 3A; 4A Inicial - entrada de todos os itens da Teoria da Expectância, crença tipo "bxe"

para o modo; 4B Final - modelo final do processo stepwise backwards do modelo 4A. 
Tabela 7.13: Modelos GLM para construto Norma Social x crenças salientes, modo Ônibus, IEM PU1, amostra "alunos geral"

\begin{tabular}{|c|c|c|c|c|c|c|c|c|c|c|c|c|c|c|c|c|c|}
\hline \multirow[b]{2}{*}{ Crença } & \multirow{2}{*}{$\begin{array}{c}n=596 \\
\text { Variável }\end{array}$} & \multicolumn{2}{|c|}{ 1A Inicial } & \multicolumn{2}{|c|}{1 B Final } & \multicolumn{2}{|c|}{$2 A$ Inicial } & \multicolumn{2}{|c|}{2 B Final } & \multicolumn{2}{|c|}{ 3A Inicial } & \multicolumn{2}{|c|}{3 B Final } & \multicolumn{2}{|c|}{ 4A Inicial } & \multicolumn{2}{|c|}{ 4B Final } \\
\hline & & $\beta$ & $p$ & $\beta$ & $p$ & $\beta$ & $p$ & $\beta$ & $p$ & $\beta$ & $p$ & $\beta$ & $p$ & $\beta$ & $p$ & $\beta$ & $p$ \\
\hline & Constante & 3.34 & $<2 \mathrm{e}-16$ & 3.34 & $<2 \mathrm{e}-16$ & 3.34 & $<2 \mathrm{e}-16$ & 3.34 & $<2 \mathrm{e}-16$ & 3.28 & $<2 \mathrm{e}-16$ & 3.31 & $<2 \mathrm{e}-16$ & 3.31 & $<2 \mathrm{e}-16$ & 3.32 & $<2 \mathrm{e}-16$ \\
\hline \multirow{3}{*}{$\begin{array}{l}\text { Vantagem de } \\
\text { ter o passe } \\
\text { estudantil }\end{array}$} & CONCBO1 & 0.18 & 0.00 & 0.19 & 0.00 & 0.16 & 0.00 & 0.18 & 0.00 & 0.14 & 0.00 & 0.15 & 0.00 & & & & \\
\hline & CONCBE1 & & & & & 0.01 & 0.84 & & & -0.04 & 0.28 & & & & & & \\
\hline & CBO1xCBE1 & & & & & & & & & -0.08 & 0.00 & -0.07 & 0.00 & -0.13 & $2.6 \mathrm{e}-05$ & -0.13 & 0.00 \\
\hline \multirow{3}{*}{$\begin{array}{l}\text { Não Chega } \\
\text { atrasado }\end{array}$} & CONCBO2 & 0.09 & 0.00 & 0.09 & 0.00 & 0.09 & 0.00 & 0.09 & 0.00 & 0.08 & 0.00 & 0.09 & 0.00 & & & & \\
\hline & CONCBE2 & & & & & -0.01 & 0.78 & & & -0.02 & 0.50 & & & & & & \\
\hline & CBO2xCBE2 & & & & & & & & & -0.02 & 0.22 & & & -0.01 & 0.75 & & \\
\hline \multirow{3}{*}{$\begin{array}{c}\text { Não é seguro } \\
\text { dentro do } \\
\text { ônibus }\end{array}$} & CONCBO3 & 0.02 & 0.55 & & & 0.03 & 0.24 & & & 0.02 & 0.41 & & & & & & \\
\hline & CONCBE3 & & & & & 0.01 & 0.71 & & & 0.00 & 0.87 & & & & & & \\
\hline & CBO3xCBE3 & & & & & & & & & -0.02 & 0.36 & & & -0.03 & 0.21 & & \\
\hline \multirow[b]{3}{*}{ Superlotado } & CONCBO4 & -0.05 & 0.05 & -0.05 & 0.06 & -0.06 & 0.04 & -0.04 & 0.08 & -0.06 & 0.03 & -0.05 & 0.04 & & & & \\
\hline & CONCBE4 & & & & & 0.00 & 0.94 & & & -0.02 & 0.39 & & & & & & \\
\hline & CBO4xCBE4 & & & & & & & & & 0.03 & $0,08^{*}$ & 0.03 & 0.09 & 0.01 & 0.59 & & \\
\hline \multirow[b]{3}{*}{ Incentivo pais } & CONCNO1 & 0.22 & $<2 \mathrm{e}-16$ & 0.22 & $<2 \mathrm{e}-16$ & 0.18 & 0.00 & 0.18 & 0.00 & 0.20 & 0.00 & 0.21 & 0.00 & & & & \\
\hline & CONCNE1 & & & & & 0.07 & 0.01 & 0.08 & 0.00 & 0.07 & 0.01 & 0.07 & 0.00 & & & & \\
\hline & CNO1xCNE1 & & & & & & & & & 0.05 & 0.00 & 0.07 & 0.00 & 0.03 & 0.19 & 0.04 & 0.10 \\
\hline \multirow{3}{*}{ Apoio amigos } & CONCNO2 & 0.23 & $<2 \mathrm{e}-16$ & 0.23 & $<2 \mathrm{e}-16$ & 0.19 & 0.00 & 0.21 & 0.00 & 0.19 & 0.00 & 0.21 & 0.00 & & & & \\
\hline & CONCNE2 & & & & & 0.02 & 0.37 & & & 0.03 & 0.32 & & & & & & \\
\hline & CNO2xCNE2 & & & & & & & & & 0.01 & 0.45 & & & 0.01 & 0.60 & & \\
\hline \multirow{3}{*}{$\begin{array}{c}\text { É perigoso no } \\
\text { trecho a pé } \\
\text { escola/parada }\end{array}$} & CONCCO1 & -0.01 & 0.67 & & & 0.00 & 0.99 & & & 0.01 & 0.80 & & & & & & \\
\hline & CONCCE1 & & & & & -0.02 & 0.42 & & & -0.02 & 0.43 & & & & & & \\
\hline & CCO1xCCE1 & & & & & & & & & 0.00 & 0.92 & & & 0.02 & 0.35 & & \\
\hline \multirow{3}{*}{$\begin{array}{l}\text { É inseguro } \\
\text { esperar na } \\
\text { parada }\end{array}$} & CONCCO3 & 0.02 & 0.44 & & & 0.02 & 0.42 & & & 0.01 & 0.64 & & & & & & \\
\hline & CONCCE3 & & & & & 0.06 & 0.03 & & & 0.06 & 0.02 & & & & & & \\
\hline & CCO3xCCE3 & & & & & & & & & -0.01 & 0.47 & & & -0.01 & 0.59 & & \\
\hline \multirow{3}{*}{$\begin{array}{c}\text { Tem uma linha } \\
\text { direta } \\
\text { casa/escola }\end{array}$} & CONCCO4 & 0.03 & 0.13 & & & 0.03 & 0.18 & & & 0.03 & 0.16 & & & & & & \\
\hline & CONCCE4 & & & & & -0.02 & 0.44 & & & 0.00 & 0.92 & & & & & & \\
\hline & CCO4xCCE4 & & & & & & & & & 0.04 & 0.01 & & & 0.03 & 0.04 & 0.04 & 0.03 \\
\hline \multicolumn{2}{|c|}{ Teste Chi quadrado } & \multicolumn{2}{|c|}{1.00} & \multicolumn{2}{|c|}{1.00} & \multicolumn{2}{|c|}{1.00} & \multicolumn{2}{|c|}{1.00} & & & & & & & & \\
\hline Pseudo- $R^{2}$ & & & & & & & & & & & & & & & & & \\
\hline
\end{tabular}

Obs.: Especificação dos modelos: 1A - entrada de todos os itens de crença tipo "b" para o modo; $1 \mathrm{~B}$ - Final - modelo final do processo stepwise backwards do modelo $1 \mathrm{~A} ; 2 \mathrm{~A}$ - entradas de

todos os itens de crença, tipo "b" e "e", para o modo; 2B Final - modelo final do processo stepwise backwards do modelo 2A; 3A - entradas de todos os itens de crença, tipo "b", "e" e "bxe",

todas centralizadas, para o modo; 3B Final - modelo final do processo stepwise backwards do modelo 3A; 4A Inicial - entrada de todos os itens da Teoria da Expectância, crença tipo "bxe"

para o modo; 4B Final - modelo final do processo stepwise backwards do modelo 4A. 
Tabela 7.14: Modelos GLM para construto Controle Percebido x crenças salientes, modo Ônibus, IEM PU1, amostra "alunos geral"

\begin{tabular}{|c|c|c|c|c|c|c|c|c|c|c|c|c|c|c|c|c|c|}
\hline \multirow[b]{2}{*}{ Crença } & \multirow{2}{*}{$\begin{array}{c}n=566 \\
\text { Variável }\end{array}$} & \multicolumn{2}{|c|}{ 1A Inicial } & \multicolumn{2}{|c|}{1 B Final } & \multicolumn{2}{|c|}{$2 A$ Inicial } & \multicolumn{2}{|c|}{2 B Final } & \multicolumn{2}{|c|}{ 3A Inicial } & \multicolumn{2}{|c|}{3 B Final } & \multicolumn{2}{|c|}{ 4A Inicial } & \multicolumn{2}{|c|}{ 4B Final } \\
\hline & & $\beta$ & $p$ & $\beta$ & $p$ & $\beta$ & $p$ & $\beta$ & $p$ & $\beta$ & $p$ & $\beta$ & $p$ & $\beta$ & $p$ & $\beta$ & $p$ \\
\hline & Constante & 3.76 & $<2 \mathrm{e}-16$ & 3.76 & $<2 \mathrm{e}-16$ & 3.76 & $<2 \mathrm{e}-16$ & 3.76 & $<2 \mathrm{e}-16$ & 3.75 & $<2 \mathrm{e}-16$ & 3.74 & $<2 \mathrm{e}-16$ & 3.81 & $<2 \mathrm{e}-16$ & 3.80 & $<2 \mathrm{e}-16$ \\
\hline \multirow{3}{*}{$\begin{array}{c}\text { Vantagem de } \\
\text { ter o passe } \\
\text { estudantil } \\
\end{array}$} & CONCBO1 & 0.26 & 0.00 & 0.26 & 0.00 & 0.16 & $1.87 \mathrm{e}-05$ & 0.18 & 0.00 & 0.15 & $8.26 \mathrm{e}-05$ & 0.20 & 0.00 & & & & \\
\hline & CONCBE1 & & & & & 0.19 & 0.00 & 0.22 & 0.00 & 0.21 & 0.00 & 0.24 & 0.00 & & & & \\
\hline & CBO1xCBE1 & & & & & & & & & 0.02 & 0.58 & & & -0.14 & 0.00 & -0.14 & 0.00 \\
\hline \multirow{3}{*}{$\begin{array}{l}\text { Não Chega } \\
\text { atrasado }\end{array}$} & CONCBO2 & 0.02 & 0.48 & & & 0.02 & 0.55 & & & 0.02 & 0.54 & & & & & & \\
\hline & CONCBE2 & & & & & 0.06 & 0.03 & & & 0.07 & 0.02 & & & & & & \\
\hline & CBO2xCBE2 & & & & & & & & & 0.01 & 0.70 & & & 0.01 & 0.66 & & \\
\hline \multirow{3}{*}{$\begin{array}{c}\text { Não é seguro } \\
\text { dentro do } \\
\text { ônibus }\end{array}$} & CONCBO3 & -0.02 & 0.52 & & & 0.03 & 0.34 & & & 0.03 & 0.37 & & & & & & \\
\hline & \begin{tabular}{|l|} 
CONCBE3 \\
\end{tabular} & & & & & -0.02 & 0.55 & & & -0.01 & 0.77 & & & & & & \\
\hline & CBO3xCBE3 & & & & & & & & & -0.05 & 0.02 & & & -0.06 & 0.04 & -0.06 & 0.04 \\
\hline \multirow{3}{*}{ Superlotado } & CONCBO4 & -0.01 & 0.88 & & & -0.01 & 0.74 & & & -0.01 & 0.76 & & & & & & \\
\hline & CONCBE4 & & & & & 0.01 & 0.82 & & & -0.01 & 0.64 & & & & & & \\
\hline & CBO4xCBE4 & & & & & & & & & 0.06 & 0.01 & & & 0.06 & 0.04 & 0.06 & 0.04 \\
\hline \multirow{3}{*}{ Incentivo pais } & CONCNO1 & 0.23 & 0.00 & 0.24 & 0.00 & 0.08 & 0.01 & 0.11 & 0.00 & 0.09 & 0.00 & 0.13 & 0.00 & & & & \\
\hline & CONCNE1 & & & & & 0.17 & 0.00 & 0.24 & 0.00 & 0.18 & 0.00 & 0.26 & $<2 \mathrm{e}-16$ & & & & \\
\hline & CNO1xCNE1 & & & & & & & & & 0.03 & 0.20 & 0.04 & 0.08 & 0.02 & 0.52 & & \\
\hline \multirow{3}{*}{ Apoio amigos } & CONCNO2 & 0.07 & 0.04 & 0.07 & 0.04 & -0.01 & 0.68 & & & 0.00 & 0.91 & & & & & & \\
\hline & CONCNE2 & & & & & 0.14 & 0.00 & & & 0.13 & 0.00 & & & & & & \\
\hline & CNO2xCNE2 & & & & & & & & & -0.01 & 0.63 & & & -0.02 & 0.43 & & \\
\hline \multirow{3}{*}{$\begin{array}{l}\text { É perigoso no } \\
\text { trecho a pé } \\
\text { escola/parada }\end{array}$} & CONCCO1 & -0.07 & 0.01 & -0.09 & 0.00 & -0.04 & 0.10 & -0.07 & 0.00 & -0.04 & 0.13 & -0.08 & 0.00 & & & & \\
\hline & CONCCE1 & & & & & -0.01 & 0.65 & & & 0.00 & 0.85 & & & & & & \\
\hline & CCO1xCCE1 & & & & & & & & & -0.01 & 0.69 & & & 0.02 & 0.39 & & \\
\hline \multirow{3}{*}{$\begin{array}{c}\text { É inseguro } \\
\text { esperar na } \\
\text { parada }\end{array}$} & CONCCO3 & -0.03 & 0.34 & & & -0.04 & 0.25 & & & -0.03 & 0.28 & & & & & & \\
\hline & CONCCE3 & & & & & 0.06 & $0,06^{*}$ & & & 0.06 & $0,08^{*}$ & & & & & & \\
\hline & CCO3xCCE3 & & & & & & & & & 0.04 & $0,1^{*}$ & & & 0.02 & 0.58 & & \\
\hline \multirow{3}{*}{$\begin{array}{c}\text { Tem uma linha } \\
\text { direta } \\
\text { casa/escola }\end{array}$} & CONCCO4 & 0.10 & 0.00 & 0.10 & 0.00 & 0.04 & $0,09 *$ & 0.05 & $0,08^{*}$ & 0.03 & 0.19 & & & & & & \\
\hline & CONCCE4 & & & & & 0.08 & 0.00 & 0.09 & 0.00 & 0.08 & 0.00 & & & & & & \\
\hline & CCO4xCCE4 & & & & & & & & & -0.01 & 0.40 & & & -0.02 & 0.26 & & \\
\hline \multicolumn{2}{|c|}{ Teste Chi quadrado } & \multicolumn{2}{|c|}{0.9999998} & \multicolumn{2}{|c|}{0.9999998} & \multicolumn{2}{|c|}{1.00} & \multicolumn{2}{|c|}{1.00} & & 00 & & .00 & & & & 50 \\
\hline Pseudo- $R^{2}$ & & & & & & & 48 & & 44 & & 50 & & .43 & & & & 04 \\
\hline
\end{tabular}

Obs.: Especificação dos modelos: 1A - entrada de todos os itens de crença tipo "b" para o modo; $1 \mathrm{~B}$ - Final - modelo final do processo stepwise backwards do modelo $1 \mathrm{~A} ; 2 \mathrm{~A}$ - entradas de

todos os itens de crença, tipo "b" e "e", para o modo; 2B Final - modelo final do processo stepwise backwards do modelo 2A; 3A - entradas de todos os itens de crença, tipo "b", "e" e "bxe",

todas centralizadas, para o modo; 3B Final - modelo final do processo stepwise backwards do modelo 3A; 4A Inicial - entrada de todos os itens da Teoria da Expectância, crença tipo "bxe"

para o modo; 4B Final - modelo final do processo stepwise backwards do modelo 4A. 
Tabela 7.15: Modelos GLM para construto Intenção x crenças salientes, modo Ônibus, IEM PU1, amostra "alunos geral"

\begin{tabular}{|c|c|c|c|c|c|c|c|c|c|c|c|c|c|c|c|c|c|}
\hline \multirow[b]{2}{*}{ Crença } & \multirow{2}{*}{$\begin{array}{c}n=590 \\
\text { Variável }\end{array}$} & \multicolumn{2}{|c|}{ 1A Inicial } & \multicolumn{2}{|c|}{1 B Final } & \multicolumn{2}{|c|}{$2 A$ Inicial } & \multicolumn{2}{|c|}{2 B Final } & \multicolumn{2}{|c|}{ 3A Inicial } & \multicolumn{2}{|c|}{3 B Final } & \multicolumn{2}{|c|}{$4 A$ Inicial } & \multicolumn{2}{|c|}{ 4B Final } \\
\hline & & $\beta$ & $p$ & $\beta$ & $p$ & $\beta$ & $p$ & $\beta$ & $p$ & $\beta$ & $p$ & $\beta$ & $p$ & $\beta$ & $p$ & $\beta$ & $p$ \\
\hline & Constante & 3.60 & $<2 \mathrm{e}-16$ & 3.60 & $<2 \mathrm{e}-16$ & 3.60 & $<2 \mathrm{e}-16$ & 3.60 & $<2 \mathrm{e}-16$ & 3.61 & $<2 \mathrm{e}-16$ & 3.60 & $<2 \mathrm{e}-16$ & 3.68 & $<2 \mathrm{e}-16$ & 3.69 & $<2 \mathrm{e}-16$ \\
\hline \multirow{3}{*}{$\begin{array}{l}\text { Vantagem de } \\
\text { ter o passe } \\
\text { estudantil } \\
\end{array}$} & CONCBO1 & 0.13 & 0.00 & 0.13 & 0.00 & 0.07 & 0.08 & 0.12 & 0.00 & 0.07 & $0,085^{*}$ & 0.12 & 0.00 & & & & \\
\hline & CONCBE1 & & & & & 0.08 & $0,07 *$ & 0.15 & 0.00 & 0.07 & 0.10 & 0.15 & 0.00 & & & & \\
\hline & CBO1xCBE1 & & & & & & & & & 0.00 & 0.99 & & & -0.11 & 0.01 & -0.11 & 0.01 \\
\hline \multirow{3}{*}{$\begin{array}{l}\text { Não Chega } \\
\text { atrasado }\end{array}$} & CONCBO2 & -0.04 & 0.28 & & & -0.05 & 0.10 & & & -0.05 & 0.11 & & & & & & \\
\hline & CONCBE2 & & & & & 0.07 & 0.04 & & & 0.07 & 0.03 & & & & & & \\
\hline & CBO2xCBE2 & & & & & & & & & 0.02 & 0.29 & & & 0.04 & 0.18 & & \\
\hline \multirow{3}{*}{$\begin{array}{c}\text { Não é seguro } \\
\text { dentro do } \\
\text { ônibus }\end{array}$} & CONCBO3 & -0.06 & 0.13 & -0.07 & 0.03 & -0.02 & 0.55 & & & -0.02 & 0.60 & & & & & & \\
\hline & CONCBE3 & & & & & -0.01 & 0.73 & & & 0.00 & 0.93 & & & & & & \\
\hline & CBO3xCBE3 & & & & & & & & & -0.02 & 0.43 & & & -0.02 & 0.51 & & \\
\hline \multirow[b]{3}{*}{ Superlotado } & CONCBO4 & -0.03 & 0.39 & & & -0.04 & 0.22 & & & -0.04 & 0.25 & & & & & & \\
\hline & CONCBE4 & & & & & -0.01 & 0.68 & & & -0.01 & 0.77 & & & & & & \\
\hline & CBO4xCBE4 & & & & & & & & & -0.01 & 0.63 & & & -0.01 & 0.69 & & \\
\hline \multirow[b]{3}{*}{ Incentivo pais } & CONCNO1 & 0.45 & $<2 \mathrm{e}-16$ & 0.44 & $<2 \mathrm{e}-16$ & 0.32 & $<2 \mathrm{e}-16$ & 0.35 & $<2 \mathrm{e}-16$ & 0.31 & $<2 \mathrm{e}-16$ & 0.35 & $<2 \mathrm{e}-16$ & & & & \\
\hline & CONCNE1 & & & & & 0.19 & 0.00 & 0.27 & 0.00 & 0.19 & 0.00 & 0.27 & 0.00 & & & & \\
\hline & CNO1xCNE1 & & & & & & & & & -0.03 & 0.24 & & & -0.08 & 0.01 & -0.08 & 0.01 \\
\hline \multirow[b]{3}{*}{ Apoio amigos } & CONCNO2 & 0.11 & 0.00 & 0.11 & 0.00 & 0.03 & 0.45 & & & 0.03 & 0.46 & & & & & & \\
\hline & CONCNE2 & & & & & 0.08 & 0.03 & & & 0.09 & 0.02 & & & & & & \\
\hline & CNO2xCNE2 & & & & & & & & & 0.01 & 0.69 & & & 0.02 & 0.63 & & \\
\hline \multirow{3}{*}{$\begin{array}{l}\text { É perigoso no } \\
\text { trecho a pé } \\
\text { escola/parada }\end{array}$} & CONCCO1 & -0.04 & 0.19 & & & -0.02 & 0.42 & & & -0.02 & 0.48 & & & & & & \\
\hline & CONCCE1 & & & & & 0.02 & 0.57 & & & 0.01 & 0.68 & & & & & & \\
\hline & CCO1xCCE1 & & & & & & & & & -0.03 & 0.19 & & & 0.00 & 0.97 & & \\
\hline \multirow{3}{*}{$\begin{array}{l}\text { É inseguro } \\
\text { esperar na } \\
\text { parada }\end{array}$} & CONCCO3 & 0.01 & 0.82 & & & 0.00 & 0.98 & & & 0.00 & 0.94 & & & & & & \\
\hline & CONCCE3 & & & & & 0.08 & 0.02 & & & 0.08 & 0.04 & & & & & & \\
\hline & CCO3xCCE3 & & & & & & & & & 0.00 & 0.91 & & & 0.00 & 0.89 & & \\
\hline \multirow{3}{*}{$\begin{array}{c}\text { Tem uma linha } \\
\text { direta } \\
\text { casa/escola }\end{array}$} & CONCCO4 & 0.09 & 0.00 & 0.09 & 0.00 & 0.04 & 0.20 & & & 0.04 & 0.20 & & & & & & \\
\hline & CONCCE4 & & & & & 0.06 & 0.03 & & & 0.07 & 0.03 & & & & & & \\
\hline & CCO4xCCE4 & & & & & & & & & 0.01 & 0.43 & & & 0.01 & 0.78 & & \\
\hline \multicolumn{2}{|c|}{ Teste Chi quadrado } & \multicolumn{2}{|c|}{0.99} & \multicolumn{2}{|c|}{0.99} & \multicolumn{2}{|c|}{1.00} & \multicolumn{2}{|c|}{0.99} & & & & & & & & -06 \\
\hline Pseudo- $R^{2}$ & & & 38 & & & & & & 44 & & & & 44 & & & & \\
\hline
\end{tabular}


Para a relação da Norma Social com as crenças, modo Ônibus, Tabela 7.13, todos os modelos são significativos. Os incrementos de explicação entre os modelos $1 \mathrm{~A}$ e $2 \mathrm{~A}$ e entre o modelo $2 \mathrm{~A}$ e $3 \mathrm{~A}$ são, respectivamente, $2 \%$ e $3 \%$. O modelo $3 \mathrm{~B}$ é o que contém o maior número de variáveis explicativas significativas, acrescentando explicação para o construto Norma Social. Um destaque é dado à crença "incentivo dos pais", com os três itens ("b", 'e", e "bxe") significativos. Variáveis relacionadas às crenças "vantagem de ter o passe estudantil", "não chegar atrasado", "superlotado" e "apoio dos amigos" também se mostraram significativas nos modelos 1B, 2B e 3B.

Para o construto Controle Percebido, em sua relação com as crenças salientes, modo Ônibus, Tabela 7.14, todos os modelos são significativos, embora a pequena capacidade de explicação dos modelos 4A e 4B, com menos de 5\%. O modelo 4B tem conjunto de variáveis significativas bem diferente dos conjuntos dos modelos $1 \mathrm{~B}$ e $2 \mathrm{~B}$. As variáveis significativas nos modelos $2 \mathrm{~B}$ são as mesmas que as do modelo $1 \mathrm{~B}$, exceto para a variável CONCCNO2 ("apoio dos amigos"). Mostraram-se significativas nos modelos 1B, $2 \mathrm{~B}$ e 3B variáveis ligadas às crenças "vantagem de ter o passe estudantil", "incentivo dos pais" e "é perigoso no trecho a pé escola/parada".

No caso da relação do construto Intenção com as crenças salientes, modo Ônibus, Tabela 7.15, os modelos 4A e 4B não são significativos, enquanto todos os demais o são. $\mathrm{O}$ acréscimo de explicação entre os modelos $1 \mathrm{~A}$ e $2 \mathrm{~A}$ é de $10 \%$, enquanto que a inclusão das variáveis ligadas à Teoria da Expectância não trouxe nenhum aumento para o PseudoR2. Variáveis ligadas às crenças "vantagem de ter o passe estudantil" e "incentivo dos pais" mostraram-se significativas nos modelos 1B, 2B e 3B.

Tal como nos estudos de Elliott et al.(2005), a modelagem das crenças considerando a decomposição em itens de conteúdo ("b"), força ("e"), e do produto ("bxe") (modelos do tipo 3A inicial e 3B final) apresentaram superioridade aos modelos que consideraram apenas o conteúdo (modelos 1A inicial e 1B final), ou só ao produto (modelo 4A inicial e 4B final. Como demonstração deste resultado, a Tabela 7.16 apresenta uma comparação dos resultados do presente estudo (em termos do pseudo- $\mathrm{R}^{2}$ ) com os de Elliott et al.(2005), com relação aos modelos finais tipo 1B, apenas com conteúdo de crenças e 3B, com os três tipos de itens, conteúdo, força e produto. 
Tabela 7.16: Comparação dos ganhos pela inclusão dos itens de força de crença "e" e produto "bxe" ao conteúdo de crença "b"

\begin{tabular}{|c|c|c|c|c|c|c|c|}
\hline \multirow{3}{*}{ Construto } & \multirow{3}{*}{$\begin{array}{c}\text { Modo } \\
\text { Modelos }\end{array}$} & \multicolumn{4}{|c|}{ Estudo } & \multirow{2}{*}{\multicolumn{2}{|c|}{ Elliott et al. (2005) }} \\
\hline & & \multicolumn{2}{|c|}{ Automóvel da Família } & \multicolumn{2}{|c|}{ Ônibus } & & \\
\hline & & $1 \mathrm{~B}$ & $3 \mathrm{~B}$ & $1 \mathrm{~B}$ & $3 \mathrm{~B}$ & $1 \mathrm{~B}$ & $3 \mathrm{~B}$ \\
\hline \multirow{3}{*}{ Atitude } & $\mathrm{R}^{2}$ & 0,24 & 0,47 & 0,33 & 0,49 & 0,31 & 0,42 \\
\hline & $\Delta \mathrm{R}^{2}$ & -- & 0,23 & -- & 0,16 & -- & 0,11 \\
\hline & $\%$ melhora & -- & $96 \%$ & -- & $48 \%$ & -- & $35 \%$ \\
\hline \multirow{3}{*}{$\begin{array}{c}\text { Norma } \\
\text { Social }\end{array}$} & $\mathrm{R}^{2}$ & 0,30 & 0,37 & 0,42 & 0,46 & 0,41 & 0,42 \\
\hline & $\Delta \mathrm{R}^{2}$ & -- & 0,07 & -- & 0,04 & -- & 0,01 \\
\hline & $\%$ melhora & -- & $23 \%$ & -- & $10 \%$ & -- & $2 \%$ \\
\hline \multirow{3}{*}{$\begin{array}{l}\text { Controle } \\
\text { Percebido }\end{array}$} & $\mathrm{R}^{2}$ & 0,14 & 0,31 & 0,30 & 0,43 & 0,14 & 0,42 \\
\hline & $\Delta \mathrm{R}^{2}$ & -- & 0,17 & -- & 0,13 & -- & 0,28 \\
\hline & $\%$ melhora & -- & $121 \%$ & -- & $43 \%$ & -- & $200 \%$ \\
\hline \multirow{3}{*}{ Intenção } & $\mathrm{R}^{2}$ & 0,28 & 0,35 & 0,38 & 0,44 & 0,31 & 0,41 \\
\hline & $\Delta \mathrm{R}^{2}$ & -- & 0,07 & -- & 0,06 & -- & 0,10 \\
\hline & $\%$ melhora & -- & $25 \%$ & -- & $16 \%$ & -- & $32 \%$ \\
\hline
\end{tabular}

\subsection{MODELAGEM DA INTENÇÃO}

A relação das crenças com a intenção já foi mostrada na seção 7.2. Na presente seção, é explorada a relação da intenção com as medidas diretas da TCP, variáveis sociodemográficas, hábito e comportamento passado, para os modos Automóvel da Família e Ônibus. Conforme pode ser visto na Tabela 7.2, esses modos foram os que apresentaram maiores percentuais de utilização e de opiniões dos respondentes dentre os estudados para as duas IEMs.

As modelagens da Intenção são apresentadas de forma hierárquica em duas etapas. $\mathrm{Na}$ primeira etapa, são testadas apenas a Intenção em relação aos construtos Atitude, Norma Social e Controle Percebido, seguindo a abordagem clássica da Teoria do Comportamento Planejado (Modelos 1A). Na segunda etapa, são acrescidas aos modelos iniciais de cada modo, as variáveis sociodemográficas, o hábito e o comportamento passado (Modelos 2A). Pelo processo de modelagem backwards, a segunda etapa leva a um modelo final composto apenas de variáveis significativas na explicação da intenção de uso dos dois modos analisados (Modelos 2B).

Foram realizados dois tipos de modelagem: i) modelagem sequencial sem variáveis latentes - através de MLGs, considerando cada construto como a média dos escores dos itens de medida direta, e não como variáveis latentes; ii) modelagem sequencial com variáveis latentes - através de Modelos de Variáveis Latentes, onde os construtos são obtidos pelos respectivos itens de medida direta. Ao final, os resultados obtidos nos dois 
tipos de modelagem foram comparados. O propósito dessa comparação foi verificar o ganho na compreensão dos fenômenos estudados produzido pelo uso de um modelo mais sofisticado, pela consideração das variáveis latentes (modelos do tipo ii) que requer programas computacionais mais específicos para a calibração, em lugar de um modelo cuja calibração é mais simples, sem a consideração específica de variáveis latentes, (modelos do tipo i). Essa verificação é importante na medida em que a facilidade de aplicação do procedimento proposto é um requisito básico para aumentar seu potencial de utilização futura pelas IEMs.

A verificação de que os dados não apresentavam a normalidade necessária ao uso da estimação por mínimos quadrados levou à adaptação das modelagens da intenção. Para os modelos tipo “ii” foram utilizadas modelagens do tipo Equações Estruturais, do tipo Análise Fatorial Confirmatória - AFC, com o uso preferencial da estimação ADF (Asymptotically Distribution Free). Para os modelos do tipo "i” foram utilizadas modelagens do tipo Modelos Lineares Generalizados - MLG, com estimação por quaseverossimilhança, e função de ligação "identidade". As adaptações trazem restrições aos dois tipos de modelagem. Nos modelos tipo "i”, as variáveis foram modeladas como "não normais", porém a não consideração do erro de medida advindo dos itens que compõem a média dos construtos pode levar ao aumento de resíduos (Ben-Akiva et al.,2002).

Por outro lado, nos modelos tipo "ii", o uso da estimação ADF relaxou os pressupostos de normalidade na Análise Fatorial Confirmatória, porém tal estimação é apropriada apenas para amostras iguais ou superior a 2000 respondentes (Byrne,2010). Quando possível, no processo de modelagem backwards, o modelo tipo "ii" foi identificado pela estimação ADF. Nos casos onde não pode ser identificado o modelo, iniciou-se o processo com a modelagem pela Máxima Verossimilhança, até atingir o modelo final, ótimo e, em seguida, este modelo foi testado pela estimação ADF. Este procedimento foi recomendado por Byrne (2010) para ser adotado apenas em estudos exploratórios, para amostras entre 200 e 300 respondentes e ausência de normalidade nos dados. A constante do modelo não é estimada pelo método ADF. A Figura 7.2 apresenta o diagrama de caminhos para os modelos de intenção estudados, por modo e do tipo ii. As Tabelas 7.17 a 7.20 apresentam os resultados desta modelagem, para cada IEM, para os modos Automóvel da Família e Ônibus. 


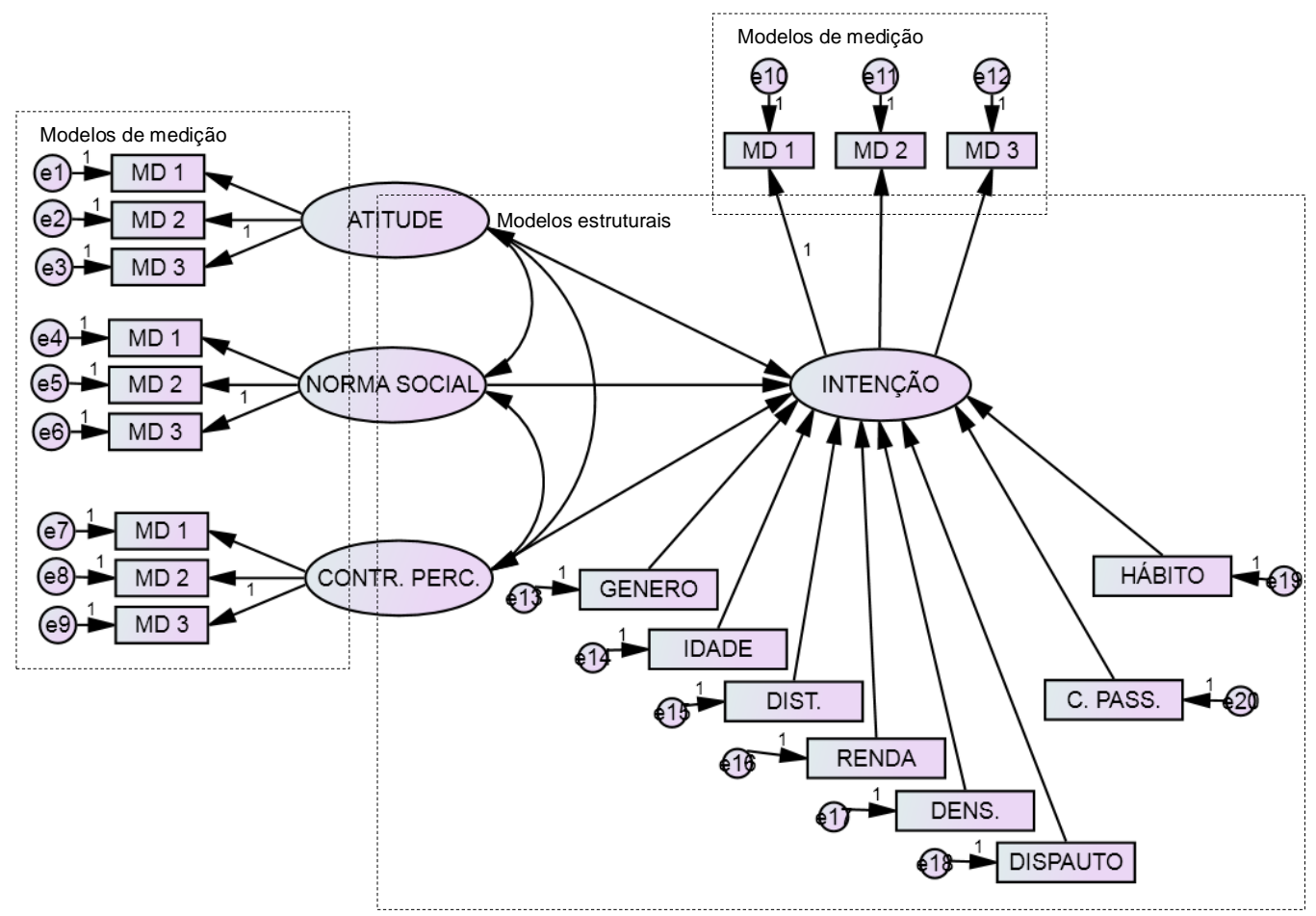

Figura 7.2: Diagrama de caminhos dos modelos de variável latente (modelos tipo ii) para a intenção por modo.

Obs.: MD - item de medida direta de cada construto para o modo considerado.

Considerando os resultados dos modelos tipo 1A e 2B, apresentados nas Tabelas 7.17 a 7.20, a TCP, que postula que a Intenção tem como antecedentes a Atitude, a Norma Social e o Controle Percebido, se confirmou em todos os modelos do tipo Modelos Lineares Generalizados - MLGs, estimação por quase-verossimilhança. Já para os modelos de Análise Fatorial Confirmatória - AFC, com a consideração de variáveis latentes, apenas para os modelos tipo 2B do modo Ônibus, a teoria foi confirmada totalmente. Para os modelos do modo Automóvel da Família, na IEM PU 1 foram significativos os construtos Norma Social e Controle Percebido, enquanto que na IEM PU 2 somente o Controle Percebido mostrou-se significativo para explicar a Intenção.

As variáveis Controle Percebido e Comportamento Passado mostraram-se significativas em todas as modelagens tipo 2B, tanto nos modelos MLGs, quanto AFCs, nas duas IEMs. Nos modelos MLG, a explicação do modelo medida pelo Pseudo-R $\mathbf{R}^{2}$ varia de 47 a $70 \%$. Os gráficos de resíduos (disponíveis nos Apêndices R e S) também mostram a validade do modelo sob os pressupostos dos gráficos CURE. 
Tabela 7.17: Modelagem Intenção no modo Automóvel da Família, na IEM PU 1, amostra "alunos geral"

\begin{tabular}{|c|c|c|c|c|c|c|c|c|c|c|c|c|}
\hline & \multicolumn{12}{|c|}{ Modo Automóvel da Família $(n=407)$} \\
\hline & \multicolumn{6}{|c|}{ Modelos MLG sem variáveis latentes } & \multicolumn{6}{|c|}{ Modelos AFC com variáveis latentes } \\
\hline & \multicolumn{2}{|c|}{ Modelo 1A - quasi } & \multicolumn{2}{|c|}{ Modelo 2A - quasi } & \multicolumn{2}{|c|}{ Modelo 2B - quasi } & \multirow{2}{*}{\multicolumn{2}{|c|}{$\begin{array}{c}\text { Modelo 1A - MV } \\
X^{2}=3,951 \\
\text { CFI }=0,912 \\
\text { RMSEA }=0,085 \\
\text { GFI }=0,926 \\
\text { RMR }=0,086\end{array}$}} & \multirow{2}{*}{\multicolumn{2}{|c|}{$\begin{array}{c}\text { Modelo 2A - MV } \\
X^{2}=3,780 \\
\text { CFI }=0,770 \\
\text { RMSEA }=0,083 \\
\text { GFI }=0,865 \\
\text { RMR }=1506790,34\end{array}$}} & \multirow{2}{*}{\multicolumn{2}{|c|}{$\begin{array}{c}\text { Modelo 2B - MV } \\
X^{2}=4,599 \\
\text { CFI }=0,848 \\
\text { RMSEA }=0,094 \\
\text { GFI }=0,918 \\
\text { RMR }=232,310\end{array}$}} \\
\hline & Pseudo & $\begin{array}{l}=1 ; \\
=0,51397 ;\end{array}$ & & & $\begin{array}{r}X \\
\text { Pseudo-R }\end{array}$ & 0,55552 & & & & & & \\
\hline Variável & $\beta$ & p-valor & $\beta$ & p-valor & $\beta$ & p-valor & $\beta$ & p-valor & $\beta$ & p-valor & $\beta$ & p-valor \\
\hline Constante & $-0,22267$ & 0,26710 & $-0,776$ & 0,27427 & $-0,515$ & 0,01284 & --- & --- & --- & -- & $\begin{array}{l}-- \\
---\end{array}$ & --- \\
\hline ATITUDE & 0,17745 & 0,00019 & 0,148 & 0,00164 & 0,148 & 0,00127 & $-0,066$ & 0,471 & $-0,079$ & 0.000 & --- & --- \\
\hline NORMA & 0,23999 & $4,48 \mathrm{E}-06$ & 0,212 & $3,19 \mathrm{E}-05$ & 0,214 & $2,31 \mathrm{E}-05$ & 0,466 & 0,001 & 0,424 & 0,002 & 0,356 & 0,002 \\
\hline CONTROLE & 0,54092 & $2 \mathrm{E}-16$ & 0,468 & $<2 \mathrm{E}-16$ & 0,466 & $<2 \mathrm{E}-16$ & 0,653 & 0,000 & 0,562 & 0,000 & 0,539 & 0,000 \\
\hline GENERO & --- & --- & $-0,0237$ & 0,75933 & --- & --- & --- & --- & $-0,025$ & 0,650 & --- & --- \\
\hline$I D A D E$ & --- & --- & 0,0066 & 0,87613 & --- & --- & --- & --- & $-0,004$ & 0,002 & --- & --- \\
\hline RENDA & --- & --- & $2,36 \mathrm{E}-07$ & 0,97295 & --- & --- & --- & --- & 0,000 & 0,983 & --- & --- \\
\hline DISTAÑNCIA & --- & --- & 0,0000114 & 0,01123 & 0,000010 & $0,01229 *$ & --- & --- & 0,000 & 0,002 & 0,000 & 0,003 \\
\hline DENSIDADE & --- & --- & $-3,88 \mathrm{E}-07$ & 0,8727 & --- & --- & --- & --- & 0,000 & 0,983 & --- & --- \\
\hline DISPAUTO & --- & --- & 0,177 & 0,14434 & --- & --- & --- & --- & 0,148 & 0,084 & 0,165 & 0,057 \\
\hline$H A B A F$ & --- & --- & 0,0243 & 0,864 & --- & --- & --- & --- & 0,048 & 0,618 & --- & --- \\
\hline$C P A F$ & --- & --- & 0,194 & $1,23 \mathrm{E}-07$ & 0,195 & $2,62-08$ & --- & --- & 0,141 & 0,000 & 0,158 & 0,000 \\
\hline
\end{tabular}

Obs.: * significância a 10\%; Modelo 1A - Inicial - Intenção x construtos TCP; Modelo 2A - Inicial - Intenção x construtos TCP, Sociodemográficas, Habito e Comportamento Passado; Modelo 2B - Final - Intenção x construtos TCP, Sociodemográficas, Hábito e Comportamento Passado; $X^{2}$ - Teste de Chi-quadrado para resíduos e graus de liberdade; Pseudo R ${ }^{2}$ - Teste de Efron; Gráficos de resíduos CURE no Apêndice R, para os modelos 1A e 2B; Para a definição dos índices de ajuste dos modelos de variáveis latentes, ver Tabela 4.4; quasi - estimação por quase - verossimilhança; MV - estimação por Máxima Verossimilhança; ADF - estimação por Assymptotically Distribution Free. 
Tabela 7.18: Modelagem Intenção no modo Ônibus, na IEM PU 1, amostra "alunos geral”

\begin{tabular}{|c|c|c|c|c|c|c|c|c|c|c|c|c|}
\hline & \multicolumn{12}{|c|}{ Modo Ônibus (n=590) } \\
\hline & \multicolumn{6}{|c|}{ Modelos MLG sem variáveis latentes } & \multicolumn{6}{|c|}{ Modelos AFC com variáveis latentes } \\
\hline & \multicolumn{2}{|c|}{ Modelo 1A - quasi } & \multicolumn{2}{|c|}{ Modelo 2A - quasi } & \multicolumn{2}{|c|}{ Modelo 2B - quasi } & \multirow{2}{*}{\multicolumn{2}{|c|}{$\begin{array}{c}\text { Modelo 1A - MV } \\
X^{2}=6,511 ; \\
\text { CFI }=0,908 \\
\text { RMSEA }=0,097 \\
\text { GFI }=0,911 \\
\text { RMR }=0,083\end{array}$}} & \multirow{2}{*}{\multicolumn{2}{|c|}{$\begin{array}{c}\text { Modelo 2A - MV } \\
X^{2}=4,501 ; \\
\text { CFI }=0,824 \\
\text { RMSEA }=0,077 \\
\text { GFI }=0,886 \\
\text { RMR }=1610221,952\end{array}$}} & \multirow{2}{*}{\multicolumn{2}{|c|}{$\begin{array}{c}\text { Modelo 2B- MV } \\
X^{2}=6,026 ; \\
\text { CFI }=0,882 \\
\text { RMSEA }=0,092 \\
\text { GFI }=0,900 \\
\text { RMR }=0,131\end{array}$}} \\
\hline & Pseudo- & $\begin{array}{l}=1 ; \\
0,54614 ;\end{array}$ & & & $\begin{array}{r}X \\
\text { Pseudo- } R\end{array}$ & : & & & & & & \\
\hline Variável & $\beta$ & p-valor & $\beta$ & p-valor & $\beta$ & p-valor & $\beta$ & p-valor & $\beta$ & p-valor & $\beta$ & p-valor \\
\hline Constante & 0,25129 & 0,113 & $-0,3068$ & 0,5845 & $-0,15375$ & 0,3495 & ---- & ---- & ---- & --- & ---- & ---- \\
\hline ATITUDE & 0,44216 & $<2 \mathrm{E}-16$ & 0,4308 & $<2 \mathrm{e}-16$ & 0,43122 & $<2 \mathrm{e}-16$ & 2,220 & 0,000 & 1,902 & 0,000 & 1,901 & 0,000 \\
\hline NORMA & 0,28593 & $1,56 \mathrm{E}-10$ & 0,2655 & $1,19 \mathrm{e}-09$ & 0,26698 & $5,97 \mathrm{E}-10$ & 0,293 & 0,193 & 0,328 & $0,095 *$ &,- 333 & $0,090 *$ \\
\hline CONTROLE & 0,24296 & $8,33 \mathrm{E}-08$ & 0,1933 & $1,57 \mathrm{e}-05$ & 0,19056 & $1,58 \mathrm{E}-05$ & $-1,979$ & 0,000 & $-1,651$ & 0,000 & $-1,650$ & 0,000 \\
\hline GENERO & ---- & ---- & $-0,006256$ & 0,9251 & ---- & ---- & ---- & ---- & 0,001 & 0,982 & ---- & ---- \\
\hline$I D A D E$ & ---- & ---- & 0,008581 & 0,7956 & ---- & ---- & ---- & ---- & 0,000 & 0,993 & ---- & ---- \\
\hline RENDA & ---- & ---- & $1,372 \mathrm{e}-06$ & 0,8302 & --- & ---- & ---- & ---- & 0,000 & 0,995 & ---- & ---- \\
\hline DISTAÑNCIA & ---- & ---- & $3,923 \mathrm{e}-07$ & 0,9183 & ---- & ---- & ---- & ---- & 0,000 & 0,772 & ---- & ---- \\
\hline DENSIDADE & ---- & ---- & $1,761 \mathrm{e}-06$ & 0,5180 & ---- & ---- & ---- & ---- & 0,000 & 0,635 & ---- & ---- \\
\hline DISPAUTO & ---- & ---- & $-0,01783$ & 0,8628 & ---- & ---- & ---- & ---- & $-0,002$ & 0,983 & ---- & ---- \\
\hline$H A B O N$ & ---- & ---- & 0,3080 & $0,0549 *$ & 0,30947 & $0,0515^{*}$ & ---- & ---- & 0,253 & $0,065^{*}$ & 0,254 & $0,065^{*}$ \\
\hline$C P O N$ & ---- & ---- & 0,1628 & $4,33 \mathrm{e}-09$ & 0,16253 & $1,53 \mathrm{e}-09$ & ---- & ---- & 0,143 & 0,000 & 0,140 & 0,000 \\
\hline
\end{tabular}

Obs.: * significância a 10\%; Modelo 1A - Inicial - Intenção x construtos TCP; Modelo 2A - Inicial - Intenção x construtos TCP, Sociodemográficas, Hábito e Comportamento Passado; Modelo 2B - Final - Intenção x construtos TCP,e Sociodemográficas, Hábito e Comportamento Passado; X² - Teste de Chi-quadrado para resíduos e graus de liberdade; Pseudo R ${ }^{2}$ - Teste de Efron; Gráficos de resíduos CURE no Apêndice R, para os modelos 1A e 2B; Para a definição dos índices de ajuste dos modelos de variáveis latentes, ver Tabela 4.4; quasi - estimação por quase - verossimilhança; MV - estimação por Máxima Verossimilhança; ADF - estimação por Assymptotically Distribution Free. 
Tabela 7.19: Modelagem Intenção no modo Automóvel da Família, na IEM PU 2, amostra "alunos geral"

\begin{tabular}{|c|c|c|c|c|c|c|c|c|c|c|c|c|}
\hline & \multicolumn{12}{|c|}{ Modo Automóvel da Família $(n=239)$} \\
\hline & \multicolumn{6}{|c|}{ Modelos MLG sem variáveis latentes } & \multicolumn{6}{|c|}{ Modelos AFC com variáveis latentes } \\
\hline & \multicolumn{2}{|c|}{ Modelo 1A - quasi } & \multicolumn{2}{|c|}{ Modelo 2A - quasi } & \multicolumn{2}{|c|}{ Modelo 2B - quasi } & \multirow{2}{*}{\multicolumn{2}{|c|}{$\begin{array}{c}\text { Modelo 1A - MV } \\
X^{2}=2,444 \\
\text { CFI }=0,941 \\
\text { RMSEA }=0,078 \\
\text { GFI }=0,923 \\
\text { RMR }=0,093\end{array}$}} & \multirow{2}{*}{\multicolumn{2}{|c|}{$\begin{array}{c}\text { Modelo 2A - MV } \\
X^{2}=2,36 \\
\text { CFI }=0,835 \\
\text { RMSEA }=0,076 \\
\text { GFI }=0,861 \\
\text { RMR }=1525531,834\end{array}$}} & \multirow{2}{*}{\multicolumn{2}{|c|}{$\begin{array}{c}\text { Modelo 2B - ADF } \\
X^{2}=3,891 \\
\text { CFI }=0,792 \\
\text { RMSEA }=0,110 \\
\text { GFI }=0,955 \\
\text { RMR }=0,297\end{array}$}} \\
\hline & \multicolumn{2}{|c|}{$\begin{array}{c}X^{2}=1 \\
\text { Pseudo- } R^{2}=0,6793\end{array}$} & \multicolumn{2}{|c|}{$X^{2}=1$} & \multicolumn{2}{|c|}{$\begin{array}{c}X^{2}=0,00 \\
\text { Pseudo- } R^{2}=0,6991\end{array}$} & & & & & & \\
\hline Variável & $\beta$ & p-valor & $\beta$ & p-valor & $\beta$ & p-valor & $\beta$ & p-valor & $\beta$ & p-valor & $\beta$ & p-valor \\
\hline Constante & $-0,32092$ & $0,075475^{*}$ & $-1,07 e+00$ & 0,23595 & $-1,35998$ & $0,006858^{*}$ & ---- & ---- & ---- & ---- & ---- & ---- \\
\hline ATITUDE & 0,29964 & $3,4 \mathrm{e}-09$ & 0,2814 & $2,31 \mathrm{e}-08$ & 0,28906 & $5,01 \mathrm{e}-09$ & 0,316 & 0,002 & 0,282 & 0,03 & ---- & ---- \\
\hline NORMA & 0,19964 & 0,000644 & 0,1827 & 0,00161 & 0,18859 & 0,000961 & 0,212 & 0,113 & 0,179 & 0,162 & ---- & ---- \\
\hline CONTROLE & 0,53282 & $<2 \mathrm{e}-16$ & 0,4924 & $<2 \mathrm{e}-16$ & 0,49283 & $<2 \mathrm{e}-16$ & 0,509 & 0,000 & 0,475 & 0,000 & 0,775 & 0,000 \\
\hline GENERO & ---- & ---- & 0,008392 & 0,92290 & ---- & ---- & ---- & ---- & $-0,004$ & 0,959 & ---- & ---- \\
\hline$I D A D E$ & ---- & ---- & $-0,01644$ & 0,733313 & ---- & $\begin{array}{l}--- \\
\end{array}$ & ---- & $\begin{array}{l}--- \\
\end{array}$ & $-0,022$ & 0,596 & ---- & ---- \\
\hline RENDA & ---- & ---- & $-1,999 \mathrm{e}-06$ & 0,88955 & $\begin{array}{l}--- \\
\end{array}$ & ---- & ---- & ---- & 0,000 & 0,943 & ---- & ---- \\
\hline DISTAÑNCIA & ---- & ---- & $2,021 \mathrm{e}-06$ & 0,68728 & ---- & ---- & ---- & ---- & 0,000 & 0,724 & ---- & ---- \\
\hline DENSIDADE & ---- & ---- & $1,876 \mathrm{e}-07$ & 0,96291 & ---- & ---- & ---- & ---- & 0,000 & 0,801 & ---- & ---- \\
\hline DISPAUTO & ---- & ---- & 0,8749 & $0,06835^{*}$ & 0,89383 & $0,054045^{*}$ & ---- & ---- & 0,743 & $0,072 *$ & ---- & ---- \\
\hline$H A B A F$ & ---- & ---- & 0,1872 & 0,15453 & ---- & --- & ---- & ---- & 0,159 & 0,135 & $\begin{array}{l}--- \\
\end{array}$ & ---- \\
\hline$C P A F$ & ---- & ---- & 0,09988 & 0,00461 & 0,11267 & 0,000882 & ---- & ---- & 0,084 & 0,003 & 0,130 & 0,000 \\
\hline $\begin{array}{l}\text { Obs.: * signifi } \\
\text { Passado; Mod } \\
\text { para resíduos } \\
\text { modelos de va } \\
\text { Distribution } F\end{array}$ & eis late & ver Tabela & iicial - Inte & o $\mathrm{x}$ const & TCP; M & lo $2 \mathrm{~A}-\mathrm{Ini}$ & Inte & constru & $P$, So & ográfica & bito e $\mathrm{C}$ & prtament \\
\hline
\end{tabular}


Tabela 7.20: Modelagem Intenção no modo Ônibus, na IEM PU 2, amostra "alunos geral"

\begin{tabular}{|c|c|c|c|c|c|c|c|c|c|c|c|c|}
\hline & \multicolumn{12}{|c|}{ Modo Ônibus (n=283) } \\
\hline & \multicolumn{6}{|c|}{ Modelos MLG sem variáveis latentes } & \multicolumn{6}{|c|}{ Modelos AFC com variáveis latentes } \\
\hline & \multicolumn{2}{|c|}{ Modelo 1A - quasi } & \multicolumn{2}{|c|}{ Modelo 2A - quasi } & \multicolumn{2}{|c|}{ Modelo 2B - quasi } & \multirow{2}{*}{\multicolumn{2}{|c|}{$\begin{array}{c}\text { Modelo 1A - MV } \\
X^{2}=4,442 ; \\
\text { CFI }=0,850 \\
\text { RMSEA }=0,110 \\
\text { GFI }=0,881 \\
\text { RMR }=0,100\end{array}$}} & \multicolumn{2}{|c|}{ Modelo 2A } & \multicolumn{2}{|c|}{ Modelo 2B } \\
\hline & \multicolumn{2}{|c|}{$\begin{array}{c}X^{2}=1 \\
\text { Pseudo- } R^{2}=0,47835\end{array}$} & \multicolumn{2}{|c|}{$X^{2}=1$} & \multicolumn{2}{|c|}{$\begin{aligned} X^{2} & =1 \\
\text { Pseudo- } R^{2} & =0,540647\end{aligned}$} & & & \multicolumn{2}{|c|}{$\begin{array}{c}\text { Modelo não identificado } \\
(M V \text { e ADF })\end{array}$} & \multicolumn{2}{|c|}{$\begin{array}{c}\text { Modelo não } \\
\text { identificado }(M V e \\
A D F)\end{array}$} \\
\hline Variável & $\beta$ & p-valor & $\beta$ & p-valor & $\beta$ & p-valor & $\beta$ & p-valor & $\beta$ & p-valor & $\beta$ & p-valor \\
\hline Constante & 0,34063 & 0,112 & $-0,4110$ & 0,611002 & $-0,02111$ & 0,928515 & +--- & ---- & ---- & ---- & ---- & ---- \\
\hline ATITUDE & 0,31012 & $4,44 \mathrm{e}-07$ & 0,3102 & $1,82 \mathrm{e}-07$ & 0,3160 & $7,43 \mathrm{e}-08$ & $-1,953$ & 0,836 & $\begin{array}{ll}--- \\
\end{array}$ & ---- & ---- & ---- \\
\hline NORMA & 0,38656 & $4,40 \mathrm{e}-10$ & 0,3832 & $1,10 \mathrm{e}-10$ & 0,3810 & $8,56 \mathrm{e}-11$ & $-12,466$ & 0,743 & $\begin{array}{ll}--- \\
\end{array}$ & $\begin{array}{ll}--- \\
\end{array}$ & ---- & ---- \\
\hline CONTROLE & 0,27164 & $9,06 \mathrm{e}-06$ & 0,2550 & $1,36 \mathrm{e}-05$ & 0,2544 & $1,19 \mathrm{e}-05$ & 17,024 & 0,735 & ---- & ---- & ---- & ---- \\
\hline GENERO & ---- & ---- & 0,3028 & 0,000475 & 0,2791 & 0,000783 & ---- & ---- & ---- & $\begin{array}{ll}--- \\
\end{array}$ & $\begin{array}{ll}--- \\
\end{array}$ & $\begin{array}{ll}--- \\
\end{array}$ \\
\hline$I D A D E$ & ---- & ---- & 0,02730 & 0,553642 & ---- & ---- & ---- & ---- & ---- & ---- & ---- & ---- \\
\hline RENDA & ---- & ---- & $-0,000033085$ & 0,016566 & $-0,0000280$ & 0,019171 & ---- & ---- & ---- & $\begin{array}{ll}--- \\
\end{array}$ & ---- & ---- \\
\hline DISTAÑNCIA & ---- & ---- & $-4,321 \mathrm{e}-06$ & 0,357085 & --- & --- & ---- & ---- & ---- & ---- & ---- & ---- \\
\hline DENSIDADE & $\begin{array}{ll}--- \\
\end{array}$ & $\begin{array}{ll}--- \\
\end{array}$ & $-2,145 \mathrm{e}-06$ & 0,558982 & ---- & $\begin{array}{ll}--- \\
\end{array}$ & ---- & ---- & ---- & ---- & ---- & ---- \\
\hline DISPAUTO & ---- & ---- & 0,04167 & 0,906910 & $\begin{array}{ll}--- \\
\end{array}$ & ---- & ---- & ---- & ---- & ---- & ---- & ---- \\
\hline HABON & ---- & ---- & 0,1586 & 0,352440 & ---- & ---- & ---- & ---- & ---- & ---- & ---- & ---- \\
\hline CPON & ---- & ---- & 0,1046 & 0,001009 & 0,1102 & 0,000364 & ---- & $\begin{array}{ll}--- \\
\end{array}$ & ---- & $\begin{array}{ll}--- \\
\end{array}$ & ---- & ---- \\
\hline $\begin{array}{l}\text { Obs.: }{ }^{*} \text { signifi } \\
\text { Passado; Mod } \\
\text { para resíduos } \\
\text { modelos de va } \\
\text { Distribution } F\end{array}$ & $\begin{array}{l}\text { ncia a } 10 \% \\
2 B \text { - Fina }\end{array}$ & $\begin{array}{l}\text { Modelo 1A } \\
\text { - Intenção }\end{array}$ & Inicial - Intençã & x construtos & $\overline{\mathrm{CP}}$; Modelo & A - Inicial - & tenção $x$ & rutos $\mathrm{T}$ & Sociode & cas, Há & Com & $\begin{array}{l}\text { ento } \\
\text { uadrado } \\
\text { dos } \\
\text { ototically }\end{array}$ \\
\hline
\end{tabular}


Nas modelagens tipo AFC, os valores do teste de Chi-quadrado ajustado para os graus de liberdade dos modelos variaram de 1,821 a 6,51. Seu valor superior, para o caso do modelo 1A, modo Ônibus, na IEM PU 1, tem valor acima do limite apontado pela bibliografia (<5). Este modelo, 1A, e os modelos 2A e 2B, para o modo Ônibus na IEM PU1, não são coerentes com a teoria, pelo sinal negativo em alguns construtos da TCP. O resíduo RMR apresenta valores bem acima de seu valor crítico $(\leq 0,05)$, em todos os modelos AFC, indicando problemas de ajuste, ou especificação do modelo. O teste CFI, que compara o Chi-quadrado do modelo estimado com o modelo independente, não atingiu seu valor crítico $(\geq 0,95)$, em nenhum dos modelos AFC estimados. Já, de acordo com o RMSEA, os modelos 2B, para os modos Automóvel da Família, e 1A para o modo Ônibus, da IEM PU 1 apresentaram ajuste pobre $(>0,1)$. Todas as demais situações apresentaram ajustes medíocres $(<0,1)$. Segundo o índice relativo à variância explicada pelo modelo GFI, todos os modelos apresentaram valores próximos de 1,0, indicando um bom ajuste. Conclui-se que os modelos AFC não apresentaram a consistência necessária por um conjunto razoável de indicadores.

Verifica-se que nem todos os modelos AFC puderam ser identificados pela estimação $\mathrm{ADF}$, em função do tamanho das amostras disponíveis, mas apenas pela máxima verossimilhança. Os baixos ajustes dos modelos AFC estimados parecem indicar, portanto, a sensibilidade dessa estimação com o método da máxima verossimilhança à presença da não normalidade. Desta forma, os modelos MLG se mostraram mais consistentes, mesmo sem a consideração explícita dos construtos como variáveis latentes. Assim, a menos que a análise dos dados revele a presença de normalidade, situação em que a estimativa das Equações Estruturais pelo método da máxima verossimilhança se aplica, ou a amostra dos respondentes tenha tamanho compatível com a utilização dos modelos ADF, a modelagem da intenção deve ser feita com a técnica dos MLG.

Cabe destacar que o tamanho da amostra de respondentes nas IEMs depende tanto do número de alunos da escola quanto da disposição dos mesmos em participar do estudo, uma vez que não há como a direção da escola impor essa participação. A seguir, as análises dos resultados das variáveis significativas na estimação da intenção serão analisadas apenas para os modelos MLG. As Figuras 7.3 a 7.6 apresentam as estruturas dos modelos finais, tipo 2B, obtidos apenas com variáveis significativas para a intenção. 


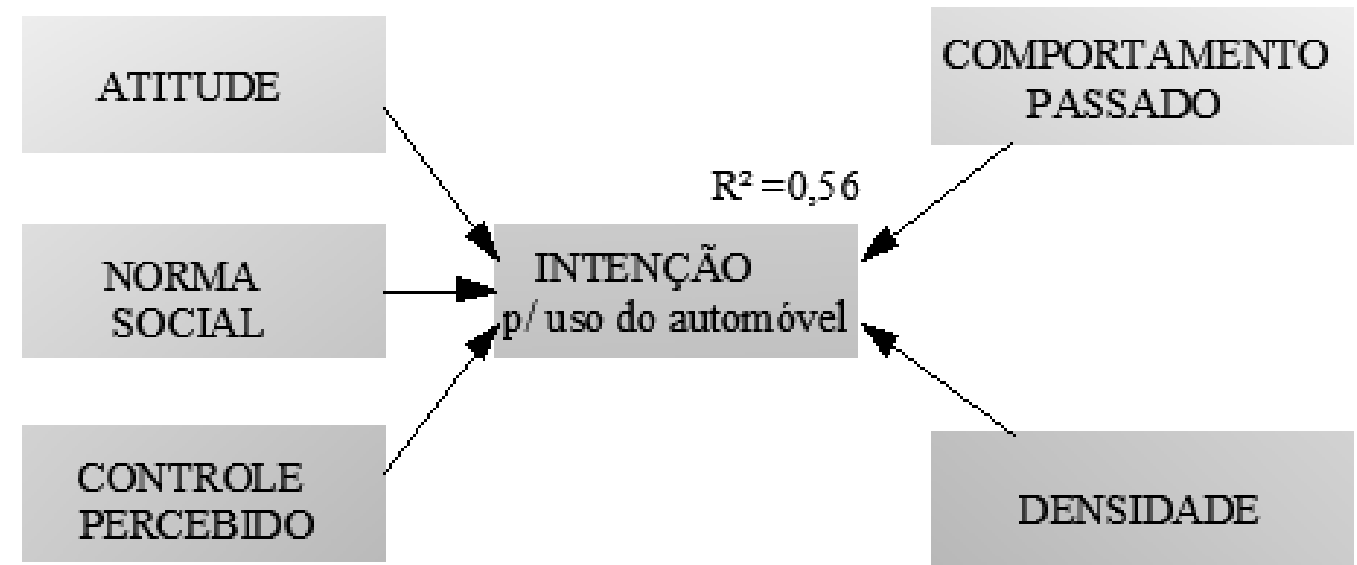

Figura 7.3: Estrutura do modelo final da intenção para o modo Automóvel da Família na IEM PU 1

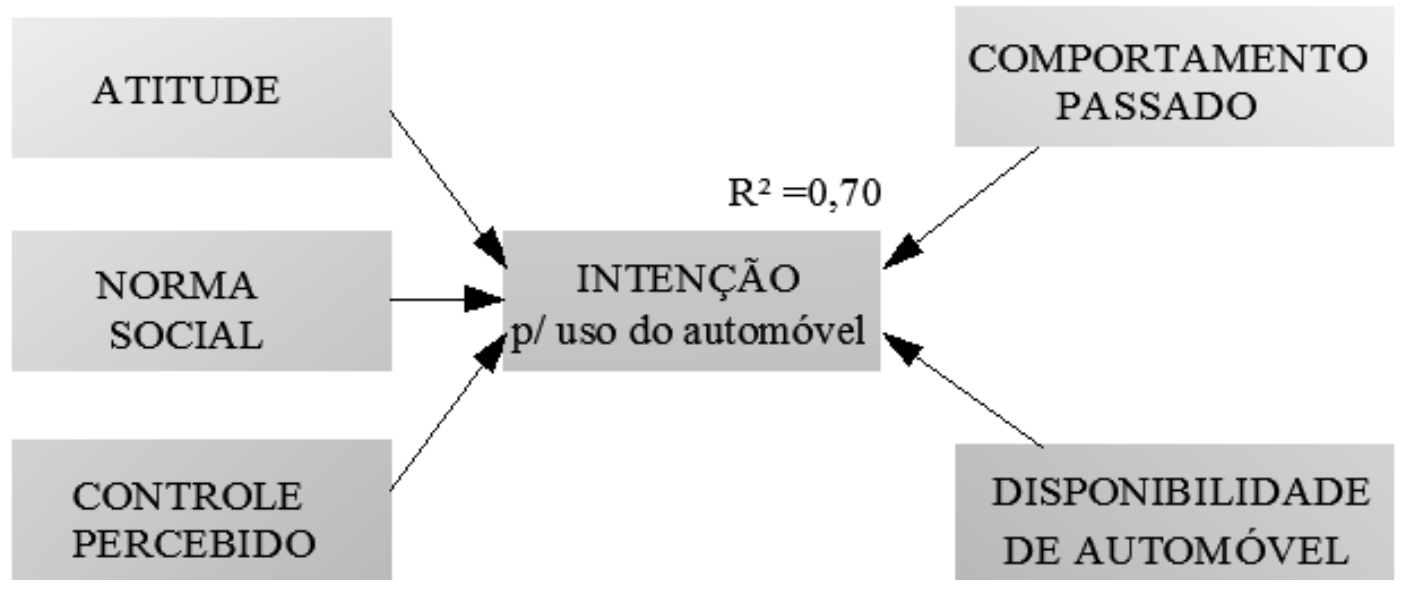

Figura 7.4: Estrutura do modelo final da intenção para o modo Automóvel da Família na IEM PU 2

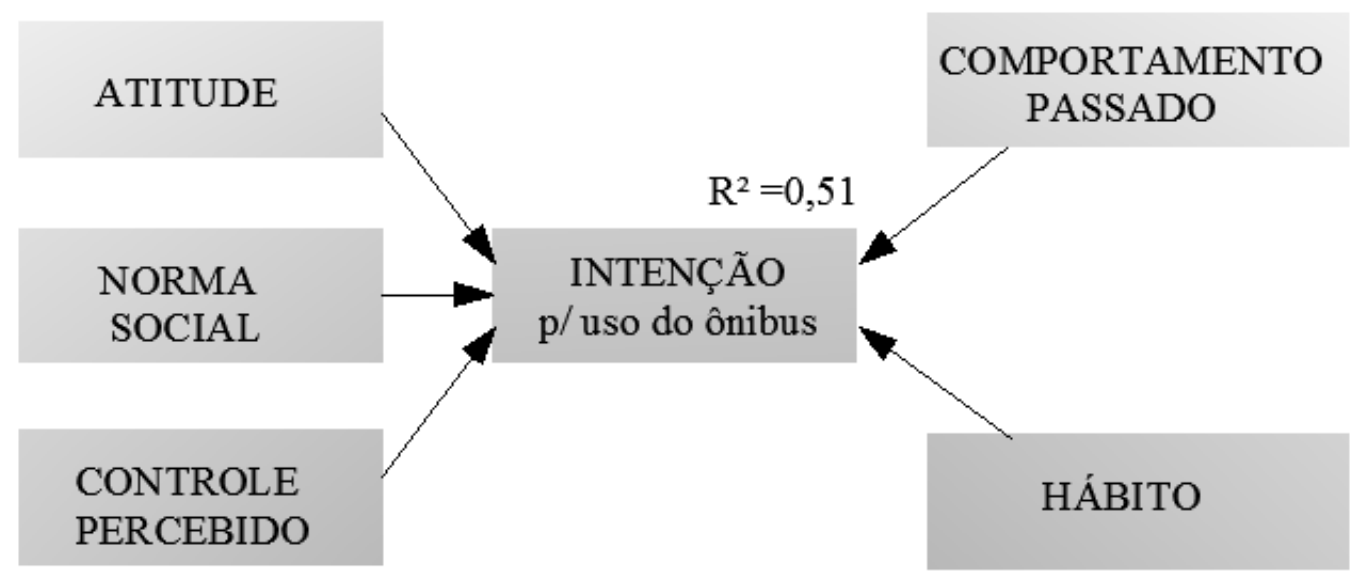

Figura 7.5: Estrutura do modelo final da intenção para o modo Ônibus na IEM PU 1 


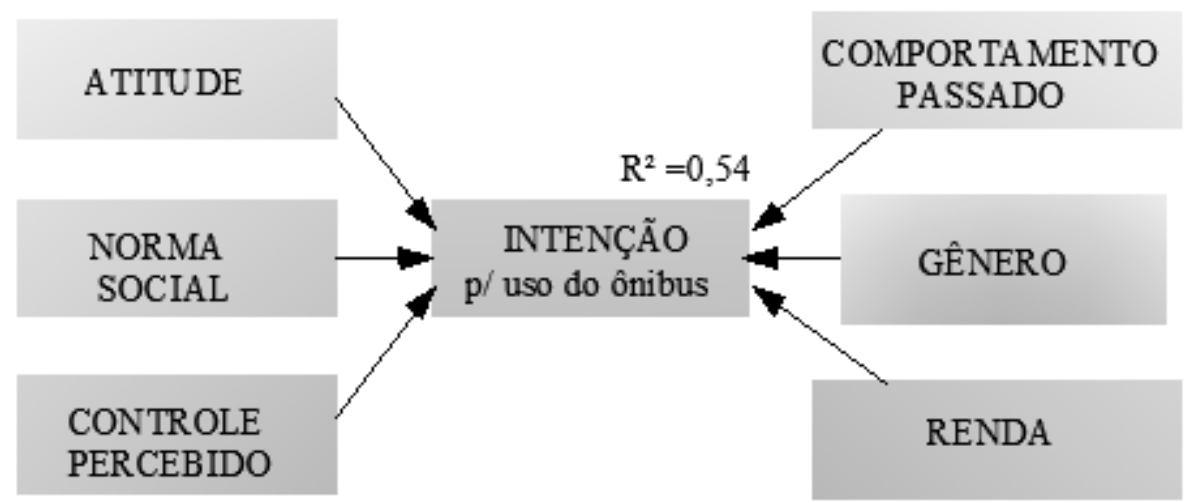

Figura 7.6: Estrutura do modelo final da intenção para o modo Ônibus na IEM PU 2.

Além das variáveis dos construtos da TCP (Atitude, Norma Social e Controle Percebido) e do Comportamento Passado, algumas variáveis sociodemográficas se mostraram significativas nos modelos tipo 2B, por MLG. A distância, no caso da IEM PU 1, modo Automóvel da Família, tem coeficiente muito pequeno, mas positivo. Tal fato indica que quem mora mais longe da escola tem uma maior intenção de usar o automóvel. Tal observação é compatível com diferentes citações na literatura (ver seção 2.3), sempre relacionando a distância ao maior uso dos modos motorizados, principalmente do automóvel individual.

A disponibilidade do automóvel no domicílio aparece como contribuinte para uma maior intenção de uso do automóvel na IEM PU 2. Rosa (2010) também identificou a disponibilidade de automóvel no domicílio com relação ao uso do automóvel, em alunos de IEFs. O Hábito de usar o modo Ônibus é significativo para a intenção desse modo, na IEM PU 1. Para a intenção de usar o modo Ônibus, Bamberg et al., (2003) também apontaram o hábito como significativo. A renda, embora com um valor do coeficiente baixo, contribui negativamente para o uso do modo Ônibus na IEM PU 2, ou seja, quanto maior a renda, menor a intenção de usar o modo Ônibus. Tal observação é coerente com diferentes estudos (como em Wilson et al.,2010 e Sidharthan et al.,2010).

Já o gênero (ser menina), foi observado como contribuinte positivamente para aumentar a intenção de uso do modo Ônibus na IEM PU 2, compatível com os achados das relações bivariadas (seção 6.5.4), mas contraditório com a literatura revisada, onde Zwerts e Wets (2006) na Bélgica, e Fox et al., 2012, observaram o oposto. Em síntese, das variáveis testadas como explicativas da intenção em usar os modos Automóvel da Família e Ônibus 
nas duas IEMs, somente as variáveis Idade e Densidade não se mostraram significativas em nenhum dos modelos obtidos.

\subsection{MODELAGEM DO COMPORTAMENTO}

As modelagens que integram esta seção identificaram quais atributos afetam a escolha modal nas IEMs participantes, para as variáveis pesquisadas e coerentes com a teoria base da pesquisa, a TCP. Elas visaram a verificação da hipótese de pesquisa, segundo a qual o procedimento proposto permite identificar, dentre outros atributos, dimensões psicossociais dos alunos e a interação dos pais e alunos na realização da escolha modal.

No procedimento apresentado no Capítulo 5, foram propostos quatro tipos de modelagem do comportamento: i) em relação ao estudo da escolha de cada modo em particular; ii) modelagem integrada; iii) modelagem da interação dentre pais e alunos. Entretanto, apenas as opções "i" e "iii" serão apresentadas aqui.

A opção "ii" teve como restrição o acesso ao programa computacional adequado para a realização da modelagem. A modelagem integrada propunha a modelagem do comportamento por um modelo de escolha discreta integrado com as variáveis latentes, antecedentes do comportamento. São poucos os pacotes computacionais capazes de realizar a modelagem integrada, como o GAUSS, MPLUS e o PHYTON BIOGEME, sendo o último de acesso livre. Com vistas a viabilizar as modelagens pelo programa PHYTON BIOGEME, foram realizados esforços de revisão bibliográfica e contatos com o desenvolvedor, mas sem sucesso. Um dos desdobramentos da presente pesquisa para futuros desenvolvimentos é a aplicação da modelagem integrada para os dados disponíveis, embora se reconheça que o tamanho das amostras pode ser uma restrição para a obtenção de modelos válidos.

Seguindo os achados de Bahamonde-Birke e Ortúzar (2014), alternativamente optou-se por desenvolver modelos sequenciais (como apresentado na Figura 4.5) para as modelagens da escolha de cada modo em particular e de forma binária. Os modelos de comportamento testaram, primeiramente, o modelo básico da TCP, apresentado na Figura 3.2, onde apenas a Intenção e o Controle Percebido teriam influência na escolha modal. 
Apesar de não integrarem o modelo teórico proposto na Figura 3.2, e em decorrência da observação que em raros casos as variáveis sociodemográficas tiveram influência na modelagem da intenção, optou-se por realizar um teste incluindo tais variáveis, também com relação ao comportamento, verificando se poderiam ser encontrados modelos significativos, e teoricamente correntes, que pudessem explicar a opção modal.

\subsubsection{MODELAGEM DO COMPORTAMENTO POR MODO - MODELOS BINÁRIOS}

As análises foram desenvolvidas no programa BIOGEME 1.8, e os construtos psicológicos Intenção e Controle percebido, foram representados pelas médias dos seus itens de medida direta. O uso do modo Ônibus foi considerado disponível para todos os usuários. No caso do modo Automóvel da Família, a variável proxi DISPAUTO pretendia capturar a disponibilidade do automóvel na família. Ela não foi obtida diretamente dos respondentes, mas por inferências em bases demográficas (ver descrição no Apêndice J). Esta variável foi usada para descrever as amostras, porém, em geral, não se apresentou significativa nas modelagens de intenção, onde poderia, como as demais variáveis sócio demográficas, revelar sua influência sobre a intenção e a decorrente escolha modal. Dessa forma, para efeito desse estudo, no qual são utilizadas amostras pequenas, foi considerado que, se o estudante tivesse vontade, ele teria a disponibilidade de ser conduzido na ida ou na volta da escola de automóvel.

A Figura 7.7 apresenta a estrutura dos modelos binários estudados sobre o comportamento de escolha do modo, por IEM. Os resultados das modelagens são apresentados nas Tabelas 7.21 e 7.22, por escola, IEM PU 1 e IEM PU 2, para os modos Automóvel da Família e Ônibus, em viagens de ida e de volta. 


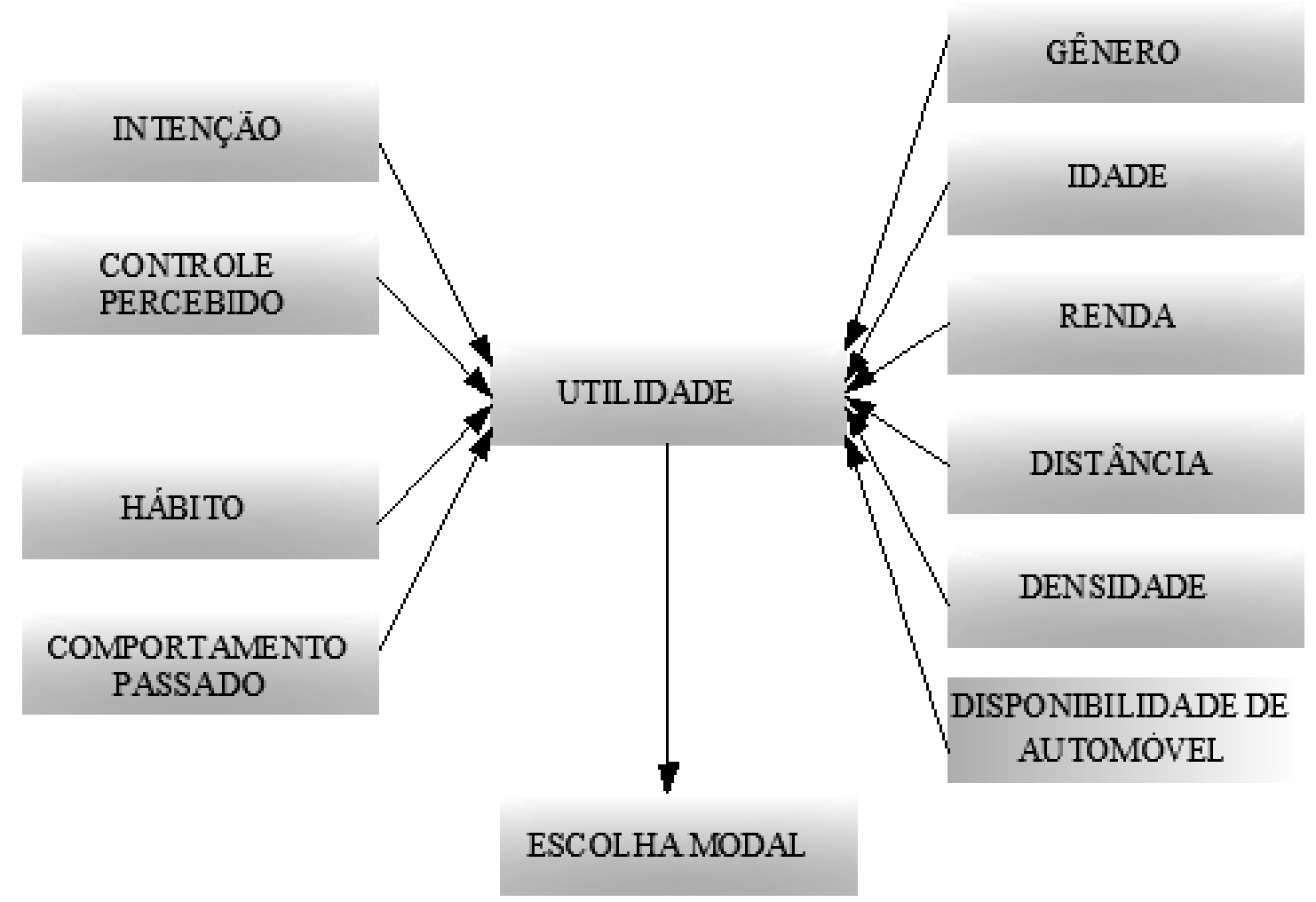

Figura 7.7: Estrutura dos modelos binários estudados sobre o comportamento de escolha do modo, por IEM e por modo, pra amostra "alunos geral".

Pelas Tabelas 7.21 e 7.22 observa-se que a capacidade de explicação dos modelos ( $\rho^{2}$ ajustado) variou nos modelos $1 \mathrm{~A}$ entre 0,170 e 0,406 na IEM PU 1, e entre 0,079 e 0,282, na IEM PU 2. Para os modelos 2B, onde mais variáveis participaram da modelagem, a capacidade de explicação esteve entre 0,227 e 0,458 na IEM PU 1, e entre 0,172 e 0,422 na IEM PU 2. 
Tabela 7.21: Escolha do modo na IEM PU 1, amostra "alunos geral"

\begin{tabular}{|c|c|c|c|c|c|c|c|c|c|c|c|c|}
\hline & \multicolumn{6}{|c|}{ Modo Automóvel da Família na Ida $(n=412)$} & \multicolumn{6}{|c|}{ Modo Automóvel da Família na Volta $(n=410)$} \\
\hline & \multicolumn{2}{|c|}{ Modelo 1A } & \multicolumn{2}{|c|}{ Modelo 2A } & \multicolumn{2}{|c|}{ Modelo 2B } & \multicolumn{2}{|c|}{ Modelo 1A } & \multicolumn{2}{|c|}{ Modelo 2A } & \multicolumn{2}{|c|}{ Modelo 2B } \\
\hline & \multicolumn{2}{|c|}{$\begin{array}{c}\rho^{2}(0,416) ; \rho^{2} a j(0,406) ; \\
\text { Acerto } 81 \% ; \operatorname{RVS}(237,61)\end{array}$} & \multicolumn{2}{|c|}{$\begin{array}{c}\rho^{2}(0,479) ; \rho^{2} a j(0,441) ; \\
\text { Acerto87\%;RVS }(273,75)\end{array}$} & \multicolumn{2}{|c|}{$\begin{array}{c}\rho^{2}(0,472) ; \rho^{2} a j(0,458) ; \\
\text { Acerto85\%;RVS }(269,387)\end{array}$} & \multicolumn{2}{|c|}{$\begin{array}{c}\rho^{2}(0,320) ; \rho^{2} a j(0,310) ; \\
\text { Acerto } 79 \% ; \operatorname{RVS}(182,12)\end{array}$} & \multicolumn{2}{|c|}{$\begin{array}{c}\rho^{2}(0,365) ; \rho^{2} a j(0,326) ; \\
\text { Acerto82\%;RVS }(207.51)\end{array}$} & \multicolumn{2}{|c|}{$\begin{array}{l}\rho^{2}(0,354) ; \rho^{2} a j(0,344) ; \\
\text { Acerto } 82 \% ; R V S(201,5)\end{array}$} \\
\hline Variável & $\beta$ & p-valor & $\beta$ & p-valor & $\beta$ & p-valor & $\beta$ & p-valor & $\beta$ & p-valor & $\beta$ & p-valor \\
\hline Constante & $-5,63$ & 0,00 & $-0,0711$ & 0,98 & $-9,43$ & 0,00 & $-4,98$ & 0,00 & $-3,34$ & 0,18 & $-5,68$ & 0,00 \\
\hline$M E D A F D C P$ & 0,222 & 0,23 & $-0,0396$ & 0,84 & ---- & ---- & 0,18 & 0,27 & 0,014 & 0,94 & ---- & ---- \\
\hline MEDAFDIT & 0,980 & 0,00 & 0,764 & 0,00 & 0,719 & 0,00 & 0,962 & 0,00 & 0,761 & 0,00 & 0,800 & 0,00 \\
\hline GENERO & ---- & ---- & $-0,428$ & 0,17 & ---- & ---- & ---- & ---- & 0,0961 & 0,73 & ---- & ---- \\
\hline$I D A D E$ & ---- & $\begin{array}{ll}--- \\
\end{array}$ & $-0,384$ & 0,03 & ---- & ---- & $\begin{array}{ll}--- \\
\end{array}$ & $\begin{array}{l}--- \\
\end{array}$ & $-0,169$ & 0,27 & ---- & ---- \\
\hline RENDA & $\begin{array}{ll}--- \\
\end{array}$ & ---- & $-2,5 \mathrm{E}-06$ & 0,93 & ---- & $\begin{array}{ll}--- \\
\end{array}$ & ---- & ---- & 0,0000248 & 0,99 & ---- & $\begin{array}{ll}--- \\
\end{array}$ \\
\hline DISTAÑNIA & ---- & ---- & $-0,000027$ & 0,16 & ---- & ---- & ---- & ---- & $-0,000012$ & 0,47 & ---- & ---- \\
\hline DENSIDADE & ---- & ---- & $-5,68 \mathrm{E}-06$ & 0,61 & ---- & ---- & ---- & ---- & $-3,23 \mathrm{E}-06$ & 0,73 & ---- & ---- \\
\hline DISPAUTO & ---- & ---- & 0,0862 & 0,86 & ---- & ---- & ---- & ---- & 0,275 & 0,55 & ---- & ---- \\
\hline$H A B A F$ & ---- & ---- & 0,817 & 0,12 & 1,40 & 0,01 & ---- & ---- & 0,503 & 0,29 & ---- & $\begin{array}{ll}--- \\
\end{array}$ \\
\hline \multirow[t]{4}{*}{$C P A F$} & ---- & ---- & 0,657 & 0,00 & 0,603 & 0,00 & ---- & ---- & 0,525 & 0,00 & 0,561 & 0,00 \\
\hline & \multicolumn{6}{|c|}{ Modo Ônibus na Ida (n=600) } & \multicolumn{6}{|c|}{ Modo Ônibus na Volta $(n=596)$} \\
\hline & \multicolumn{2}{|c|}{ Modelo 1A } & \multicolumn{2}{|c|}{ Modelo 2A } & \multicolumn{2}{|c|}{ Modelo 2B } & \multicolumn{2}{|c|}{ Modelo 1A } & \multicolumn{2}{|c|}{ Modelo 2A } & \multicolumn{2}{|c|}{ Modelo 2B } \\
\hline & \multicolumn{2}{|c|}{$\begin{array}{c}\rho^{2}(0,276) ; \rho^{2} a j(0,269) ; \\
\text { Acerto } 77 \% ; \operatorname{RVS}(229,50)\end{array}$} & \multicolumn{2}{|c|}{$\begin{array}{c}\rho^{2}(0,389) ; \rho^{2} a j(0,363) ; \\
\text { Acerto81\%;RVS }(363,53)\end{array}$} & \multicolumn{2}{|c|}{$\begin{array}{c}\rho^{2}(0,386) ; \rho^{2} a j(0,374) ; \\
\text { Acerto } 82 \% ; R V S(321,449)\end{array}$} & \multicolumn{2}{|c|}{$\begin{array}{c}\rho^{2}(0,177) ; \rho^{2} a j(0,170) ; \\
\text { Acerto } 71 \% ; \operatorname{RVS}(146,60)\end{array}$} & \multicolumn{2}{|c|}{$\begin{array}{c}\rho^{2}(0,239) ; \rho^{2} a j(0,212) ; \\
\text { Acerto } 73 \% ; R V S(197,57)\end{array}$} & $\begin{array}{c}\rho^{2}(0,236 \\
\text { Acerto } 74\end{array}$ & $\begin{array}{l}a j(0,227) ; \\
V S(195,3)\end{array}$ \\
\hline Variável & $\beta$ & p-valor & $\beta$ & p-valor & $\beta$ & p-valor & $\beta$ & p-valor & $\beta$ & p-valor & $\beta$ & p-valor \\
\hline Constante & $-2,91$ & 0,00 & $-6,45$ & 0,00 & $-4,77$ & 0,00 & $-2,77$ & 0,00 & $-4,51$ & 0,01 & $-4,31$ & 0,00 \\
\hline$M E D O N D C P$ & 0,155 & 0,18 & 0,0765 & 0,57 & ---- & ---- & 0,0179 & 0,87 & -0.0467 & 0,70 & ---- & ---- \\
\hline MEDONDIT & 0,919 & 0,00 & 0,797 & 0,00 & 0,813 & 0,00 & 0,881 & 0,00 & 0,778 & 0,00 & 0,741 & 0,00 \\
\hline GENERO & ---- & ---- & 0,227 & 0,32 & ---- & ---- & ---- & ---- & $-0,059$ & 0,77 & ---- & ---- \\
\hline$I D A D E$ & ---- & ---- & 0,0687 & 0,54 & ---- & $\begin{array}{ll}--- \\
\end{array}$ & ---- & ---- & 0,0238 & 0,81 & $\begin{array}{ll}--- \\
\end{array}$ & $\begin{array}{ll}--- \\
\end{array}$ \\
\hline RENDA & ---- & ---- & 0,000012 & 0,61 & ---- & ---- & ---- & ---- & $2,47 \mathrm{E}-06$ & 0,90 & ---- & ---- \\
\hline DISTAÑNCIA & ---- & ---- & $7,85 \mathrm{E}-06$ & 0,55 & ---- & ---- & $\begin{array}{ll}--- \\
\end{array}$ & ---- & $8,27 \mathrm{E}-06$ & 0,48 & ---- & ---- \\
\hline DENSIDADE & ---- & ---- & 0,00 & 0,13 & $-0,000013$ & $0,09 *$ & ---- & ---- & $-7,40 \mathrm{E}-06$ & 0,36 & ---- & ---- \\
\hline DISPAUTO & ---- & ---- & 0,155 & 0,66 & ---- & ---- & ---- & ---- & $-0,0834$ & 0,79 & ---- & ---- \\
\hline HABON & ---- & ---- & 1,61 & 0,01 & 1,64 & 0,01 & ---- & ---- & 1,11 & 0,03 & 1,12 & 0,03 \\
\hline CPON & ---- & ---- & 0,69 & 0,00 & 0,699 & 0,00 & ---- & ---- & 0,46 & 0,00 & 0,477 & 0,00 \\
\hline
\end{tabular}

Obs: * significância a 10\%; RVS - Teste de Razão da Verossimilhança; Modelo 1A - Inicial c/ var. Intenção e Controle Percebido; Modelo 2A - Inicial c/ var. Intenção, Controle

Percebido, Hábito, Comportamento Passado e Sociodemográficas; Modelo 2B - final - c/ var. Intenção, Controle Percebido, Hábito, Comportamento Passado e Sociodemográficas (somente as significativas); 
Tabela 7.22: Escolha do modo na IEM PU 2, amostra "alunos geral"

\begin{tabular}{|c|c|c|c|c|c|c|c|c|c|c|c|c|}
\hline & \multicolumn{6}{|c|}{ Modo Automóvel da Família na Ida $(n=242)$} & \multicolumn{6}{|c|}{ Modo Automóvel da Família na Volta $(n=236)$} \\
\hline & \multirow{2}{*}{\multicolumn{2}{|c|}{$\begin{array}{c}\text { Modelo 1A } \\
\rho^{2}(0,261) ; \rho^{2} a j(0,243) ; \\
\text { Acerto } 79 \% R V S(87,59)\end{array}$}} & \multirow{2}{*}{\multicolumn{2}{|c|}{$\begin{array}{c}\text { Modelo 2A } \\
\rho^{2}(0,462) ; \rho^{2} a j(0,397) ; \\
\text { Acerto85\%RVS }(155,03\end{array}$}} & \multicolumn{2}{|c|}{ Modelo 2B } & \multicolumn{2}{|c|}{ Modelo 1A } & \multicolumn{2}{|c|}{ Modelo 2A } & \multicolumn{2}{|c|}{ Modelo 2B } \\
\hline & & & & & $\begin{array}{l}\rho^{2}(0,452) ; \rho^{2} c \\
\text { Acerto } 84 \% R V\end{array}$ & $\begin{array}{l}0,422) ; \\
151,526\end{array}$ & $\begin{array}{l}\rho^{2}(0,301) ; \\
\text { Acerto } 78 \%\end{array}$ & $\begin{array}{l}0,282) ; \\
(98,40)\end{array}$ & $\begin{array}{l}\rho^{2}(0,404) ; \rho \\
\text { Acerto } 82 \% ; 1\end{array}$ & $\begin{array}{l}0,337) ; \\
(132,33)\end{array}$ & $\begin{array}{r}\rho^{2}(0,379) ; \\
\text { Acerto } 80 \% R\end{array}$ & $\begin{array}{l}j(0,355) \\
(124,121)\end{array}$ \\
\hline Variável & $\beta$ & p-valor & $\beta$ & p-valor & $\beta$ & p-valor & $\beta$ & p-valor & $\beta$ & p-valor & $\beta$ & p-valor \\
\hline Constante & $-4,37$ & 0,00 & $-12,50$ & 0,84 & $-7,42$ & 0,00 & $-3,53$ & 0,00 & $-47,2$ & 0,00 & $-4,7$ & 0,00 \\
\hline$M E D A F D C P$ & 0,15 & 0,49 & 0,00 & 1,00 & $\begin{array}{l}--- \\
\end{array}$ & $\begin{array}{ll}--- \\
\end{array}$ & 0,107 & 0,65 & $-0,0699$ & 0,79 & $\begin{array}{ll}--- \\
\end{array}$ & ---- \\
\hline MEDAFDIT & 0,97 & 0,00 & 0,78 & 0,00 & 0,831 & 0,00 & 0,568 & 0,01 & 0,321 & 0,2 & 0,362 & 0,04 \\
\hline GENERO & $\begin{array}{ll}--- \\
\end{array}$ & $\begin{array}{ll}--- \\
\end{array}$ & $-0,87$ & 0,03 & $-0,789$ & 0,04 & ---- & $\begin{array}{ll}--- \\
\end{array}$ & $-0,820$ & 0,03 & $-0,677$ & 0,06 \\
\hline$I D A D E$ & $\begin{array}{ll}---- \\
\end{array}$ & $\begin{array}{ll}--- \\
\end{array}$ & $-0,13$ & 0,53 & ---- & $\begin{array}{ll}--- \\
\end{array}$ & $\begin{array}{ll}--- \\
\end{array}$ & $\begin{array}{ll}--- \\
\end{array}$ & $-0,287$ & 0,16 & ---- & $\begin{array}{ll}--- \\
\end{array}$ \\
\hline RENDA & ---- & ---- & 0,000116 & $0,06^{*}$ & 0,000142 & 0,01 & ---- & ---- & 0,0000653 & 0,23 & ---- & ---- \\
\hline DISTAÑNCIA & ---- & $\begin{array}{ll}--- \\
\end{array}$ & 0,00 & 0,89 & ---- & ---- & ---- & ---- & 0,00000825 & 0,71 & ---- & ---- \\
\hline DENSIDADE & ---- & $\begin{array}{ll}--- \\
\end{array}$ & 0,00 & 0,42 & ---- & $\begin{array}{ll}--- \\
\end{array}$ & ---- & $\begin{array}{ll}--- \\
\end{array}$ & $-0,0000171$ & 0,39 & ---- & ---- \\
\hline DISPAUTO & ---- & ---- & 7,09 & 0,91 & ---- & ---- & ---- & ---- & 46,9 & 0,00 & ---- & ---- \\
\hline$H A B A F$ & ---- & ---- & 0,80 & 0,18 & $\begin{array}{ll}--- \\
\end{array}$ & $\begin{array}{ll}--- \\
\end{array}$ & ---- & ---- & 0,84 & 1,00 & $\begin{array}{ll}--- \\
\end{array}$ & $\begin{array}{ll}--- \\
\end{array}$ \\
\hline \multirow[t]{4}{*}{$C P A F$} & ---- & ---- & 1,07 & 0,00 & 1,07 & 0,00 & ---- & ---- & 0,686 & 0,00 & 0,714 & 0,00 \\
\hline & \multicolumn{6}{|c|}{ Modo Ônibus na Ida $(n=290)$} & \multicolumn{6}{|c|}{ Modo Ônibus na Volta $(n=286)$} \\
\hline & \multicolumn{2}{|c|}{ Modelo 1A } & \multicolumn{2}{|c|}{ Modelo 2A } & \multicolumn{2}{|c|}{ Modelo 2B } & \multicolumn{2}{|c|}{ Modelo 1A } & \multicolumn{2}{|c|}{ Modelo 2A } & \multicolumn{2}{|c|}{ Modelo 2B } \\
\hline & \multicolumn{2}{|c|}{$\begin{array}{l}\rho^{2}(0,093) ; \rho^{2} a j(0,079) ; \\
\text { Acerto66\%RVS }(37,58)\end{array}$} & \multicolumn{2}{|c|}{$\begin{array}{l}\rho^{2}(0,204) ; \rho^{2} a j(0,149) ; \\
\text { Acerto } 73 \% R V S(81,96)\end{array}$} & \multicolumn{2}{|c|}{$\begin{array}{l}\rho^{2}(0,197) ; \rho^{2} a j(0,172) ; \\
\text { Acerto } 73 \% R V S(79,043)\end{array}$} & \multicolumn{2}{|c|}{$\begin{array}{l}\rho^{2}(0,195) ; \rho^{2} a j(0,180) ; \\
\text { Acerto } 71 \% R V S(77,42)\end{array}$} & \multicolumn{2}{|c|}{$\begin{array}{c}\rho^{2}(0,298) ; \rho^{2} a j(0,242) ; \\
\text { Acerto } 78 \% R V S(117,97)\end{array}$} & \multicolumn{2}{|c|}{$\begin{array}{c}\rho^{2}(0,288) ; \rho^{2} a j(0,253) ; \\
\text { Acerto } 78 \% R V S(114,374)\end{array}$} \\
\hline Variável & $\beta$ & p-valor & $\beta$ & p-valor & $\beta$ & p-valor & $\beta$ & p-valor & $\beta$ & p-valor & $\beta$ & p-valor \\
\hline Constante & $-1,74$ & 0,00 & $-4,55$ & $0,1^{*}$ & $-3,15$ & 0,00 & $-1,77$ & 0,00 & $-8,1$ & 0,01 & $-7,31$ & 0,01 \\
\hline MEDONDCP & $-0,10$ & 0,53 & $-0,06$ & 0,74 & $\begin{array}{ll}--- \\
\end{array}$ & $\begin{array}{ll}--- \\
\end{array}$ & $-0,173$ & 0,32 & $-0,146$ & 0,46 & $\begin{array}{ll}--- \\
\end{array}$ & $\begin{array}{ll}--- \\
\end{array}$ \\
\hline MEDONDIT & 0,70 & 0,00 & 0,55 & 0,00 & 0,516 & 0,00 & 0,905 & 0,00 & 0,762 & 0,00 & 0,687 & 0,00 \\
\hline GENERO & $\begin{array}{ll}--- \\
\end{array}$ & ---- & 0,23 & 0,42 & ---- & ---- & ---- & ---- & 0,605 & 0,05 & 0,591 & 0,05 \\
\hline$I D A D E$ & ---- & $\begin{array}{ll}--- \\
\end{array}$ & 0,16 & 0,3 & ---- & ---- & ---- & ---- & 0,258 & 0,12 & 0,274 & $0,10^{*}$ \\
\hline RENDA & ---- & $\begin{array}{ll}--- \\
\end{array}$ & $-0,0000856$ & $0,06^{*}$ & $-0,0000992$ & 0,01 & ---- & ---- & $-0,0000789$ & 0,10 & $-0,0000994$ & 0,00 \\
\hline DISTAÑNCIA & ---- & ---- & 0,00 & 0,69 & ---- & ---- & ---- & ---- & 0,0000144 & 0,40 & --- & ---- \\
\hline DENSIDADE & ---- & ---- & 0,00 & 0,01 & 0,0000334 & 0,01 & ---- & ---- & 0,0000592 & 0,00 & 0,0000555 & 0,00 \\
\hline DISPAUTO & ---- & ---- & $-1,33$ & 0,36 & ---- & --- & ---- & ---- & 0,829 & 0,49 & ---- & ---- \\
\hline$H A B O N$ & ---- & ---- & 0,44 & 0,43 & ---- & ---- & ---- & ---- & 0,777 & 0,21 & ---- & ---- \\
\hline CPON & ---- & ---- & 0,48 & 0,00 & 0,504 & 0,00 & ---- & ---- & 0,324 & 0,00 & 0,334 & 0,00 \\
\hline
\end{tabular}

Obs: * significância a 10\%; RVS - Teste de Razão da Verossimilhança; Modelo 1A - Inicial c/ var. Intenção e Controle Percebido; Modelo 2A - Inicial c/ var. Intenção, Controle

Percebido, Hábito, Comportamento Passado e Sociodemográficas; Modelo 2B - final - c/ var. Intenção, Controle Percebido, Hábito, Comportamento Passado e Sociodemográficas (somente as variáveis significativas). 
$\mathrm{O}$ percentual de acerto da probabilidade de escolha do modo modelado (estimado $\mathrm{x}$ observado) se apresentou acima de $70 \%$ em 23 dos 24 casos modelados (12 casos para cada IEM). Em todos os casos modelados, nas IEM PU 1 e IEM PU2, todos os modelos iniciais tipo 1A (apenas com Intenção e Controle Percebido), e finais 2B (com variáveis significativas do processo backwards aplicado ao modelo 2A), a intenção se mostrou significativa e positiva.

O Controle Percebido, por sua vez, não se apresentou significativo em nenhum dos modelos tipos 1A e 2B, não confirmando o modelo teórico da TCP, e o modelo teórico proposto para a pesquisa na Figura3.2. Este resultado se assemelha mais ao apresentado na Teoria da Ação Racional, antecedente da TCP, que não considerava a influência do Controle Percebido nas decisões racionais.

Esta consideração pode indicar um contexto do fenômeno da escolha modal diferente daquele non qual a TCP foi desenvolvida. As estruturas dos modelos finais - tipo 2B, para viagens de ida e volta, e para os dois modos estudados nas IEMs PU 1 e PU 2, são apresentadas nas Figuras 7.8 a 7.11 .

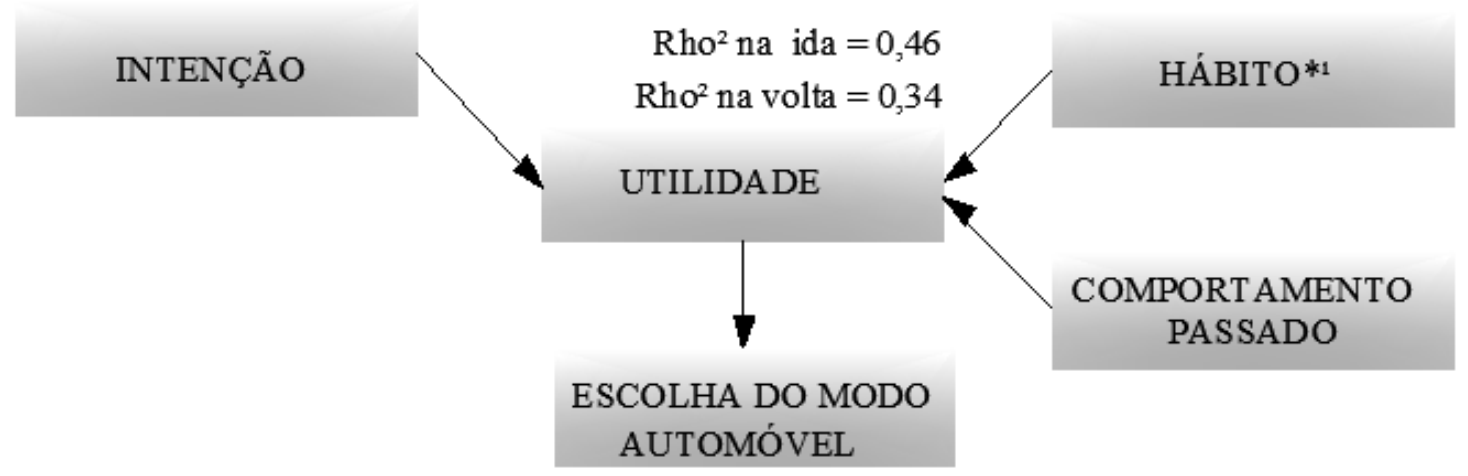

Figura 7.8: Estrutura do modelo final para escolha do modo Automóvel da Família na ida ou na volta na IEM PU 1.

Obs.: *1 - Apenas na ida; 


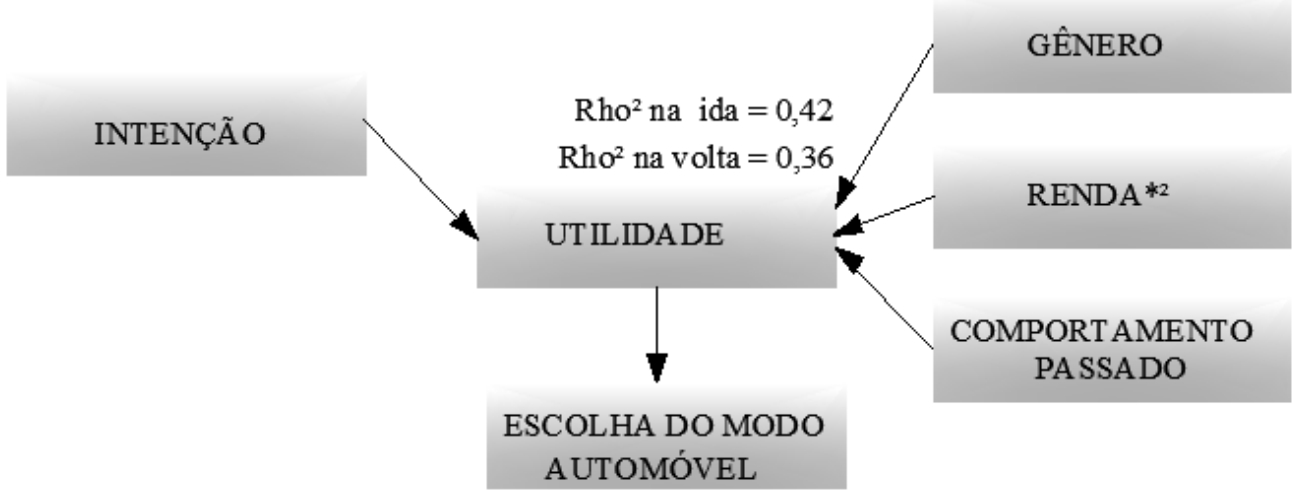

Figura 7.9: Estrutura do modelo final para escolha do modo Automóvel da Família na ida ou na volta na IEM PU 2.

Obs.: $* * 2-$ apenas na volta.

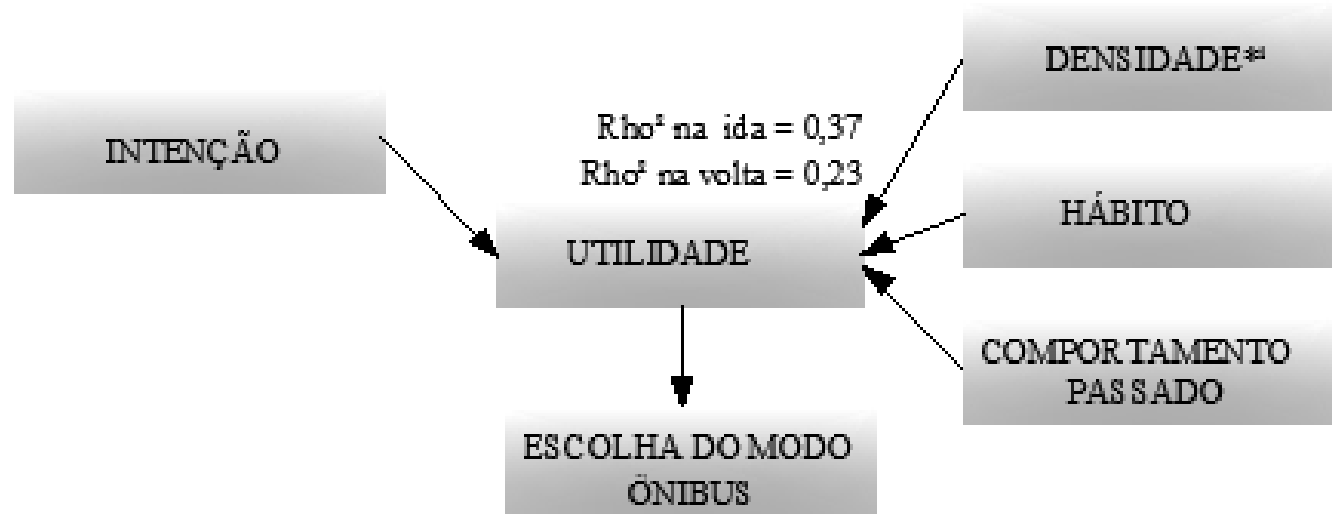

Figura 7.10: Estrutura do modelo final para escolha do modo Õnibus, na ida ou na volta na IEM PU 1.

Obs.: $* 1-$ Apenas na ida;

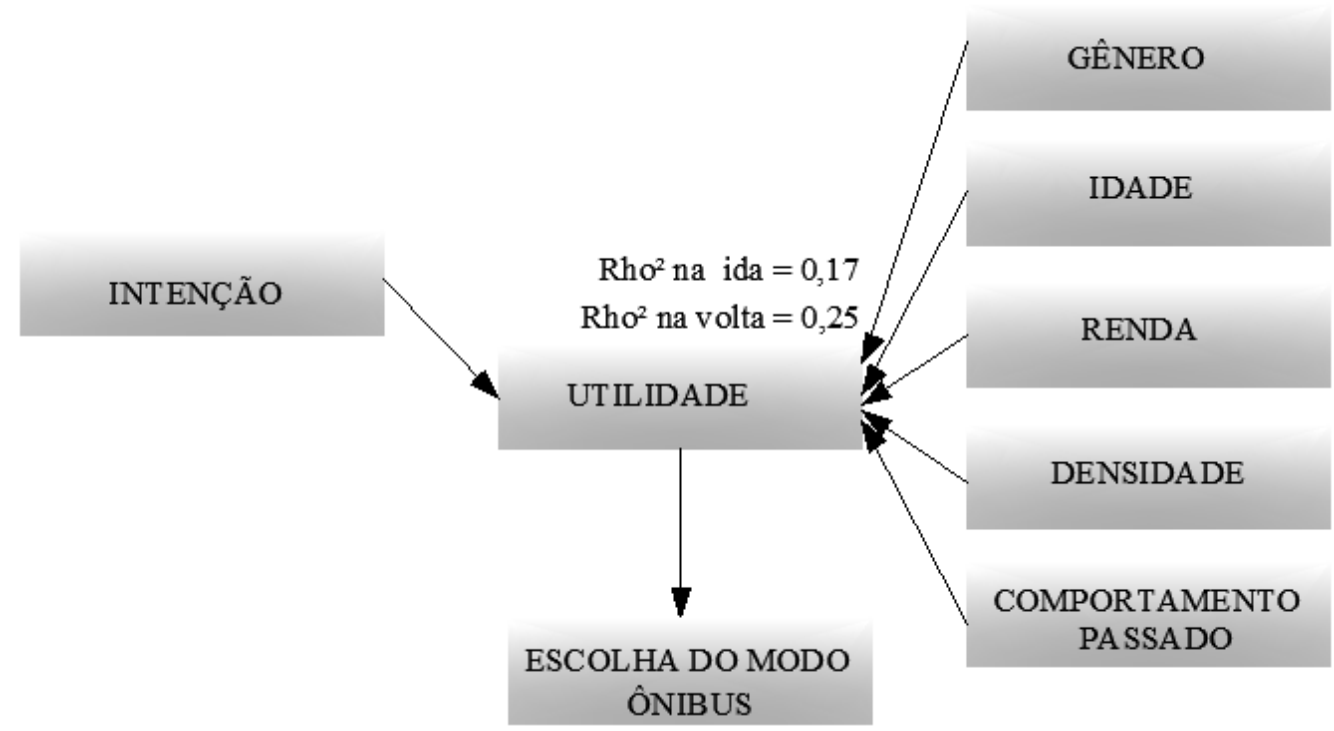

Figura 7.11: Estrutura do modelo final para escolha do modo Ônibus na ida ou na volta na IEM PU 2. 
O comportamento passado (CPAF para modo Automóvel da Família e CPON para o modo Ônibus) incluído nos modelos tipo 2A se apresentou significativo em todos os modelos 2B. Assim, depreende-se que os respondentes usuários de certo modo de transporte tendam à estabilidade no tempo quanto à escolha modal em viagens escolares. Ou seja, estratégias de GM que visem à mudança de comportamento devem focar na experimentação de modos alternativos.

Outras variáveis se mostraram significativas entre as modelagens: hábito no uso do automóvel (na IEM PU 1, na ida, com coeficiente positivo); hábito no uso do ônibus (na IEM PU 1, ida e volta, com coeficiente positivo); densidade (na IEM PU 1, ônibus na ida, com coeficiente negativo, e IEM PU 2, ônibus, na ida e na volta, com coeficiente positivo); renda ( na IEM PU 2, automóvel na ida com coeficiente positivo, e ônibus na ida e na volta, com coeficiente negativo); gênero, variável binária em que 1=Feminino e 0=Masculino (na IEM PU 2, automóvel na ida e na volta, com coeficiente negativo, e ônibus, na volta, com coeficiente positivo); idade (apenas na IEM PU 2, ônibus volta, com coeficiente positivo).

Por esses resultados, percebe-se que na IEM PU 2 as variáveis sociodemográficas integraram mais os modelos significativamente, para os dois modos analisados, do que para a IEM PU 1 (apenas a distância, modo Ônibus na ida). Sobre o hábito, nos casos significativos na IEM PU 1, o valor dos coeficientes é o maior do conjunto de variáveis no modelo, acima de 1,0, contribuindo tanto para o uso do ônibus, quanto para o uso do automóvel. A densidade apresentou significado diferente entre a IEM PU 1 (na ida) e IEM PU 2 (na ida e na volta), apenas para o modo Ônibus. Na IEM PU 1, o coeficiente é negativo, indicando que a localidade de residência com maior densidade levaria a um menor uso do modo Ônibus.

Já na IEM PU 2, o coeficiente é positivo, indicando que a localidade de residência com maior densidade levaria a um maior uso do modo Ônibus. As especificidades da distribuição de residências para as amostras "alunos geral" das IEM PU 1 e IEMPU 2 foram apresentadas nas Figuras 6.3 e 6.4, com relevantes diferenças entre elas, sugerindo o suporte às diferentes interpretações com relação à densidade. A variável renda apresentou resultados compatíveis com relatos dos estudos revisados, como também apontado para a intenção, indicando que, para os alunos da IEM PU 2, a maior renda 
indicaria um maior uso do automóvel e menor uso do ônibus. Os resultados para a variável gênero (binária, onde um "1" indica feminino), mostram que, na IEM PU 2, as meninas usam menos o modo Automóvel da Família, em todas as viagens, e mais o modo Ônibus nas viagens de volta. Ainda na IEM PU 2, a variável idade indicou que alunos mais velhos utilizariam mais o modo Ônibus para sair da escola.

\subsubsection{MODELAGEM DA INTERAÇÃO ENTRE PAIS E ALUNOS}

A hipótese da pesquisa parte do pressuposto que a escolha modal é afetada pela opinião dos pais/responsáveis, juntamente com a dos alunos, que realizam as viagens. Para testar a hipótese de que o procedimento permite identificar, dentre outros atributos, a interação dos pais e alunos na realização da escolha do modo de transporte a ser utilizado pelos estudantes, o modelo apresentado na Figura 3.3 foi calibrado para a opinião pareada de alunos e pais/responsáveis.

Para esta modelagem, foram utilizadas as amostras resultantes do Tratamento T2, cujos resultados foram apresentados na Tabela 7.1. Outra consideração foi sobre dados ausentes nas variáveis. Foram eliminadas das bases de dados as seguintes variáveis, que apresentaram mais de $10 \%$ de casos ausentes, depois do tratamento T2: do modo Automóvel da Família, PIDADE, AFCBO2 e AFCCO2; e do modo Ônibus, PIDADE e PNAUTO.

As amostras pareadas diminuíram muito em número de observações validadas. Até aqui as análises se propuseram a gerar informações em separado para cada IEM. Para o teste da hipótese, foi considerado que a interação de opinião para a decisão do modo de transporte poderia integrar respondentes das duas IEMs, pois bastaria uma ocorrência em uma IEM para que a hipótese pudesse ser confirmada. A possibilidade de unir as amostras das IEM PU 1 e IEM PU 2, para os modos Automóvel da Família e Ônibus, foi testada pelo teste de poder no programa GPower 3.1.9.2 (Faul et al.,2007). O teste do poder foi avaliado para cada tamanho de amostra disponível, em separado ou integrando as duas IEMs, para efeitos grandes e médios e $\alpha=0,05$. Os resultados são apresentados na Tabela 7.23 . 
Tabela 7.23: Teste de poder para amostras pareadas resultantes do tratamento $\mathrm{T} 2$

\begin{tabular}{c|cccccc}
\hline & \multicolumn{9}{c}{ Efeito médio $-0,3$} \\
\hline IEM & \multicolumn{2}{|c}{ IEM PU1 } & \multicolumn{2}{c}{ IEM PU2 } & \multicolumn{2}{c}{ IEM PU1 E IEM PU 2 } \\
\hline Modo & AF & ON & AF & ON & AF & ON \\
\hline $\mathrm{n}$ & 14 & 27 & 12 & 27 & 26 & 54 \\
\hline Poder & 0,29 & 0,48 & 0,27 & 0,48 & 0,47 & 0,74 \\
\hline
\end{tabular}

Foram utilizados modelos binários logit, para as variáveis dependentes modo na ida e modo na volta, codificadas de forma binária, para o uso ou não do modo considerado, contra todas as outras possibilidades pesquisadas. As variáveis independentes são representadas pela média dos itens de medida direta dos construtos, a intenção dos alunos (variável MEDAFIT), a intenção dos pais (variável MEDPAFIT), o controle percebido (variável MEDAFCP), e o controle percebido dos pais (variável MEDPAFCP). Foi considerado que todos os respondentes teriam a disponibilidade dos dois modos, Automóvel da Família e Ônibus. Os dados foram processados no programa BIOGEME 1.8. Os modelos iniciais se referem ao modelo postulado na Figura 3.3 desta tese e o final; os modelos finais contêm apenas as variáveis significativas, e foi obtido pelo processo de retirada em etapas tipo backwards. A Figura 7.12 apresenta a estrutura dos modelos binários estudados sobre a interação da opinião de alunos e pais/responsáveis, e a Tabela 7.24 apresenta os resultados das análises.

Pela Tabela 7.24, observa-se a presença da constante negativa e significativa em todos os modelos. A intenção dos alunos (variáveis MEDAFIT e MEDONIT) é a variável explicativa significativa mais presente nos modelos finais. Alguns coeficientes referentes aos pais sugerem a confirmação da hipótese de estudo. É o caso do modelo final do modo Automóvel da Família na Volta e o modelo final do modo Ônibus na Ida, com a variável relativa ao controle percebido dos pais positiva e significativa.

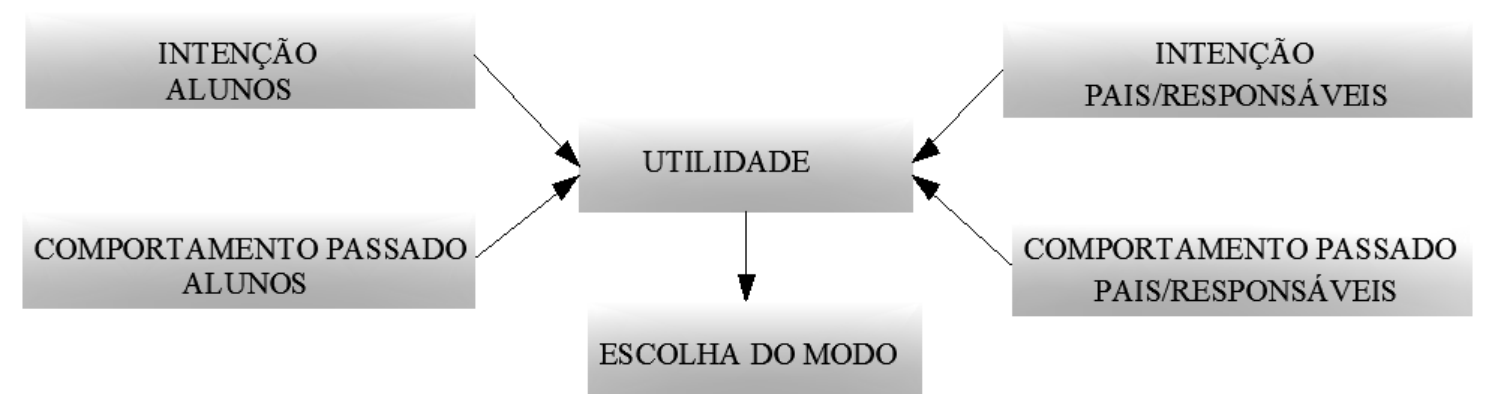

Figura 7.12: Estrutura dos modelos binários estudados sobre a interação da opinião dos alunos e pais/responsáveis na escolha modal, para amostras integradas IEMPU 1 e IEM PU 2. 
Tabela 7.24: Modelos para o teste da interação da opinião de pais/responsáveis e alunos, para as amostras integradas IEM PU 1 e IEM PU 2.

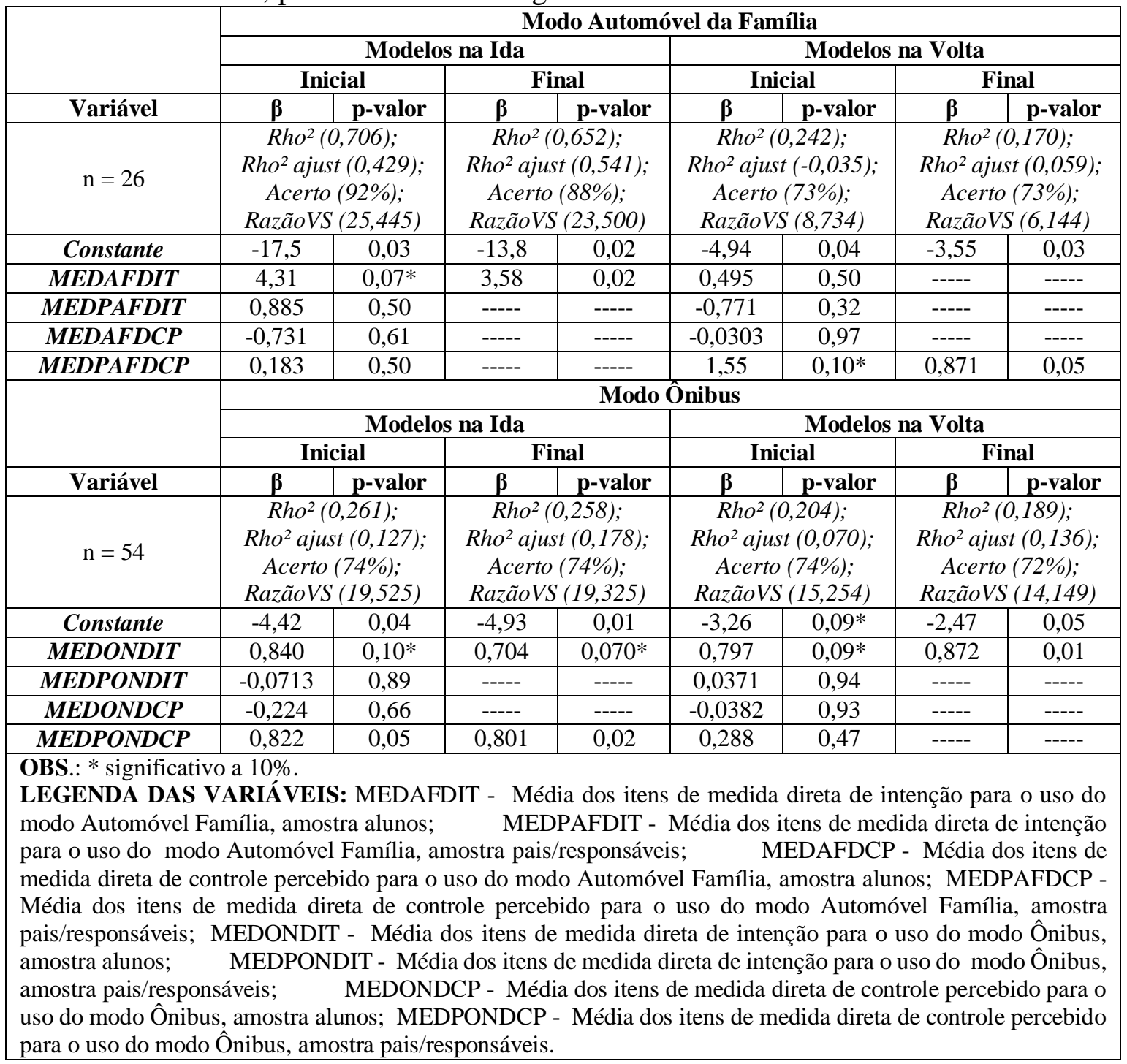

As Figuras 7.13 e 7.14 apresentam as estruturas dos modelos finais para os modos Automóvel da Família e Ônibus, tanto para a ida, quanto para a volta, nas duas IEMs PU 1 e PU 2. Observa-se que o modelo final do modo Automóvel da Família na volta apresentou o Controle Percebido dos pais, e não a Intenção dos pais/responsáveis, e nem de alunos, como variável explicativa única, além da constante. Este resultado sugere que o comportamento de usar ou não o modo Automóvel da Família na saída do turno da escola é mais afetado pela percepção do controle dos pais (segurança, liberdade de realização, etc.) para que o aluno realize a viagem de saída por este modo.

Apesar das conclusões das modelagens permitirem a confirmação da hipótese de pesquisa, os resultados obtidos, quanto ao reconhecimento de que a interação de pais e 
alunos efetivamente ocorre, tais resultados devem ser tomados com cautela. Isto é, das quatro situações analisadas, apenas duas apontaram itens significativos referentes à opinião dos pais e somente em uma (modelo ida para o modo Ônibus) as variáveis dos dois grupos (intenção do aluno e controle percebido dos pais/responsáveis) interagem na

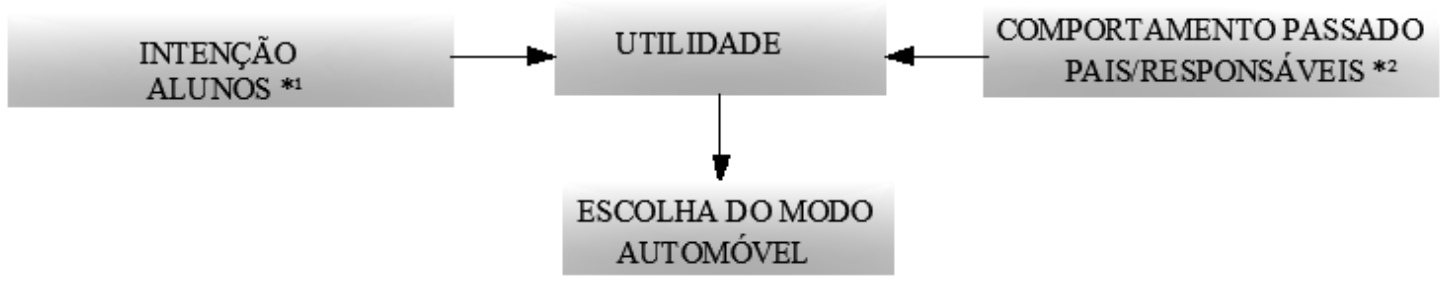

Figura 7.13: Estrutura dos modelos finais da interação entre alunos e pais/responsáveis para o modo Automóvel da Família, para as duas IEMs, na ida e na volta.

tomada de decisão.

Obs.: *1 - Apenas na ida; *2 - apenas na volta;

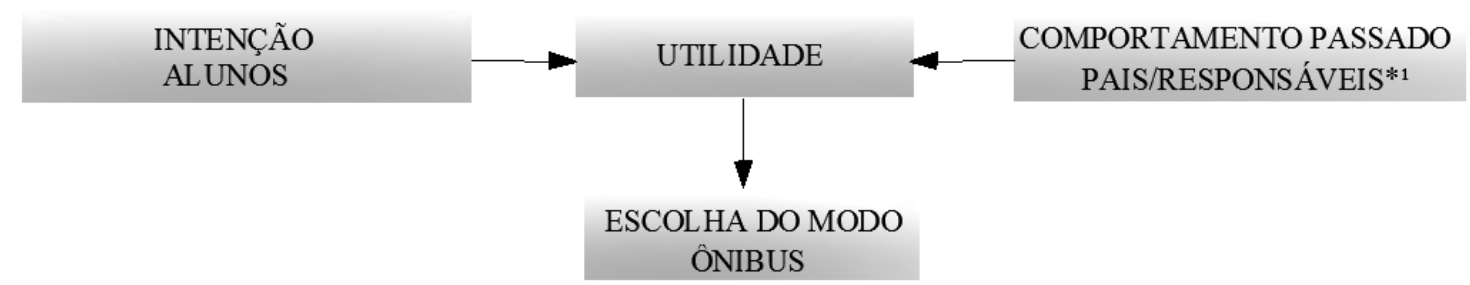

Figura 7.14: Estrutura dos modelos finais da interação entre alunos e pais/responsáveis para o modo Ônibus, para as duas IEMs, na ida e na volta.

Obs.: *1 - Apenas na ida;

Se não se pode admitir a confirmação da presença da interação de opinião entre os dois grupos em todas as situações, caráter geral do comportamento esperado que norteou a elaboração da hipótese de pesquisa, os resultados também não permitem refutar por completo a ocorrência desse comportamento para as duas IEMs avaliadas. Esse resultado, portanto, indica que, para efeito de estudos futuros da escolha modal em diferentes IEMs, a aplicação do procedimento proposto, que permite verificar a presença de interação da opinião entre alunos e seus respectivos pais/responsáveis na decisão de escolha do modo de transporte para a realização das viagens escolares é justificável.

\subsection{TÓPICOS CONCLUSIVOS}

As abordagens qualitativas e quantitativas incluídas no procedimento se mostraram adequadas e eficazes na identificação dos atributos influenciadores da escolha modal nas 
IEMs participantes. As análises estatísticas utilizadas também se mostraram relevantes para a obtenção de resultados confiáveis. As análises quantitativas, aplicadas às IEMs em Brasília, confirmaram a utilidade desse procedimento para que fossem identificados atributos influenciadores da escolha modal nas viagens escolares nessas IEMs, dentre os quais a possibilidade de interação entre pais e alunos para a realização dessa escolha.

A verificação da ausência de normalidade e variância constante nas variáveis das amostras consideradas requereu análises mais aprofundadas na aplicação do procedimento, exigindo modelos e métodos de estimação que relaxassem tais pressupostos. Os Modelos Lineares Generalizados, pelo método de estimação da quaseverossimilhança, se mostraram capazes de representar adequadamente os fenômenos estudados.

$\mathrm{Na}$ análise exploratória das crenças, pode ser testada a não aderência da categorização intuitiva das crenças obtidas nos grupos focais para com os construtos da TCP. Por essa razão, a investigação das crenças que afetam cada construto foi feita com base no elenco total de crenças salientes levantadas nos grupos focais. O teste mais aprofundado das crenças salientes e os construtos foi realizada apenas para a IEM PU 1, pela densidade de análises requerida. $\mathrm{O}$ elemento chave da análise das crenças é aquele que tem o conteúdo da crença (item " $b$ "). A saída de um item do tipo " $b$ " não significativo no processo backwards, levou à eliminação dos itens "e" e "bxe" simultaneamente.

$\mathrm{Na}$ busca por um subconjunto de crenças com maior impacto sobre os construtos, e que possa subsidiar a formulação de estratégias de Gerenciamento da Mobilidade, devem ser considerados os modelos finais de maior explicação. Na aplicação realizada para a IEM PU 1, em geral, os modelos finais apenas com variáveis significativas com maior poder de explicação foram os do tipo 3B. Semelhantemente, os piores modelos foram aqueles que consideraram apenas o produto, ou seja, os baseados unicamente na Teoria da Expectância.

Na modelagem da intenção, foram utilizados dois tipos de modelos, MLGs e AFCs, com diferentes resultados, sendo que a modelagem MLG se mostrou mais consistente. Os resultados indicaram que, para os dados amostrais considerados, as variáveis básicas da TCP (Atitude, Norma Social e Controle Percebido), aliada ao Comportamento Passado 
afetam a intenção de usar ou não os modos Ônibus e Automóvel da Família. Os resultados com relação às variáveis sociodemográficas, específicos para cada caso, revelaram que apenas as variáveis Idade e Densidade não se mostraram significativas em nenhum dos modelos obtidos. Com relação à variável Hábito, ela se mostrou significativa apenas para explicar a intenção de uso do modo Ônibus dos estudantes da IEM PU 1.

Para o comportamento, a Intenção e o Comportamento Passado são as variáveis explicativas presentes em todos os modelos estimados, como influenciadores da escolha do modo Ônibus e modo Automóvel da Família. A variável Hábito mostrou-se significativa em três dos quatro modelos elaborados para a IEM PU 1, mas não foi relevante para nenhum modelo da IEM PU 2. Situação contrária ocorreu com a variável Gênero, significativa em três modelos da IEM PU 2 e em nenhum da IEM PU 1. Outras variáveis como Densidade na localidade de residência, Renda, e Idade sugerem relações diferenciadas por modo e por IEM.

O comportamento esperado de interação da opinião de pais e alunos para a escolha do modo de transporte nas viagens escolares foi verificado em apenas uma das situações analisadas: escolha do modo Ônibus na ida para a escolha. Nessa situação, as variáveis Intenção do Estudante e Controle Percebido dos Pais mostraram-se estatisticamente significativas para $\alpha=10 \%$. Nos modelos para as outras situações, ora foi significativa apenas a intenção do estudante (ida pelo modo Automóvel da Família e volta pelo modo Ônibus), ora apenas o Controle Percebido dos pais (volta pelo modo Automóvel da Família).

Essa falta de homogeneidade na identificação da interação da opinião de pais e alunos precisa ser considerada com cautela, uma vez que as amostras utilizadas nas análises foram muito pequenas (26 respondentes para o modo Automóvel da Família e 54 respondentes para o modo Ônibus). De qualquer modo, é possível afirmar que os resultados obtidos permitem confirmar a hipótese da pesquisa quanto à capacidade do procedimento em identificar a presença dessa interação. 


\section{CONCLUSÕES E RECOMENDAÇÕES}

Estudar a escolha modal não é um objetivo novo de pesquisa (Ortúzar e Willumsen, 2011). O que há de diferente nas pesquisas das últimas décadas é que a análise da escolha modal tenha como objetivo obter elementos para a promoção de um menor uso do automóvel. O Gerenciamento da Mobilidade depende, portanto, das análises de como se realizam as decisões na escolha modal para adequação de suas estratégias. Os Programas de Gerenciamento da Mobilidade têm como objetivo modificar padrões de dependência do uso do automóvel em viagens cotidianas, em comunidades vinculadas a PGVs específicos (Cairns et al.2004).

As IEMs são PGVs, e estudos em áreas escolares merecem a atenção dos pesquisadores da escolha modal por envolver o grupo mais vulnerável no trânsito, as crianças e adolescentes. Além disso, o uso do automóvel cotidianamente em viagens escolares restringe a oportunidade de atividade física, e não promove hábitos para a mobilidade sustentável na vida adulta (Cairns, 2000). A presente pesquisa procurou contribuir com a compreensão dos processos subjacentes à escolha modal nas viagens por motivo ensino vinculadas a Instituições de Ensino Médio (IEMs).

O presente capítulo refere os principais resultados obtidos na presente pesquisa e aborda diferentes aspectos do trabalho tais como o alcance dos objetivos estabelecidos, a técnica de modelagem empregada, a verificação da hipótese da pesquisa, além das limitações para o seu desenvolvimento. Na última seção do capítulo são apresentadas recomendações para futuros trabalhos dentro da mesma linha de pesquisa.

\subsection{DO ALCANCE DO OBJETIVO DA PESQUISA}

O objetivo geral da pesquisa foi alcançado, com a elaboração de um procedimento para a identificação de atributos intervenientes no comportamento da escolha modal em IEMs. O procedimento desenvolvido foi aplicado com sucesso em três IEMs em Brasília (uma apenas parcialmente). O desenvolvimento do procedimento envolveu esforços em conduzir uma pesquisa eticamente adequada. Entretanto, a aprovação ética para autorização da realização da coleta de dados e a extensão da própria coleta em duas etapas, 
limitou o tempo disponível para o desenvolvimento das análises estatísticas adequadas da aplicação do procedimento.

A aplicação do procedimento envolveu a elaboração de instrumentos de sistematização e padronização dos processos e a pesquisa de melhores técnicas de análise de dados. Algumas adaptações da metodologia foram necessárias na medida em que o procedimento era aplicado e testado. Preliminarmente foi indicada a modelagem por Modelos de Regressão Linear Múltipla - MRLM, mais populares e de fácil interpretação.

Com a identificação de ausência de normalidade na maioria das variáveis envolvidas no estudo, os MRLMs não puderam ser utilizados e no seu lugar foram adotados Modelos Lineares Generalizados - modelos MLGs, com o método de estimação por quaseverossimilhança. Esta opção viabilizou a análise exploratória das crenças salientes em relação aos construtos da TCP e as modelagens da Intenção. Para a realização dos estudos do comportamento (escolha modal), estava previsto o uso de Modelos Integrados de Escolha Discreta e Variáveis Latentes - ICLV. Esta técnica de modelagem não pode ser empregada devido à impossibilidade de acesso aos programas computacionais requeridos para sua utilização no tempo disponível para a análise dos dados. Essa situação levou à adoção do segundo método mais recomendado pela bibliografia para os estudos de escolhas discreta na presença de variáveis latentes: os modelos sequenciais. A Tabela 8.1 resume as técnicas de modelagem consideradas nos modelos finais mais significativos na aplicação do procedimento proposto em IEMs de Brasília.

Tabela 8.1: Resumo das técnicas de modelagens utilizadas nos modelos finais mais significativos na aplicação do procedimento em IEMs de Brasília

\begin{tabular}{|c|c|c|c|}
\hline Etapa & $\begin{array}{l}\text { Análise Exploratória } \\
\text { das crenças }\end{array}$ & $\begin{array}{l}\text { Modelagem da } \\
\text { intenção }\end{array}$ & $\begin{array}{c}\text { Modelagem do } \\
\text { comportamento na } \\
\text { escolha modal } \\
\end{array}$ \\
\hline Técnicas & $\begin{array}{c}\text { Análise Fatorial; } \\
\text { MGLs }\end{array}$ & MGLs & $\begin{array}{c}\text { Estimação sequencial: } \\
\text { análise fatorial seguido } \\
\text { de MED logit binário } \\
\text { por modo }\end{array}$ \\
\hline Produto desejado & $\begin{array}{c}\text { Elenco de crenças } \\
\text { salientes significativas } \\
\text { por construto TCP }\end{array}$ & $\begin{array}{c}\text { Antecedentes } \\
\text { significativos da } \\
\text { intenção }\end{array}$ & $\begin{array}{c}\text { Atributos } \\
\text { influenciadores da } \\
\text { escolha modal }\end{array}$ \\
\hline Variáveis Dependentes & Construtos TCP & Intenção & Escolha de cada modo \\
\hline $\begin{array}{c}\text { Variáveis } \\
\text { Independentes } \\
\end{array}$ & $\begin{array}{c}\text { Conjunto de todas as } \\
\text { crenças }\end{array}$ & $\begin{array}{c}\text { Construtos da TCP e } \\
\text { sociodemográficas }\end{array}$ & $\begin{array}{c}\text { Construtos da TCP e } \\
\text { sociodemográficas }\end{array}$ \\
\hline
\end{tabular}


Os construtos da TCP foram representados pelas médias dos seus itens de medida direta. A simplificação da obtenção desses fatores pela média é suportada pela bibliografia (DiStefano et al., 2009). Uma condição adicional foi a transformação das variáveis categóricas ordenadas, medidas pelas escalas likert, em variáveis numéricas contínuas, facilitando a identificação dos modelos propostos.

O procedimento desenvolvido é passível de replicação em outras localidades, para outras IEMs, além das estudadas em Brasília. Entretanto, as especificidades de cada comunidade escolar pode demandar adaptações, tais como indicado em cada etapa ao longo da tese. Por exemplo, o conjunto de modos de transporte viáveis pode ser bem diferente do pesquisado aqui. Se os tamanhos da amostra, ausência dos pressupostos do modelo, ou qualquer outro impedimento com a coleta de dados não permitir a condução completa do procedimento, caberá ao pesquisador interpretar a escolha modal perante as restrições encontradas, limitando suas conclusões.

Os modelos aqui desenvolvidos não pretendem ser mais complexos que os demais revisados na bibliografia. Pelo contrário, uma das contribuições do estudo foi, por exemplo, o teste de modelos MLGs, de fácil manipulação por programas de acesso livre como o "R", em contrapartida a programas de variável latente, de acesso mais restrito. Em relação aos modelos tradicionais de escolha modal, que utilizam mais frequentemente os atributos das alternativas, da viagem e características sociodemográficas dos indivíduos (grupos 2, 5, e 4 de Zhou, 2012) (Ortúzar, e Willumnsen, 2011), o procedimento proposto se mostrou mais eficiente na explicação da escolha modal de cada comunidade escolar.

A eficiência do procedimento, verificada na sua aplicação em IEMs de Brasília, pode ser explicada em, pelo menos, três aspectos: i) permitiu apontar, através do estudo das crenças salientes significativas, características específicas de percepção da mobilidade em cada IEM, passíveis de subsidiar intervenções que visem um menor uso do automóvel nas viagens escolares; ii) devido a características próprias da comunidade escolar, muitas características sociodemográficas da localidade de residência ou do próprio respondente não se mostraram estatisticamente significativas para explicar a variação das escolhas modais estudadas. Por outro lado, em todos os modelos as dimensões psicossociais se mostraram significativas, compondo diferentes conjuntos de atributos significativos para 
a explicação das escolhas modais; iii) o uso de modelos integrados de escolha discreta e variável latente não pode ser testado no presente estudo. Porém, até onde alcançou a revisão da literatura, os modelos dessa classe são mais complexos que os modelos adotados na tese.

\subsection{DO MODELO TEÓRICO ADOTADO}

A adoção do enfoque da psicologia social como suporte teórico da pesquisa trouxe contribuições para o estudo da escolha modal, como já era indicado nas revisões bibliográficas consideradas (Ben-Akiva et.al, 2002). Para os dados amostrais considerados na aplicação do procedimento, a teoria refletida nos modelos teóricos apresentados nas Figuras 3.2 e 3.3 não se aplicou em sua totalidade. A mediação dos construtos Atitude, Norma Social e Controle Percebido pela Intenção de realizar o comportamento foi confirmada. No tocante ao comportamento, a teoria se confirmou apenas em parte: a influência do Controle Percebido sobre o comportamento foi capturada diretamente pela intenção, de maneira análoga à postulada pela Teoria da Ação Racional - TAR (Fishbein e Ajzen, 1975), antecedente da TCP. Não obstante as especificidades encontradas, os construtos psicológicos se mostraram mais significativos e presentes que as variáveis tradicionais sociodemográficas, nas relações com as escolhas modais estudadas.

\subsection{LIMITAÇÕES DO ESTUDO}

Foram várias as limitações para o desenvolvimento do presente estudo. Os principais tópicos envolvem a amostragem, a adaptação de linguagem dos questionários e os vieses observados na opinião das comunidades escolares.

\subsubsection{AMOSTRAGEM}

Mesmo com o esforço em realizar a duas coletas de dados, os tamanhos resultantes das amostras tratadas, sem dados ausentes, limitaram a possibilidade de realização de algumas das análises propostas. Esta restrição afetou, por exemplo, a realização do teste da hipótese de pesquisa, sobre a interação de alunos e seus respectivos pais/responsáveis na decisão da escolha do modo nas viagens escolares. A aplicação do procedimento às 
três IEMs de Brasília revelou que o contato inicial com as direções das escolas candidatas a participar da pesquisa, que define inclusive a forma de aplicação dos questionários, é um passo importante para a ampliação da participação da comunidade escolar, visando obter o maior número possível de respondentes aos questionários. O acesso da pesquisadora em sala, vetado na IEM PR1, por exemplo, implicou em questionários incompletos e o seu posterior descarte da base de dados.

Por outro lado, como não é possível garantir que, mesmo com todo o apoio da direção das escolas, os estudantes e, sobretudo, seus pais tenham elevado grau de adesão à pesquisa, conclui-se que seria melhor adaptar o procedimento proposto no sentido de incluir os alunos das demais séries e não somente os da $1^{\mathrm{a}}$ série. Isso vale, sobretudo, para o caso de Brasília, em que o porte médio das IEMs inclui número de matrículas de 120 (três turmas de 40 alunos) a perto de 400 (10 turmas de ensino médio por turno (Brasil, 2013). Casos, como o da IEM PU 1, com 17 turmas de $1^{\text {a }}$ série no turno da tarde, e que teve a melhor amostragem das três participantes, são poucos.

\subsubsection{ADAPTAÇÃO DA LINGUAGEM AO ADOLESCENTE}

Para a elaboração dos questionários foram seguidas as recomendações de Ajzen (2000). Entretanto, observou-se que a categorização intuitiva das crenças salientes obtida nos grupos focais não se relacionou com os construtos, como previsto. Isto pode ser resultado de diferenças de compreensão do conteúdo das crenças apresentadas pelos estudantes por parte da pesquisadora. Isto é, é possível que a redação final de alguma crença não corresponda exatamente à ideia manifestada no grupo focal. Em aplicações futuras, portanto, seria interessante que a redação do texto das crenças e mesmo sua categorização de acordo com os construtos da TCP seja realizada com a participação direta dos estudantes.

\subsubsection{VIESES OBSERVADOS}

De alguma forma, seja pela convivência cotidiana homogeneizando as opiniões e vivências, seja pelas razões da escolha da IEM, perfil da escola, reconhece-se que nas comunidades escolares não se deve esperar muita variabilidade das opiniões e informações dos usuários. Esta é uma diferença básica entre pesquisar a população como 
um todo (como em Karmargianni et al., 2015), ou pesquisar uma comunidade específica: a assimetria dos dados. Reconhecendo tal possibilidade, esforços devem ser realizados para testar, tratar ou adequar os processos de estimação para análise da escolha modal nas IEMs.

\subsection{RESULTADOS DOS GRUPOS FOCAIS}

A realização da abordagem exploratória qualitativa pela técnica de grupos focais foi bastante eficiente. Disponibilizado apenas os minutos de intervalos das aulas nos turnos em cada IEM participante, as reuniões conseguiram atingir o objetivo de explorar as principais crenças salientes subjacentes à mobilidade em cada escola. Os temas mais recorrentes citados nas reuniões foram: i) a segurança pessoal (ou a ausência dela) nos percursos a pé necessários ao acesso/egresso dos modos públicos de transporte, Ônibus e Metrô; ii) a influência dos grupos de referência, pais e amigos; iii) a preocupação/compromisso com a pontualidade nas viagens escolares; iv) a influência dos contextos ambientais no uso dos modos não motorizados.

\subsection{RESULTADOS DOS PERFIS DE MOBILDADE}

A abordagem exploratória quantitativa possibilitou a elaboração de perfis de mobilidade, específicos para cada IEM. Acompanhando os estudos tradicionais de transporte (Ortúzar e Willumsen, 2011; Zhou, 2012), a partir da informação do endereçamento, fornecida pelos respondentes, foram elaboradas variáveis sócio demográficas para inclusão nos modelos propostos. As variáveis Renda, Densidade e Disponibilidade de automóvel no domicílio se basearam no valor médio domiciliar do setor censitário, ou o mais próximo da localização de residência informada pelo respondente. Nas análises quantitativas exploratórias esses dados ajudaram na elaboração dos perfis da mobilidade. Entretanto, quando testados nas modelagens que se seguiram, não se apresentaram tão significativos na explicação da escolha modal, como foram os itens psicológicos.

A distância entre a casa/escola foi obtida pela georreferenciação dos endereços (CEP) informados. A distribuição espacial das localidades de residência explicitou as diferenças na captação de alunos de cada IEM, agrupados em setores. A variável Distância, à semelhança das variáveis sociodemográficas, apresentou apenas significâncias pontuais 
nos modelos da etapa quantitativa. A pesquisa foi eficaz em captar os modos de transporte mais frequentemente utilizados. Os dois modos de transporte mais utilizados nas duas IEMs Públicas, o modo Ônibus e o modo Automóvel da Família, foram os modos eleitos para a condução das modelagens mais detalhadas na análise quantitativa preditiva. Também foram observadas as tendências na opção de mudança de modo para os usuários descontentes com o modo atualmente utilizado, com destaque para o modo Ônibus.

As análises bivariadas, variáveis sociodemográficas versus modo utilizado na ida, revelaram características dos usuários, específicas para cada IEM e, em geral: i) os meninos utilizam mais os modos não motorizados que as meninas; ii) as meninas utilizam mais os modos motorizados públicos; iii) o Transporte Escolar (transporte fretado) é preferido por quem mora longe e tem renda mais baixa; iv) a disponibilidade do automóvel no domicílio, bem como a maior disponibilidade de estacionamento na escola (caso das IEMs públicas) não significa, necessariamente, que esse modo seja preferido para realizar as viagens escolares. Tais achados podem subsidiar políticas de melhoria da capilaridade das redes públicas de transporte e estratégias de GM com foco no gênero.

\subsection{RESULTADOS DO ESTUDO EXPLORATÓRIO DAS CRENÇAS}

A análise exploratória das crenças é importante para dar especificidade às estratégias de GM para cada escola. Os resultados do estudo exploratório das crenças foram variados, incluindo aspectos divergentes à teoria de suporte do estudo. A análise fatorial não confirmou a categorização intuitiva sugerida pela TCP. Esse resultado pode ser fruto de especificidades das comunidades estudadas (diferenças culturais, por exemplo) ou, então, estar associado à evolução natural do comportamento humano, que recomenda revi $\sim$ soa e eventuais ajustes nas teorias comportamentais ao longo do tempo. Nas diferentes modelagens de crenças versus construtos foi verificado que uma crença pode afetar mais de um construto e, em contrapartida, algumas crenças não explicam de modo significativo nenhum dos construtos da TCP. As ocorrências observadas das crenças significativas obtidas para cada construto nos processos de modelagem são apresentadas nas Tabelas 8.2 e 8.3 . 
Tabela 8.2: Ocorrência das relações significativas das crenças com construtos da TCP para o modo Automóvel da Família na IEM PU1

\begin{tabular}{|c|c|c|c|c|c|c|c|c|c|c|c|c|c|c|}
\hline \multirow[b]{2}{*}{ Crença } & \multirow[b]{2}{*}{ Variável } & \multicolumn{4}{|c|}{1 B Final } & \multicolumn{4}{|c|}{2 B Final } & \multicolumn{4}{|c|}{3 B Final } & \multirow[b]{2}{*}{ Totais } \\
\hline & & Atitude & Norma & Controle & Intenção & Atitude & Norma & Controle & Intenção & Atitude & Norma & Controle & Intenção & \\
\hline \multirow{4}{*}{$\begin{array}{c}\text { Usar carro piora } \\
\text { congestionament } \\
\text { o }\end{array}$} & Constante & $\mathrm{X}$ & $\mathrm{X}$ & $\mathrm{X}$ & $\mathrm{X}$ & $\mathrm{X}$ & $\mathrm{X}$ & $\mathrm{X}$ & $\mathrm{X}$ & $\mathrm{X}$ & $\mathrm{X}$ & $\mathrm{X}$ & $\mathrm{X}$ & 12 \\
\hline & CAFCBO1 & & $X$ & & & & $\mathrm{X}$ & & & & $X$ & & & 3 \\
\hline & CAFCBE1 & & & & & & & & & & & & & $\mathbf{0}$ \\
\hline & CBO1xCBE1 & & & & & & & & & & & & & $\mathbf{0}$ \\
\hline \multirow{3}{*}{ É seguro } & CAFCBO2 & $\mathrm{X}$ & $\mathrm{X}$ & & & $\mathrm{X}$ & $\mathrm{X}$ & & & $X$ & $\mathrm{X}$ & & & 6 \\
\hline & CAFCBE2 & & & & & $X$ & & & & $\mathrm{X}$ & & & & 2 \\
\hline & CBO2xCBE2 & & & & & & & & & & & & & $\mathbf{0}$ \\
\hline \multirow{3}{*}{$\begin{array}{l}\text { Costuma chegar } \\
\text { no horário certo }\end{array}$} & CAFCBO3 & $X$ & & & & & & & & & & & & $\mathbf{1}$ \\
\hline & CAFCBE3 & & & & & & & & & & & & & $\mathbf{0}$ \\
\hline & \begin{tabular}{|l|}
$\mathrm{CBO} 3 x \mathrm{CBE} 3$ \\
\end{tabular} & & & & & & & & & & & & & $\mathbf{0}$ \\
\hline \multirow{3}{*}{$\begin{array}{l}\text { Preferência dos } \\
\text { pais em trazer de } \\
\text { carro }\end{array}$} & CAFCNO1 & $X$ & $X$ & $X$ & $\mathrm{X}$ & & $X$ & $\mathrm{X}$ & $X$ & & $X$ & $X$ & $X$ & 10 \\
\hline & CAFCNE1 & & & & & & & $X$ & $\mathrm{X}$ & & & $\mathrm{X}$ & $\mathrm{X}$ & 4 \\
\hline & CNO1xCNE1 & & & & & & & & & & $\mathrm{X}$ & & & $\mathbf{1}$ \\
\hline \multirow{3}{*}{$\begin{array}{l}\text { Apoio dos } \\
\text { amigos }\end{array}$} & CAFCNO2 & $X$ & $X$ & $X$ & $\mathrm{X}$ & $X$ & $X$ & & & $X$ & $\mathrm{X}$ & & & 8 \\
\hline & CAFCNE2 & & & & & $X$ & $\mathrm{X}$ & & & $\mathrm{X}$ & $\mathrm{X}$ & & & 4 \\
\hline & CNO2xCNE2 & & & & & & & & & & $\mathrm{X}$ & & & $\mathbf{1}$ \\
\hline \multirow{3}{*}{ É caro } & CAFCCO1 & $\mathrm{X}$ & & $X$ & $\mathrm{X}$ & & & $X$ & $\mathrm{X}$ & & & $X$ & $\mathrm{X}$ & 7 \\
\hline & CAFCCE1 & & & & & & & $X$ & $X$ & & & $\mathrm{X}$ & $\mathrm{X}$ & 4 \\
\hline & CCO1xCCE1 & & & & & & & & & & & & & 0 \\
\hline \multirow{3}{*}{$\begin{array}{c}\text { Impede } \\
\text { atividades de pós } \\
\text { turno }\end{array}$} & CAFCCO2 & & $\mathrm{X}$ & $\mathrm{X}$ & $\mathrm{X}$ & & $\mathrm{X}$ & $X$ & $X$ & & $\mathrm{X}$ & $\mathrm{X}$ & $\mathrm{X}$ & 9 \\
\hline & CAFCCE2 & & & & & & & & & & & & & $\mathbf{0}$ \\
\hline & CCO2xCCE2 & & & & & & & & & & & & & $\mathbf{0}$ \\
\hline
\end{tabular}

Especificação dos modelos: 1B - modelo final do processo backwards do modelo com entrada de todos os itens de crença tipo "b" para o modo; 2B - modelo final do processo backwards do modelo com entradas de todos os itens de crença, tipo "b" e "e", para o modo; 3B Final - modelo final do processo backwards do modelo com entradas de todos os itens de crença, tipo "b", "e" e "bxe", todas centralizadas, para o modo. 
Tabela 8.3: Ocorrência das relações significativas das crenças com construtos da TCP para o modo "Ônibus" na IEM PU1

\begin{tabular}{|c|c|c|c|c|c|c|c|c|c|c|c|c|c|c|}
\hline \multirow[b]{2}{*}{ Crença } & \multirow[b]{2}{*}{ Variável } & \multicolumn{4}{|c|}{1 B Final } & \multicolumn{4}{|c|}{2 B Final } & \multicolumn{4}{|c|}{3 B Final } & \multirow[b]{2}{*}{ Totais } \\
\hline & & Atitude & Norma & Controle & Intenção & Atitude & Norma & Controle & Intenção & Atitude & Norma & Controle & Intenção & \\
\hline & Constante & $\mathrm{X}$ & $\mathrm{X}$ & $\mathrm{X}$ & $\mathrm{X}$ & $\mathrm{X}$ & $\mathrm{X}$ & $\mathrm{X}$ & $\mathrm{X}$ & $\mathrm{X}$ & $\mathrm{X}$ & $\mathrm{X}$ & $\mathrm{X}$ & 12 \\
\hline \multirow{3}{*}{$\begin{array}{l}\text { Vantagem de ter } \\
\text { o passe estudantil }\end{array}$} & CONCBO1 & $\mathrm{X}$ & & $\mathrm{X}$ & $\mathrm{X}$ & $\mathrm{X}$ & $\mathrm{X}$ & $\mathrm{X}$ & $\mathrm{X}$ & $\mathrm{X}$ & $\mathrm{X}$ & $\mathrm{X}$ & $\mathrm{X}$ & 11 \\
\hline & CONCBE1 & & & & & & & $\mathrm{X}$ & $\mathrm{X}$ & & & $\mathrm{X}$ & $\mathrm{X}$ & 4 \\
\hline & \begin{tabular}{|l|} 
CBO1xCBE1 \\
\end{tabular} & & & & & & & & & & $\mathrm{X}$ & & & 1 \\
\hline \multirow{3}{*}{$\begin{array}{l}\text { Não Chega } \\
\text { atrasado }\end{array}$} & CONCBO2 & & $\mathrm{X}$ & & & & $\mathrm{X}$ & & & & $\mathrm{X}$ & & & 3 \\
\hline & CONCBE2 & & & & & & & & & & & & & 0 \\
\hline & CBO2xCBE2 & & & & & & & & & & & & & 0 \\
\hline \multirow{3}{*}{$\begin{array}{l}\text { Não é seguro } \\
\text { dentro do ônibus }\end{array}$} & CONCBO3 & $\mathrm{X}$ & & & & & & & & & & & & 1 \\
\hline & CONCBE3 & & & & $\mathrm{X}$ & & & & & & & & & 1 \\
\hline & CBO3xCBE3 & & & & & & & & & & & & & 0 \\
\hline \multirow{3}{*}{ Superlotado } & CONCBO4 & $\mathrm{X}$ & $\mathrm{X}$ & & & $X$ & $\mathrm{X}$ & & & $X$ & $\mathrm{X}$ & & & 6 \\
\hline & CONCBE4 & & & & & & & & & & & & & 0 \\
\hline & CBO4xCBE4 & & & & & & & & & $X$ & $X$ & & & 2 \\
\hline \multirow{3}{*}{ Incentivo pais } & CONCNO1 & $\mathrm{X}$ & $\mathrm{X}$ & $\mathrm{X}$ & $\mathrm{X}$ & $\mathrm{X}$ & $\mathrm{X}$ & $\mathrm{X}$ & $\mathrm{X}$ & $X$ & $X$ & $\mathrm{X}$ & $\mathrm{X}$ & 12 \\
\hline & \begin{tabular}{|l|} 
CONCNE1 \\
\end{tabular} & & & & & $X$ & $\mathrm{X}$ & $\mathrm{X}$ & $\mathrm{X}$ & $\mathrm{X}$ & $\mathrm{X}$ & $\mathrm{X}$ & $\mathrm{X}$ & 8 \\
\hline & CNO1xCNE1 & & & & & & & & & & $\mathrm{X}$ & $\mathrm{X}$ & & 2 \\
\hline \multirow{3}{*}{ Apoio amigos } & CONCNO2 & $\mathrm{X}$ & $X$ & $\mathrm{X}$ & $\mathrm{X}$ & & $\mathrm{X}$ & & & & $\mathrm{X}$ & & & 6 \\
\hline & CONCNE2 & & & & & & & & & & & & & 0 \\
\hline & CNO2xCNE2 & & & & & & & & & & & & & 0 \\
\hline \multirow{3}{*}{$\begin{array}{l}\text { É perigoso no } \\
\text { trecho a pé } \\
\text { escola/parada }\end{array}$} & CONCCO1 & $\mathrm{X}$ & & $\mathrm{X}$ & & $X$ & & $\mathrm{X}$ & & $\mathrm{X}$ & & $\mathrm{X}$ & & 6 \\
\hline & CONCCE1 & & & & & & & & & & & & & 0 \\
\hline & CCO1xCCE1 & & & & & & & & & & & & & 0 \\
\hline \multirow{3}{*}{$\begin{array}{c}\text { É inseguro } \\
\text { esperar na parada }\end{array}$} & \begin{tabular}{|l|}
$\mathrm{CONCCO} 3$ \\
\end{tabular} & $X$ & & & & $X$ & & & & $\mathrm{X}$ & & & & 3 \\
\hline & CONCCE3 & & & & & $\mathrm{X}$ & & & & $\mathrm{X}$ & & & & 2 \\
\hline & CCO3xCCE3 & & & & & & & & & & & & & 0 \\
\hline \multirow{3}{*}{$\begin{array}{l}\text { Tem uma linha } \\
\text { direta casa/escola }\end{array}$} & CONCCO4 & $X$ & & $X$ & $\mathrm{X}$ & & & $\mathrm{X}$ & & & & & & 4 \\
\hline & CONCCE4 & & & & & & & $X$ & & & & & & 1 \\
\hline & CCO4xCCE4 & & & & & & & & & & & & & 0 \\
\hline
\end{tabular}

Especificação dos modelos: 1B - modelo final do processo backwards do modelo com entrada de todos os itens de crença tipo "b" para o modo; 2B - modelo final do processo backwards do modelo com entradas de todos os itens de crença, tipo "b" e "e", para o modo; 3B Final - modelo final do processo backwards do modelo com entradas de todos os itens de crença, tipo "b", "e" e "bxe", todas centralizadas, para o modo. 
Como apresentado para na Tabela 8.1, para o modo Automóvel da Família, as crenças: CAFCNO1 ("percepção de que os pais preferem trazer de carro"), a crença CAFCCO2 ("usar automóvel para irou voltar da escola impede a realização de atividades após turno"), CAFCNO2 (“percepção do apoio dos amigos”) e a crença CAFCCO1 (“É caro") foram as crenças com maior número de ocorrências entre os modelos desenvolvidos para este modo, com ocorrência de 10/12, 9/12,8/12 e 7/12 casos, respectivamente. Na Tabela 8.2, para o modo Ônibus, observa-se que as crenças significativas mais recorrentes são: a crença CONCNO1 ("Incentivo dos pais"), CONCBO1 ("vantagem de ter passe estudantil"), CONCBO4 ("Superlotado"), CONCNO2 ("Apoio dos amigos") e CONCCO1 ("É perigoso no trecho a pé entre a escola e a parada").

Para a IEM PU 1, portanto, a partir dos resultados significativos do modelo 3B (Tabelas 8.1 e 8.2) pode-se identificar que, para o modo Automóvel da Família: i) a Atitude está associada à crenças que expressam vantagens do modo; ii) a Norma Social está relacionada à opinião dos pais e dos amigos, além das considerações de ser seguro, contribuir para piorar o congestionamento, e restringir a agenda pós turno; iii) o Controle e a Intenção têm resultados idênticos e se relacionam à opinião dos pais, ao custo e às restrições de agenda. Para o modo Ônibus: i) a Atitude é explicada por crenças que mostram aspectos negativos do modo; ii) a Norma Social está relacionada ao apoio dos pais e dos amigos, a ter passe estudantil e a ser superlotado; iii) o Controle está relacionado à opinião dos pais, à superlotação e a ter passe estudantil; iv) a Intenção está relacionada ao incentivo dos pais e ao passe estudantil.

O desdobramento das crenças salientes em duas afirmativas de crenças aumentou o tamanho do questionário e, provavelmente, o estresse do respondente, com a tarefa. Entretanto, como demonstrado na Tabela 7.16, os ganhos com esse desdobramento nas modelagens foram significativos. Sugere-se, portanto, que, a não ser por restrições orçamentárias justificáveis, a aplicação do procedimento sempre inclua tal análise. Os conjuntos de crenças significativos nos modelos finais refletem condições específicas da mobilidade dos estudantes em cada IEM. Os modelos finais obtidos para a IEM PU 1 são apresentados na Tabela 8.4. 
Tabela 8.4: Melhores modelos MLG para os construtos da TCP obtidos a partir das crenças, na IEM PU1, para amostra "alunos geral".

\begin{tabular}{|c|c|c|c|c|c|c|}
\hline \multirow{2}{*}{ MODO } & \multirow{2}{*}{ CONSTRUTO } & \multirow{2}{*}{\multicolumn{2}{|c|}{ EQUAÇÃO }} & \multirow{2}{*}{$\begin{array}{c}\text { Pseudo - } \\
\mathbf{R}^{2}\end{array}$} & \multicolumn{2}{|c|}{ FONTE } \\
\hline & & & & & No. Tabela & \\
\hline \multirow{4}{*}{$\begin{array}{l}\text { Automóvel } \\
\text { da Família }\end{array}$} & Atitude & \multicolumn{2}{|c|}{$\mathrm{AT}=3,93+0,14$ CAFCBO2 + 0,39 CAFCBE2 + 0,09 CAFCNO2 + 0,21 CAFCNE2 } & 0,47 & 7.8 & $2 \mathrm{~B} / 3 \mathrm{~B}$ \\
\hline & Norma Social & \multicolumn{2}{|c|}{$\begin{array}{l}\mathrm{NS}=3,55+0,07 \text { CAFCBO1 + 0,12 CAFCBO2 + 0,17 CAFCNO1 - 0,04 CNO1xCNE1 + 0,15 } \\
\text { CAFCNO2 + 0,16 CAFCNE2 + 0,08 CNO2xCNE2 + 0,05 CAFCCO2 }\end{array}$} & 0,37 & 7.9 & 3B \\
\hline & $\begin{array}{l}\text { ntrole } \\
\text { rcebido }\end{array}$ & \multicolumn{2}{|c|}{$\begin{array}{l}\mathrm{CP}=3,32+0,17 \text { CAFCNO1 + 0,32 CAFCNE1 - 0,10 CAFCCO1 + 0,12 CAFCCE1 + 0,07 } \\
\mathrm{CAFCCO2}\end{array}$} & 0,31 & 7.10 & $2 \mathrm{~B} / 3 \mathrm{~B}$ \\
\hline & Intenção & \multicolumn{2}{|c|}{$\begin{array}{l}\mathrm{IN}=3,12+0,32 \text { CAFCNO1 + 0,20 CAFCNE1 - 0,11 CAFCCO1 + 0,16 CAFCCE1 + 0,08 } \\
\text { CAFCCO2 }\end{array}$} & 0,35 & 7.11 & $2 \mathrm{~B} / 3 \mathrm{~B}$ \\
\hline \multirow{4}{*}{ Ônibus } & itude & \multicolumn{2}{|c|}{$\begin{array}{l}\mathrm{AT}=3,34+0,13 \text { CONCBO1 - 0,14 CONCBO4 + 0,16 CONCNO1 + 0,43 CONCNE1 - 0,06 } \\
\text { CONCCO1 - 0,10 CONCCO3 + 0,10 CONCCE3 }\end{array}$} & 0,49 & 7.12 & 2B \\
\hline & Norma Social & \multicolumn{2}{|c|}{$\begin{array}{l}\mathrm{NS}=3,31+0,15 \mathrm{CONCBO} 1-0,07 \mathrm{CBO} 1 \mathrm{xCBE} 1+0,09 \mathrm{CONCBO}-0,05 \mathrm{CONCBO} 4+0,03 \\
\mathrm{CBO} 4 \mathrm{xCBE} 4+0,21 \mathrm{CONCNO}+0,07 \mathrm{CONCNE} 1+0,07 \mathrm{CNO} 1 \mathrm{xCNE} 1+0,21 \mathrm{CONCNO} 2\end{array}$} & 0,46 & 7.13 & 3B \\
\hline & $\begin{array}{l}\text { trole } \\
\text { ebido }\end{array}$ & \multicolumn{2}{|c|}{$\begin{array}{l}\mathrm{CP}=3,76+0,18 \text { CONCBO} 1+0,22 \text { CONCBE} 1+0,11 \text { CONCNO1 + 0,24 CONCNE1 - 0,07 } \\
\text { CONCCO1 + 0,05 CONCCO4 + 0,09 CONCCE } 4\end{array}$} & 0,44 & 7.14 & 2B \\
\hline & Intenção & \multicolumn{2}{|c|}{$\mathrm{IN}=3,60+0,12$ CONCBO1 + 0,15 CONCBE1 + 0,35 CONCNO1 + 0,27 CONCNE1 } & 0,44 & 7.15 & \\
\hline \multicolumn{3}{|c|}{$\begin{array}{l}\text { CAFCBO1 = Objeto da crença "Usar carro piora congestionamento"; } \\
\text { CAFCBO2 = Objeto da crença "É seguro"; } \\
\text { CAFCBE2 = Força da crença "É seguro"; } \\
\text { CAFCNO1 = Objeto da crença "Preferência dos pais em trazer de carro"; } \\
\text { CAFCNE1 = Força da crença "Preferência dos pais em trazer de carro"; } \\
\text { CNO1xCNE1 = Produto do objeto e força da crença "Preferência dos pais em trazer de } \\
\text { carro"; } \\
\text { CAFCNO2 = Objeto da crença "Apoio dos amigos"; } \\
\text { CAFCNE2 = Força da crenç "Apoio dos amigos"; } \\
\text { CNO2xCNE2 = Produto do objeto e força da crença "Apoio dos amigos"; } \\
\text { CAFCCO1 = Objeto da crença "É caro"; } \\
\text { CAFCCE1 = Força da crença "É caro"; } \\
\text { CAFCCO2 = Objeto da crença "Impede atividades de pós turno"; } \\
\text { CONCBO1 = Objeto da crença "Vantagem de ter o passe estudantil"; }\end{array}$} & \multicolumn{4}{|c|}{$\begin{array}{l}\text { CONCBE1 = Força da crença "Vantagem de ter o passe estudantil"; } \\
\text { CBO1xCBE1 = Produto do objeto e força da crença "Vantagem de ter o passe estudantil"; } \\
\text { CONCBO2 = Objeto da crença "Não chega atrasado"; } \\
\text { CONCBO4 = Objeto da crença "Superlotado"; } \\
\text { CBO4xCBE4 = Produto do objeto e força da crença "Superlotado"; } \\
\text { CONCNO1 = Objeto da crença "Incentivo pais"; } \\
\text { CONCNE1 = Força da crença "Incentivo pais"; } \\
\text { CNO1xCNE1 = Produto do objeto e força da crença "Incentivo pais"; } \\
\text { CONCNO2 = Objeto da crença "Apoio amigos"; } \\
\text { CONCCO1 = Objeto da crença "É perigoso no trecho a pé escola/parada"; } \\
\text { CONCCO3 = Objeto da crença "É inseguro esperar na parada"; } \\
\text { CONCCE3 = Força da crença "É inseguro esperar na parada"; } \\
\text { CONCCO4 = Objeto da crença "Tem uma linha direta casa/escola"; } \\
\text { CONCCE4 = Força da crença "Tem uma linha direta casa/escola"; }\end{array}$} \\
\hline
\end{tabular}


Na Tabela 8.5 são apresentadas algumas sugestões de intervenção no gerenciamento da mobilidade em cada IEM a partir dos resultados observados das relações dos construtos com as crenças salientes.

Tabela 8.5: Sugestões de Intervenção de GM nas IEMs estudadas

\begin{tabular}{ll}
\hline Construto & Estratégias \\
\hline Atitude & $\begin{array}{l}\text { Campanhas para mudanças conceituais sobre a utilização dos modos em } \\
\text { viagens cotidianas, com o uso exemplar de familiares e amigos. } \\
\text { Divulgar externalidades decorrentes do uso do automóvel (acidentes, } \\
\text { congestionamentos, comprometimento do orçamento familiar). }\end{array}$ \\
\hline Norma Social & $\begin{array}{l}\text { Campanhas para motivação do uso (ou não) do modo a partir da opinião dos } \\
\text { pais e amigos. } \\
\text { Campanhas para melhoria da conduta no uso do modo. }\end{array}$ \\
\hline Controle Percebido & $\begin{array}{l}\text { Campanhas para melhorar a percepção da viabilização do uso do modo. } \\
\text { Se estiver ao alcance do promotor do Programa de GM, melhorar as condições } \\
\text { de utilização do uso do modo, como: }\end{array}$ \\
a) Melhorias na iluminação dos trajetos a pé; \\
b) Melhoria da segurança pública nos ambientes relacionados com o uso \\
do modo (caminhada, espera, viagem); \\
c) Melhoria operacional dos modos públicos (confiabilidade, horários, \\
tempo de terminal, integração). \\
Divulgação das características operacionais dos modos públicos, como trajetos \\
das linhas, tabelas de horários e uso do passe estudantil.
\end{tabular}

\subsection{RESULTADOS DAS MODELAGENS DA INTENÇÃO}

As modelagens da intenção contribuíram com aspectos metodológicos, teóricos e preditivos. Os aspectos metodológicos são relativos ao uso dos modelos MLG e a simplificação da fatoração dos itens de medida direta dos construtos pela sua média. Dos aspectos teóricos, destaca-se a confirmação da utilidade de uso da TCP para a análise do fenômeno da escolha modal. Por fim, as contribuições preditivas foram a obtenção de modelos significativos e teoricamente coerentes.

Na comparação das modelagens da intenção e do comportamento, enquanto a primeira inclui o Controle Percebido, a segunda não. Observa-se, portanto, que a Intenção captura toda a variabilidade da variável Controle Percebido, mediando sua relação com o comportamento. Os modelos finais obtidos para a amostra "alunos geral" das duas IEMs, para os modos Automóvel da Família e Ônibus, são apresentados na Tabela 8.6. 
Tabela 8.6: Melhores modelos MLG para os antecedentes da intenção, para modos Automóvel da Família e Ônibus, nas duas IEMs, para amostra "alunos geral".

\begin{tabular}{|c|c|c|c|c|c|}
\hline \multirow{2}{*}{ IEM } & \multirow{2}{*}{ MODO } & \multirow{2}{*}{ EQUAÇÃO } & \multirow{2}{*}{$\begin{array}{c}\text { Pseudo - } \\
\mathbf{R}^{2}\end{array}$} & \multicolumn{2}{|c|}{ FONTE } \\
\hline & & & & No. Tabela & Modelo \\
\hline \multirow{2}{*}{ IEM PU 1} & $\begin{array}{l}\text { Automóvel } \\
\text { da Família }\end{array}$ & $\begin{array}{l}\text { INT }_{\text {Auto }}=-0,515+0,15 \text { ATITUDE + 0,21 NORMA + 0,47 CONTROLE + 0,00001 DISTÂNCIA + } \\
0,195 \text { CPAF }\end{array}$ & 0,56 & 7.17 & $\begin{array}{c}\text { 2B } \\
\text { quasi }\end{array}$ \\
\hline & Ônibus & $\begin{array}{l}\text { INT Ônibus }=-0,15+0,43 \text { ATITUDE + 0,27 NORMA + 0,19 CONTROLE + 0,31 HABON + 0,16 } \\
\text { CPON }\end{array}$ & 0,51 & 7.18 & $\begin{array}{c}2 \mathrm{~B} \\
\text { quasi }\end{array}$ \\
\hline \multirow{2}{*}{ IEM PU 2} & $\begin{array}{l}\text { Automóvel } \\
\text { da Família }\end{array}$ & $\begin{array}{l}\text { INT }_{\text {Auto }}=-1,36+0,29 \text { ATITUDE + 0,19 NORMA + 0,49 CONTROLE + 0,89 DISPAUTO + } \\
0,11 \text { CPAF }\end{array}$ & 0,70 & 7.19 & $\begin{array}{c}2 \mathrm{~B} \\
\text { quasi }\end{array}$ \\
\hline & Ônibus & $\begin{array}{l}\text { INT }_{\text {Onibus }}=-0,02+0,32 \text { ATITUDE + 0,38 NORMA + 0,25 CONTROLE + 0,28 GÊNERO - 0,00003 } \\
\text { RENDA + 0,11 CPON }\end{array}$ & 0,54 & 7.20 & $\begin{array}{c}2 \mathrm{~B} \\
\text { quasi }\end{array}$ \\
\hline
\end{tabular}

OBS: quando modelos diferentes apresentaram o mesmo Pseudo- $\mathrm{R}^{2}$ foi selecionado o modelo com menor número de variáveis (parcimônia).

\section{LEGENDA DAS VARIÁVEIS:}

ATITUDE - Média dos itens de medida direta de Atitude para o uso do modo (Automóvel da Família ou Ônibus), na amostra "alunos geral";

NORMA - Média dos itens de medida direta de Norma Social para o uso do modo (Automóvel da Família ou Ônibus), na amostra "alunos geral";

CONTROLE - Média dos itens de medida direta de Controle Percebido para o uso do modo (Automóvel da Família ou Ônibus), na amostra "alunos geral”;

CPAF - Comportamento passado no uso do modo Automóvel da Família;

CPON - Comportamento passado no uso do modo Onibus;

HABON - Hábito no uso do modo Ônibus;

DISTÂNCIA - Distância euclidiana entre casa e escola;

DISPAUTO - Disponibilidade do automóvel no domicílio;

GÊNERO - Binária, sendo "1" para feminino;

RENDA - Renda média familiar do setor censitário da localidade de residência. 


\subsection{RESULTADOS DAS MODELAGENS DO COMPORTAMENTO}

Na predição do comportamento de escolha modal para a amostra "alunos geral", as variáveis independentes significativas obtidas no processo de modelagem foram a Intenção, como esperado, e o Comportamento Passado, divergindo dos resultados de estudos anteriores (como em Bamberg et al., 2003). O uso dos modelos de escolha discreta, com a estimação sequencial, e o uso de um programa computacional de livre acesso, simplificou e facilitou a modelagem da escolha modal, condição importante para a aplicação do procedimento em outras IEMs. Entretanto, a não realização das modelagens integradas, por modelos do tipo ICLV, não permitiu a realização de análise comparativa entre os resultados produzidos pelas duas formas de estimação. Ou seja, a ausência da modelagem ICLV impediu que se pudesse indicar se esta modelagem produziria resultados superiores aos produzidos pela modelagem sequencial realizada.

\subsubsection{RESULTADO DO TESTE SOBRE A INTERAÇÃO DE OPINIÃO ENTRE PAIS/RESPONSÁVEIS E ALUNOS NA ESCOLHA MODAL}

Esta foi a etapa de pesquisa mais impactada pelo tamanho da amostra resultante dos tratamentos de dados ausentes. O poder das amostras em representar a interação de opinião sobre e a escolha modal foi muito baixa, para efeitos médios. Os resultados obtidos revelaram que, para as IEMs estudadas, a hipótese de interação não pode ser refutada. Entretanto, há que se reconhecer que sua aceitação não se deu em todas as situações pesquisadas. Assim, é possível referir que o procedimento proposto é capaz de investigar a interação, e esta investigação deve ser testada sempre que for aplicado o procedimento em outras IEMs.

Na Tabela 8.7 é apresentado o conjunto de modelos obtidos para o comportamento de escolha modal dos estudantes das IEMs consideradas. Os modelos apresentados especificamente para cada instituição referem-se às amostras "alunos geral' de cada IEM. Já os modelos apresentados para as duas instituições agregadas foram elaborados para a amostra integrada formada pelas amostras pareadas das duas IEMs. Os modelos apresentados na tabela correspondem à parte determinística dos modelos, da utilidade de cada modo (Viq), conforme apresentado na seção 4.6. 
Tabela 8.7: Modelos sobre o comportamento da escolha modal obtidos nas IEMs estudadas.

\begin{tabular}{|c|c|c|c|c|c|}
\hline \multirow{2}{*}{ IEM } & \multirow{2}{*}{ MODO } & \multirow{2}{*}{ EQUAÇÃO } & \multirow{2}{*}{$\rho^{2} \mathbf{a j}$} & \multicolumn{2}{|c|}{ FONTE } \\
\hline & & & & No. Tabela & Modelo \\
\hline \multirow{4}{*}{ IEM PU 1} & $\begin{array}{l}\text { Automóvel da } \\
\text { Família - Ida }\end{array}$ & $\mathrm{COMP}_{\text {Auto ida }}=-9,43+0,72 \mathrm{MDAFDIT}+1,40 \mathrm{HABAF}+0,6 \mathrm{CPAF}$ & 0,46 & 7.21 & 2B \\
\hline & $\begin{array}{l}\text { Automóvel da } \\
\text { Família - Volta }\end{array}$ & $\mathrm{COMP}_{\text {Auto volta }}=-5,68+0,89 \mathrm{MEDAFDIT}+0,56 \mathrm{CPAF}$ & 0,34 & 7.21 & 2B \\
\hline & Ônibus - Ida & $\mathrm{COMP}_{\text {Onibus ida }}=-4,77+0,81$ MEDONDIT $-0,0000135$ DENSIDADE + 1,64 HABON + 0,7 CPON & 0,37 & 7.21 & 2B \\
\hline & Ônibus - Volta & $\mathrm{COMP}_{\text {Onibus volta }}=-4,31+0,74$ MEDONDIT $+1,12 \mathrm{HABON}+0,48 \mathrm{CPON}$ & 0,23 & 7.21 & 2B \\
\hline \multirow{4}{*}{ IEM PU 2} & $\begin{array}{l}\text { Automóvel da } \\
\text { Família - Ida }\end{array}$ & $\mathrm{COMP}_{\text {Auto ida }}=-7,42+0,83$ MEDAFDIT $-0,79$ GÊNERO + 0,00014 RENDA +1,07 CPAF & 0,42 & 7.22 & 2B \\
\hline & $\begin{array}{l}\text { Automóvel da } \\
\text { Família - Volta }\end{array}$ & $\mathrm{COMP}_{\text {Auto volta }}=-4,7+0,36 \mathrm{MEDAFDIT}-0,68 \mathrm{GÊNERO} \mathrm{+} \mathrm{0,71} \mathrm{CPAF}$ & 0,36 & 7.22 & 2B \\
\hline & Ônibus - Ida & $\mathrm{COMP}_{\text {Onibus ida }}=-3,15+0,52 \mathrm{MEDONDIT}-0,000099$ RENDA + 0,000033 DENSIDADE + 0,50 CPON & 0,17 & 7.22 & 2B \\
\hline & Ônibus - Volta & $\begin{array}{l}\text { COMP Ônibus volta }=-7,31+0,69 \text { MEDONDIT + 0,59 GÊNERO + 0,27 IDADE - 0,000099 RENDA + } \\
0,000055 \text { DENSIDADE + 0,33 CPON }\end{array}$ & 0,25 & 7.22 & 2B \\
\hline \multirow{4}{*}{$\begin{array}{l}\text { IEMs } \\
\text { agregadas } \\
\text { - interação } \\
\text { pais/resp. } \\
\text { e alunos }\end{array}$} & $\begin{array}{l}\text { Automóvel da } \\
\text { Família - Ida }\end{array}$ & $\mathrm{COMP}_{\text {Auto ida }}=-13,8+3,58$ MEDAFDIT & 0,54 & 7.24 & Final \\
\hline & $\begin{array}{l}\text { Automóvel da } \\
\text { Família - Volta }\end{array}$ & $\mathrm{COMP}_{\text {Auto volta }}=-3,55+0,871 \mathrm{MEDPAFDCP}$ & 0,06 & 7.24 & Final \\
\hline & Ônibus - Ida & $\mathrm{COMP}_{\text {Onibus ida }}=-4,93+0,704$ MEDONDIT $+0,801$ MEDPONDCP & 0,18 & 7.24 & Final \\
\hline & Ônibus - Volta & $\mathrm{COMP}_{\text {Onibus volta }}=-2,47+0,872$ MEDONDIT & 0,14 & 7.24 & Final \\
\hline $\begin{array}{l}\text { OBS: quan } \\
\text { LEGENDA } \\
\text { MEDAFDIT } \\
\text { MEDONDI } \\
\text { HABAF - H } \\
\text { HABON - I } \\
\text { CPAF - Con } \\
\text { CPON - Co } \\
\text { DENSIDAD } \\
\text { GENNERO - } \\
\text { RENDA - R } \\
\text { MEDPAFD } \\
\text { MEDPOND }\end{array}$ & $\begin{array}{l}\text { o modelos diferen } \\
\text { DAS VARIÁVE } \\
\text { - Média dos itens } \\
\text { - Média dos itens } \\
\text { bito no uso do mo } \\
\text { ábito no uso do mo } \\
\text { portamento passad } \\
\text { aportamento passa } \\
\text { - Densidade do } \\
\text { Binária, sendo "1" } \\
\text { nda média familia } \\
\text { P - Média dos iten } \\
\text { P - Média dos iter }\end{array}$ & $\begin{array}{l}\text { resentaram o mesmo Pseudo-R² foi selecionado o modelo com menor número de variáveis (parcimônia). } \\
\text { dida direta de intenção para o uso do modo Automóvel da Família, amostra alunos; } \\
\text { edida direta de intenção para o uso do modo Ônibus, amostra alunos; } \\
\text { itomóvel da Família; } \\
\text { hibus; } \\
\text { so do modo Automóvel da Família; } \\
\text { uso do modo Ônibus; } \\
\text { ensitário da localidade de residência; } \\
\text { eminino; } \\
\text { etor censitário da localidade de residência; } \\
\text { hedida direta de controle percebido para o uso do modo Automóvel da Família, amostra pais/responsáveis; } \\
\text { nedida direta de controle percebido para o uso do modo Ônibus, amostra pais/responsáveis. }\end{array}$ & & & \\
\hline
\end{tabular}




\subsection{RECOMENDAÇÕES PARA TRABALHOS FUTUROS}

Primeiramente recomenda-se que seja realizada a modelagem do comportamento pelo modelo ICLV, com verificação prática dos ganhos do uso deste tipo de modelagem, que justifique o uso da técnica mais requintada. Além disso, futuros trabalhos visando modelar a intenção da escolha modal devem testar o uso de Equações Estruturais desde que as amostras permitam a adoção dessa técnica de modelagem com a devida consideração da distribuição de probabilidade das variáveis envolvidas.

O procedimento proposto, ao ser aplicado em escolas específicas de Brasília, não teve como propósito a identificação de atributos intervenientes na escola modal dos estudantes das IEMs para a cidade, em sua totalidade. Isto é, não visaram qualquer tipo de generalização. Seu foco foi o de explicar a escolha modal em cada uma das escolas estudadas. No entanto, sua aplicação à uma amostra de escolas da cidade, selecionadas aleatoriamente, pode permitir a realização de inferências sobre a escolha modal em IEMs para toda a cidade.

O contexto de aplicação da pesquisa, a cidade de Brasília, tem suas especificidades urbanísticas, incomuns à maior parte dos municípios brasileiros, quiçá em outros países. Avaliar o quanto suas especificidades ambientais e urbanísticas influenciaram (ou não) os resultados obtidos poderia indicar outras recomendações metodológicas para a aplicação do procedimento desenvolvido em outros contextos.

Quando realizadas as modelagens sobre a influência das crenas salientes sobre cada construto, apenas os resultados de uma IEM foram modelados, pela necessidade de intensivo processamento dos dados. Os resultados obtidos não confirmaram totalmente a teoria. Tais achados podem ser específicos para a comunidade escolar estudada, ou indicar outras dimensões do fenômeno estudado. Propõem-se que a análise seja estendida para a IEM PU 2, ou outras IEMs a serem pesquisadas, para a verificação se os resultados obtidos na IEM PU 1 sobre a relação entre as crenças e os construtos da TCP são confirmados.

As contradições teóricas observadas pelas análises dos dados empíricos precisam ser melhor investigadas. Pelas amostras disponíveis, os resultados das análises estatísticas 
apontaram tais contradições obtidas não são conclusivos. Salienta-se a necessidade de confirmação dos achados semânticos das análises fatoriais das crenças salientes e da análise da interação da opinião dos alunos e seus respectivos pais/responsáveis.

No presente estudo, apenas os modos Automóvel da Família e Ônibus foram incluídos nas análises quantitativas preditivas (modelagens). Porém, com apresentado no Capítulo 6, muitas relações descritivas entre as variáveis pesquisadas e os demais modos de transporte nas viagens às IEMs foram observadas. Sugere-se a identificação de técnicas analíticas compatíveis com as amostras obtidas, de forma a conduzir análises mais abrangentes (modelagens) também para estes modos.

Outro desdobramento possível da pesquisa é a realização de experimentos em cada IEM, avaliando se as estratégias sugeridas pelos atributos identificados como intervenientes na escolha modal de fato produzem uma repartição modal diferente. É de fundamental interesse aquelas mudanças que possam produzir uma repartição modal mais sustentável, com menor uso do automóvel. Esses experimentos pretendem avaliar, também, se as sugestões de Gerenciamento da Mobilidade - GM elencadas a partir dos resultados obtidos têm aceitabilidade por parte da comunidade escolar envolvida. Experimentos dessa natureza foram relatados com sucesso em estudos revisados, porém não puderam ser incorporados no escopo de tempo da presente pesquisa. 


\section{REFERÊNCIAS BIBLIOGRÁFICAS}

AIKEN, L.S.; WEST, S.G. (1991) Multiple regression: testing and interpreting interactions. Newbury Park, London, New deli: Sage publications.

AJZEN, I. (1991) The theory of planned behavior. Organizational Behavior and Human Process $50 \mathrm{p}$. $179-211$

AJZEN, I. (2000) Construction of a standard questionnaire for the theory of planned behavior. Disponível em: http://people.umass.edu/aizen/pdf/tpb.measurement.pdf. Consultado em 23/06/2015.

ALEMU, D; TSUTSUMI, J. G. (2011) Examining modal choice disparities in high school students. In. Transport. V.164. TR2. P. 77-85.

AMARAL, G.J.A.; CORDEIRO, G.M. (2003) Modelo de alocação de investimentos entre instituições federais de ensino superior: uma aplicação dos modelos lineares generalizados. In. Revista de Matemática e Estatística. São Paulo. V.21. n2. P55-69.

AMIRARALAVIIFAR, M. K.; ANUAR, M.K. (2012) Structural equation modeling vs multiple regression: the first and second generation of multivariate techniques. In. IRACST-Engineering Science and Technology: an international Journal (ESTIJ). V.2.N.2.

BABBIE, E. (2013) The practice of social research. 13ed. Wadsworth, Cengage learning. International Edition.

BADRI, M. A. (2013) School travel modes: factors influencing parental choice in Abu Dhabi. In. International Journal of Education, Economics and Development. V. 4. N. 3. P. 203-208.

BAHAMONDE-BIRKE, F; ORTÚZAR, J.D. (2014) Is sequential estimation a suitable second best estimation of hybrid choice models? In. Transportation Research Record. V. 2429. P 51-58.

BAMBERG, S., AJZEN, I., SCHMIDT, P. (2003). Choice of travel mode in the theory of planned behavior: The roles of past behavior, habit, and reasoned action.In. Basic and Applied Social Psychology, $25,175-188$.

BAMBERG, S.; SCHIMIDT, P. (2003) Predicting student's car use for university routes with the models of Ajzen, Schwartz and Triandis. In. Environment and behavior. Disponível em: http://eab.sagepub.com/. Consultado em 23/06/2012.

BARDIN, L. (2009) Análise de Conteúdo. Lisboa, Portugal: Edições 70, LDA.

BEJLERI, I.; STEINER, R.L; FISCHMAN, A. SCHUMUCKER, J.M. (2011) Using GIS to analyze the roles of barriers and facilitators to walking in children's travel to school. Paper presented in TRB annual Meeting 2010.

BEN-AKIVA, M.; BIERLAIRE, M.; WALKER, J. (2003) Discrete Choice Analysis. Draft.

BEN-AKIVA, M.; MCFADDEN, D.; GÄRLING T.; GOPINATH, D.; WALKER, J.; BOLDUC, D.; BÖRSCH-SUPAN, A.; DELCHIÈ, P.; LARICHEV, O.; MORIKAWA, T.; POLYDOROPOULOU, A.; RAD, V. (1999) Extended framework for modeling choice behavior. In. Marketing letters. v.10. p.187203.

BEN-AKIVA, M.; WALKER, J.; BERNARDINO, A. T.; GOPINATH, D.A.; MORIKAWA, T.; POLYDOROPOULOU, A. (2002) Integration Choice and Latent Variables Models. In MAHMASSONI, H. S. (ed). Perpetual motion: travel behavior research opportunities and application challenges. Amsterdam: Elsevier. P. 431-470.

BERTAZZO, A. B. S.; JACQUES, M. A. P. (2010) Estudo da geração de viagens em instituições de ensino médio. In Transportes (Rio de Janeiro), v. 18, p. $42-53$. 
BERTAZZO, A. B. S.; JACQUES, M. A. P. (2012) O gerenciamento da mobilidade e a escolha modal em escolas em Brasília. In: Anais do PLURIS 2012: V Congresso Luso-Brasileiro para o Planejamento Urbano, Regional, Integrado e Sustentável, Brasília: PLURIS, 2012.

BHAT, C.R. (2000) Flexible model structures for discrete choice analysis. In. HENSHER, D.A.; BUTTON, K.J. Handbook of transportation modeling. Oxford: Elsevier.

BHAT, C.R.; DUBEY, S.K. (2014) A new estimation approach to integrate latent psychological constructs in choice modelling. In Transportation Research Part B.v.67. p. 68-85.

BIERLAIRE, M. (2003) BIOGEME: a free package for the estimation of discrete choice models. In. Proceedings of the $3^{\text {rd }}$ swiss transportation research conference. Ascoria, Switerzeland.

BIERLAIRE, M. (2008) Estimation of discrete choice models with BIOGEME 1.8. Disponível em biogem.epfl.ch. Consultado em 27/11/2015.

BISQUERA, R; SARRIERA, J. C.; MARTÍNEZ, F. (2004) Introdução à estatística: enfoque informático com o pacote estatístico SPSS. Porto Alegre: Artmed.

BRASIL (2012) Lei n. 12587/12. Política Nacional de Mobilidade Urbana. Disponível em: http://www.planalto.gov.br/ccivil_03/_ato2011-2014/2012/lei/112587.htm. Consultado em 27/11/2015.

BRASIL (2013) Data escola. Censo escolar 2013. Disponível em: http://www.dataescolabrasil.inep.gov.br/dataEscolaBrasil/. Consultado em: 27/11/2015.

BYRNE, B.M. (2010) Structural equation modeling with AMOS: basic concepts, applications and programming. 2ed. New York: Taylor and Francis Group.

CAIRNS, S. (2000) Coming of age - the travel of young adults. In Town and Country Planning. London.

CAIRNS, S.; SLOMAN, L.; NEWSON, C.; KIRKBRIDE, A.; GOODWIN, P. (2004) Smarter Choices: changing the way we travel. London: Department for Transport. Disponível em: http://www.acttravelwise.org/uploads/docs/DfTReport-SmarterChoices-

ChangingtheWayWeTravelChapter1Introduction.pdf. Consultado em 10/12/2011

CALLIPER. (2002) Calliper Corporation. TransCAD: transportation GIS software. V. 4.5.

CAMPBELL, E. K.; WANG, Q. (2008) Driven to school: factors affecting mode choice and the amount of parent driven trips. Disponível em: http://www.uvm.edu/ transctr/pdf/DriventoSchoolFactors.pdf. Consultado em 21/07/2015.

CAMPBELL, H.L.; BARRY, C.L. J, J. N.; FINNEY, S.J. (2008) Configural, metric and Scalar Invariance of the Modified Achievement Goal Questionnaire Across African American and White Students. In. Educational and Psychological Measurement. V.68. N.6.

CARVER, A.; TIMPERIO, A.; CRAWFORD, D. (2013) Parental Chauffers: what drives their transport choice? In. Journal of Transport Geography. 26(2013). P. 72-77.

CHACHA, P.; BWIRE, H. (2013) Analysis of factors affecting schoolchildren travel mode choice in Dar Es Salaan. In $32^{\text {nd }}$ Southern African Transport Conference 2013. Pretoria.

CHAN, J.S. (2015) Quasi-likelihood. Disponível em: www.maths.usyd.edu.au/u/jchan/GLM/Quasilikelihood.pdf. Consultado em: 03/02/2016.

CHEN, C.; CHAO, W. (2011) Habitual or reasoned? Using the theory of planned behavior, technology acceptance model, and habit to examine switching intentions toward public. In. Transportation Research. Part F. v.14. p. 128-137. 
CIALDINI, R.B.; TROST, M.R. (1998) Social influence: social norms, conformity and compliance. In. GILBERT, D. T.; FISKE, S.T.; LINDSEY, G. (Eds) The Handbook of Social Psychology, 4ed, New York, McGraw-Hill.

CODEPLAN. COMPANHIA DE PLANEJAMENTO DO DISTRITO FEDERAL (2013) Pesquisa metropolitana por amostra de domicílios - PMAD 2013. Disponível em: www.codeplan.df.gov.br. Consultado em 25/11/2015.

CODEPLAN. COMPANHIA DE PLANEJAMENTO DO DISTRITO FEDERAL (2014) Pesquisa distrital por amostra de domicílios - PDAD/DF 2013. Disponível em: www.codeplan.df.gov.br. Consultado em 25/11/2015.

COHEN, J. (1992) A power primer. In Psychological Bulletin. Vol. 1/ 2. N.1.p.155-159.

COLliER, A.; COTTERILL, A.; EVERETT, T.; MUCKLE, R., PIKE, T.; VANSTONE, A. (2010) Understanding and influencing behaviors: a review of social research, economics and policy making in Defra. [Draft for discussion].

COSTA, J. O. (2013) Desenvolvimento dum modelo de previsão de acidentes. Tese (doutoramento). Universidade do Minho. Escola de Engenharia. Braga, Portugal.

CRISTO, F. (2013) O hábito de usar automóvel tem relação como transporte coletivo ruim? Tese (doutorado). Universidade de Brasília. Instituto de Psicologia. Programa de Pós-graduação em Psicologia Social, do trabalho e das Organizações. Brasília.

CUNTO, F. J. C.; NODARI, C. T. (2011) Aspectos conceituais sobre o desenvolvimento de modelos de previsão de acidentes de trânsito. In. Anais do XXV ANPET, Congresso de Pesquisa e Ensino em Transportes. Belo Horizonte.

CURTIS, C.; PERKINS, T. (2006) Travel Behavior: a review of recent literature. In Impacts of transit led development in a new corridor, working paper n.3.

CUSTODIO, T.N.; BARBIN, D. (2005) Comparação de modelos mistos visando à estimação do coeficiente de herdabilidade para dados de proporções. In Revista de Matemática e Estatística. São Pualo. V.23. n.2. p 23-31

DANAF, M; ABOU-ZEID, M.; KAYSI, I. A. (2014) Modeling travel choices of students at a private, urban university: insights and policy implications. In. Transport Policy 2014. V. 2:3. P. 142- 152.

DELMELLE, E.M.; DELMELLE, E.C. (2012) Exploring spatio-temporal commuting patterns in a university environment. In Transport Policy. V21.N1. p. 1-9.

DENATRAN. Departamento Nacional de Trânsito (2000). Manual brasileiro de sinalização de trânsito: sinalização de áreas escolares. Brasília: DENATRAN / FGV.

DIAS, C.A. (2000). Grupo focal: técnica de coleta de dados em pesquisas qualitativas. In. Informação $e$ sociedade: estudos. V.10 N. 2. P. 141-158.

DISTEFANO, C; ZHU, M.; MINDRILÃ, D. (2009). Understanding and using factor scores: considerations for the applied researcher. In. Practical Assessment, Research and Evaluation. N 14 (20).

DISTRITO FEDERAL. SECRETARIA DE ESTADO DE OBRAS (2008). Plano Diretor de Drenagem Urbana do Distrito Federal. Brasília: Concremat Engenharia.

DNIT. Departamento Nacional de Infraestrutura de transportes. (2006). Manual de estudos de tráfego. Rio de Janeiro. Disponível em: http://wwwl.dnit.gov.br/arChivos_internet/ipr/ipr_new/manuais/manual_estudos_trafego.pdf. Consultado em 16/07/2015 
EAGLY, A.H.; CHAIKEN, S. (1998) Attitude Structure and Function. In. GILBERT, D. T.; FISKE, S. T.; LINDSEY, G. (Eds) The Handbook of Social Psychology, 4ed, New York, McGraw-Hill.

EGMOND, C, BRUEL, S. (2007) Nothing is as practical as a good theory: analysis of theories and a tool for developing interventions to influence energy-related behavior. [Draft]. Atenas.

ELLIOTT, M.A.; ARMITAGE, C.J.; BAUGHAN, C.J. (2003) Driver's compliance with speed limits: an application of the theory of planned behavior. In Journal of Applied Psychology. Vol. 88. N5. Pp 964972.

ELLIOTT, M.A.; ARMITAGE, C.J.; BAUGHAN, C.J. (2005) Exploring the beliefs underpinning driver's intentions to comply with speed limits. In. Transportation Research Part F. V 8. P. 459-479.

EPA. UNITED STATES ENVIRONMENTAL PROTECTION AGENCY. (2008) Youth travel to school: community design relationships with mode choice, vehicle emissions and healthy body weight. Lawrence Frank Company Inc.

ERIKSSON, L.; GARVILL, J.; NORDLUND, A. M. (2008) Interrupting habitual car use: the importance of car habit strength and moral motivation for personal car use reduction. In. Transportation Research. V. 11. P.10-23.

ERMAGUM, A.; SAMIMI, A.; RASHI, T. H. (2013) Tolerable walking distance to school: application of a hazard-based and a random utility method. In. International Choice Modelling Conference 2013.

EWING, R.; CERVERO, R. (2001) Travel and built environment: a synthesis. In. Transportation Research Record. V.1780. p. 87-114.

EWING, R.; SCHROEER, W.; GREENE, W. (2004). School location and student travel: analysis of factors affecting mode choice. In: Transport Research Record: Journal of Transportation Research Board. N. 1895. TRB. National Research Council. Washington, D.C.

FARIA, E.O.; BRAGA, M.G.C. (2003) O comportamento de motoristas e pedestres na percepção de alunos de escolas públicas e particulares do Rio de Janeiro. In Anais do XVII Congresso de Pesquisa e Ensino em Transportes. V.1. Rio de Janeiro.

FAUL, F., ERDFELDER, E., LANG, A.-G.; BUCHNER, A. (2007) G*Power 3: A flexible statistical power analysis program for the social, behavioral, and biomedical sciences. Behavior Research Methods, 39, 175-191.

FAULKNER, G.; STONE, M.; BULIUNG, R.; WONG, B.; MITRA, R. (2013) School travel and children's physical activity: a cross-sectional study examining the influence of distance. In. BMC Public Health 2013. V.13: 1166. P 1-9.

FISHBEIN, M.; AJZEN, I. (1975) Belief, attitude, intention, and behavior: An introduction to theory and research. Reading, MA: Addison-Wesley.

FOX, J.; BHANU, P.; VAN VUREN, T.; ADEEB, M.; MACDONALD, M. (2012) Adding escort travel as a separate purpose - example for the west midlands region of the UK. Disponível em: http://abstracts.aetransport.org/paper/index/id/4066/confid/1. Consultado em 22/07/2015.

FUJII, S. (2003) Prospect for mobility management in Japan. Disponível em: http://www.internationaltransportforum.org/IntOrg/ecmt/urban/Tokyo05/Fujii.pdf. Consultado em $10 / 12 / 2011$.

FUJII, S.; KITAMURA, R. (2003) What does a one-month free bus ticket do to habitual drivers? An experimental analysis of habit and attitude change. In. Transportation. 30. P 81-95.

FUJII, S.; TANIGUCHI, A. (2005a) Reducing Family car-use by providing travel advice by providing travel advice or requesting behavioral plans: an experimental analysis of travel feedback programs. In Transportation Research. Part. D. 10. 385-393. 
FUJII, S.; TANIGUCHI, A. (2005b) Travel feedback programs: communicative mobility management measures for changing travel behavior. In. Proceedings of the Eastern Asia Society for Transportation Studies, Vol. 5, pp 2320-2329, 2005.

GÄRLING, T.; AXHAUSEN, K.W. (2003) Introduction: habitual travel choice. In. Transportation. V.30. p.1-11.

GÄRLING, T.; FUJII, S. (2002) Structural equation modeling of determinants of planning. In. Scandinavian Journal of Psychology. V. 43. P. 1-8.

GOLDNER, L. G.; BEPPLER, F.; PRIM, J. (2012) Análise da mobilidade em um campus universitário. In. Anais do Congresso PLURIS. Brasília: PLURIS.

GOLLWITZER, P.M. (1993) Goal achievement: the role of intentions. In. European review of social Psychology. V. 4. P. 141-185.

GOLOB, T.; BRADLEY, M.A.; POLAK, J.N. (1995) Travel and activity participation as influenced by car availability and use. In. No UCTC. N. 286. Berkeley: The University of California Transportation Center.

GUJARATI, D.N. (2004) Basic Econometrics.4ed. New York: McGraw-Hill.

GÜNTHER, H. (2003) Como Elaborar um Questionário. (Série: Planejamento de Pesquisa nas Ciências Sociais, N.01). Brasília, DF: UnB, Laboratório de Psicologia Ambiental.

HAIR, J.F.; BLACK, W.C.; BABIN, B. J.; ANDERSON, R. E.; TATHAN, R. L. (2009) Análise multivariada de dados. 6ed. Porto Alegre: Bookman.

HAQUE, B.; CHAYAN, M. H.; RANA, M. (2013) SP modeling of mode choice for school trips in Sylhet City. In. Asian Journal of Engineering, sciences and technology. V. 3:2.

HARDIN, J.W.; HILBE, J.M. (2001) Generalized Linear Models and Extensions. 2ed. Stata Press: College Statio, Texas.

HAUER, E. (2004) Statistical Road Safety Modeling. In. Transportation Research Record: Journal of the Transportation Research Board. N.1897. TRB. National Research Council, Washington, DC. P8187.

HENDRICKX, J. (2002) Review of regression models for categorical dependent variables using Stata by Long and Freese. In The Stata journal. V. 2. N.1 p.103-105.

HOLANDA, D.C. (2006). Metodologia para avaliação da acessibilidade na localização das escolas públicas do ensino fundamental. Estudo de caso: Fortaleza. Dissertação (Mestrado). Programa de Mestrado em Engenharia de Transportes. Universidade Federal do Ceará. Fortaleza.

HUNECK, M.; BLOBAUM, A.; MATTIES, E.; HOGER, R. (2001) Responsibility and environment: ecological norm orientation and external factors in the domain of travel mode choice behavior. In. environment and Behavior.v.33. p. 830-852.

IBGE. Instituto Brasileiro de Geografia e Estatística. (2010). Censo 2010. Disponível em: http://censo2010.ibge.gov.br/resultados. Consultado em 11/02/2015.

IBM (2011) IBM SPSS AMOS V20.

IBM (2011) IBM SPSS STATISTICS V21.

ITE. INSTITUTE OF TRANSPORTATION ENGINEERS (2010) Trip Generation. $9^{\text {th }}$ ed. Washington, DC. 
KARMARGIANNI, M.; DUBEY, S.; POLYDOROPOULOU, A.; BHAT, C. (2015) Investigating the subjective and objective factors influencing teenagers' school travel mode choice - an integrated choice and latent variable model. Disponível em: http://www.caee.utexas.edu/prof/bhat/full_papers.htm. Consultado em 19/06/2015.

KARMARGIANNI, M.; POLYDOROPOULOU, A; GOULIAS, K. G. (2012) Teenagers travel patterns for school and after-school activities. Procedia social and behavioral sciences. 48. P 3635-3650.

KLINE, R.B. (2011) Principles and practice of structural equation modeling. 3ed. New York: Guilford Press.

KLÖCKNER, C.A.; FRIEDSCHSMEIER, T. (2011) A multi-level approach to travel mode choice: how person characteristics and situation specific aspects determine car use in a student sample. In. Transportation Research Part F. V. 14. P. 261-277.

LANG, D.; COLLINS, D.; KEARNS, R. (2011) Understanding modal choice for the trip to school. Journal or Transport Geography 19. P. 509-514.

LEE-GOSSELIN, M.E.H.; PAS, E.I. (1997) The implications of emerging contexts for travel behavior research, In. STOPHER, P.R.; LEE-GOSSELIN, M.E.H. eds. Understanding Travel Behavior in an Era of Change. Elsevier: Amsterdam.

LESLIE, E.; KREMER, P.; TOUMBOUROU, J.W.; WILLIAMS, J. W. (2010) Gender differences in personal, social and environmental influences on active travel to and from school for Australian adolescents. Journal of Science and Medicine in Sport. 13. P597-601.

LITMAN, T. (2009) Are Vehicle Travel Reduction Targets Justified? Evaluating Mobility Management Policy Objectives Such As Targets To Reduce VMT And Increase Use Of Alternative Modes. Disponível em: www.vtpi.org.br. Consultado em 24/11/2011.

LITMAN, T. (2010) Commute trip reduction. Disponível em http://www.vtpi.org/tdmtdm9.htm. Consultado em 03/08/2012.

LONG, J.S. (1997) Regression models for categorical and limited dependent variables. Thousand oaks: Sage.

MACCALlUM, R. C.; AUSTIN, J. T. (2000) Applications of structural equation modeling in psychological research. In. Annual Reviews of Psychology. V.51. p. 201-226.

MARINO, C. A. (2014) Entendiendo las preferencias y actitudes al escoger el medio de transporte en estudiantes universitarios. In. Saber y Hacer. Revista de Ingeniería de la USIL. V1. N. 1. P 11-25.

MAROCO, J.; GARCIA-MARQUES, T. (2006) Qual a fiabilidade do alfa de Cronbach? Questões antigas e soluções modernas? In. Laboratório de Psicologia. 4(1). p.65-90.

MARSHALL, J.; WILSON, R.D.; MEYER, K.L.; RAJANGAM, S.K.; MCDONALD, N.C.; WILSON, E.J. (2009) Vehicle emissions during children's school commuting: impacts of education policy. In. Environment Science and Technology. 2009.

MCDONALD, N.C. (2007) Active transportation to school: trends among schoolchildren, 1969-2001. In. American Journal of Preventive Medicine. V. 32. p. 509-516.

MCDONALD, N.C.; AALBORG, A.E. (2009) Why parents drive children to school: implications for safe routes to school programs. In. Journal of The American Planning Association. V.20.

MCMILLAN, T. E. (2005) Urban form and child's trip to school: the current literature and framework for future research. In. Journal of Planning Literature. 2005. p.19-40.

MEDEIROS, F. S.; NODARI, C.T. (2011) Identificação e análise de atributos para compor indicadores de desempenho para o transporte rodoviário interestadual de passageiros. In. Revista ANTT. V.3. N.1. 
MIRANDA, H. F.; MANCINI, M. T.; AZEVEDO FILHO, M. A. N. A.; ALVES, V. F. B.; RODRIGUES DA SILVA, A. N. (2009) Barreiras para a implantação de Planos de Mobilidade. In: Anais do XXIII Congresso de Pesquisa e Ensino em Transportes, 2009, Vitória: Associação Nacional de Pesquisa e Ensino em Transportes.

MICROSOFT (2013) Microsoft Office Professional Plus. Excel 2013.

MIRANDA, R. F.; MELlO, L. M. S.; BERTAZZO, A. B. S.; SilvA, E. F. F.; JACQUES, M. A. P. (2014) Estudo das operações de embarque e desembarque de estudantes de Instituições de Ensino Médio. In Transportes. V.22. p. 65-75.

MONTGOMERY, H. (1994) Towards a perspective theory of decision-making and judgment. In. Acta Psychologica. V. 87. P. 155-178.

MULLER, S.; TSCHARKTSCHIEW, S. HAASE, K. (2008) Travel to school mode choice modelling and patterns of school choice in urban areas. In Journal of Transport Geography. V.16. p. 342-357.

MURTAGH, S.; ROWE, D.A.; ELLIOTT, M. A.; MCMINN, D.; NELSON, N.M. (2012) Predicting active school travel: the role of planned behavior and habit strength. International Journal of Behavioral Nutrition and Physical Activity. N. 9. P 65.

MUTHÉN, B.O. (1984) A general structural equation model with dichotomous, ordered categorical and continuous latent variable. In. Psychometrika. V.49. n.1 p. 115-132.

NACHTINGAL, C.; KROEHNE, U.; FUNKE, F.; STEYER, R. (2003) (Why) Should we use SEM? Pros and cons of Structural Equation Modeling. In. Methods of Psychological Research on line. V.8.N.2 p.122.

NETO, I.L. (2014) Determinantes psicossociais do uso do transporte público: um estudo comparativo entre o Distrito Federal (Brasil) e a região de Hampton Roads - VA (Estados Unidos). (Doutorado). Universidade de Brasília. Instituto de Psicologia. Programa de Pós-graduação em Psicologia Social, do trabalho e das Organizações. Brasília.

NUNES, B.F.; COSTA, A. (2007) Distrito Federal e Brasília: dinâmica urbana, violência e heterogeneidade social. In. Cadernos Metrópole. N17. p 35-77.

ORTÚZAR, J.D.; WILLUMSEN, L.G. (2011) Modeling Transport. 4ed. Ed. John Wiley \& Sons: Londres, 2011.

PASQUALLI, L. (2012) Análise Fatorial para pesquisadores. Brasília: LabPAM.

PAULA, G.A. (2013) Modelos de Regressão com apoio computacional. São Paulo: Universidade de São Paulo.

PETTY, R.E.; WEGENER, D.T. (1998) Attitude change: multiple roles for persuasion variables. In. GILBERT, D. T.; FISKE, S.T.; LINDSEY, G. (Eds) The Handbook of Social Psychology, 4ed, New York, McGraw-Hill.

PILATI, R.; LAROS, J.A. (2007) Modelos de equações estruturais em psicologia: conceitos e aplicações. In. Psicologia: teoria e prática. V.23. n.2 p. 205-216.

PROVIDELO, J.K.; SANCHES, S.P.(2010) Percepções de indivíduos acerca do uso da bicicleta como modo de transporte. In. Transportes, v.18-2. P 53-61.

RHOULAC, T.D. (2005) Bus or car? The classic choice in school transportation. Transportation Research Board. N. 1922. P 98-104. 
ROCHA, D.C.T.; FREITAS, I.M.D.P. (2007) Potencialidades da aplicação da técnica de grupo focal nos estudos sobre gerenciamento da mobilidade em polos geradores de tráfego. In. Anais da XXI ANPETCongresso Nacional de Ensino e Pesquisa em transportes. Rio de Janeiro: ANPET, 2007.

ROSA, F. D. (2010) Fatores que influenciam na opção por modo de transporte de crianças para a escola: estudo de caso de São Carlos/SP. Dissertação (mestrado). Universidade Federal de São Carlos. São Carlos.

RYE. T; WELSCH, J; PLEVNIK, A; TOMMASI, R. (2011) First steps towards cross-national transfer in integrating mobility management and land use planning in the EU and Switzerland. Transport Policy (Oxford), 18. p. 33-543.

SAM. E. F.; ADU-BOAHEN, K.; KISSAH-KORSAH, K. (2014) Assessing the factors that influence public transport mode preference and patronage: perspectives of students of University of Cape Coast (UCC). International Journal of Development and Sustainability. V3. N2. P 323-336.

SANCHES, S. P.; ROSA, F. D.; FERREIRA, M. A. G. (2010) Fatores que influenciam o modo de transporte de crianças para a escola. In Anais do PLURIS 2010. Lisboa.

SCHLOSSBERG, M.; GREENE, J.; PHILLIPS, P.P.; JOHNSON, B.; PARKER, B. (2006) School trips. In Journal of American Planning Association. V. 72. N. 3. P 337-346.

SCHLOSSBERG, M.; PHILLIPS, P.P.; JOHNSON, B.; PARKER, B. (2005) How do they get there? A spatial analysis of a sprawl school in Oregon. In Planning, Practice and Research. V.20. n. 2. P 147-162.

SHAPIRO, S.S.; WILK, M.B. (1965) An analysis of variance test for normality (complete samples). In Biometrika. V.52. N 314. p. 591-611.

SHIMIZU, T. (2010) Decisão nas organizações. 3ed. São Paulo: Atlas.

SHOKOOHI, R; HANIF, N.R.; DALI, M. (2012) Influence of the socio-Economic factors on children's school travel. In. ASEAN Conference on Environment Behavior Studies. Bankok: July, 2012.

SIDHARTHAN, R.; BHAT, C. R.; PENDYALA, R. M.; GOULIAS, K. G. (2010) A model of children's school travel mode choice behavior accounting for spatial and social interactions effects. Disponível em: http://www.caee.utexas.edu/prof/bhat/ABSTRACTS/SchoolModeChoice_15March2011.pdf.

Consultado em 22/07/2015.

SIEGEL, S.; CASTELLAN, N.J. (2006) Estatística não paramétrica para ciências do comportamento. 2ed. Porto Alegre: Artmed.

SILVA, E.F.F.; MELO, W. C.; BERTAZZO, A. B. S.; ARRUDA, F. S.; TAKANO, M. S. M. (2014) Fatores que influenciam a escolha do modo automóvel em viagens a instituições de ensino superior em Brasília. In. Anais Pluris 2014. Lisboa.

SILVA, J.R. S.; ASSIS, S.M.B. (2010) Grupo focal e análise de conteúdo como estratégia metodológica qualitativa em pesquisas nos distúrbios de desenvolvimento. In Cadernos de pós graduação em distúrbios do desenvolvimento. V.10. n1. P 146-152.

SRIROONGVIKRAI, K.; CHOOCHARUKUL, K.; FUJII, S. (2010) How effective are transit price incentives for university students with available car and urban rail options? An experimental study in Bangkok. In Journal of Society and Transportation and Traffic Studies. (JSTS). V.1. N.3.

STEVENS, J. (2010) A sustainable journey to school: global issues, local places, children's lives. Durham theses, Durham University.

TABACHNICK, B.G.; FIDEL, L.S. (2007) Using multivariate statistcs.5ed. Boston: Pearson.

TEMME, D.; PAULSSEN, M.; DANNEWALD, T. (2008) Incorporating latent variables into discrete choice models: a simultaneous estimation approach using SEM. In Business Research. V1. Issue 2. p. 220-237. 
THOMPSON, B. (2005) Exploratory and confirmatory factor analysis: understanding concepts and applications. 2ed. Washington: American Psychological Association, 2005.

THORGERSEN, J. (2007) Social marketing of alternative transportation modes. In GÄRLING, T.; STEAD, L. (Ed.) Threats from car traffic to the Quality of Urban Life: problems, causes and solutions. Elsevier: Amsterdam, 2007.

THULL, J.; LAUSTERER, H. (2003) Mobility Management for high school students in Christchurch, New Zealand. In Anais do $26^{\text {th }}$ Australian Transport Research Forum. Wellington.

TOOLE, S (2011) Transportation choices to and from primary schools in the Sutherlands Shire. Bachelor Science School of Earth and Environmental Sciences, University of Wollogong.

TORRES, C.V. (2011) Breve revisão de psicologia social: revisão de conceitos básicos da psicologia social. [Apostila da disciplina Introdução à Psicologia Social]. UnB: Brasília, 2011.

TORRES, C.V. (2012) Notas das aulas de Psicologia Social Avançada. UnB: Brasília, 2012.

VAN-RISTELL, J.A. (2011) Investigating the impacts of policy on school travel. Doctoral thesis. Loughborough University. Disponível em: http://homepages.lboro.ac.uk/ cvmpe/img/Jessica_van_Ristell_thesis_final_version.pdf. Consultado em: $30 / 07 / 2014$.

VERPLANKEN, B.; AARTS, H.; VAN KNIPPENBERG, A. (1994) Attitude versus general habit: antecedents of travel mode choice. In. Journal of Applied Social Psychology. v. 24-4. p. 285-300.

WAISELFISZ, J.J. (2012) Mapa da violência 2012: Crianças e adolescentes do Brasil. Rio de Janeiro: CEBELA.

WEE, B. V. (2007) Environmental effects on urban traffic. In. GÄRLING, T.; STEAD, L. (Eds.) Threats from car traffic to the Quality of Urban Life: problems, causes and solutions. Elsevier: Amsterdam, 2007.

WHALEN, K. E.; PÁEZ, A.; CARRASCO, J.A. (2013) Mode choice of university students commuting to school and the role of active travel. In. Journal of Transport Geography. 31(2013). p. 132-142

WILSON, E. J.; MARSHALL, J.; WILSON, R.; KRIZEK, K. J. (2010) By foot, bus or car: children's school travel and school choice policy. Environmental and Planning. A. V.42. p 2168-2185.

YARLAGADDA, A.K.; SRINIVANSAN, S. (2008) Modeling children's school travel mode and parental escort decisions. In. Transportation. V. 35. p.201-208.

YOON, S. Y.; DOUDNIKOFF, M.; GOULIAS, K. G. (2011) Spatial analysis of propensity to escort children to school in southern California. Transportation Research Record. N. 2230. p 132-142.

ZHOU, J. (2012). Sustainable commute in a car-dominant city: factors affecting mode choices among university students. In. Transportation Research. Part A 46 (2012) p.1013-1029.

ZHU, X. (2007) School environmental and green transportation. In ARCC Spring Research Conference. Eugene-Oregon.

ZWERTS, W.; WETS, G. (2006) Children's travel behavior: world of difference. Unpublished Conference paper, TRB's $85^{\text {th }}$ Annual Meeting, 2006. 
APÊNDICES 
APÊNDICE A - Tabela de revisão de estudos sobre a escolha modal em Instituições de Ensino 
APÊNDICE A: Tabela de revisão de estudos sobre a escolha modal em Instituições de ensino - Parte 1/6 (ver observações na parte 6/6)

\begin{tabular}{|c|c|c|c|c|c|c|c|c|}
\hline Ano & Autores & Local & $\begin{array}{l}\text { População } \\
\text { Alvo }\end{array}$ & $\begin{array}{c}\text { Fonte de } \\
\text { dados }\end{array}$ & $\mathbf{n}$ & $\begin{array}{c}\text { Modos } \\
\text { estudados }\end{array}$ & Análises & Variáveis estudadas \\
\hline 2003 & $\begin{array}{l}\text { Bamberg, S.; Ajzen,I; } \\
\text { Schmidt, P.; }\end{array}$ & Alemanha & Alunos IES & Quest. & 1316 & $\begin{array}{c}\text { Auto; a pé; } \\
\text { bicicleta }\end{array}$ & MEE & $\begin{array}{l}\text { TCP; Hábito e Norma (MAN); } \\
\text { comportamento passado }\end{array}$ \\
\hline 2003 & Bamberg,S., Schmidt,P. & Alemanha & Alunos IES & Quest. & 1000 & Auto e não auto & CFA & TCP, Hábito (TCI) Norma (MAN) \\
\hline 2003 & $\begin{array}{l}\text { Faria, E.O.; Braga, } \\
\text { M.G.C. }\end{array}$ & Brasil & Alunos de IEF & Quest. & 400 & $\begin{array}{l}\text { A pé; ônibus; } \\
\text { auto }\end{array}$ & $\begin{array}{l}\text { Análise do } \\
\text { discurso }\end{array}$ & $\begin{array}{l}\text { Tipo de escola; posse de automóvel; } \\
\text { gênero; renda; escolaridade e ocupação } \\
\text { responsável; supervisão das viagens; } \\
\text { percepção do comportamento de risco no } \\
\text { trânsito } \\
\end{array}$ \\
\hline 2003 & Thull, J.; Lausterer, H. & $\begin{array}{l}\text { Nova } \\
\text { Zelândia }\end{array}$ & Alunos IEM & Quest. & 1200 & $\begin{array}{l}\text { A pé, bicicleta; } \\
\text { Auto; ônibus; } \\
\text { moto; TE }\end{array}$ & Descritivas & $\begin{array}{l}\text { Diferença na ida e na volta; distância à } \\
\text { escola; gênero; tempo de viagem; modo } \\
\text { atual e modo preferido }\end{array}$ \\
\hline 2004 & $\begin{array}{l}\text { Cairns, S; Sloman, L.; } \\
\text { Newson, C.; Anable, J.; } \\
\text { Kirkbride,A.; } \\
\text { Goodwin,P }\end{array}$ & $\begin{array}{l}\text { Reino } \\
\text { Unido }\end{array}$ & 24 IEM e IEF & $\begin{array}{l}\text { Experimento; } \\
\text { Diário Viagem; } \\
\text { PlanoViagem. }\end{array}$ & $* *$ & A pé; auto; TE & Diversas & $\begin{array}{l}\text { Segurança viária; atividade física; } \\
\text { aprendizagem; cidadania; inclusão social }\end{array}$ \\
\hline 2005 & Fujii, S.; Taniguchi, A. & Japão & $\begin{array}{l}\text { Alunos e pais } \\
\text { IEF }\end{array}$ & $\begin{array}{l}\text { Experimento; } \\
\text { Diário Viagem }\end{array}$ & 292 & Auto & Descritivas & Tempo de viagem e emissões de $\mathrm{CO} 2$ \\
\hline 2005 & Rhoulac, T.D. & EUA & Pais IEF & Quest. & 800 & Auto; TE & Modelos & $\begin{array}{l}\text { Estudantes no domicílio; série; renda } \\
\text { domiciliar; percepção dos pais para a } \\
\text { segurança por modo; conveniência para } \\
\text { cada modo; modo na ida e na volta; }\end{array}$ \\
\hline 2005 & $\begin{array}{l}\text { Schlossberg, M.; } \\
\text { Phillips, P. P.; Johnson, } \\
\text { B.; Parker,B. }\end{array}$ & EUA & $\begin{array}{l}\text { Pais de alunos } \\
\text { de IEF }\end{array}$ & Quest. & 108 & $\begin{array}{l}\text { Auto; a pé; } \\
\text { carona; } \\
\text { bicicleta; TE }\end{array}$ & $\begin{array}{c}\text { Descritivas; } \\
\text { Análise espacial }\end{array}$ & $\begin{array}{l}\text { Tipo de vizinhança; utilização dos modos; } \\
\text { conforto; clima; distância }\end{array}$ \\
\hline 2006 & Holanda, D.C. & Brasil & Alunos de IEF & Quest. & 510 & $\begin{array}{l}\text { A pé; bicicleta; } \\
\text { ônibus; auto; } \\
\text { bicicleta; moto }\end{array}$ & Descritivas & $\begin{array}{l}\text { Gênero; idade; bairro de residência; } \\
\text { pessoa que conduz o aluno; segurança } \\
\text { viária; condições da via e da calçada; } \\
\text { tempo de viagem; distância }\end{array}$ \\
\hline 2006 & $\begin{array}{l}\text { Schlossberg, M.; } \\
\text { Greene, J.; Phillips, } \\
\text { P.P.; Johnson, B.; } \\
\text { Parlker, B. } \\
\end{array}$ & EUA & $\begin{array}{l}\text { Famílias de } \\
\text { alunos de IEF }\end{array}$ & Quest; & 292 & $\begin{array}{l}\text { A pé; bicicleta; } \\
\text { auto e ônibus }\end{array}$ & $\begin{array}{l}\text { Descritivas; } \\
\text { MNL; } \\
\text { Análise } \\
\text { espacial; }\end{array}$ & $\begin{array}{l}\text { Modo de ida na volta; gênero; série; raça; } \\
\text { autos na família; renda; distância; } \\
\text { qualidade das vias e calçadas; segurança e } \\
\text { gerenciamento viário; clima }\end{array}$ \\
\hline
\end{tabular}


APÊNDICE A: Tabela de revisão de estudos sobre a escolha modal em Instituições de ensino - Parte 2/6(ver observações na parte 6/6)

\begin{tabular}{|c|c|c|c|c|c|c|c|c|}
\hline Ano & Autores & Local & População Alvo & Fonte de dados & $\mathbf{n}$ & $\begin{array}{c}\text { Modos } \\
\text { estudados }\end{array}$ & Análises & Variáveis estudadas \\
\hline 2006 & $\begin{array}{l}\text { Zwerts, W. ;Wets, } \\
\text { G.; }\end{array}$ & Bélgica & $\begin{array}{c}\text { Pais e alunos de IEF } \\
\text { e IEM }\end{array}$ & $\begin{array}{c}\text { Quest.; } \\
\text { Diário Viagem }\end{array}$ & 2546 & $\begin{array}{l}\text { Ônibus; auto; } \\
\text { bicicleta }\end{array}$ & Cluster; MNL; & $\begin{array}{l}\text { Idade, gênero; série; usa passe escolar; renda, } \\
\text { n. de crianças na família }\end{array}$ \\
\hline 2007 & McDonald, N.C. & EUA & $\begin{array}{l}\text { Alunos de IEF e } \\
\text { IEM }\end{array}$ & $\begin{array}{l}\text { Entrevista } \\
\text { Domiciliar }\end{array}$ & 36553 & $\begin{array}{l}\text { TE; Auto; TP; } \\
\text { a pé; bicicleta }\end{array}$ & $\begin{array}{l}\text { Binário Logit } \\
\text { Descritivas }\end{array}$ & $\begin{array}{l}\text { Idade; gênero; série; etnia; distância; renda; } \\
\text { acesso a auto; tipo de escola }\end{array}$ \\
\hline 2007 & Zhu, X. & EUA & Alunos de IEF & Quest. & $* *$ & A pé & Regressão linear & $\begin{array}{c}\text { Etnia; ambiente; forma urbana; distância de } \\
\text { caminhada; densidade; segurança pessoal e } \\
\text { de tráfego }\end{array}$ \\
\hline 2008 & $\begin{array}{l}\text { EPA - United States } \\
\text { Environmental } \\
\text { Protection Agency }\end{array}$ & EUA & $\begin{array}{c}\text { Alunos de IEM e } \\
\text { IEF }\end{array}$ & Censo & 19500 & $\begin{array}{l}\text { A pé; auto; TE; } \\
\text { carona }\end{array}$ & $\begin{array}{l}\text { MNL e Logit } \\
\text { aninhado }\end{array}$ & $\begin{array}{l}\text { Segurança viária e pessoal; padrões de } \\
\text { viagens dos pais e jovens; medidas do } \\
\text { desenho do bairro; poluentes do ar; } \mathrm{CO} 2 / \\
\text { viagem; peso e alturas individuais }\end{array}$ \\
\hline 2008 & $\begin{array}{l}\text { Müller, S.; } \\
\text { Tscharaktschiew, S.; } \\
\text { Haase, K. }\end{array}$ & Alemanha & Alunos de IEM & Quest. & 4700 & $\begin{array}{l}\text { TP; a pé; auto; } \\
\text { bicicleta; moto }\end{array}$ & $\begin{array}{c}\text { Análise } \\
\text { espacial; MNL }\end{array}$ & $\begin{array}{l}\text { Bairro de residência; escola de matrícula; } \\
\text { idade, gênero; disponibilidade de auto; } \\
\text { licença para dirigir; tempo; clima }\end{array}$ \\
\hline 2008 & $\begin{array}{c}\text { Campbell, E.K.; } \\
\text { Wang, Q. }\end{array}$ & EUA & $\begin{array}{l}\text { Pais de alunos de } \\
\text { IEF }\end{array}$ & Quest. & 497 & $\begin{array}{l}\text { A pé; bicicleta; } \\
\text { ônibus; auto } \\
\text { carona }\end{array}$ & $\begin{array}{l}\text { Logit Binário; } \\
\text { MRLN }\end{array}$ & $\begin{array}{l}\text { Atitude; distância; idade; série; educação do } \\
\text { responsável; renda; conveniência; uso de } \\
\text { vários modos }\end{array}$ \\
\hline 2008 & $\begin{array}{l}\text { Yarlagadda, A.K.; } \\
\text { Srinivasan, S. }\end{array}$ & EUA & $\begin{array}{c}\text { Alunos de IEM e } \\
\text { IEF }\end{array}$ & Censo & 4352 & $\begin{array}{l}\text { Bicicleta; a pé } \\
\text { TE; TP; Auto }\end{array}$ & MNL & $\begin{array}{c}\text { Idade, gênero, série; renda; uso do solo; } \\
\text { ocupação dos pais; etnia; flexibilidade no } \\
\text { horário de trabalho; distância; posse autos; } \\
\text { licenças para dirigir; menores no domicílio; } \\
\text { supervisão na viagem; ciclovias; viagem de } \\
\text { ida de volta }\end{array}$ \\
\hline 2009 & $\begin{array}{c}\text { Marshall, J.; } \\
\text { Wilson, R.D.; } \\
\text { Meyer, K.L.; } \\
\text { Rajangam, S.K.; } \\
\text { Mcdonald, N.C.; } \\
\text { Wilson, E.J.; }\end{array}$ & EUA & Pais de alunos IEF & Quest. & 803 & $\begin{array}{l}\text { Auto; TE; a pé; } \\
\text { bicicleta }\end{array}$ & MNL & $\begin{array}{l}\text { Viagem ida ou volta; distância; escolha da } \\
\text { escola; série; gênero; etnia; renda; utilização } \\
\text { de diferentes modos; viagem encadeada }\end{array}$ \\
\hline 2009 & $\begin{array}{l}\text { McDonald N.C.; } \\
\text { Aalborg, A.E. }\end{array}$ & EUA & $\begin{array}{l}\text { Pais de alunos de } \\
\text { IEF }\end{array}$ & $\begin{array}{l}\text { Quest. Por } \\
\text { telefone }\end{array}$ & 403 & $\begin{array}{l}\text { Auto; bicicleta; } \\
\text { TP; TE; a pé }\end{array}$ & Descritivas & $\begin{array}{l}\text { Idade; raça; gênero; posse de auto no } \\
\text { domicílio; renda }\end{array}$ \\
\hline
\end{tabular}


APÊNDICE A: Tabela de revisão de estudos sobre a escolha modal em Instituições de ensino - Parte 3/6 (ver observações na parte 6/6)

\begin{tabular}{|c|c|c|c|c|c|c|c|c|}
\hline Ano & Autores & Local & População Alvo & $\begin{array}{c}\text { Fonte de } \\
\text { dados }\end{array}$ & $\mathbf{n}$ & $\begin{array}{c}\text { Modos } \\
\text { estudados }\end{array}$ & Análises & Variáveis estudadas \\
\hline 2010 & $\begin{array}{l}\text { Leslie, P.; } \\
\text { Kremer, P; } \\
\text { Tomborou, J. W.; } \\
\text { Williams, J. W. E; }\end{array}$ & Australia & Alunos de IEM & $\begin{array}{l}\text { Quest. } \\
\text { on line }\end{array}$ & 2961 & $\begin{array}{l}\text { Ativos (a pé e } \\
\text { bicicleta), e não } \\
\text { ativos (carro, } \\
\text { ônibus, trem } \\
\text { bonde) }\end{array}$ & Logit binário & $\begin{array}{l}\text { Atividade física; auto relato sobre a saúde; } \\
\text { modo na ida e na volta; uso do solo; gênero; } \\
\text { idade; série; segurança; norma social }\end{array}$ \\
\hline 2010 & $\begin{array}{l}\text { Providelo, J.K.; } \\
\text { Sanches, S.P. }\end{array}$ & Brasil & Alunos IES & Quest. & 447 & Bicicleta & EFA & $\begin{array}{c}\text { Atitude; gênero; idade; escolaridade; } \\
\text { infraestrutura }\end{array}$ \\
\hline 2010 & $\begin{array}{l}\text { Sanches, S.P.; } \\
\text { Rosa, F.D.; } \\
\text { Ferreira, M. A. G. }\end{array}$ & Brasil & $\begin{array}{l}\text { Pais de alunos de } \\
\text { IEF }\end{array}$ & Quest. & 784 & $\begin{array}{l}\text { Auto; ônibus; } \\
\text { bicicleta; a pé; } \\
\text { TE } \\
\end{array}$ & Descritivas & $\begin{array}{c}\text { Gênero; idade; quem leva a criança para a } \\
\text { escola; série; tempo de viagem; distância } \\
\text { casa-escola }\end{array}$ \\
\hline 2010 & Rosa, F. D. & Brasil & $\begin{array}{l}\text { Pais de alunos de } \\
\text { IEF }\end{array}$ & Quest. & 782 & $\begin{array}{l}\text { Auto; carona; } \\
\text { bicicleta; TE; } \\
\text { ônibus; a pé }\end{array}$ & $\begin{array}{l}\text { MNL e análise } \\
\text { espacial }\end{array}$ & $\begin{array}{l}\text { Modo de ida e de volta; idade; gênero; série; } \\
\text { atitudes; norma social e cultural; hábito; } \\
\text { distância; ocupação dos pais; renda; } \\
\text { supervisão da viagem; licenças para dirigir; } \\
\text { viagens encadeadas; disponibilidade de } \\
\text { autos; segurança viária; e pessoal }\end{array}$ \\
\hline 2010 & Stevens, J. & Reino Unido & $\begin{array}{c}\text { Alunos de IEM e } \\
\text { IEF }\end{array}$ & Relatos & $* *$ & $* *$ & Qualitativo & $\begin{array}{l}\text { Relatos sobre saúde; meio ambiente; } \\
\text { espaços públicos; percepção dos modos de } \\
\text { transporte; segurança pessoal }\end{array}$ \\
\hline 2010 & $\begin{array}{l}\text { Sidharthan, R.; } \\
\text { Bhat, C.R.; } \\
\text { Pendyala, R.M.; } \\
\text { Goulias, K.G. }\end{array}$ & EUA & $\begin{array}{c}\text { Alunos de IEM e } \\
\text { IEF }\end{array}$ & Censo & 1193 & $\begin{array}{l}\text { A pé; TE; auto; } \\
\text { bicicleta }\end{array}$ & $\begin{array}{l}\text { Probit; } \\
\text { Estimação por } \\
\text { MACML; }\end{array}$ & $\begin{array}{l}\text { Idade; gênero; tempo de viagem; renda } \\
\text { familiar; posse de auto; distância; segurança } \\
\text { viária e pessoal; clima }\end{array}$ \\
\hline 2010 & $\begin{array}{l}\text { Sriroongvikrai, K; } \\
\text { Choocharukul, K.; } \\
\text { Fujii, S. } \\
\end{array}$ & Bangkok & Alunos IES & Experimento & 53 & Auto e trem & $\begin{array}{l}\text { Frequências } \\
\text { antes/depois } \\
\text { intervenção }\end{array}$ & $\begin{array}{c}\text { Gênero; idade; posse de auto; distância; } \\
\text { tempo de viagem; tempo de acesso à } \\
\text { estação }\end{array}$ \\
\hline 2010 & $\begin{array}{l}\text { Wilson, E.J.; } \\
\text { Marshall, J.; } \\
\text { Wilson, R.; } \\
\text { Krizek, K.J. }\end{array}$ & EUA & $\begin{array}{l}\text { Pais de alunos de } \\
\text { IEF }\end{array}$ & Questionário & 1433 & $\begin{array}{c}\text { A pé; ônibus; } \\
\text { auto; }\end{array}$ & $\begin{array}{l}\text { MNL e análise } \\
\text { espacial }\end{array}$ & $\begin{array}{l}\text { Tipo de escola; raça; qualidade ônibus; } \\
\text { modo na ida e na volta; atitude pais; política } \\
\text { educacional; distância; uso do solo; calçada; }\end{array}$ \\
\hline
\end{tabular}


APÊNDICE A: Tabela de revisão de estudos sobre a escolha modal em Instituições de ensino - Parte 4/6 (ver observações na parte 6/6)

\begin{tabular}{|c|c|c|c|c|c|c|c|c|}
\hline Ano & Autores & Local & População Alvo & $\begin{array}{c}\text { Fonte de } \\
\text { dados }\end{array}$ & $\mathbf{n}$ & $\begin{array}{c}\text { Modos } \\
\text { estudados }\end{array}$ & Análises & Variáveis estudadas \\
\hline 2011 & $\begin{array}{c}\text { Alemu,D.; } \\
\text { Tsutsumi, J.G. }\end{array}$ & Japão & Alunos de IEM & Quest. & 739 & $\begin{array}{l}\text { Bicicleta; a pé; } \\
\text { auto; ônibus; } \\
\text { monotrilho }\end{array}$ & MNL & $\begin{array}{c}\text { Distância; tempo de viagem e de espera; } \\
\text { modo na ida e na volta; idade; série; renda } \\
\text { familiar; posse/acessibilidade a automóveis; } \\
\text { gênero; tarifa }\end{array}$ \\
\hline 2011 & $\begin{array}{l}\text { Bejleri, I; Steiner, } \\
\text { R.L.; Fischman, A.; } \\
\text { Schumucker, J.M. }\end{array}$ & EUA & Alunos de IEF & Quest. & 32 & A pé; & $\begin{array}{l}\text { Análise } \\
\text { especial; }\end{array}$ & Distâncias de caminhada \\
\hline 2011 & $\begin{array}{l}\text { Lang, D.; Collins, } \\
\text { D.; Kearns, R. }\end{array}$ & $\begin{array}{c}\text { Nova } \\
\text { Zelândia }\end{array}$ & $\begin{array}{l}\text { Mães de alunos } \\
\text { de IEF }\end{array}$ & $\begin{array}{l}\text { Grupos } \\
\text { focais }\end{array}$ & 30 & Auto; a pé & $\begin{array}{l}\text { Análise de } \\
\text { conteúdo; }\end{array}$ & $\begin{array}{l}\text { Fatores de decisão; percepções/ significados } \\
\text { sociais na caminhada e uso de auto }\end{array}$ \\
\hline 2011 & $\begin{array}{l}\text { Klöckner, C.A.; } \\
\text { Friedrichsmeier, T. }\end{array}$ & Alemanha & Alunos IES & Quest. & 3560 & Auto e não auto & $\begin{array}{l}\text { MEE em } 2 \\
\text { níveis }\end{array}$ & $\begin{array}{l}\text { Preferência por modo; dia e hora da viagem; } \\
\text { propósito; disponibilidade de auto; tempo } \\
\text { de viagem; TP; clima; }\end{array}$ \\
\hline 2011 & Toole, S. & Australia & $\begin{array}{l}\text { Pais e alunos de } \\
\text { IEF }\end{array}$ & $\begin{array}{l}\text { Quest. pais; } \\
\text { desenhos e } \\
\text { grupo focal; }\end{array}$ & 71 & $\begin{array}{l}\text { Auto; TP; } \\
\text { Bicicleta; }\end{array}$ & $\begin{array}{l}\text { Descritivas; } \\
\text { análises } \\
\text { cruzadas }\end{array}$ & $\begin{array}{l}\text { Percepções da comunidade e ambiente; } \\
\text { atitude; comportamento; idade; distância. }\end{array}$ \\
\hline 2011 & $\begin{array}{l}\text { Yoon S. Y.; } \\
\text { Doudnikoff, M; } \\
\text { Goulias, K. G.; }\end{array}$ & EUA & Alunos IEF & Censo & $* *$ & A pé; auto; & $\begin{array}{l}\text { Análise } \\
\text { espacial; } \\
\text { binário logit }\end{array}$ & $\begin{array}{l}\text { Independência nas viagens escolares; uso de } \\
\text { modos ativos; condução p/ pai ou mãe; } \\
\text { densidade; barreiras físicas; sócio } \\
\text { demográficas; local casa e emprego; }\end{array}$ \\
\hline 2011 & Van-Ristell, J.A. & Reino Unido & $\begin{array}{l}\text { Alunos de IEF e } \\
\text { IEM } \\
\end{array}$ & Censo. & $\begin{array}{c}7.484 .0 \\
01\end{array}$ & $\begin{array}{l}\text { Auto; ônibus; a } \\
\text { pé; bicicleta; TP }\end{array}$ & MNL & $\begin{array}{l}\text { Gênero; idade; políticas públicas; distância; } \\
\text { tarifas; etnia; densidade do tráfego }\end{array}$ \\
\hline 2012 & $\begin{array}{l}\text { Bertazzo, A.B.S.; } \\
\text { Jacques, M.A.P. }\end{array}$ & Brasil & Alunos IEMs & Quest. & 3163 & $\begin{array}{l}\text { Auto; ônibus; } \\
\text { a pé }\end{array}$ & MNL & $\begin{array}{l}\text { Tipo escola; distância caminhada; renda, } \\
\text { tipo origem }\end{array}$ \\
\hline 2012 & $\begin{array}{l}\text { Delmelle, E.M.; } \\
\text { Delmelle, E.C. }\end{array}$ & EUA & Alunos IES & Quest. & 567 & $\begin{array}{l}\text { Auto, a pé, } \\
\text { bicicleta; } \\
\text { carona; ônibus }\end{array}$ & $\begin{array}{c}\text { Preferência } \\
\text { declarada }\end{array}$ & $\begin{array}{l}\text { Gênero; posse de automóvel; menores no } \\
\text { domicílio; estacionamento; distância; clima; } \\
\text { topografia; frequência de uso dos modos; } \\
\text { condições de tráfego; série }\end{array}$ \\
\hline 2012 & $\begin{array}{l}\text { Fox, J.; Patruni, B.; } \\
\text { Van Vuren, T.; } \\
\text { Adeeb M.; } \\
\text { MacDonald, M. }\end{array}$ & Reino Unido & Pais de alunos & $\begin{array}{l}\text { Entrevistas } \\
\text { domiciliares }\end{array}$ & 5000 & $\begin{array}{l}\text { Auto; carona; } \\
\quad \text { ônibus; } \\
\text { bicicleta; a pé }\end{array}$ & $\begin{array}{l}\text { Modelo } \\
\text { baseado em } \\
\text { atividades }\end{array}$ & $\begin{array}{c}\text { Gênero; idade; nível educacional; } \\
\text { supervisão das viagens; pessoas empregadas } \\
\text { na família; menores no domicílio; } \\
\text { acessibilidade a autos }\end{array}$ \\
\hline 2012 & $\begin{array}{c}\text { Goldner, L.; } \\
\text { Beppler, F.; Prim,J }\end{array}$ & Brasil & Alunos IES & Quest. & 575 & $\begin{array}{l}\text { Auto; a pé; } \\
\text { ônibus }\end{array}$ & Descritivas & $\begin{array}{l}\text { Gênero; idade; origem/destino; tempo } \\
\text { viagem; via de acesso; horário viagem }\end{array}$ \\
\hline
\end{tabular}


APÊNDICE A: Tabela de revisão de estudos sobre a escolha modal em Instituições de ensino - Parte 5/6 (ver observações na parte 6/6)

\begin{tabular}{|c|c|c|c|c|c|c|c|c|}
\hline Ano & Autores & Local & População Alvo & $\begin{array}{c}\text { Fonte de } \\
\text { dados }\end{array}$ & $\mathbf{n}$ & $\begin{array}{c}\text { Modos } \\
\text { estudados }\end{array}$ & Análises & Variáveis estudadas \\
\hline 2012 & $\begin{array}{l}\text { Karmagianni, M; } \\
\text { Polydoroupolou, A.; } \\
\text { Goulias, K.G. }\end{array}$ & Grécia & Alunos IEM & $\begin{array}{l}\text { Entrevistas e } \\
\text { Quest. On } \\
\text { line }\end{array}$ & 364 & $\begin{array}{l}\text { A pé; bicicleta; } \\
\text { moto; auto; TP; }\end{array}$ & $\begin{array}{c}\text { MNL } \\
\text { Preferência } \\
\text { declarada }\end{array}$ & $\begin{array}{l}\text { Padrões de viagens primárias e encadeadas; } \\
\text { Modo na ida e na volta; }\end{array}$ \\
\hline 2012 & $\begin{array}{l}\text { Murtagh, s.; } \\
\text { Rowe, D. A.; } \\
\text { Elliot, M. A.; } \\
\text { Mcminn, D.; } \\
\text { Nelson, N.M.; }\end{array}$ & UK & Alunos IEF & Quest. & 126 & $\begin{array}{l}\text { Auto; Ônibus; } \\
\text { a pé; }\end{array}$ & $\begin{array}{l}\text { Regressão } \\
\text { Linear } \\
\text { HierárChica }\end{array}$ & Hábito; TPB \\
\hline 2012 & $\begin{array}{c}\text { Shokoohi, R; } \\
\text { Hanif,N.R.; Dali,M. }\end{array}$ & Irã & $\begin{array}{l}\text { Pais de alunos de } \\
\text { IEF }\end{array}$ & Quest. & 561 & $\begin{array}{l}\text { A pé; carona; } \\
\text { TE }\end{array}$ & MNL & $\begin{array}{l}\text { Gênero; série; renda; distância; modo } \\
\text { preferido; percepção da segurança viária }\end{array}$ \\
\hline 2012 & Zhou, J & EUA & Alunos IES & Quest. & 769 & $\begin{array}{l}\text { Auto; carona, } \\
\text { TP }\end{array}$ & $\begin{array}{l}\text { Descritivas: } \\
\text { Análise } \\
\text { espacial; } \\
\text { MNL; }\end{array}$ & $\begin{array}{l}\text { Gênero; ano na universidade; idade; tipo de } \\
\text { moradia; influência de seus pares; utilização } \\
\text { de diferentes modos; tempo de viagem }\end{array}$ \\
\hline 2013 & Badri, M.A. & $\begin{array}{l}\text { Emirados } \\
\text { Árabes }\end{array}$ & $\begin{array}{l}\text { Pais de alunos de } \\
\text { IEF }\end{array}$ & $\begin{array}{l}\text { Grupo focal } \\
\text { e Quest. }\end{array}$ & 1145 & $\begin{array}{l}\text { A pé; auto } \\
\text { carona; TE }\end{array}$ & Grupo focal & $\begin{array}{l}\text { Condições de tráfego; distância; sistema } \\
\text { viário; gênero dos pais; gênero das crianças; } \\
\text { série; autos no domicílio; nacionalidade; } \\
\text { menores no domicílio }\end{array}$ \\
\hline 2013 & $\begin{array}{l}\text { Carver, A.; } \\
\text { Timperio, A.; } \\
\text { Crawford, D. }\end{array}$ & Austrália & $\begin{array}{l}\text { Pais e alunos de } \\
\text { IEF }\end{array}$ & Quest. & 688 & Auto e não auto & $\begin{array}{l}\text { Descritivas; } \\
\text { Logit; análise } \\
\quad \text { de relato }\end{array}$ & $\begin{array}{c}\text { Distância; localização da escola; série; } \\
\text { gênero; ocupação pais; idade; autos na } \\
\text { família; supervisão da viagem; motivos de } \\
\text { conduzir criança à escola }\end{array}$ \\
\hline 2013 & Chacha, P; Bwire,H. & Tanzânia & $\begin{array}{l}\text { Alunos e pais de } \\
\text { alunos de IEF e } \\
\text { IEM }\end{array}$ & Quest. & 1511 & $\begin{array}{l}\text { Ônibus; auto; } \\
\text { bicicleta; TP; } \\
\text { a pé }\end{array}$ & MNL & $\begin{array}{l}\text { Tempo de viagem; segurança; distância; } \\
\text { gênero; renda familiar; disponibilidade de } \\
\text { automóvel; emprego }\end{array}$ \\
\hline 2013 & $\begin{array}{l}\text { Ermagum, A.; } \\
\text { Samini, A.; } \\
\text { Rashidi, T.H. }\end{array}$ & Irã & $\begin{array}{l}\text { Alunos de IEM e } \\
\text { IEF; }\end{array}$ & Quest. & 4700 & $\begin{array}{l}\text { A pé; bicicleta; } \\
\text { auto;TE; TP }\end{array}$ & $\begin{array}{l}\text { Logit } \\
\text { aninhado e de } \\
\text { análise de } \\
\text { risco; }\end{array}$ & $\begin{array}{l}\text { Idade, gênero e número de irmãos; distância } \\
\text { renda familiar, ocupação dos pais, nível } \\
\text { educacional dos pais, posse de automóvel; } \\
\text { densidade populacional, caminhabilidade. }\end{array}$ \\
\hline 2013 & $\begin{array}{l}\text { Faulkner, G.; Stone, } \\
\text { M.; Buliung, R.; } \\
\text { Wong, B.; Mitra, R. }\end{array}$ & Canadá & $\begin{array}{l}\text { Pais de alunos de } \\
\text { IEF }\end{array}$ & Quest. & 785 & $\begin{array}{l}\text { A pé; bicicleta; } \\
\text { TE; TP }\end{array}$ & $\begin{array}{l}\text { Regressão } \\
\text { linear; }\end{array}$ & $\begin{array}{l}\text { Idade; tipo do bairro; modo de viagem } \\
\text { relatado pelos pais; distância casa-escola; } \\
\text { gênero; atividade física }\end{array}$ \\
\hline
\end{tabular}


APÊNDICE A: Tabela de revisão de estudos sobre a escolha modal em Instituições de ensino - Parte 6/6;

\begin{tabular}{|c|c|c|c|c|c|c|c|c|}
\hline Ano & Autores & Local & População Alvo & $\begin{array}{c}\text { Fonte de } \\
\text { dados }\end{array}$ & $\mathbf{n}$ & $\begin{array}{c}\text { Modos } \\
\text { estudados }\end{array}$ & Análises & Variáveis estudadas \\
\hline 2013 & $\begin{array}{l}\text { Haque, B.; Chayan, } \\
\text { M. H.;Rama, M }\end{array}$ & Bangladesh & $\begin{array}{l}\text { Pais de alunos de } \\
\text { IEF }\end{array}$ & $\begin{array}{l}\text { Grupo focal } \\
\text { e quest. }\end{array}$ & 120 & $\begin{array}{l}\text { Auto; moto; } \\
\text { rickshaw; TE }\end{array}$ & $\begin{array}{l}\text { MNL; Pref. } \\
\text { declarada }\end{array}$ & $\begin{array}{l}\text { Gênero; ocupação pais; renda; custo da } \\
\text { viagem; local de parada; tamanho auto; }\end{array}$ \\
\hline 2013 & $\begin{array}{l}\text { Whalen, k.E.; Páez, } \\
\text { A.; Carrasco, J.A }\end{array}$ & Canadá & Alunos IES & Quest. & 1385 & $\begin{array}{l}\text { Bicicleta, a pé, } \\
\text { ônibus e auto }\end{array}$ & $\begin{array}{l}\text { Logit } \\
\text { aninhado e } \\
\text { MNL }\end{array}$ & $\begin{array}{l}\text { Idade; naturalidade; arranjo familiar; série; } \\
\text { gênero; acesso ao auto; tempo de viagem; } \\
\text { atitudes; supervisão viagem; tipo/tempo de } \\
\text { habitação; tempo de acesso/ transferência } \\
\text { em TP; densidade; Tipo da rua/calçada }\end{array}$ \\
\hline 2014 & $\begin{array}{c}\text { Danaf,M; Abou- } \\
\text { Zeid, M;Kaysi, I.A }\end{array}$ & Líbano & Alunos de IES & Quest. & 594 & Auto; TP; taxi & MNL & Renda; tempo e custo da viagem; gênero \\
\hline 2014 & $\begin{array}{l}\text { Sam, E.F.; Adu- } \\
\text { Boahen, K; Kissah- } \\
\text { Korsah, K.; } \\
\end{array}$ & Ghana & Alunos de IES & $\begin{array}{l}\text { Quest. } \\
\text { Entrevistas }\end{array}$ & 100 & $\mathrm{TP}$ & Descritivas & Tarifa; segurança; conforto; confiabilidade; \\
\hline 2014 & $\begin{array}{l}\text { Silva, E. F. F.; } \\
\text { Melo, W. C.; } \\
\text { Bertazzo, A. B. S.; } \\
\text { Arruda, F. S.; } \\
\text { Takano, M. S. M. }\end{array}$ & Brasil & Alunos de IES & Quest. & 393 & Auto e não auto & EFA; MNL & $\begin{array}{l}\text { Turno; estado civil; idade; gênero; renda; } \\
\text { licença para dirigir; posse de automóvel; } \\
\text { distância; norma social; atitude }\end{array}$ \\
\hline 2014 & Marino, C.A.; & Peru & Alunos IES & Quest. & 70 & $\begin{array}{l}\text { A pé; auto; taxi; } \\
\text { TP; carona; } \\
\text { bicicleta }\end{array}$ & Descritivas & $\begin{array}{c}\text { Gênero; tempo de viagem; segurança viária; } \\
\text { motivação para usar TP }\end{array}$ \\
\hline 2015 & $\begin{array}{l}\text { Kamargianni, M.; } \\
\text { Dubey, S.; } \\
\text { Polydoropoulou, A.; } \\
\text { Bhat, C.; }\end{array}$ & Chipre & Alunos IEMs & Quest. & 2171 & $\begin{array}{l}\text { Carona; Moto; } \\
\text { ônibus; a pé; } \\
\text { bicicleta }\end{array}$ & $\begin{array}{l}\text { Pref.Declarada } \\
\text { ICLV }\end{array}$ & $\begin{array}{l}\text { Qualidade da calçada; existência ciclovias; } \\
\text { clima; tempo e custo da viagem; TP; } \\
\text { escolaridade dos pais; gênero; renda; } \\
\text { atividade física }\end{array}$ \\
\hline $\begin{array}{l}\text { Notas: } \\
\text { ensino } \\
\text { interpe } \\
\text { Choice }\end{array}$ & ** - Diversas amostras & $\begin{array}{l}\text { tivação da n } \\
\text { del. }\end{array}$ & a; MNL - Mode & git; Multin & 1. & T & coximated $C$ & $\begin{array}{l}\text { rr equações estruturais; IES - Instituições de } \\
\text { orte escolar; TCI - teoria do comportamento } \\
\text { site Marginal Likelihood; ICLV- Integrated }\end{array}$ \\
\hline
\end{tabular}


APÊNDICE B- Termos de Consentimento Livre e Esclarecido (autorização dos pais para participação dos filhos, para pais participantes, para filhos participantes) 


\section{APÊNDICE B - MODELOS TCLE}

\section{TERMO DE CONSENTIMENTO LIVRE E ESCLARECIDO}

Autorização dos pais para participação dos filhos

O (A) seu (sua) filho (a) está sendo convidado (a) para participar a participar da pesquisa de doutorado "Gerenciamento da mobilidade em viagens realizadas por estudantes de instituições de ensino médio: alternativas mediadas pela psicologia social", de responsabilidade de Ângela Beatriz Souza Bertazzo, aluna de doutorado da Universidade de Brasília. O objetivo desta pesquisa é desenvolver um procedimento de identificação de fatores intervenientes para o gerenciamento da mobilidade urbana, voltado à redução do número total de viagens por automóveis de e para Instituições de Ensino Médio. Assim, gostaria de consultá-lo (a) sobre seu interesse e disponibilidade de cooperar com a pesquisa.

Você e seu (sua) filho (a) receberão todos os esclarecimentos necessários antes, durante e após a finalização da pesquisa. Em algumas etapas, será necessário o contato via email. Entretanto, a pesquisadora propõe a confidencialidade dos dados, ou seja, não repassar, divulgar banco de dados, ou qualquer informação de identificação individual para qualquer outro fim que não seja os explicitados na pesquisa. Fica assegurado que o seu nome, e-mail, voz ou qualquer outra informação pessoal recebida durante a pesquisa, como também o de seu (sua) filho(a) não será divulgado, mantendo a confidencialidade das informações. Os dados provenientes de sua participação na pesquisa, tais como questionários, entrevistas, fitas de gravação, ficarão sob a guarda do pesquisador responsável pela pesquisa.

A coleta de dados será realizada por meio de reuniões gravadas com pais e alunos, e questionários estruturados. É para estes procedimentos que você está sendo convidado a participar. Sua participação na pesquisa não implica em nenhum risco.

Espera-se com esta pesquisa conhecer como a comunidade de uma Instituição de Ensino Médio pode gerenciar a sua escolha de modo de transporte, visando maior sustentabilidade para sua cidade, e maior qualidade de vida para cada indivíduo envolvido.

A participação de seu (sua) filho (a) é voluntária e livre de qualquer remuneração ou benefício. Você é livre para recusar-se a participar, retirar seu consentimento ou interromper sua participação a qualquer momento. A recusa em participar não irá acarretar qualquer penalidade ou perda de benefícios.

Se você tiver qualquer dúvida em relação à pesquisa, você pode me contatar através do telefone 6181560852 ou pelo e-mail angela.bertazzo@ @otmail.com.

A eChipe de pesquisa garante que os resultados do estudo serão devolvidos aos participantes por meio do email informado, podendo ser publicados posteriormente na comunidade científica.

Este projeto foi revisado e aprovado pelo Comitê de Ética em Pesquisa do Instituto de Ciências Humanas da Universidade de Brasília - CEP/IH. As informações com relação à assinatura do TCLE ou os direitos do sujeito da pesquisa podem ser obtidos através do e-mail do CEP/IH cep_ih@unb.br.

Este documento foi elaborado em duas vias, uma ficará com o(a) pesquisador(a) responsável pela pesquisa e a outra com o senhor(a). de de 


\section{TERMO DE CONSENTIMENTO LIVRE E ESCLARECIDO Pais participantes}

Você está sendo convidado a participar da pesquisa de doutorado "Gerenciamento da mobilidade em viagens realizadas por estudantes de instituições de ensino médio: alternativas mediadas pela psicologia social", de responsabilidade de Ângela Beatriz Souza Bertazzo, aluna de doutorado da Universidade de Brasília. O objetivo desta pesquisa é desenvolver um procedimento de identificação de fatores intervenientes para o gerenciamento da mobilidade urbana, voltado à redução do número total de viagens por automóveis de e para Instituições de Ensino Médio. Assim, gostaria de consultá-lo (a) sobre seu interesse e disponibilidade de cooperar com a pesquisa.

Você receberá todos os esclarecimentos necessários antes, durante e após a finalização da pesquisa. Em algumas etapas, será necessário o contato via e-mail. Entretanto, a pesquisadora propõe a confidencialidade dos dados, ou seja, não repassar, divulgar banco de dados, ou qualquer informação de identificação individual para qualquer outro fim que não seja os explicitados na pesquisa. Fica assegurado que o seu nome, e-mail, voz ou qualquer outra informação pessoal recebida durante a pesquisa, não será divulgado, mantendo a confidencialidade das informações. Os dados provenientes de sua participação na pesquisa, tais como questionários, entrevistas, fitas de gravação, ficarão sob a guarda do pesquisador responsável pela pesquisa.

A coleta de dados será realizada por meio de reuniões gravadas com pais e alunos, e questionários estruturados. É para estes procedimentos que você está sendo convidado a participar. Sua participação na pesquisa não implica em nenhum risco.

Espera-se com esta pesquisa conhecer como a comunidade de uma Instituição de Ensino Médio pode gerenciar a sua escolha de modo de transporte, visando maior sustentabilidade para sua cidade, e maior qualidade de vida para cada indivíduo envolvido.

Sua participação é voluntária e livre de qualquer remuneração ou benefício. Você é livre para recusar-se a participar, retirar seu consentimento ou interromper sua participação a qualquer momento. A recusa em participar não irá acarretar qualquer penalidade ou perda de benefícios.

Se você tiver qualquer dúvida em relação à pesquisa, você pode me contatar através do telefone 6181560852 ou pelo e-mail angela.bertazzo@ hotmail.com.

A eChipe de pesquisa garante que os resultados do estudo serão devolvidos aos participantes por meio do e-mail informado, podendo ser publicados posteriormente na comunidade científica.

Este projeto foi revisado e aprovado pelo Comitê de Ética em Pesquisa do Instituto de Ciências Humanas da Universidade de Brasília - CEP/IH. As informações com relação à assinatura do TCLE ou os direitos do sujeito da pesquisa podem ser obtidos através do e-mail do CEP/IH cep_ih@unb.br.

Este documento foi elaborado em duas vias, uma ficará com o(a) pesquisador(a) responsável pela pesquisa e a outra com o senhor(a).

Assinatura do (a) participante

Assinatura do (a) pesquisador (a)

Brasília, de de 


\section{TERMO DE ASSENTIMENTO}

Filhos participantes

Você está sendo convidado a participar da pesquisa "Gerenciamento da mobilidade em viagens realizadas por estudantes de instituições de ensino médio: alternativas mediadas pela psicologia social", de responsabilidade de Ângela Beatriz Souza Bertazzo, aluna de doutorado da Universidade de Brasília.

O objetivo desta pesquisa é desenvolver um procedimento para elaboração de programas de mobilidade urbana para comunidades de Escolas de Ensino Médio. Assim, gostaria de consultá-lo (a) sobre seu interesse e disponibilidade de cooperar com a pesquisa, através da manifestação da sua opinião sobre o tema.

Sua participação é voluntária e livre de qualquer remuneração ou benefício. Você é livre para recusar-se a participar, retirar seu consentimento ou interromper sua participação a qualquer momento. A recusa em participar não irá acarretar qualquer penalidade ou perda de benefícios.

Fica assegurado que o seu nome, e-mail, voz ou qualquer outra informação pessoal recebida durante a pesquisa, não será divulgado, mantendo a confidencialidade das informações. Os dados provenientes de sua participação na pesquisa, tais como questionários entrevistas, fitas de gravação, ficarão sob a guarda da pesquisadora responsável pela pesquisa.

Se você tiver qualquer dúvida em relação à pesquisa, você pode me contatar através do telefone 6181560852 ou pelo e-mail angela.bertazzo@ hotmail.com. A eChipe de pesquisa garante que os resultados do estudo serão devolvidos aos participantes por meio do e-mail informado, podendo ser publicados posteriormente na comunidade científica.

Este projeto foi revisado e aprovado pelo Comitê de Ética em Pesquisa do Instituto de Ciências Humanas da Universidade de Brasília - CEP/IH. As informações com relação à assinatura do TCLE ou os direitos do sujeito da pesquisa podem ser obtidos através do e-mail do CEP/IH cep_ih@unb.br.

Este documento foi elaborado em duas vias, uma ficará com o(a) pesquisador(a) responsável pela pesquisa e a outra com você.

Assinatura do (a) participante

Assinatura da pesquisadora

Brasília, de de 
APÊNDICE C - Questionário Institucional 


\section{APÊNDICE C - QUESTIONÁRIO INSTITUCIONAL}

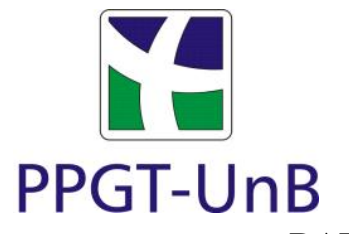

Universidade de Brasília - UnB

Faculdade de Tecnologia

Departamento de Engenharia Civil e Ambiental

PESQUISA ACADÊMICA

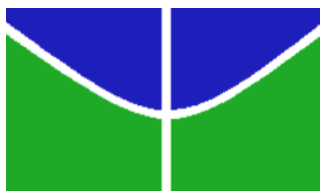

DADOS GERAIS DA INSTITUIÇÃO - ANO LETIVO

a) Nome:

b) Endereço:

\section{Tipo:}

( ) Ensino Fundamental

( ) Ensino Médio

Pessoa de contato:

Nome:

Telefone:

Fax:

E-mail:

c) Área do terreno: $\quad \mathbf{m}^{2}$

d) Área construída: $\quad \mathbf{m}^{2}$

e) Número de salas de aula:

f) Número total de vagas para estacionamento:

Possui vagas de estacionamento reservadas para professores e funcionários?

( ) Não ( ) Sim

Possui vagas de estacionamento reservadas para alunos?
( ) Não
( ) $\operatorname{Sim}$ vagas)

Possui vagas de estacionamento reservadas para visitantes?
( ) Não
( ) $\operatorname{Sim}$ vagas)

Possui local para o estacionamento de bicicletas?
( ) Não
( ) $\operatorname{Sim}$ vagas)

g) Frequentadores regulares da instituição por turno

\begin{tabular}{|l|l|l|l|l|}
\hline Turno & $\begin{array}{l}\text { Horário de início e } \\
\text { término do turno }\end{array}$ & $\begin{array}{c}\text { Número de } \\
\text { Funcionários }\end{array}$ & $\begin{array}{l}\text { Número de } \\
\text { Professores }\end{array}$ & $\begin{array}{c}\text { Número de } \\
\text { Alunos }\end{array}$ \\
\hline Matutino & & & & \\
\hline Vespertino & & & & \\
\hline Noturno & & & & \\
\hline Total & & & & \\
\hline
\end{tabular}

Obs: Informar sobre a existência de turno integral e atividades no contraturno e a frequiência média de alunos e professores nessas atividades e se existem atividades aos sábados.

Informar também se, no número de professores, estão contados professores de apoio ou reforço escolar que vão eventualmente ao colégio

\begin{tabular}{|c|c|c|}
\hline Turno & Turma & Número de Alunos \\
\hline MATUTINO 1' ANO & $\mathbf{1}^{\circ} \mathrm{A}$ & \\
\hline MATUTINO $2^{\circ}$ ANO & $2^{\circ} \mathrm{A}$ & \\
\hline MATUTINO $3^{\circ}$ ANO & $\mathbf{3}^{\mathbf{0}} \mathrm{A}$ & \\
\hline
\end{tabular}

h) Principais pontos de acesso à instituição 
APÊNDICE D - Roteiro para avaliação do contexto físico das IEMs 


\title{
APÊNDICE D - ROTEIRO PARA AVALIAÇÃO DO CONTEXTO FÍSICO DAS
}

IEMs;

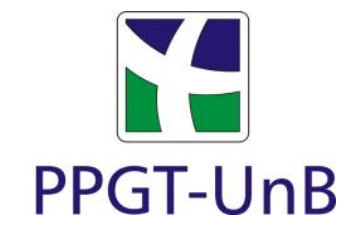

PPGT-UnB

\author{
Universidade de Brasília - UnB \\ Faculdade de Tecnologia \\ Departamento de Engenharia Civil e Ambiental \\ PESQUISA ACADÊMICA \\ CONTEXTO FÍSICO
}

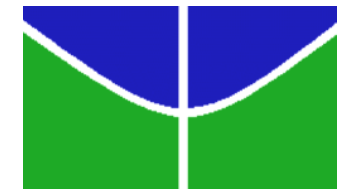

Identificação IEM:

Endereço:

MAPA 01 - raio de 2000 metros; Fonte Google Earth

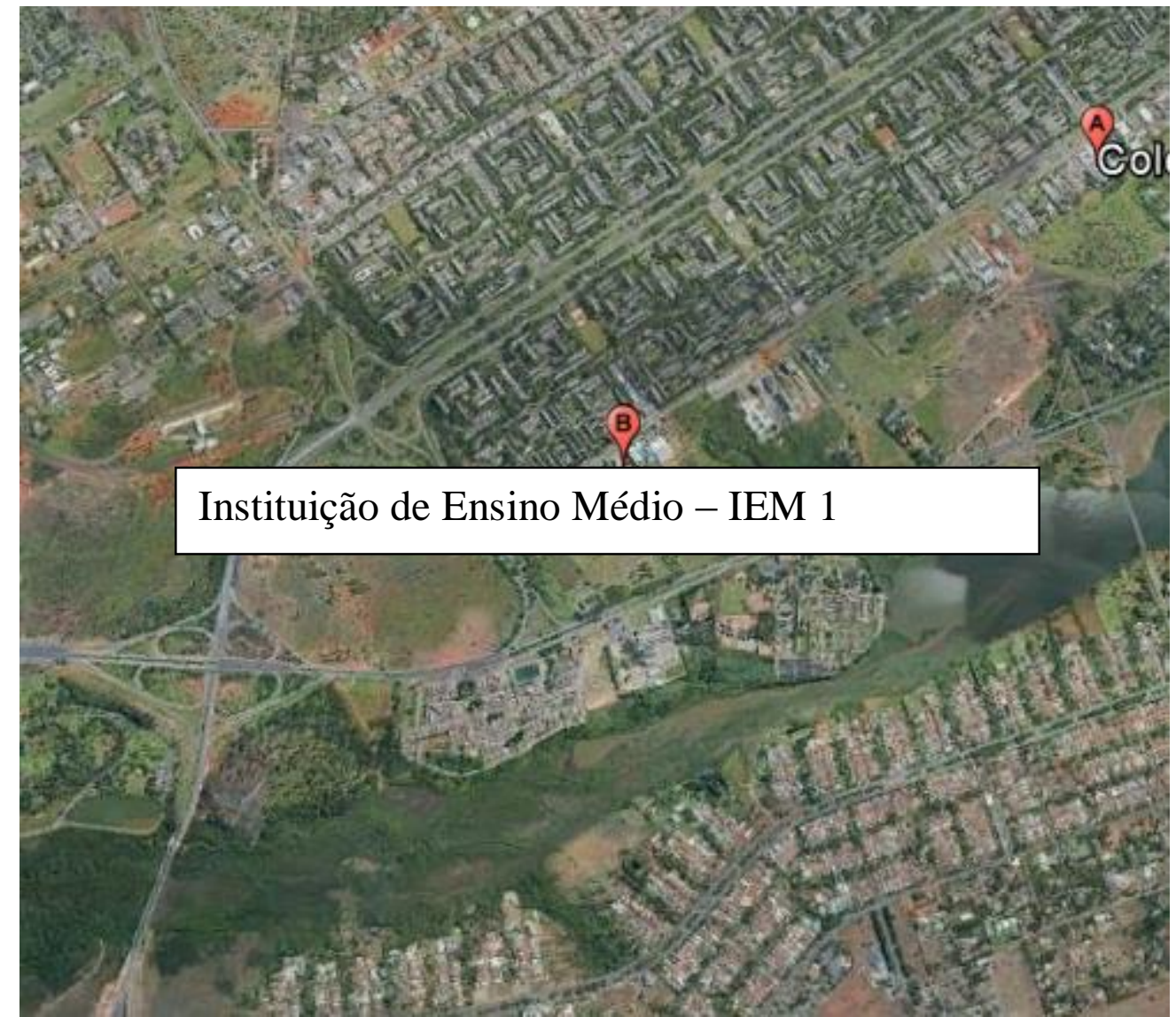

Anotar a localização de:

- Vias com serviço de ônibus públicos;

- Pontos de ônibus e metrô;

- Tipo de uso do solo do entorno (residencial, comercial, etc.) misto- qual \%); 
MAPA 02 - raio de 500 metros; Fonte Google Earth

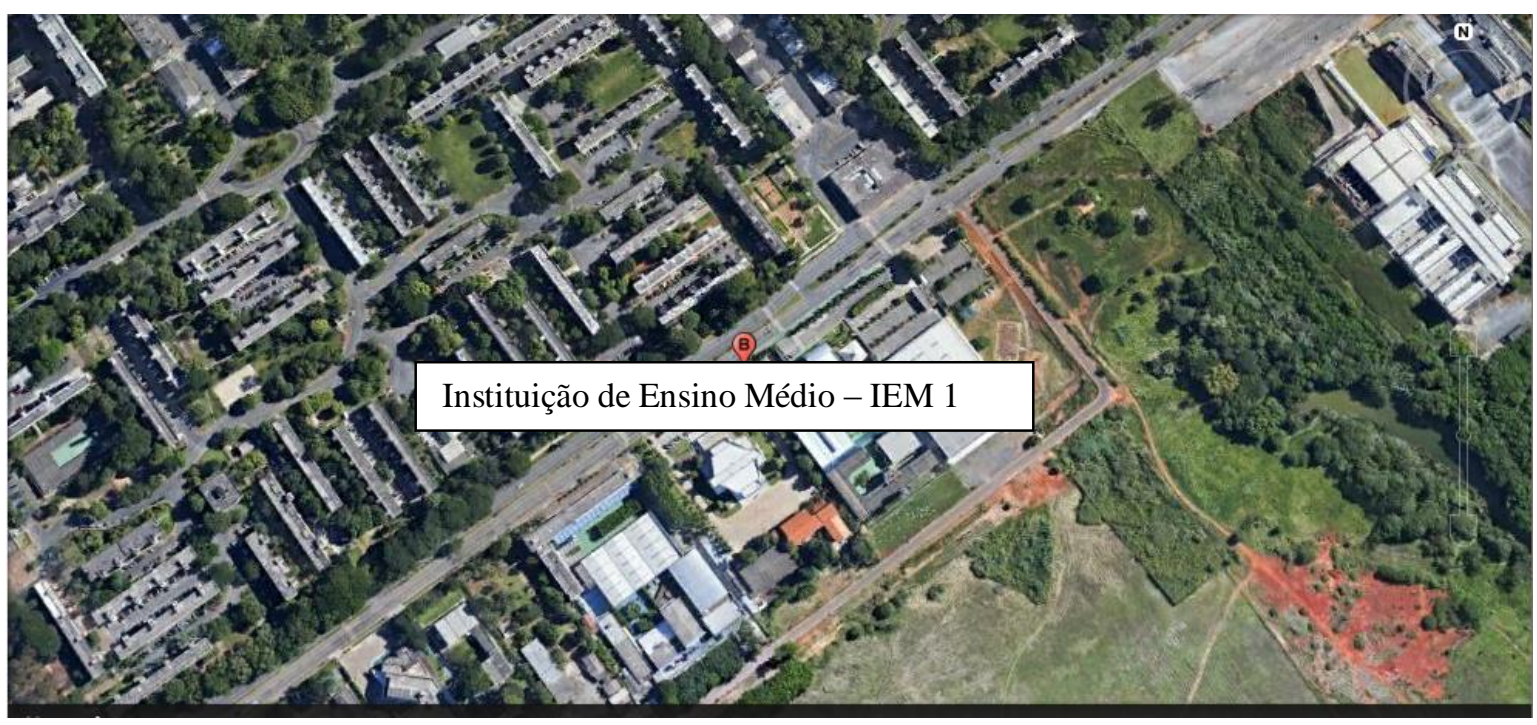

Anotar a localização de:

- Portões de acesso de veículos e de pedestres;

-Paradas de transporte escolar;

-Pontos de embarque e desembarque de automóveis;

- Estacionamentos;

- Ciclovias nas imediações;

- A existência de áreas de apoio, como bicicletários e banheiros com duchas;

- Sinalizações para a segurança viária em travessias de pedestres e bicicletas com modos motorizados, nas imediações da escola; 
APENNDICE E - Questionário para participação de pais na etapa de grupos focais 


\section{APÊNDICE E - QUESTIONÁRIO PARA PARTICIPAÇÃO DE PAIS NA ETAPA DE GRUPOS FOCAIS}

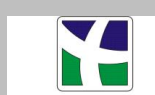

PPGT-UnB
Universidade de Brasília - UnB Faculdade de Tecnologia Departamento de Engenharia Civil e Ambiental PESQUISA ACADÊMICA
Escola + verde

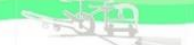

\section{QUESTIONÁRIO PARA REUNIÃO DE GRUPO FOCAL - PAIS}

Este questionário é parte de uma pesquisa realizada pelo Programa de Pós-graduação em Transportes - PPGT, da Universidade de Brasília. Seu objetivo é desenvolver um procedimento para a elaboração de programas de Gerenciamento da Mobilidade (GM) para Instituições de Ensino Médio (IEMs), baseado na identificação de fatores intervenientes no comportamento de escolha modal para o transporte de estudantes de e para essas instituições de ensino.

Convidamos você, pai/mãe ou responsável dos alunos convidados a participarem dos grupos focais, a contribuir com a pesquisa respondendo ao conjunto de questões sobre a utilização de diferentes modos de transporte para ir ou vir da escola. Considere a possibilidade dos alunos desta escola poderem utilizar diferentes modos de transporte para ir ou vir da escola, e dê sua opinião apontando a resposta que venha imediatamente à sua cabeça. Coloque sua resposta abaixo da pergunta correspondente.

Não existem respostas certas ou erradas. Estamos interessados em conhecer a sua opinião sobre a utilização de diferentes modos para ir ou vir da escola. As repostas (sem identificação pessoal) deverão contribuir para a construção da percepção coletiva da comunidade escolar sobre sua mobilidade, que acontecerá na reunião de grupo focal.

\section{Questão 1 - Identificação dos modos viáveis}

A partir da lista abaixo, assinale todos os modos de transporte que você considera que estão disponíveis para a realização dos deslocamentos de e para a escola, nos horários de entrada e saída dos turnos.

\begin{tabular}{|l|l|l|l|}
\hline & $\begin{array}{l}\text { Automóvel; transportando apenas 1 } \\
\text { estudante; }\end{array}$ & $\begin{array}{l}\text { Automóvel transportando dois } \\
\text { ou mais estudantes; }\end{array}$ \\
\hline Transporte escolar; & Bicicleta; \\
\hline Ônibus; & & A pé (todo o percurso); \\
\hline Metrô; & \\
\hline
\end{tabular}

Questão 2 - Quais são as vantagens que você vê que seu (sua) filho(a) use cada modo de transporte para vir e sair da escola nos horários de entrada e saída dos turnos?

\begin{tabular}{|l|l|}
\hline MODO & VANTAGEM \\
\hline $\begin{array}{l}\text { Automóvel; transportando apenas } 1 \\
\text { estudante; }\end{array}$ & \\
\hline $\begin{array}{l}\text { Automóvel transportando dois ou } \\
\text { mais estudantes; }\end{array}$ & \\
\hline Transporte escolar; & \\
\hline Ônibus; & \\
\hline Metrô; & \\
\hline Bicicleta; & \\
\hline A pé & \\
\hline
\end{tabular}


Questão 3 - Quais são as desvantagens que você vê que seu (sua) filho(a) use cada modo de transporte para vir e voltar da escola nos horários de entrada e saída dos turnos?

\begin{tabular}{|l|l|}
\hline MODO & DESVANTAGEM \\
\hline $\begin{array}{l}\text { Automóvel; transportando apenas } 1 \\
\text { estudante; }\end{array}$ & \\
\hline $\begin{array}{l}\text { Automóvel transportando dois ou } \\
\text { mais estudantes; }\end{array}$ & \\
\hline Transporte escolar; & \\
\hline Ônibus; & \\
\hline Metrô; & \\
\hline Bicicleta; & \\
\hline A pé & \\
\hline
\end{tabular}

Questão 4 - Que pessoas ou grupos de pessoas aprovariam que você deixasse que seu(sua) filho(a) usasse cada modo de transporte?

\begin{tabular}{|l|l|}
\hline MODO & QUEM APROVARIA \\
\hline $\begin{array}{l}\text { Automóvel; transportando apenas } 1 \\
\text { estudante; }\end{array}$ & \\
\hline $\begin{array}{l}\text { Automóvel transportando dois ou } \\
\text { mais estudantes; }\end{array}$ & \\
\hline Transporte escolar; & \\
\hline Ônibus; & \\
\hline Metrô; & \\
\hline Bicicleta; & \\
\hline A pé & \\
\hline
\end{tabular}

Questão 5 - Que pessoas ou grupos de pessoas não aprovariam que você deixasse que seu(sua) filho(a) usasse cada modo de transporte?

\begin{tabular}{|l|l|}
\hline MODO & QUEM NÃO APROVARIA \\
\hline $\begin{array}{l}\text { Automóvel; transportando apenas 1 } \\
\text { estudante; }\end{array}$ & \\
\hline $\begin{array}{l}\text { Automóvel transportando dois ou } \\
\text { mais estudantes; }\end{array}$ & \\
\hline Transporte escolar; & \\
\hline Ônibus; & \\
\hline Metrô; & \\
\hline Bicicleta; & \\
\hline A pé & \\
\hline
\end{tabular}

Questão 6 - Que fatores ou circunstâncias facilitariam ou permitiriam que você deixasse que seu(sua) filho(a) usasse cada modo de transporte?

\begin{tabular}{|l|l|}
\hline MODO & O QUE FACILITARIA \\
\hline $\begin{array}{l}\text { Automóvel; transportando apenas } 1 \\
\text { estudante; }\end{array}$ & \\
\hline $\begin{array}{l}\text { Automóvel transportando dois ou } \\
\text { mais estudantes; }\end{array}$ & \\
\hline Transporte escolar; & \\
\hline Ônibus; & \\
\hline Metrô; & \\
\hline Bicicleta; & \\
\hline
\end{tabular}


A pé

Questão 7 - Que fatores ou circunstâncias dificultariam ou impediriam que você deixasse que seu(sua) filho(a) usasse cada modo de transporte?

\begin{tabular}{|l|l|}
\hline MODO & O QUE DIFICULTARIA \\
\hline $\begin{array}{l}\text { Automóvel; transportando apenas } 1 \\
\text { estudante; }\end{array}$ & \\
\hline $\begin{array}{l}\text { Automóvel transportando dois ou } \\
\text { mais estudantes; }\end{array}$ & \\
\hline Transporte escolar; & \\
\hline Ônibus; & \\
\hline Metrô; & \\
\hline Bicicleta; & \\
\hline A pé & \\
\hline
\end{tabular}

\section{Para terminar informe suas características individuais:}

Dados do(a) respondente:

Sou: ( ) pai ( ) mãe Responsável ( ) do aluno da Série

Dados da viagem do respondente aluno:

Modo que o(a) aluno(a) mais utiliza para ir à escola:

Modo que o(a) aluno(a) mais utiliza para voltar da escola:

CEP ou Quadra/Bairro de residência do aluno(a):

Agradecemos sua contribuição individual. Caso queira participar da reunião de grupo focal que discutirá a mobilidade na escola veja o agendamento abaixo:

Reunião de grupo focal na escola:

Data:

Horário: 
APÊNDICE F - Planejamento e protocolo do grupo focal 


\section{APÊNDICE F - PLANEJAMENTO E PROTOCOLO DO GRUPO FOCAL}

Comportamento a ser estudado - escolha de determinado modo de transporte para vir ou voltar da IEM na última semana;

População - estudantes e pais de estudantes de Instituições de ensino médio;

1. Introdução e motivação da pesquisa;

Recepcionar os participantes e comentar:

"Esta reunião de grupo focal é parte de uma pesquisa realizada pelo Programa de Pós-graduação em Transportes da Universidade de Brasília. Seu objetivo é desenvolver um procedimento para a elaboração de programas de Gerenciamento da Mobilidade (GM) para Instituições de Ensino Médio (IEMs), baseado na identificação de fatores intervenientes no comportamento de escolha modal para o transporte de estudantes de e para essas instituições de ensino". Ler o termo TCLE de assentimento, e solicitar que, caso concordem com o termo, assinalem a concordância na primeira folha do questionário impresso. Os alunos devem trazer a autorização dos pais por escrito para participarem.

\section{Apresentação pessoal do moderador e de todos os presentes;}

\section{Apresentação da organização do evento;}

Entregar questionário inicial e comentar:

"Para a primeira parte da reunião estamos interessados nas opiniões individuais de cada participante. Cada um de vocês está recebendo um conjunto de questões a serem respondidos para cada modo de transportes. Não existem respostas certas ou erradas, pois estamos tão somente interessados em conhecer a sua opinião. Em resposta às questões, por favor, aponte a resposta que venha imediatamente à sua cabeça. Coloque cada resposta abaixo de cada pergunta. Todas as respostas serão tratadas de forma confidencial." Informe também que as opiniões colhidas nesta reunião subsidiarão um questionário que será aplicado a um grupo maior de alunos e pais.

\section{Preenchimento individual do questionário}

Orientar o preenchimento através de leitura dirigida das questões, e ao final comentar:

"Depois de dar sua opinião sobre cada modo de transporte, anote ao final alguns dados pessoais seus: A que turma você pertence (ou o seu filho); o CEP ou Bairro/quadra de residência; seu sexo (gênero); sua idade. Caso queira se identifique ao final.

\section{Identificação da percepção coletiva sobre a mobilidade de estudantes para a IEM.}

Para iniciar o estudo precisamos elencar todos os modos de transporte que o grupo considera viáveis para a realização dos deslocamentos de e para a escola, nos horários de entrada e saída dos turnos. Para facilitar a resposta das demais questões, anotaremos no quadro os modos de transporte considerados viáveis pelo grupo. Em seguida o grupo comentará as suas respostas por modo de transporte identificando as respostas que melhor qualificariam o comportamento de escolha do modo de transporte para a comunidade escolar.

\section{Agradecimento à participação e informação das demais etapas de pesquisa.}


APÊNDICE G - Questionário disponibilizado aos alunos na etapa de grupos focais 


\section{APÊNDICE G - QUESTIONÁRIO DISPONIBILIZADO AOS ALUNOS NA ETAPA DE GRUPOS FOCAIS;}

\section{Escola + verde}

QUESTIONÁRIO PARA A REUNIÃO DE GRUPOS FOCAIS

Esta reunião de grupo focal é parte de uma pesquisa realizada pelo Programa de Pósgraduação em Transportes da Universidade de Brasília. Seu objetivo é desenvolver um procedimento para a elaboração de programas de Gerenciamento da Mobilidade (GM) para Instituições de Ensino Médio (IEMs), baseado na identificação de fatores intervenientes no comportamento de escolha modal para o transporte de estudantes de e para essas instituições de ensino.

Cada participante está recebendo um conjunto de questões a serem respondidos para cada modo de transportes. Considere a possibilidade dos alunos utilizar diferentes modos de transporte para ir ou vir da escola. Não existem respostas certas ou erradas, pois estamos tão somente interessados em conhecer a sua opinião sobre a utilização de diferentes modos para ir ou vir da escola. Em resposta às questões, por favor, aponte a resposta que venha imediatamente à sua cabeça. Coloque cada resposta abaixo de cada pergunta. Todas as respostas serão tratadas de forma confidencial.

\section{Questão 1 - Identificação dos modos viáveis}

A partir da lista abaixo, assinale todos os modos de transporte que você considera que estão disponíveis para a realização dos deslocamentos de e para a escola, nos horários de entrada e saída dos turnos.

\begin{tabular}{|l|l|l|l|}
\hline ( ) & $\begin{array}{l}\text { Automóvel; transportando apenas 1 } \\
\text { estudante; }\end{array}$ & ( ) & $\begin{array}{l}\text { Automóvel transportando dois } \\
\text { ou mais estudantes; }\end{array}$ \\
\hline ( $\quad$ ) & Transporte escolar; & ( ) & Bicicleta; \\
\hline ( $\quad$ ) & Ônibus; & ( ) & A pé (todo o percurso); \\
\hline ( ) & Metrô; & & \\
\hline
\end{tabular}

Questão 2 - Quais são as vantagens que você vê em usar cada modo de transporte para vir e voltar da escola nos horários de entrada e saída dos turnos?

\begin{tabular}{|l|l|}
\hline MODO & VANTAGEM \\
\hline $\begin{array}{l}\text { Automóvel; transportando apenas 1 } \\
\text { estudante; }\end{array}$ & \\
\hline $\begin{array}{l}\text { Automóvel transportando dois ou } \\
\text { mais estudantes; }\end{array}$ & \\
\hline Transporte escolar; & \\
\hline Ônibus; & \\
\hline Metrô; & \\
\hline Bicicleta; & \\
\hline A pé & \\
\hline
\end{tabular}


Questão 3 - Quais são as desvantagens que você vê em usar cada modo de transporte para vir e voltar da escola nos horários de entrada e saída dos turnos?

\begin{tabular}{|l|l|}
\hline MODO & DESVANTAGEM \\
\hline $\begin{array}{l}\text { Automóvel; transportando apenas 1 } \\
\text { estudante; }\end{array}$ & \\
\hline $\begin{array}{l}\text { Automóvel transportando dois ou } \\
\text { mais estudantes; }\end{array}$ & \\
\hline Transporte escolar; & \\
\hline Ônibus; & \\
\hline Metrô; & \\
\hline Bicicleta; & \\
\hline A pé & \\
\hline
\end{tabular}

Questão 4 - Que pessoas ou grupos de pessoas aprovariam que você (ou seu filho-a) usasse cada modo de transporte?

\begin{tabular}{|l|l|}
\hline MODO & QUEM APROVARIA \\
\hline $\begin{array}{l}\text { Automóvel; transportando apenas 1 } \\
\text { estudante; }\end{array}$ & \\
\hline $\begin{array}{l}\text { Automóvel transportando dois ou } \\
\text { mais estudantes; }\end{array}$ & \\
\hline Transporte escolar; & \\
\hline Ônibus; & \\
\hline Metrô; & \\
\hline Bicicleta; & \\
\hline A pé & \\
\hline
\end{tabular}

Questão 5 - Que pessoas ou grupos de pessoas não aprovariam que você (ou seu filhoa) usasse cada modo de transporte?

\begin{tabular}{|l|l|}
\hline MODO & QUEM NÃO APROVARIA \\
\hline $\begin{array}{l}\text { Automóvel; transportando apenas 1 } \\
\text { estudante; }\end{array}$ & \\
\hline $\begin{array}{l}\text { Automóvel transportando dois ou } \\
\text { mais estudantes; }\end{array}$ & \\
\hline Transporte escolar; & \\
\hline Ônibus; & \\
\hline Metrô; & \\
\hline Bicicleta; & \\
\hline A pé & \\
\hline
\end{tabular}


Questão 6 - Que fatores ou circunstâncias facilitariam ou permitiriam que você (ou seu filho) usasse esse modo de transporte para ir ou voltar da escola?

\begin{tabular}{|l|l|}
\hline MODO & O QUÊ FACILITARIA \\
\hline $\begin{array}{l}\text { Automóvel; transportando apenas 1 } \\
\text { estudante; }\end{array}$ & \\
\hline $\begin{array}{l}\text { Automóvel transportando dois ou } \\
\text { mais estudantes; }\end{array}$ & \\
\hline Transporte escolar; & \\
\hline Ônibus; & \\
\hline Metrô; & \\
\hline Bicicleta; & \\
\hline A pé & \\
\hline
\end{tabular}

Questão 7 - - Que fatores ou circunstâncias dificultariam ou impediriam que você (ou seu filho) usasse esse modo de transporte para ir ou voltar da escola?

\begin{tabular}{|l|l|}
\hline MODO & O QUÊ DIFICULTARIA \\
\hline $\begin{array}{l}\text { Automóvel; transportando apenas 1 } \\
\text { estudante; }\end{array}$ & \\
\hline $\begin{array}{l}\text { Automóvel transportando dois ou } \\
\text { mais estudantes; }\end{array}$ & \\
\hline Transporte escolar; & \\
\hline Ônibus; & \\
\hline Metrô; & \\
\hline Bicicleta; & \\
\hline A pé & \\
\hline
\end{tabular}

Para terminar informe suas características individuais:

Turma: _ _ CEP ou Quadra/Bairro de residência:

Gênero: ___ Feminino; __ Masculino; _ Idade:

Meu nome (opcional):

Agradecemos sua contribuição individual. Participe também, na sequência da reunião, na elaboração das percepções coletivas sobre a mobilidade para a sua escola. 
APÊNDICE H - Questionário para alunos - Utilizado na etapa quantitativa 


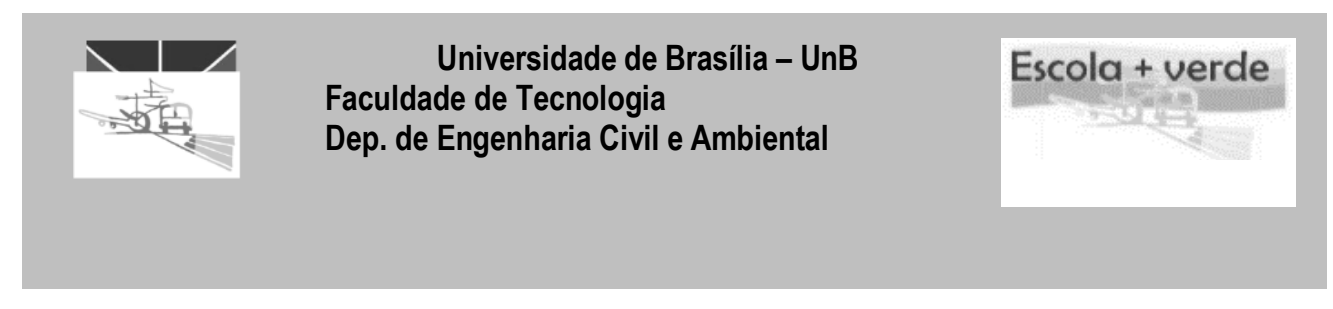

Você está sendo convidado a participar da pesquisa "Gerenciamento da mobilidade em viagens realizadas por estudantes de instituições de ensino médio: alternativas mediadas pela psicologia social", de responsabilidade de Ângela Beatriz Souza Bertazzo, aluna de doutorado da Universidade de Brasília. 0 objetivo desta pesquisa é desenvolver um procedimento para elaboração de programas de mobilidade urbana para comunidades de Escolas de Ensino Médio. Assim, gostaria de consultá-lo (a) sobre seu interesse e disponibilidade de cooperar com a pesquisa, através da manifestação da sua opinião sobre o tema.

Sua participação é voluntária e livre de qualquer remuneração ou benefício. Você é livre para recusarse a participar, retirar seu consentimento ou interromper sua participação a qualquer momento. A recusa em participar não irá acarretar qualquer penalidade ou perda de benefícios. Fica assegurado que o seu nome, email, voz ou qualquer outra informação pessoal recebida durante a pesquisa, não será divulgado, mantendo a confidencialidade das informações. Os dados provenientes de sua participação na pesquisa ficarão sob a guarda da pesquisadora responsável pela pesquisa.

Se você tiver qualquer dúvida em relação à pesquisa, você pode me contatar através do telefone 61 81560852 ou pelo e-mail angela.bertazzo@hotmail.com. A eChipe de pesquisa garante que os resultados do estudo serão devolvidos aos participantes por meio do email informado, podendo ser publicados posteriormente na comunidade científica. Este projeto foi revisado e aprovado pelo Comitê de Ética em Pesquisa do Instituto de Ciências Humanas da Universidade de Brasília - CEP/IH. As informações com relação à assinatura do TCLE ou os direitos do sujeito da pesquisa podem ser obtidas através do e-mail do CEP/IH cep_ih@unb.br.

\section{POR FAVOR, SE VOCÊ CONCORDOU COM OS TERMOS ACIMA, MARQUE SUA} CONCORDÂNCIA E ASSINE LOGO ABAIXO.

\section{Concordo em participar}

ASSINATURA:

DATA;

Obrigada por sua colaboração! 


\section{Modo a pé}

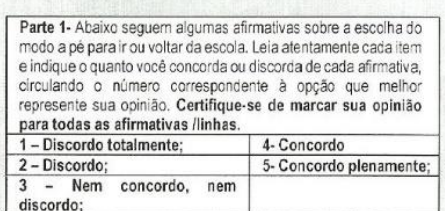

\begin{tabular}{|l|l|l|l|l|l|}
\hline$E$ É cansativo ir ou voltar a pe da & 1 & 2 & 3 & 4 & 5
\end{tabular}

Ascola.

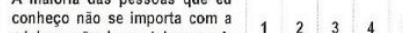

minha opça de camin

Meus amigos me a

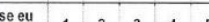

essoas próximas a mor act

\begin{tabular}{ll|l|l|l|l|}
$\begin{array}{l}\text { que minha opcáo de caminhar } \\
\text { para ir ou voltar da escola e }\end{array}$ & 1 & 2 & 3 & 4
\end{tabular}

\begin{tabular}{l|lll|l|l|}
\hline Prettadendo caminhar para ir ou & 1 & 2 & 3 & 4
\end{tabular}

\begin{tabular}{|l|l|l|l|l|l|}
\hline \multirow{E}{E}{ Eseguro ir ou voltar a pé da } & 1 & 2 & 3 & 4 & 5 \\
\hline
\end{tabular}

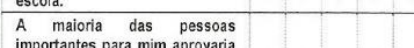

$\begin{array}{llllllll}\text { minha opcáo de caminhar da } & 1 & 2 & 3 & 4 & 5\end{array}$

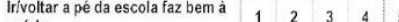

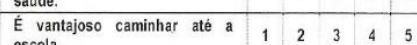

\begin{tabular}{|l|l|l|l|l|l|}
\hline $\begin{array}{l}\text { Meus pais me incentivam a ir ou } \\
\text { voltar da escola a pe. }\end{array}$ & 1 & 2 & 3 & 4 & 5 \\
\hline Oat
\end{tabular}

\begin{tabular}{l|l|l|l|l|l|}
\hline $\begin{array}{l}\text { O caminho para in ou voltar a pé } \\
\text { da ascola é éluminado. }\end{array}$ & 1 & 2 & 3 & 4 & 5 \\
\hline
\end{tabular}

Parte 2: A seguir jugue as afrmativas abaixo, numa esccla ce 1 a

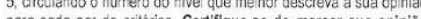
para todas as afirmativas linhas. Minha intençăo de ir ou voltar da escola caminhando é:

$\begin{array}{llllllll}\text { Fraca } & 1 & 2 & 3 & 4 & 5 & \text { Forte }\end{array}$ Devo avaliar se o caminho é iluminado para irrvoltar a pé da \begin{tabular}{lllllllll}
\hline Dificilmente & 1 & 2 & 3 & 4 & 5 & Provavelmente \\
\hline
\end{tabular}
Página $1 / 8$

Nas proximas semanas, eu irei o u vollarei da escola caminhando. \begin{tabular}{llllllll} 
Dificilmente & 1 & 2 & 3 & 4 & 5 & Certamente \\
\hline
\end{tabular} Considero o fato de meus amigos me apoiarem a irivoltar a pé da \begin{tabular}{l|lllllll|}
\hline Negativo & 1 & 2 & 3 & 4 & 5 & Positivo \\
\hline
\end{tabular} Para mim, caminhar para i ir ou voltar da escola seria: \begin{tabular}{l|llllll|l|} 
Ruim & 1 & 2 & 3 & 4 & 5 & Bom \\
\hline
\end{tabular} Para mim, caminhar para ir ou voltar da escola seria: Procuparsecon ser mis sol

$\begin{array}{lllllllll}\text { Ruim } & 1 & 2 & 3 & 4 & 5 & \text { Bom }\end{array}$

Para mim, caminhar para ir ou voltar da escola seria:

Desagradavel $110 \begin{array}{llllll}1 & 2 & 3 & 4 & 5 & \text { Agradavel }\end{array}$

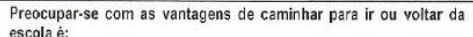
\begin{tabular}{lllllllll}
\hline Ruim & 1 & 2 & 3 & 4 & 5 & Bom
\end{tabular} Para mim, caminhar para ir ou voltar da escole ser. $\begin{array}{lllllll}\text { Negativo } & 1 & 2 & 3 & 4 & 5 & \text { Positivo }\end{array}$ Devo avaliar se o trajeto è cansativo para irivivoltara pés da escola \begin{tabular}{llllllll} 
Dificilmente & 1 & 2 & 3 & 4 & 5 & Provavelmente \\
\hline
\end{tabular} Prezar pela seguranca a co caminhar para ire voltar da escola é: $\begin{array}{llllllll}\text { Ruim } & 1 & 2 & 3 & 4 & 5 & \text { Bom }\end{array}$ Considero o fato de meus pais me incentivarem a ir ou voltar da \begin{tabular}{lllllllll}
\hline & escola a pe como: \\
\hline Negativo & 1 & 2 & 3 & 4 & 5 & Postivo
\end{tabular}

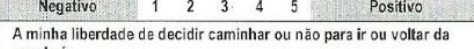
A minha liberdade de dectarl cand
escola e:

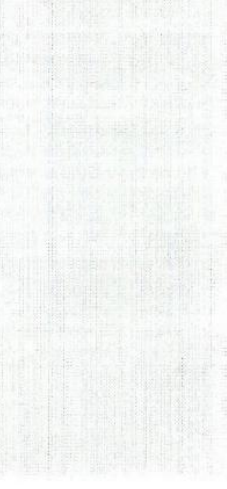


Página 2

Modo Automóvel carona Parte 1. Abaixo sevyen alyumas affirmativas sobre a escolha do nodo automovel carona para ir ou voltar da escola Leia a':entament
cada item e airmativa, circulando o numero correspondente à opgăo cue melh represente sua opiniễo. Cerno
todas as afirmativas llinhas

\begin{tabular}{l|l} 
1-Discordo totalmente; & 4. Concordo \\
\hline 2-Discordo; & 5. Concordo \\
\hline -
\end{tabular} \begin{tabular}{l|l} 
2-Discordo; & 3-Concordo plenamente; \\
\hline -Nem concordo, nem discordo; &
\end{tabular}

$\begin{array}{llllllll}\begin{array}{l}\text { Dar ou pegar carona para ir ou voltar } \\ \text { da escola }\end{array} \text { facilita fazer novas } & 1 & 2 & 3 & 4 & 5\end{array}$ \begin{tabular}{l} 
amizades. \\
\hline Pretendo darlpegar carona para ir ou \\
\hline A
\end{tabular}

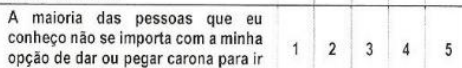
opçáo de dar ou pegar car
ou voltar da escola.

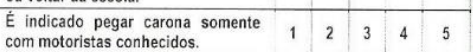
\begin{tabular}{lll|l|l|l|l|}
$\begin{array}{l}\text { Meus pais me incentivam a dar ou } \\
\text { pegar carona para ir ou voltar da }\end{array}$ & 1 & 2 & 3 & 4 & 5
\end{tabular}

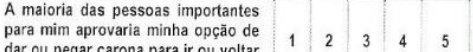

dar ou pearc
da escola

\begin{tabular}{l|l|l|l|l|l}
\hline $\begin{array}{l}\text { Pesssoas próximas a mim acham que } \\
\text { minha opçâ de dar ou pegar carona }\end{array}$ & 1 & 2 & 3 & 4 & 5
\end{tabular}

arai ir ous voltar da a escola ear carona

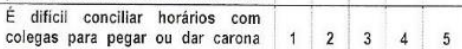

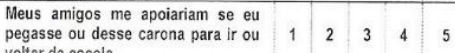

voltar da escola

\begin{tabular}{l|l|l|l|l|l|}
$\begin{array}{l}\text { Euma boa idela dar ou pegar carona } \\
\text { para ir ou voltar da escola. }\end{array}$ & 1 & 2 & 3 & 4 & 5 \\
\hline
\end{tabular}

\begin{tabular}{|l|l|l|l|l|l|}
\hline $\begin{array}{l}\text { E seguro pegar ou dar carona a } \\
\text { colegas para ir ou voltar da escola. }\end{array}$ & 1 & 2 & 3 & 4 & 5 \\
\hline
\end{tabular}

\begin{tabular}{ll|l|l|l|l|}
$\begin{array}{l}\text { Quem pega carona para ir uu voltar } \\
\text { da escola deve "rachar" a gasolina. }\end{array}$ & 1 & 2 & 3 & 4 & 5
\end{tabular}

Parte 2: A seguir julgue as afirmalivas abaixo, numa escala de 1 a 5 ,

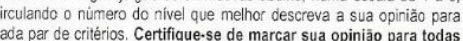
ss afirmativas llinhas.

Para mim, dar ou pegar carona para ir ou voltar da escola seria:

$\begin{array}{llllllll}\text { Desagradavel } & 1 & 2 & 3 & 4 & 5 & \text { Agradavel }\end{array}$

Considero fato de meus amigos me apoiarem a dar ou pegar carona
para irr voltar da escola coma

para in voltar da escola

$\begin{array}{lllllllll}\text { Negativo } & 1 & 2 & 3 & 4 & 5 & \text { Positivo }\end{array}$
Para mim, dar ou pegar carona para irt voltar da escola seria:

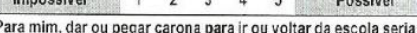
Negativo $\quad \begin{array}{lllllll}1 & 2 & 3 & 4 & 5 & \text { Positivo }\end{array}$ Prezar pela segurança ao pegar ou dar carona a colegas para ir evoltar da escola e: \begin{tabular}{c|ccccc|c} 
Ruim & 1 & 2 & 3 & 4 & 5 & Bom \\
\hline Minha intençāo de pegar ou dar carona pera ir ou voltar da
\end{tabular}

$\begin{array}{llllllll}\text { Fraca } & 1 & 2 & 3 & 4 & 5 & \text { Fotte }\end{array}$ Para mim, dar ou pegar carona para ir ou voltar da escola seria:-

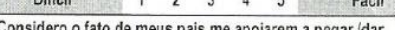

carona como:

$\begin{array}{llllllll}\text { Negativo } & 1 & 2 & 3 & 4 & 5 & \text { Positivo }\end{array}$ Nas próximas semanas, eu irei pegar ou dar carona para ir \begin{tabular}{ccccccc}
\hline ou voltar da escola. & & & & \\
\hline Diffilmente & 1 & 2 & 3 & 4 & 5 & Certamente \\
\hline Pate & & &
\end{tabular} \begin{tabular}{lllllll} 
Dificcilmente & 1 & 2 & 3 & 4 & 5 & Certamente \\
\hline Para mim, dar ou pegar carona para ir ou voltar da escola seria:
\end{tabular} Para mim, dar ou pegar carona para ir ou voltar da escola seria: Ponderar sobre as vantagens de pegar ou dar carona ao i o ou voltar da escola è: $\begin{array}{llllllll}\text { Ruim } & 1 & 2 & 3 & 4 & 5 & \text { Bom }\end{array}$ Devo considerar se eu conheço o motorista para pegar carona para ir ou voltar da escol \begin{tabular}{llllllll}
\hline Dificilmente & 1 & 2 & 3 & 4 & 5 & Provavelmente \\
\hline Prite &
\end{tabular} Para mim, fazer novas amizades ao dar ou pegar carona para Rin Se eu fosse pegar carona $\begin{array}{llllll} & 4 & 4 & 5 & \text { Bom }\end{array}$ racharia a gasolina \begin{tabular}{llllllll} 
Dificilmente & 1 & 2 & 3 & 4 & 5 & Provavelmente \\
\hline Defris
\end{tabular} Devo pensar em conciliar horários para pegar ou dar carona $\begin{array}{llllllll}\text { Dificilmente } & 1 & 2 & 3 & 4 & 5 & \text { Provavelmente }\end{array}$ A minha liberdade de pegar ou dar carona para ir ou voltar da

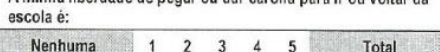

\section{Modo transporte escolar}

Parte 1. Abaixo seguem agumas afirmativas sobre a escolha
do modo transporte escolara para ir ou voltar da escola. Leia

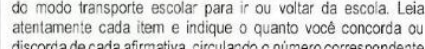

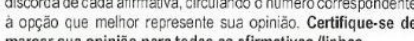

- Discordo;

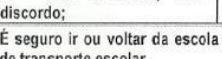

$\begin{array}{lllllllll}\begin{array}{l}\text { que minha opcäo de usar } \\ \text { transporte escolar para ir ou }\end{array} & 1 & 2 & 3 & 4 & 5\end{array}$

voltar da escola è acertada.

\begin{tabular}{|l|l|l|l|l|l|}
\hline Usar transporte escolar é caro. & 1 & 2 & 3 & 4 & 5 \\
\hline A
\end{tabular}

A maioria das pessoos

$\begin{array}{lllllll}\begin{array}{c}\text { importantes para mim aprovaria } \\ \text { minha oppáa de eusar transporte }\end{array} & 1 & 2 & 3 & 4 & 5\end{array}$

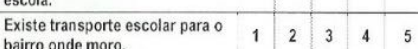

\begin{tabular}{|l|l|l|l|l|l|}
\hline $\begin{array}{l}\text { bairro onde moro. } \\
\begin{array}{l}\text { E perigoso ficar esperando pelo } \\
\text { transporte escolar }\end{array}\end{array}$ & 1 & 2 & 3 & 4 & 5 \\
\hline
\end{tabular}

A maioria das pessoas que en
conheco nào se importa com

\begin{tabular}{l|l|l|l|l|l|}
$\begin{array}{l}\text { minhh oppáa de usartransporte } \\
\text { escolar para ir ou voltar da }\end{array}$ & 1 & 2 & 3 & 4 & 5 \\
\hline
\end{tabular}

escolar para ir ou voltar
escola.

Meus amigos me apoiariam
eu utilizasse transporte escold

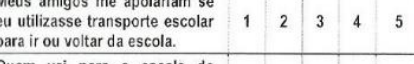

transporte escolar
chegar no horario certo.

escolar para is on voltar da

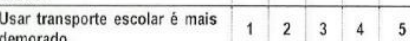

Meus pais nāo contratariam un

Meus pals nao contratariam un
servigo de transporte escolar

para mim, mesmo que tivessent
condiçés financeiras para iss.

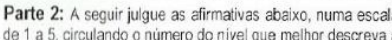

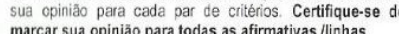

Considero o fato de meus pais decidirem por mim a

Constidero o fato de muss pais decidiriem por
contratąio do serviç de de transporte escolar como:

\begin{tabular}{lllllllll}
\hline Negativo & 1 & 2 & 3 & 4 & 5 & Positivo
\end{tabular}
Página $3 / 8$ para ir ou voltar da escola seria $\begin{array}{llllllll}\text { Desagradavel } & 1 & 2 & 3 & 4 & 5 & \text { Agradavel }\end{array}$ Prear pela segurança ao usar transporte escolar $\mathrm{e}$ : $\begin{array}{lllllll}\text { Ruim } & 1 & 2 & 3 & 4 & 5\end{array}$ Bom Considero o fato de meus amigos me apoiarem, se eu utilizar $\begin{array}{llllllll}\text { Negativo } & 1 & 2 & 3 & 4 & 5 & \text { Positivo }\end{array}$

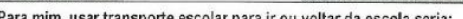

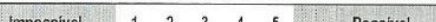
Devo cuidar pela minha interidde fisica ao esperar pelo transporte

\begin{tabular}{l|lllllll|} 
Diffcilmente & 1 & 2 & 3 & 4 & 5 & Provavelmente \\
\hline
\end{tabular} Prezar pela pontualidade ao usar transporte escolar é: $\begin{array}{lllllllll}\text { Ruim } & 1 & 2 & 3 & 4 & 5 & \text { Bom }\end{array}$ Para mim, usar transporte escolar para ir ou voltar da escola seria: $\begin{array}{lllllllll}\text { Negativo } & 1 & 2 & 3 & 4 & 5 & \text { Positivo }\end{array}$ Devo considerar o preco do servico para contratar o transporte

$\begin{array}{llllllll} & 1 & 2 & 3 & 4 & 5 & \text { Provavelmente }\end{array}$

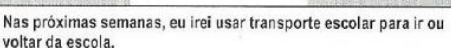

$\begin{array}{llllllll}1 & 2 & 3 & 4 & 5 & \text { Certamente }\end{array}$

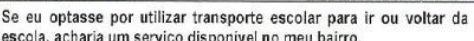
$\begin{array}{lllllll}\text { Dificilmente } & 1 & 2 & 3 & 4 & 5\end{array}$

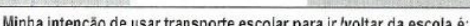
peocupar-me com o tempo de viegem ao usar transporte escolar é: $\begin{array}{lllllllll}\text { Ruim } & 1 & 2 & 3 & 4 & 5 & \text { Bom }\end{array}$ Para mim, usar transporte escolar para ir ou voltar da escola seria:

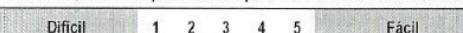
Para mim, usar transporte escolar para ir ou voltar da escola seria: $\begin{array}{llllllll}\text { Ruim } & 1 & 2 & 3 & 4 & 5 & \text { Bom }\end{array}$ A minha liberdade de usar transporte escolar para ir ou voltar da escola e:

\begin{tabular}{l|lllll|l|l|} 
Nenhuma & 1 & 2 & 3 & 4 & 5 & Total
\end{tabular} 


\section{Página $4 / 8$}

\section{Modo automóvel da família}

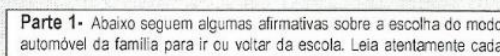

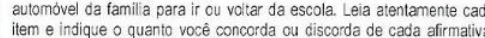

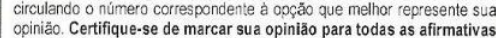
\begin{tabular}{l} 
linhas \\
\hline 1-Discord totalmente;
\end{tabular} \begin{tabular}{|l|l|}
\hline 2-Discordototalmente; & 4 C Concordo \\
\hline 3-Nem concordo, nem discordo: & 5. Concordo plenamente; \\
\hline
\end{tabular} \begin{tabular}{|l|l|l|l|l|l|}
\hline $\begin{array}{l}\text { Meus amigos me apoiariam se eu } \\
\text { utilizasse carro para ir ou voltar da }\end{array}$ & 1 & 2 & 3 & 4 & 5 \\
\hline
\end{tabular} \begin{tabular}{l} 
escola. \\
\hline Meus pais preferem me trazer de
\end{tabular} A maioria das pessoas que eu
conheco năo se importa coma minha opçăo de usar automóvel da familia 150 Pretendo usar a atomóvel da familita \begin{tabular}{ll|lllll}
\hline paranti ir ou voltar da escola. & a familia & 1 & 2 & 3 & 4 & 5
\end{tabular} $\begin{array}{lllllll}1 & 2 & 3 & 4 & 5\end{array}$ voltar da esco. \begin{tabular}{|l|l|llllll}
\hline Quem vai para a escola de carro nåo & 1 & 2 & 3 & 4 & 5
\end{tabular}

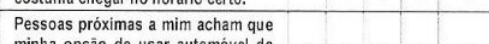
$\begin{array}{llllllll}\begin{array}{l}\text { minha opcaio de usar automovel da } \\ \text { familia para ir ou voltar da escola e }\end{array} & 1 & 2 & 3 & 4 & 5\end{array}$ \begin{tabular}{|l|l|l|l|l|l|}
\hline Ir ou voltar da escola de carro é caro. & 1 & 2 & 3 & 4 & 5 \\
\hline
\end{tabular}

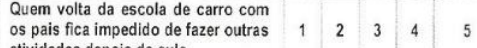
\begin{tabular}{|c|c|c|c|c|c|}
$\begin{array}{c}\text { Vir ou voltar da escola de carro } \\
\text { contribui para } \\
\text { piorar }\end{array}$ o & 1 & 2 & 3 & 4 & 5 \\
\hline
\end{tabular}

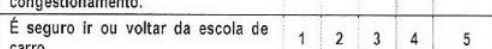

2: Parte 2-A seguiri ulugue as afirmalivas abaiko, numa essala de 1 a 5 ,

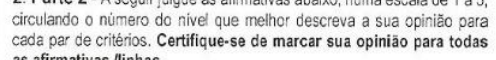

Considero o fato de meus pais preferirem me trazer de carro para a

\begin{tabular}{ll|lllll|l|l|} 
Negativo & 1 & 2 & 3 & 4 & 5 & Positivo \\
\hline
\end{tabular} Para mim, usar automóvel da familia para ir ou voltar da escola seria: \begin{tabular}{l|lllllll} 
Ruim & 1 & 2 & 3 & 4 & 5 & Bom
\end{tabular} A minha liberdade de usar automóvel da familia para ir ou voltar da

\begin{tabular}{l|lllll|l|} 
Nenhuma & 1 & 2 & 3 & 4 & 5 & Total
\end{tabular}

\section{Modo metrô}

Nas próximas semanas, eu irei usar automóvel da famili

Dificilmente $\quad \begin{array}{llllllll}1 & 2 & 3 & 4 & 5 & \text { Certamente }\end{array}$ Prezar pela pontualidade ao usar carro para ir ou voltar $d a$

$\begin{array}{llllllll}\text { Ruim } & 1 & 2 & 3 & 4 & 5 & \text { Bom }\end{array}$ Para mim, usar automóvel da familia para ir ou voltar da escola

$\begin{array}{llllllll}\text { Dificil } & 1 & 2 & 3 & 4 & 5 & \text { Fácil }\end{array}$ linha intenção de usar automóvel da famllia para ir ou volter

\begin{tabular}{l|lllllll|} 
Fraca & 1 & 2 & 3 & 4 & 5 & Forte
\end{tabular} Para mim usar ato seria:

$\begin{array}{llllllll}\text { Impossivel } & 1 & 2 & 3 & 4 & 5 & \text { Possivel }\end{array}$ Para mim, usar automóvel da familila para ir ou voltar da escola

$\begin{array}{llllllll}\text { Negativo } & 1 & 2 & 3 & 4 & 5 & \text { Positivo }\end{array}$ Devo considerar o custo de usar carro para decidiri rivvoltar da
escola de carro \begin{tabular}{llllllll} 
Dificilmente & 1 & 2 & 3 & 4 & 5 & Provavelmente \\
\hline
\end{tabular} Para mim, usar automóvel da familia para ir ou voltar da escola

\begin{tabular}{llllllll|}
\hline Desagradavel & 1 & 2 & 3 & 4 & 5 & Agradável \\
\hline
\end{tabular} Eu nãof faria nada depois da aula se voltasse da escola de carro com meus pais.

\begin{tabular}{lllllllll}
\hline Dificilmente & 1 & 2 & 3 & 4 & 5 & Provavelmente \\
\hline
\end{tabular} Prezar pela segurança ao usar carro para ir ou voltar dia escold $\begin{array}{llllllll}\text { Rulm } & 1 & 2 & 3 & 4 & 5 & \text { Bom }\end{array}$ Preocupar-se com os congestionamentos ao usar carro para
vir ou voltar da escolaét: $\begin{array}{llllllll}\text { Ruim } & 1 & 2 & 3 & 4 & 5 & \text { Bom }\end{array}$ Considero o fato de meus amigos me apoiarem a usar 0 \begin{tabular}{lllllllll}
\hline Negativo & 1 & 2 & 3 & 4 & 5 & Positivo
\end{tabular}

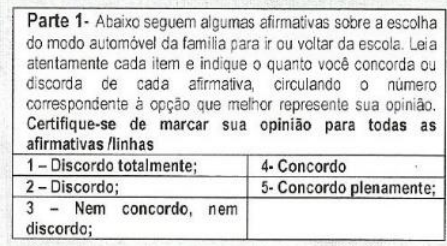

A maioria das pessoas que eu

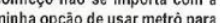

ir ou voltar da escola.

\begin{tabular}{llllllll}
\hline Otrecho a pé entre a escola e a & 1 & 2 & 3 & 4 & 5
\end{tabular}

\begin{tabular}{|l|l|l|l|l|l|}
\hline A viagem dentro do metros nằo é & 1 & 2 & 3 & 4 & 5 \\
\hline
\end{tabular} segura.

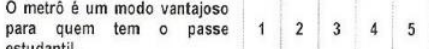

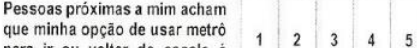

para ir
acertrada

\begin{tabular}{l|lllllll}
\hline $\begin{array}{l}\text { Meusuamigos me apoiariam se } \\
\text { eu utilizasse metro para ir ou }\end{array}$ & 1 & 2 & 3 & 4 & 5
\end{tabular}

\begin{tabular}{c|c|c|c|c|c|c|}
\hline $\begin{array}{c}\text { confortável usar metró, } \\
\text { mesmo quando se viajaja em pê. }\end{array}$ & 1 & 2 & 3 & 4 & 5 \\
\hline
\end{tabular}

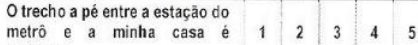

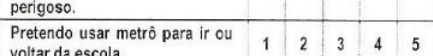

voltar da escola.

\begin{tabular}{lllllllll}
\hline $\begin{array}{c}\text { A maloria das pessoas } \\
\text { importantes para mim aprovaria }\end{array}$ & 1 & 2 & 3 & 4 & 5
\end{tabular}

minha opçăo de usar metrô $\mathrm{p}$

ir ou voltar da escola.

\begin{tabular}{llllllll} 
& metró. & 1 & 2 & 3 & 4 & 5 \\
\hline
\end{tabular}

Não è seguro esperar pelo $\mathrm{m}$

\begin{tabular}{llllll}
1 & 2 & 3 & 4 & 5 \\
\hline
\end{tabular}

Quem vai para a escola
Página $5 /$

Parte 2: A seguir jugue as ffirmativas abaixo, numa escela de 1 a 5 .

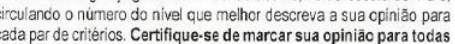
Devereas $\begin{array}{lllllll}\text { Difcilmente } & 1 & 2 & 3 & 4 & 5 & \end{array}$

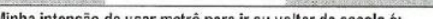
\begin{tabular}{lllllllll}
\hline Fraca & 1 & 2 & 3 & 4 & 5 & & & Fote
\end{tabular} Para mim, usar metró para ii ou voltar da escole seriar Ruim $\begin{array}{lllllll}1 & 2 & 3 & 4 & 5\end{array}$ Considero o fato de meus pais me incentivarem a vir ou volter de escola de metró como: \begin{tabular}{l|llllll} 
Negativo & 1 & 2 & 3 & 4 & 5
\end{tabular}$\quad$ Positiv Para mim, usar metró para ir ou voltar da escola seria: \begin{tabular}{lllllll} 
Impossivel & 1 & 2 & 3 & 4 & 5 & Possiva \\
\hline & Para mim &
\end{tabular} Para mim, usar metró para ir ou voltar da escola seria:

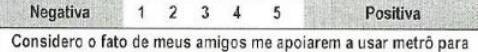
$\begin{array}{llllllll}\text { Nirvoltar da escola como: } & & & & \\ \text { Negativo } & 1 & 2 & 3 & 4 & 5 & \text { Positivo }\end{array}$ Nas próximas semanas, eu irei usar metró para ir ou voltar da escola

\begin{tabular}{llllllll}
\hline Dificilmente & 1 & 2 & 3 & 4 & 5 & Certamente \\
\hline
\end{tabular} Para mim, usar metró para ir ou yoltar da es cola seria:

$\begin{array}{lllllll}\text { Dificil } & 1 & 2 & 3 & 4 & 5\end{array} \quad$ Facil Acho que posso ser agredido no trecho entre a escola a e estação \begin{tabular}{llllllll}
\hline Dificilmente & 1 & 2 & 3 & 4 & 5 & Provavelmente
\end{tabular} Acho que posso ser agredido no trecho entre a estaçăo do metrò \begin{tabular}{llllllll}
\hline Difcilimente & 1 & 2 & 3 & 4 & 5 & Provavelmente \\
\hline &
\end{tabular} Ter passe estudantil para usar ometro e: Para mim, usar metrôp para ir ou yoltar da escola seria:

\begin{tabular}{lllllllll}
\hline Desagradivel & 1 & 2 & 3 & 4 & 5 & 5
\end{tabular} Prezar pelo conforto ao usar o metró

Ruim $122^{2} 4$ Bom Ruim 12 (2 4 Aminhal iberdade de usarmetró para ir ou $\begin{array}{lllllll}\text { Nenhuma } & 1 & 2 & 3 & 4 & 5\end{array} \quad$ Total

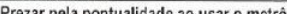

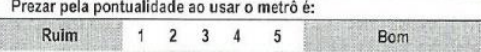




\section{Página 618}

Modo ônibus (público)

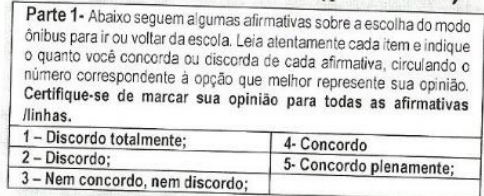
\begin{tabular}{ll|l|l|l|l|}
$\begin{array}{l}\text { A viagem dentro do ônibus não é } \\
\text { segura. }\end{array}$ & 1 & 2 & 3 & 4 & 5 \\
\hline Meusa a
\end{tabular} \begin{tabular}{|l|l|l|l|l|l|}
\hline $\begin{array}{l}\text { Meus amigos me apoiariam se eu } \\
\text { utilizasse onibus para ir ou voltar da }\end{array}$ & 1 & 2 & 3 & 4 & 5 \\
\hline
\end{tabular}

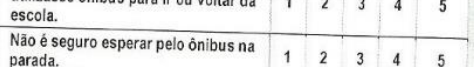
parada.

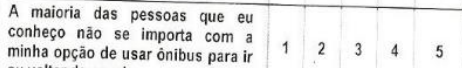

\begin{tabular}{ll|l|l|l|l|l|}
$\begin{array}{l}\text { Oónibus e e um modo vantajoso para } \\
\text { cuem temo passe estudantil. }\end{array}$ & 1 & 2 & 3 & 4 & 5 \\
\hline
\end{tabular} Pessoas próximas a mim ach

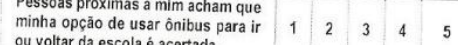
0 trecho a pé entre a escola e a

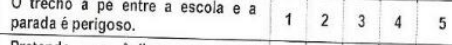
\begin{tabular}{|l|l|l|l|l|l|l|}
\hline $\begin{array}{l}\text { Pretendo usar oonibus para ir ou } \\
\text { voltar da escola. }\end{array}$ & 1 & 2 & 3 & 4 & 5 \\
\hline
\end{tabular}

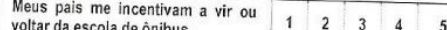
\begin{tabular}{l|l|l|l|l|l|l|}
\hline $\begin{array}{l}\text { Quem vai para a escolla de onibus } \\
\text { nào costuman cheagar atrasado }\end{array}$ & 1 & 2 & 3 & 4 & 5 \\
\hline
\end{tabular} A maioria das pessoas importantes

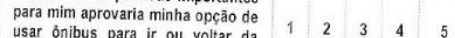

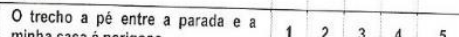
\begin{tabular}{|l|l|l|l|l|l|}
\hline entre a minha casa e e escola anibus & 1 & 2 & 3 & 4 & 5 \\
\hline
\end{tabular} \begin{tabular}{l|l|l|l|l|l|}
$\begin{array}{l}\text { Oo ônibus é superlotado para quem } \\
\text { vai ou volta da essola. }\end{array}$ & 1 & 2 & 3 & 4 & 5 \\
\hline
\end{tabular}

Parte 2: A seguir juluge as affmalivas abaixo, numa escela de 1 a 5 .

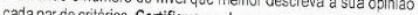
as afirmativivas llinhas. Para mim, usar ónibus para ir ou voltar da escola seria: \begin{tabular}{lllllllll} 
Dificil & 1 & 2 & 3 & 4 & 5 & Fácil \\
\hline
\end{tabular}

\begin{tabular}{l} 
Para mim, usar ônibus para ir ou voltar da escola seria: \\
Negativa \\
\hline
\end{tabular}
Para mim, usar ônibus para i o ou voltar da escola seria: Impossivel $\quad \begin{array}{lllllll}1 & 2 & 3 & 4 & 5 & \text { Possivel }\end{array}$ Considero o fato de meus amigos me apoiarem a usar ônibus

$\begin{array}{lllllllll}\text { Negativo } & 1 & 2 & 3 & 4 & 5 & \text { Positivo }\end{array}$ Prezar pela segurança dentro do ônibus

$\begin{array}{lllllllll}\text { Rulm } & 1 & 2 & 3 & 4 & 5 & \text { Bom }\end{array}$ Nas próximas semanas, eu iré usar ônibus para ir ou voltar da

$\begin{array}{llllllll}\text { Dificilmente } & 1 & 2 & 3 & 4 & 5 & \text { Certamente }\end{array}$ Ter passe estudantil para usar ônibus

Ruim $\quad \begin{array}{llllllll}1 & 2 & 3 & 4 & 5 & \text { Bom }\end{array}$

Winha intenç̧ăo de usar onnibus para ir ou voltar da escola á: $\begin{array}{llllllll}\text { Fraca } & 1 & 2 & 3 & 4 & 5 & \text { Forte }\end{array}$

Devo prezar pela segurança ao esperar pelo ônibus na parada. Dificilmente $\quad \begin{array}{lllllll}1 & 2 & 3 & 4 & 5 & \text { Provavelmente }\end{array}$ Para mim, usar ônibus para ir ou voltar da escola seria: Ruim $\quad \begin{array}{llllllll}1 & 2 & 3 & 4 & 5 & \text { Bom }\end{array}$ Considero o fato de meus pais me incentivarem a vir ou voltar

$\begin{array}{llllllll}\text { Negativo } & 1 & 2 & 3 & 4 & 5 & \text { Positivo }\end{array}$ Para mim, usar ônibus para ir ou voltar da escola seria: $\begin{array}{llllllll}\text { Desagradavel } & 1 & 2 & 3 & 4 & 5 & \text { Agradavel }\end{array}$ Cuidar a pontualidade ao usar ònibus para i para a escola é:

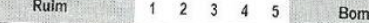
Acho que posso ser agredido no trecho entre a escola e a

$\begin{array}{llllllll}\text { Dificilmente } & 1 & 2 & 3 & 4 & 5 & \text { Provavelmente }\end{array}$ Para mim, seria possivel utilizar uma linha direta de ônibus para $\begin{array}{lllllllll}\text { Dificilmente } & 1 & 2 & 3 & 4 & 5 & \text { Provavelmente }\end{array}$ A minha liberdade de usar ónibus para ir ou voltar da escola éc$\begin{array}{llllllll}\text { Nenhuma } & 1 & 2 & 3 & 4 & 5 & \text { Total }\end{array}$ Preocupar-se com a lotaçăo do ónibus para ir ou voltar da
escola â: $\begin{array}{llllllll}\text { Ruim } & 1 & 2 & 3 & 4 & 5 & \text { Bom }\end{array}$

\section{Modo bicicleta}

Parte 1. Abaixo seguem algumas afrmativas sobre a escol

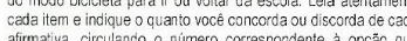

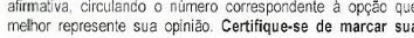
opinizio para todas as affrmativas llinhas.

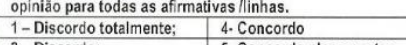
\begin{tabular}{l|l}
\hline 2-Discordo; & 5.Concordo plenamente; \\
\hline 3 -Nem concordo, nem \\
discordo:
\end{tabular}

\begin{tabular}{l}
$\begin{array}{l}\text { Meus amigos me apoiariam se eu } \\
\text { utilizasse bicicleta para ir ou }\end{array}$ \\
\hline
\end{tabular} voltar da escola.

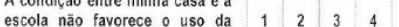
Parra mim, usar bicicicleta para i r ou voltar da escola seria:

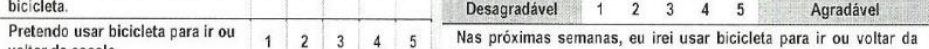

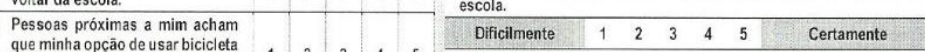
\begin{tabular}{llllllllll}
$\begin{array}{l}\text { que minha opcäa de usar bicicletata } \\
\text { para ir ou voltar da escola } \mathrm{e}\end{array}$ & 1 & 2 & 3 & 4 & 5 & $\begin{array}{l}\text { Dificlimente } \\
\text { Para mim, usar bicicleta para ir ou voltar da escola seria: }\end{array}$ \\
\hline
\end{tabular}

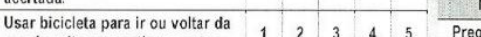

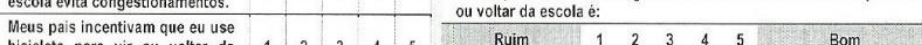

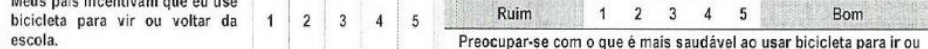

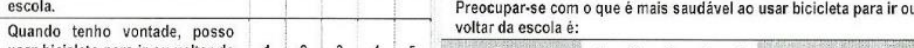
$\begin{array}{llllllllll}4 & 5 & \text { Ruim } & 1 & 2 & 3 & 4 & 5 & \text { Bom }\end{array}$ \begin{tabular}{l}
$\begin{array}{l}\text { A maioria das pessoas que eu } \\
\text { conhegé nào se importa com a }\end{array}$ \\
\hline
\end{tabular}

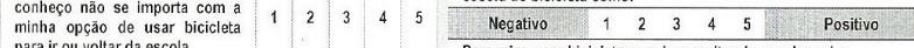
\begin{tabular}{l} 
para ir ou voltar da escola. \\
Moro muito longe da escola para \\
\hline A
\end{tabular}

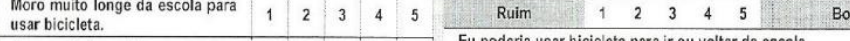
A maioria das pessoas
importantes para mim aprovaria

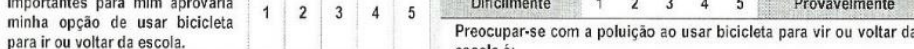

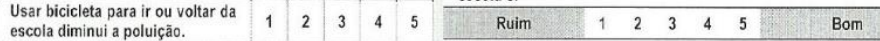

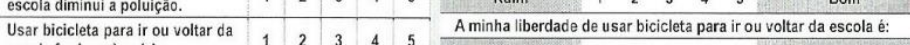

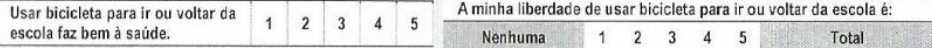

Parte 2: A seguiri jugyue as afirmativas abaixo, numa escala co opiniäo para cada par de critiérios. Certififiue-se de marccar sua Considero of fato de meus amigos $\mathrm{m}$,
bicicieta para irlyoltar da escolla como:

\begin{tabular}{llllllll}
\hline Negativo & 1 & 2 & 3 & 4 & 5 & Postivo
\end{tabular} 


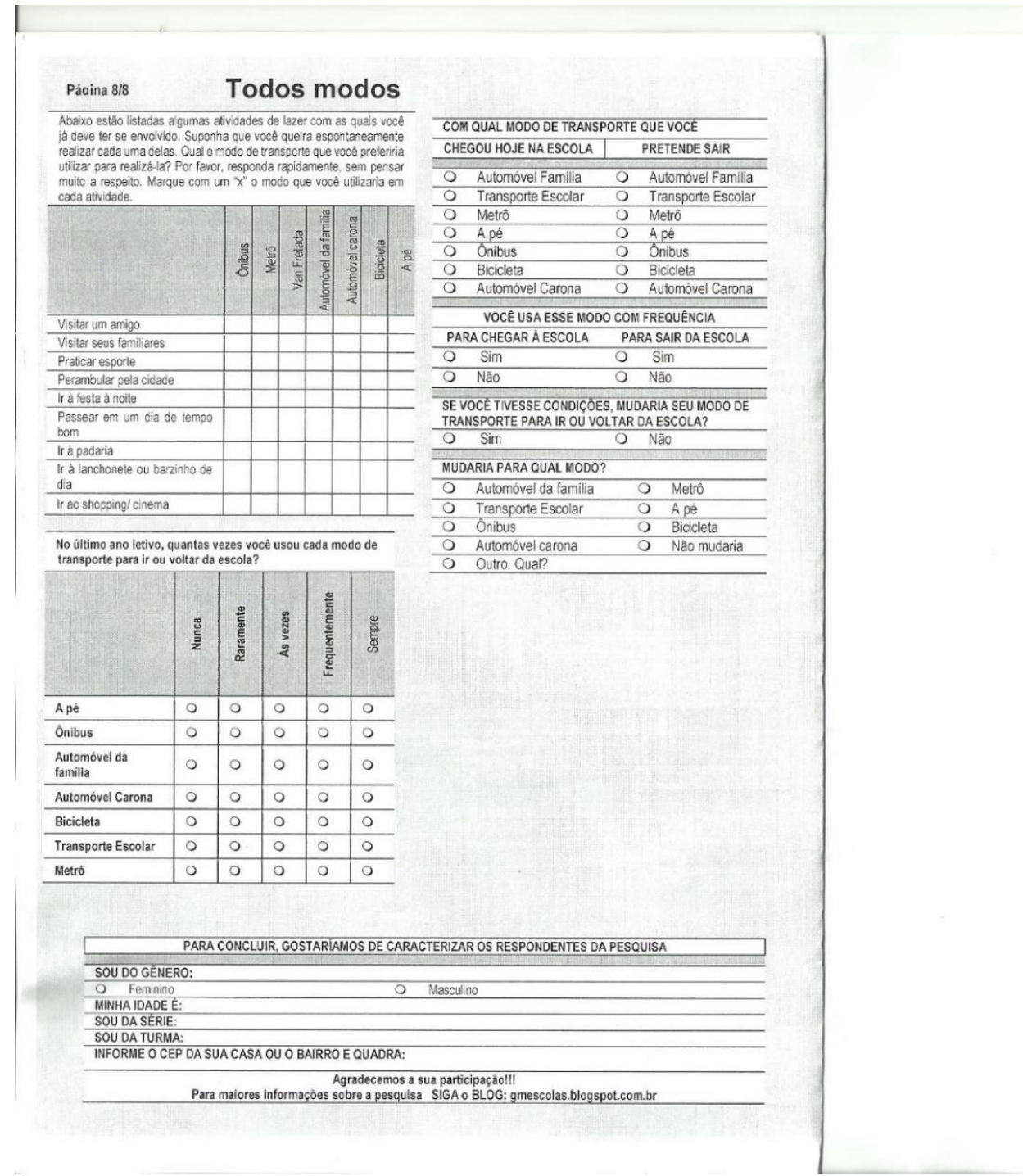


APÊNDICE I - Questionário para pais - Utilizado na etapa quantitativa 


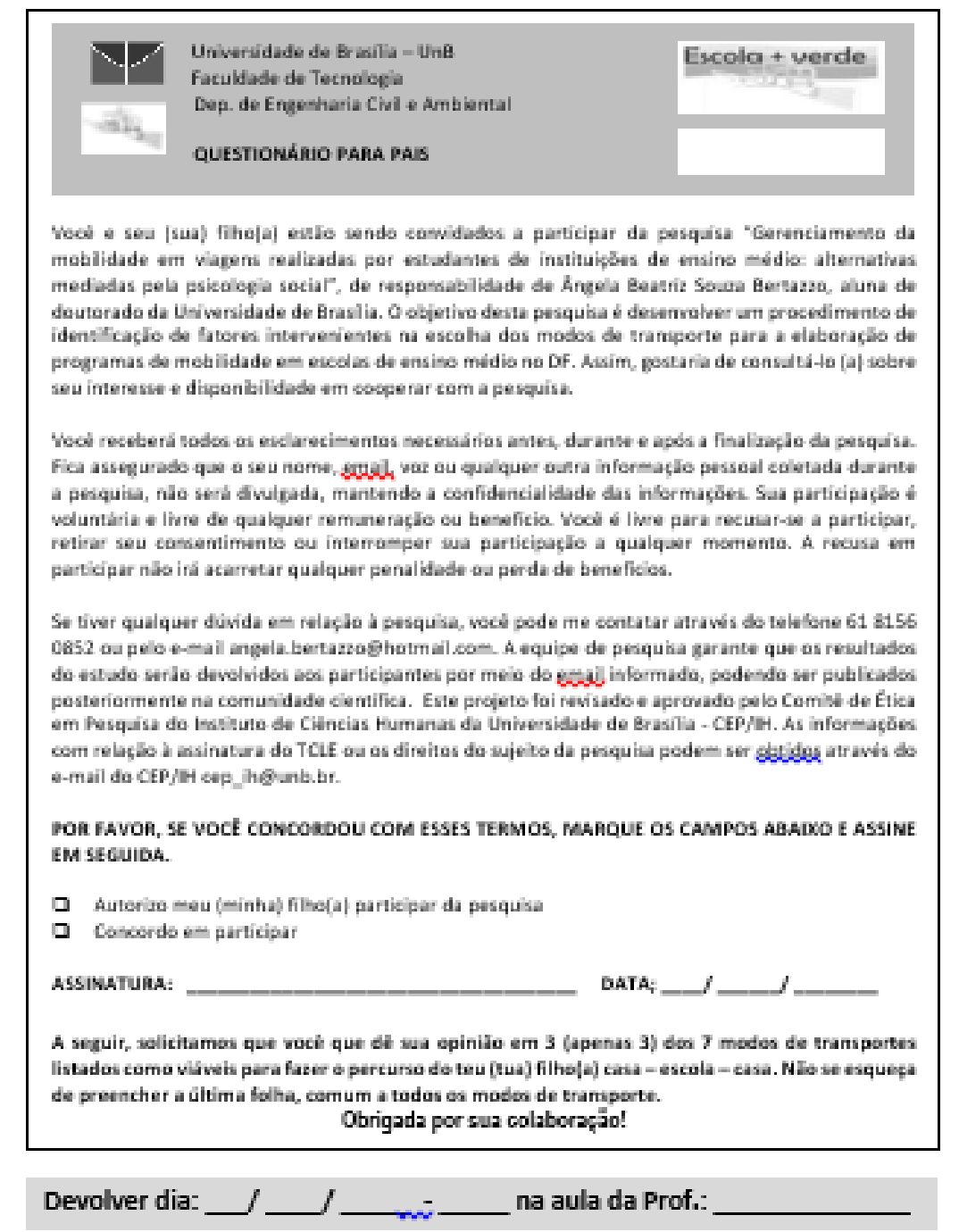




\section{Modo a pé}

Parte 1. Abaiko seguem algumas afrmativas sobre a escolha

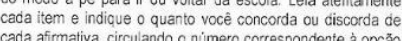

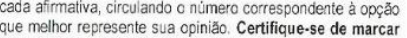

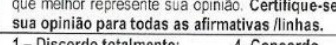

\begin{tabular}{ll} 
1-Discordo totamente; & 4-Concordo \\
\hline 2-Discordo: & 5 -Concordo plenamente;
\end{tabular}

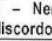

Meu (minha) fillo (a) pode ser

$\begin{array}{lllllll}\text { assaltado(a) se caminhar para ir } & 1 & 2 & 3 & 4 & 5\end{array}$

A mineri do pessos

\begin{tabular}{lll|l|l|l}
$\begin{array}{l}\text { A maioria das pessoas que eu } \\
\text { conheco nao se importa se meu } \\
\text { (minha) filho(a) vai ou volta da }\end{array}$ & 1 & 2 & 3 & 4 & 5
\end{tabular}

escola a pé.

$\begin{array}{llllllll}\begin{array}{l}\text { Meus amigos acham bom que } \\ \text { meu (ninha) fliho (a) caminhe }\end{array} & 1 & 2 & 3 & 4 & 5\end{array}$

para a esco

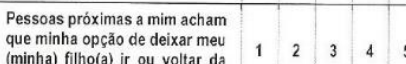

escola a pé é acertada.

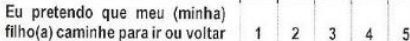

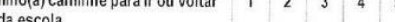

\begin{tabular}{|l|l|l|l|l|l|}
\hline $\begin{array}{l}\text { Ir ou voltar a pé da escola é } \\
\text { económico. }\end{array}$ & 1 & 2 & 3 & 4 & 5 \\
\hline A A
\end{tabular}

A maioria das pessoas

$\begin{array}{llllllll}\text { importantes para mim aprovaria } & 1 & & & & \\ \text { que meu (minha) filio (a) fosse } & 1 & 2 & 3 & 4 & 5\end{array}$

caminhando.

\begin{tabular}{l|l|l|l|l|l|}
$\begin{array}{l}\text { Ir ou voltar a pé da escola faz } \\
\text { bem à saúde. }\end{array}$ & 1 & 2 & 3 & 4 & 5 \\
\hline
\end{tabular}

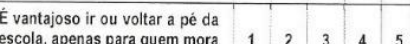

\begin{tabular}{l|l|l|l|l|l|l|l|l|l|} 
perto. & \\
\hline
\end{tabular}

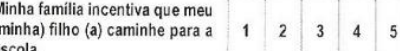

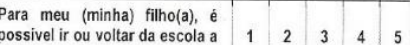

As calcadas do trecho entre
Anssa casa e e escola nào

permitem que meu (minh
silho(a) caminhe para a escole

Página 1/8

Parte 2: A seguiri juguve as affmativas abaixo, numa esccala de 1 a 5 , circulando

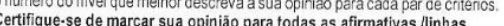
Winha intençäo que meu (minha) fillo(a) vil volie do Froga \begin{tabular}{ccccccc} 
Fraca & 1 & 2 & 3 & 4 & 5 & Fraca \\
\hline
\end{tabular} vá ou volte a pé da escola.

\begin{tabular}{llllllll} 
Dificilimente & 1 & 2 & 3 & 4 & 5 & Provavelmente \\
\hline
\end{tabular} Peu (minha) filloo(a), irvoltar da escola a pé seria

Dificil $\quad \begin{array}{llllll}1 & 2 & 3 & 4 & 5\end{array} \quad$ Fácil Pretendo encorajar que meu(minha) filho(a) vál volte da escola a pé.

\begin{tabular}{llllllll} 
Dificilmente & 1 & 2 & 3 & 4 & 5 & Provavelmente \\
\hline
\end{tabular} Considero o fato de meus amigos acharem bom que meu (minha) fillho (a)

\begin{tabular}{ll|llllll} 
Negativo & 1 & 2 & 3 & 4 & 5 & Positivo
\end{tabular} Permitit que meu (minha) filho(a) fosse ou voltasse da escola a pé seria:

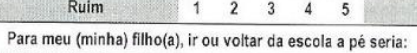
$\begin{array}{llllllll}\text { Impossivel } & 1 & 2 & 3 & 4 & 5 & \text { Possivel }\end{array}$ Preocupar-se com o que è mais saudável para irlv voltar da escola $\begin{array}{llllllll}\text { Ruim } & 1 & 2 & 3 & 4 & 5 & \text { Bom }\end{array}$ Permititr que meu (minha) filiho(a) fosse ou voltasse da escola a pé seria: $\begin{array}{llllllll}\text { Desagradavel } & 1 & 2 & 3 & 4 & 5 & \text { Agradavel }\end{array}$ Preocupar-se com as vantagens de caminhar para ir ou voltar da escola é: $\begin{array}{lllllllll}\text { Ruim } & 1 & 2 & 3 & 4 & 5 & \text { Bom }\end{array}$ Permitit que meu (minha) filho(a) fosse ou voltasse da escola a pé seria: $\begin{array}{lllllllll}\text { Negativo } & 1 & 2 & 3 & 4 & 5 & \text { Positivo }\end{array}$ Deve-se avaliar se o trajeto é perigoso para que meu (minha) filho (a) vá avolie a pe da escola.

\begin{tabular}{l|lllllll} 
Dificilmente & 1 & 2 & 3 & 4 & 5 & Provavelmente \\
\hline
\end{tabular} Preocupar-se com o que é mais econômico para ir ou voltar da escola Pron

$\begin{array}{llllllll}\text { Ruim } & 1 & 2 & 3 & 4 & 5 & \text { Bom }\end{array}$ Considero ofato de minha familia incentivar meu (minha) filho (a) a ir ou voltar da escola a pé con on

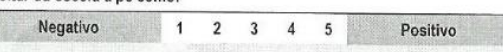

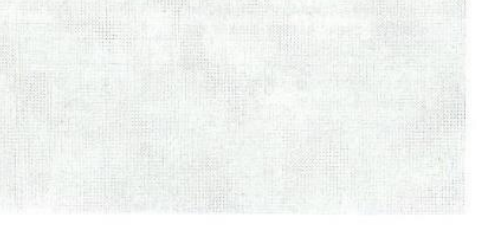


Página 2/8

Modo automóvel carona Parte 1. Abaixo seguen algumas afirmativas sobre a escolina do modo automovel carona para ir ou voliar da escola. Leia
atentamente cada item e indique o quanto vocé concorda ou

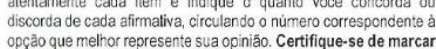

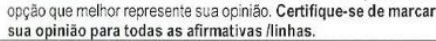
2-Discordo; $\quad 5$ - Concordo plenamente; $\begin{array}{llllllll}\begin{array}{l}\text { Pegar carona para ir ou voltar da } \\ \text { escola contribui para diminuir } 0\end{array} & 1 & 2 & 3 & 4 & 5\end{array}$

\begin{tabular}{l|lllllll}
\hline $\begin{array}{c}\text { Eu pretendo que meu (minha) } \\
\text { fillho(a) dé ou pegue carona para ir }\end{array}$ & 1 & 2 & 3 & 4 & 5
\end{tabular} A maioria das pessor

conheço nào se importa que meu
ir ou voltar da esco

É possivel formar um grupo de carona com os vizinhos para nos nossos filios da escola. \begin{tabular}{l|llllll}
$\begin{array}{c}\text { Minha familia acha bom que meu } \\
\text { minha) filho(a) pegue carona para }\end{array}$ & 1 & 2 & 3 & 4 & 5
\end{tabular} ir ou voltar ca escol \begin{tabular}{l|llllll}
$\begin{array}{l}\text { Amaioria das pessoas importantes } \\
\text { para mim aprovaria que meu }\end{array}$ & 1 & 2 & 3 & 4 & 5
\end{tabular} para $\min$ aprovaria que me
(winha) filho (a) pegasse ou dess carona para ir ou voltar da escola. Pessoas próximas a mim acham
que minha opgăo de dar carona $+4^{3}, 5$ (minha) filho(a) pegue carona co
colegas parai ou voltar da escol

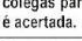
lormar um grupo de carona para

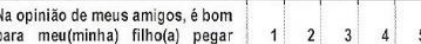
$\dot{E}$ cómodo para men (minha) filho
(a) pegar carona com com colegess

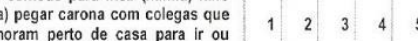
voltar da escola

\begin{tabular}{l|llllll}
\hline $\begin{array}{c}\text { É seguro pegar ou dar carona a } \\
\text { colegas para irou voltar da escola }\end{array}$ & 1 & 2 & 3 & 4 & 5
\end{tabular}

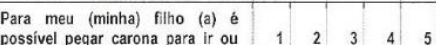
voltar da escola

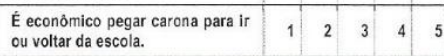

Parte 2: A seguir jugue as afrmalives abaixo, numa escela sua opinizáo para cada par de criterios. Certifique-se de volys Permitit que meu (minha) filho(a) pegue carona para i i ou
voltar d a escola seria $\begin{array}{llllllll}\text { Desagradável } & 1 & 2 & 3 & 4 & 5 & \text { Agradivel }\end{array}$ Considero o fato de meus amigos acharem bom que meu
minha) filino (a) pegue carona para irit voltar da escola

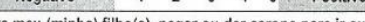
voltar ca escola seria: Impossivel 1 Permitir que meu (minha) filiho(a) pegue chor $\begin{array}{llllllll}\text { Negativo } & 1 & 2 & 3 & 4 & 5 & \text { Positivo }\end{array}$ Prezar pela segurança ao pegar ou dar carona a colegas $\begin{array}{llllllll}\text { Ruim } & 1 & 2 & 3 & 4 & 5 & \text { Bom }\end{array}$ Minha intençăo que meu (minha) filho(a) dè ou pegue carona para ir ou voltar da escola é: $\begin{array}{llllllll}\text { Fraca } & 1 & 2 & 3 & 4 & 5 & \text { Forte } \\ & & \end{array}$ Para meu (minha) filiho(a), pegar ou dar carona para ir ou
voltar da esccola seria: $\begin{array}{llllllll}\text { Dificil } & 1 & 2 & 3 & 4 & 5 & \text { Fácil }\end{array}$ Considero o fato da minha familia achar bom que meu
(minha) filho (a) pegue carona para ir ou voltar da escola Negativo $\quad \begin{array}{lllllll}1 & 2 & 3 & 4 & 5 & \text { Positivo }\end{array}$ Pretendo encorajar meu (minha) filho(a) a dar ou pegar $\begin{array}{lllllll}\text { Dificilimente } & 1 & 2 & 3 & 4 & 5 & \text { Certamente }\end{array}$ ermitit que meu (minha) filho(a) pegue carona para i irou $\begin{array}{llllllll}\text { voltar da escola seria: } & & & & & \\ \text { A Rum } & 1 & 2 & 3 & 4 & 5 & \text { Bom }\end{array}$ \begin{tabular}{c|cc} 
Ruim & 1 & 2 \\
\hline Acomodidade de pegar carona &
\end{tabular}

$\begin{array}{lllllllll}\text { Ruim } & 1 & 2 & 3 & 4 & 5 & \text { Bom }\end{array}$ Eu formaria um grupo de carona com os vizinhos para nos
revezarmos levando ou trazendo nossos filhos da escolata $\begin{array}{lllllll}\text { Dificilmente } & 1 & 2 & 3 & 4 & 5\end{array}$ Provavelme

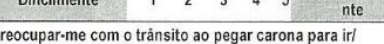
Proocupar-me como otransito ao pegar carona para in
voltar da escola è: $\begin{array}{llllllll}\text { Ruim } & 1 & 2 & 3 & 4 & 5 & \text { Bom }\end{array}$ Preocupar-me com a economia a pegar carona para ir \begin{tabular}{ccccccc}
\hline ou voltar da escola é: & & & & & \\
\hline Ruim & 1 & 2 & 3 & 4 & 5 & Bom
\end{tabular} Deveria pensar em conciliar horarios para formar um grupo
de carona para meu (minha) filiho(a) ir ou voltar da escola.

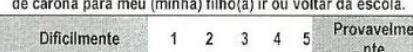

\section{Modo transporte escolar}

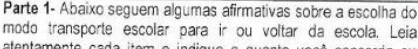

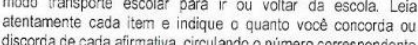

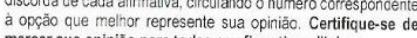

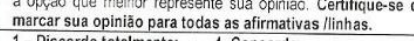
\begin{tabular}{ll} 
1-Discordo totalmente; & 4-Concordo \\
\hline 2-Discordo: & 5-Concordo plenamente;
\end{tabular} 3 - Nem concordo, nem

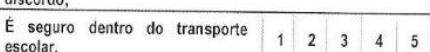

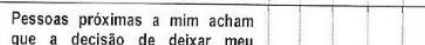

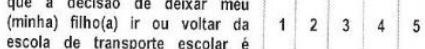

E caro, para mim, contratar o
servico de transporte escolar para

meu (minha) minota.

\begin{tabular}{lllllll}
\hline para & 1 & 2 & 3 & 4 & 5 \\
\hline
\end{tabular}

para mim paprovaria

bairre tandsporte escc.
bair onderamos.

$\begin{array}{llllll}1 & 2 & 3 & 4 & 5\end{array}$

\begin{tabular}{|l|l|l|l|l|}
\hline & 2 & 3 & 4 & 5 \\
\hline
\end{tabular}

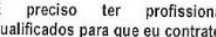

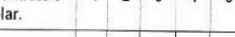

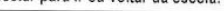

\begin{tabular}{|l|l|l|l|l|l|l|}
$\begin{array}{l}\text { Meus amigos acham que é bom } \\
\text { para meu (minha) fillo(a) usar }\end{array}$ & 1 & 2 & 3 & 4 & 5
\end{tabular}

chegar atrasado(a)
ce

transporte escolar para ir ou voltar
da escola.

Eu pretendo que meu (minha)
filho(a) use transporte escolar para

percurso maior se vent vazer um

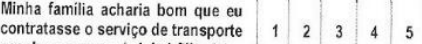

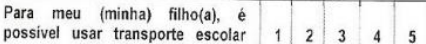

possivel usar transporte
para ir ou voltar da escola.
Página 3

Parte 2: A seguir julgue as afimativas abaixo, numa escala de 1 a 5 ,
circulando onumero do nivel que melhor descreva a sua oojiniajo para cad par de onitérios. Certifique -se de marcar sua opiniäo para todas as Considero o fato de minha familia achar bom que eu contratasse o $\begin{array}{llllllll}\text { Negativo } & 1 & 2 & 3 & 4 & 5 & \text { Positivo }\end{array}$

Permitir que meu (minha) filho(a) utilize o transporte escolar para ir ou voltar da escola seria: $\begin{array}{llllllll}\text { Desagradável } & 1 & 2 & 3 & 4 & 5 & \text { Agradável }\end{array}$ Pecar pela segurançat hove vectulo de transporte escolare: Ruim $\begin{array}{llllllll}1 & 2 & 3 & 4 & 5 & \text { Bom }\end{array}$ Considero o fato de meus amigos acharem bom para meu (minha) Negativo $\quad \begin{array}{lllll}1 & 2 & 3 & 4\end{array}$ Positivo transporte escolar para ir ou voltar da Impossivel $1 \begin{array}{lllllll} & 1 & 2 & 3 & 4 & 5 & \text { Possivel }\end{array}$ Deveria verfiticar se existem profissionais qualificados para contratar o \begin{tabular}{lllllllll} 
Dificilmente & 1 & 2 & 3 & 4 & 5 & Provavelmente \\
\hline
\end{tabular} Prezar pela pontualidade ao usar transporte escolar é: $\begin{array}{llllllll} & \text { Ruim } & 1 & 2 & 3 & 4 & 5 & \text { Bom }\end{array}$ voltar da escola seria \begin{tabular}{c|cccccc|c|} 
Negativo & 1 & 2 & 3 & 4 & 5 & Positivo \\
\hline Deveria &
\end{tabular} Deveria considerar o preço do sevviço para contratar o transporte \begin{tabular}{l|lllllll} 
Dificilimente & 1 & 2 & 3 & 4 & 5 & Provavelmente \\
\hline
\end{tabular} Pretendo encorajar meu (minha) filiho(a) a usar transpoorte escolar para

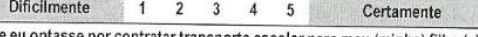
Ir ou voltar da esecolata achararia um servicico disponivel no meu bairro. (a) \begin{tabular}{llllllll} 
Dificilmente & 1 & 2 & 3 & 4 & 5 & Provavelmente \\
\hline
\end{tabular} Minna intençao que meu (minha) fino(a) use transporte escolar para ir
ou voltar da escola $\mathrm{e}$ : \begin{tabular}{llllllll}
\hline Fraca & 1 & 2 & 3 & 4 & 5 & Forte \\
\hline
\end{tabular} Preocupar-me como tamanho do percurso ao usart transporte escolar é: Para meu (minha) filiho(a), usar transporte escolar para ir ou voltar da \begin{tabular}{ccccccc|c}
\hline Dificil & 1 & 2 & 3 & 4 & 5 & Fácil
\end{tabular} Permititr que meu (minha) filho(a) utilize o transpoote escolar para ir ou \begin{tabular}{l|llllllll} 
Ruim & 1 & 2 & 3 & 4 & 5 & Bom
\end{tabular} 


\begin{tabular}{|c|c|c|c|c|c|c|}
\hline \multicolumn{7}{|l|}{ na 4} \\
\hline \multicolumn{7}{|c|}{ Modo automóvel da família } \\
\hline \multirow{2}{*}{\multicolumn{6}{|c|}{ 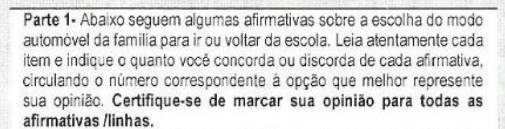 }} & 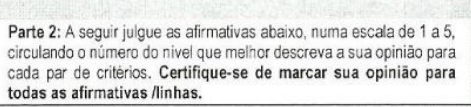 \\
\hline & & & & & & $\begin{array}{l}\text { Considero ofato da familia incentivar que mev (minha) filiho(a) seja } \\
\text { va ou volte da escola no automovel da familia como: }\end{array}$ \\
\hline \multirow{2}{*}{\multicolumn{6}{|c|}{ 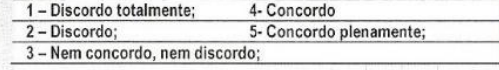 }} & $\begin{array}{llllllll}\text { Negativo } & 1 & 2 & 3 & 4 & 5 & \text { Positivo } \\
\end{array}$ \\
\hline & & & & & & $\begin{array}{l}\text { Permititr que meu (minha) filho(a) seja conduzido com 。 } \\
\text { automovel da familia para ir ou voltar da escola seria: }\end{array}$ \\
\hline \multirow{2}{*}{$\begin{array}{l}\text { Meus amigos incentivam que meu(minha) } \\
\text { filho(a) seja transportado no automóvel da } \\
\text { familia para ir ou voltar da escola. }\end{array}$} & & & \multirow[b]{2}{*}{3} & \multirow{2}{*}{\multicolumn{2}{|c|}{\begin{tabular}{l|l}
45 & 5 \\
\end{tabular}}} & $\begin{array}{llllllll}\text { Ruim } & 1 & 2 & 3 & 4 & 5 & \text { Bom }\end{array}$ \\
\hline & & & & & & $\begin{array}{l}\text { Pretendo levar ou buscar meu (minha) filho(a) na escola a } \\
\text { usando automóvel da familia. }\end{array}$ \\
\hline \multirow{2}{*}{$\begin{array}{l}\text { A familia incentiva que meu (minha) } \\
\text { fihho(a) seja transportado(a) no automovel } \\
\text { da familia para ir ou voltar da escola. }\end{array}$} & \multirow{2}{*}{1} & \multirow{2}{*}{2} & & \multirow{2}{*}{\multicolumn{2}{|c|}{5}} & $\begin{array}{llllllll}\text { Dificilmente } & 1 & 2 & 3 & 4 & 5 & \text { Certamente } \\
\end{array}$ \\
\hline & & & & & & Preocupar-me com o tránsito perto da escola é: \\
\hline \multirow{3}{*}{$\begin{array}{l}\text { A maioria das pessoas que eu conheço } \\
\text { nẫo se importa que minha familia utilize o } \\
\text { automovel para buscar ou levar meu } \\
\text { (mimha) filho(a) para a escola. }\end{array}$} & \multirow{3}{*}{1} & \multirow{3}{*}{2} & \multirow{3}{*}{3} & \multirow{3}{*}{\multicolumn{2}{|c|}{45}} & $\begin{array}{llllll}\text { Ruim } & 1 & 2 & 3 & 4 & 5\end{array}$ \\
\hline & & & & & & $\begin{array}{l}\text { Para meu (minha) filho(a), usar automóvel da familia para irf } \\
\text { voltar da escola seria: }\end{array}$ \\
\hline & & & & & & $\begin{array}{llllllll}\text { Dificil } & 1 & 2 & 3 & 4 & 5 & \text { Fácil }\end{array}$ \\
\hline \multirow{2}{*}{$\begin{array}{l}\text { Eu pretendo usar automóvel da familia } \\
\text { para levar ou buscar meu (minha) filho (a) } \\
\text { na escola }\end{array}$} & \multirow[t]{2}{*}{1} & \multirow{2}{*}{\multicolumn{2}{|c|}{2}} & & 5 & $\begin{array}{l}\text { Minha intençäo de levar ou buscar meu (minha) fillo(a) na escola } \\
\text { usando automovel da familia e: }\end{array}$ \\
\hline & & & & & & $\begin{array}{llllllll}\text { Fraca } & 1 & 2 & 3 & 4 & 5 & \text { Forte }\end{array}$ \\
\hline & 1 & 2 & 3 & 4 & 5 & $\begin{array}{l}\text { Para meu (minha) filho(a), usar automóvel d } \\
\text { voltar da escola seria: }\end{array}$ \\
\hline & & & & & & $\begin{array}{lllll}1 & 2 & 3 & 4 & 5\end{array}$ \\
\hline & & & & & & $\begin{array}{l}\text { Permitir que meu (minha) filho(a) seja conduzido com o } \\
\text { automóvel da familia para ir ou voltar da escola seria: }\end{array}$ \\
\hline & 1 & 2 & 3 & 4 & 5 & Negativo $\quad \begin{array}{lllllll}1 & 2 & 3 & 4 & 5 & \text { Positivo }\end{array}$ \\
\hline & & & & & & $\begin{array}{l}\text { Deveria considerar a compatibilidade de horários para que mu } \\
\text { (minha) filho(a) seja levado (a) ou trazido(a) da escola de carro. }\end{array}$ \\
\hline & 1 & 2 & 3 & 4 & 5 & $\begin{array}{llllllll}\text { Dificilmente } & 1 & 2 & 3 & 4 & 5 & \text { Provavelmente }\end{array}$ \\
\hline & & & & & & $\begin{array}{l}\text { Permitir que meu (minha) fillo(a) seja cond } \\
\text { automovel da familila para ir ou voltar dae escola se }\end{array}$ \\
\hline $\begin{array}{l}\text { Os con } \\
\text { permitem }\end{array}$ & 1 & 2 & 3 & 4 & 5 & $\begin{array}{llllll}\text { Desagradivel } & 1 & 2 & 3 & 4\end{array}$ \\
\hline & & & & & & $\begin{array}{l}\text { Deveria considerar as condiçöes do trânsito } \\
\text { (minha) filho(a) seja levado(a) ou traziido(a) da es }\end{array}$ \\
\hline & 1 & 2 & 3 & 4 & 5 & $\begin{array}{llllllll} & \text { Dificilmente } & 1 & 2 & 3 & 4 & 5 & \text { Provavelmente }\end{array}$ \\
\hline & & & & & & $\begin{array}{l}\text { Prezar pela segurança ao usar automóvel da familia } \mathrm{p} \\
\text { da escola é: }\end{array}$ \\
\hline & 1 & 2 & 3 & 4 & 5 & $\begin{array}{llllllll}\text { Ruim } & 1 & 2 & 3 & 4 & 5 & \text { Bom }\end{array}$ \\
\hline & & & & & & 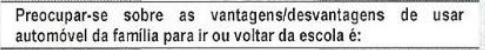 \\
\hline $\begin{array}{l}\text { Meu (n) } \\
\text { automóve }\end{array}$ & 1 & 2 & 3 & 4 & 5 & Ruim $\quad \begin{array}{llllllll}1 & 2 & 3 & 4 & 5 & \text { BC }\end{array}$ \\
\hline & & & & & & $\begin{array}{l}\text { o fato de meus amigos incentivarem que meu(minha) } \\
\text { ou volte da escola no automovel da familia como: }\end{array}$ \\
\hline & 1 & & & & & $\begin{array}{llllll}\text { Negativo } & 1 & 2 & 3 & 4 & 5\end{array}$ \\
\hline $\begin{array}{c}\text { Para me } \\
\text { automóvel }\end{array}$ & 1 & & 3 & & & $\begin{array}{l}\text { Deveria considerar o trajeto do motorista pi que mel } \\
\text { filho(a) seja levado/trazido (a) da escola no automovelc }\end{array}$ \\
\hline & & & & & & Provavelmente \\
\hline
\end{tabular}

\section{Modo metrô}

Página $5 / 8$

Parte 1. Abaixo seguem algumas afirmalivas sobre a escolha do
modo metró para ir ou voliar da escola. Leia atentamente cadio item e indique o quanto vocé concorráa ou discorda de cada
afrmaiva, circulando o número correspondente à opçăo que melhor representite sua opininäo. Certifíque-se de marcar sua opinilä para todas as afirmativas llinhas 2-Discordo: $\quad$ 5-Concordo plenemente. Mring intenga A maioria das pessoas que eu 1 . ou voltar da escola. Para meu (minha) filho(a) usar metrô para i ro ou voltar da escola seria:

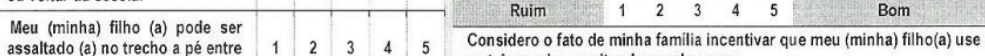

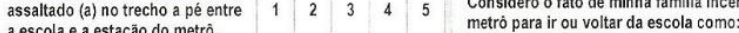

Esegativo $\begin{array}{lllllll}1 & 2 & 3 & 4 & 5 & \text { Positivo }\end{array}$

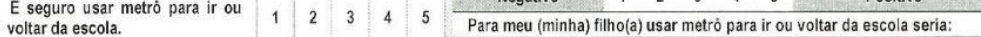

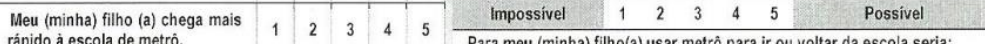

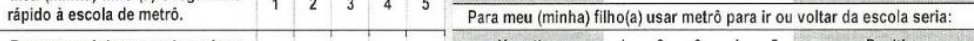
$\begin{aligned} & \text { Pessoas próximas a mim acham } \\ & \text { oue a opgāo de deixar meu }\end{aligned}$
a $\begin{array}{lllll}4 & 5 & \text { Considero ofato de meus amigos acharem bom meu (minha) filho (a) usar }\end{array}$ ou voltar da escola é acertada.

Meus amigos acham uma boa $\quad{ }_{1} \quad{ }_{1} \quad \begin{array}{llllllll}\text { Negativo } & 1 & 2 & 3 & 4 & 5 & \text { Positivo }\end{array}$

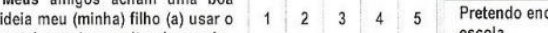

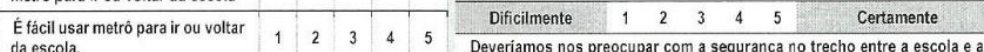
Meu (mines) filloge) pose ser

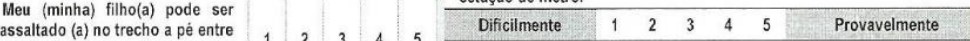
a estaģăo do metró $\mathrm{e}$ a nossa

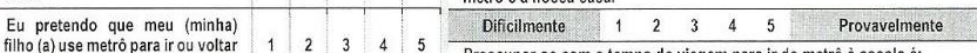

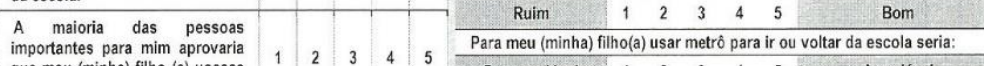

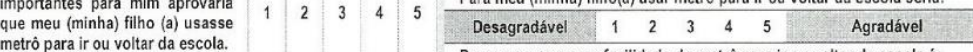
Minha familia incentiva que meu

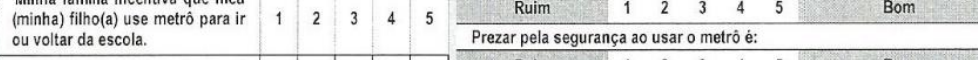

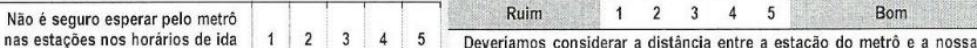
ou volta da escola.

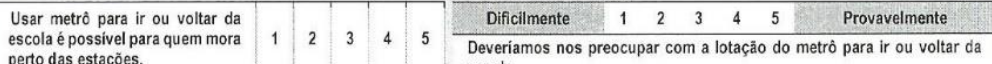

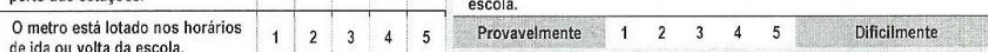

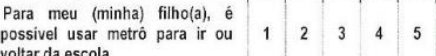


Página 618

\section{Modo ônibus (público)}

Parte 1. Abaixo seguem lgumas afirmativas sobre a escohh do modo
onnibus para ir ou voltar da escola. Leia atentamentie cada iteme indique o

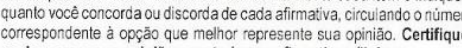

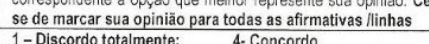
\begin{tabular}{ll}
2 -Discordo; & 5. Concordo plenamente; \\
\hline 3-Nem concordo, nem discordo; &
\end{tabular} \begin{tabular}{|l|l|l|l|l|l|}
\hline $\begin{array}{l}\text { Os ónibus não tèm horário certo para } \\
\text { passar. }\end{array}$ & 1 & 2 & 3 & 4 & 5 \\
\hline
\end{tabular} \begin{tabular}{|l|l|l|l|l|l|}
\hline $\begin{array}{l}\text { Meus amigos apoiariam se meu (minha) } \\
\text { filho(a) usasse o onibus para ir ou voltar }\end{array}$ & 1 & 2 & 3 & 4 & 5 \\
\hline
\end{tabular} da escola.

\begin{tabular}{|l|l|l|l|l|l|}
\hline $\begin{array}{l}E \text { E perigoso ficar esperando o ónibus na } \\
\text { parada }\end{array}$ & 1 & 2 & 3 & 4 & 5 \\
\hline A
\end{tabular} \begin{tabular}{|l|l|l|l|l|l|}
\hline A maioria das pessoas que eu conheco & & & & \\
\hline
\end{tabular} năo se importa que meu (minha) filho(a)
use onibus para ir ou voltar da escola

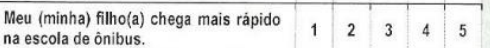
$\begin{array}{llllllll}\begin{array}{l}\text { Pessoas próximas a mim acham que a } \\ \text { opsço de deixar meu uminat filho(a) }\end{array} & 1 & 2 & 3 & 4 & 5\end{array}$ usartadia.

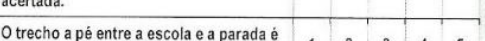

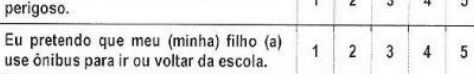

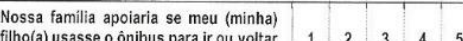

ca escola.

\begin{tabular}{lllllllll}
\hline $\begin{array}{l}\text { Năo compensa usar onibus para ir ou } \\
\text { voltar da escola por causa da }\end{array}$ & 1 & 2 & 3 & 4 & 5
\end{tabular}

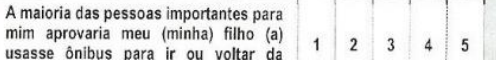

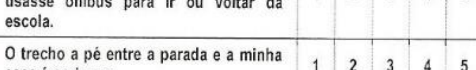

\begin{tabular}{lllllll}
1 & 2 & 3 & 4 & 5 \\
\hline
\end{tabular}

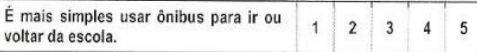

\begin{tabular}{|l|l|l|l|l|l|}
\hline $\begin{array}{l}\text { Para meu (minha) filho(a), é possivel } \\
\text { usar ónibus para ir ou voltar da escola. }\end{array}$ & 1 & 2 & 3 & 4 & 5 \\
\hline
\end{tabular}

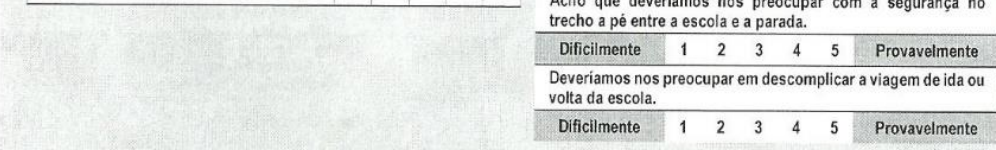
para cada par de critererios. Cerrififuetese de marcar sua opiniáa Para meu (minha) filloo(a) usar ônibus para i ir /voltar da escola \begin{tabular}{lllllllll}
\hline Dificil & 1 & 2 & 3 & 4 & 5 & Fácil
\end{tabular} 8 escol $\begin{array}{llllllll}\text { seria: } & & & & & \\ \text { Negativo } & 1 & 2 & 3 & 4 & 5 & \text { Positivo }\end{array}$ ara meu(minha) filho(a) usar ónibus $p /$ irf voltar da escola $\begin{array}{lllllllll}\text { Impossivel } & 1 & 2 & 3 & 4 & 5 & \text { Possivel }\end{array}$ Considero o fato de meus amigos apoiarem que meu (minha)
filho(a) use o onnibus para ir ou voltar da escola comou

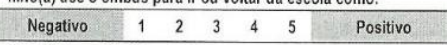
Considerar os horários de ónibus para ir ou voltar da escola é: $\begin{array}{llllllll}\text { Ruim } & 1 & 2 & 3 & 4 & 5 & \text { Bom }\end{array}$ Petendo encorajar meu (minha) filho(a) a usar ónibus para ir ou voltar da escola. \begin{tabular}{llllllll} 
Dificilmente & 1 & 2 & 3 & 4 & 5 & Certamente \\
\hline & &
\end{tabular} Preocupar-se como tempo de viagem de ónibus para ir ou $\begin{array}{lllllllll}\text { Ruim } & 1 & 2 & 3 & 4 & 5 & \text { Bom }\end{array}$ Minha intençăo que meu (minha) filho(a) use ônibus para ir ou vertar ascola e:

Fraca $\quad \begin{array}{lllllll}1 & 2 & 3 & 4 & 5 & \text { Fote }\end{array}$ \begin{tabular}{llllll}
\hline Devo prezar pela segurança ao esperar pelo ónibus na parada. \\
Dificilmente & 1 & 2 & 3 & 4 & 5
\end{tabular} Provavelmente Para meu (minha) filho(a) usar ónibus para ir ou voltar da escola \begin{tabular}{l|lllllll} 
Ruim & 1 & 2 & 3 & 4 & 5 & Bom
\end{tabular} Considero o fato de minha familia apoiar que meu (minha)
filho(a) use o onnibus para ir ou voltar da escola como: \begin{tabular}{llllllll} 
Negativo & 1 & 2 & 3 & 4 & 5 & Positivo \\
\hline PS &
\end{tabular} Para meu (minha) filho(a) usar ônibus para ir ou voltar da escola $\begin{array}{llllllll}\text { Desagradável } & 1 & 2 & 3 & 4 & 5 & \text { Agradável }\end{array}$ Considerara a lotaçâo do ónibus para ir ou voltar da escola é: Acho que deveriamos nos preocupar com a seguranga no
trecho a pe entre a nossa casa e a parada. $\begin{array}{llllll} & 4 & 5 & \text { Provavelmente } \\ \end{array}$ da escos $\begin{array}{lllllllll}\text { Dificilmente } & 1 & 2 & 3 & 4 & 5 & \text { Provavelmente }\end{array}$
Parte 2: A seguir julgue as afirmativas abaxo, numa escala de 1 $\begin{array}{cccccccc}\text { Ruim } & 1 & 2 & 3 & 4 & 5 & \text { Bom } \\ \text { Acho que deveriamos nos preocupar com a segurança no } & \end{array}$ Dificilmente 12 a parada. 5 Provavelmente

\section{Modo bicicleta}

Parte 1. Abaixo seguem algumas afimalivas sobre a escolha do

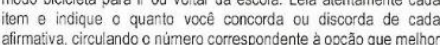

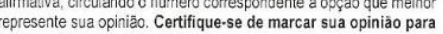
todas as afirmativas linh has. \begin{tabular}{ll} 
1-Discordo totalmente; & 4 - Concordo \\
\hline 2-Discordo; & 5 - Concordo plenamente;
\end{tabular} $3-$ Ne
discordo: \begin{tabular}{lllllll}
\hline $\begin{array}{l}\text { Meus amigos me appiariam que meu } \\
\text { (minha) filho(a) usasse a bicicleta }\end{array}$ & 1 & 2 & 3 & 4 & 5
\end{tabular} (minha) filho(a) usasse a
para vir ou voltar da escola.

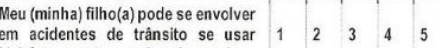

$\begin{array}{llllllll}\begin{array}{l}\text { Eu pretendo que meu (minha) fillo (a) } \\ \text { use a bicicieta para ir ou voltar da }\end{array} & 1 & 2 & 3 & 4 & 5\end{array}$ escola

\begin{tabular}{l|llllll}
$\begin{array}{l}\text { Pessoas proximas a mim acham que } \\
\text { opçâ de deixar meu (minha) }\end{array}$ & 1 & 2 & 3 & 4 & 5
\end{tabular}

finhola usar a bicicleta pa.
voltar da escola a acertada.

$\begin{array}{lllllll}\begin{array}{l}\text { Usar bicicleta para ir ou voltar da } \\ \text { escola e possivel para quem mora }\end{array} & 1 & 2 & 3 & 4 & 5\end{array}$

\begin{tabular}{ll|lll|lll}
\hline $\begin{array}{l}\text { Nossa familia apoiaria que meu } \\
\text { (minha) filho(a) usasse a bicicleta }\end{array}$ & 1 & 2 & 3 & 4 & 5
\end{tabular} (minha) fillo(a) suasse a
para vir ou voltar da escola.

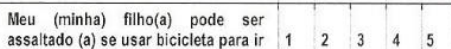

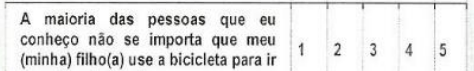
(minha) filho(a) use
ou voltar da escola

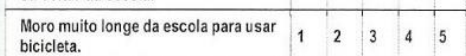
\begin{tabular}{l}
\hline A maioria das pessoas importantes \\
para mim aprovaria que meu (minha)
\end{tabular}

Meu (minha) fillho (a) é respeitado(a) casa e a escola.

\begin{tabular}{l|l|l|l|l|l|}
\hline $\begin{array}{l}\text { Usar bicicleta para ir ou voltar da } \\
\text { escola faz bem a saude. }\end{array}$ & 1 & 2 & 3 & 4 & 5 \\
\hline Acour
\end{tabular} \begin{tabular}{|l|l|l|l|}
\hline A condiçăo do trecho entre a escolla $\mathrm{e}$ & \\
\hline
\end{tabular}

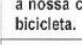

\begin{tabular}{ll|l|l|l|l|}
$\begin{array}{l}\text { Para meu (minha) filho(a), é possivel } \\
\text { usar bicicleta para ir ou voltar da }\end{array}$ & 1 & 2 & 3 & 4 & 5
\end{tabular}
Pagina 7

Parte 2: A seguir jugue as afirmativas abaixo, nume ececelo de 1 a

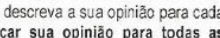

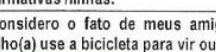
$\begin{array}{llllllll}\text { Negativo } & 1 & 2 & 3 & 4 & 5 & \text { Positivo }\end{array}$ $\begin{array}{llllllll}\text { Impossivel } & 1 & 2 & 3 & 4 & 5 & \text { Possivel }\end{array}$ Considero a distancia a percorrer antes de decidir usar bicicleteta para ir ou voltar da escola

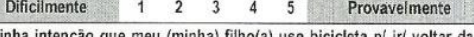
(a)

Acho que deverimos nos procoupar com acidentes de tránsito para isarbicicleta para ir ou voltar da escola. \begin{tabular}{llllllll} 
Dificilmente & 1 & 2 & 3 & 4 & 5 & Provavelmente \\
\hline
\end{tabular}

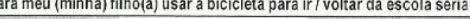
$\begin{array}{llllllll}\text { Dificil } & 1 & 2 & 3 & 4 & 5 & \text { Fácil }\end{array}$ Para meu (minha) fitho(a) usara a bicicicteta para ir voltar ca a scolla serlia $\begin{array}{llllllll}\text { Desagradável } & 1 & 2 & 3 & 4 & 5 & \text { Agradavel }\end{array}$ $\begin{array}{llllllll}\text { Dificilmente } & 1 & 2 & 3 & 4 & 5\end{array} \quad$ Certamente

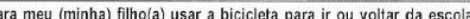

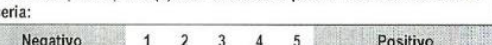

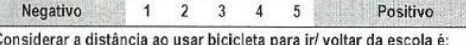

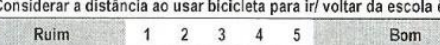

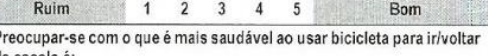
$\begin{array}{lllllllll} & \text { Rulm } & 1 & 2 & 3 & 4 & 5 & \text { Bom }\end{array}$

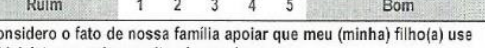
\begin{tabular}{l} 
Negativo ori ou voltar da escola como: \\
\hline
\end{tabular} Para meu (minha) filho(a) usar a bicicleta para ir / voltar da escola seria: $\begin{array}{llllllll}\text { Ruim } & 1 & 2 & 3 & 4 & 5 & \text { Bom }\end{array}$ Acho que deveriamos nos preocupar com assaltos no trajeto de

\begin{tabular}{|l|lllllll|}
\hline Dificilmente & 1 & 2 & 3 & 4 & 5 & Provavelmente \\
\hline
\end{tabular}

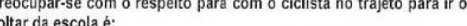

$\begin{array}{llllllll}\text { Ruim } & 1 & 2 & 3 & 4 & 5 & \text { Bom } \\ \text { Acho que deveriamos nos preocupar com a condiçăo do trecho para }\end{array}$ \begin{tabular}{l|lllllll} 
usar bicicleta para ir ou voltar da escola. & \\
\hline Dificilmente & 1 & 2 & 3 & 4 & 5
\end{tabular} Provavelmente 


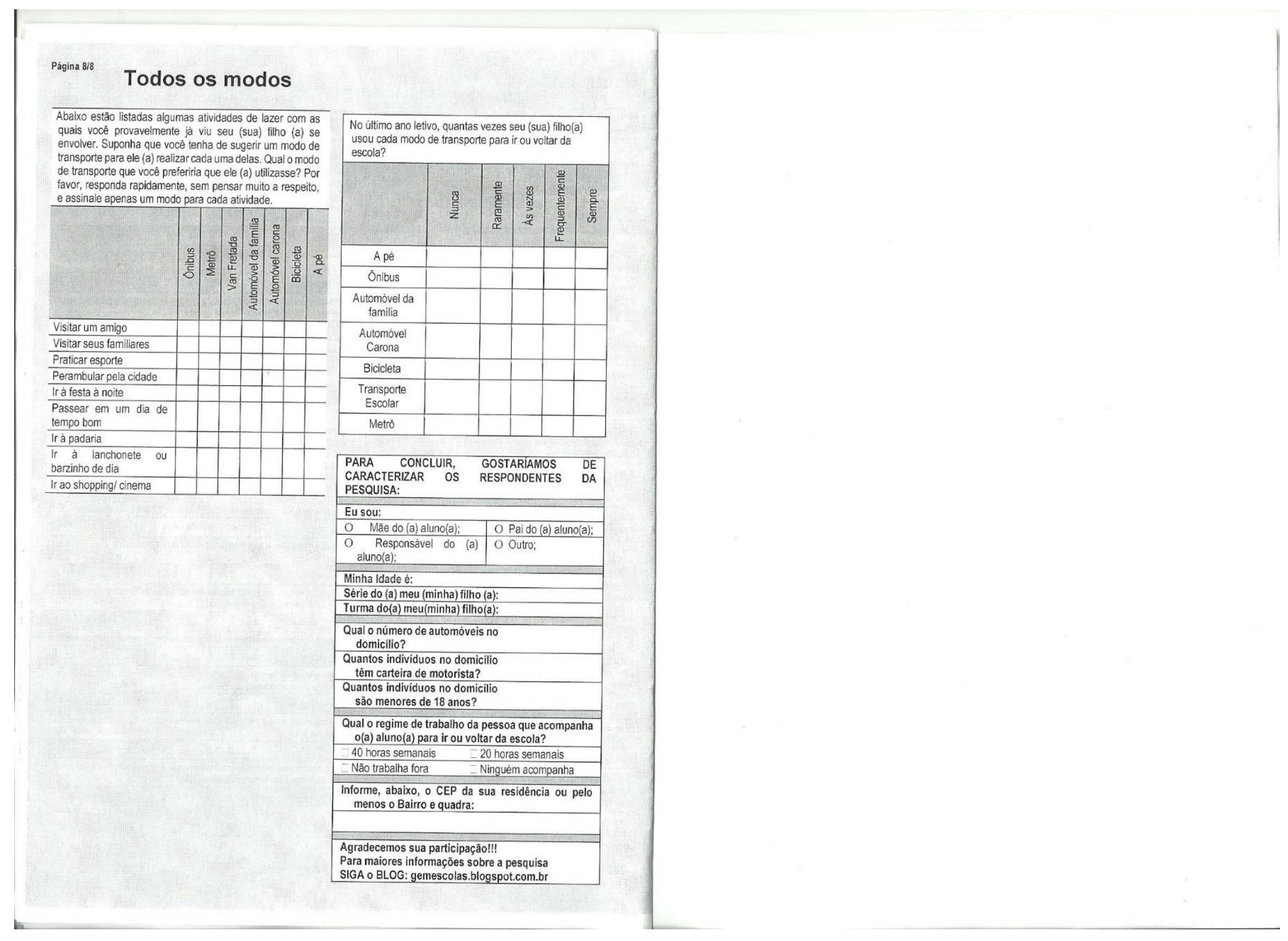


APÊNDICE J - Descrição das variáveis utilizadas nas abordagens quantitativas nos questionários para alunos 
APÊNDICE J - Descrição das variáveis relativas aos alunos, utilizadas na abordagem quantitativa - Parte 1/21

\begin{tabular}{|c|c|c|c|c|}
\hline GRUPO & IDENTIFICAÇÃO & CATEGORIA & CRENCSA & DESCRIÇÃO OU ITEM DO QUESTIONÁRIO \\
\hline \multirow{3}{*}{ GERAL } & ID & Ordinal & NA & Número do respondente. \\
\hline & ESCOLA & Nominal categórica & NA & Informado na coleta de dados. \\
\hline & NQUEST & Ordinal & NA & Número do questionário - apenas para alunos pareados. \\
\hline \multirow{9}{*}{$\begin{array}{l}\text { SOCIO } \\
\text { DEMOGRAFICAS }\end{array}$} & GENERO & Nominal binária & NA & Informado pelo respondente (Feminino - 1; Masculino - 0). \\
\hline & IDADE & Numérica & NA & Informado pelo respondente. \\
\hline & SERIE & Nominal categórica & NA & Informado pelo respondente. \\
\hline & TURMA & Nominal categórica & NA & Informado pelo respondente. \\
\hline & LOCALIDADE & Nominal categórica & NA & $\begin{array}{l}\text { Bairro, região administrativa ou localidade de residência do respondente. Informada } \\
\text { diretamente pelo respondente, ou obtida pelo endereçamento informado pelo } \\
\text { respondente. }\end{array}$ \\
\hline & DISTÂNCIA & Numérica contínua & NA & $\begin{array}{l}\text { Em metros. Refere-se à distância euclidiana do portão da escola a um ponto médio } \\
\text { no setor censitário considerado (IBGE 2010). Obtido pelo GIS TRANSCAD } 4.5 \\
\text { (Calliper, 2002). O setor censitário considerado é derivado da informação do } \\
\text { endereçamento informado pelo respondente. }\end{array}$ \\
\hline & RENDA & Numérica contínua & NA & $\begin{array}{l}\text { Proxy de renda em reais - A partir do Censo IBGE 2010, renda total mensal no setor } \\
\text { censitário dividido pelo total de domicílios no setor censitário considerado (IBGE, } \\
\text { 2010). O setor censitário considerado é derivado da informação do endereçamento } \\
\text { informado pelo respondente. }\end{array}$ \\
\hline & DENSIDADE & Numérica contínua & NA & $\begin{array}{l}\text { Em habitantes por } \mathrm{Km}^{2} \text { - Total de moradores em domicílios particulares dividido } \\
\text { pela área do setor censitário na residência do respondente. A área foi obtida no GIS } \\
\text { TRANSCAD } 4.5 \text { (Calliper, 2002). O setor censitário considerado é derivado da } \\
\text { informação do endereçamento informado pelo respondente. }\end{array}$ \\
\hline & DISPAUTO & Numérica binária & NA & $\begin{array}{l}\text { Proxy para a disponibilidade do automóvel no domicílio pela renda e localidade de } \\
\text { residência. Recebe valor "1" se a variável "RENDA" for maior que o } 3^{\circ} \text { quartil do } \\
\text { conjunto de dados para a variável "renda bruta" em domicílios sem automóveis, } \\
\text { localidade na PDAD ou PMAD (CODEPLAN, } 2014 \text { e CODEPLAN, 2013). }\end{array}$ \\
\hline \multirow{6}{*}{ MODO } & MODOIDA & Numérica categórica & NA & Item - "Com qual modo de transporte você chegou hoje à escola?". \\
\hline & MODOVOLTA & Numérica categórica & NA & Item - "Com qual modo de transporte você pretende sair da escola?". \\
\hline & FREQIDA & Numérica binária & NA & Item - "Você usa esse modo com frequência para chegar à escola?" (Sim-1; não- 0). \\
\hline & FREQVOLTA & Numérica binária & NA & Item - "Você usa esse modo com frequência para sair da escola?" (Sim - 1; não - 0). \\
\hline & INTMUDANCA & Numérica binária & NA & $\begin{array}{l}\text { Item - "Se você tivesse condições, mudaria seu modo de transporte para ir ou voltar } \\
\text { da escola?" (Sim - 1; não - 0). }\end{array}$ \\
\hline & OPCAOMUDANCA & Numérica categórica & NA & Item - "Mudaria para qual modo?”. \\
\hline
\end{tabular}


APÊNDICE J - Descrição das variáveis relativas aos alunos, utilizadas na abordagem quantitativa - Parte $2 / 21$

\begin{tabular}{|c|c|c|c|c|}
\hline GRUPO & IDENTIFICAÇÃO & CATEGORIA & CRENÇA & DESCRIÇÃO OU ITEM DO QUESTIONÁRIO \\
\hline \multirow{12}{*}{$\begin{array}{l}\text { MODO } \\
\text { A PÉ }\end{array}$} & APDAT1 & Numérica Ordinal & NA & $\begin{array}{l}\text { Direta Atitude 1 - Item - "Para mim, caminhar para ir ou voltar da escola seria: (1- } \\
\text { DESAGRADÁVEL, 2, 3, 4, 5- AGRADÁVEL)". }\end{array}$ \\
\hline & APDAT2 & Numérica Ordinal & NA & $\begin{array}{l}\text { Direta Atitude } 2 \text { - Item - "Para mim, caminhar para ir ou voltar da escola seria: (1 } \\
\text { - NEGATIVO, 2, 3, 4, 5 - POSITIVO)". }\end{array}$ \\
\hline & APDAT3 & Numérica Ordinal & NA & $\begin{array}{l}\text { Direta Atitude } 3 \text { - Item - "Para mim, caminhar para ir ou voltar da escola seria: (1- } \\
\text { RUIM, 2, 3, 4, 5 - BOM)". }\end{array}$ \\
\hline & APDNS1 & Numérica Ordinal & NA & $\begin{array}{l}\text { Direta Norma Social } 1 \text { - Item - "A maioria das pessoas importantes para mim } \\
\text { aprovaria minha opção de caminhar da próxima vez que for ou voltar da escola. (1 - } \\
\text { DISCORDO TOTALMENTE/2 - DISCORDO / } 3 \text { - NEM CONCORDO, NEM } \\
\text { DISCORDO / } 4 \text { - CONCORDO / } 5 \text { - CONCORDO PLENAMENTE)". }\end{array}$ \\
\hline & APDNS2 & Numérica Ordinal & NA & $\begin{array}{l}\text { Direta Norma Social } 2 \text { - Item "Pessoas próximas a mim acham que minha opção } \\
\text { de caminhar para ir ou voltar da escola é acertada. (1 - DISCORDO } \\
\text { TOTALMENTE/2 - DISCORDO / } 3 \text { - NEM CONCORDO, NEM DISCORDO / } 4 \text { - } \\
\text { CONCORDO / } 5 \text { - CONCORDO PLENAMENTE)". }\end{array}$ \\
\hline & APDNS3 & Numérica Ordinal & NA & $\begin{array}{l}\text { Direta Norma Social } 3 \text { - Item "A maioria das pessoas que eu conheço não se } \\
\text { importa com a minha opção de caminhar para ir ou voltar da escola. (1 - DISCORDO } \\
\text { TOTALMENTE/2 - DISCORDO / } 3 \text { - NEM CONCORDO, NEM DISCORDO / } 4 \text { - } \\
\text { CONCORDO / } 5 \text { - CONCORDO PLENAMENTE)"; }\end{array}$ \\
\hline & APDCP1 & Numérica Ordinal & NA & $\begin{array}{l}\text { Direta Controle Percebido } 1 \text { - Item "A minha liberdade de decidir caminhar ou } \\
\text { não para ir ou voltar a pé da escola é: (1-NENHUMA; } 2,3,4,5 \text { - TOTAL)". }\end{array}$ \\
\hline & APDCP2 & Numérica Ordinal & NA & $\begin{array}{l}\text { Direta Controle Percebido 2 - Item "Para mim, caminhar para ir ou voltar da escola } \\
\text { seria: (1- DIFÍCIL, 2, 3, 4, 5- FÁCIL)". }\end{array}$ \\
\hline & APDCP3 & Numérica Ordinal & NA & $\begin{array}{l}\text { Direta Controle Percebido } 3 \text { - Item "Para mim, caminhar para ir ou voltar da escola } \\
\text { seria: (1- IMPOSSÍVEL, 2, 3, 4, 5 - POSSÍVEL)". }\end{array}$ \\
\hline & APDIT1 & Numérica Ordinal & NA & $\begin{array}{l}\text { Direta Intenção } 1 \text { - Item "Pretendo caminhar para ir ou voltar da escola. (1 - } \\
\text { DISCORDO TOTALMENTE/2 - DISCORDO / } 3 \text { - NEM CONCORDO, NEM } \\
\text { DISCORDO / } 4 \text { - CONCORDO / } 5 \text { - CONCORDO PLENAMENTE)". }\end{array}$ \\
\hline & APDIT2 & Numérica Ordinal & NA & $\begin{array}{l}\text { Direta Intenção } 2 \text { - Item "Minha intenção de ir ou voltar da escola caminhando é: } \\
\text { (1- FRACA; 2, 3, 4, 5 - FORTE)". }\end{array}$ \\
\hline & APDIT3 & Numérica Ordinal & NA & $\begin{array}{l}\text { Direta Intenção } 3 \text { - Item "Nas próximas semanas, eu irei ou voltarei da escola } \\
\text { caminhando. (1- DIFICILMENTE, 2 3, 4, 5- CERTAMENTE)". }\end{array}$ \\
\hline
\end{tabular}


APÊNDICE J - Descrição das variáveis relativas aos alunos, utilizadas na abordagem quantitativa - Parte 3/21

\begin{tabular}{|c|c|c|c|c|}
\hline GRUPO & IDENTIFICAÇÃO & CATEGORIA & CRENÇA & DESCRIÇÃO OU ITEM DO QUESTIONÁRIO \\
\hline \multirow{11}{*}{ MODO A PÉ } & APCBO1 & Numérica Ordinal & $b$ & $\begin{array}{l}\text { Crença Comportamental } 1 \text { - Outcome - Item "Ir/voltar a pé da escola faz bem à } \\
\text { saúde. (1 - DISCORDO TOTALMENTE/2 - DISCORDO / } 3 \text { - NEM CONCORDO, } \\
\text { NEM DISCORDO / } 4 \text { - CONCORDO / } 5 \text { - CONCORDO PLENAMENTE)". }\end{array}$ \\
\hline & APCBE1 & Numérica Ordinal & e & $\begin{array}{l}\text { Crença Comportamental } 1 \text { - Evaluation - Item "Preocupar-se com ser mais } \\
\text { saudável para ir ou voltar da escola caminhando é: (1- RUIM, 2, 3, 4, 5- BOM)". }\end{array}$ \\
\hline & АРCBO2 & Numérica Ordinal & $b$ & $\begin{array}{l}\text { Crença Comportamental } 2 \text { - Outcome - Item "É seguro ir ou voltar a pé da escola. } \\
\text { (1 - DISCORDO TOTALMENTE/2 - DISCORDO / } 3 \text { - NEM CONCORDO, NEM } \\
\text { DISCORDO / } 4 \text { - CONCORDO / } 5 \text { - CONCORDO PLENAMENTE)". }\end{array}$ \\
\hline & APCBE2 & Numérica Ordinal & e & $\begin{array}{l}\text { Crença comportamental } 2 \text { - Evaluation - Item "Prezar pela segurança ao caminhar } \\
\text { para ir e voltar da escola é: (1- RUIM, 2, 3, 4, 5 - BOM)". }\end{array}$ \\
\hline & АРCBO3 & Numérica Ordinal & $b$ & $\begin{array}{l}\text { Crença Comportamental } 3 \text { - Outcome - Item "É vantajoso caminhar até a escola. } \\
\text { (1 - DISCORDO TOTALMENTE/2 - DISCORDO / } 3 \text { - NEM CONCORDO, NEM } \\
\text { DISCORDO / } 4 \text { - CONCORDO / } 5 \text { - CONCORDO PLENAMENTE)". }\end{array}$ \\
\hline & APCBE3 & Numérica Ordinal & $\mathrm{e}$ & $\begin{array}{l}\text { Crença Comportamental } 3 \text { - Evaluation - Item "Preocupar-se com as vantagens } \\
\text { de caminhar para ir ou voltar da escola é: (1- RUIM, 2, 3, 4, 5 - BOM)". }\end{array}$ \\
\hline & APCNO1 & Numérica Ordinal & $b$ & $\begin{array}{l}\text { Crença Normativa } 1 \text { - Belief Strenght - Item "Meus pais me incentivam a ir ou } \\
\text { voltar da escola a pé. (1 - DISCORDO TOTALMENTE/2 - DISCORDO / } 3 \text { - NEM } \\
\text { CONCORDO, NEM DISCORDO / } 4 \text { - CONCORDO / } 5 \text { - CONCORDO } \\
\text { PLENAMENTE)". }\end{array}$ \\
\hline & APCNE1 & Numérica Ordinal & e & $\begin{array}{l}\text { Crença Normativa } 1 \text { - Motivation to Comply - Item "Considero o fato de meus } \\
\text { pais me incentivarem a ir ou voltar da escola a pé como: (1- NEGATIVO, 2, 3, 4, 5- } \\
\text { POSITIVO)". }\end{array}$ \\
\hline & APCNO2 & Numérica Ordinal & $b$ & $\begin{array}{l}\text { Crença Normativa } 2 \text { - Belief Strenght - Item "Meus amigos me apoiariam se eu } \\
\text { viesse ou voltasse da escola a pé. (1 - DISCORDO TOTALMENTE/2 - DISCORDO } \\
\text { / } 3 \text { - NEM CONCORDO, NEM DISCORDO / } 4 \text { - CONCORDO / } 5 \text { - CONCORDO } \\
\text { PLENAMENTE)". }\end{array}$ \\
\hline & APCNE2 & Numérica Ordinal & $\mathrm{e}$ & $\begin{array}{l}\text { Crença Normativa } 2 \text { - Motivation to Comply - Item "Considero o fato de meus } \\
\text { amigos me apoiarem a ir/voltar a pé da escola como: (1-NEGATIVO, 2, 3, 4, } 5 \text { - } \\
\text { POSITIVO)". }\end{array}$ \\
\hline & APCCO1 & Numérica Ordinal & $b$ & $\begin{array}{l}\text { Crença de controle1 - Control Belief Strenght - Item "É cansativo ir ou voltar a pé } \\
\text { da escola. ( } 1 \text { - DISCORDO TOTALMENTE/2 - DISCORDO / } 3 \text { - NEM } \\
\text { CONCORDO, NEM DISCORDO / } 4 \text { - CONCORDO / } 5 \text { - CONCORDO } \\
\text { PLENAMENTE)". }\end{array}$ \\
\hline
\end{tabular}


APÊNDICE J - Descrição das variáveis relativas aos alunos, utilizadas na abordagem quantitativa - Parte 4/21

\begin{tabular}{|c|c|c|c|c|}
\hline GRUPO & IDENTIFICAÇÃO & CATEGORIA & CRENÇA & DESCRIÇÃO OU ITEM DO QUESTIONÁRIO \\
\hline \multirow{3}{*}{ MODO A PÉ } & APCCE1 & Numérica Ordinal & e & $\begin{array}{l}\text { Crença de controle } 1 \text { - Power of Control Factor - Item "Devo avaliar se o trajeto } \\
\text { é cansativo para ir/voltar a pé da escola. (1- DIFICILMENTE, 2, 3, 4, 5- } \\
\text { PROVAVELMENTE)". }\end{array}$ \\
\hline & $\mathrm{APCCO} 2$ & Numérica Ordinal & $b$ & $\begin{array}{l}\text { Crença de Controle } 2 \text { - Control Belief Strenght - Item "O caminho para ir ou voltar } \\
\text { a pé da escola é iluminado. (1 - DISCORDO TOTALMENTE/2 - DISCORDO / } 3 \\
\text { - NEM CONCORDO, NEM DISCORDO / } 4 \text { - CONCORDO / } 5 \text { - CONCORDO } \\
\text { PLENAMENTE)". }\end{array}$ \\
\hline & APCCE2 & Numérica Ordinal & $e$ & $\begin{array}{l}\text { Crença de Controle } 2 \text { - Power of Control Factor - Item "Devo avaliar se o caminho } \\
\text { é iluminado para ir/voltar a pé da escola. (1 - DIFICILMENTE, 2,3, 4, } 5 \text { - } \\
\text { PROVAVELMENTE)". }\end{array}$ \\
\hline \multirow{8}{*}{$\begin{array}{l}\text { MODOAUTO } \\
\text { CARONA }\end{array}$} & ACDAT1 & Numérica Ordinal & NA & $\begin{array}{l}\text { Direta Atitude } 1 \text { - Item "Para mim, dar ou pegar carona para ir ou voltar da escola } \\
\text { seria: (1- DESAGRADÁVEL, 2, 3, 4, 5 - AGRADÁVEL)". }\end{array}$ \\
\hline & ACDAT2 & Numérica Ordinal & NA & $\begin{array}{l}\text { Direta Atitude } 2 \text { - Item "Para mim, dar ou pegar carona para ir/ voltar da escola } \\
\text { seria: (1 NEGATIVO, 2,3,4, 5- POSITIVO)". }\end{array}$ \\
\hline & ACDAT3 & Numérica Ordinal & NA & $\begin{array}{l}\text { Direta Atitude } 3 \text { - Item "Para mim, dar ou pegar carona para ir ou voltar da escola } \\
\text { seria: (1- RUIM, 2, 3, 4, 5- BOM)". }\end{array}$ \\
\hline & ACDNS1 & Numérica Ordinal & NA & $\begin{array}{l}\text { Direta Norma Social } 1 \text { - Item "A maioria das pessoas importantes para mim } \\
\text { aprovaria minha opção de dar ou pegar carona para ir ou voltar da escola. (1 - } \\
\text { DISCORDO TOTALMENTE/2 - DISCORDO / } 3 \text { - NEM CONCORDO, NEM } \\
\text { DISCORDO / } 4 \text { - CONCORDO / } 5 \text { - CONCORDO PLENAMENTE)". }\end{array}$ \\
\hline & ACDNS2 & Numérica Ordinal & NA & $\begin{array}{l}\text { Direta Norma Social } 2 \text { - Item "Pessoas próximas a mim acham que minha opção } \\
\text { de dar ou pegar carona para ir ou voltar da escola é acertada. (1 - DISCORDO } \\
\text { TOTALMENTE/2 - DISCORDO / } 3 \text { - NEM CONCORDO, NEM DISCORDO / } 4 \text { - } \\
\text { CONCORDO / } 5 \text { - CONCORDO PLENAMENTE)". }\end{array}$ \\
\hline & ACDNS3 & Numérica Ordinal & NA & $\begin{array}{l}\text { Direta Norma Social } 3 \text { - Item "A maioria das pessoas que eu conheço não se } \\
\text { importa com a minha opção de dar ou pegar carona para ir ou voltar da escola. (1 - } \\
\text { DISCORDO TOTALMENTE/2 - DISCORDO / } 3 \text { - NEM CONCORDO, NEM } \\
\text { DISCORDO / } 4 \text { - CONCORDO / } 5 \text { - CONCORDO PLENAMENTE)". }\end{array}$ \\
\hline & ACDCP1 & Numérica Ordinal & NA & $\begin{array}{l}\text { Direta Controle Percebido } 1 \text { - Item "A minha liberdade de pegar ou dar carona } \\
\text { para ir ou voltar da escola é: (1- NENHUMA, } 2,3,4,5 \text { - TOTAL)". }\end{array}$ \\
\hline & $\mathrm{ACDCP2}$ & Numérica Ordinal & NA & $\begin{array}{l}\text { Direta Controle Percebido } 2 \text { - Item "Para mim, dar ou pegar carona para ir ou } \\
\text { voltar da escola seria: (1- DIFÍCIL, 2, 3, 4,5-FÁCIL)". }\end{array}$ \\
\hline
\end{tabular}


APÊNDICE J - Descrição das variáveis relativas aos alunos, utilizadas na abordagem quantitativa - Parte 5/21

\begin{tabular}{|c|c|c|c|c|}
\hline GRUPO & IDENTIFICAÇÃO & CATEGORIA & CRENÇA & DESCRIÇÃO OU ITEM DO QUESTIONÁRIO \\
\hline \multirow{11}{*}{$\begin{array}{l}\text { MODOAUTO } \\
\text { CARONA }\end{array}$} & ACDCP3 & Numérica Ordinal & NA & $\begin{array}{l}\text { Direta Controle Percebido 3-Item "Para mim, dar ou pegar carona para ir/ voltar } \\
\text { da escola seria: (1- IMPOSSÍVEL, 2, 3, 4, 5- POSSÍVEL)". }\end{array}$ \\
\hline & ACDIT1 & Numérica Ordinal & NA & $\begin{array}{l}\text { Direta Intenção } 1 \text { - Item "Pretendo dar/pegar carona para ir ou voltar da escola. (1 } \\
\text { - DISCORDO TOTALMENTE/2 - DISCORDO / } 3 \text { - NEM CONCORDO, NEM } \\
\text { DISCORDO / } 4 \text { - CONCORDO / } 5 \text { - CONCORDO PLENAMENTE)". }\end{array}$ \\
\hline & ACDIT2 & Numérica Ordinal & NA & $\begin{array}{l}\text { Direta Intenção 2 - Item "Minha intenção de pegar ou dar carona para ir ou voltar } \\
\text { da escola é: (1- FRACA, 2, 3, 4, 5 - FORTE)". }\end{array}$ \\
\hline & ACDIT3 & Numérica Ordinal & NA & $\begin{array}{l}\text { Direta Intenção 3 - Item "Nas próximas semanas, eu irei pegar ou dar carona para } \\
\text { ir ou voltar da escola. (1- DIFICILMENTE, } 2,3,4,5 \text { - CERTAMENTE)". }\end{array}$ \\
\hline & ACCBO1 & Numérica Ordinal & $b$ & $\begin{array}{l}\text { Crença Comportamental } 1 \text { - Outcome - Item "É uma boa ideia dar ou pegar carona } \\
\text { para ir ou voltar da escola. (1 - DISCORDO TOTALMENTE/2 - DISCORDO / } 3 \text { - } \\
\text { NEM CONCORDO, NEM DISCORDO / } 4 \text { - CONCORDO / } 5 \text { - CONCORDO } \\
\text { PLENAMENTE)". }\end{array}$ \\
\hline & ACCBE1 & Numérica Ordinal & $e$ & $\begin{array}{l}\text { Crença Comportamental } 1 \text { - Evaluation - Item "Ponderar sobre as vantagens de } \\
\text { pegar ou dar carona ao ir ou voltar da escola é: (1 - RUIM, 2, 3, 4, 5 - BOM)". }\end{array}$ \\
\hline & $\mathrm{ACCBO2}$ & Numérica Ordinal & $b$ & $\begin{array}{l}\text { Crença Comportamental } 2 \text { - Outcome - Item "É seguro pegar ou dar carona a } \\
\text { colegas para ir ou voltar da escola. (1 - DISCORDO TOTALMENTE/2 - } \\
\text { DISCORDO / } 3 \text { - NEM CONCORDO, NEM DISCORDO / } 4 \text { - CONCORDO / } 5 \text { - } \\
\text { CONCORDO PLENAMENTE)". }\end{array}$ \\
\hline & ACCBE2 & Numérica Ordinal & $e$ & $\begin{array}{l}\text { Crença Comportamental } 2 \text { - Evaluation - Item "Prezar pela segurança ao pegar } \\
\text { ou dar carona a colegas para ir e voltar da escola é:(1- RUIM, 2, 3, 4, 5 - BOM)". }\end{array}$ \\
\hline & АCCBO3 & Numérica Ordinal & $b$ & $\begin{array}{l}\text { Crença Comportamental } 3 \text { - Outcome - Item "Dar ou pegar carona para ir ou } \\
\text { voltar da escola facilita fazer novas amizades. (1 - DISCORDO TOTALMENTE/2 } \\
\text { - DISCORDO / } 3 \text { - NEM CONCORDO, NEM DISCORDO / } 4 \text { - CONCORDO / } 5 \text { - } \\
\text { CONCORDO PLENAMENTE)". }\end{array}$ \\
\hline & ACCBE3 & Numérica Ordinal & $e$ & $\begin{array}{l}\text { Crença Comportamental } 3 \text { - Evaluation - Item "Para mim, fazer novas amizades } \\
\text { ao dar ou pegar carona para ir ou voltar da escola é: (1- RUIM, 2, 3, 4, 5 - BOM)". }\end{array}$ \\
\hline & ACCNO1 & Numérica Ordinal & $b$ & $\begin{array}{l}\text { Crença Normativa } 1 \text { - Belief Strenght - Item "Meus pais me incentivam a dar ou } \\
\text { pegar carona para ir ou voltar da escola. (1 - DISCORDO TOTALMENTE/2 - } \\
\text { DISCORDO / } 3 \text { - NEM CONCORDO, NEM DISCORDO / } 4 \text { - CONCORDO / } 5 \text { - } \\
\text { CONCORDO PLENAMENTE)". }\end{array}$ \\
\hline
\end{tabular}


APÊNDICE J - Descrição das variáveis relativas aos alunos, utilizadas na abordagem quantitativa - Parte 6/21

\begin{tabular}{|c|c|c|c|c|}
\hline GRUPO & \multirow{2}{*}{$\begin{array}{l}\text { IDENTIFICAÇÃO } \\
\text { ACCNE1 }\end{array}$} & \multirow{2}{*}{$\begin{array}{c}\text { CATEGORIA } \\
\text { Numérica Ordinal }\end{array}$} & \multirow{2}{*}{$\begin{array}{c}\text { CRENCSA } \\
e\end{array}$} & \multirow{2}{*}{$\begin{array}{l}\text { DESCRIÇÃO OU ITEM DO QUESTIONÁRIO } \\
\text { Crença Normativa } 1 \text { - Motivation to Comply - Item "Considero o fato de meus } \\
\text { pais me apoiarem a pegar /dar carona como: (1- NEGATIVO, 2, 3, 4, } 5 \text { - } \\
\text { POSITIVO)". }\end{array}$} \\
\hline \multirow{9}{*}{$\begin{array}{ll}\text { MODO } & \text { AUTO } \\
\text { CARONA } & \end{array}$} & & & & \\
\hline & ACCNO2 & Numérica Ordinal & $b$ & $\begin{array}{l}\text { Crença Normativa } 2 \text { - Belief Strenght - Item "Meus amigos me apoiariam se eu } \\
\text { pegasse ou desse carona para ir ou voltar da escola. (1 - DISCORDO } \\
\text { TOTALMENTE/2 - DISCORDO / } 3 \text { - NEM CONCORDO, NEM DISCORDO / } 4 \text { - } \\
\text { CONCORDO / } 5 \text { - CONCORDO PLENAMENTE)". }\end{array}$ \\
\hline & ACCNE2 & Numérica Ordinal & $e$ & $\begin{array}{l}\text { Crença Normativa } 2 \text { - Motivation to Comply - Item "Considero o fato de meus } \\
\text { amigos me apoiarem a dar ou pegar carona para ir/ voltar da escola como: (1- } \\
\text { NEGATIVO, } 2,3,4,5 \text { - POSITIVO)". }\end{array}$ \\
\hline & ACCCO1 & Numérica Ordinal & $b$ & $\begin{array}{l}\text { Crença de Controle } 1 \text { - Control Belief Strenght - Item "É difícil conciliar horários } \\
\text { com colegas para pegar ou dar carona para ir ou voltar da escola. (1 - DISCORDO } \\
\text { TOTALMENTE/2 - DISCORDO / } 3 \text { - NEM CONCORDO, NEM DISCORDO / } 4 \text { - } \\
\text { CONCORDO / } 5 \text { - CONCORDO PLENAMENTE)". }\end{array}$ \\
\hline & ACCCE1 & Numérica Ordinal & $e$ & $\begin{array}{l}\text { Crença de Controle } 1 \text { - Power of Control Factor - Item "Devo pensar em conciliar } \\
\text { horários para pegar ou dar carona para ir ou voltar da escola. (1 - DIFICILMENTE, } \\
2,3,4,5 \text { - PROVAVELMENTE)". }\end{array}$ \\
\hline & $\mathrm{ACCCO2}$ & Numérica Ordinal & $b$ & $\begin{array}{l}\text { Crença de Controle } 2 \text { - Control Belief Strenght - Item "É indicado pegar carona } \\
\text { somente com motoristas conhecidos. (1 - DISCORDO TOTALMENTE/2 - } \\
\text { DISCORDO / } 3 \text { - NEM CONCORDO, NEM DISCORDO / } 4 \text { - CONCORDO / } 5 \text { - } \\
\text { CONCORDO PLENAMENTE)". }\end{array}$ \\
\hline & ACCCE2 & Numérica Ordinal & $e$ & $\begin{array}{l}\text { Crença de Controle - } 2 \text { - Power of Control Factor - Item "Devo considerar se eu } \\
\text { conheço o motorista para pegar carona para ir ou voltar da escola (1 - } \\
\text { DIFICILMENTE, 2, 3, 4, 5 - PROVAVELMENTE)"; }\end{array}$ \\
\hline & $\mathrm{ACCCO3}$ & Numérica Ordinal & $b$ & $\begin{array}{l}\text { Crença de Controle } 3 \text { - Control Belief Strenght - Item "Quem pega carona para ir } \\
\text { ou voltar da escola deve "rachar" a gasolina. (1 - DISCORDO TOTALMENTE/2 - } \\
\text { DISCORDO / } 3 \text { - NEM CONCORDO, NEM DISCORDO / } 4 \text { - CONCORDO / } 5 \text { - } \\
\text { CONCORDO PLENAMENTE)". }\end{array}$ \\
\hline & ACCCE3 & Numérica Ordinal & $\mathrm{e}$ & $\begin{array}{l}\text { Crença de Controle } 3 \text { - Power of Control Factor - Item "Se eu fosse pegar carona } \\
\text { para ir ou voltar da escola, eu racharia a gasolina. (1 - DIFICILMENTE, 2, 3, 4, } 5 \text { - } \\
\text { PROVAVELMENTE)". }\end{array}$ \\
\hline
\end{tabular}


APÊNDICE J - Descrição das variáveis relativas aos alunos, utilizadas na abordagem quantitativa - Parte 7/21

\begin{tabular}{|c|c|c|c|c|}
\hline GRUPO & IDENTIFICAÇÃO & CATEGORIA & CRENÇA & DESCRIÇÃO OU ITEM DO QUESTIONÁRIO \\
\hline \multirow{12}{*}{$\begin{array}{l}\text { MODO } \\
\text { TRANSPORTE } \\
\text { ESCOLAR }\end{array}$} & TEDAT1 & Numérica Ordinal & NA & $\begin{array}{l}\text { Direta Atitude } 1 \text { - Item "Para mim, usar transporte escolar para ir ou voltar da } \\
\text { escola seria: (1- DESAGRADÁVEL, 2, 3, 4, 5- AGRADÁVEL)". }\end{array}$ \\
\hline & TEDAT2 & Numérica Ordinal & NA & $\begin{array}{l}\text { Direta Atitude } 2 \text { - Item "Para mim, usar transporte escolar para ir ou voltar da } \\
\text { escola seria: (1- NEGATIVO, 2, 3, 4, 5- POSITIVO)". }\end{array}$ \\
\hline & TEDAT3 & Numérica Ordinal & NA & $\begin{array}{l}\text { Direta de Atitude 3 - Item "Para mim, usar transporte escolar para ir ou voltar da } \\
\text { escola seria: (1- RUIM, 2, 3, 4, 5- BOM)". }\end{array}$ \\
\hline & TEDNS1 & Numérica Ordinal & NA & $\begin{array}{l}\text { Direta Norma Social } 1 \text { - Item "A maioria das pessoas importantes para mim } \\
\text { aprovaria minha opção de usar transporte escolar para ir ou voltar da escola (1 - } \\
\text { DISCORDO TOTALMENTE/2 - DISCORDO / } 3 \text { - NEM CONCORDO, NEM } \\
\text { DISCORDO / } 4 \text { - CONCORDO / } 5 \text { - CONCORDO PLENAMENTE)". }\end{array}$ \\
\hline & TEDNS2 & Numérica Ordinal & NA & $\begin{array}{l}\text { Direta Norma Social } 2 \text { - Item "Pessoas próximas a mim acham que minha opção } \\
\text { de usar transporte escolar para ir ou voltar da escola (1 - DISCORDO } \\
\text { TOTALMENTE/2 - DISCORDO / } 3 \text { - NEM CONCORDO, NEM DISCORDO / } 4 \text { - } \\
\text { CONCORDO / } 5 \text { - CONCORDO PLENAMENTE)". }\end{array}$ \\
\hline & TEDNS3 & Numérica Ordinal & NA & $\begin{array}{l}\text { Direta Norma Social } 3 \text { - Item "A maioria das pessoas que eu conheço não se } \\
\text { importa com a minha opção de usar transporte escolar para ir ou voltar da escola. (1 } \\
\text { - DISCORDO TOTALMENTE/2 - DISCORDO / } 3 \text { - NEM CONCORDO, NEM } \\
\text { DISCORDO / } 4 \text { - CONCORDO / } 5 \text { - CONCORDO PLENAMENTE)". }\end{array}$ \\
\hline & TEDCP1 & Numérica Ordinal & NA & $\begin{array}{l}\text { Direta de Controle Percebido } 1 \text { - Item "A minha liberdade de usar transporte } \\
\text { escolar para ir ou voltar da escola é: (1- NENHUMA, 2, 3, 4, 5-TOTAL)". }\end{array}$ \\
\hline & TEDCP2 & Numérica Ordinal & NA & $\begin{array}{l}\text { Direta de Controle Percebido } 2 \text { - Item "Para mim, usar transporte escolar para ir } \\
\text { ou voltar da escola seria: (1- DIFÍCIL, 2, 3, 4, 5 - FÁCIL)". }\end{array}$ \\
\hline & TEDCP3 & Numérica Ordinal & NA & $\begin{array}{l}\text { Direta Controle Percebido } 3 \text { - Item "Para mim, usar transporte escolar para ir ou } \\
\text { voltar da escola seria: (1- IMPOSSÍVEL, } 2,3,4,5 \text { - POSSÍVEL)". }\end{array}$ \\
\hline & TEDIT1 & Numérica Ordinal & NA & $\begin{array}{l}\text { Direta Intenção } 1 \text { - Item "Pretendo usar transporte escolar para ir ou voltar da } \\
\text { escola. (1 - DISCORDO TOTALMENTE/2 - DISCORDO / } 3 \text { - NEM CONCORDO, } \\
\text { NEM DISCORDO / } 4 \text { - CONCORDO / } 5 \text { - CONCORDO PLENAMENTE)". }\end{array}$ \\
\hline & TEDIT2 & Numérica Ordinal & NA & $\begin{array}{l}\text { Direta de Intenção } 2 \text { - Item "Minha intenção de usar transporte escolar para ir } \\
\text { /voltar da escola é: (1- FRACA, 2, 3, 4, 5 - FORTE)". }\end{array}$ \\
\hline & TEDIT3 & Numérica Ordinal & NA & $\begin{array}{l}\text { Direta Intenção } 3 \text { - Item "Nas próximas semanas, eu irei usar transporte escolar } \\
\text { para ir ou voltar da escola. (1- DIFICLMENTE, 2, 3, 4, 5- CERTAMENTE)". }\end{array}$ \\
\hline
\end{tabular}


APÊNDICE J - Descrição das variáveis relativas aos alunos, utilizadas na abordagem quantitativa - Parte 8/21

\begin{tabular}{|c|c|c|c|c|}
\hline GRUPO & IDENTIFICAÇÃO & CATEGORIA & CRENÇA & DESCRIÇÃO OU ITEM DO QUESTIONÁRIO \\
\hline \multirow{9}{*}{$\begin{array}{l}\text { MODO } \\
\text { TRANSPORTE } \\
\text { ESCOLAR }\end{array}$} & TECBO1 & Numérica Ordinal & $b$ & $\begin{array}{l}\text { Crença Comportamental 1 - Outcome - Item "Usar transporte escolar é mais } \\
\text { demorado. (1 - DISCORDO TOTALMENTE/2 - DISCORDO / } 3 \text { - NEM } \\
\text { CONCORDO, NEM DISCORDO / } 4 \text { - CONCORDO / } 5 \text { - CONCORDO } \\
\text { PLENAMENTE)". }\end{array}$ \\
\hline & TECBE1 & Numérica Ordinal & $e$ & $\begin{array}{l}\text { Crença Comportamental } 1 \text { - Evaluation - Item "Preocupar-me com o tempo de } \\
\text { viagem ao usar transporte escolar é: (1- RUIM, 2, 3, 4, 5-BOM)". }\end{array}$ \\
\hline & TECBO2 & Numérica Ordinal & $b$ & $\begin{array}{l}\text { Crença Comportamental } 2 \text { - Outcome - Item "É seguro ir ou voltar da escola de } \\
\text { transporte escolar. ( } 1 \text { - DISCORDO TOTALMENTE/2 - DISCORDO / } 3 \text { - NEM } \\
\text { CONCORDO, NEM DISCORDO / } 4 \text { - CONCORDO / } 5 \text { - CONCORDO } \\
\text { PLENAMENTE)". }\end{array}$ \\
\hline & TECBE2 & Numérica Ordinal & $e$ & $\begin{array}{l}\text { Crença Comportamental } 2 \text { - Evaluation - Item "Prezar pela segurança ao usar } \\
\text { transporte escolar é: (1- RUIM, 2, 3, 4, 5 - BOM)". }\end{array}$ \\
\hline & TECBO3 & Numérica Ordinal & $b$ & $\begin{array}{l}\text { Crença Comportamental 3 - Outcome - Item "Quem vai para a escola de } \\
\text { transporte escolar costuma chegar no horário certo. ( } 1 \text { - DISCORDO } \\
\text { TOTALMENTE/2 - DISCORDO / } 3 \text { - NEM CONCORDO, NEM DISCORDO / } 4 \text { - } \\
\text { CONCORDO / } 5 \text { - CONCORDO PLENAMENTE)". }\end{array}$ \\
\hline & TECBE3 & Numérica Ordinal & $e$ & $\begin{array}{l}\text { Crença Comportamental } 3 \text { - Evaluation - Item "Prezar pela pontualidade ao usar } \\
\text { transporte escolar é: (1 - RUIM, 2, 3, 4, 5- BOM)". }\end{array}$ \\
\hline & TECNO1 & Numérica Ordinal & $b$ & $\begin{array}{l}\text { Crença Normativa } 1 \text { - Control Belief Strenght - Item "Meus pais não contratariam } \\
\text { um serviço de transporte escolar para mim, mesmo que tivessem condições } \\
\text { financeiras para isso. (1 - DISCORDO TOTALMENTE/2 - DISCORDO / } 3 \text { - NEM } \\
\text { CONCORDO, NEM DISCORDO / } 4 \text { - CONCORDO / } 5 \text { - CONCORDO } \\
\text { PLENAMENTE)". }\end{array}$ \\
\hline & TECNE1 & Numérica Ordinal & $e$ & $\begin{array}{l}\text { Crença Normativa } 1 \text { - Motivation to Comply - Item "Considero o fato de meus } \\
\text { pais decidirem por mim a contratação do serviço de transporte escolar como: (1- } \\
\text { NEGATIVO, 2, 3, } 4,5 \text { - POSITIVO)". }\end{array}$ \\
\hline & TECNO2 & Numérica Ordinal & $b$ & $\begin{array}{l}\text { Crença Normativa } 2 \text { - Belief Strenght - Item "Meus amigos me apoiariam se eu } \\
\text { utilizasse transporte escolar para ir ou voltar da escola. (1 - DISCORDO } \\
\text { TOTALMENTE/2 - DISCORDO / } 3 \text { - NEM CONCORDO, NEM DISCORDO / } 4 \text { - } \\
\text { CONCORDO / } 5 \text { - CONCORDO PLENAMENTE)". }\end{array}$ \\
\hline
\end{tabular}


APÊNDICE J - Descrição das variáveis relativas aos alunos, utilizadas na abordagem quantitativa - Parte 9/21

\begin{tabular}{|c|c|c|c|c|}
\hline GRUPO & IDENTIFICAÇÃO & CATEGORIA & CRENCA & DESCRIÇÃO OU ITEM DO QUESTIONÁRIO \\
\hline \multirow{7}{*}{$\begin{array}{l}\text { MODO } \\
\text { TRANSPORTE } \\
\text { ESCOLAR }\end{array}$} & TECNE2 & Numérica Ordinal & $e$ & $\begin{array}{l}\text { Crença Normativa } 2 \text { - Motivation to Comply - Item "Considero o fato de meus } \\
\text { amigos me apoiarem, se eu utilizar transporte escolar, como: (1 - NEGATIVO, 2, 3, } \\
\text { 4, } 5 \text { - POSITIVO)". }\end{array}$ \\
\hline & TECCO1 & Numérica Ordinal & $b$ & $\begin{array}{l}\text { Crença de Controle } 1 \text { - Control Belief Strenght } \text { - Item "É perigoso ficar esperando } \\
\text { pelo transporte escolar (1 - DISCORDO TOTALMENTE/2 - DISCORDO / } 3 \text { - NEM } \\
\text { CONCORDO, NEM DISCORDO / } 4 \text { - CONCORDO / } 5 \text { - CONCORDO } \\
\text { PLENAMENTE)". }\end{array}$ \\
\hline & TECCE1 & Numérica Ordinal & $e$ & $\begin{array}{l}\text { Crença de Controle } 1 \text { - Power of Control Factor - Item "Devo cuidar pela minha } \\
\text { integridade física ao esperar pelo transporte escolar. (1- DIFICILMENTE, 2, 3, 4, } 5 \\
\text { - PROVAVELMENTE)". }\end{array}$ \\
\hline & TECCO2 & Numérica Ordinal & $b$ & $\begin{array}{l}\text { Crença de Controle } 2 \text { - Power of Control Factor - Item "Usar transporte escolar é } \\
\text { caro. (1 - DISCORDO TOTALMENTE/2 - DISCORDO / } 3 \text { - NEM CONCORDO, } \\
\text { NEM DISCORDO / } 4 \text { - CONCORDO / } 5 \text { - CONCORDO PLENAMENTE)"; }\end{array}$ \\
\hline & TECCE2 & Numérica Ordinal & $e$ & $\begin{array}{l}\text { Crença de Controle } 2 \text { - Power of Control Factor - Item "Devo considerar o preço } \\
\text { do serviço para contratar o transporte escolar. (1 - DIFICILMENTE, 2, 3, 4, } 5 \text { - } \\
\text { PROVAVELMENTE)". }\end{array}$ \\
\hline & TECCO3 & Numérica Ordinal & $b$ & $\begin{array}{l}\text { Crença de Controle } 3 \text { - Control Belief Strenght - Item "Existe transporte escolar } \\
\text { para o bairro onde moro. ( } 1 \text { - DISCORDO TOTALMENTE/2 - DISCORDO / } 3 \text { - } \\
\text { NEM CONCORDO, NEM DISCORDO / } 4 \text { - CONCORDO / } 5 \text { - CONCORDO } \\
\text { PLENAMENTE)". }\end{array}$ \\
\hline & TECCE3 & Numérica Ordinal & $e$ & $\begin{array}{l}\text { Crença de Controle } 3 \text { - Power od Control Factor - Item "Se eu optasse por utilizar } \\
\text { transporte escolar para ir ou voltar da escola, acharia um serviço disponível no meu } \\
\text { bairro. (1- DIFICILMENTE, 2, 3, 4, 5 - PROVAVELMENTE)". }\end{array}$ \\
\hline \multirow{3}{*}{$\begin{array}{l}\text { MODO } \\
\text { AUTOMÓVEL DA } \\
\text { FAMÍLIA }\end{array}$} & AFDAT1 & Numérica Ordinal & NA & $\begin{array}{l}\text { Direta Atitude } 1 \text { - Item "Para mim, usar automóvel da família para ir ou voltar da } \\
\text { escola seria: (1- DESAGRADÁVEL, 2, 3, 4, 5 - AGRADÁVEL)". }\end{array}$ \\
\hline & AFDAT2 & Numérica Ordinal & NA & $\begin{array}{l}\text { Direta Atitude } 2 \text { - Item "Para mim, usar automóvel da família para ir ou voltar da } \\
\text { escola seria: (1 - NEGATIVO, 2, 3, 4, 5- POSITIVO)". }\end{array}$ \\
\hline & AFDAT3 & Numérica Ordinal & NA & $\begin{array}{l}\text { Direta Atitude 3 - Item "Para mim, usar automóvel da família para ir ou voltar da } \\
\text { escola seria: (1- RUIM, 2, 3, 4, 5- BOM)". }\end{array}$ \\
\hline
\end{tabular}


APÊNDICE J - Descrição das variáveis relativas aos alunos, utilizadas na abordagem quantitativa - Parte 10/21

\begin{tabular}{|c|c|c|c|c|}
\hline GRUPO & IDENTIFICAÇÃO & CATEGORIA & CRENÇA & DESCRIÇÃO OU ITEM DO QUESTIONÁRIO \\
\hline \multirow{10}{*}{$\begin{array}{l}\text { MODO } \\
\text { AUTOMÓVEL } \\
\text { DA FAMÍLIA }\end{array}$} & AFDNS1 & Numérica Ordinal & NA & $\begin{array}{l}\text { Direta Norma Social } 1 \text { - Item "A maioria das pessoas importantes para mim } \\
\text { aprovaria minha opção de usar automóvel da família para ir ou voltar da escola. (1 - } \\
\text { DISCORDO TOTALMENTE/2 - DISCORDO / } 3 \text { - NEM CONCORDO, NEM } \\
\text { DISCORDO / } 4 \text { - CONCORDO / } 5 \text { - CONCORDO PLENAMENTE)". }\end{array}$ \\
\hline & AFDNS2 & Numérica Ordinal & NA & $\begin{array}{l}\text { Direta Norma Social } 2 \text { - Item "Pessoas próximas a mim acham que minha opção } \\
\text { de usar automóvel da família para ir ou voltar da escola é acertada. (1 - DISCORDO } \\
\text { TOTALMENTE/2 - DISCORDO / } 3 \text { - NEM CONCORDO, NEM DISCORDO / } 4 \text { - } \\
\text { CONCORDO / } 5 \text { - CONCORDO PLENAMENTE)". }\end{array}$ \\
\hline & AFDNS3 & Numérica Ordinal & NA & $\begin{array}{l}\text { Direta Norma Social } 3 \text { - Item “A maioria das pessoas que eu conheço não se } \\
\text { importa com a minha opção de usar automóvel da família para ir ou voltar da escola. } \\
\text { (1 - DISCORDO TOTALMENTE/2 - DISCORDO / } 3 \text { - NEM CONCORDO, NEM } \\
\text { DISCORDO / } 4 \text { - CONCORDO / } 5 \text { - CONCORDO PLENAMENTE)”. }\end{array}$ \\
\hline & AFDCP1 & Numérica Ordinal & NA & $\begin{array}{l}\text { Direta Controle Percebido } 1 \text { - Item "A minha liberdade de usar automóvel da } \\
\text { família para ir ou voltar da escola é: (1- NENHUMA, 2, 3, 4, 5 - TOTAL)". }\end{array}$ \\
\hline & AFDCP2 & Numérica Ordinal & NA & $\begin{array}{l}\text { Direta Controle Percebido } 2 \text { - Item "Para mim, usar automóvel da família para ir } \\
\text { ou voltar da escola seria: (1- DIFÍCIL, } 2,3,4,5 \text { - FÁCIL)". }\end{array}$ \\
\hline & AFDCP3 & Numérica Ordinal & NA & $\begin{array}{l}\text { Direta Controle Percebido } 3 \text { - Item "Para mim, usar automóvel da família para ir } \\
\text { ou voltar da escola seria: (1- IMPOSSÍVEL, 2, 3, 4, 5- POSSÍVEL)". }\end{array}$ \\
\hline & AFDIT1 & Numérica Ordinal & NA & $\begin{array}{l}\text { Direta Intenção } 1 \text { - Item "Pretendo usar automóvel da família para ir ou voltar da } \\
\text { escola. (1 - DISCORDO TOTALMENTE/2 - DISCORDO / } 3 \text { - NEM CONCORDO, } \\
\text { NEM DISCORDO / } 4 \text { - CONCORDO / } 5 \text { - CONCORDO PLENAMENTE)". }\end{array}$ \\
\hline & AFDIT2 & Numérica Ordinal & NA & $\begin{array}{l}\text { Direta Intenção 2 - Item "Minha intenção de usar automóvel da família para ir ou } \\
\text { voltar da escola é: (1- FRACA, 2, 3, 4, 5 - FORTE)". }\end{array}$ \\
\hline & AFDIT3 & Numérica Ordinal & NA & $\begin{array}{l}\text { Direta Intenção 3 - Item "Nas próximas semanas, eu irei usar automóvel da família } \\
\text { para ir ou voltar da escola. (1- DIFICILMENTE, 2, 3, 4, 5 - CERTAMENTE)". }\end{array}$ \\
\hline & AFCBO1 & Numérica Ordinal & $b$ & $\begin{array}{l}\text { Crença Comportamental } 1 \text { - Outcome - Item "Vir ou voltar da escola de carro } \\
\text { contribui para piorar o congestionamento. (1 - DISCORDO TOTALMENTE/2 - } \\
\text { DISCORDO / } 3 \text { - NEM CONCORDO, NEM DISCORDO / } 4 \text { - CONCORDO / } 5 \text { - } \\
\text { CONCORDO PLENAMENTE)". }\end{array}$ \\
\hline
\end{tabular}


APÊNDICE J - Descrição das variáveis relativas aos alunos, utilizadas na abordagem quantitativa - Parte 11/21

\begin{tabular}{|c|c|c|c|c|}
\hline GRUPO & IDENTIFICAÇÃO & CATEGORIA & CRENÇA & DESCRIÇÃO OU ITEM DO QUESTIONÁRIO \\
\hline \multirow{10}{*}{$\begin{array}{l}\text { MODO } \\
\text { AUTOMÓVEL } \\
\text { DA FAMÍLIA }\end{array}$} & AFCBE1 & Numérica Ordinal & 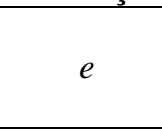 & $\begin{array}{l}\text { Crença Comportamental } 1-\text { Evaluation - Item "Preocupar-se com os } \\
\text { congestionamentos ao usar carro para vir ou voltar da escola é: (1- RUIM, 2, 3, 4, } 5 \\
\text { - BOM)". }\end{array}$ \\
\hline & AFCBO2 & Numérica Ordinal & $b$ & $\begin{array}{l}\text { Crença Comportamental } 2 \text { - Outcome - Item "É seguro ir ou voltar da escola de } \\
\text { carro. (1 - DISCORDO TOTALMENTE/2 - DISCORDO / } 3 \text { - NEM CONCORDO, } \\
\text { NEM DISCORDO / } 4 \text { - CONCORDO / } 5 \text { - CONCORDO PLENAMENTE)". }\end{array}$ \\
\hline & AFCBE2 & Numérica Ordinal & $e$ & $\begin{array}{l}\text { Crença Comportamental } 2 \text { - Evaluation - Item "Prezar pela segurança ao usar } \\
\text { carro para ir ou voltar da escola é: (1- RUIM, 2, 3, 4, 5 - BOM)". }\end{array}$ \\
\hline & AFCBO3 & Numérica Ordinal & $b$ & $\begin{array}{l}\text { Crença Comportamental } 3 \text { - Outcome - Item "Quem vai para a escola de carro } \\
\text { não costuma chegar no horário certo. (1 - DISCORDO TOTALMENTE/2 - } \\
\text { DISCORDO / } 3 \text { - NEM CONCORDO, NEM DISCORDO / } 4 \text { - CONCORDO / } 5 \text { - } \\
\text { CONCORDO PLENAMENTE)". }\end{array}$ \\
\hline & AFCBE3 & Numérica Ordinal & $e$ & $\begin{array}{l}\text { Crença Comportamental - Evaluation - Item "Prezar pela pontualidade ao usar } \\
\text { carro para ir ou voltar da escola é: (1- RUIM, 2, 3, 4, 5 - BOM)". }\end{array}$ \\
\hline & AFCNO1 & Numérica Ordinal & $b$ & $\begin{array}{l}\text { Crença Normativa } 1 \text { - Belief Strenght - Item "Meus pais preferem me trazer de } \\
\text { carro para a escola. (1 - DISCORDO TOTALMENTE/2 - DISCORDO / } 3 \text { - NEM } \\
\text { CONCORDO, NEM DISCORDO / } 4 \text { - CONCORDO / } 5 \text { - CONCORDO } \\
\text { PLENAMENTE)". }\end{array}$ \\
\hline & AFCNE1 & Numérica Ordinal & $e$ & $\begin{array}{l}\text { Crença Normativa 1 - Motivation to Comply - Item "Considero o fato de meus } \\
\text { pais preferirem me trazer de carro para a escola como: (1- NEGATIVO, 2, 3, 4, 5- } \\
\text { POSITIVO)". }\end{array}$ \\
\hline & AFCNO2 & Numérica Ordinal & $b$ & $\begin{array}{l}\text { Crença Normativa } 2 \text { - Belief Strenght - Item "Meus amigos me apoiariam se eu } \\
\text { utilizasse carro para ir ou voltar da escola. (1 - DISCORDO TOTALMENTE/2 - } \\
\text { DISCORDO / } 3 \text { - NEM CONCORDO, NEM DISCORDO / } 4 \text { - CONCORDO / } 5 \text { - } \\
\text { CONCORDO PLENAMENTE)". }\end{array}$ \\
\hline & AFCNE2 & Numérica Ordinal & $e$ & $\begin{array}{l}\text { Crença Normativa } 2 \text { - Motivation to Comply - Item "Considero o fato de meus } \\
\text { amigos me apoiarem a usar o automóvel da família para ir/voltar da escola como: } \\
\text { (1- NEGATIVO, } 2,3,4,5 \text { - POSITIVO)". }\end{array}$ \\
\hline & AFCCO1 & Numérica Ordinal & $b$ & $\begin{array}{l}\text { Crença de Controle } 1 \text { - Control Belief Strenght - Item "Ir ou voltar da escola de } \\
\text { carro é caro. (1 - DISCORDO TOTALMENTE/2 - DISCORDO / } 3 \text { - NEM } \\
\text { CONCORDO, NEM DISCORDO / } 4 \text { - CONCORDO / } 5 \text { - CONCORDO } \\
\text { PLENAMENTE)". }\end{array}$ \\
\hline
\end{tabular}


APÊNDICE J - Descrição das variáveis relativas aos alunos, utilizadas na abordagem quantitativa - Parte 12/21

\begin{tabular}{|c|c|c|c|c|}
\hline GRUPO & IDENTIFICAÇÃO & CATEGORIA & CRENÇA & DESCRIÇÃO OU ITEM DO QUESTIONÁRIO \\
\hline \multirow{3}{*}{$\begin{array}{l}\text { MODO } \\
\text { AUTOMÓVEL DA } \\
\text { FAMÍLIA }\end{array}$} & AFCCE1 & Numérica Ordinal & 3 & $\begin{array}{l}\text { Crença de Controle } 1 \text { - Power of Control Factor - Item "Devo considerar o custo } \\
\text { de usar carro para decidir ir/voltar da escola de carro. (1 - DIFICILMENTE, 2, 3, 4, } \\
5 \text { - PROVAVELMENTE)". }\end{array}$ \\
\hline & $\mathrm{AFCCO2}$ & Numérica Ordinal & $b$ & $\begin{array}{l}\text { Crença de Controle } 2 \text { - Control Belief Strenght - Item "Quem volta da escola de } \\
\text { carro com os pais fica impedido de fazer outras atividades depois da aula. (1 - } \\
\text { DISCORDO TOTALMENTE/2 - DISCORDO / } 3 \text { - NEM CONCORDO, NEM } \\
\text { DISCORDO / } 4 \text { - CONCORDO / } 5 \text { - CONCORDO PLENAMENTE)". }\end{array}$ \\
\hline & AFCCE2 & Numérica Ordinal & $e$ & $\begin{array}{l}\text { Crença de Controle } 2 \text { - Power od Control Factor - Item "Eu não faria nada depois } \\
\text { da aula se voltasse da escola de carro com meus pais. (1 - DIFICILMENTE, 2, 3, 4, } \\
5 \text { - PROVAVELMENTE)". }\end{array}$ \\
\hline \multirow{6}{*}{ MODO METRÔ } & MTDAT1 & Numérica Ordinal & NA & $\begin{array}{l}\text { Direta Atitude 1 - Item "Para mim, usar metrô para ir ou voltar da escola seria: (1- } \\
\text { DESAGRADÁVEL, 2, 3, 4, 5 - AGRADÁVEL)". }\end{array}$ \\
\hline & MTDAT2 & Numérica Ordinal & NA & $\begin{array}{l}\text { Direta Atitude } 2 \text { - Item "Para mim, usar metrô para ir ou voltar da escola seria: (1- } \\
\text { NEGATIVO, 2, 3, 4, 5 - POSITIVO)". }\end{array}$ \\
\hline & MTDAT3 & Numérica Ordinal & NA & $\begin{array}{l}\text { Direta Atitude } 3 \text { - Item "Para mim, usar metrô para ir ou voltar da escola seria: (1- } \\
\text { RUIM, 2, 3, 4, 5 - BOM)". }\end{array}$ \\
\hline & MTDNS1 & Numérica Ordinal & NA & $\begin{array}{l}\text { Direta Norma Social } 1 \text { - Item "A maioria das pessoas importantes para mim } \\
\text { aprovaria minha opção de usar metrô para ir ou voltar da escola (1 - DISCORDO } \\
\text { TOTALMENTE/2 - DISCORDO / } 3 \text { - NEM CONCORDO, NEM DISCORDO / } 4 \text { - } \\
\text { CONCORDO / } 5 \text { - CONCORDO PLENAMENTE)". }\end{array}$ \\
\hline & MTDNS2 & Numérica Ordinal & NA & $\begin{array}{l}\text { Direta Norma Social } 2 \text { - Item "Pessoas próximas a mim acham que minha opção } \\
\text { de usar metrô para ir ou voltar da escola é acertada. (1 - DISCORDO } \\
\text { TOTALMENTE/2 - DISCORDO / } 3 \text { - NEM CONCORDO, NEM DISCORDO / } 4 \text { - } \\
\text { CONCORDO / } 5 \text { - CONCORDO PLENAMENTE)". }\end{array}$ \\
\hline & MTDNS3 & Numérica Ordinal & NA & $\begin{array}{l}\text { Direta Norma Social } 3 \text { - Item "A maioria das pessoas que eu conheço não se } \\
\text { importa com a minha opção de usar metrô para ir ou voltar da escola. (1 - } \\
\text { DISCORDO TOTALMENTE/2 - DISCORDO / } 3 \text { - NEM CONCORDO, NEM } \\
\text { DISCORDO / } 4 \text { - CONCORDO / } 5 \text { - CONCORDO PLENAMENTE)". }\end{array}$ \\
\hline
\end{tabular}


APÊNDICE J - Descrição das variáveis relativas aos alunos, utilizadas na abordagem quantitativa - Parte 13/21

\begin{tabular}{|c|c|c|c|c|}
\hline GRUPO & IDENTIFICAÇÃO & CATEGORIA & CRENÇA & DESCRIÇÃO OU ITEM DO QUESTIONÁRIO \\
\hline \multirow{12}{*}{ MODO METRÔ } & MTDCP1 & Numérica Ordinal & NA & $\begin{array}{l}\text { Direta Controle Percebido } 1 \text { - Item "A minha liberdade de usar metrô para ir ou } \\
\text { voltar da escola é: (1- NENHUMA, 2, 3, 4, 5-TOTAL)". }\end{array}$ \\
\hline & MTDCP2 & Numérica Ordinal & NA & $\begin{array}{l}\text { Direta Controle Percebido } 2 \text { - Item "Para mim, usar metrô para ir ou voltar da } \\
\text { escola seria: (1- DIFÍCIL, 2, 3, 4, 5 - FÁCIL)". }\end{array}$ \\
\hline & MTDCP3 & Numérica Ordinal & NA & $\begin{array}{l}\text { Direta Controle Percebido } 3 \text { - Item "Para mim, usar metrô para ir ou voltar da } \\
\text { escola seria: (1- IMPOSSÍVEL, } 2,3,4,5 \text { - POSSÍVEL)". }\end{array}$ \\
\hline & MTDIT1 & Numérica Ordinal & NA & $\begin{array}{l}\text { Direta Intenção } 1 \text { - Item "Pretendo usar metrô para ir ou voltar da escola. (1 - } \\
\text { DISCORDO TOTALMENTE/2 - DISCORDO / } 3 \text { - NEM CONCORDO, NEM } \\
\text { DISCORDO / } 4 \text { - CONCORDO / } 5 \text { - CONCORDO PLENAMENTE)". }\end{array}$ \\
\hline & MTDIT2 & Numérica Ordinal & NA & $\begin{array}{l}\text { Direta Intenção 2 - Item "Minha intenção de usar metrô para ir ou voltar da escola } \\
\text { é: (1- FRACA, 2, 3, 4, 5 - FORTE)". }\end{array}$ \\
\hline & MTDIT3 & Numérica Ordinal & NA & $\begin{array}{l}\text { Direta Intenção 3 - Item "Nas próximas semanas, eu irei usar metrô para ir ou voltar } \\
\text { da escola. (1- DIFICILMENTE, 2, 3, 4, 5- CERTAMENTE)". }\end{array}$ \\
\hline & МТСBO1 & Numérica Ordinal & $b$ & $\begin{array}{l}\text { Crença Comportamental 1 - Outcome - Item "O metrô é um modo vantajoso para } \\
\text { quem tem o passe estudantil. (1 - DISCORDO TOTALMENTE/2 - DISCORDO / } 3 \\
\text { - NEM CONCORDO, NEM DISCORDO / } 4 \text { - CONCORDO / } 5 \text { - CONCORDO } \\
\text { PLENAMENTE)". }\end{array}$ \\
\hline & MTCBE1 & Numérica Ordinal & $e$ & $\begin{array}{l}\text { Crença Comportamental } 1 \text { - Evaluation - Item "Ter passe estudantil para usar o } \\
\text { metrô é: (1- RUIM, 2, 3, 4, 5 - BOM)". }\end{array}$ \\
\hline & МТСBO2 & Numérica Ordinal & $b$ & $\begin{array}{l}\text { Crença Comportamental } 2 \text { - Outcome - Item "É confortável usar metrô, mesmo } \\
\text { quando se viaja em pé. (1 - DISCORDO TOTALMENTE/2 - DISCORDO / } 3 \text { - NEM } \\
\text { CONCORDO, NEM DISCORDO / } 4 \text { - CONCORDO / } 5 \text { - CONCORDO } \\
\text { PLENAMENTE)". }\end{array}$ \\
\hline & MTCBE2 & Numérica Ordinal & $e$ & $\begin{array}{l}\text { Crença Comportamental } 2 \text { - Evaluation - Item "Prezar pelo conforto ao usar o } \\
\text { metrô é: (1- RUIM, 2, 3, 4, 5-BOM)". }\end{array}$ \\
\hline & МТСBO3 & Numérica Ordinal & $b$ & $\begin{array}{l}\text { Crença Comportamental } 3 \text { - Outcome - Item "A viagem dentro do metrô não é } \\
\text { segura. (1 - DISCORDO TOTALMENTE/2 - DISCORDO / } 3 \text { - NEM CONCORDO, } \\
\text { NEM DISCORDO / } 4 \text { - CONCORDO / } 5 \text { - CONCORDO PLENAMENTE)". }\end{array}$ \\
\hline & MTCBE3 & Numérica Ordinal & $e$ & $\begin{array}{l}\text { Crença Comportamental } 3 \text { - Evaluation - Item "Prezar pela segurança ao usar o } \\
\text { metrô é: (1- RUIM, 2, 3, 4, } 5 \text { - BOM)". }\end{array}$ \\
\hline
\end{tabular}


APÊNDICE J - Descrição das variáveis relativas aos alunos, utilizadas na abordagem quantitativa - Parte 14/21

\begin{tabular}{|c|c|c|c|c|}
\hline GRUPO & IDENTIFICAÇ̃̃O & CATEGORIA & CRENCA & DESCRIÇÃO OU ITEM DO QUESTIONÁRIO \\
\hline \multirow{9}{*}{ MODO METRÔ } & МТCBO4 & Numérica Ordinal & $b$ & $\begin{array}{l}\text { Crença Comportamental } 4 \text { - Outcome - Item "Quem vai para a escola de metrô, } \\
\text { chega no horário certo. ( } 1 \text { - DISCORDO TOTALMENTE/2 - DISCORDO / } 3 \text { - } \\
\text { NEM CONCORDO, NEM DISCORDO / } 4 \text { - CONCORDO / } 5 \text { - CONCORDO } \\
\text { PLENAMENTE)". }\end{array}$ \\
\hline & MTCBE4 & Numérica Ordinal & $e$ & $\begin{array}{l}\text { Crença Comportamental } 4 \text { - Evaluation - Item "Prezar pela pontualidade ao usar } \\
\text { o metrô é: (1- RUIM, 2, 3, 4, 5 - BOM)". }\end{array}$ \\
\hline & MTCNO1 & Numérica Ordinal & $b$ & $\begin{array}{l}\text { Crença Normativa } 1 \text { - Belief Strenght - Item "Meus pais me incentivam a vir ou } \\
\text { voltar da escola de metrô. (1 - DISCORDO TOTALMENTE/2 - DISCORDO / } 3 \text { - } \\
\text { NEM CONCORDO, NEM DISCORDO / } 4 \text { - CONCORDO / } 5 \text { - CONCORDO } \\
\text { PLENAMENTE)". }\end{array}$ \\
\hline & MTCNE1 & Numérica Ordinal & $e$ & $\begin{array}{l}\text { Crença Normativa } 1 \text { - Motivation to Comply - Item "Considero o fato de meus } \\
\text { pais me incentivarem a vir ou voltar da escola de metrô como: (1- NEGATIVO, 2, } \\
3,4,5 \text { - POSITIVO)". }\end{array}$ \\
\hline & MTCNO2 & Numérica Ordinal & $b$ & $\begin{array}{l}\text { Crença Normativa } 2 \text { - Belief Strenght - Item "Meus amigos me apoiariam se eu } \\
\text { utilizasse metrô para ir ou voltar da escola. (1 - DISCORDO TOTALMENTE/2 - } \\
\text { DISCORDO / } 3 \text { - NEM CONCORDO, NEM DISCORDO / } 4 \text { - CONCORDO / } 5 \text { - } \\
\text { CONCORDO PLENAMENTE)". }\end{array}$ \\
\hline & MTCNE2 & Numérica Ordinal & $e$ & $\begin{array}{l}\text { Crença Normativa } 2 \text { - Motivation to Comply - Item "Considero o fato de meus } \\
\text { amigos me apoiarem a usar metrô para ir/voltar da escola como: (1- NEGATIVO, 2, } \\
\text { 3, 4,5 - POSITIVO)". }\end{array}$ \\
\hline & MTCCO1 & Numérica Ordinal & $b$ & $\begin{array}{l}\text { Crença de Controle } 1 \text { - Control Belief Strenght } \text { - Item "O trecho a pé entre a escola } \\
\text { e a estação do metrô é perigoso. (1 - DISCORDO TOTALMENTE/2 - DISCORDO } \\
\text { / } 3 \text { - NEM CONCORDO, NEM DISCORDO / } 4 \text { - CONCORDO / } 5 \text { - CONCORDO } \\
\text { PLENAMENTE)". }\end{array}$ \\
\hline & MTCCE1 & Numérica Ordinal & $e$ & $\begin{array}{l}\text { Crença de Controle } 1 \text { - Power of Control Factor - Item "Acho que posso ser } \\
\text { agredido no trecho entre a escola e a estação de metrô. (1- DIFICILMENTE, 2, 3, 4, } \\
5 \text { - PROVAVELMENTE)". }\end{array}$ \\
\hline & MTCCO2 & Numérica Ordinal & $b$ & $\begin{array}{l}\text { Crença de Controle } 2 \text { - Control Belief Strenght - Item "O trecho a pé entre a } \\
\text { estação do metrô e a minha casa é perigoso. ( } 1 \text { - DISCORDO TOTALMENTE/2 - } \\
\text { DISCORDO / } 3 \text { - NEM CONCORDO, NEM DISCORDO / } 4 \text { - CONCORDO / } 5 \text { - } \\
\text { CONCORDO PLENAMENTE)". }\end{array}$ \\
\hline
\end{tabular}


APÊNDICE J - Descrição das variáveis relativas aos alunos, utilizadas na abordagem quantitativa - Parte 15/21

\begin{tabular}{|c|c|c|c|c|}
\hline GRUPO & IDENTIFICAÇÃO & CATEGORIA & CRENÇA & DESCRIÇÃO OU ITEM DO QUESTIONÁRIO \\
\hline \multirow{3}{*}{ MODO METRÔ } & MTCCE2 & Numérica Ordinal & $e$ & $\begin{array}{l}\text { Crença de Controle } 2 \text { - Power of Control Factor - Item "Acho que posso ser } \\
\text { agredido no trecho entre a estação do metrô e a minha casa. (1- DIFICILMENTE, } \\
2,3,4,5 \text { - PROVAVELMENTE)". }\end{array}$ \\
\hline & MTCCO3 & Numérica Ordinal & $b$ & $\begin{array}{l}\text { Crença de Controle } 3 \text { - Control Belief Strenght - Item "Não é seguro esperar pelo } \\
\text { metrô nas estações. (1 - DISCORDO TOTALMENTE/2 - DISCORDO / } 3 \text { - NEM } \\
\text { CONCORDO, NEM DISCORDO / } 4 \text { - CONCORDO / } 5 \text { - CONCORDO } \\
\text { PLENAMENTE)". }\end{array}$ \\
\hline & MTCCE3 & Numérica Ordinal & $e$ & $\begin{array}{l}\text { Crença de Controle } 3 \text { - Power Control Factor - Item "Devo prezar pela segurança } \\
\text { ao esperar pelo metrô nas estações. (1- DIFICILMENTE, 2, 3, 4, 5 - } \\
\text { PROVAVELMENTE)". }\end{array}$ \\
\hline \multirow{8}{*}{ MODO ÔNIBUS } & ONDAT1 & Numérica Ordinal & NA & $\begin{array}{l}\text { Direta Atitude 1 - Item "Para mim, usar ônibus para ir ou voltar da escola seria: (1- } \\
\text { DESAGRADÁVEL, 2, 3, 4, 5 - AGRADÁVEL)". }\end{array}$ \\
\hline & ONDAT2 & Numérica Ordinal & NA & $\begin{array}{l}\text { Direta Atitude } 2 \text { - Item "Para mim, usar ônibus para ir ou voltar da escola seria: (1- } \\
\text { NEGATIVO, 2, 3, 4, 5 - POSITIVO)". }\end{array}$ \\
\hline & ONDAT3 & Numérica Ordinal & NA & $\begin{array}{l}\text { Direta Atitude } 3 \text { - Item "Para mim, usar ônibus para ir ou voltar da escola seria: (1- } \\
\text { RUIM, 2, 3, 4, } 5 \text { - BOM)". }\end{array}$ \\
\hline & ONDNS1 & Numérica Ordinal & NA & $\begin{array}{l}\text { Direta Norma Social 1 - Item "A maioria das pessoas importantes para mim } \\
\text { aprovaria minha opção de usar ônibus para ir ou voltar da escola. (1 - DISCORDO } \\
\text { TOTALMENTE/2 - DISCORDO / } 3 \text { - NEM CONCORDO, NEM DISCORDO / } 4 \text { - } \\
\text { CONCORDO / } 5 \text { - CONCORDO PLENAMENTE)". }\end{array}$ \\
\hline & ONDNS2 & Numérica Ordinal & NA & $\begin{array}{l}\text { Direta Norma Social } 2 \text { - Item "Pessoas próximas a mim acham que minha opção } \\
\text { de usar ônibus para ir ou voltar da escola é acertada. (1 - DISCORDO } \\
\text { TOTALMENTE/2 - DISCORDO / } 3 \text { - NEM CONCORDO, NEM DISCORDO / } 4 \text { - } \\
\text { CONCORDO / } 5 \text { - CONCORDO PLENAMENTE)". }\end{array}$ \\
\hline & ONDNS3 & Numérica Ordinal & NA & $\begin{array}{l}\text { Direta Norma Social } 3 \text { - Item "A maioria das pessoas que eu conheço não se } \\
\text { importa com a minha opção de usar ônibus para ir ou voltar da escola. (1 - } \\
\text { DISCORDO TOTALMENTE/2 - DISCORDO / } 3 \text { - NEM CONCORDO, NEM } \\
\text { DISCORDO / } 4 \text { - CONCORDO / } 5 \text { - CONCORDO PLENAMENTE)". }\end{array}$ \\
\hline & ONDCP1 & Numérica Ordinal & NA & $\begin{array}{l}\text { Direta Controle Percebido } 1 \text { - Item "A minha liberdade de usar ônibus para ir ou } \\
\text { voltar a pé da escola é: ( } 1 \text { - NENHUMA, } 2,3,4,5 \text { - TOTAL)". }\end{array}$ \\
\hline & ONDCP2 & Numérica Ordinal & NA & $\begin{array}{l}\text { Direta Controle Percebido } 2 \text { - Item "Para mim, usar ônibus para ir ou voltar da } \\
\text { escola seria: (1- DIFÍCIL, 2, 3, 4, 5 - FÁCIL)". }\end{array}$ \\
\hline
\end{tabular}


APÊNDICE J - Descrição das variáveis relativas aos alunos, utilizadas na abordagem quantitativa - Parte 16/21

\begin{tabular}{|c|c|c|c|c|}
\hline GRUPO & IDENTIFICAÇÃO & CATEGORIA & CRENÇA & DESCRIÇÃO OU ITEM DO QUESTIONÁRIO \\
\hline \multirow{12}{*}{ MODO ÔNIBUS } & ONDCP3 & Numérica Ordinal & NA & $\begin{array}{l}\text { Direta Controle Percebido } 3 \text { - Item "Para mim, usar ônibus para ir ou voltar da } \\
\text { escola seria: (IMPOSSÍVEL, 2, 3, 4, } 5 \text { - POSSÍVEL)". }\end{array}$ \\
\hline & ONDIT1 & Numérica Ordinal & NA & $\begin{array}{l}\text { Direta Intenção } 1 \text { - Item "Pretendo usar ônibus para ir ou voltar da escola. (1 - } \\
\text { DISCORDO TOTALMENTE/2 - DISCORDO / } 3 \text { - NEM CONCORDO, NEM } \\
\text { DISCORDO / } 4 \text { - CONCORDO / } 5 \text { - CONCORDO PLENAMENTE)". }\end{array}$ \\
\hline & ONDIT2 & Numérica Ordinal & NA & $\begin{array}{l}\text { Direta Intenção } 2 \text { - Item "Minha intenção de usar ônibus para ir ou voltar da escola } \\
\text { é: (1- FRACA, 2, 3, 4, } 5 \text { - FORTE)". }\end{array}$ \\
\hline & ONDIT3 & Numérica Ordinal & NA & $\begin{array}{l}\text { Direta Intenção } 3 \text { - Item "Nas próximas semanas, eu irei usar ônibus para ir ou } \\
\text { voltar da escola. (1- DIFICILMENTE, } 2,3,4,5 \text { - CERTAMENTE)". }\end{array}$ \\
\hline & ONCBO1 & Numérica Ordinal & $b$ & $\begin{array}{l}\text { Crença Comportamental 1 - Outcome - Item "O ônibus é um modo vantajoso para } \\
\text { quem tem o passe estudantil. (1 - DISCORDO TOTALMENTE/2 - DISCORDO / } 3 \\
\text { - NEM CONCORDO, NEM DISCORDO / } 4 \text { - CONCORDO / } 5 \text { - CONCORDO } \\
\text { PLENAMENTE)". }\end{array}$ \\
\hline & ONCBE1 & Numérica Ordinal & $e$ & $\begin{array}{l}\text { Crença Comportamental } 1 \text { - Evaluation - Item "Ter passe estudantil para usar } \\
\text { ônibus é: (1- RUIM, 2, 3, 4, 5-BOM)". }\end{array}$ \\
\hline & ONCBO2 & Numérica Ordinal & $b$ & $\begin{array}{l}\text { Crença Comportamental } 2 \text { - Outcome - Item "Quem vai para a escola de ônibus } \\
\text { não costuma chegar atrasado. (1 - DISCORDO TOTALMENTE/2 - DISCORDO / } \\
3 \text { - NEM CONCORDO, NEM DISCORDO / } 4 \text { - CONCORDO / } 5 \text { - CONCORDO } \\
\text { PLENAMENTE)". }\end{array}$ \\
\hline & ONCBE2 & Numérica Ordinal & $e$ & $\begin{array}{l}\text { Crença Comportamental } 2 \text { - Evaluation - Item "Cuidar a pontualidade ao usar } \\
\text { ônibus para ir para a escola é: (1- RUIM, 2, 3, 4, 5- BOM)". }\end{array}$ \\
\hline & ONCBO3 & Numérica Ordinal & $b$ & $\begin{array}{l}\text { Crença Comportamental } 3 \text { - Outcome - Item “A viagem dentro do ônibus não é } \\
\text { segura (1 - DISCORDO TOTALMENTE/2 - DISCORDO / } 3 \text { - NEM CONCORDO, } \\
\text { NEM DISCORDO / } 4 \text { - CONCORDO / } 5 \text { - CONCORDO PLENAMENTE); }\end{array}$ \\
\hline & ONCBE3 & Numérica Ordinal & $e$ & $\begin{array}{l}\text { Crença Comportamental 3 - Evaluation - Item "Prezar pela segurança dentro do } \\
\text { ônibus é: (1- RUIM, } 2,3,4,5 \text { - BOM)". }\end{array}$ \\
\hline & ONCBO4 & Numérica Ordinal & $b$ & $\begin{array}{l}\text { Crença Comportamental } 4 \text { - Outcome - Item "O ônibus é superlotado para quem } \\
\text { vai ou volta da escola. (1 - DISCORDO TOTALMENTE/2 - DISCORDO / } 3 \text { - NEM } \\
\text { CONCORDO, NEM DISCORDO / } 4 \text { - CONCORDO / } 5 \text { - CONCORDO } \\
\text { PLENAMENTE)". }\end{array}$ \\
\hline & ONCBE4 & Numérica Ordinal & $e$ & $\begin{array}{l}\text { Crença Comportamental } 4 \text { - Evaluation - Item "Preocupar-se com a lotação do } \\
\text { ônibus para ir ou voltar da escola é: (1- RUIM, 2, 3, 4, 5- BOM)". }\end{array}$ \\
\hline
\end{tabular}


APÊNDICE J - Descrição das variáveis relativas aos alunos, utilizadas na abordagem quantitativa - Parte 17/21

\begin{tabular}{|c|c|c|c|c|}
\hline GRUPO & IDENTIFICAÇÃO & CATEGORIA & CRENÇA & DESCRIÇÃO OU ITEM DO QUESTIONÁRIO \\
\hline \multirow{9}{*}{ MODO ÔNIBUS } & ONCNO1 & Numérica Ordinal & $b$ & $\begin{array}{l}\text { Crença Normativa } 1 \text { - Belief Outcome - Item "Meus pais me incentivam a vir ou } \\
\text { voltar da escola de ônibus. (1 - DISCORDO TOTALMENTE/2 - DISCORDO / } 3 \text { - } \\
\text { NEM CONCORDO, NEM DISCORDO / } 4 \text { - CONCORDO / } 5 \text { - CONCORDO } \\
\text { PLENAMENTE)", }\end{array}$ \\
\hline & ONCNE1 & Numérica Ordinal & $e$ & $\begin{array}{l}\text { Crença Normativa } 1 \text { - Motivation to Comply - Item "Considero o fato de meus pais } \\
\text { me incentivarem a vir ou voltar da escola de ônibus como: (1- NEGATIVO, } 2,3,4 \text {, } \\
5 \text { - POSITIVO)". }\end{array}$ \\
\hline & ONCNO2 & Numérica Ordinal & $b$ & $\begin{array}{l}\text { Crença Normativa } 2 \text { - Belief Strenght - Item "Meus amigos me apoiariam se eu } \\
\text { utilizasse ônibus para ir ou voltar da escola. (1 - DISCORDO TOTALMENTE/2 - } \\
\text { DISCORDO / } 3 \text { - NEM CONCORDO, NEM DISCORDO / } 4 \text { - CONCORDO / } 5 \text { - } \\
\text { CONCORDO PLENAMENTE)". }\end{array}$ \\
\hline & ONCNE2 & Numérica Ordinal & $e$ & $\begin{array}{l}\text { Crença Normativa } 2 \text { - Motivation to Comply - Item "Considero o fato de meus } \\
\text { amigos me apoiarem a usar ônibus para ir/voltar da escola como (1- NEGATIVO, } \\
2,3,4,5 \text { - POSITIVO)". }\end{array}$ \\
\hline & ONCCO1 & Numérica Ordinal & $b$ & $\begin{array}{l}\text { Crença de Controle } 1 \text { - Control Belief Strenght } \text { - Item "O trecho a pé entre a escola } \\
\text { e a parada é perigoso. ( } 1 \text { - DISCORDO TOTALMENTE/2 - DISCORDO / } 3 \text { - NEM } \\
\text { CONCORDO, NEM DISCORDO / } 4 \text { - CONCORDO / } 5 \text { - CONCORDO } \\
\text { PLENAMENTE)". }\end{array}$ \\
\hline & ONCCE1 & Numérica Ordinal & $e$ & $\begin{array}{l}\text { Crença de Controle } 1 \text { - Power of Control Factor - Item "Acho que posso ser } \\
\text { agredido no trecho a pé entre a escola e a parada. (1- DIFICILMENTE, 2, 3, 4, 5 - } \\
\text { PROVAVELMENTE)". }\end{array}$ \\
\hline & $\mathrm{ONCCO} 2$ & Numérica Ordinal & $b$ & $\begin{array}{l}\text { Crença de Controle } 2 \text { - Control Belief Strenght } \text { - Item "O trecho a pé entre a parada } \\
\text { e a minha casa é perigoso. (1 - DISCORDO TOTALMENTE/2 - DISCORDO / } 3 \text { - } \\
\text { NEM CONCORDO, NEM DISCORDO / } 4 \text { - CONCORDO / } 5 \text { - CONCORDO } \\
\text { PLENAMENTE)". }\end{array}$ \\
\hline & ONCCE2 & Numérica Ordinal & $e$ & $\begin{array}{l}\text { Crença de Controle } 1 \text { - Power of Control Factor - Item "Acho que posso ser } \\
\text { agredido no trecho a pé a parada e a minha casa. (1- DIFICILMENTE, 2, 3, 4, 5- } \\
\text { PROVAVELMENTE)". }\end{array}$ \\
\hline & ONCCO3 & Numérica Ordinal & $b$ & $\begin{array}{l}\text { Crença de Controle } 3 \text { - Control Belief Strenght - Item "Não é seguro esperar pelo } \\
\text { ônibus na parada. ( } 1 \text { - DISCORDO TOTALMENTE/2 - DISCORDO / } 3 \text { - NEM } \\
\text { CONCORDO, NEM DISCORDO / } 4 \text { - CONCORDO / } 5 \text { - CONCORDO } \\
\text { PLENAMENTE)". }\end{array}$ \\
\hline
\end{tabular}


APÊNDICE J - Descrição das variáveis relativas aos alunos, utilizadas na abordagem quantitativa - Parte 18/21

\begin{tabular}{|c|c|c|c|c|}
\hline GRUPO & IDENTIFICAÇÃO & CATEGORIA & CRENÇA & DESCRIÇÃO OU ITEM DO QUESTIONÁRIO \\
\hline \multirow{3}{*}{ MODO ÔNIBUS } & ONCCE3 & Numérica Ordinal & $e$ & $\begin{array}{l}\text { Crença de Controle } 3 \text { - Power of Control Factor - Item "Devo prezar pela } \\
\text { segurança ao esperar pelo ônibus na parada. (1- DIFICILMENTE, 2, 3, 4, 5- } \\
\text { PROVAVELMENTE)". }\end{array}$ \\
\hline & ONCCO4 & Numérica Ordinal & $b$ & $\begin{array}{l}\text { Crença de Controle } 4 \text { - Control Belief Strenght - Item "Existe uma linha direta de } \\
\text { onibus entre a minha casa e a escola. (1 - DISCORDO TOTALMENTE/2 - } \\
\text { DISCORDO / } 3 \text { - NEM CONCORDO, NEM DISCORDO / } 4 \text { - CONCORDO / } 5 \text { - } \\
\text { CONCORDO PLENAMENTE)". }\end{array}$ \\
\hline & ONCCE4 & Numérica Ordinal & $e$ & $\begin{array}{l}\text { Crença de Controle } 4 \text { - Power of Control Factor - Item "Para mim, seria possível } \\
\text { utilizar uma linha direta de ônibus para ir ou voltar da escola. (1- DIFICILMENTE, } \\
2,3,4,5 \text { - PROVAVELMENTE)". }\end{array}$ \\
\hline \multirow{8}{*}{$\begin{array}{l}\text { MODO } \\
\text { BICICLETA }\end{array}$} & BCDAT1 & Numérica Ordinal & NA & $\begin{array}{l}\text { Direta Atitude 1 - Item "Para mim, usar bicicleta para ir ou voltar da escola seria: } \\
\text { (1- DESAGRADÁVEL, 2, 3, 4, 5 - AGRADÁVEL)". }\end{array}$ \\
\hline & BCDAT2 & Numérica Ordinal & NA & $\begin{array}{l}\text { Direta Atitude } 2 \text { - Item "Para mim, usar bicicleta para ir ou voltar da escola seria: } \\
\text { (1- NEGATIVO, 2, 3, 4, 5 - POSITIVO)". }\end{array}$ \\
\hline & BCDAT3 & Numérica Ordinal & NA & $\begin{array}{l}\text { Direta Atitude } 3 \text { - Item "Para mim, usar bicicleta para ir ou voltar da escola seria: } \\
\text { (1- RUIM, } 2,3,4,5 \text { - BOM)". }\end{array}$ \\
\hline & BCDNS1 & Numérica Ordinal & NA & $\begin{array}{l}\text { Direta Norma Social 1 - Item "A maioria das pessoas importantes para mim } \\
\text { aprovaria minha opção de usar bicicleta para ir ou voltar da escola. (1 - DISCORDO } \\
\text { TOTALMENTE/2 - DISCORDO / } 3 \text { - NEM CONCORDO, NEM DISCORDO / } 4 \text { - } \\
\text { CONCORDO / } 5 \text { - CONCORDO PLENAMENTE)". }\end{array}$ \\
\hline & BCDNS2 & Numérica Ordinal & NA & $\begin{array}{l}\text { Direta Norma Social } 2 \text { - Item "Pessoas próximas a mim acham que minha opção } \\
\text { de usar bicicleta para ir ou voltar da escola é acertada. (1 - DISCORDO } \\
\text { TOTALMENTE/2 - DISCORDO / } 3 \text { - NEM CONCORDO, NEM DISCORDO / } 4 \text { - } \\
\text { CONCORDO / } 5 \text { - CONCORDO PLENAMENTE)". }\end{array}$ \\
\hline & BCDNS3 & Numérica Ordinal & NA & $\begin{array}{l}\text { Direta Norma Social } 3 \text { - Item "A maioria das pessoas que eu conheço não se } \\
\text { importa com a minha opção de usar bicicleta para ir ou voltar da escola. (1 - } \\
\text { DISCORDO TOTALMENTE/2 - DISCORDO / } 3 \text { - NEM CONCORDO, NEM } \\
\text { DISCORDO / } 4 \text { - CONCORDO / } 5 \text { - CONCORDO PLENAMENTE)". }\end{array}$ \\
\hline & BCDCP1 & Numérica Ordinal & NA & $\begin{array}{l}\text { Direta Controle Percebido } 1 \text { - Item "A minha liberdade de usar bicicleta para ir ou } \\
\text { voltar da escola é: (1- NENHUMA, 2, 3, 4, 5- TOTAL)". }\end{array}$ \\
\hline & BCDCP2 & Numérica Ordinal & NA & $\begin{array}{l}\text { Direta Controle Percebido } 2 \text { - Item "Para mim, usar bicicleta para ir ou voltar da } \\
\text { escola seria: (1- DIFÍCIL, 2, 3, 4, 5 - FÁCIL)". }\end{array}$ \\
\hline
\end{tabular}


APÊNDICE J - Descrição das variáveis relativas aos alunos, utilizadas na abordagem quantitativa - Parte 19/21

\begin{tabular}{|c|c|c|c|c|}
\hline GRUPO & IDENTIFICAÇÃO & CATEGORIA & CRENÇA & DESCRIÇÃO OU ITEM DO QUESTIONÁRIO \\
\hline \multirow{11}{*}{$\begin{array}{l}\text { MODO } \\
\text { BICICLETA }\end{array}$} & BCDCP3 & Numérica Ordinal & NA & $\begin{array}{l}\text { Direta Controle Percebido } 3 \text { - Item "Para mim, usar bicicleta para ir ou voltar da } \\
\text { escola seria: (1- IMPOSSÍVEL, 2, 3, 4, 5 - POSSÍVEL)". }\end{array}$ \\
\hline & BCDIT1 & Numérica Ordinal & NA & $\begin{array}{l}\text { Direta Intenção } 1 \text { - Item "Pretendo usar bicicleta para ir ou voltar da escola. (1 - } \\
\text { DISCORDO TOTALMENTE/2 - DISCORDO / } 3 \text { - NEM CONCORDO, NEM } \\
\text { DISCORDO / } 4 \text { - CONCORDO / } 5 \text { - CONCORDO PLENAMENTE)". }\end{array}$ \\
\hline & BCDIT2 & Numérica Ordinal & NA & $\begin{array}{l}\text { Direta Intenção } 2 \text { - Item "Minha intenção de usar bicicleta para ir ou voltar da } \\
\text { escola é: (1- FRACA, 2, 3, 4, 5 - FORTE)". }\end{array}$ \\
\hline & BCDIT3 & Numérica Ordinal & NA & $\begin{array}{l}\text { Direta Intenção } 3 \text { - Item "Nas próximas semanas, eu irei usar bicicleta para ir ou } \\
\text { voltar da escola. (1- DIFICILMENTE, } 2,3,4,5 \text { - PROVAVELMENTE)". }\end{array}$ \\
\hline & ВCCBO1 & Numérica Ordinal & $b$ & $\begin{array}{l}\text { Crença Comportamental } 1 \text { - Outcome - Item "Usar bicicleta para ir ou voltar da } \\
\text { escola faz bem à saúde. (1 - DISCORDO TOTALMENTE/2 - DISCORDO / } 3 \text { - } \\
\text { NEM CONCORDO, NEM DISCORDO / } 4 \text { - CONCORDO / } 5 \text { - CONCORDO } \\
\text { PLENAMENTE)". }\end{array}$ \\
\hline & BCCBE1 & Numérica Ordinal & $e$ & $\begin{array}{l}\text { Crença Comportamental } 1 \text { - Evaluation - Item "Preocupar-se com o que é mais } \\
\text { saudável ao usar bicicleta para ir ou voltar da escola é: (1- RUIM, 2, 3, 4, 5- BOM)"; }\end{array}$ \\
\hline & ВСCBO2 & Numérica Ordinal & $b$ & $\begin{array}{l}\text { Crença Comportamental } 2 \text { - Outcome - Item "Usar bicicleta para ir ou voltar da } \\
\text { escola evita congestionamentos. (1 - DISCORDO TOTALMENTE/2 - DISCORDO } \\
\text { / } 3 \text { - NEM CONCORDO, NEM DISCORDO / } 4 \text { - CONCORDO / } 5 \text { - CONCORDO } \\
\text { PLENAMENTE)". }\end{array}$ \\
\hline & BCCBE2 & Numérica Ordinal & $e$ & $\begin{array}{l}\text { Crença Comportamental } 2 \text { - Evaluation - Item "Preocupar-se com os } \\
\text { congestionamentos ao usar bicicleta para vir ou voltar da escola é: (1- RUIM, 2, 3, } \\
4,5 \text { - BOM)". }\end{array}$ \\
\hline & ВССBO3 & Numérica Ordinal & $b$ & $\begin{array}{l}\text { Crença Comportamental } 3 \text { - Outcome - Item "Usar bicicleta para ir ou voltar da } \\
\text { escola diminui a poluição. ( } 1 \text { - DISCORDO TOTALMENTE/2 - DISCORDO / } 3 \text { - } \\
\text { NEM CONCORDO, NEM DISCORDO / } 4 \text { - CONCORDO / } 5 \text { - CONCORDO } \\
\text { PLENAMENTE)". }\end{array}$ \\
\hline & ВCCBE3 & Numérica Ordinal & $e$ & $\begin{array}{l}\text { Crença Comportamental 3 - Evaluation - Item "Preocupar-se com a poluição ao } \\
\text { usar bicicleta para vir ou voltar da escola é: (1- RUIM, 2, 3, 4, 5- BOM)". }\end{array}$ \\
\hline & BCCNO1 & Numérica Ordinal & $b$ & $\begin{array}{l}\text { Crença Normativa } 1 \text { - Belief Strenght - Item "Meus pais incentivam que eu use } \\
\text { bicicleta para vir ou voltar da escola. (1 - DISCORDO TOTALMENTE/2 - } \\
\text { DISCORDO / } 3 \text { - NEM CONCORDO, NEM DISCORDO / } 4 \text { - CONCORDO / } 5 \text { - } \\
\text { CONCORDO PLENAMENTE)". }\end{array}$ \\
\hline
\end{tabular}


APÊNDICE J - Descrição das variáveis relativas aos alunos, utilizadas na abordagem quantitativa - Parte 20/21

\begin{tabular}{|c|c|c|c|c|}
\hline GRUPO & IDENTIFICAÇÃOO & CATEGORIA & CRENÇA & DESCRIÇÃO OU ITEM DO QUESTIONÁRIO \\
\hline \multirow{9}{*}{$\begin{array}{l}\text { MODO } \\
\text { BICICLETA }\end{array}$} & BCCNE1 & Numérica Ordinal & 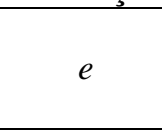 & $\begin{array}{l}\text { Crença Normativa } 1 \text { - Motivation to Comply - Item "Considero o fato de meus pais } \\
\text { me incentivarem a vir ou voltar da escola de bicicleta como: (1- NEGATIVO, 2, 3, } \\
4,5 \text { - POSITIVO)". }\end{array}$ \\
\hline & BCCNO2 & Numérica Ordinal & $b$ & $\begin{array}{l}\text { Crença Normativa } 2 \text { - Belief Strenght - Item "Meus amigos me apoiariam se eu } \\
\text { utilizasse bicicleta para ir ou voltar da escola. (1 - DISCORDO TOTALMENTE/2 - } \\
\text { DISCORDO / } 3 \text { - NEM CONCORDO, NEM DISCORDO / } 4 \text { - CONCORDO / } 5 \text { - } \\
\text { CONCORDO PLENAMENTE)". }\end{array}$ \\
\hline & BCCNE2 & Numérica Ordinal & $e$ & $\begin{array}{l}\text { Crença Normativa } 2 \text { - Motivation to Comply - Item "Considero o fato de meus } \\
\text { amigos me apoiarem no uso da bicicleta para ir/voltar da escola como: (1- } \\
\text { NEGATIVO, } 2,3,4,5 \text { - POSITIVO)". }\end{array}$ \\
\hline & ВCCCO1 & Numérica Ordinal & $b$ & $\begin{array}{l}\text { Crença de Controle } 1 \text { - Control Belief Strenght - Item "Moro muito longe da escola } \\
\text { para usar bicicleta. (1 - DISCORDO TOTALMENTE/2 - DISCORDO / } 3 \text { - NEM } \\
\text { CONCORDO, NEM DISCORDO / } 4 \text { - CONCORDO / } 5 \text { - CONCORDO } \\
\text { PLENAMENTE)". }\end{array}$ \\
\hline & BCCCE1 & Numérica Ordinal & $e$ & $\begin{array}{l}\text { Crença de Controle } 1 \text { - Power of Control Factor - Item "Considero a distância a } \\
\text { percorrer antes de decidir usar bicicleta para ir ou voltar da escola. (1- } \\
\text { DIFICILMENTE, 2, 3, 4, 5- PROVAVELMENTE)". }\end{array}$ \\
\hline & ВCCCO2 & Numérica Ordinal & $b$ & $\begin{array}{l}\text { Crença de Controle } 2 \text { - Control Belief Strenght - Item "Quando tenho vontade, } \\
\text { posso usar bicicleta para ir ou voltar da escola. (1 - DISCORDO TOTALMENTE/2 } \\
\text { - DISCORDO / } 3 \text { - NEM CONCORDO, NEM DISCORDO / } 4 \text { - CONCORDO / } 5 \text { - } \\
\text { CONCORDO PLENAMENTE)". }\end{array}$ \\
\hline & BCCCE2 & Numérica Ordinal & $e$ & $\begin{array}{l}\text { Crença de Controle } 2 \text { - Power of Control Factor - Item "Eu poderia usar bicicleta } \\
\text { para ir ou voltar da escola. (1- DIFICILMENTE, 2, 3, 4, 5- PROVAVELMENTE)"; }\end{array}$ \\
\hline & $\mathrm{BCCCO3}$ & Numérica Ordinal & $b$ & $\begin{array}{l}\text { Crença de Controle } 3 \text { - Control Belief Strenght - Item "A condição entre minha } \\
\text { casa e a escola não favorece o uso da bicicleta. (1 - DISCORDO TOTALMENTE/2 } \\
\text { - DISCORDO / } 3 \text { - NEM CONCORDO, NEM DISCORDO / } 4 \text { - CONCORDO / } 5 \text { - } \\
\text { CONCORDO PLENAMENTE)". }\end{array}$ \\
\hline & BCCCE3 & Numérica Ordinal & $e$ & $\begin{array}{l}\text { Crença de Controle } 3 \text { - Power of Control Factor - Item "Devo considerar a } \\
\text { condição entre minha casa e a escola para usar bicicleta. (1- DIFICILMENTE, 2, 3, } \\
\text { 4, } 5 \text { - PROVAVELMENTE)". }\end{array}$ \\
\hline
\end{tabular}


APÊNDICE J - Descrição das variáveis relativas aos alunos, utilizadas na abordagem quantitativa - Parte 21/21

\begin{tabular}{|c|c|c|c|c|}
\hline GRUPO & IDENTIFICAÇत̃ $O$ & CATEGORIA & CRENCA & DESCRIÇÃO OU ITEM DO QUESTIONÁRIO \\
\hline \multirow{7}{*}{ HÁBITO } & HABON & Numérica Contínua & NA & Hábito para modo Ônibus. \\
\hline & HABAP & Numérica Contínua & NA & Hábito para modo A pé. \\
\hline & HABAC & Numérica Contínua & NA & Hábito para modo Automóvel Carona. \\
\hline & HABBC & Numérica Contínua & NA & Hábito para modo Bicicleta. \\
\hline & HABAF & Numérica Contínua & NA & Hábito para modo Automóvel da Família. \\
\hline & HABVF & Numérica Contínua & NA & Hábito para modo Van Fretada. \\
\hline & HABMT & Numérica Contínua & NA & Hábito para modo Metrô. \\
\hline
\end{tabular}

Forma de apuração da medida do hábito: Item "Abaixo estão listadas algumas atividades de lazer com as quais você já deve ter se envolvido. Suponha que você queira espontaneamente realizar cada uma delas. Qual o modo de transporte que você preferiria utilizar p/ realizá-la? Por favor, responda rapidamente, sem pensar muito a respeito. Assinale apenas um modo p/ cada atividade. Visitar um amigo; Visitar seus familiares; Praticar esportes; Perambular pela cidade; Ir à festa à noite; Passear em um dia bom; Ir à padaria; Ir a uma lanchonete ou barzinho; Ir no shopping/cinema;". Apuração: contar citações/modo e dividir pelo número de respostas válidas no conjunto de situações.

\begin{tabular}{|l|l|l|l|l|} 
& CPAP & Numérica Contínua & NA & Comportamento passado para modo A pé. \\
\cline { 2 - 5 } & CPON & Numérica Contínua & NA & Comportamento passado para modo Ônibus. \\
\cline { 2 - 5 } COMPORT. & CPAF & Numérica Contínua & NA & Comportamento passado para modo Automóvel da Família. \\
\cline { 2 - 5 } & CPAC & Numérica Contínua & NA & Comportamento passado para modo Automóvel Carona. \\
\cline { 2 - 5 } & CPBC & Numérica Contínua & NA & Comportamento passado para modo Bicicleta. \\
\cline { 2 - 5 } & CPTE & Numérica Contínua & NA & Comportamento passado para modo Transporte Escolar. \\
\cline { 2 - 5 } & CPMT & Numérica Contínua & NA & Comportamento passado para modo Metrô. \\
\hline
\end{tabular}

Forma de apuração da medida do comportamento passado: Item "No último ano letivo, quantas vezes você usou cada modo de transporte para ir ou voltar da escola? 1NUNCA; 2 - RARAMENTE ;3 - ÀS VEZES; 4 - FREQUENTEMENTE; 5 - SEMPRE".

Obs.: NA - Não aplicável; $b$ - crença do objeto; $e$ - força da crença. A definição em inglês do tipo da crença é referente a Elliott $e t$ al.(2005). 
APÊNDICE K - Descrição das variáveis utilizadas nas abordagens quantitativas nos questionários para pais 
APÊNDICE K - Descrição das variáveis relativas aos pais/responsáveis, utilizadas na abordagem quantitativa - Parte $1 / 22$

\begin{tabular}{|c|c|c|c|c|}
\hline GRUPO & IDENTIFICAÇÃO & CATEGORIA & CRENÇA & DESCRIÇÃO OU ITEM DO QUESTIONÁRIO \\
\hline \multirow{4}{*}{ GERAL } & RESPONDENTE & Numérica Ordinal & NA & Número do respondente. \\
\hline & ESCOLA & Nominal categórica & NA & Informado na coleta de dados. \\
\hline & NOME & Nominal & NA & Informado pelo respondente. \\
\hline & NQUEST & Numérica Ordinal & NA & Número do questionário. \\
\hline \multirow{10}{*}{$\begin{array}{l}\text { SOCIO } \\
\text { DEMOGRÁFICAS }\end{array}$} & PQUALIF & Nominal categórica & NA & Qualificação do respondente em relação ao aluno (mãe; pai; responsável; outro). \\
\hline & PGENERO & Nominal binária & NA & Gênero do respondente (Feminino -1; Masculino - 0). \\
\hline & PIDADE & Numérica & NA & Idade do respondente. \\
\hline & SERIE & Nominal categórica & NA & Série do aluno, informado pelo respondente. \\
\hline & TURMA & Nominal categórica & NA & Turma do aluno, informado pelo respondente. \\
\hline & NAUTO & Numérica discreta & NA & Número de automóveis no domicílio, informado pelo respondente. \\
\hline & NCART & Numérica discreta & NA & $\begin{array}{l}\text { Número de indivíduos com carteira de motorista no domicílio, informado pelo } \\
\text { respondente. }\end{array}$ \\
\hline & NMENOR & Numérica discreta & NA & $\begin{array}{l}\text { Número de indivíduos menores de } 18 \text { anos no domicílio, informado pelo } \\
\text { respondente. }\end{array}$ \\
\hline & REGTRAB & Nominal categórica & NA & $\begin{array}{l}\text { Regime de trabalho da pessoa que acompanha o aluno para ir ou voltar da escola (40 } \\
\text { hs semanais; } 20 \text { horas semanais; não trabalha fora; ninguém acompanha). }\end{array}$ \\
\hline & LOCALIDADE & Nominal categórica & NA & $\begin{array}{l}\text { Bairro, região administrativa ou localidade de residência do respondente. Informada } \\
\text { diretamente pelo respondente, ou obtida pelo endereçamento informado pelo } \\
\text { respondente. }\end{array}$ \\
\hline
\end{tabular}


APÊNDICE K - Descrição das variáveis relativas aos pais/responsáveis, utilizadas na abordagem quantitativa - Parte $2 / 22$

\begin{tabular}{|c|c|c|c|c|}
\hline GRUPO & IDENTIFICAÇÃ $O$ & CATEGORIA & CRENÇA & DESCRIÇÃO OU ITEM DO QUESTIONÁRIO \\
\hline \multirow{12}{*}{ MODO A PÉ } & PAPDAT1 & Numérica Ordinal & NA & $\begin{array}{l}\text { Direta Atitude 1 - Item - "Permitir que meu(minha) filho(a) fosse ou voltasse da } \\
\text { escola a pé seria: (1- DESAGRADÁVEL, 2,3,4,5-AGRADÁVEL)". }\end{array}$ \\
\hline & PAPDAT2 & Numérica Ordinal & NA & $\begin{array}{l}\text { Direta Atitude } 2 \text { - Item "Permitir que meu(minha) filho(a) fosse ou voltasse da } \\
\text { escola a pé seria: (1- NEGATIVO, 2,3,4, 5- POSITIVO)". }\end{array}$ \\
\hline & PAPDAT3 & Numérica Ordinal & NA & $\begin{array}{l}\text { Direta Atitude } 3 \text { - Item "Permitir que meu(minha) filho(a) fosse ou voltasse da } \\
\text { escola a pé seria: (1- RUIM, 2,3,4, 5- BOM)". }\end{array}$ \\
\hline & PAPDNS1 & Numérica Ordinal & NA & $\begin{array}{l}\text { Direta Norma Social 1 - Item "A maioria das pessoas importantes para mim } \\
\text { aprovaria que meu(minha) filho(a) fosse ou voltasse da escola caminhando (1- } \\
\text { DISCORDO TOTALMENTE; } 2 \text { - DISCORDO; 3- NEM CONCORDO, NEM } \\
\text { DISCORDO; 4- CONCORDO; 5- CONCORDO PLENAMENTE)". }\end{array}$ \\
\hline & PAPDNS2 & Numérica Ordinal & NA & $\begin{array}{l}\text { Direta Norma Social } 2 \text { - Item "Pessoas próximas a mim acham que a opção de } \\
\text { deixar meu(minha) filho(a) ir ou voltar da escola a pé é acertada (1- DISCORDO } \\
\text { TOTALMENTE; } 2 \text { - DISCORDO; 3- NEM CONCORDO, NEM DISCORDO; 4- } \\
\text { CONCORDO; 5- CONCORDO PLENAMENTE)". }\end{array}$ \\
\hline & PAPDNS3 & Numérica Ordinal & NA & $\begin{array}{l}\text { Direta Norma Social } 3 \text { - Item "A maioria das pessoas que conheço não se importa } \\
\text { se meu(minha) filho(a) vai ou volta da escola a pé (1- DISCORDO TOTALMENTE; } \\
2 \text { - DISCORDO; 3- NEM CONCORDO, NEM DISCORDO; 4- CONCORDO; 5- } \\
\text { CONCORDO PLENAMENTE)". }\end{array}$ \\
\hline & PAPDCP1 & Numérica Ordinal & NA & $\begin{array}{l}\text { Direta Controle Percebido1-Item "Para meu(minha)filho(a), é possível ir/voltar da } \\
\text { escola a pé (1-DISCORDO TOTALMENTE;2-DISCORDO;3-NEM CONCORDO, } \\
\text { NEM DISCORDO;4-CONCORDO;5-CONCORDO PLENAMENTE)". }\end{array}$ \\
\hline & PAPDCP2 & Numérica Ordinal & NA & $\begin{array}{l}\text { Direta Controle Percebido } 2 \text { - Item "Para meu(minha) filho(a) ir/voltar da escola a } \\
\text { pé seria (1- DIFÍCIL, 2,3,4,5 - FÁCIL)". }\end{array}$ \\
\hline & PAPDCP3 & Numérica Ordinal & NA & $\begin{array}{l}\text { Direta Controle Percebido } 3 \text { - Item "Para meu(minha) filho(a) ir/voltar da escola a } \\
\text { pé seria (1- IMPOSSÍVEL, 2,3,4,5 - POSSÍVEL)". }\end{array}$ \\
\hline & PAPDIT1 & Numérica Ordinal & NA & $\begin{array}{l}\text { Direta Intenção 1 - Item "Eu pretendo que meu(minha) filho(a) caminhe para ir ou } \\
\text { voltar da escola (1- DISCORDO TOTALMENTE; } 2 \text { - DISCORDO; 3- NEM } \\
\text { CONCORDO, NEM DISCORDO; 4- CONCORDO; 5- CONCORDO } \\
\text { PLENAMENTE)". }\end{array}$ \\
\hline & PAPDIT2 & Numérica Ordinal & NA & $\begin{array}{l}\text { Direta Intenção } 2 \text { - Item "Minha intenção que meu(minha) filho(a) vá/volte a pé da } \\
\text { escola é (1- FRACA, 2, 3, 4, 5 - FORTE)". }\end{array}$ \\
\hline & PAPDIT3 & Numérica Ordinal & NA & $\begin{array}{l}\text { Direta Intenção } 3 \text { - Item "Pretendo encorajar que meu(minha) filho(a) vá/volte da } \\
\text { escola a pé (1-DIFICILMENTE, 2, 3, 4, 5 - PROVAVELMENTE)". }\end{array}$ \\
\hline
\end{tabular}


APÊNDICE K - Descrição das variáveis relativas aos pais/responsáveis, utilizadas na abordagem quantitativa - Parte 3/22

\begin{tabular}{|c|c|c|c|c|}
\hline GRUPO & IDENTIFICAÇÃO & CATEGORIA & CRENÇA & DESCRIÇÃO OU ITEM DO QUESTIONÁRIO \\
\hline \multirow{10}{*}{ MODO A PÉ } & PAPCBO1 & Numérica Ordinal & $b$ & $\begin{array}{l}\text { Crença Comportamental 1 - Outcome - Item "Ir/voltar a pé da escola faz bem à à } \\
\text { saúde (1- DISCORDO TOTALMENTE; } 2 \text { - DISCORDO; 3- NEM CONCORDO, } \\
\text { NEM DISCORDO; 4- CONCORDO; 5- CONCORDO PLENAMENTE)". }\end{array}$ \\
\hline & PAPCBE1 & Numérica Ordinal & $e$ & $\begin{array}{l}\text { Crença Comportamental } 1 \text { - Evaluation - Item "Preocupar-se com o que é mais } \\
\text { saudável para ir/voltar da escola caminhando é (1 - RUIM, 2, 3, 4, 5 - BOM)". }\end{array}$ \\
\hline & РАРCBO2 & Numérica Ordinal & $b$ & $\begin{array}{l}\text { Crença Comportamental 2 - Outcome - Item "Ir ou voltar a pé da escola é } \\
\text { econômico (1- DISCORDO TOTALMENTE; } 2 \text { - DISCORDO; 3- NEM } \\
\text { CONCORDO, NEM DISCORDO; 4- CONCORDO; 5- CONCORDO } \\
\text { PLENAMENTE)". }\end{array}$ \\
\hline & PAPCBE2 & Numérica Ordinal & $e$ & $\begin{array}{l}\text { Crença Comportamental } 2 \text { - Evaluation - Item "Preocupar-se com o que é mais } \\
\text { econômico para ir ou voltar da escola caminhando é (1 - RUIM, 2, 3, 4, 5- BOM)". }\end{array}$ \\
\hline & РАРCBO3 & Numérica Ordinal & $b$ & $\begin{array}{l}\text { Crença Comportamental } 3 \text { - Outcome } \text { - Item "É vantajoso ir/voltar a pé da escola, } \\
\text { apenas para quem mora perto (1- DISCORDO TOTALMENTE; } 2 \text { - DISCORDO; } \\
\text { 3- NEM CONCORDO, NEM DISCORDO; 4- CONCORDO; 5- CONCORDO } \\
\text { PLENAMENTE)". }\end{array}$ \\
\hline & PAPCBE3 & Numérica Ordinal & $e$ & $\begin{array}{l}\text { Crença Comportamental } 3 \text { - Evaluation - Item "Preocupar-se com as vantagens } \\
\text { de caminhar para ir ou voltar da escola é (1 - RUIM, 2, 3, 4, 5 - BOM)". }\end{array}$ \\
\hline & PAPCNO1 & Numérica Ordinal & $b$ & $\begin{array}{l}\text { Crença Normativa 1 - Belief Strenght - Item "Minha família incentiva que meu } \\
\text { (minha) filho(a) caminhe para a escola (1- DISCORDO TOTALMENTE; } 2 \text { - } \\
\text { DISCORDO; 3- NEM CONCORDO, NEM DISCORDO; 4- CONCORDO; } 5 \text { - } \\
\text { CONCORDO PLENAMENTE)". }\end{array}$ \\
\hline & PAPCNE1 & Numérica Ordinal & $e$ & $\begin{array}{l}\text { Crença Normativa } 1 \text { - Motivation to comply - Item "Considero o fato de minha } \\
\text { família incentivar meu(minha) filho(a) vá ou volte a pé da escola (1- NEGATIVO, } \\
2,3,4,5 \text { - POSITIVO)". }\end{array}$ \\
\hline & PAPCNO2 & Numérica Ordinal & $b$ & $\begin{array}{l}\text { Crença Normativa } 2 \text { - Belief Strenght } \text { - Item "Meus amigos acham bom que meu } \\
\text { (minha) filho (a) caminhe para a escola (1- DISCORDO TOTALMENTE; } 2 \text { - } \\
\text { DISCORDO; 3- NEM CONCORDO, NEM DISCORDO; 4- CONCORDO; 5- } \\
\text { CONCORDO PLENAMENTE)". }\end{array}$ \\
\hline & PAPCNE2 & Numérica Ordinal & $e$ & $\begin{array}{l}\text { Crença Normativa 2- Motivation to comply - Item "Considero o fato de meus } \\
\text { amigos acharem bom que meu(minha) filho(a) a ir ou voltar da escola a pé como (1- } \\
\text { NEGATIVO, } 2,3,4,5 \text { - POSITIVO)". }\end{array}$ \\
\hline
\end{tabular}


APÊNDICE K - Descrição das variáveis relativas aos pais/responsáveis, utilizadas na abordagem quantitativa - Parte 4/22

\begin{tabular}{|c|c|c|c|c|}
\hline GRUPO & IDENTIFICAÇÃO & CATEGORIA & CRENÇA & DESCRIÇÃO OU ITEM DO QUESTIONÁRIO \\
\hline \multirow{3}{*}{ MODO A PÉ } & PAPCCE1 & Numérica Ordinal & $e$ & $\begin{array}{l}\text { Crença de controle } 1 \text { - Power of Control Factor } \text { - Item "Deve-se avaliar se o trajeto } \\
\text { é perigoso para que meu (minha) filho(a) vá ou volte a pé da escola (1- } \\
\text { DIFICILMENTE, 2, 3, 4, 5, - PROVAVELMENTE)". }\end{array}$ \\
\hline & PAPCCO2 & Numérica Ordinal & $b$ & $\begin{array}{l}\text { Crença de controle } 2 \text { - Control Belief Strenght } \text { - Item "As calçadas no trecho entre } \\
\text { nossa casa e a escola não permitem que meu (minha) filho(a) caminhe para a escola } \\
\text { (1- DISCORDO TOTALMENTE; } 2 \text { - DISCORDO; 3- NEM CONCORDO, NEM } \\
\text { DISCORDO; 4- CONCORDO; 5- CONCORDO PLENAMENTE)". }\end{array}$ \\
\hline & PAPCCE2 & Numérica Ordinal & $e$ & $\begin{array}{l}\text { Crença de controle } 2 \text { - Power of Control Factor - Item "Devem-se avaliar as } \\
\text { condições das calçadas para que meu(minha) filho(a) vá ou volte a pé da escola (1- } \\
\text { DIFICILMENTE, } 2,3,4,5,- \text { PROVAVELMENTE)". }\end{array}$ \\
\hline \multirow{7}{*}{$\begin{array}{l}\text { MODO } \\
\text { AUTOMÓVEL } \\
\text { CARONA }\end{array}$} & PACDAT1 & Numérica Ordinal & NA & $\begin{array}{l}\text { Direta Atitude 1 - Item - "Permitir que meu(minha) filho(a) pegue carona para ir } \\
\text { ou voltar da escola seria: (1- DESAGRADÁVEL, 2,3,4, 5- AGRADÁVEL)". }\end{array}$ \\
\hline & PACDAT2 & Numérica Ordinal & NA & $\begin{array}{l}\text { Direta Atitude 2 - Item "Permitir que meu(minha) filho(a) pegue carona para ir ou } \\
\text { voltar da escola seria: (1- NEGATIVO, 2,3,4,5- POSITIVO)". }\end{array}$ \\
\hline & PACDAT3 & Numérica Ordinal & NA & $\begin{array}{l}\text { Direta Atitude } 3 \text { - Item "Permitir que meu(minha) filho(a) pegue carona para ir ou } \\
\text { voltar da escola seria: (1- RUIM, 2,3,4, 5- BOM)". }\end{array}$ \\
\hline & PACDNS1 & Numérica Ordinal & NA & $\begin{array}{l}\text { Direta Norma Social 1 - Item "A maioria das pessoas importantes para mim } \\
\text { aprovaria que meu (minha) filho(a) pegasse ou desse carona para ir ou voltar da } \\
\text { escola (1- DISCORDO TOTALMENTE; } 2 \text { - DISCORDO; 3- NEM CONCORDO, } \\
\text { NEM DISCORDO; 4- CONCORDO; 5- CONCORDO PLENAMENTE)". }\end{array}$ \\
\hline & PACDNS2 & Numérica Ordinal & NA & $\begin{array}{l}\text { Direta Norma Social } 2 \text { - Item "Pessoas próximas a mim acham que a opção de } \\
\text { deixar meu(minha) filho(a)pegue carona com colegas para ir ou voltar da escola é } \\
\text { acertada (1-DISCORDO TOTALMENTE; } 2 \text { - DISCORDO; 3- NEM CONCORDO, } \\
\text { NEM DISCORDO; 4- CONCORDO; 5- CONCORDO PLENAMENTE)". }\end{array}$ \\
\hline & PACDNS3 & Numérica Ordinal & NA & $\begin{array}{l}\text { Direta Norma Social 3 - Item "A maioria das pessoas que conheço não se importa } \\
\text { se meu(minha) filho(a) dê ou pegue carona para ir ou voltar da escola (1- } \\
\text { DISCORDO TOTALMENTE; } 2 \text { - DISCORDO; 3- NEM CONCORDO, NEM } \\
\text { DISCORDO; 4- CONCORDO; 5- CONCORDO PLENAMENTE)". }\end{array}$ \\
\hline & PACDCP1 & Numérica Ordinal & NA & $\begin{array}{l}\text { Direta Controle Percebido } 1 \text { - Item "Para meu(minha) filho(a), é possível pegar } \\
\text { carona para ir ou voltar da escola (1- DISCORDO TOTALMENTE; } 2 \text { - } \\
\text { DISCORDO; 3- NEM CONCORDO, NEM DISCORDO; 4- CONCORDO; 5- } \\
\text { CONCORDO PLENAMENTE)". }\end{array}$ \\
\hline
\end{tabular}


APÊNDICE K - Descrição das variáveis relativas aos pais/responsáveis, utilizadas na abordagem quantitativa - Parte 5/22

\begin{tabular}{|c|c|c|c|c|}
\hline GRUPO & IDENTIFICAÇÃO & CATEGORIA & CRENÇA & DESCRIÇÃO OU ITEM DO QUESTIONÁRIO \\
\hline \multirow[t]{11}{*}{$\begin{array}{l}\text { MODO } \\
\text { AUTOMÓVEL } \\
\text { CARONA }\end{array}$} & PACDCP2 & Numérica Ordinal & NA & $\begin{array}{l}\text { Direta Controle Percebido } 2 \text { - Item "Para meu(minha) filho(a) pegar ou dar carona } \\
\text { para ir ou voltar da escola seria (1- DIFÍCIL, 2,3,4,5 - FÁCIL)". }\end{array}$ \\
\hline & PACDCP3 & Numérica Ordinal & NA & $\begin{array}{l}\text { Direta Controle Percebido } 3 \text { - Item "Para meu(minha) filho(a) pegar ou dar carona } \\
\text { para ir ou voltar da escola seria (1- IMPOSSÍVEL, 2,3,4,5 - POSSÍVEL)". }\end{array}$ \\
\hline & PACDIT1 & Numérica Ordinal & NA & $\begin{array}{l}\text { Direta Intenção 1 - Item "Eu pretendo que meu(minha) filho(a) pegue ou dê carona } \\
\text { para ir ou voltar da escola (1- DISCORDO TOTALMENTE; } 2 \text { - DISCORDO; 3- } \\
\text { NEM CONCORDO, NEM DISCORDO; 4- CONCORDO; 5- CONCORDO } \\
\text { PLENAMENTE)". }\end{array}$ \\
\hline & PACDIT2 & Numérica Ordinal & NA & $\begin{array}{l}\text { Direta Intenção } 2 \text { - Item "Minha intenção que meu(minha) filho(a) dê ou pegue } \\
\text { carona para ir ou voltar da escola é (1- FRACA, } 2,3,4,5 \text { - FORTE)". }\end{array}$ \\
\hline & PACDIT3 & Numérica Ordinal & NA & $\begin{array}{l}\text { Direta Intenção } 3 \text { - Item "Pretendo encorajar que meu(minha) filho(a) a dar ou } \\
\text { pegar carona para ir ou da escola (1-DIFICILMENTE, 2, 3, 4, 5 - } \\
\text { PROVAVELMENTE)". }\end{array}$ \\
\hline & PACCBO1 & Numérica Ordinal & $b$ & $\begin{array}{l}\text { Crença Comportamental } 1 \text { - Outcome - Item "É cômodo para meu (minha) filho } \\
\text { (a) pegar carona com colegas que moram perto de casa para ir ou voltar da escola } \\
\text { (1- DISCORDO TOTALMENTE; } 2 \text { - DISCORDO; 3- NEM CONCORDO, NEM } \\
\text { DISCORDO; 4- CONCORDO; 5- CONCORDO PLENAMENTE)". }\end{array}$ \\
\hline & PACCBE1 & Numérica Ordinal & $e$ & $\begin{array}{l}\text { Crença Comportamental } 1 \text { - Evaluation - Item " A comodidade de pegar carona é } \\
(1 \text { - RUIM, 2, 3, 4, 5 - BOM)". }\end{array}$ \\
\hline & PACCBO2 & Numérica Ordinal & $b$ & $\begin{array}{l}\text { Crença Comportamental } 2 \text { - Outcome - Item "É seguro pegar ou dar carona a } \\
\text { colegas para ir ou voltar da escola (1- DISCORDO TOTALMENTE; } 2 \text { - } \\
\text { DISCORDO; 3- NEM CONCORDO, NEM DISCORDO; 4- CONCORDO; 5- } \\
\text { CONCORDO PLENAMENTE)". }\end{array}$ \\
\hline & PACCBE2 & Numérica Ordinal & $e$ & $\begin{array}{l}\text { Crença Comportamental } 2 \text { - Evaluation - Item "Prezar pela segurança ao pegar ou } \\
\text { dar carona a colegas para ir ou voltar da escola é: (1 - RUIM, 2, 3, 4,5 - BOM)". }\end{array}$ \\
\hline & PACCBO3 & Numérica Ordinal & $b$ & $\begin{array}{l}\text { Crença Comportamental 3 - Outcome - Item "Pegar carona para ir ou voltar da } \\
\text { escola contribui para diminuir o trânsito (1- DISCORDO TOTALMENTE; } 2 \text { - } \\
\text { DISCORDO; 3- NEM CONCORDO, NEM DISCORDO; 4- CONCORDO; 5- } \\
\text { CONCORDO PLENAMENTE)". }\end{array}$ \\
\hline & PACCBE3 & Numérica Ordinal & $e$ & $\begin{array}{l}\text { Crença Comportamental } 3 \text { - Evaluation - Item "Preocupar-me com o trânsito ao } \\
\text { pegar carona para ir ou voltar da escola é (1 - RUIM, 2, 3, 4, 5 - BOM)". }\end{array}$ \\
\hline
\end{tabular}


APÊNDICE K - Descrição das variáveis relativas aos pais/responsáveis, utilizadas na abordagem quantitativa - Parte 6/22

\begin{tabular}{|c|c|c|c|c|}
\hline GRUPO & IDENTIFICAÇÃO & CATEGORIA & CRENÇA & DESCRIÇÃO OU ITEM DO QUESTIONÁRIO \\
\hline & PACCBO4 & Numérica Ordinal & $b$ & $\begin{array}{l}\text { Crença Comportamental } 4 \text { - Outcome-Item "É econômico pegar carona p/ ir/voltar } \\
\text { da escola(1-DISCORDO TOTALMENTE;2 - DISCORDO; } 3 \text { - NEM CONCORDO, } \\
\text { NEM DISCORDO; } 4 \text { - CONCORDO; } 5 \text { - CONCORDO PLENAMENTE)". }\end{array}$ \\
\hline & PACCBE4 & Numérica Ordinal & $e$ & $\begin{array}{l}\text { Crença Comportamental } 4 \text { - Evaluation - Item "Preocupar-me com a economia ao } \\
\text { pegar carona para ir ou voltar da escola é (1 - RUIM, 2, 3, 4, 5 - BOM)". }\end{array}$ \\
\hline \multirow[t]{8}{*}{$\begin{array}{l}\text { MODO } \\
\text { AUTOMÓVEL } \\
\text { CARONA }\end{array}$} & PACCNO1 & Numérica Ordinal & $b$ & $\begin{array}{l}\text { Crença Normativa } 1 \text { - Belief Strenght - Item "Minha família acha bom que meu } \\
\text { (minha) filho(a) pegue carona para ir ou voltar da escola (1- DISCORDO } \\
\text { TOTALMENTE; } 2 \text { - DISCORDO; 3- NEM CONCORDO, NEM DISCORDO; 4- } \\
\text { CONCORDO; } 5 \text { - CONCORDO PLENAMENTE)". }\end{array}$ \\
\hline & PACCNE1 & Numérica Ordinal & $e$ & $\begin{array}{l}\text { Crença Normativa } 1 \text { - Motivation to comply - Item "Considero o fato de minha } \\
\text { família achar bom que meu(minha) filho(a) pegue carona para ir ou voltar da escola } \\
\text { como (1- NEGATIVO, } 2,3,4,5 \text { - POSITIVO)". }\end{array}$ \\
\hline & PACCNO2 & Numérica Ordinal & $b$ & $\begin{array}{l}\text { Crença Normativa } 2 \text { - Belief Strenght } \text { - Item "Na opinião de meus amigos, é bom } \\
\text { para meu (minha) filho (a) pegar carona para ir ou voltar da escola (1- DISCORDO } \\
\text { TOTALMENTE; } 2 \text { - DISCORDO; 3- NEM CONCORDO, NEM DISCORDO; 4- } \\
\text { CONCORDO; 5- CONCORDO PLENAMENTE)". }\end{array}$ \\
\hline & PACCNE2 & Numérica Ordinal & $e$ & $\begin{array}{l}\text { Crença Normativa 2- Motivation to comply - Item "Considero o fato de meus } \\
\text { amigos acharem bom que meu(minha) filho(a) a ir ou voltar da escola de carona } \\
\text { como (1- NEGATIVO, } 2,3,4,5 \text { - POSITIVO)". }\end{array}$ \\
\hline & PACCCO1 & Numérica Ordinal & $b$ & $\begin{array}{l}\text { Crença de controle } 1 \text { - Control Belief Strenght - Item "É difícil conciliar horários } \\
\text { para formar um grupo de carona para meu(minha) filho(a) ir ou voltar da escola (1- } \\
\text { DISCORDO TOTALMENTE; } 2 \text { - DISCORDO; 3- NEM CONCORDO, NEM } \\
\text { DISCORDO; 4- CONCORDO; 5- CONCORDO PLENAMENTE)". }\end{array}$ \\
\hline & PACCCE1 & Numérica Ordinal & $e$ & $\begin{array}{l}\text { Crença de controle } 1 \text { - Power of Control Factor - Item "Deveria pensar em } \\
\text { conciliar horários para formar um grupo de carona para meu (minha) filho(a) ir ou } \\
\text { voltar da escola (1- DIFICILMENTE, 2, 3, 4, 5, - PROVAVELMENTE)". }\end{array}$ \\
\hline & $\mathrm{PACCCO2}$ & Numérica Ordinal & $b$ & $\begin{array}{l}\text { Crença de controle } 2 \text { - Control Belief Strenght - Item "É possível formar um grupo } \\
\text { de carona com os vizinhos para nos revezarmos levando/trazendo nossos filhos para } \\
\text { a escola (1- DISCORDO TOTALMENTE; } 2 \text { - DISCORDO; 3- NEM CONCORDO, } \\
\text { NEM DISCORDO; 4- CONCORDO; 5- CONCORDO PLENAMENTE)". }\end{array}$ \\
\hline & PACCCE2 & Numérica Ordinal & $e$ & $\begin{array}{l}\text { Crença de controle } 2 \text { - Power of Control Factor - Item "Eu formaria um grupo de } \\
\text { carona com os vizinhos para nos revezarmos levando ou trazendo nossos filhos da } \\
\text { escola (1- DIFICILMENTE, 2, 3, 4, 5, - PROVAVELMENTE)". }\end{array}$ \\
\hline
\end{tabular}


APÊNDICE K - Descrição das variáveis relativas aos pais/responsáveis, utilizadas na abordagem quantitativa - Parte 7/22

\begin{tabular}{|c|c|c|c|c|}
\hline GRUPO & IDENTIFICAÇÃO & CATEGORIA & CRENÇA & DESCRIÇÃO OU ITEM DO QUESTIONÁRIO \\
\hline \multirow{11}{*}{$\begin{array}{l}\text { MODO } \\
\text { TRANSPORTE } \\
\text { ESCOLAR }\end{array}$} & PTEDAT1 & Numérica Ordinal & NA & $\begin{array}{l}\text { Direta Atitude } 1 \text { - Item - "Permitir que meu(minha) filho(a) utilize o transporte } \\
\text { escolar para ir ou voltar da escola seria: (1- DESAGRADÁVEL, 2,3,4, 5- } \\
\text { AGRADÁVEL)". }\end{array}$ \\
\hline & PTEDAT2 & Numérica Ordinal & NA & $\begin{array}{l}\text { Direta Atitude } 2 \text { - Item "Permitir que meu(minha) filho(a) utilize o transporte } \\
\text { escolar para ir ou voltar da escola seria: (1- NEGATIVO, 2,3,4, 5- POSITIVO)". }\end{array}$ \\
\hline & PTEDAT3 & Numérica Ordinal & NA & $\begin{array}{l}\text { Direta Atitude } 3 \text { - Item "Permitir que meu(minha) filho(a) utilize o transporte } \\
\text { escolar para ir ou voltar da escola seria: (1- RUIM, 2,3,4, 5- BOM)". }\end{array}$ \\
\hline & PTEDNS1 & Numérica Ordinal & NA & $\begin{array}{l}\text { Direta Norma Social 1 - Item "A maioria das pessoas importantes para mim } \\
\text { aprovaria que meu (minha) filho(a) usasse transporte escolar para ir ou voltar da } \\
\text { escola (1- DISCORDO TOTALMENTE; } 2 \text { - DISCORDO; 3- NEM CONCORDO, } \\
\text { NEM DISCORDO; 4- CONCORDO; 5- CONCORDO PLENAMENTE)". }\end{array}$ \\
\hline & PTEDNS2 & Numérica Ordinal & NA & $\begin{array}{l}\text { Direta Norma Social } 2 \text { - Item "Pessoas próximas a mim acham que a opção de } \\
\text { deixar meu(minha) filho(a) ir ou voltar da escola de transporte escolar é acertada (1- } \\
\text { DISCORDO TOTALMENTE; } 2 \text { - DISCORDO; 3- NEM CONCORDO, NEM } \\
\text { DISCORDO; 4- CONCORDO; 5- CONCORDO PLENAMENTE)". }\end{array}$ \\
\hline & PTEDNS3 & Numérica Ordinal & NA & $\begin{array}{l}\text { Direta Norma Social } 3 \text { - Item "A maioria das pessoas que conheço não se importa } \\
\text { se meu(minha) filho(a) use transporte escolar para ir ou voltar da escola (1- } \\
\text { DISCORDO TOTALMENTE; } 2 \text { - DISCORDO; 3- NEM CONCORDO, NEM } \\
\text { DISCORDO; 4- CONCORDO; 5- CONCORDO PLENAMENTE)". }\end{array}$ \\
\hline & PTEDCP1 & Numérica Ordinal & NA & $\begin{array}{l}\text { Direta Controle Percebido } 1 \text { - Item "Para meu(minha) filho(a), é possível usar } \\
\text { transporte escolar para ir ou voltar da escola (1- DISCORDO TOTALMENTE; } 2 \text { - } \\
\text { DISCORDO; 3- NEM CONCORDO, NEM DISCORDO; 4- CONCORDO; 5- } \\
\text { CONCORDO PLENAMENTE)". }\end{array}$ \\
\hline & PTEDCP2 & Numérica Ordinal & NA & $\begin{array}{l}\text { Direta Controle Percebido } 2 \text { - Item "Para meu(minha) filho(a) usar transporte } \\
\text { escolar para ir ou voltar da escola seria (1- DIFÍCIL, 2,3,4,5 - FÁCIL)". }\end{array}$ \\
\hline & PTEDCP3 & Numérica Ordinal & NA & $\begin{array}{l}\text { Direta Controle Percebido } 3 \text { - Item "Para meu(minha) filho(a) usar transporte } \\
\text { escolar para ir ou voltar da escola seria (1- IMPOSSÍVEL, 2,3,4,5 - POSSÍVEL)". }\end{array}$ \\
\hline & PTEDIT1 & Numérica Ordinal & NA & $\begin{array}{l}\text { Direta Intenção } 1 \text { - Item "Eu pretendo que meu(minha) filho(a) use transporte } \\
\text { escolar para ir ou voltar da escola (1- DISCORDO TOTALMENTE; } 2 \text { - } \\
\text { DISCORDO; 3- NEM CONCORDO, NEM DISCORDO; 4- CONCORDO; 5- } \\
\text { CONCORDO PLENAMENTE)". }\end{array}$ \\
\hline & PTEDIT2 & Numérica Ordinal & NA & $\begin{array}{l}\text { Direta Intenção } 2 \text { - Item "Minha intenção que meu(minha) filho(a) use transporte } \\
\text { escolar para ir ou voltar da escola é (1- FRACA, 2, 3, 4, 5 - FORTE)". }\end{array}$ \\
\hline
\end{tabular}


APÊNDICE K - Descrição das variáveis relativas aos pais/responsáveis, utilizadas na abordagem quantitativa - Parte 8/22

\begin{tabular}{|c|c|c|c|c|}
\hline GRUPO & IDENTIFICAÇÃ O & CATEGORIA & CRENÇA & DESCRIÇÃO OU ITEM DO QUESTIONÁRIO \\
\hline \multirow{10}{*}{$\begin{array}{l}\text { MODO } \\
\text { TRANSPORTE } \\
\text { ESCOLAR }\end{array}$} & PTEDIT3 & Numérica Ordinal & NA & $\begin{array}{l}\text { Direta Intenção } 3 \text { - Item "Pretendo encorajar que meu(minha) filho(a) a usar } \\
\text { transporte escolar para ir ou voltar da escola (1-DIFICILMENTE, 2, 3, 4, } 5 \text { - } \\
\text { PROVAVELMENTE)". }\end{array}$ \\
\hline & PTECBO1 & Numérica Ordinal & $b$ & $\begin{array}{l}\text { Crença Comportamental } 1 \text { - Outcome } \text { - Item "Meu (minha) filho (a) vai fazer um } \\
\text { percurso maior se usar transporte escolar para ir ou voltar da escola (1- DISCORDO } \\
\text { TOTALMENTE; } 2 \text { - DISCORDO; 3- NEM CONCORDO, NEM DISCORDO; 4- } \\
\text { CONCORDO; 5- CONCORDO PLENAMENTE)". }\end{array}$ \\
\hline & PTECBE1 & Numérica Ordinal & $e$ & $\begin{array}{l}\text { Crença Comportamental } 1 \text { - Evaluation - Item "Preocupar-me com o tamanho do } \\
\text { percurso ao usar o transporte escolar é: (1 - RUIM, 2, 3, 4, 5 - BOM)". }\end{array}$ \\
\hline & РТЕCBO2 & Numérica Ordinal & $b$ & $\begin{array}{l}\text { Crença Comportamental } 2 \text { - Outcome - Item "É seguro dentro do transporte } \\
\text { escolar (1- DISCORDO TOTALMENTE; } 2 \text { - DISCORDO; 3- NEM CONCORDO, } \\
\text { NEM DISCORDO; 4- CONCORDO; 5- CONCORDO PLENAMENTE)". }\end{array}$ \\
\hline & PTECBE2 & Numérica Ordinal & $e$ & $\begin{array}{l}\text { Crença Comportamental } 2 \text { - Evaluation - Item "Prezar pela segurança no veículo } \\
\text { de transporte escolar é (1 - RUIM, 2, 3, 4, 5 - BOM)". }\end{array}$ \\
\hline & РТЕСBO3 & Numérica Ordinal & $b$ & $\begin{array}{l}\text { Crença Comportamental 3 - Outcome - Item "Meu (minha) filho(a) nunca vai } \\
\text { chegar atrasado se usar transporte escolar para ir ou voltar da escola (1- DISCORDO } \\
\text { TOTALMENTE; } 2 \text { - DISCORDO; 3- NEM CONCORDO, NEM DISCORDO; } 4 \text { - } \\
\text { CONCORDO; 5- CONCORDO PLENAMENTE)". }\end{array}$ \\
\hline & PTECBE3 & Numérica Ordinal & $e$ & $\begin{array}{l}\text { Crença Comportamental } 3 \text { - Evaluation - Item "Prezar pela pontualidade ao usar } \\
\text { o transporte escolar é:(1 - RUIM, 2, 3, 4, 5 - BOM)". }\end{array}$ \\
\hline & PTECNO1 & Numérica Ordinal & $b$ & $\begin{array}{l}\text { Crença Normativa 1 - Belief Strenght - Item "Minha família acharia bom que eu } \\
\text { contratasse um serviço de transporte escolar para meu (minha) filho(a) (1- } \\
\text { DISCORDO TOTALMENTE; } 2 \text { - DISCORDO; 3- NEM CONCORDO, NEM } \\
\text { DISCORDO; 4- CONCORDO; } 5 \text { - CONCORDO PLENAMENTE)". }\end{array}$ \\
\hline & PTECNE1 & Numérica Ordinal & $e$ & $\begin{array}{l}\text { Crença Normativa } 1 \text { - Motivation to comply - Item "Considero o fato de minha } \\
\text { família achar bom que eu contratasse o serviço de transporte escolar para } \\
\text { meu(minha) filho(a) como (1- NEGATIVO, } 2,3,4,5 \text { - POSITIVO)". }\end{array}$ \\
\hline & PTECNO2 & Numérica Ordinal & $b$ & $\begin{array}{l}\text { Crença Normativa } 2 \text { - Belief Strenght } \text { - Item "Meus amigos acham que é bom para } \\
\text { meu (minha) filho (a) usar transporte escolar (1-DISCORDO TOTALMENTE; } 2 \text { - } \\
\text { DISCORDO; 3- NEM CONCORDO, NEM DISCORDO; 4- CONCORDO; 5- } \\
\text { CONCORDO PLENAMENTE)". }\end{array}$ \\
\hline
\end{tabular}

Obs.: NA - Não aplicável; $b$ - crença do objeto; $e$ - força da crença. A definição em inglês do tipo da crença é referente a Elliott $e t$ al.(2005). 
APÊNDICE K - Descrição das variáveis relativas aos pais/responsáveis, utilizadas na abordagem quantitativa - Parte 9/22

\begin{tabular}{|c|c|c|c|c|}
\hline GRUPO & IDENTIFICAÇÃOO & CATEGORIA & CRENÇA & DESCRIÇÃO OU ITEM DO QUESTIONÁRIO \\
\hline \multirow{7}{*}{$\begin{array}{l}\text { MODO } \\
\text { TRANSPORTE } \\
\text { ESCOLAR }\end{array}$} & PTECNE2 & Numérica Ordinal & $e$ & $\begin{array}{l}\text { Crença Normativa 2- Motivation to comply - Item "Considero o fato de meus } \\
\text { amigos acharem bom para meu(minha) filho(a) usar transporte escolar como (1- } \\
\text { NEGATIVO, 2, 3, 4, 5 - POSITIVO)". }\end{array}$ \\
\hline & PTECCO1 & Numérica Ordinal & $b$ & $\begin{array}{l}\text { Crença de controle } 1 \text { - Control Belief Strenght - Item "É necessário ter } \\
\text { profissionais qualificados para que eu contrate o serviço de transporte escolar (1- } \\
\text { DISCORDO TOTALMENTE; } 2 \text { - DISCORDO; 3- NEM CONCORDO, NEM } \\
\text { DISCORDO; 4- CONCORDO; 5- CONCORDO PLENAMENTE)". }\end{array}$ \\
\hline & PTECCE1 & Numérica Ordinal & $e$ & $\begin{array}{l}\text { Crença de controle } 1 \text { - Power of Control Factor - Item "Deveria verificar se } \\
\text { existem profissionais qualificados para contratar o serviço de transporte escolar (1- } \\
\text { DIFICILMENTE, 2, 3, 4, 5, - PROVAVELMENTE)". }\end{array}$ \\
\hline & PTECCO2 & Numérica Ordinal & $b$ & $\begin{array}{l}\text { Crença de controle } 2 \text { - Control Belief Strenght - Item "É caro para mim contratar } \\
\text { o serviço de transporte escolar para meu (minha) filho (a) (1- DISCORDO } \\
\text { TOTALMENTE; } 2 \text { - DISCORDO; 3- NEM CONCORDO, NEM DISCORDO; 4- } \\
\text { CONCORDO; 5- CONCORDO PLENAMENTE)". }\end{array}$ \\
\hline & PTECCE2 & Numérica Ordinal & $e$ & $\begin{array}{l}\text { Crença de controle } 2 \text { - Power of Control Factor - Item "Eu deveria considerar o } \\
\text { preço do serviço para contratar o serviço de transporte escolar (1- DIFICILMENTE, } \\
2,3,4,5, \text { - PROVAVELMENTE)". }\end{array}$ \\
\hline & PTECCO3 & Numérica Ordinal & $b$ & $\begin{array}{l}\text { Crença de controle } 3 \text { - Control Belief Strenght } \text { - Item "Existe transporte escolar } \\
\text { para o bairro onde moramos (1- DISCORDO TOTALMENTE; } 2 \text { - DISCORDO; 3- } \\
\text { NEM CONCORDO, NEM DISCORDO; 4- CONCORDO; 5- CONCORDO } \\
\text { PLENAMENTE)". }\end{array}$ \\
\hline & PTECCE3 & Numérica Ordinal & $e$ & $\begin{array}{l}\text { Crença de controle } 2 \text { - Power of Control Factor - Item "Se eu optasse por contratar } \\
\text { transporte escolar para meu (minha) filho (a), acharia um serviço disponível no meu } \\
\text { bairro (1- DIFICILMENTE, } 2,3,4,5,- \text { PROVAVELMENTE)". }\end{array}$ \\
\hline \multirow{2}{*}{$\begin{array}{l}\text { MODO } \\
\text { AUTOMÓVEL DA } \\
\text { FAMÍLIA }\end{array}$} & PAFDAT1 & Numérica Ordinal & NA & $\begin{array}{l}\text { Direta Atitude } 1 \text { - Item - "Permitir que meu(minha) filho(a)seja conduzido com o } \\
\text { automóvel da família para ir ou voltar da escola seria: (1- DESAGRADÁVEL, 2,3,4, } \\
\text { 5- AGRADÁVEL)". }\end{array}$ \\
\hline & PAFDAT2 & Numérica Ordinal & NA & $\begin{array}{l}\text { Direta Atitude } 2 \text { - Item "Permitir que meu(minha) filho(a) seja conduzido com o } \\
\text { automóvel da família para ir ou voltar da escola seria: (1- NEGATIVO, 2,3,4, 5- } \\
\text { POSITIVO)". }\end{array}$ \\
\hline
\end{tabular}


APÊNDICE K - Descrição das variáveis relativas aos pais/responsáveis, utilizadas na abordagem quantitativa - Parte 10/22

\begin{tabular}{|c|c|c|c|c|}
\hline GRUPO & IDENTIFICAÇÃO & CATEGORIA & CRENÇA & DESCRIÇÃO OU ITEM DO QUESTIONÁRIO \\
\hline \multirow{10}{*}{$\begin{array}{l}\text { MODO } \\
\text { AUTOMÓVEL DA } \\
\text { FAMÍLIA }\end{array}$} & PAFDAT3 & Numérica Ordinal & NA & $\begin{array}{l}\text { Direta Atitude } 3 \text { - Item "Permitir que meu(minha) filho(a)seja conduzido com o } \\
\text { automóvel da família para ir ou voltar da escola seria: (1- RUIM, 2,3,4, 5- BOM)". }\end{array}$ \\
\hline & PAFDNS1 & Numérica Ordinal & NA & $\begin{array}{l}\text { Direta Norma Social 1 - Item "A maioria das pessoas importantes para mim } \\
\text { aprovaria a utilização do automóvel da família para buscar ou levar meu (minha) } \\
\text { filho(a) para a escola (1- DISCORDO TOTALMENTE; } 2 \text { - DISCORDO; 3- NEM } \\
\text { CONCORDO, NEM DISCORDO; 4- CONCORDO; 5- CONCORDO } \\
\text { PLENAMENTE)". }\end{array}$ \\
\hline & PAFDNS2 & Numérica Ordinal & NA & $\begin{array}{l}\text { Direta Norma Social } 2 \text { - Item "Pessoas próximas a mim acham que a opção de usar } \\
\text { o automóvel da família para levar ou buscar meu (minha) filho(a) na escola é } \\
\text { acertada (1- DISCORDO TOTALMENTE; } 2 \text { - DISCORDO; 3- NEM CONCORDO, } \\
\text { NEM DISCORDO; 4- CONCORDO; 5- CONCORDO PLENAMENTE)". }\end{array}$ \\
\hline & PAFDNS3 & Numérica Ordinal & NA & $\begin{array}{l}\text { Direta Norma Social } 3 \text { - Item "A maioria das pessoas que conheço não se importa } \\
\text { que minha família utilize o automóvel da família para buscar ou levar meu(minha) } \\
\text { filho(a) para a escola (1- DISCORDO TOTALMENTE; } 2 \text { - DISCORDO; 3- NEM } \\
\text { CONCORDO, NEM DISCORDO; 4- CONCORDO; 5- CONCORDO } \\
\text { PLENAMENTE)". }\end{array}$ \\
\hline & PAFDCP1 & Numérica Ordinal & NA & $\begin{array}{l}\text { Direta Controle Percebido } 1 \text { - Item "Para meu(minha) filho(a), é possível usar o } \\
\text { automóvel da família para ir ou voltar da escola (1- DISCORDO TOTALMENTE; } \\
2 \text { - DISCORDO; 3- NEM CONCORDO, NEM DISCORDO; 4- CONCORDO; 5- } \\
\text { CONCORDO PLENAMENTE)". }\end{array}$ \\
\hline & PAFDCP2 & Numérica Ordinal & NA & $\begin{array}{l}\text { Direta Controle Percebido } 2 \text { - Item "Para meu(minha) filho(a), usar o automóvel } \\
\text { da família para ir/voltar da escola seria: (1- DIFÍCIL, 2,3,4,5 - FÁCIL)". }\end{array}$ \\
\hline & PAFDCP3 & Numérica Ordinal & NA & $\begin{array}{l}\text { Direta Controle Percebido } 3 \text { - Item "Para meu(minha) filho(a), usar o automóvel } \\
\text { da família para ir/voltar da escola seria (1- IMPOSSÍVEL, 2,3,4,5 - POSSÍVEL)". }\end{array}$ \\
\hline & PAFDIT1 & Numérica Ordinal & NA & $\begin{array}{l}\text { Direta Intenção } 1 \text { - Item "Eu pretendo usar automóvel da família para levar ou } \\
\text { buscar meu(minha) filho(a) na escola (1- DISCORDO TOTALMENTE; } 2 \text { - } \\
\text { DISCORDO; 3- NEM CONCORDO, NEM DISCORDO; 4- CONCORDO; 5- } \\
\text { CONCORDO PLENAMENTE)". }\end{array}$ \\
\hline & PAFDIT2 & Numérica Ordinal & NA & $\begin{array}{l}\text { Direta Intenção } 2 \text { - Item "Minha intenção de levar ou buscar meu(minha) filho(a) } \\
\text { na escola usando automóvel da família é: (1- FRACA, 2, 3, 4, 5 - FORTE)". }\end{array}$ \\
\hline & PAFDIT3 & Numérica Ordinal & NA & $\begin{array}{l}\text { Direta Intenção } 3 \text { - Item "Pretendo levar ou buscar meu(minha) filho(a) usando } \\
\text { automóvel da família (1-DIFICILMENTE, 2, 3, 4, 5 - PROVAVELMENTE)". }\end{array}$ \\
\hline
\end{tabular}


APÊNDICE K - Descrição das variáveis relativas aos pais/responsáveis, utilizadas na abordagem quantitativa - Parte $11 / 22$

\begin{tabular}{|c|c|c|c|c|}
\hline GRUPO & IDENTIFICAÇÃ O & CATEGORIA & CRENCA & DESCRIÇÃO OU ITEM DO QUESTIONÁRIO \\
\hline \multirow{9}{*}{$\begin{array}{l}\text { MODO } \\
\text { AUTOMÓVEL DA } \\
\text { FAMÍLIA }\end{array}$} & PAFCBO1 & Numérica Ordinal & $b$ & $\begin{array}{l}\text { Crença Comportamental 1 - Outcome - Item "É vantajoso transportar meu(minha) } \\
\text { filho(a) no automóvel da família para ir ou voltar da escola (1- DISCORDO } \\
\text { TOTALMENTE; } 2 \text { - DISCORDO; 3- NEM CONCORDO, NEM DISCORDO; 4- } \\
\text { CONCORDO; 5- CONCORDO PLENAMENTE)". }\end{array}$ \\
\hline & PAFCBE1 & Numérica Ordinal & $e$ & $\begin{array}{l}\text { Crença Comportamental } \mathbf{1} \text { - Evaluation - Item "Preocupar-me com as } \\
\text { vantagens/desvantagens de usar automóvel da família para ir ou voltar da escola é: } \\
(1-\mathrm{RUIM}, 2,3,4,5-\mathrm{BOM}) " \text {. }\end{array}$ \\
\hline & PAFCBO2 & Numérica Ordinal & $b$ & $\begin{array}{l}\text { Crença Comportamental 2 - Outcome - Item "Meu (minha) filho (a) estará } \\
\text { seguro(a) no automóvel da família (1- DISCORDO TOTALMENTE; } 2 \text { - } \\
\text { DISCORDO; 3- NEM CONCORDO, NEM DISCORDO; 4- CONCORDO; 5- } \\
\text { CONCORDO PLENAMENTE)". }\end{array}$ \\
\hline & PAFCBE2 & Numérica Ordinal & $e$ & $\begin{array}{l}\text { Crença Comportamental } 2 \text { - Evaluation - Item "Prezar pela segurança ao usar o } \\
\text { automóvel da família para ir ou voltar da escola é: (1 - RUIM, } 2,3,4,5 \text { - BOM)". }\end{array}$ \\
\hline & PAFCBO3 & Numérica Ordinal & $b$ & $\begin{array}{l}\text { Crença Comportamental } 3 \text { - Outcome - Item "Quando levo ou busco meu (minha) } \\
\text { filho(a) no automóvel da família na escola, contribuo para piorar o trânsito perto da } \\
\text { escola (1- DISCORDO TOTALMENTE; } 2 \text { - DISCORDO; 3- NEM CONCORDO, } \\
\text { NEM DISCORDO; 4- CONCORDO; 5- CONCORDO PLENAMENTE)". }\end{array}$ \\
\hline & PAFCBE3 & Numérica Ordinal & $e$ & $\begin{array}{l}\text { Crença Comportamental 3 - Evaluation - Item "Preocupar-me com o trânsito perto } \\
\text { da escola é: (1 - RUIM, 2, 3, 4, 5 - BOM)". }\end{array}$ \\
\hline & PAFCNO1 & Numérica Ordinal & $b$ & $\begin{array}{l}\text { Crença Normativa } 1 \text { - Belief Strenght } \text { - Item "A família incentiva que meu (minha) } \\
\text { filho(a) seja transportado(a) no automóvel da família (1- DISCORDO } \\
\text { TOTALMENTE; } 2 \text { - DISCORDO; 3- NEM CONCORDO, NEM DISCORDO; 4- } \\
\text { CONCORDO; } 5 \text { - CONCORDO PLENAMENTE)". }\end{array}$ \\
\hline & PAFCNE1 & Numérica Ordinal & $e$ & $\begin{array}{l}\text { Crença Normativa } 1 \text { - Motivation to comply - Item "Considero o fato de minha } \\
\text { família incentivar que meu(minha) filho(a) vá ou volte da escola no automóvel da } \\
\text { família como (1- NEGATIVO, } 2,3,4,5 \text { - POSITIVO)". }\end{array}$ \\
\hline & PAFCNO2 & Numérica Ordinal & $b$ & $\begin{array}{l}\text { Crença Normativa } 2 \text { - Belief Strenght - Item "Meus amigos incentivam que meu } \\
\text { (minha) filho (a) seja transportado no automóvel da família para ir ou voltar da } \\
\text { escola (1- DISCORDO TOTALMENTE; } 2 \text { - DISCORDO; 3- NEM CONCORDO, } \\
\text { NEM DISCORDO; 4- CONCORDO; 5- CONCORDO PLENAMENTE)". }\end{array}$ \\
\hline
\end{tabular}


APÊNDICE K - Descrição das variáveis relativas aos pais/responsáveis, utilizadas na abordagem quantitativa - Parte 12/22

\begin{tabular}{|c|c|c|c|c|}
\hline GRUPO & IDENTIFICAÇÃ O & CATEGORIA & CRENCA & DESCRIÇÃO OU ITEM DO QUESTIONÁRIO \\
\hline \multirow{7}{*}{$\begin{array}{l}\text { MODO } \\
\text { AUTOMÓVEL DA } \\
\text { FAMÍLIA }\end{array}$} & PAFCNE2 & Numérica Ordinal & $e$ & $\begin{array}{l}\text { Crença Normativa 2- Motivation to comply - Item "Considero o fato de meus } \\
\text { amigos incentivarem que meu(minha) filho(a) vá ou volte da escola no automóvel } \\
\text { da família como (1- NEGATIVO, } 2,3,4,5 \text { - POSITIVO)". }\end{array}$ \\
\hline & PAFCCO1 & Numérica Ordinal & $b$ & $\begin{array}{l}\text { Crença de controle } 1 \text { - Control Belief Strenght } \text { - Item "Os compromissos diários } \\
\text { da família não permitem que meu(minha) filho(a) seja levado/trazido da escola de } \\
\text { carro (1- DISCORDO TOTALMENTE; } 2 \text { - DISCORDO; 3- NEM CONCORDO, } \\
\text { NEM DISCORDO; 4- CONCORDO; 5- CONCORDO PLENAMENTE)". }\end{array}$ \\
\hline & PAFCCE1 & Numérica Ordinal & $e$ & $\begin{array}{l}\text { Crença de controle } 1 \text { - Power of Control Factor - Item "Deveria considerar a } \\
\text { compatibilidade de horários para que meu(minha) filho (a) seja levado(a) ou } \\
\text { trazido(a) de escola de carro (1- DIFICILMENTE, } 2,3,4,5,- \\
\text { PROVAVELMENTE)". }\end{array}$ \\
\hline & PAFCCO2 & Numérica Ordinal & $b$ & $\begin{array}{l}\text { Crença de controle } 2 \text { - Control Belief Strenght - Item "As condições do trânsito } \\
\text { impedem que meu(minha) filho(a) seja transportado(a) no automóvel da família para } \\
\text { ir ou voltar da escola (1- DISCORDO TOTALMENTE; } 2 \text { - DISCORDO; 3- NEM } \\
\text { CONCORDO, NEM } \quad \text { DISCORDO; } 4-\text { CONCORDO; 5- CONCORDO } \\
\text { PLENAMENTE)". }\end{array}$ \\
\hline & PAFCCE2 & Numérica Ordinal & $e$ & $\begin{array}{l}\text { Crença de controle } 2 \text { - Power of Control Factor - Item "Deveria considerar as } \\
\text { condições do trânsito para que meu(minha) filho(a) seja levado(a) ou trazido(a) da } \\
\text { escola de carro (1- DIFICILMENTE, 2, 3, 4, 5, - PROVAVELMENTE)". }\end{array}$ \\
\hline & PAFCCO3 & Numérica Ordinal & $b$ & $\begin{array}{l}\text { Crença de controle } 3 \text { - Control Belief Strenght - Item "Meu (minha) filho(a) é } \\
\text { transportado no automóvel da família para ir ou voltar da escola porque é caminho } \\
\text { para o motorista (1- DISCORDO TOTALMENTE; } 2 \text { - DISCORDO; 3- NEM } \\
\text { CONCORDO, NEM DISCORDO; 4- CONCORDO; 5- CONCORDO } \\
\text { PLENAMENTE)". }\end{array}$ \\
\hline & PAFCCE3 & Numérica Ordinal & $e$ & $\begin{array}{l}\text { Crença de controle } 3 \text { - Power of Control Factor - Item "Deveria considerar o trajeto } \\
\text { do motorista para que meu(minha) filho(a) seja levado(a) ou trazido(a) da escola de } \\
\text { carro (1- DIFICILMENTE, } 2,3,4,5, \text { - PROVAVELMENTE)". }\end{array}$ \\
\hline \multirow{3}{*}{ MODO METRÔ } & PMTDAT1 & Numérica Ordinal & NA & $\begin{array}{l}\text { Direta Atitude } 1 \text { - Item - "Para meu(minha) filho(a) usar metrô para ir ou voltar } \\
\text { da escola seria: (1- DESAGRADÁVEL, 2,3,4, 5- AGRADÁVEL)". }\end{array}$ \\
\hline & PMTDAT2 & Numérica Ordinal & NA & $\begin{array}{l}\text { Direta Atitude } 2 \text { - Item "Para meu(minha) filho(a) usar metrô para ir ou voltar da } \\
\text { escola seria: (1- NEGATIVO, 2,3,4, 5- POSITIVO)". }\end{array}$ \\
\hline & PMTDAT3 & Numérica Ordinal & NA & $\begin{array}{l}\text { Direta Atitude } 3 \text { - Item "Para meu(minha) filho(a) usar metrô para ir ou voltar da } \\
\text { escola seria: (1- RUIM, 2,3,4, 5- BOM)". }\end{array}$ \\
\hline
\end{tabular}


APÊNDICE K - Descrição das variáveis relativas aos pais/responsáveis, utilizadas na abordagem quantitativa - Parte 13/22

\begin{tabular}{|c|c|c|c|c|}
\hline GRUPO & IDENTIFICAÇÃO & CATEGORIA & CRENÇA & DESCRIÇÃO OU ITEM DO QUESTIONÁRIO \\
\hline \multirow{10}{*}{ MODO METRÔ } & PMTDNS1 & Numérica Ordinal & NA & $\begin{array}{l}\text { Direta Norma Social 1 - Item "A maioria das pessoas importantes para mim } \\
\text { aprovaria que meu (minha) filho(a) usasse metrô para ir ou voltar da escola (1- } \\
\text { DISCORDO TOTALMENTE; } 2 \text { - DISCORDO; 3- NEM CONCORDO, NEM } \\
\text { DISCORDO; 4- CONCORDO; 5- CONCORDO PLENAMENTE)". }\end{array}$ \\
\hline & PMTDNS2 & Numérica Ordinal & NA & $\begin{array}{l}\text { Direta Norma Social } 2 \text { - Item "Pessoas próximas a mim acham que a opção de } \\
\text { deixar meu(minha) filho(a) usar metrô para ir ou voltar da escola é acertada (1- } \\
\text { DISCORDO TOTALMENTE; } 2 \text { - DISCORDO; 3- NEM CONCORDO, NEM } \\
\text { DISCORDO; 4- CONCORDO; 5- CONCORDO PLENAMENTE)". }\end{array}$ \\
\hline & PMTDNS3 & Numérica Ordinal & NA & $\begin{array}{l}\text { Direta Norma Social } 3 \text { - Item "A maioria das pessoas que conheço não se importa } \\
\text { se meu(minha) filho(a) use metrô para ir ou voltar da escola (1- DISCORDO } \\
\text { TOTALMENTE; } 2 \text { - DISCORDO; 3- NEM CONCORDO, NEM DISCORDO; 4- } \\
\text { CONCORDO; 5- CONCORDO PLENAMENTE)". }\end{array}$ \\
\hline & PMTDCP1 & Numérica Ordinal & NA & $\begin{array}{l}\text { Direta Controle Percebido } 1 \text { - Item "Para meu(minha) filho(a), é possível usar } \\
\text { metrô para ir ou voltar da escola (1- DISCORDO TOTALMENTE; } 2 \text { - DISCORDO; } \\
\text { 3- NEM CONCORDO, NEM DISCORDO; 4- CONCORDO; 5- CONCORDO } \\
\text { PLENAMENTE)". }\end{array}$ \\
\hline & PMTDCP2 & Numérica Ordinal & NA & $\begin{array}{l}\text { Direta Controle Percebido } 2 \text { - Item "Para meu (minha) filho (a) usar metrô para } \\
\text { ir/voltar da escola seria (1- DIFÍCIL, 2,3,4,5 - FÁCIL)". }\end{array}$ \\
\hline & PMTDCP3 & Numérica Ordinal & NA & $\begin{array}{l}\text { Direta Controle Percebido } 3 \text { - Item "Para meu (minha) filho (a) usar metrô para } \\
\text { ir/voltar da escola seria (1- IMPOSSÍVEL, } 2,3,4,5 \text { - POSSÍVEL)". }\end{array}$ \\
\hline & PMTDIT1 & Numérica Ordinal & NA & $\begin{array}{l}\text { Direta Intenção } 1 \text { - Item "Eu pretendo que meu(minha) filho(a) use metrô para ir } \\
\text { ou voltar da escola (1- DISCORDO TOTALMENTE; } 2 \text { - DISCORDO; 3- NEM } \\
\text { CONCORDO, NEM DISCORDO; 4- CONCORDO; 5- CONCORDO } \\
\text { PLENAMENTE)". }\end{array}$ \\
\hline & PMTDIT2 & Numérica Ordinal & NA & $\begin{array}{l}\text { Direta Intenção } 2 \text { - Item "Minha intenção que meu(minha) filho(a) use metrô para } \\
\text { ir ou voltar da escola é (1- FRACA, } 2,3,4,5 \text { - FORTE)". }\end{array}$ \\
\hline & PMTDIT3 & Numérica Ordinal & NA & $\begin{array}{l}\text { Direta Intenção } 3 \text { - Item "Pretendo encorajar que meu(minha) filho(a) use metrô } \\
\text { para ir ou voltar da escola (1-DIFICILMENTE, 2, 3, 4, 5 - PROVAVELMENTE)". }\end{array}$ \\
\hline & PMTCBO1 & Numérica Ordinal & $b$ & $\begin{array}{l}\text { Crença Comportamental } 1 \text { - Outcome - Item "Meu (minha) filho(a) chega mais } \\
\text { rápido à escola de metrô (1- DISCORDO TOTALMENTE; } 2 \text { - DISCORDO; 3- } \\
\text { NEM CONCORDO, NEM DISCORDO; 4- CONCORDO; 5- CONCORDO } \\
\text { PLENAMENTE)". }\end{array}$ \\
\hline
\end{tabular}


APÊNDICE K - Descrição das variáveis relativas aos pais/responsáveis, utilizadas na abordagem quantitativa - Parte $14 / 22$

\begin{tabular}{|c|c|c|c|c|}
\hline GRUPO & IDENTIFICAÇÃO & CATEGORIA & CRENÇA & DESCRIÇÃO OU ITEM DO QUESTIONÁRIO \\
\hline \multirow{10}{*}{ MODO METRÔ } & PMTCBE1 & Numérica Ordinal & 3 & $\begin{array}{l}\text { Crença Comportamental } 1 \text { - Evaluation - Item "Preocupar-se com o tempo de } \\
\text { viagem para ir de metrô à escola é (1 - RUIM, 2, 3, 4, 5- BOM)". }\end{array}$ \\
\hline & PMTCBO2 & Numérica Ordinal & $b$ & $\begin{array}{l}\text { Crença Comportamental } 2 \text { - Outcome } \text { - Item "É fácil usar metrô para ir ou voltar } \\
\text { da escola (1- DISCORDO TOTALMENTE; } 2 \text { - DISCORDO; } 3-\text { NEM } \\
\text { CONCORDO, NEM DISCORDO; 4- CONCORDO; 5- CONCORDO } \\
\text { PLENAMENTE)". }\end{array}$ \\
\hline & PMTCBE2 & Numérica Ordinal & $e$ & $\begin{array}{l}\text { Crença Comportamental } 2 \text { - Evaluation - Item "Preocupar-se com a facilidade do } \\
\text { metrô para ir ou voltar da escola é: (1 - RUIM, 2, 3, 4, 5-BOM)". }\end{array}$ \\
\hline & PMTCBO3 & Numérica Ordinal & $b$ & $\begin{array}{l}\text { Crença Comportamental 3 - Outcome - Item "É seguro usar o metrô para ir ou } \\
\text { voltar da escola (1- DISCORDO TOTALMENTE; 2 - DISCORDO; 3- NEM } \\
\text { CONCORDO, NEM DISCORDO; 4- CONCORDO; 5- CONCORDO } \\
\text { PLENAMENTE)". }\end{array}$ \\
\hline & PMTCBE3 & Numérica Ordinal & $e$ & $\begin{array}{l}\text { Crença Comportamental } 3 \text { - Evaluation - Item "Prezar pela segurança ao usar o } \\
\text { metrô é (1 - RUIM, 2, 3, 4, 5 - BOM)". }\end{array}$ \\
\hline & PMTCNO1 & Numérica Ordinal & $b$ & $\begin{array}{l}\text { Crença Normativa } 1 \text { - Belief Strenght } \text { - Item "A família incentiva que meu (minha) } \\
\text { filho(a) use metrô para ir ou voltar da escola (1- DISCORDO TOTALMENTE; } 2 \text { - } \\
\text { DISCORDO; 3- NEM CONCORDO, NEM DISCORDO; 4- CONCORDO; } 5 \text { - } \\
\text { CONCORDO PLENAMENTE)". }\end{array}$ \\
\hline & PMTCNE1 & Numérica Ordinal & $e$ & $\begin{array}{l}\text { Crença Normativa } 1 \text { - Motivation to comply - Item "Considero o fato de minha } \\
\text { família incentivar que meu(minha) filho(a) use metrô para ir ou voltar da escola } \\
\text { como (1- NEGATIVO, } 2,3,4,5 \text { - POSITIVO)". }\end{array}$ \\
\hline & PMTCNO2 & Numérica Ordinal & $b$ & $\begin{array}{l}\text { Crença Normativa } 2 \text { - Belief Strenght } \text { - Item "Meus amigos acham uma boa ideia } \\
\text { meu (minha) filho (a) usar o metrô para ir ou voltar da escola (1- DISCORDO } \\
\text { TOTALMENTE; } 2 \text { - DISCORDO; 3- NEM CONCORDO, NEM DISCORDO; 4- } \\
\text { CONCORDO; 5- CONCORDO PLENAMENTE)". }\end{array}$ \\
\hline & PMTCNE2 & Numérica Ordinal & $e$ & $\begin{array}{l}\text { Crença Normativa 2- Motivation to comply - Item "Considero o fato de meus } \\
\text { amigos acharem bom meu (minha) filho(a) usar o metrô para ir ou voltar da escola } \\
\text { como (1- NEGATIVO, } 2,3,4,5 \text { - POSITIVO)". }\end{array}$ \\
\hline & PMTCCO1 & Numérica Ordinal & $b$ & $\begin{array}{l}\text { Crença de controle } 1 \text { - Control Belief Strenght } \text { - Item "Meu (minha) filho(a) pode } \\
\text { ser assaltado(a) no trecho a pé entre a escola e a estação do metrô (1- DISCORDO } \\
\text { TOTALMENTE; } 2 \text { - DISCORDO; 3- NEM CONCORDO, NEM DISCORDO; 4- } \\
\text { CONCORDO; 5- CONCORDO PLENAMENTE)". }\end{array}$ \\
\hline
\end{tabular}


APÊNDICE K - Descrição das variáveis relativas aos pais/responsáveis, utilizadas na abordagem quantitativa - Parte $15 / 22$

\begin{tabular}{|c|c|c|c|c|}
\hline GRUPO & IDENTIFICAÇÃO & CATEGORIA & CRENÇA & DESCRIÇÃO OU ITEM DO QUESTIONÁRIO \\
\hline \multirow{9}{*}{ MODO METRÔ } & PMTCCE1 & Numérica Ordinal & 3 & $\begin{array}{l}\text { Crença de controle } 1 \text { - Power of Control Factor - Item "Deveríamos nos preocupar } \\
\text { com a segurança no trecho entre a escola e o metrô (1- DIFICILMENTE, 2, 3, 4, 5, } \\
\text { - PROVAVELMENTE)". }\end{array}$ \\
\hline & PMTCCO2 & Numérica Ordinal & $b$ & $\begin{array}{l}\text { Crença de controle } 2 \text { - Control Belief Strenght } \text { - Item " Meu (minha) filho(a) pode } \\
\text { ser assaltado(a) no trecho a pé entre a estação do metrô e a nossa casa (1- } \\
\text { DISCORDO TOTALMENTE; } 2 \text { - DISCORDO; 3- NEM CONCORDO, NEM } \\
\text { DISCORDO; 4- CONCORDO; 5- CONCORDO PLENAMENTE)". }\end{array}$ \\
\hline & PMTCCE2 & Numérica Ordinal & $e$ & $\begin{array}{l}\text { Crença de controle } 2 \text { - Power of Control Factor - Item "Deveríamos nos preocupar } \\
\text { com a segurança no trecho entre a estação do metrô e a nossa casa (1- } \\
\text { DIFICILMENTE, } 2,3,4,5 \text {, - PROVAVELMENTE)". }\end{array}$ \\
\hline & PMTCCO3 & Numérica Ordinal & $b$ & $\begin{array}{l}\text { Crença de controle } 3 \text { - Control Belief Strenght - Item "Não é seguro esperar pelo } \\
\text { metrô nas estações nos horários de ida e volta da escola (1- DISCORDO } \\
\text { TOTALMENTE; } 2 \text { - DISCORDO; 3- NEM CONCORDO, NEM DISCORDO; 4- } \\
\text { CONCORDO; 5- CONCORDO PLENAMENTE)". }\end{array}$ \\
\hline & PMTCCE3 & Numérica Ordinal & $e$ & $\begin{array}{l}\text { Crença de controle } 3 \text { - Power of Control Factor - Item "Deveríamos prezar pela } \\
\text { segurança ao esperar pelo metrô nas estações (1- PROVAVELMENTE, 2, 3, 4, 5, - } \\
\text { DIFICILMENTE)". }\end{array}$ \\
\hline & PMTCCO4 & Numérica Ordinal & $b$ & $\begin{array}{l}\text { Crença de controle } 4 \text { - Control Belief Strenght } \text { - Item "Usar metrô par ir ou voltar } \\
\text { da escola é possível para quem mora perto das estações (1- DISCORDO } \\
\text { TOTALMENTE; } 2 \text { - DISCORDO; 3- NEM CONCORDO, NEM DISCORDO; 4- } \\
\text { CONCORDO; 5- CONCORDO PLENAMENTE)". }\end{array}$ \\
\hline & PMTCCE4 & Numérica Ordinal & $e$ & $\begin{array}{l}\text { Crença de controle } 4 \text { - Power of Control Factor - Item "Deveríamos considerar a } \\
\text { distância entre a estação do metrô e a nossa casa para usar o metrô (1- } \\
\text { DIFICILMENTE, } 2,3,4,5 \text {, - PROVAVELMENTE)". }\end{array}$ \\
\hline & PMTCCO5 & Numérica Ordinal & $b$ & $\begin{array}{l}\text { Crença de controle 5 - Control Belief Strenght - Item "O metrô está lotado nos } \\
\text { horários de ida ou volta da escola (1- DISCORDO TOTALMENTE; } 2 \text { - } \\
\text { DISCORDO; 3- NEM CONCORDO, NEM DISCORDO; 4- CONCORDO; 5- } \\
\text { CONCORDO PLENAMENTE)". }\end{array}$ \\
\hline & PMTCCE5 & Numérica Ordinal & $e$ & $\begin{array}{l}\text { Crença de controle } 5 \text { - Power of Control Factor - Item "Deveríamos nos preocupar } \\
\text { com a lotação do metrô para ir ou voltar da escola (1- PROVAVELMENTE, 2, 3, 4, } \\
5, \text { - DIFICILMENTE)". }\end{array}$ \\
\hline
\end{tabular}


APÊNDICE K - Descrição das variáveis relativas aos pais/responsáveis, utilizadas na abordagem quantitativa - Parte $16 / 22$

\begin{tabular}{|c|c|c|c|c|}
\hline GRUPO & IDENTIFICAÇÃO & CATEGORIA & CRENÇA & DESCRIÇÃO OU ITEM DO QUESTIONÁRIO \\
\hline \multirow{11}{*}{ MODO ÔNIBUS } & PONDAT1 & Numérica Ordinal & NA & $\begin{array}{l}\text { Direta Atitude } 1 \text { - Item - "Para meu(minha) filho(a) usar ônibus para ir ou voltar } \\
\text { da escola seria: (1- DESAGRADÁVEL, 2,3,4, 5- AGRADÁVEL)". }\end{array}$ \\
\hline & PONDAT2 & Numérica Ordinal & NA & $\begin{array}{l}\text { Direta Atitude } 2 \text { - Item "Para meu(minha) filho(a) usar ônibus para ir ou voltar da } \\
\text { escola seria: (1- NEGATIVO, 2,3,4,5- POSITIVO)". }\end{array}$ \\
\hline & PONDAT3 & Numérica Ordinal & NA & $\begin{array}{l}\text { Direta Atitude } 3 \text { - Item "Para meu(minha) filho(a) usar ônibus para ir ou voltar da } \\
\text { escola seria: (1- RUIM, 2,3,4, 5- BOM)". }\end{array}$ \\
\hline & PONDNS1 & Numérica Ordinal & NA & $\begin{array}{l}\text { Direta Norma Social 1 - Item "A maioria das pessoas importantes para mim } \\
\text { aprovaria que meu (minha) filho(a) usasse ônibus para ir ou voltar da escola (1- } \\
\text { DISCORDO TOTALMENTE; } 2 \text { - DISCORDO; 3- NEM CONCORDO, NEM } \\
\text { DISCORDO; 4- CONCORDO; 5- CONCORDO PLENAMENTE)". }\end{array}$ \\
\hline & PONDNS2 & Numérica Ordinal & NA & $\begin{array}{l}\text { Direta Norma Social } 2 \text { - Item "Pessoas próximas a mim acham que a opção de } \\
\text { deixar meu(minha) filho(a) usar ônibus para ir ou voltar da escola é acertada (1- } \\
\text { DISCORDO TOTALMENTE; } 2 \text { - DISCORDO; 3- NEM CONCORDO, NEM } \\
\text { DISCORDO; 4- CONCORDO; 5- CONCORDO PLENAMENTE)". }\end{array}$ \\
\hline & PONDNS3 & Numérica Ordinal & NA & $\begin{array}{l}\text { Direta Norma Social } 3 \text { - Item "A maioria das pessoas que conheço não se importa } \\
\text { que meu(minha) filho(a) use ônibus para ir ou voltar da escola (1- DISCORDO } \\
\text { TOTALMENTE; } 2 \text { - DISCORDO; 3- NEM CONCORDO, NEM DISCORDO; 4- } \\
\text { CONCORDO; 5- CONCORDO PLENAMENTE)". }\end{array}$ \\
\hline & PONDCP1 & Numérica Ordinal & NA & $\begin{array}{l}\text { Direta Controle Percebido } 1 \text { - Item "Para meu(minha) filho(a), é possível usar } \\
\text { ônibus para ir ou voltar da escola (1- DISCORDO TOTALMENTE; } 2 \text { - } \\
\text { DISCORDO; 3- NEM CONCORDO, NEM DISCORDO; 4- CONCORDO; 5- } \\
\text { CONCORDO PLENAMENTE)". }\end{array}$ \\
\hline & PONDCP2 & Numérica Ordinal & NA & $\begin{array}{l}\text { Direta Controle Percebido } 2 \text { - Item "Para meu(minha) filho(a) usar ônibus para } \\
\text { ir/voltar da escola seria (1- DIFÍCIL, 2,3,4,5 - FÁCIL)". }\end{array}$ \\
\hline & PONDCP3 & Numérica Ordinal & NA & $\begin{array}{l}\text { Direta Controle Percebido } 3 \text { - Item "Para meu(minha) filho(a) usar ônibus para } \\
\text { ir/voltar da escola seria (1- IMPOSSÍVEL, 2,3,4,5 - POSSÍVEL)". }\end{array}$ \\
\hline & PONDIT1 & Numérica Ordinal & NA & $\begin{array}{l}\text { Direta Intenção } 1 \text { - Item "Eu pretendo que meu(minha) filho(a) use ônibus para ir } \\
\text { ou voltar da escola (1- DISCORDO TOTALMENTE; } 2 \text { - DISCORDO; 3- NEM } \\
\text { CONCORDO, NEM DISCORDO; 4- CONCORDO; 5- CONCORDO } \\
\text { PLENAMENTE)". }\end{array}$ \\
\hline & PONDIT2 & Numérica Ordinal & NA & $\begin{array}{l}\text { Direta Intenção } 2 \text { - Item "Minha intenção que meu(minha) filho(a) use ônibus para } \\
\text { ir ou voltar da escola é (1- FRACA, } 2,3,4,5 \text { - FORTE)". }\end{array}$ \\
\hline
\end{tabular}


APÊNDICE K - Descrição das variáveis relativas aos pais/responsáveis, utilizadas na abordagem quantitativa - Parte 17/22

\begin{tabular}{|c|c|c|c|c|}
\hline GRUPO & IDENTIFICAÇÃO & CATEGORIA & CRENÇA & DESCRIÇÃO OU ITEM DO QUESTIONÁRIO \\
\hline \multirow{10}{*}{ MODO ÔNIBUS } & PONDIT3 & Numérica Ordinal & NA & $\begin{array}{l}\text { Direta Intenção } 3 \text { - Item "Pretendo encorajar meu(minha) filho(a) a usar ônibus } \\
\text { para ir ou voltar da escola (1-DIFICILMENTE, } 2,3,4,5 \text { - CERTAMENTE)". }\end{array}$ \\
\hline & PONCBO1 & Numérica Ordinal & $b$ & $\begin{array}{l}\text { Crença Comportamental } 1 \text { - Outcome - Item "Meu (minha) filho(a) chega mais } \\
\text { rápido na escola de ônibus (1- DISCORDO TOTALMENTE; } 2 \text { - DISCORDO; 3- } \\
\text { NEM CONCORDO, NEM DISCORDO; 4- CONCORDO; 5- CONCORDO } \\
\text { PLENAMENTE)". }\end{array}$ \\
\hline & PONCBE1 & Numérica Ordinal & $e$ & $\begin{array}{l}\text { Crença Comportamental } 1 \text { - Evaluation - Item "Preocupar-se com o tempo de } \\
\text { viagem de ônibus para ir ou voltar da escola é (1 - RUIM, 2, 3, 4, 5- BOM)". }\end{array}$ \\
\hline & PONCBO2 & Numérica Ordinal & $b$ & $\begin{array}{l}\text { Crença Comportamental } 2 \text { - Outcome - Item "Não compensa usar o ônibus para ir } \\
\text { ou voltar da escola por causa da superlotação (1- DISCORDO TOTALMENTE; } 2 \text { - } \\
\text { DISCORDO; 3- NEM CONCORDO, NEM DISCORDO; 4- CONCORDO; 5- } \\
\text { CONCORDO PLENAMENTE)". }\end{array}$ \\
\hline & PONCBE2 & Numérica Ordinal & $e$ & $\begin{array}{l}\text { Crença Comportamental } 2 \text { - Evaluation - Item "Considerar a lotação do ônibus } \\
\text { para ir ou voltar da escola é (1 - RUIM, 2, 3, 4, 5 - BOM)". }\end{array}$ \\
\hline & PONCBO3 & Numérica Ordinal & $b$ & $\begin{array}{l}\text { Crença Comportamental } 3 \text { - Outcome - Item "Os ônibus não têm horário certo } \\
\text { para passar (1- DISCORDO TOTALMENTE; } 2 \text { - DISCORDO; 3- NEM } \\
\text { CONCORDO, NEM DISCORDO; 4- CONCORDO; 5- CONCORDO } \\
\text { PLENAMENTE)". }\end{array}$ \\
\hline & PONCBE3 & Numérica Ordinal & $e$ & $\begin{array}{l}\text { Crença Comportamental } 3 \text { - Evaluation - Item "Considerar os horários de ônibus } \\
\text { para ir ou voltar da escola é (1 - RUIM, 2, 3, 4, 5 - BOM)". }\end{array}$ \\
\hline & PONCNO1 & Numérica Ordinal & $b$ & $\begin{array}{l}\text { Crença Normativa } 1 \text { - Belief Strenght - Item "Nossa família apoiaria se meu } \\
\text { (minha) filho(a) usasse ônibus para ir ou voltar da escola (1- DISCORDO } \\
\text { TOTALMENTE; } 2 \text { - DISCORDO; } 3 \text { - NEM CONCORDO, NEM DISCORDO; } 4 \text { - } \\
\text { CONCORDO; } 5 \text { - CONCORDO PLENAMENTE)". }\end{array}$ \\
\hline & PONCNE1 & Numérica Ordinal & $e$ & $\begin{array}{l}\text { Crença Normativa } 1 \text { - Motivation to comply - Item "Considero o fato de minha } \\
\text { família apoiar que meu(minha) filho(a) use ônibus para ir ou voltar da escola como } \\
\text { (1- NEGATIVO, } 2,3,4,5 \text { - POSITIVO)". }\end{array}$ \\
\hline & PONCNO2 & Numérica Ordinal & $b$ & $\begin{array}{l}\text { Crença Normativa } 2 \text { - Belief Strenght - Item "Meus amigos apoiariam se meu } \\
\text { (minha) filho (a) usasse ônibus para ir ou voltar da escola (1- DISCORDO } \\
\text { TOTALMENTE; } 2 \text { - DISCORDO; 3- NEM CONCORDO, NEM DISCORDO; 4- } \\
\text { CONCORDO; 5- CONCORDO PLENAMENTE)". }\end{array}$ \\
\hline
\end{tabular}


APÊNDICE K - Descrição das variáveis relativas aos pais/responsáveis, utilizadas na abordagem quantitativa - Parte $18 / 22$

\begin{tabular}{|c|c|c|c|c|}
\hline GRUPO & IDENTIFICAÇÃO & CATEGORIA & CRENÇA & DESCRIÇÃO OU ITEM DO QUESTIONÁRIO \\
\hline \multirow{9}{*}{ MODO ÔNIBUS } & PONCNE2 & Numérica Ordinal & $e$ & $\begin{array}{l}\text { Crença Normativa 2- Motivation to comply - Item "Considero o fato de meus } \\
\text { amigos apoiarem que meu (minha) filho(a) use ônibus para ir ou voltar da escola } \\
\text { como (1- NEGATIVO, } 2,3,4,5 \text { - POSITIVO)". }\end{array}$ \\
\hline & PONCCO1 & Numérica Ordinal & $b$ & $\begin{array}{l}\text { Crença de controle 1 - Control Belief Strenght } \text { - Item "O trecho a pé entre a escola } \\
\text { e a parada é perigoso (1- DISCORDO TOTALMENTE; } 2 \text { - DISCORDO; 3- NEM } \\
\text { CONCORDO, NEM DISCORDO; 4- CONCORDO; 5- CONCORDO } \\
\text { PLENAMENTE)". }\end{array}$ \\
\hline & PONCCE1 & Numérica Ordinal & $e$ & $\begin{array}{l}\text { Crença de controle } 1 \text { - Power of Control Factor - Item "Acho que deveríamos nos } \\
\text { preocupar com a segurança no trecho a pé entre a escola e a parada (1- } \\
\text { DIFICILMENTE, 2, 3, 4, 5, - PROVAVELMENTE)". }\end{array}$ \\
\hline & PONCCO2 & Numérica Ordinal & $b$ & $\begin{array}{l}\text { Crença de controle 2 - Control Belief Strenght } \text { - Item "O trecho a pé entre a parada } \\
\text { e a minha casa é perigoso (1- DISCORDO TOTALMENTE; } 2 \text { - DISCORDO; 3- } \\
\text { NEM CONCORDO, NEM DISCORDO; 4- CONCORDO; 5- CONCORDO } \\
\text { PLENAMENTE)". }\end{array}$ \\
\hline & PONCCE2 & Numérica Ordinal & $e$ & $\begin{array}{l}\text { Crença de controle } 2 \text { - Power of Control Factor - Item "Acho que deveríamos nos } \\
\text { preocupar com a segurança no trecho a pé entre a nossa casa e a parada (1- } \\
\text { DIFICILMENTE, } 2,3,4,5,- \text { PROVAVELMENTE)". }\end{array}$ \\
\hline & PONCCO3 & Numérica Ordinal & $b$ & $\begin{array}{l}\text { Crença de controle } 3 \text { - Control Belief Strenght } \text { - Item "É perigoso ficar esperando } \\
\text { o ônibus na parada (1- DISCORDO TOTALMENTE; } 2 \text { - DISCORDO; 3- NEM } \\
\text { CONCORDO, NEM DISCORDO; 4- CONCORDO; 5- CONCORDO } \\
\text { PLENAMENTE)". }\end{array}$ \\
\hline & PONCCE3 & Numérica Ordinal & $e$ & $\begin{array}{l}\text { Crença de controle } 3 \text { - Power of Control Factor - Item "Devo prezar pela segurança } \\
\text { ao esperar pelo ônibus na parada (1- DIFICILMENTE, 2, 3, 4, 5, - } \\
\text { PROVAVELMENTE)". }\end{array}$ \\
\hline & PONCCO4 & Numérica Ordinal & $b$ & $\begin{array}{l}\text { Crença de controle } 4 \text { - Control Belief Strenght - Item "É mais simples usar ônibus } \\
\text { para ir ou voltar da escola (1- DISCORDO TOTALMENTE; } 2 \text { - DISCORDO; 3- } \\
\text { NEM CONCORDO, NEM DISCORDO; 4- CONCORDO; 5- CONCORDO } \\
\text { PLENAMENTE)". }\end{array}$ \\
\hline & PONCCE4 & Numérica Ordinal & $e$ & $\begin{array}{l}\text { Crença de controle } 4 \text { - Power of Control Factor - Item "Deveríamos nos preocupar } \\
\text { em descomplicar a viagem de ida ou volta da escola (1- DIFICILMENTE, 2, 3, 4, 5, } \\
\text { - PROVAVELMENTE)". }\end{array}$ \\
\hline
\end{tabular}


APÊNDICE K - Descrição das variáveis relativas aos pais/responsáveis, utilizadas na abordagem quantitativa - Parte 19/22

\begin{tabular}{|c|c|c|c|c|}
\hline GRUPO & IDENTIFICAÇÃO & CATEGORIA & CRENÇA & DESCRIÇÃO OU ITEM DO QUESTIONÁRIO \\
\hline \multirow{11}{*}{$\begin{array}{l}\text { MODO } \\
\text { BICICLETA }\end{array}$} & PBCDAT1 & Numérica Ordinal & NA & $\begin{array}{l}\text { Direta Atitude } 1 \text { - Item "Para meu(minha) filho(a) usar a bicicleta para ir ou voltar } \\
\text { da escola seria: (1- DESAGRADÁVEL, 2,3,4, 5- AGRADÁVEL)". }\end{array}$ \\
\hline & PBCDAT2 & Numérica Ordinal & NA & $\begin{array}{l}\text { Direta Atitude } 2 \text { - Item "Para meu(minha) filho(a) usar a bicicleta para ir ou voltar } \\
\text { da escola seria: (1- NEGATIVO, 2,3,4,5- POSITIVO)". }\end{array}$ \\
\hline & PBCDAT3 & Numérica Ordinal & NA & $\begin{array}{l}\text { Direta Atitude } 3 \text { - Item "Para meu(minha) filho(a) usar a bicicleta para ir ou voltar } \\
\text { da escola seria: (1- RUIM, 2,3,4, 5- BOM)". }\end{array}$ \\
\hline & PBCDNS1 & Numérica Ordinal & NA & $\begin{array}{l}\text { Direta Norma Social 1 - Item "A maioria das pessoas importantes para mim } \\
\text { aprovaria que meu (minha) filho(a) usasse bicicleta para ir ou voltar da escola (1- } \\
\text { DISCORDO TOTALMENTE; } 2 \text { - DISCORDO; 3- NEM CONCORDO, NEM } \\
\text { DISCORDO; 4- CONCORDO; 5- CONCORDO PLENAMENTE)". }\end{array}$ \\
\hline & PBCDNS2 & Numérica Ordinal & NA & $\begin{array}{l}\text { Direta Norma Social } 2 \text { - Item "Pessoas próximas a mim acham que a opção de } \\
\text { deixar meu (minha) filho(a) usar bicicleta para ir ou voltar da escola é acertada (1- } \\
\text { DISCORDO TOTALMENTE; } 2 \text { - DISCORDO; 3- NEM CONCORDO, NEM } \\
\text { DISCORDO; 4- CONCORDO; 5- CONCORDO PLENAMENTE)". }\end{array}$ \\
\hline & PBCDNS3 & Numérica Ordinal & NA & $\begin{array}{l}\text { Direta Norma Social } 3 \text { - Item "A maioria das pessoas que conheço não se importa } \\
\text { se meu (minha) filho(a) use a bicicleta para ir ou voltar da escola (1- DISCORDO } \\
\text { TOTALMENTE; } 2 \text { - DISCORDO; 3- NEM CONCORDO, NEM DISCORDO; 4- } \\
\text { CONCORDO; 5- CONCORDO PLENAMENTE)". }\end{array}$ \\
\hline & PBCDCP1 & Numérica Ordinal & NA & $\begin{array}{l}\text { Direta Controle Percebido } 1 \text { - Item "Para meu(minha) filho(a), é possível usar } \\
\text { bicicleta para ir ou voltar da escola (1- DISCORDO TOTALMENTE; } 2 \text { - } \\
\text { DISCORDO; 3- NEM CONCORDO, NEM DISCORDO; 4- CONCORDO; 5- } \\
\text { CONCORDO PLENAMENTE)". }\end{array}$ \\
\hline & PBCDCP2 & Numérica Ordinal & NA & $\begin{array}{l}\text { Direta Controle Percebido } 2 \text { - Item "Para meu(minha) filho(a) usar bicicleta para } \\
\text { ir/voltar da escola seria (1- DIFÍCIL, 2,3,4,5 - FÁCIL)". }\end{array}$ \\
\hline & РBCDCP3 & Numérica Ordinal & NA & $\begin{array}{l}\text { Direta Controle Percebido } 3 \text { - Item "Para meu(minha) filho(a) usar bicicleta para } \\
\text { ir/voltar da escola seria (1- IMPOSSÍVEL, 2,3,4,5 - POSSÍVEL)". }\end{array}$ \\
\hline & PBCDIT1 & Numérica Ordinal & NA & $\begin{array}{l}\text { Direta Intenção } 1 \text { - Item "Eu pretendo que meu(minha) filho(a) use bicicleta para } \\
\text { ir ou voltar da escola (1- DISCORDO TOTALMENTE; } 2 \text { - DISCORDO; 3- NEM } \\
\text { CONCORDO, NEM DISCORDO; 4- CONCORDO; 5- CONCORDO } \\
\text { PLENAMENTE)". }\end{array}$ \\
\hline & PBCDIT2 & Numérica Ordinal & NA & $\begin{array}{l}\text { Direta Intenção } 2 \text { - Item "Minha intenção que meu(minha) filho(a) use bicicleta } \\
\text { para ir/voltar da escola é (1- FRACA, 2, 3, 4, 5 - FORTE)". }\end{array}$ \\
\hline
\end{tabular}


APÊNDICE K - Descrição das variáveis relativas aos pais/responsáveis, utilizadas na abordagem quantitativa - Parte 20/22

\begin{tabular}{|c|c|c|c|c|}
\hline GRUPO & IDENTIFICAÇÃO & CATEGORIA & CRENÇA & DESCRIÇÃO OU ITEM DO QUESTIONÁRIO \\
\hline \multirow{10}{*}{$\begin{array}{l}\text { MODO } \\
\text { BICICLETA }\end{array}$} & PBCDIT3 & Numérica Ordinal & NA & $\begin{array}{l}\text { Direta Intenção } 3 \text { - Item "Pretendo encorajar que meu(minha) filho(a) a usar } \\
\text { bicicleta para ir/voltar da escola (1-DIFICILMENTE, } 2,3,4,5 \text { - CERTAMENTE)". }\end{array}$ \\
\hline & РBCCBO1 & Numérica Ordinal & $b$ & $\begin{array}{l}\text { Crença Comportamental } 1 \text { - Outcome } \text { - Item "Usar bicicleta para ir ou voltar da } \\
\text { escola faz bem à saúde (1-DISCORDO TOTALMENTE; } 2 \text { - DISCORDO; 3- NEM } \\
\text { CONCORDO, NEM DISCORDO; 4- CONCORDO; 5- CONCORDO } \\
\text { PLENAMENTE)". }\end{array}$ \\
\hline & PBCCBE1 & Numérica Ordinal & $e$ & $\begin{array}{l}\text { Crença Comportamental } 1 \text { - Evaluation - Item "Preocupar-se com o que é mais } \\
\text { saudável ao usar a bicicleta para ir ou voltar da escola é (1 - RUIM, 2, 3, 4, } 5 \text { - } \\
\text { BOM)". }\end{array}$ \\
\hline & РBCCBO2 & Numérica Ordinal & $b$ & $\begin{array}{l}\text { Crença Comportamental } 2 \text { - Outcome - Item "Usar bicicleta para ir ou voltar da } \\
\text { escola é possível para quem mora perto da escola (1- DISCORDO TOTALMENTE; } \\
2 \text { - DISCORDO; 3- NEM CONCORDO, NEM DISCORDO; 4- CONCORDO; 5- } \\
\text { CONCORDO PLENAMENTE)". }\end{array}$ \\
\hline & PBCCBE2 & Numérica Ordinal & $e$ & $\begin{array}{l}\text { Crença Comportamental } 2 \text { - Evaluation - Item "Considerar a distância ao usar a } \\
\text { bicicleta para ir/voltar da escola é: (1 - RUIM, 2, 3, 4, 5 - BOM)". }\end{array}$ \\
\hline & РВССBO3 & Numérica Ordinal & $b$ & $\begin{array}{l}\text { Crença Comportamental } 3 \text { - Outcome - Item "Meu (minha) filho(a) é respeitado } \\
\text { (a) como ciclista no trajeto entre a nossa casa e a escola (1- DISCORDO } \\
\text { TOTALMENTE; } 2 \text { - DISCORDO; 3- NEM CONCORDO, NEM DISCORDO; } 4 \text { - } \\
\text { CONCORDO; 5- CONCORDO PLENAMENTE)". }\end{array}$ \\
\hline & PBCCBE3 & Numérica Ordinal & $e$ & $\begin{array}{l}\text { Crença Comportamental } 3 \text { - Evaluation - Item "Preocupar-se com o respeito para } \\
\text { com o ciclista no trajeto para ir ou voltar da escola é (1 - RUIM, 2, 3, 4, 5 - BOM)". }\end{array}$ \\
\hline & PBCCNO1 & Numérica Ordinal & $b$ & $\begin{array}{l}\text { Crença Normativa } 1 \text { - Belief Strenght - Item "Nossa família apoiaria que meu } \\
\text { (minha) filho(a) usasse a bicicleta para ir ou voltar da escola (1- DISCORDO } \\
\text { TOTALMENTE; } 2 \text { - DISCORDO; 3- NEM CONCORDO, NEM DISCORDO; 4- } \\
\text { CONCORDO; } 5 \text { - CONCORDO PLENAMENTE)". }\end{array}$ \\
\hline & PBCCNE1 & Numérica Ordinal & $e$ & $\begin{array}{l}\text { Crença Normativa } 1 \text { - Motivation to comply - Item "Considero o fato de minha } \\
\text { família apoiar que meu(minha) filho(a) use a bicicleta para ir ou voltar da escola } \\
\text { como (1- NEGATIVO, } 2,3,4,5 \text { - POSITIVO)". }\end{array}$ \\
\hline & PBCCNO2 & Numérica Ordinal & $b$ & $\begin{array}{l}\text { Crença Normativa } 2 \text { - Belief Strenght - Item "Meus amigos apoiariam se meu } \\
\text { (minha) filho (a) usasse a bicicleta para ir ou voltar da escola (1- DISCORDO } \\
\text { TOTALMENTE; } 2 \text { - DISCORDO; 3- NEM CONCORDO, NEM DISCORDO; 4- } \\
\text { CONCORDO; 5- CONCORDO PLENAMENTE)". }\end{array}$ \\
\hline
\end{tabular}


APÊNDICE K - Descrição das variáveis relativas aos pais/responsáveis, utilizadas na abordagem quantitativa - Parte $21 / 22$

\begin{tabular}{|c|c|c|c|c|}
\hline GRUPO & IDENTIFICAÇÃO & CATEGORIA & CRENÇA & DESCRIÇÃO OU ITEM DO QUESTIONÁRIO \\
\hline \multirow{9}{*}{$\begin{array}{l}\text { MODO } \\
\text { BICICLETA }\end{array}$} & PBCCNE2 & Numérica Ordinal & $e$ & $\begin{array}{l}\text { Crença Normativa 2- Motivation to comply - Item "Considero o fato de meus } \\
\text { amigos apoiarem que meu (minha) filho(a) use a bicicleta para ir ou voltar da escola } \\
\text { como (1- NEGATIVO, } 2,3,4,5 \text { - POSITIVO)". }\end{array}$ \\
\hline & PBCCCO1 & Numérica Ordinal & $b$ & $\begin{array}{l}\text { Crença de controle 1-Control Belief Strenght } \text { - Item "Moro muito longe da escola } \\
\text { para usar bicicleta (1- DISCORDO TOTALMENTE; } 2 \text { - DISCORDO; 3- NEM } \\
\text { CONCORDO, NEM DISCORDO; 4- CONCORDO; 5- CONCORDO } \\
\text { PLENAMENTE)". }\end{array}$ \\
\hline & PBCCCE1 & Numérica Ordinal & $e$ & $\begin{array}{l}\text { Crença de controle } 1 \text { - Power of Control Factor - Item "Considero a distância a } \\
\text { percorrer antes de decidir usar bicicleta para ir ou voltar da escola (1- } \\
\text { DIFICILMENTE, 2, 3, 4, 5, - PROVAVELMENTE)". }\end{array}$ \\
\hline & $\mathrm{PBCCCO2}$ & Numérica Ordinal & $b$ & $\begin{array}{l}\text { Crença de controle } 2 \text { - Control Belief Strenght - Item "Meu (minha) filho (a) pode } \\
\text { ser assaltado se usar a bicicleta para ir ou voltar da escola (1- DISCORDO } \\
\text { TOTALMENTE; } 2 \text { - DISCORDO; 3- NEM CONCORDO, NEM DISCORDO; 4- } \\
\text { CONCORDO; 5- CONCORDO PLENAMENTE)". }\end{array}$ \\
\hline & PBCCCE2 & Numérica Ordinal & $e$ & $\begin{array}{l}\text { Crença de controle } 2 \text { - Power of Control Factor - Item "Acho que deveríamos nos } \\
\text { preocupar com assaltos no trajeto de bicicleta para ir ou voltar da escola (1- } \\
\text { DIFICILMENTE, } 2,3,4,5,- \text { PROVAVELMENTE)". }\end{array}$ \\
\hline & PBCCCO3 & Numérica Ordinal & $b$ & $\begin{array}{l}\text { Crença de controle } 3 \text { - Control Belief Strenght } \text { - Item " Meu (minha) filho (a) pode } \\
\text { se envolver em acidentes de trânsito se usar a bicicleta para ir ou voltar da escola (1- } \\
\text { DISCORDO TOTALMENTE; } 2 \text { - DISCORDO; 3- NEM CONCORDO, NEM } \\
\text { DISCORDO; 4- CONCORDO; 5- CONCORDO PLENAMENTE)". }\end{array}$ \\
\hline & PBCCCE3 & Numérica Ordinal & $e$ & $\begin{array}{l}\text { Crença de controle } 3 \text { - Power of Control Factor - Item "Acho que deveríamos nos } \\
\text { preocupar com acidentes de trânsito para usar bicicleta para ir ou voltar da escola (1- } \\
\text { DIFICILMENTE, 2, 3, 4, 5, - PROVAVELMENTE)". }\end{array}$ \\
\hline & PBCCCO4 & Numérica Ordinal & $b$ & $\begin{array}{l}\text { Crença de controle } 4 \text { - Control Belief Strenght } \text { - Item "A condição do trecho entre } \\
\text { a escola e a nossa casa não favorece o uso da bicicleta (1- DISCORDO } \\
\text { TOTALMENTE; } 2 \text { - DISCORDO; 3- NEM CONCORDO, NEM DISCORDO; 4- } \\
\text { CONCORDO; 5- CONCORDO PLENAMENTE)". }\end{array}$ \\
\hline & PBCCCE4 & Numérica Ordinal & $e$ & $\begin{array}{l}\text { Crença de controle 4- Power of Control Factor - Item "Acho que deveríamos nos } \\
\text { preocupar com a condição do trecho entre a escola e a nossa casa para usar bicicleta } \\
\text { para ir ou voltar da escola (1- DIFICILMENTE, } 2,3,4,5,- \text { PROVAVELMENTE)". }\end{array}$ \\
\hline
\end{tabular}


APÊNDICE K - Descrição das variáveis relativas aos pais/responsáveis, utilizadas na abordagem quantitativa - Parte 22/22

\begin{tabular}{|c|c|c|c|}
\hline GRUPO & IDENTIFICAÇÃO & CATEGORIA & CRENÇA \\
\hline \multirow{6}{*}{ HÁBITO } & PHABON & Numérica Contínua & NA \\
\hline & PHABAP & Numérica Contínua & NA \\
\hline & PHABAC & Numérica Contínua & NA \\
\hline & PHABBC & Numérica Contínua & NA \\
\hline & PHABAF & Numérica Contínua & NA \\
\hline & PHABVF & Numérica Contínua & NA \\
\hline
\end{tabular}

DESCRIÇÃO OU ITEM DO QUESTIONÁRIO

Forma de apuração da medida do hábito: Item "Abaixo estão listadas algumas atividades de lazer as quais você provavelmente já viu seu (sua) filho (a) se envolver. Suponha que você tenha de sugerir um modo de transporte para ele(a) realizar cada uma delas. Qual o modo de transporte que você preferiria que ele(a) utilizasse? Por favor, responda rapidamente, sem pensar muito a respeito, e assinale apenas um modo para cada atividade". Atividades: visitar um amigo; visitar seus familiares; praticar esporte; perambular pela cidade; ir a festa à noite; passear num dia de tempo bom; ir à padaria; ir à lanchonete ou barzinho de dia; ir ao shopping/cinema

\begin{tabular}{|l|l|c|c|l|}
\multirow{4}{*}{$\begin{array}{l}\text { COMPORT. } \\
\text { PASSADO }\end{array}$} & PCPAP & Numérica Contínua & NA & Comportamento passado para o modo A pé. \\
\cline { 2 - 5 } & PCPON & Numérica Contínua & NA & Comportamento passado para o modo Onnibus. \\
\cline { 2 - 5 } & PCPAF & Numérica Contínua & NA & Comportamento passado para o modo Automóvel da Família. \\
\cline { 2 - 5 } & PCPAC & Numérica Contínua & NA & Comportamento passado para o modo Automóvel Carona. \\
\cline { 2 - 5 } & PCPBC & Numérica Contínua & NA & Comportamento passado para o modo Bicicleta. \\
\cline { 2 - 5 } & PCPTE & Numérica Contínua & NA & Comportamento passado para o modo Transporte Escolar. \\
\cline { 2 - 5 } & PCPMT & Numérica Contínua & NA & Comportamento passado para o modo Metrô. \\
\hline
\end{tabular}

Forma de apuração da medida do comportamento passado: Item "No último ano letivo, quantas vezes seu (sua) filho(a) usou cada modo de transporte par ir ou voltar da escola?" (1- NUNCA; 2 - RARAMENTE; 3 - ÀS VEZES; 4 - FREQUENTEMENTE; 5 - SEMPRE).

Obs.: NA - Não aplicável; $b$ - crença do objeto; $e$ - força da crença. A definição em inglês do tipo da crença é referente a Elliott $e t$ al.(2005). 
APÊNDICE L - Elenco de crenças para os modos de transporte considerados viáveis na opinião dos alunos e pais/responsáveis. 
APÊNDICE L: Elenco de crenças para os modos de transporte considerados viáveis na opinião dos alunos e pais/responsáveis (parte 1/7) Opinião dos alunos Opinião dos pais/responsáveis

\begin{tabular}{|c|c|c|}
\hline \multicolumn{3}{|c|}{ Modo A pé } \\
\hline$b$ & Ir/voltar a pé da escola faz bem à saúde. & Ir/voltar a pé da escola faz bem à saúde. \\
\hline$e$ & Preocupar-se com o que é mais saudável para ir à escola é (ruim/bom). & Preocupar-se com o que é mais saudável para ir/voltar da escola caminhando é (ruim/bom). \\
\hline$b$ & É seguro ir/voltar a pé da escola. & Meu (minha) filho(a) pode ser assaltado(a) se caminhar para ir ou voltar da escola. \\
\hline$e$ & Prezar pela segurança ao caminhar para ir ou voltar da escola é (ruim/bom). & $\begin{array}{l}\text { Devo avaliar se o trecho é perigoso para que meu (minha) filho(a) vá ou volte a pé da } \\
\text { escola. }\end{array}$ \\
\hline$b$ & É vantajoso caminhar até a escola. & É vantajoso ir/voltar a pé da escola, apenas para quem mora perto. \\
\hline$e$ & $\begin{array}{l}\text { Preocupar-se com as vantagens de caminhar para ir ou voltar da escola é } \\
\text { (ruim/bom). }\end{array}$ & Preocupar-se com as vantagens de caminhar para ir ou voltar da escola é (ruim/bom). \\
\hline$b$ & Meus pais me incentivam ir/voltar a pé da escola. & Minha família incentiva que meu (minha) filho(a) caminhe para a escola. \\
\hline$e$ & $\begin{array}{l}\text { Considero o fato de meus pais me incentivarem para ir ou voltar da escola como } \\
\text { (negativo/positivo). }\end{array}$ & $\begin{array}{l}\text { Considero o fato de minha família incentivar meu(minha) filho(a) vá ou volte a pé da escola } \\
\text { (negativo/positivo). }\end{array}$ \\
\hline$b$ & Meus amigos me apoiariam se eu viesse ou voltasse a pé da escola. & Meus amigos acham bom que meu (minha) filho (a) caminhe para a escola. \\
\hline$e$ & $\begin{array}{l}\text { Considero o fato de meus amigos me apoiarem para ir ou voltar da escola como } \\
\text { (negativo/positivo). }\end{array}$ & $\begin{array}{l}\text { Considero o fato de meus amigos acharem bom que meu(minha) filho(a) a ir ou voltar da } \\
\text { escola a pé como (negativo/positivo). }\end{array}$ \\
\hline$b$ & É cansativo ir/voltar a pé da escola. & \\
\hline$e$ & Devo avaliar se o trajeto é cansativo para ir/voltar a pé da escola. & \\
\hline$b$ & O caminho para ir ou voltar a pé da escola é iluminado. & \\
\hline$e$ & Devo avaliar se o caminho é iluminado para ir/voltar a pé da escola. & \\
\hline$b$ & & $\begin{array}{l}\text { As calçadas no trecho entre nossa casa e a escola não permitem que meu (minha) filho(a) } \\
\text { caminhe para a escola. }\end{array}$ \\
\hline$e$ & & $\begin{array}{l}\text { Devem-se avaliar as condições das calçadas para que meu(minha) filho(a) vá ou volte a pé } \\
\text { da escola. }\end{array}$ \\
\hline$b$ & & Ir ou voltar a pé da escola é econômico. \\
\hline$e$ & & $\begin{array}{l}\text { Preocupar-se com o que é mais econômico para ir ou voltar da escola caminhando é } \\
\text { (ruim/bom). }\end{array}$ \\
\hline
\end{tabular}


APÊNDICE L: Elenco de crenças para os modos de transporte considerados viáveis na opinião dos alunos e pais/responsáveis (parte 2/7)

$$
\text { Opinião dos alunos }
$$

Opinião dos pais/responsáveis

\begin{tabular}{|c|c|c|}
\hline & & \\
\hline \\
\hline \multicolumn{2}{|r|}{$\begin{array}{l}\text { Modo automóvel transportando dois ou mais estudantes - Automóvel Carona } \\
b \quad \text { É uma boa ideia pegar carona par ir ou voltar da escola }\end{array}$} & \\
\hline$e$ & $\begin{array}{l}\text { Ponderar sobre as vantagens de pegar ou dar carona ao ir/voltar da escola é } \\
\text { (ruim/bom). }\end{array}$ & A comodidade de pegar carona é (Ruim/bom). \\
\hline$b$ & É seguro pegar ou dar carona a colegas para ir ou voltar da escola. & É seguro pegar carona para ir ou voltar da escola. \\
\hline$e$ & $\begin{array}{l}\text { Prezar pela segurança ao pegar ou dar carona a colegas para ir ou voltar da escola é } \\
\text { (ruim/ bom). }\end{array}$ & $\begin{array}{l}\text { Prezar pela segurança ao pegar ou dar carona a colegas para ir ou voltar da escola é (ruim/ } \\
\text { bom). }\end{array}$ \\
\hline$b$ & Dar ou pegar carona para ir ou voltar da escola facilita fazer novas amizades. & \\
\hline$e$ & $\begin{array}{l}\text { Para mim, fazer novas amizades ao dar ou pegar carona para ir ou voltar da escola } \\
\text { é (ruim/bom). }\end{array}$ & \\
\hline$b$ & Meus pais me incentivam a pegar/dar carona para ir ou voltar da escola. & Minha família acha bom que meu(minha) filho(a) pegue carona para ir/voltar da escola. \\
\hline$e$ & $\begin{array}{l}\text { Considero o fato de meus pais me apoiarem a pegar/dar carona como } \\
\text { (negativo/positivo). }\end{array}$ & $\begin{array}{l}\text { Considero o fato minha família achar bom que meu (minha) filho (a) pegue carona para ir } \\
\text { ou voltar da escola, como (negativo/positivo). }\end{array}$ \\
\hline$b$ & $\begin{array}{l}\text { Meus amigos me apoiariam se eu pegasse ou desse carona para ir ou voltar da } \\
\text { escola. }\end{array}$ & $\begin{array}{l}\text { Na opinião de meus amigos, é bom para meu (minha) filho(a) pegar carona para ir ou voltar } \\
\text { da escola. }\end{array}$ \\
\hline$e$ & $\begin{array}{l}\text { Considero o fato de meus amigos me apoiarem a pegar/dar carona como } \\
\text { (negativo/positivo). }\end{array}$ & $\begin{array}{l}\text { Considero o fato de meus amigos acharem bom que meu (minha) filho (a) pegue carona } \\
\text { para ir ou voltar da escola, como (negativo/positivo). }\end{array}$ \\
\hline$b$ & $\begin{array}{l}\text { É difícil conciliar horários com colegas para pegar ou dar carona para ir ou voltar } \\
\text { da escola. }\end{array}$ & $\begin{array}{l}\text { É difícil conciliar horários para formar um grupo de carona para meu (minha) filho (a) ir } \\
\text { ou voltar da escola }\end{array}$ \\
\hline$e$ & $\begin{array}{l}\text { Devo pensarem conciliar horários para pegar ou dar carona para ir ou voltar da } \\
\text { escola. }\end{array}$ & $\begin{array}{l}\text { Deveria pensar em conciliar horários para formar um grupo de carona para meu (minha) } \\
\text { filho(a) ir ou voltar da escola }\end{array}$ \\
\hline$b$ & É indicado pegar carona somente com motoristas conhecidos. & \\
\hline$e$ & $\begin{array}{l}\text { Devo considerar se eu conheço o motorista para pegar carona para ir ou voltar da } \\
\text { escola. }\end{array}$ & \\
\hline$b$ & Quem pega carona deve "rachar" a gasolina. & É econômico pegar carona para ir ou voltar da escola. \\
\hline$e$ & Se eu fosse pegar carona para ir ou voltar da escola, eu racharia a gasolina. & Preocupar-me com a economia ao pegar carona para ir/ou voltar da escola é (ruim/bom). \\
\hline$b$ & & $\begin{array}{l}\text { É possível formar um grupo de carona com os vizinhos para nos revezarmos levando/ } \\
\text { buscando nossos filhos na escola. }\end{array}$ \\
\hline$e$ & & $\begin{array}{l}\text { Eu formaria um grupo de carona com os vizinhos par nos revezarmos levando u trazendo } \\
\text { nossos filhos da escola (dificilmente/provavelmente) }\end{array}$ \\
\hline$b$ & & Pegar carona para ir ou voltar da escola contribui para diminuir o trânsito. \\
\hline$e$ & & $\begin{array}{l}\text { Preocupar-me com o trânsito ao pegar ou dar carona a colegas para ir ou voltar da escola é } \\
\text { (ruim/bom). }\end{array}$ \\
\hline
\end{tabular}


APÊNDICE L: Elenco de crenças para os modos de transporte considerados viáveis na opinião dos alunos e pais/responsáveis (parte 3/7) Opinião dos alunos Opinião dos pais/responsáveis

\begin{tabular}{|c|c|c|}
\hline & & \\
\hline \multicolumn{3}{|c|}{ Modo Transporte Escolar } \\
\hline$b$ & Usar transporte escolar é mais demorado. & $\begin{array}{l}\text { Meu (minha) filho(a) vai fazer um percurso maior se usar transporte escolar para ir } \\
\text { ou voltar da escola. }\end{array}$ \\
\hline$e$ & Preocupar-me com o tempo de viagem ao usar transporte escolar é (ruim/bom). & $\begin{array}{l}\text { Preocupar-me com o tamanho do percurso para usar o transporte escolar é } \\
\text { (ruim/bom) }\end{array}$ \\
\hline$b$ & É seguro ir ou voltar da escola de transporte escolar. & É seguro dentro do transporte escolar. \\
\hline$e$ & Prezar pela segurança ao usar o transporte escolar é (ruim/bom). & Prezar pela segurança no veículo de transporte escolar é (ruim/bom). \\
\hline$b$ & Quem vai para a escola de transporte escolar costuma chegar no horário certo. & $\begin{array}{l}\text { Meu (minha) filho(a) nunca vai chegar atrasado se usar transporte escolar para ir ou } \\
\text { voltar da escola }\end{array}$ \\
\hline$e$ & Prezar pela pontualidade ao usar transporte escolar é (ruim/bom). & Prezar pela pontualidade ao usar transporte escolar é (ruim/bom). \\
\hline$b$ & $\begin{array}{l}\text { Meus pais não contratariam um serviço de transporte escolar para mim, mesmo que } \\
\text { tivessem condições financeiras para isso. }\end{array}$ & $\begin{array}{l}\text { Minha família acha bom que eu contrate o serviço de transporte escolar para meu } \\
\text { (minha) filho(a). }\end{array}$ \\
\hline$e$ & $\begin{array}{l}\text { Considero o fato de meus pais decidirem por mim a contratação do serviço de } \\
\text { transporte escolar como (negativo/positivo). }\end{array}$ & $\begin{array}{l}\text { Considero o fato de minha família achar bom que eu contratasse do serviço de } \\
\text { transporte escolar para meu (minha) filho(a) como (negativo/positivo). }\end{array}$ \\
\hline$b$ & $\begin{array}{l}\text { Meus amigos me apoiariam se eu utilizasse transporte escolar para ir ou voltar da } \\
\text { escola. }\end{array}$ & Meus amigos acham que é bom para meu (minha) filho(a) usar transporte escolar. \\
\hline$e$ & $\begin{array}{l}\text { Considero o fato de meus amigos me apoiarem, se eu utilizar transporte escolar, } \\
\text { como (negativo/positivo). }\end{array}$ & $\begin{array}{l}\text { Considero o fato de minha família acharem bom para meu (minha) filho(a) usar } \\
\text { transporte escolar como (negativo/positivo). }\end{array}$ \\
\hline $\begin{array}{l}b \\
e\end{array}$ & $\begin{array}{l}\text { É perigoso ficar esperando pelo transporte escolar. } \\
\text { Devo cuidar pela minha integridade física ao esperar pelo transporte escolar. }\end{array}$ & \\
\hline$b$ & Usar transporte escolar é caro. & É caro para mim contratar o serviço de transporte escolar para meu(minha) filho (a). \\
\hline$e$ & Devo considerar o preço do serviço para contratar o transporte escolar. & $\begin{array}{l}\text { Eu deveria considerar o preço do serviço para contratar o serviço de transporte } \\
\text { escolar (dificilmente/provavelmente). }\end{array}$ \\
\hline$b$ & Existe transporte escolar para o bairro onde moro. & Existe transporte escolar para o bairro onde moramos. \\
\hline$e$ & $\begin{array}{l}\text { Se eu optasse por utilizar transporte escola para ir ou voltar da escola, acharia um } \\
\text { serviço disponível no meu bairro. }\end{array}$ & $\begin{array}{l}\text { Se eu optasse em contratar transporte escola para meu(minha) filho(a) ir ou voltar } \\
\text { da escola, acharia um serviço disponível no meu bairro } \\
\text { (dificilmente/provavelmente). }\end{array}$ \\
\hline $\begin{array}{l}b \\
e\end{array}$ & & $\begin{array}{l}\text { É preciso ter profissionais qualificados para eu contratar o transporte escolar. } \\
\text { Deveria verificar se existem profissionais qualificados para contratar o serviço de } \\
\text { transporte escolar (dificilmente/provavelmente). }\end{array}$ \\
\hline
\end{tabular}


APÊNDICE L: Elenco de crenças para os modos de transporte considerados viáveis na opinião dos alunos e pais/responsáveis (parte 4/7)

$$
\text { Opinião dos alunos }
$$

Opinião dos pais/responsáveis

\section{Modo automóvel transportando apenas um estudante - Automóvel da Família}

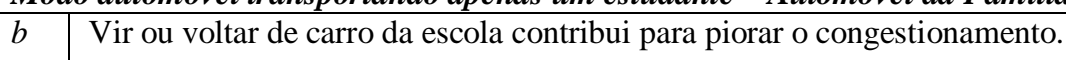

e Preocupar-se com os congestionamentos ao usar carro para ir/voltar da escola é (ruim/bom)

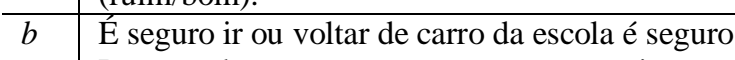

$e \quad$ Prezar pela segurança ao usar carro para ir ou voltar da escola é (ruim/bom).

$b$ Quem vai para a escola de carro não costuma chegar no horário certo.

$e \quad$ Prezar pela pontualidade ao usar carro para ir ou voltar da escola é (ruim/bom).

\begin{tabular}{l|l}
\hline$b$ & Meus pais preferem me trazer de carro para a escola.
\end{tabular}

e Considero o fato de meus pais preferirem me trazer de carro para a escola como (negativo/positivo)

\begin{tabular}{ll}
\hline$b$ & Meus amigos me apoiariam se eu utilizasse carro para ir ou voltar da escola.
\end{tabular}

$e \quad$ Considero o fato de meus amigos me apoiarem a usar automóvel da família para ir/voltar da escola como (negativo/positivo)

\begin{tabular}{l|l}
$b$ & Ir ou voltar da escola de carro é caro.
\end{tabular}

$e \quad$ Devo considerar o custo de usar carro para decidir ir/voltar da escola de carro.

$b$ Quem volta da escola com os pais fica impedido de fazer outras atividades depois da escola.

$e \quad$ Eu não faria nada depois da aula se voltasse da escola de carro com meus pais

$e$

$e$
Quando meu (minha) filho(a) usa automóvel da família para ir ou voltar da escola, ele está contribuindo para piorar o trânsito perto da escola.

Preocupar-me com o trânsito perto da escola é (ruim/bom).

Meu (minha) filho (a) estará seguro no automóvel da família.

Prezar pela segurança ao usar carro para ir/voltar da escola é(ruim/bom).

Minha família incentiva que meu(minha) filho(a) seja transportado(a) no automóvel da família

Considero o fato de minha família incentivar que meu(minha) filho(a) vá ou volte da escola no automóvel da família como (negativo/positivo).

Meus amigos incentivam que meu (minha) filho(a) seja transportado no automóvel da família para ir ou voltar da escola

Considero o fato de meus amigos incentivarem que meu(minha) filho(a) vá ou volte da escola no automóvel da família como (negativo/positivo).

É vantajoso transportar meu(minha) filho(a) de carro para ir ou voltar da escola.

Preocupar-me com as vantagens/desvantagens de usar automóvel da família para ir/ voltar da escola é (ruim/bom).

Os compromissos diários da família não permitem que meu(minha) filho(a) seja levado/trazido da escola de carro.

Deveria considerar a compatibilidade de horários para que meu(minha) filho(a) seja levado/trazido da escola de carro (dificilmente/provavelmente).

As condições do trânsito impedem que meu(minha) filho(a) seja transportado(a) no automóvel da família para ir ou voltar da escola

Deveria considerar as condições de trânsito que meu(minha) filho(a) seja levado/trazido da escola de carro (dificilmente/provavelmente).

Meu (minha) filho(a) é transportado no automóvel da família para ir ou voltar da escola porque é caminho para o motorista

Deveria considerar o trajeto do motorista $\mathrm{p} /$ que meu(minha) filho(a) seja levado/trazido da escola no automóvel da família (dificilmente/provavelmente).

Obs.: b - afirmativa sobre o valor da crença; e - afirmativa referente à força da crença; 
APÊNDICE L: Elenco de crenças para os modos de transporte considerados viáveis na opinião dos alunos e pais/responsáveis (parte 5/7) Opinião dos alunos Opinião dos pais/responsáveis

\begin{tabular}{|c|c|c|}
\hline \multicolumn{2}{|r|}{ Opinião dos alunos } & \multirow[t]{2}{*}{ Opinião dos pais/responsáveis } \\
\hline Mc & o metrô & \\
\hline $\begin{array}{l}b \\
e\end{array}$ & $\begin{array}{l}\text { O metrô é um modo de transporte vantajoso para quem tem o passe estudantil. } \\
\text { Ter passe estudantil para usar o metrô é (ruim/bom). }\end{array}$ & \\
\hline $\begin{array}{l}b \\
e\end{array}$ & $\begin{array}{l}\text { É confortável usar o metrô, mesmo quando se viaja em pé. } \\
\text { Prezar pelo conforto ao usar o metrô é (ruim/bom). }\end{array}$ & $\begin{array}{l}\text { O metro está lotado nos horários que meu (minha) filho (a) vai/volta da escola. } \\
\text { Deveríamos nos preocupar com a lotação do metrô para ir ou voltar da escola } \\
\text { (dificilmente/provavelmente). }\end{array}$ \\
\hline $\begin{array}{l}b \\
e\end{array}$ & $\begin{array}{l}\text { A viagem dentro do metrô não é segura. } \\
\text { Prezar pela segurança ao usar o metrô é (ruim/bom). }\end{array}$ & $\begin{array}{l}\text { É seguro usar metrô para ir ou voltar da escola. } \\
\text { Prezar pela segurança ao usar o metrô é (ruim/bom). }\end{array}$ \\
\hline $\begin{array}{l}b \\
e\end{array}$ & $\begin{array}{l}\text { Quem vai para a escola de metrô, chega no horário certo. } \\
\text { Prezar pela pontualidade ao usar o metrô é (ruim/bom). }\end{array}$ & $\begin{array}{l}\text { Meu (minha) filho(a) chega mais rápido à escola de metrô. } \\
\text { Preocupar-me com o tempo de viagem para ir de metrô à escola é (ruim/bom). }\end{array}$ \\
\hline $\begin{array}{l}b \\
e\end{array}$ & $\begin{array}{l}\text { Meus pais me incentivam a vir ou voltar da escola de metrô. } \\
\text { Considero o fato de meus pais me incentivarem a vir ou voltar da escola de metrô como } \\
\text { (negativo/positivo). }\end{array}$ & $\begin{array}{l}\text { A família incentiva que meu (minha) filho(a) use metrô para ir ou voltar da escola. } \\
\text { Considero o fato de minha família incentivar que meu (minha) filho(a) use metrô para } \\
\text { ir ou voltar da escola como (negativo/positivo). }\end{array}$ \\
\hline$b$ & $\begin{array}{l}\text { Meus amigos me apoiariam se utilizasse metrô para ir ou voltar da escola. } \\
\text { Considero o fato de meus amigos me apoiarem a usar metrô para ir/voltar da escola } \\
\text { como (negativo/positivo). }\end{array}$ & $\begin{array}{l}\text { Meus amigos acham uma boa ideia meu (minha) filho(a) usar metrô para ir ou voltat } \\
\text { da escola. } \\
\text { Considero o fato de meus amigos acharem uma boa ideia meu (minha) filho(a) usat } \\
\text { metrô para ir ou voltar da escola como (negativo/positivo). }\end{array}$ \\
\hline $\begin{array}{l}b \\
e\end{array}$ & $\begin{array}{l}\text { O trecho a pé entre a escola e a estação do metrô é perigoso. } \\
\text { Acho que posso ser agredido no trecho entre a escola e a estação de metrô. }\end{array}$ & $\begin{array}{l}\text { Meu (minha) filho(a) pode ser assaltado no trecho a pé entre a escola e a estação. } \\
\text { Deveríamos nos preocupar com a segurança no trecho entre a escola e o metrô } \\
\text { (dificilmente/provavelmente). }\end{array}$ \\
\hline $\begin{array}{l}b \\
e\end{array}$ & $\begin{array}{l}\text { O trecho a pé ente a estação do metrô e a minha casa é perigoso. } \\
\text { Acho que posso ser agredido no trecho entre a estação de metrô e a minha casa. }\end{array}$ & $\begin{array}{l}\text { Meu (minha) filho(a) pode ser assaltado no trecho a pé entre a estação e a nossa casa. } \\
\text { Deveríamos nos preocupar com a segurança no trecho entre a estação do metrô e a } \\
\text { nossa casa (dificilmente/provavelmente). }\end{array}$ \\
\hline $\begin{array}{l}b \\
e\end{array}$ & $\begin{array}{l}\text { Não é seguro esperar pelo metrô nas estações. } \\
\text { Devo prezar pela segurança ao esperar pelo metrô nas estações. }\end{array}$ & $\begin{array}{l}\text { Não é seguro esperar pelo metrô nas estações nos horários de ida/volta da escola. } \\
\text { Deveríamos prezar pela segurança ao esperar pelo metrô nas estações } \\
\text { (dificilmente/provavelmente). }\end{array}$ \\
\hline $\begin{array}{l}b \\
e\end{array}$ & & $\begin{array}{l}\text { E fácil usar metrô para ir ou voltar da escola. } \\
\text { Preocupar-me com a facilidade do metrô para ir ou voltar da escola é (ruim/bom). }\end{array}$ \\
\hline $\begin{array}{l}b \\
e\end{array}$ & & $\begin{array}{l}\text { Usar metrô para ir ou voltar da escola é possível para quem mora perto das estações. } \\
\text { Deveríamos considerar a distância entre a estação e a nossa casa para usar o metrô } \\
\text { (dificilmente/provavelmente). }\end{array}$ \\
\hline
\end{tabular}


APÊNDICE L: Elenco de crenças para os modos de transporte considerados viáveis na opinião dos alunos e pais/responsáveis (parte 6/7) Opinião dos alunos

Opinião dos pais/responsáveis

\begin{tabular}{|c|c|c|}
\hline \multirow{2}{*}{\multicolumn{3}{|c|}{ Modo Ônibus (público) }} \\
\hline & & \\
\hline \multicolumn{3}{|c|}{\begin{tabular}{l|l}
$b$ & O ônibus é um modo vantajoso para quem tem o passe estudantil.
\end{tabular}} \\
\hline$b$ & Quem vai para a escola de ônibus não costuma chegar atrasado. & Ônibus não tem horário certo para passar. \\
\hline$e$ & Cuidar a pontualidade ao usar ônibus para ir para a escola é (ruim/bom). & Considerar os horários de ônibus para ir ou voltar da escola é (ruim/bom). \\
\hline $\begin{array}{l}b \\
e\end{array}$ & $\begin{array}{l}\text { A viagem dentro do ônibus não é segura. } \\
\text { Prezar pela segurança dentro do ônibus é (ruim/bom). }\end{array}$ & É seguro utilizar ônibus para ir ou voltar da escola. \\
\hline$b$ & O ônibus é superlotado para quem vai/volta da escola. & Não compensa usar ônibus para ir ou voltar da escola por causa da superlotação. \\
\hline$e$ & Preocupar-me com a lotação do ônibus para ir ou voltar da escola é (ruim/bom). & Considerar a lotação do ônibus para ir ou voltar da escola é (ruim/bom). \\
\hline$b$ & Os meus pais me incentivam a vir ou voltar da escola de ônibus. & $\begin{array}{l}\text { Nossa família apoiaria se meu (minha) filho (a) usasse ônibus para ir ou voltar da } \\
\text { escola. }\end{array}$ \\
\hline$e$ & $\begin{array}{l}\text { Considero o fato de meus pais me incentivarem a vir ou voltar da escola de ônibus } \\
\text { como(negativo/positivo). }\end{array}$ & $\begin{array}{l}\text { Considero o fato da minha família apoiar que meu(minha) filho(a) use ônibus para ir } \\
\text { ou voltar da escola como (negativo/positivo). }\end{array}$ \\
\hline$b$ & Meus amigos me apoiariam se eu viesse ou voltasse da escola de ônibus. & $\begin{array}{l}\text { Meus amigos apoiariam se meu (minha) filho (a) usasse ônibus para ir ou voltar da } \\
\text { escola. }\end{array}$ \\
\hline$e$ & $\begin{array}{l}\text { Considero o fato de meus me apoiarem a usar ônibus para ir/voltar da escola } \\
\text { como(negativo/positivo). }\end{array}$ & $\begin{array}{l}\text { Considero o fato de meus amigos apoiarem que meu(minha) filho(a) use ônibus para ir } \\
\text { ou voltar da escola como (negativo/positivo). }\end{array}$ \\
\hline$b$ & O trecho a pé entre a escola e a parada é perigoso. & O trecho a pé entre a escola e a parada é perigoso. \\
\hline$e$ & $\begin{array}{l}\text { Acho que posso ser agredido no trecho a pé entre a escola e a parada } \\
\text { (dificilmente/provavelmente). }\end{array}$ & $\begin{array}{l}\text { Acho que deveríamos nos preocupar com a segurança no trecho a pé entre a escola e a } \\
\text { parada (dificilmente/provavelmente). }\end{array}$ \\
\hline$b$ & O trecho a pé entre a parada e minha casa é perigoso. & O trecho a pé entre a parada e a nossa casa é perigoso. \\
\hline$e$ & $\begin{array}{l}\text { Acho que posso ser agredido no trecho entre a parada e a minha casa } \\
\text { (dificilmente/provavelmente). }\end{array}$ & $\begin{array}{l}\text { Acho que deveríamos nos preocupar com a segurança no trecho a pé entre a nossa casa } \\
\text { e a parada (dificilmente/provavelmente). }\end{array}$ \\
\hline$b$ & Não é seguro esperar pelo ônibus na parada. & É perigoso ficar esperando ônibus na parada. \\
\hline$e$ & $\begin{array}{l}\begin{array}{l}\text { Devo prezar pela segurança ao esperar pelo ônibus na parada } \\
\text { (dificilmente/provavelmente). }\end{array}\end{array}$ & $\begin{array}{l}\begin{array}{l}\text { Devo prezar pela segurança ao esperar pelo ônibus na parada } \\
\text { (dificilmente/provavelmente). }\end{array} \\
\text { (dilme }\end{array}$ \\
\hline$b$ & Existe uma linha de ônibus direta entre a minha casa e a escola. & \\
\hline$e$ & $\begin{array}{l}\text { Para mim, seria possível utilizar uma linha direta de ônibus para ir ou voltar da escola } \\
\text { (dificilmente/provavelmente). }\end{array}$ & \\
\hline $\begin{array}{l}b \\
e\end{array}$ & & $\begin{array}{l}\text { É mais simples usar ônibus para ir ou voltar da escola. } \\
\text { Deveríamos nos preocupar em descomplicar a viagem de ida ou volta da escola. }\end{array}$ \\
\hline$b$ & & Meu(minha) filho(a) chega mais rápido na escola de ônibus. \\
\hline$e$ & & Preocupar-se com o tempo de viagem para ir ou voltar da escola é (ruim/bom). \\
\hline
\end{tabular}


APÊNDICE L: Elenco de crenças para os modos de transporte considerados viáveis na opinião dos alunos e pais/responsáveis (parte 7/7) Opinião dos alunos

Opinião dos pais/responsáveis

\begin{tabular}{|c|c|c|}
\hline \multirow{2}{*}{\multicolumn{3}{|c|}{ Modo Bicicleta }} \\
\hline & & \\
\hline$b$ & Usar bicicleta para ir ou voltar da escola faz bem à saúde. & Usar bicicleta para ir/ voltar da escola faz bem à saúde. \\
\hline$e$ & Preocupar-me com o mais saudável ao usar bicicleta p/ ir/voltar da escola é (ruim/bom). & Preocupar-me c/ o mais saudável ao usar bicicleta p/ ir/voltar da escola é (ruim/bom). \\
\hline$b$ & Usar bicicleta para ir ou voltar da escola evita congestionamentos. & \\
\hline$e$ & $\begin{array}{l}\text { Preocupar-me com os congestionamentos ao usar bicicleta } \mathrm{p} / \text { ir/voltar da escola é } \\
\text { (ruim/bom). }\end{array}$ & \\
\hline$b$ & Usar bicicleta para ir ou voltar da escola diminui a poluição. & \\
\hline$e$ & Preocupar-me com a poluição ao usar bicicleta para ir ou voltar da escola é (ruim/bom). & \\
\hline$b$ & Meus pais me incentivam que eu use bicicleta para ir ou voltar da escola. & Nossa família apoiaria que meu (minha) filho (a) usasse bicicleta p/ ir/voltar da escola. \\
\hline$e$ & $\begin{array}{l}\text { Considero o fato de meus pais me incentivarem a vir ou voltar da escola de bicicleta } \\
\text { como (negativo/positivo). }\end{array}$ & $\begin{array}{l}\text { Considero o fato de minha família apoiar que meu (minha) filho (a) usasse bicicleta } \\
\text { para ir ou voltar da escola como (negativo/positivo). }\end{array}$ \\
\hline$b$ & Meus amigos me apoiariam se eu fosse ou voltasse da escola de bicicleta. & Meus amigos apoiariam se meu (minha) filho (a) usasse bicicleta p/ ir/voltar da escola. \\
\hline$e$ & $\begin{array}{l}\text { Considero o fato de meus amigos me apoiarem no uso da bicicleta para a ir/voltar da } \\
\text { escola como (negativo/positivo). }\end{array}$ & $\begin{array}{l}\text { Considero o fato de meus amigos apoiarem que meu (minha) filho (a) use bicicleta para } \\
\text { ir ou voltar da escola como (negativo/positivo). }\end{array}$ \\
\hline$b$ & Moro muito longe da escola para usar bicicleta. & Moro muito longe da escola para usar bicicleta. \\
\hline$e$ & $\begin{array}{l}\text { Considero a distância a percorrer antes de decidir usar bicicleta para ir ou voltar da } \\
\text { escola (dificilmente/provavelmente). }\end{array}$ & $\begin{array}{l}\text { Considero a distância a percorrer antes de decidir usar bicicleta para ir ou voltar da } \\
\text { escola (dificilmente/provavelmente). }\end{array}$ \\
\hline $\begin{array}{l}b \\
e\end{array}$ & $\begin{array}{l}\text { Quando tenho vontade, posso usar bicicleta para ir ou voltar da escola. } \\
\text { Eu poderia usar bicicleta para ir ou voltar da escola (dificilmente/provavelmente). }\end{array}$ & \\
\hline$b$ & A condição do trecho entre minha casa e a escola não favorece o uso da bicicleta. & A condição do trecho entre a escola e a nossa casa não favorece o uso da bicicleta. \\
\hline$e$ & $\begin{array}{l}\text { Devo considerar a condição entre minha casa e a escola para usar bicicleta } \\
\text { (dificilmente/provavelmente). }\end{array}$ & $\begin{array}{l}\text { Acho que deveríamos nos preocupar com a condição do trecho entre a escola e a nossa } \\
\text { casa para usar bicicleta para ir ou voltar da escola (dificilmente/provavelmente). }\end{array}$ \\
\hline$b$ & & Meu (minha) filho(a) é respeitado(a) como ciclista no trajeto entre nossa casa e a escola. \\
\hline$e$ & & $\begin{array}{l}\text { Preocupar-me com o respeito para com o ciclista no trajeto para ir ou voltar da escola } \\
\text { é (ruim/bom). }\end{array}$ \\
\hline$b$ & & Usar bicicleta para ir ou voltar da escola é possível para quem mora perto da escola. \\
\hline$e$ & & Considerar a distância ao usar a bicicleta para ir/voltar da escola é (ruim/bom). \\
\hline$b$ & & Meu(minha) filho(a) pode ser assaltado (a) se usar bicicleta para ir ou voltar da escola. \\
\hline$e$ & & $\begin{array}{l}\text { Acho que deveríamos nos preocupar com assaltos no trajeto de bicicleta para ir ou } \\
\text { voltar da escola (dificilmente/provavelmente). }\end{array}$ \\
\hline$b$ & & $\begin{array}{l}\text { Meu(minha) filho(a) pode se envolver em acidentes de trânsito se usar bicicleta p/ } \\
\text { ir/voltar da escola. }\end{array}$ \\
\hline$e$ & & $\begin{array}{l}\text { Acho que deveríamos nos preocupar com acidentes de trânsito para usar bicicleta para } \\
\text { ir ou voltar da escola (dificilmente/provavelmente) }\end{array}$ \\
\hline & & \\
\hline
\end{tabular}


APÊNDICE M - Notas sobre a Densidade Demográfica 
APÊNDICE M - Notas sobre a Densidade Demográfica

A densidade demográfica, ou populacional é uma medida relativa, de comparação de áreas urbanas. Ela aumenta com: i) diminuição do tamanho dos lotes; aumento do número de unidades habitacionais por lote e verticalização de ocupação; diminuição do espaço público (Distrito Federal, 2008). As maiores densidades populacionais estão relacionadas a áreas urbanas consolidadas e boa oferta de serviços públicos. Para o DF, a densidade na área central se aproxima à densidade das cidades americanas, enquanto as localidades periféricas se aproximam da média nacional. A tabela abaixo apresenta os dados de densidade demográfica de algumas áreas urbanas para comparação com os dados da pesquisa, para o ano base de 2000 .

Tabela M1: Densidades Demográfica no Brasil, DF e localidades do DF

\begin{tabular}{|c|c|}
\hline \multicolumn{2}{|c|}{ Brasil - 22,43 hab/km² } \\
\hline \multicolumn{2}{|c|}{ Distrito Federal - 444,07 hab/km². } \\
\hline Localidades no $D F$ & Densidade $\left(\mathrm{hab} / \mathrm{km}^{2}\right)$ \\
\hline Cruzeiro & 7106,00 \\
\hline Guará & 2527,04 \\
\hline Candangolândia & 2354,51 \\
\hline Núcleo Bandeirante & 1854,53 \\
\hline Samambaia & 1550,61 \\
\hline Ceilândia & 1483,18 \\
\hline Recanto das Emas & 919,35 \\
\hline Riacho Fundo & 759,28 \\
\hline Lago Norte & 513,21 \\
\hline Taguatinga & 472,91 \\
\hline Santa Maria & 467,11 \\
\hline Sobradinho & 442,67 \\
\hline Brasília & 419,47 \\
\hline Gama & 226,19 \\
\hline São Sebastião & 167,86 \\
\hline Lago Sul & 147,9 \\
\hline Brazlândia & 111,16 \\
\hline Planaltina & 95,7 \\
\hline Paranoá & 64,44 \\
\hline
\end{tabular}

Fontes: Nunes e Costa (2007); Distrito Federal (2008); IBGE (2010). 
APÊNDICE N - Estatísticas descritivas e testes de normalidade para variáveis participantes das etapas de modelagem na IEM PU1 
APENDICE N1 - Estatísticas descritivas e testes de normalidade univariada - IEM PU 1 - tratamento T2 - amostra alunos geral

\begin{tabular}{|c|c|c|c|c|c|c|c|c|c|c|c|c|c|c|c|c|c|c|c|c|c|c|}
\hline & & & & & & & & & & TES & EZCUR & & TESTE Z & ASSIM & & $\begin{array}{l}\text { TE SHAI } \\
\text { WILK }\end{array}$ & & $\begin{array}{r}\mathrm{T} \\
\text { KOLM } \\
\text { SM }\end{array}$ & $\begin{array}{l}\text { TE } \\
\text { GOROV } \\
\text { NOV }\end{array}$ & & TESTE LE & ENE \\
\hline & & & & STATÍST & CAS DES & CRITIV & & & & & raiz $(24 / n)$ & & ass/rai & (6/n) & & $\begin{array}{l}\text { VAR SE } \\
\text { TR NOR } \\
\end{array}$ & & $\begin{array}{l}\mathrm{H} 0=\mathrm{V}, \\
\mathrm{DISTR}\end{array}$ & $\begin{array}{l}\text { SEGUE } \\
\text { ORMAL }\end{array}$ & & $\begin{array}{r}\mathrm{h} 0=\mathrm{NT} \\
\text { DIFEREN }\end{array}$ & \\
\hline VARIÁVEL & $\begin{array}{l}\overleftrightarrow{\Xi} \\
\text { 至 }\end{array}$ & 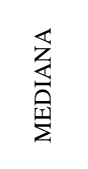 & $\begin{array}{l}\text { Oิ } \\
\stackrel{0}{\Sigma}\end{array}$ & 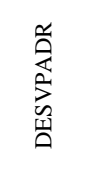 & 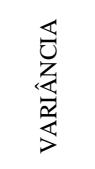 & $\sum_{i}^{\stackrel{O}{Z}}$ & $\sum_{\substack{x\\
}}^{0}$ & 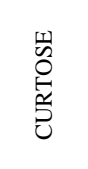 & 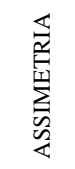 & 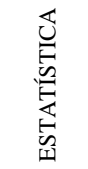 & 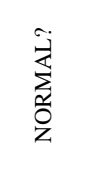 & 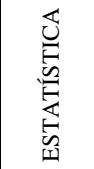 & 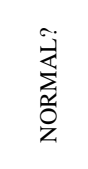 & 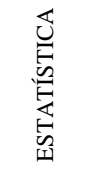 & $=$ & $\begin{array}{l}\dot{\vec{z}} \\
\dot{z} \\
\dot{z}\end{array}$ & 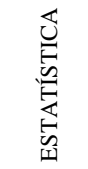 & $=$ & $\begin{array}{l}\hat{j} \\
\sum_{0} \\
\stackrel{z}{z}\end{array}$ & 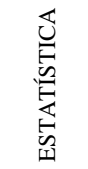 & 2 & 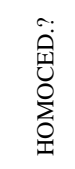 \\
\hline$n=851$ & & & & & & & & & & $\begin{array}{c}z \\
\text { crítico } \\
\end{array}$ & $<1,96$ & $\begin{array}{c}z \\
\text { crítico } \\
\end{array}$ & $<1,96$ & $\begin{array}{c}P \\
\text { crítico } \\
\end{array}$ & $>0,05$ & & $\begin{array}{c}P \\
\text { crítico } \\
\end{array}$ & $>0,05$ & & $\begin{array}{c}P \\
\text { crítico } \\
\end{array}$ & $>0,05$ & \\
\hline & & & & & & & & & & raiz & 0,168 & raiz & 0,084 & & & & & & & & & \\
\hline GENERO & 0,55 & 1,00 & 1,00 & 0,50 & 0,25 & 0,00 & 1,00 & $-1,96$ & $-0,21$ & $-11,67$ & NÃO & $-2,51$ & NÃO & 0,633 & 0,000 & NÃO & 0,37 & 0,000 & NÃO & 21,97 & 0,000 & NÃO \\
\hline IDADE & 15,43 & 15,00 & 15,00 & 0,96 & 0,91 & 5,00 & 19,00 & 16,22 & $-1,09$ & 96,61 & NÃO & $-12,94$ & NÃO & 0,823 & 0,000 & NÃO & 0,25 & 0,000 & NÃO & 0,54 & 0,775 & SIM \\
\hline DISTÂNCIA & $\begin{array}{c}14912, \\
56\end{array}$ & $\begin{array}{c}14926 \\
05\end{array}$ & $\begin{array}{c}14926 \\
05\end{array}$ & $\begin{array}{c}9649,5 \\
7\end{array}$ & $\begin{array}{c}931142 \\
11,58\end{array}$ & 12,41 & $\begin{array}{c}63743 \\
04\end{array}$ & 1,06 & 0,71 & 6,28 & NÃO & 8,49 & NÃO & 0,948 & 0,000 & NÃO & 0,10 & 0,000 & NÃO & 1,91 & 0,076 & SIM \\
\hline RENDA & $\begin{array}{c}5776,1 \\
8\end{array}$ & $\begin{array}{c}5241,8 \\
1\end{array}$ & $\begin{array}{c}5766,5 \\
9\end{array}$ & $\begin{array}{c}5086,7 \\
5\end{array}$ & $\begin{array}{c}258750 \\
04,01\end{array}$ & 0,00 & $\begin{array}{c}43484 \\
82\end{array}$ & 8,82 & 2,35 & 52,54 & NÃO & 28,03 & NÃO & 0,790 & 0,000 & NÃO & 0,16 & 0,000 & NÃO & 2,95 & 0,007 & NÃO \\
\hline DENSIDADE & $\begin{array}{c}11989, \\
94\end{array}$ & $\begin{array}{c}11995, \\
61 \\
\end{array}$ & $\begin{array}{c}11995, \\
61 \\
\end{array}$ & $\begin{array}{c}13710, \\
83\end{array}$ & $\begin{array}{r}187986 \\
949,98 \\
\end{array}$ & 12,41 & $\begin{array}{c}180063 \\
, 68 \\
\end{array}$ & 46,60 & 5,39 & 277,50 & NÃO & 64,16 & NÃO & 0,602 & 0,000 & NÃO & 0,20 & 0,000 & NÃO & 2,82 & 0,010 & NÃO \\
\hline DISPAUTO & 0,86 & 1,00 & 1,00 & 0,35 & 0,12 & 0,00 & 1,00 & 2,28 & $-2,07$ & 13,55 & NÃO & $-24,61$ & NÃO & 0,413 & 0,000 & NÃO & 0,52 & 0,000 & NÃO & 13,12 & 0,000 & NÃO \\
\hline MODOIDA & 5,12 & 5,00 & 5,00 & 1,90 & 3,60 & 1,00 & 9,00 & 1,13 & 0,28 & 6,75 & NÃO & 3,31 & NÃO & 0,773 & 0,000 & NÃO & 0,33 & 0,000 & NÃO & Dep. & Dep & DeP. \\
\hline MODOVOLTA & 5,25 & 5,00 & 5,00 & 2,15 & 4,62 & 0,00 & 9,00 & 0,27 & 0,18 & 1,63 & SIM & 2,11 & NÃO & 0,823 & 0,000 & NÃO & 0,30 & 0,000 & NÃO & $\mathrm{a}$ & $\mathrm{a}$ & $\mathrm{a}$ \\
\hline HABON & 0,17 & 0,11 & 0,00 & 0,20 & 0,04 & 0,00 & 1,00 & 2,84 & 1,58 & 16,90 & NÃO & 18,76 & NÃO & 0,802 & 0,000 & NÃO & 0,20 & 0,000 & NÃO & 7,82 & 0,000 & NÃO \\
\hline HABAP & 0,34 & 0,33 & 0,33 & 0,20 & 0,04 & 0,00 & 1,00 & $-0,27$ & 0,13 & $-1,62$ & SIM & 1,57 & SIM & 0,965 & 0,000 & NÃO & 0,11 & 0,000 & NÃO & 1,76 & 0,105 & SIM \\
\hline HABAC & 0,04 & 0,00 & 0,00 & 0,09 & 0,01 & 0,00 & 1,00 & 28,22 & 4,16 & 168,03 & NÃO & 49,52 & NÃO & 0,488 & 0,000 & NÃO & 0,41 & 0,000 & NÃO & 4,39 & 0,000 & NÃO \\
\hline НАВBC & 0,06 & 0,00 & 0,00 & 0,12 & 0,01 & 0,00 & 1,00 & 10,43 & 2,72 & 62,08 & NÃO & 32,37 & NÃO & 0,615 & 0,000 & NÃO & 0,35 & 0,000 & NÃO & 1,70 & 0,117 & SIM \\
\hline HABAF & 0,32 & 0,25 & 0,00 & 0,27 & 0,07 & 0,00 & 1,00 & 0,04 & 0,83 & 0,25 & SIM & 9,90 & NÃO & 0,908 & 0,000 & NÃO & 0,13 & 0,000 & NÃO & 7,30 & 0,000 & NÃO \\
\hline HABVF & 0,01 & 0,00 & 0,00 & 0,06 & 0,00 & 0,00 & 1,00 & 163,11 & 11,67 & 971,24 & NÃO & 138,94 & NÃO & 0,125 & 0,000 & NÃO & 0,49 & 0,000 & NÃO & 1,66 & 0,129 & SIM \\
\hline HABMT & 0,06 & 0,00 & 0,00 & 0,12 & 0,01 & 0,00 & 1,00 & 11,48 & 2,94 & 68,36 & NÃO & 35,02 & NÃO & 0,560 & 0,000 & NÃO & 0,39 & 0,000 & NÃO & 40,32 & 0,000 & NÃO \\
\hline
\end{tabular}




\begin{tabular}{|c|c|c|c|c|c|c|c|c|c|c|c|c|c|c|c|c|c|c|c|c|c|c|}
\hline & & & & & & & & & & \multirow{2}{*}{\multicolumn{2}{|c|}{$\frac{\text { TESTE Z CURT }}{\text { curt/raiz(24/n) }}$}} & \multirow{2}{*}{\multicolumn{2}{|c|}{\begin{tabular}{|c} 
TESTE Z ASSIM \\
ass/raiz(6/n)
\end{tabular}}} & \multicolumn{3}{|c|}{ TESTE SHAPIRO-WILK } & \multicolumn{3}{|c|}{ TESTE KOLMOGOROV SMIRNOV } & \multicolumn{3}{|c|}{ TESTE LEVENE } \\
\hline & \multicolumn{9}{|c|}{ ESTATÍSTICAS DESCRITIVAS } & & & & & $\mathrm{H} 0=\mathrm{V} f$ & SEGUE & R. NORMAL & $\mathrm{H} 0=\mathrm{VAR}$ & GUE DI & NORMAL & $\mathrm{h} 0=\mathrm{N} \mathrm{Tl}$ & 4 DIFEF & NÇAS \\
\hline VARIÁVEL & 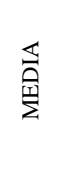 & 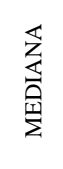 & $\frac{\circ}{\overbrace{\Sigma}^{\circ}}$ & 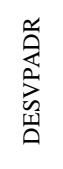 & 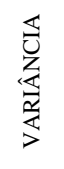 & 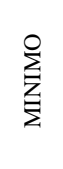 & 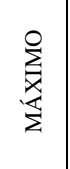 & 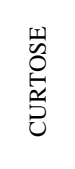 & 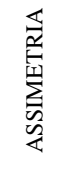 & 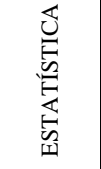 & 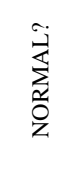 & 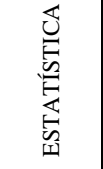 & 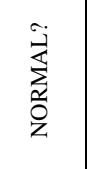 & 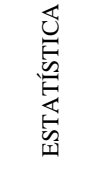 & $=$ & 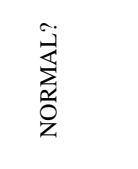 & 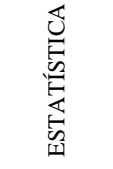 & $=$ & 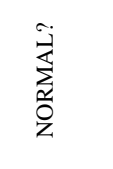 & 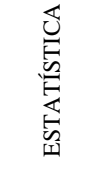 & 2 & 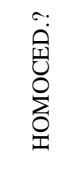 \\
\hline$n=851$ & & & & & & & & & & zcrítico & $<1,96$ & z crítico & $<1,96$ & $\begin{array}{c}P \\
\text { crítico }\end{array}$ & $>0,05$ & & P crítico & $>0,05$ & & P crítico & $>0,05$ & \\
\hline & & & & & & & & & & raiz & 0,168 & raiz & 0,084 & & & & & & & & & \\
\hline CPAP & 2,16 & 1,00 & 1,00 & 1,53 & 2,35 & 1,00 & 5,00 & $-0,86$ & 0,88 & $-5,13$ & NÃO & 10,44 & NÃO & 0,722 & 0,000 & NÃO & 0,35 & 0,000 & NÃO & 7,54 & 0,000 & NÃO \\
\hline CPON & 3,61 & 4,00 & 5,00 & 1,48 & 2,19 & 1,00 & 5,00 & $-0,99$ & 0,67 & $-5,89$ & NÃO & $-8,02$ & NÃO & 0,810 & 0,000 & NÃO & 0,23 & 0,000 & NÃO & 14,83 & 0,000 & NÃO \\
\hline CPAF & 2,74 & 3,00 & 3,00 & 1,23 & 1,52 & 1,00 & 5,00 & $-0,73$ & 0,27 & $-4,37$ & NÃO & 3,22 & NÃO & 0,904 & 0,000 & NÃO & 0,18 & 0,000 & NÃO & 0,81 & 0,559 & SIM \\
\hline CPAC & 1,65 & 1,00 & 1,00 & 0,89 & 0,78 & 1,00 & 5,00 & 1,32 & 1,35 & 7,83 & NÃO & 16,05 & NÃO & 0,735 & 0,000 & NÃO & 0,33 & 0,000 & NÃO & 4,45 & 0,000 & NÃO \\
\hline CPBC & 1,23 & 1,00 & 1,00 & 0,69 & 0,47 & 1,00 & 5,00 & 12,35 & 3,47 & 73,52 & NÃO & 41,29 & NÃO & 0,385 & 0,000 & NÃO & 0,47 & 0,000 & NÃO & 6,69 & 0,000 & NÃO \\
\hline CPTE & 1,45 & 1,00 & 1,00 & 1,10 & 1,21 & 1,00 & 5,00 & 4,85 & 2,49 & 28,89 & NÃO & 29,71 & NÃO & 0,457 & 0,000 & NÃO & 0,46 & 0,000 & NÃO & 25,68 & 0,000 & NÃO \\
\hline CPMT & 1,97 & 1,00 & 1,00 & 1,46 & 2,12 & 1,00 & 5,00 & $-0,10$ & 1,21 & $-0,59$ & SIM & 14,45 & NÃO & 0,674 & 0,000 & NÃO & 0,36 & 0,000 & NÃO & 7,67 & 0,000 & NÃO \\
\hline MTDAT1 & 3,69 & 4,00 & 5,00 & 1,24 & 1,55 & 1,00 & 5,00 & $-0,62$ & 0,58 & $-2,16$ & NÃO & $-4,00$ & NÃO & 0,85 & 0,000 & NÃO & 0,22 & 0,000 & NÃO & 12,24 & 0,000 & NÃO \\
\hline MTDAT2 & 3,57 & 4,00 & 5,00 & 1,37 & 1,88 & 1,00 & 5,00 & $-0,75$ & 0,61 & $-2,60$ & NÃO & $-4,27$ & NÃO & 0,84 & 0,000 & NÃO & 0,20 & 0,000 & NÃO & 14,01 & 0,000 & NÃO \\
\hline MTDAT3 & 3,71 & 4,00 & 5,00 & 1,34 & 1,79 & 1,00 & 5,00 & $-0,67$ & 0,67 & $-2,35$ & NÃO & $-4,69$ & NÃO & 0,83 & 0,000 & NÃO & 0,25 & 0,000 & NÃO & 16,95 & 0,000 & NÃO \\
\hline MEDMTDAT & 3,66 & 3,83 & 5,00 & 1,13 & 1,28 & 1,00 & 5,00 & $-0,44$ & 0,59 & $-1,54$ & SIM & $-4,14$ & NÃO & 0,92 & 0,000 & NÃO & 0,12 & 0,000 & NÃO & Dep. & Dep. & \\
\hline MTDNS1 & 3,42 & 3,00 & 3,00 & 1,14 & 1,29 & 1,00 & 5,00 & $-0,23$ & 0,45 & $-0,81$ & SIM & $-3,13$ & NÃO & 0,89 & 0,000 & NÃO & 0,20 & 0,000 & NÃO & 2,31 & 0,006 & NÃO \\
\hline MTDNS2 & 3,45 & 3,00 & 3,00 & 1,18 & 1,39 & 1,00 & 5,00 & $-0,36$ & 0,46 & $-1,24$ & NÃO & $-3,23$ & NÃO & 0,88 & 0,000 & NÃO & 0,20 & 0,000 & NÃO & 1,46 & 0,134 & SIM \\
\hline MTDNS3 & 3,35 & 3,00 & 3,00 & 1,32 & 1,74 & 1,00 & 5,00 & $-0,89$ & 0,35 & $-3,10$ & NÃO & $-2,45$ & NÃO & 0,89 & 0,000 & NÃO & 0,16 & 0,000 & NÃO & 1,75 & 0,051 & SIM \\
\hline
\end{tabular}




\begin{tabular}{|c|c|c|c|c|c|c|c|c|c|c|c|c|c|c|c|c|c|c|c|c|c|c|}
\hline & & & & & & & & & & \multirow{2}{*}{\multicolumn{2}{|c|}{$\begin{array}{c}\text { TESTE Z CURT } \\
\text { curt/raiz(24/n) }\end{array}$}} & \multicolumn{2}{|c|}{$\begin{array}{l}\text { TESTE Z } \\
\text { ASSIM }\end{array}$} & \multicolumn{3}{|c|}{ TESTE SHAPIRO-WILK } & \multicolumn{3}{|c|}{$\begin{array}{l}\text { TESTE KOLMOGOROV } \\
\text { SMIRNOV }\end{array}$} & \multicolumn{3}{|c|}{ TESTE LEVENE } \\
\hline & \multicolumn{9}{|c|}{ ESTATÍSTICAS DESCRITIVAS } & & & \multicolumn{2}{|c|}{ ass/raiz(6/n) } & \multicolumn{3}{|c|}{$\begin{array}{c}\mathrm{H} 0=\text { VAR SEGUE DISTR. } \\
\text { NORMAL }\end{array}$} & \multicolumn{3}{|c|}{$\begin{array}{c}\mathrm{H} 0=\text { VAR SEGUE DISTR. } \\
\text { NORMAL }\end{array}$} & \multicolumn{3}{|c|}{$\mathrm{h} 0=\mathrm{N}$ TEM DIFERENÇAS } \\
\hline VARIÁVEL & 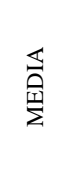 & 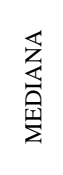 & $\begin{array}{l}0 \\
\stackrel{0}{\Sigma}\end{array}$ & 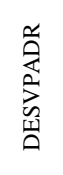 & 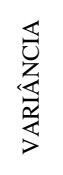 & 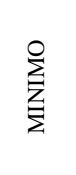 & 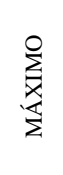 & 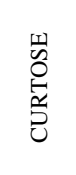 & 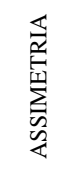 & 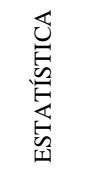 & 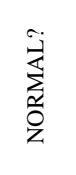 & 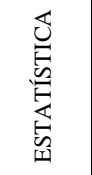 & 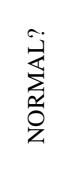 & 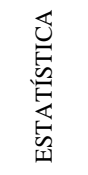 & 2 & 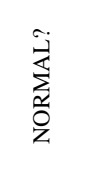 & 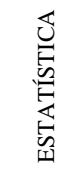 & $=$ & 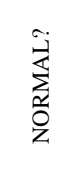 & 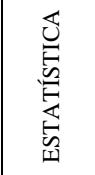 & a & 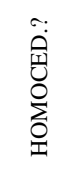 \\
\hline \multirow[t]{2}{*}{$n=851$} & & & & & & & & & & $\begin{array}{c}z \\
\text { crítico }\end{array}$ & $<1,96$ & $\begin{array}{c}z \\
\text { crítico } \\
\end{array}$ & $<1,96$ & $\begin{array}{c}P \\
\text { crítico }\end{array}$ & $>0,05$ & & $\begin{array}{c}P \\
\text { crítico }\end{array}$ & $>0,05$ & & $\begin{array}{c}P \\
\text { crítico }\end{array}$ & $>0,05$ & \\
\hline & & & & & & & & & & raiz & 0,168 & raiz & 0,084 & & & & & & & & & \\
\hline MEDMTDNS & 3,40 & 3,33 & 3,00 & 0,96 & 0,91 & 1,00 & 5,00 & 0,13 & $-0,45$ & 0,45 & NÃO & $-3,10$ & NÃO & 0,96 & 0,000 & NÃO & 0,14 & 0,000 & NÃO & 1,95 & 0,026 & NÃO \\
\hline MTDCP1 & 3,55 & 4,00 & 5,00 & 1,41 & 1,98 & 1,00 & 5,00 & $-0,92$ & $-0,55$ & $-3,20$ & NÃO & $-3,85$ & NÃO & 0,84 & 0,000 & NÃO & 0,22 & 0,000 & NÃO & 1,15 & 0,315 & SIM \\
\hline MTDCP2 & 3,33 & 3,00 & 5,00 & 1,53 & 2,33 & 1,00 & 5,00 & $-1,30$ & $-0,36$ & $-4,53$ & NÃO & $-2,47$ & NÃO & 0,84 & 0,000 & NÃO & 0,20 & 0,000 & NÃO & 3,75 & 0,000 & NÃO \\
\hline MTDCP3 & 3,59 & 4,00 & 5,00 & 1,46 & 2,14 & 1,00 & 5,00 & $-0,90$ & $-0,66$ & $-3,15$ & NÃO & $-4,59$ & NÃO & 0,81 & 0,000 & NÃO & 0,23 & 0,000 & NÃO & 3,99 & 0,000 & NÃO \\
\hline MEDMTDCP & 3,49 & 3,67 & 5,00 & 1,25 & 1,57 & 1,00 & 5,00 & $-0,74$ & $-0,53$ & $-2,59$ & NÃO & $-3,71$ & SIM & 0,91 & 0,000 & NÃO & 0,12 & 0,000 & NÃO & 2,48 & 0,003 & NÃO \\
\hline MTDIT1 & 3,47 & 4,00 & 3,00 & 1,26 & 1,59 & 1,00 & 5,00 & $-0,79$ & $-0,41$ & $-2,74$ & NÃO & $-2,87$ & NÃO & 0,89 & 0,000 & NÃO & 0,17 & 0,000 & NÃO & 1,93 & 0,027 & NÃO \\
\hline MTDIT2 & 3,51 & 3,00 & 5,00 & 1,38 & 1,91 & 1,00 & 5,00 & $-0,95$ & $-0,46$ & $-3,30$ & NÃO & $-3,18$ & NÃO & 0,85 & 0,000 & NÃO & 0,22 & 0,000 & NÃO & 6,32 & 0,000 & NÃO \\
\hline MTDIT3 & 3,18 & 3,00 & 5,00 & 1,59 & 2,54 & 1,00 & 5,00 & $-1,49$ & $-0,17$ & $-5,17$ & NÃO & $-1,21$ & SIM & 0,83 & 0,000 & NÃO & 0,21 & 0,000 & NÃO & 4,69 & 0,000 & NÃO \\
\hline MEDMTDIT & 3,39 & 3,33 & 5,00 & 1,20 & 1,44 & 1,00 & 5,00 & $-1,04$ & $-0,25$ & $-3,60$ & NÃO & $-1,75$ & SIM & 0,94 & 0,000 & NÃO & 0,11 & 0,000 & NÃO & 3,35 & 0,000 & NÃO \\
\hline СМТСвО1 & 0,00 & 0,07 & 1,07 & 1,14 & 1,29 & $-2,93$ & 1,07 & 0,19 & $-0,94$ & 0,64 & SIM & $-6,53$ & NÃO & 0,83 & 0,000 & NÃO & 0,23 & 0,000 & NÃO & 1,88 & 0,033 & NÃO \\
\hline CMTCBE1 & 0,00 & 0,88 & 0,88 & 1,25 & 1,56 & $-3,12$ & 0,88 & 0,40 & $-1,24$ & 1,39 & SIM & $-8,62$ & NÃO & 0,72 & 0,000 & NÃO & 0,35 & 0,000 & NÃO & 8,32 & 0,000 & NÃO \\
\hline СМТСВО1ХСМТВЕ1 & 0,51 & 0,11 & 0,94 & 1,74 & 3,03 & $-3,35$ & 9,13 & 10,36 & 2,37 & 36,02 & NÃO & 16,45 & NÃO & 0,73 & 0,000 & NÃO & 0,29 & 0,000 & NÃO & 6,37 & 0,000 & NÃO \\
\hline СМТСВO2 & 0,00 & 0,00 & 0,00 & 1,32 & 1,75 & $-2,00$ & 2,00 & $-1,05$ & $-0,12$ & $-3,63$ & NÃO & $-0,83$ & SIM & 0,90 & 0,000 & NÃO & 0,18 & 0,000 & NÃO & 2,10 & 0,014 & NÃO \\
\hline CMTCBE2 & 0,00 & 0,27 & 1,27 & 1,26 & 1,58 & $-2,73$ & 1,27 & $-0,51$ & $-0,69$ & $-1,76$ & SIM & $-4,79$ & NÃO & 0,85 & 0,000 & NÃO & 0,22 & 0,000 & NÃO & 2,31 & 0,006 & NÃO \\
\hline СМТСВО2ХСМТВЕ2 & 0,36 & 0,00 & 0,00 & 1,86 & 3,48 & $-5,48$ & 5,46 & 1,60 & 0,22 & 5,57 & NÃO & 1,53 & SIM & 0,93 & 0,000 & NÃO & 0,17 & 0,000 & NÃO & 5,08 & 0,000 & NÃO \\
\hline СМТСвО3 & 0,00 & $-0,31$ & $-1,31$ & 1,21 & 1,46 & $-1,31$ & 2,69 & $-0,40$ & 0,65 & $-1,40$ & SIM & 4,55 & NÃO & 0,86 & 0,000 & NÃO & 0,19 & 0,000 & NÃO & 0,74 & 0,719 & SIM \\
\hline CMTCBE3 & 0,00 & 0,09 & 1,09 & 1,22 & 1,48 & $-2,91$ & 1,09 & $-0,13$ & $-0,88$ & $-0,47$ & SIM & $-6,13$ & NÃO & 0,81 & 0,000 & NÃO & 0,27 & 0,000 & NÃO & 4,32 & 0,000 & NÃO \\
\hline СМТСВОЗХСМТВЕЗ & $-0,12$ & $-0,03$ & $-1,42$ & 1,51 & 2,28 & $-7,84$ & 3,82 & 4,85 & $-0,59$ & 16,85 & NÃO & $-4,07$ & NÃO & 0,90 & 0,000 & NÃO & 0,13 & 0,000 & NÃO & 1,71 & 0,059 & SIM \\
\hline
\end{tabular}




\begin{tabular}{|c|c|c|c|c|c|c|c|c|c|c|c|c|c|c|c|c|c|c|c|c|c|c|}
\hline & & & & & & & & & & \multirow{2}{*}{\multicolumn{2}{|c|}{\begin{tabular}{|c|} 
TESTE $Z$ CURTOSE \\
curt/raiz(24/n) \\
\end{tabular}}} & \multirow{2}{*}{\multicolumn{2}{|c|}{$\begin{array}{c}\text { TESTE Z ASSIMETRIA } \\
\text { ass/raiz( }(6 / \mathrm{n})\end{array}$}} & \multirow{2}{*}{\multicolumn{3}{|c|}{$\begin{array}{c}\text { TESTE SHAPIRO-WILK } \\
\text { H0= TEM DISTR.NORMAL } \\
\end{array}$}} & \multirow{2}{*}{\multicolumn{3}{|c|}{$\begin{array}{c}\text { TESTE KOLMOGOROV SMIRNOV } \\
\text { H0 } 0=\text { TEM DISTR. NORMAL }\end{array}$}} & \multicolumn{3}{|c|}{ TESTE LEVENE } \\
\hline & & & \multicolumn{7}{|c|}{ ESTATÍSTICAS DESCRITIVAS } & & & & & & & & & & & $\mathrm{h} 0=\mathrm{N} \tilde{\mathrm{A}}$ & OTEMD & IFER \\
\hline VARIÁVEL & 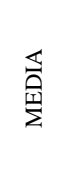 & 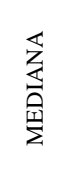 & $\begin{array}{l}\text { O } \\
\stackrel{0}{\Sigma}\end{array}$ & 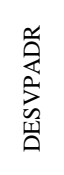 & 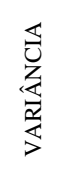 & 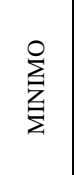 & $\sum_{\substack{x \\
\sum}}^{0}$ & $\begin{array}{l}\text { w } \\
0 \\
0 \\
0 \\
\tilde{0} \\
0\end{array}$ & 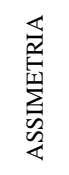 & 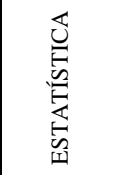 & $\begin{array}{l}\hat{j} \\
\sum_{z} \\
z \\
z\end{array}$ & 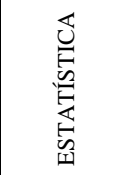 & 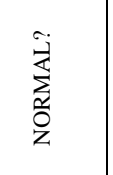 & 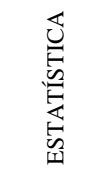 & $=$ & 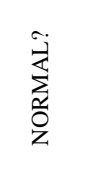 & 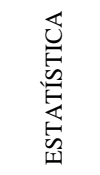 & $=$ & 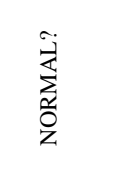 & 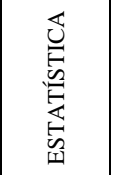 & a & 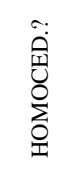 \\
\hline Variáveis com $n=290$ & & & & & & & & & & z crítico & $<1,96$ & z crítico & $<1,96$ & Pcrítico & $>0,05$ & & P crítico & $>0,05$ & & P crítico & $>0,05$ & \\
\hline & & & & & & & & & & raiz & 0,288 & raiz & 0,144 & & & & & & & & & \\
\hline СМТСвО4 & 0,00 & $-0,42$ & $-0,42$ & 1,09 & 1,19 & $-2,42$ & 1,58 & $-0,31$ & $-0,23$ & $-1,08$ & SIM & $-1,62$ & SIM & 0,88 & 0,000 & NÃO & 0,23 & 0,000 & NÃO & 2,06 & 0,017 & NÃO \\
\hline CMTCBE4 & 0,00 & 0,24 & 1,24 & 1,25 & 1,56 & $-2,76$ & 1,24 & $-0,43$ & $-0,69$ & $-1,50$ & SIM & $-4,83$ & NÃO & 0,83 & 0,000 & NÃO & 0,24 & 0,000 & NÃO & 2,35 & 0,006 & NÃO \\
\hline СМТСВО4ХСМТВЕ4 & 0,46 & 0,32 & 0,32 & 1,61 & 2,60 & $-4,37$ & 6,68 & 5,47 & 1,08 & 19,03 & NÃO & 7,48 & NÃO & 0,84 & 0,000 & NÃO & 0,18 & 0,000 & NÃO & 3,27 & 0,000 & NÃO \\
\hline CMTCNO1 & 0,00 & $-0,33$ & $-0,33$ & 1,19 & 1,42 & $-2,33$ & 1,67 & $-0,57$ & $-0,30$ & $-1,97$ & SIM & $-2,12$ & NÃO & 0,90 & 0,000 & NÃO & 0,19 & 0,000 & NÃO & 1,48 & 0,123 & SIM \\
\hline CMTCNE1 & 0,00 & $-0,43$ & $-0,43$ & 1,33 & 1,76 & $-2,43$ & 1,57 & $-0,83$ & $-0,42$ & $-2,87$ & NÃO & $-2,90$ & NÃO & 0,87 & 0,000 & NÃO & 0,17 & 0,000 & NÃO & 2,34 & 0,006 & NÃO \\
\hline CMTNO1XCMTNE1 & 0,79 & 0,38 & 0,14 & 1,78 & 3,17 & $-4,08$ & 5,66 & 1,91 & 0,57 & 6,63 & NÃO & 3,98 & NÃO & 0,89 & 0,000 & NÃO & 0,21 & 0,000 & NÃO & 3,90 & 0,000 & NÃO \\
\hline CMTCNO2 & 0,00 & $-0,53$ & $\mid-0,53$ & 1,10 & 1,20 & $-2,53$ & 1,47 & $-0,03$ & $-0,47$ & $-0,11$ & SIM & $-3,27$ & NÃO & 0,87 & 0,000 & NÃO & 0,21 & 0,000 & NÃO & 2,48 & 0,003 & NÃO \\
\hline CMTCNE2 & 0,00 & $-0,49$ & $-0,49$ & 1,26 & 1,59 & $-2,49$ & 1,51 & $-0,63$ & $-0,46$ & $-2,20$ & NÃO & $-3,22$ & NÃO & 0,87 & 0,000 & NÃO & 0,18 & 0,000 & NÃO & 2,10 & 0,014 & NÃO \\
\hline CMTNO2XCMTNE2 & 0,56 & 0,26 & 0,26 & 1,71 & 2,92 & $-3,81$ & 6,31 & 3,49 & 0,72 & 12,12 & NÃO & 5,03 & NÃO & 0,85 & 0,000 & NÃO & 0,22 & 0,000 & NÃO & 7,69 & 0,000 & NÃO \\
\hline CMTCCO1 & 0,00 & $-0,01$ & $-0,51$ & 1,22 & 1,48 & $-2,51$ & 1,49 & $-0,59$ & $-0,44$ & $-2,06$ & NÃO & $-3,07$ & NÃO & 0,88 & 0,000 & NÃO & 0,17 & 0,000 & NÃO & 1,61 & 0,082 & SIM \\
\hline CMTCCE1 & 0,00 & $-0,01$ & $-0,01$ & 1,45 & 2,11 & $-2,01$ & 1,99 & $-1,28$ & $-0,05$ & $-4,43$ & NÃO & $-0,36$ & SIM & 0,87 & 0,000 & NÃO & 0,15 & 0,000 & NÃO & 3,48 & 0,000 & NÃO \\
\hline СMTCCO1ХCMTCCE1 & 0,55 & 0,02 & 2,96 & 1,80 & 3,25 & $-4,99$ & 5,05 & 0,92 & 0,21 & 3,21 & NÃO & 1,45 & SIM & 0,94 & 0,000 & NÃO & 0,14 & 0,000 & NÃO & 2,47 & 0,003 & NÃO \\
\hline CMTCCO2 & 0,00 & $-0,15$ & $-0,15$ & 1,31 & 1,71 & $-2,15$ & 1,85 & $-0,95$ & $-0,11$ & $-3,30$ & NÃO & $-0,77$ & SIM & 0,89 & 0,000 & NÃO & 0,17 & 0,000 & NÃO & 1,84 & 0,038 & NÃO \\
\hline CMTCCE2 & 0,00 & 0,13 & 0,13 & 1,41 & 1,98 & $-1,87$ & 2,13 & $-1,19$ & 0,10 & $-4,14$ & NÃO & 0,68 & SIM & 0,88 & 0,000 & NÃO & 0,15 & 0,000 & NÃO & 4,36 & 0,000 & NÃO \\
\hline CMTCCO2ХCMTCCE2 & 0,72 & 0,13 & $-0,02$ & 1,96 & 3,86 & $-4,57$ & 4,03 & 0,11 & 0,11 & 0,37 & SIM & 0,74 & SIM & 0,90 & 0,000 & NÃO & 0,21 & 0,000 & NÃO & 2,00 & 0,021 & NÃO \\
\hline CMTCCO3 & 0,00 & 0,29 & 1,29 & 1,33 & 1,77 & $-2,71$ & 1,29 & $-0,57$ & $-0,75$ & $-1,99$ & NÃO & $-5,19$ & NÃO & 0,83 & 0,000 & NÃO & 0,22 & 0,000 & NÃO & 3,32 & 0,000 & NÃO \\
\hline CMTCCE3 & 0,00 & $-0,44$ & $-1,44$ & 1,33 & 1,78 & $-1,44$ & 2,56 & $-0,80$ & 0,56 & $-2,79$ & NẪO & 3,88 & NÃO & 0,86 & 0,000 & NÃO & 0,18 & 0,000 & NÃO & 1,62 & 0,078 & SIM \\
\hline CMTCCO3ХCMTCCE3 & $-0,26$ & $-0,40$ & \begin{tabular}{|l|}
$-1,86$ \\
\end{tabular} & 1,99 & 3,98 & $-6,94$ & 3,92 & 2,14 & $-0,51$ & 7,43 & NÃO & $-3,57$ & NÃO & 0,92 & 0,000 & NÃO & 0,15 & 0,000 & NÃO & 2,02 & 0,019 & NÃO \\
\hline
\end{tabular}




\begin{tabular}{|c|c|c|c|c|c|c|c|c|c|c|c|c|c|c|c|c|c|c|c|c|c|c|}
\hline & & & & & & & & & & \multirow{2}{*}{\multicolumn{2}{|c|}{$\begin{array}{c}\text { TESTE Z CURT } \\
\text { curt/raiz(24/n) }\end{array}$}} & \multirow{2}{*}{\multicolumn{2}{|c|}{$\begin{array}{c}\text { TESTE Z ASSIM } \\
\text { ass/raiz(6/n) }\end{array}$}} & \multirow{2}{*}{\multicolumn{3}{|c|}{$\begin{array}{c}\text { TESTE SHAPIRO-WILK } \\
\text { H0= VAR SEGUE D. NORMAL }\end{array}$}} & \multirow{2}{*}{\multicolumn{3}{|c|}{$\begin{array}{c}\text { TESTE KOLMOGOROV SMIRNOV } \\
\text { H0= VAR SEGUE D. NORMAL }\end{array}$}} & \multicolumn{3}{|c|}{ TESTE LEVENE } \\
\hline & \multicolumn{9}{|c|}{ ESTATÍSTICAS DESCRITIVAS } & & & & & & & & & & & $\mathrm{h} 0=\mathrm{N}$ TEM & DIFEREN & JÇAS \\
\hline VARIÁVEL & 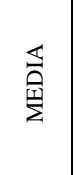 & 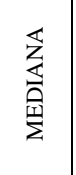 & $\begin{array}{l}0 \\
\stackrel{0}{\Sigma}\end{array}$ & 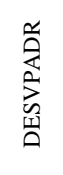 & 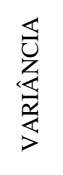 & 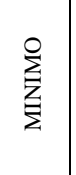 & 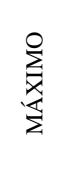 & 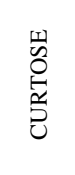 & 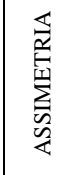 & 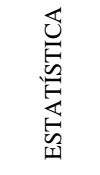 & 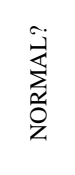 & 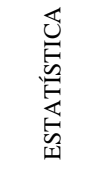 & 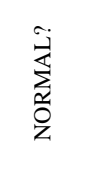 & 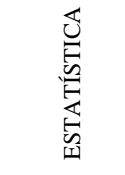 & 2 & $\frac{\hat{z}}{\sum_{0}}$ & 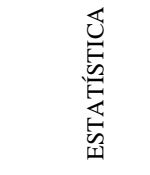 & $=$ & 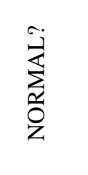 & 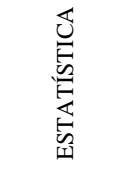 & 2 & 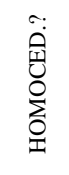 \\
\hline Variáveis com $n=600$ & & & & & & & & & & z crítico & $<1,96$ & z crítico & $<1,96$ & P crítico & $>0,05$ & & P crítico & $>0,05$ & & P crítico & $>0,05$ & \\
\hline & & & & & & & & & & raiz & 0,200 & raiz & 0,100 & & & & & & & & & \\
\hline ONDAT1 & 3,11 & 3,00 & 3,00 & 1,34 & 1,79 & 1,00 & 5,00 & $-1,00$ & $-0,12$ & $-5,02$ & NÃO & $-1,20$ & SIM & 0,89 & 0,000 & NÃO & 0,19 & 0,000 & NÃO & 10,15 & 0,000 & NÃO \\
\hline ONDAT2 & 3,48 & 3,48 & 3,00 & 1,28 & 1,65 & 1,00 & 5,00 & $-0,70$ & $-0,45$ & $-3,52$ & NÃO & $-4,52$ & NÃO & 0,87 & 0,000 & NÃO & 0,18 & 0,000 & NÃO & 22,57 & 0,000 & NÃO \\
\hline ONDAT3 & 3,43 & 3,43 & 5,00 & 1,37 & 1,89 & 1,00 & 5,00 & $-0,93$ & $-0,45$ & $-4,67$ & NÃO & $-4,50$ & NÃO & 0,87 & 0,000 & NÃO & 0,17 & 0,000 & NÃO & 11,59 & 0,000 & NÃO \\
\hline MEDONDAT & 3,34 & 3,33 & 3,00 & 1,13 & 1,29 & 1,00 & 5,00 & $-0,68$ & $-0,30$ & $-3,41$ & NÃO & $-3,01$ & NÃO & 0,95 & 0,000 & NÃO & 0,11 & 0,000 & NÃO & Depend & - & - \\
\hline ONDNS1 & 3,23 & 3,00 & 3,00 & 1,10 & 1,21 & 1,00 & 5,00 & $-0,31$ & $-0,24$ & $-1,57$ & SIM & $-2,40$ & NÃO & 0,90 & 0,000 & NÃO & 0,21 & 0,000 & NÃO & 2,33 & 0,001 & NÃO \\
\hline ONDNS2 & 3,36 & 3,00 & 3,00 & 1,07 & 1,13 & 1,00 & 5,00 & $-0,33$ & $-0,20$ & $-1,67$ & SIM & $-1,99$ & NÃO & 0,90 & 0,000 & NÃO & 0,20 & 0,000 & NÃO & 2,38 & 0,001 & NÃO \\
\hline ONDNS3 & 3,42 & 3,00 & 3,00 & 1,20 & 1,43 & 1,00 & 5,00 & $-0,67$ & $-0,37$ & $-3,34$ & NÃO & $-3,69$ & NÃO & 0,90 & 0,000 & NÃO & 0,19 & 0,000 & NÃO & 3,30 & 0,000 & NÃO \\
\hline MEDONDNS & 3,34 & 3,33 & 3,00 & 0,84 & 0,71 & 1,00 & 5,00 & 0,08 & $\mid-0,04$ & 0,38 & SIM & $-0,37$ & SIM & 0,98 & 0,000 & NÃO & 0,10 & 0,000 & NÃO & 2,15 & 0,003 & NÃO \\
\hline ONDCP1 & 3,69 & 4,00 & 5,00 & 1,30 & 1,69 & 1,00 & 5,00 & $-0,69$ & $-0,62$ & $-3,45$ & NÃO & $-6,24$ & NÃO & 0,86 & 0,000 & NÃO & 0,21 & 0,000 & NÃO & 2,82 & 0,000 & NÃO \\
\hline ONDCP2 & 3,69 & 4,00 & 5,00 & 1,30 & 1,70 & 1,00 & 5,00 & $-0,54$ & $-0,69$ & $-2,72$ & NÃO & $-6,94$ & NÃO & 0,84 & 0,000 & NÃO & 0,22 & 0,000 & NÃO & 10,24 & 0,000 & NÃO \\
\hline ONDCP3 & 3,91 & 4,00 & 5,00 & 1,21 & 1,47 & 1,00 & 5,00 & $-0,28$ & $-0,83$ & $-1,40$ & SIM & $-8,34$ & NÃO & 0,82 & 0,000 & NÃO & 0,26 & 0,000 & NÃO & 7,05 & 0,000 & NÃO \\
\hline MEDONDCP & 3,76 & 4,00 & 5,00 & 1,00 & 1,01 & 1,00 & 5,00 & $-0,58$ & $-0,51$ & $-2,89$ & NÃO & $-5,05$ & NÃO & 0,94 & 0,000 & NÃO & 0,11 & 0,000 & NÃO & 3,48 & 0,000 & NÃO \\
\hline ONDIT1 & 3,55 & 4,00 & 4,00 & 1,27 & 1,61 & 1,00 & 5,00 & $-0,60$ & $-0,62$ & $-3,00$ & NÃO & $-6,17$ & NÃO & 0,86 & 0,000 & NÃO & 0,23 & 0,000 & NÃO & 3,98 & 0,000 & NÃO \\
\hline ONDIT2 & 3,43 & 3,72 & 5,00 & 1,37 & 1,87 & 1,00 & 5,00 & $-0,94$ & $\mid-0,44$ & $-4,68$ & NÃO & $-4,43$ & NÃO & 0,87 & 0,000 & NÃO & 0,16 & 0,000 & NÃO & 5,94 & 0,000 & NÃO \\
\hline ONDIT3 & 3,83 & 5,00 & 5,00 & 1,46 & 2,13 & 1,00 & 5,00 & $-0,67$ & $-0,88$ & $-3,35$ & NÃO & $-8,80$ & NÃO & 0,77 & 0,000 & NÃO & 0,30 & 0,000 & NÃO & 9,89 & 0,000 & NÃO \\
\hline MEDONDIT & 3,60 & 3,67 & 5,00 & 1,15 & 1,32 & 1,00 & 5,00 & $-0,49$ & $-0,66$ & $-2,43$ & NÃO & $-6,61$ & NÃO & 0,93 & 0,000 & NÃO & 0,12 & 0,000 & NÃO & 5,33 & 0,000 & NÃO \\
\hline CONCBO1 & $-0,07$ & $-0,14$ & 0,86 & 1,00 & 0,99 & $-3,14$ & 0,86 & 0,89 & $\mid-1,07$ & 4,45 & NÃO & $-10,68$ & NÃO & 0,79 & 0,000 & NÃO & 0,24 & 0,000 & NÃO & 1,13 & 0,317 & SIM \\
\hline CONCBE1 & 0,04 & 0,59 & 0,59 & 1,00 & 0,99 & $-3,41$ & 0,59 & 2,26 & $-1,76$ & 11,31 & NÃO & $-17,60$ & NÃO & 0,62 & 0,000 & NÃO & 0,42 & 0,000 & NÃO & 7,57 & 0,000 & NÃO \\
\hline
\end{tabular}




\begin{tabular}{|c|c|c|c|c|c|c|c|c|c|c|c|c|c|c|c|c|c|c|c|c|c|c|}
\hline & & & & & & & & & & \multirow{2}{*}{\multicolumn{2}{|c|}{$\begin{array}{c}\text { TESTE Z CURT } \\
\text { curt/raiz(24/n) }\end{array}$}} & \multirow{2}{*}{\multicolumn{2}{|c|}{$\begin{array}{c}\text { TESTE Z ASSIM } \\
\text { ass/raiz(6/n) }\end{array}$}} & \multirow{2}{*}{\multicolumn{3}{|c|}{$\begin{array}{c}\text { TESTE SHAPIRO-WILK } \\
\text { H0= VAR SEGUE D. NORMAL }\end{array}$}} & \multirow{2}{*}{\multicolumn{3}{|c|}{$\begin{array}{c}\text { TESTE KOLMOGOROV SMIRNOV } \\
\text { H0= VAR SEGUE D. NORMAL }\end{array}$}} & \multicolumn{3}{|c|}{ TESTE LEVENE } \\
\hline & \multicolumn{9}{|c|}{ ESTATÍSTICAS DESCRITIVAS } & & & & & & & & & & & $\mathrm{h} 0=\mathrm{N}$ TEM & DIFEREN & JÇAS \\
\hline VARIÁVEL & 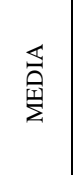 & 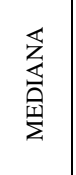 & $\begin{array}{l}0 \\
\stackrel{0}{\Sigma}\end{array}$ & 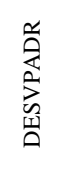 & 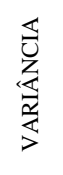 & 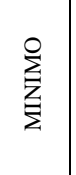 & 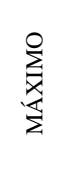 & 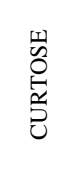 & 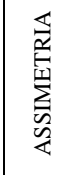 & 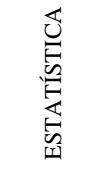 & 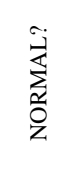 & 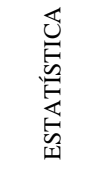 & 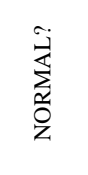 & 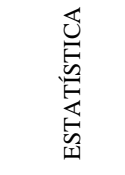 & 2 & $\frac{\hat{z}}{\sum_{0}}$ & 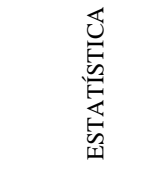 & $=$ & 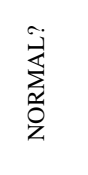 & 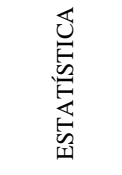 & 2 & 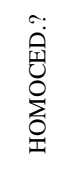 \\
\hline Variáveis com $n=600$ & & & & & & & & & & z crítico & $<1,96$ & z crítico & $<1,96$ & P crítico & $>0,05$ & & P crítico & $>0,05$ & & P crítico & $>0,05$ & \\
\hline & & & & & & & & & & raiz & 0,200 & raiz & 0,100 & & & & & & & & & \\
\hline ONDAT1 & 3,11 & 3,00 & 3,00 & 1,34 & 1,79 & 1,00 & 5,00 & $-1,00$ & $-0,12$ & $-5,02$ & NÃO & $-1,20$ & SIM & 0,89 & 0,000 & NÃO & 0,19 & 0,000 & NÃO & 10,15 & 0,000 & NÃO \\
\hline ONDAT2 & 3,48 & 3,48 & 3,00 & 1,28 & 1,65 & 1,00 & 5,00 & $-0,70$ & $-0,45$ & $-3,52$ & NÃO & $-4,52$ & NÃO & 0,87 & 0,000 & NÃO & 0,18 & 0,000 & NÃO & 22,57 & 0,000 & NÃO \\
\hline ONDAT3 & 3,43 & 3,43 & 5,00 & 1,37 & 1,89 & 1,00 & 5,00 & $-0,93$ & $-0,45$ & $-4,67$ & NÃO & $-4,50$ & NÃO & 0,87 & 0,000 & NÃO & 0,17 & 0,000 & NÃO & 11,59 & 0,000 & NÃO \\
\hline MEDONDAT & 3,34 & 3,33 & 3,00 & 1,13 & 1,29 & 1,00 & 5,00 & $-0,68$ & $-0,30$ & $-3,41$ & NÃO & $-3,01$ & NÃO & 0,95 & 0,000 & NÃO & 0,11 & 0,000 & NÃO & Depend & - & - \\
\hline ONDNS1 & 3,23 & 3,00 & 3,00 & 1,10 & 1,21 & 1,00 & 5,00 & $-0,31$ & $-0,24$ & $-1,57$ & SIM & $-2,40$ & NÃO & 0,90 & 0,000 & NÃO & 0,21 & 0,000 & NÃO & 2,33 & 0,001 & NÃO \\
\hline ONDNS2 & 3,36 & 3,00 & 3,00 & 1,07 & 1,13 & 1,00 & 5,00 & $-0,33$ & $-0,20$ & $-1,67$ & SIM & $-1,99$ & NÃO & 0,90 & 0,000 & NÃO & 0,20 & 0,000 & NÃO & 2,38 & 0,001 & NÃO \\
\hline ONDNS3 & 3,42 & 3,00 & 3,00 & 1,20 & 1,43 & 1,00 & 5,00 & $-0,67$ & $-0,37$ & $-3,34$ & NÃO & $-3,69$ & NÃO & 0,90 & 0,000 & NÃO & 0,19 & 0,000 & NÃO & 3,30 & 0,000 & NÃO \\
\hline MEDONDNS & 3,34 & 3,33 & 3,00 & 0,84 & 0,71 & 1,00 & 5,00 & 0,08 & $\mid-0,04$ & 0,38 & SIM & $-0,37$ & SIM & 0,98 & 0,000 & NÃO & 0,10 & 0,000 & NÃO & 2,15 & 0,003 & NÃO \\
\hline ONDCP1 & 3,69 & 4,00 & 5,00 & 1,30 & 1,69 & 1,00 & 5,00 & $-0,69$ & $-0,62$ & $-3,45$ & NÃO & $-6,24$ & NÃO & 0,86 & 0,000 & NÃO & 0,21 & 0,000 & NÃO & 2,82 & 0,000 & NÃO \\
\hline ONDCP2 & 3,69 & 4,00 & 5,00 & 1,30 & 1,70 & 1,00 & 5,00 & $-0,54$ & $-0,69$ & $-2,72$ & NÃO & $-6,94$ & NÃO & 0,84 & 0,000 & NÃO & 0,22 & 0,000 & NÃO & 10,24 & 0,000 & NÃO \\
\hline ONDCP3 & 3,91 & 4,00 & 5,00 & 1,21 & 1,47 & 1,00 & 5,00 & $-0,28$ & $-0,83$ & $-1,40$ & SIM & $-8,34$ & NÃO & 0,82 & 0,000 & NÃO & 0,26 & 0,000 & NÃO & 7,05 & 0,000 & NÃO \\
\hline MEDONDCP & 3,76 & 4,00 & 5,00 & 1,00 & 1,01 & 1,00 & 5,00 & $-0,58$ & $-0,51$ & $-2,89$ & NÃO & $-5,05$ & NÃO & 0,94 & 0,000 & NÃO & 0,11 & 0,000 & NÃO & 3,48 & 0,000 & NÃO \\
\hline ONDIT1 & 3,55 & 4,00 & 4,00 & 1,27 & 1,61 & 1,00 & 5,00 & $-0,60$ & $-0,62$ & $-3,00$ & NÃO & $-6,17$ & NÃO & 0,86 & 0,000 & NÃO & 0,23 & 0,000 & NÃO & 3,98 & 0,000 & NÃO \\
\hline ONDIT2 & 3,43 & 3,72 & 5,00 & 1,37 & 1,87 & 1,00 & 5,00 & $-0,94$ & $\mid-0,44$ & $-4,68$ & NÃO & $-4,43$ & NÃO & 0,87 & 0,000 & NÃO & 0,16 & 0,000 & NÃO & 5,94 & 0,000 & NÃO \\
\hline ONDIT3 & 3,83 & 5,00 & 5,00 & 1,46 & 2,13 & 1,00 & 5,00 & $-0,67$ & $-0,88$ & $-3,35$ & NÃO & $-8,80$ & NÃO & 0,77 & 0,000 & NÃO & 0,30 & 0,000 & NÃO & 9,89 & 0,000 & NÃO \\
\hline MEDONDIT & 3,60 & 3,67 & 5,00 & 1,15 & 1,32 & 1,00 & 5,00 & $-0,49$ & $-0,66$ & $-2,43$ & NÃO & $-6,61$ & NÃO & 0,93 & 0,000 & NÃO & 0,12 & 0,000 & NÃO & 5,33 & 0,000 & NÃO \\
\hline CONCBO1 & $-0,07$ & $-0,14$ & 0,86 & 1,00 & 0,99 & $-3,14$ & 0,86 & 0,89 & $\mid-1,07$ & 4,45 & NÃO & $-10,68$ & NÃO & 0,79 & 0,000 & NÃO & 0,24 & 0,000 & NÃO & 1,13 & 0,317 & SIM \\
\hline CONCBE1 & 0,04 & 0,59 & 0,59 & 1,00 & 0,99 & $-3,41$ & 0,59 & 2,26 & $-1,76$ & 11,31 & NÃO & $-17,60$ & NÃO & 0,62 & 0,000 & NÃO & 0,42 & 0,000 & NÃO & 7,57 & 0,000 & NÃO \\
\hline
\end{tabular}




\begin{tabular}{|c|c|c|c|c|c|c|c|c|c|c|c|c|c|c|c|c|c|c|c|c|c|c|}
\hline & & & & & & & & & & \multirow{2}{*}{\multicolumn{2}{|c|}{\begin{tabular}{c|} 
TESTE Z CURT \\
curt/raiz(24/n)
\end{tabular}}} & \multirow{2}{*}{\multicolumn{2}{|c|}{$\begin{array}{c}\text { TESTE Z ASSIM } \\
\text { ass/raiz(6/n) }\end{array}$}} & \multirow{2}{*}{\multicolumn{3}{|c|}{$\begin{array}{c}\text { TESTE SHAPIRO-WILK } \\
\text { H0= VAR SEGUE D. NORMAL }\end{array}$}} & \multirow{2}{*}{\multicolumn{3}{|c|}{$\begin{array}{c}\text { TESTE KOLMOGOROV SMIRNOV } \\
\text { H0= VAR SEGUE D. NORMAL }\end{array}$}} & \multicolumn{3}{|c|}{ TESTE LEVENE } \\
\hline & \multicolumn{9}{|c|}{ ESTATÍSTICAS DESCRITIVAS } & & & & & & & & & & & $\mathrm{h} 0=\mathrm{N}$ TEM & DIFEREN & JÇAS \\
\hline VARIÁVEL & 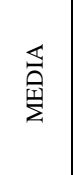 & $\begin{array}{l}\overleftrightarrow{3} \\
\text { 空 } \\
\text { 至 }\end{array}$ & $\begin{array}{l}\stackrel{0}{2} \\
\frac{0}{\Sigma}\end{array}$ & 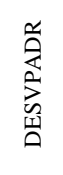 & 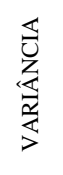 & 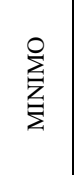 & 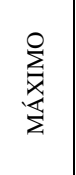 & 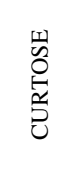 & 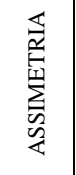 & 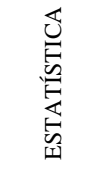 & $\begin{array}{l}\dot{j} \\
\sum_{0} \\
\text { z }\end{array}$ & 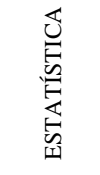 & 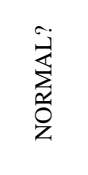 & 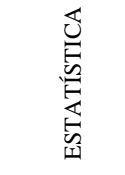 & 2 & 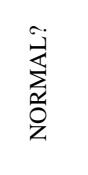 & 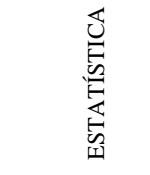 & $=$ & 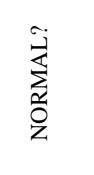 & 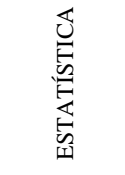 & 2 & 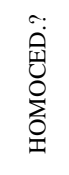 \\
\hline Variáveis com $n=600$ & & & & & & & & & & z crítico & $<1,96$ & zcrítico & $<1,96$ & P crítico & $>0,05$ & & P crítico & $>0,05$ & & P crítico & $>0,05$ & \\
\hline & & & & & & & & & & raiz & 0,200 & raiz & 0,100 & & & & & & & & & \\
\hline CONCBO1XCONBE1 & 0,31 & 0,40 & 0,51 & 1,15 & 1,32 & $-2,93$ & 10,70 & 25,76 & 3,46 & 128,80 & NÃO & 34,64 & NÃO & 0,63 & 0,000 & NÃO & 0,35 & 0,000 & NÃO & 1,54 & 0,066 & SIM \\
\hline $\mathrm{CONCBO} 2$ & $-0,02$ & $-0,42$ & $-1,42$ & 1,21 & 1,46 & $-1,42$ & 2,58 & $-0,60$ & 0,50 & $-2,99$ & NÃO & 5,03 & NÃO & 0,87 & 0,000 & NÃO & 0,18 & 0,000 & NÃO & 1,89 & 0,013 & NÃO \\
\hline CONCBE2 & 0,03 & 0,36 & 1,36 & 1,29 & 1,67 & $-2,64$ & 1,36 & $-0,73$ & $-0,58$ & $-3,63$ & NÃO & $-5,81$ & NÃO & 0,86 & 0,000 & NÃO & 0,20 & 0,000 & NÃO & 4,98 & 0,000 & NÃO \\
\hline CONCBO2XCONBE2 & 0,10 & $-0,01$ & $-1,93$ & 1,70 & 2,87 & $-6,81$ & 3,75 & 2,64 & $-0,36$ & 13,18 & NÃO & $-3,57$ & NÃO & 0,91 & 0,000 & NÃO & 0,15 & 0,000 & NÃO & 3,43 & 0,000 & NÃO \\
\hline CONCBO3 & 0,02 & $-0,21$ & $-0,21$ & 1,14 & 1,29 & $-2,21$ & 1,79 & $-0,50$ & $-0,17$ & $-2,51$ & NÃO & $-1,72$ & SIM & 0,89 & 0,000 & NÃO & 0,22 & 0,000 & NÃO & 1,90 & 0,012 & NÃO \\
\hline CONCBE3 & 0,05 & 0,10 & 1,10 & 1,24 & 1,54 & $-2,90$ & 1,10 & $-0,22$ & $-0,93$ & $-1,08$ & SIM & $-9,28$ & NÃO & 0,80 & 0,000 & NÃO & 0,28 & 0,000 & NÃO & 3,37 & 0,000 & NÃO \\
\hline CONCBO3XCONBE3 & $-0,17$ & $-0,12$ & $-0,23$ & 1,54 & 2,37 & $-5,19$ & 6,42 & 3,70 & $-0,14$ & 18,49 & NÃO & $-1,40$ & SIM & 0,89 & 0,000 & NÃO & 0,23 & 0,000 & NÃO & 4,04 & 0,000 & NÃO \\
\hline $\mathrm{CONCBO4}$ & 0,00 & 0,00 & 1,00 & 1,05 & 1,10 & $-3,00$ & 1,00 & $-0,11$ & $-0,77$ & $-0,56$ & SIM & $-7,72$ & NÃO & 0,81 & 0,000 & NÃO & 0,27 & 0,000 & NÃO & 2,89 & 0,000 & NÃO \\
\hline CONCBE4 & 0,03 & $-0,27$ & $-0,27$ & 1,43 & 2,03 & $-2,27$ & 1,73 & $-1,09$ & $-0,32$ & $-5,47$ & NÃO & $-3,17$ & NÃO & 0,86 & 0,000 & NÃO & 0,18 & 0,000 & NÃO & 5,37 & 0,000 & NÃO \\
\hline CONCBO4XCONBE4 & $-0,01$ & 0,00 & 1,74 & 1,47 & 2,16 & $-5,18$ & 6,80 & 1,68 & $-0,16$ & 8,39 & NÃO & $-1,59$ & SIM & 0,92 & 0,000 & NÃO & 0,17 & 0,000 & NÃO & 3,32 & 0,000 & NÃO \\
\hline CONCNO1 & $-0,09$ & $-0,47$ & $-0,47$ & 1,23 & 1,51 & $-2,47$ & 1,53 & $-0,57$ & $-0,48$ & $-2,84$ & NÃO & $-4,82$ & NÃO & 0,89 & 0,000 & NÃO & 0,19 & 0,000 & NÃO & 2,33 & 0,001 & NÃO \\
\hline CONCNE1 & $-0,04$ & $-0,39$ & $-0,39$ & 1,25 & 1,57 & $-2,39$ & 1,61 & $-0,72$ & $-0,26$ & $-3,61$ & NÃO & $-2,61$ & NÃO & 0,88 & 0,000 & NÃO & 0,20 & 0,000 & NÃO & 3,88 & 0,000 & NÃO \\
\hline CONCNO1XCONE1 & 0,69 & 0,19 & 0,19 & 1,79 & 3,21 & $-3,97$ & 5,92 & 2,26 & 1,11 & 11,30 & NÃO & 11,06 & NÃO & 0,87 & 0,000 & NÃO & 0,21 & 0,000 & NÃO & 6,62 & 0,000 & NÃO \\
\hline $\mathrm{CONCNO2}$ & 0,00 & $-0,37$ & $-0,37$ & 1,11 & 1,24 & $-2,37$ & 1,63 & $-0,34$ & $-0,35$ & $-1,69$ & NÃO & $-3,48$ & NÃO & 0,90 & 0,000 & NÃO & 0,19 & 0,000 & NÃO & 1,66 & 0,039 & NÃO \\
\hline CONCNE2 & 0,41 & 0,00 & 0,00 & 1,23 & 1,52 & $-2,00$ & 2,00 & $-0,62$ & $-0,35$ & $-3,09$ & NÃO & $-3,45$ & NÃO & 0,89 & 0,000 & NÃO & 0,19 & 0,000 & NÃO & 2,04 & 0,006 & NÃO \\
\hline CONCNO2XCONE2 & 0,56 & 0,00 & 0,00 & 1,57 & 2,47 & $-4,73$ & 4,73 & 1,98 & 0,16 & 9,89 & NÃO & 1,59 & SIM & 0,90 & 0,000 & NÃO & 0,17 & 0,000 & NÃO & 4,30 & 0,000 & NÃO \\
\hline CONCCO1 & 0,03 & $-0,15$ & $-0,15$ & 1,34 & 1,79 & $-2,15$ & 1,85 & $-1,08$ & $-0,18$ & $-5,41$ & NÃO & $-1,78$ & SIM & 0,89 & 0,000 & NÃO & 0,17 & 0,000 & NÃO & 1,63 & 0,045 & SIM \\
\hline CONCCE1 & $-1,99$ & $-2,00$ & $-2,00$ & 1,37 & 1,88 & $-4,00$ & 0,00 & $-1,12$ & 0,01 & $-5,62$ & NÃO & 0,10 & SIM & 0,90 & 0,000 & NÃO & 0,15 & 0,000 & NÃO & 3,12 & 0,000 & NÃO \\
\hline
\end{tabular}




\begin{tabular}{|c|c|c|c|c|c|c|c|c|c|c|c|c|c|c|c|c|c|c|c|c|c|c|}
\hline & & & & & & & & & & \multirow{2}{*}{\multicolumn{2}{|c|}{$\begin{array}{c}\text { TESTE Z CURT } \\
\text { curt/raiz(24/n) }\end{array}$}} & \multirow{2}{*}{\multicolumn{2}{|c|}{$\begin{array}{c}\text { TESTE Z ASSIM } \\
\text { ass/raiz(6/n) }\end{array}$}} & \multirow{2}{*}{\multicolumn{3}{|c|}{$\begin{array}{c}\text { TESTE SHAPIRO-WILK } \\
\text { H0= VAR SEGUE D. NORMAL }\end{array}$}} & \multirow{2}{*}{\multicolumn{3}{|c|}{$\begin{array}{c}\text { TESTE KOLMOGOROV SMIRNOV } \\
\text { H0= VAR SEGUE D. NORMAL }\end{array}$}} & \multicolumn{3}{|c|}{ TESTE LEVENE } \\
\hline & \multicolumn{9}{|c|}{ ESTATÍSTICAS DESCRITIVAS } & & & & & & & & & & & $\mathrm{h} 0=\mathrm{N}$ TEM & IFEREN & JÇAS \\
\hline VARIÁVEL & 至 & 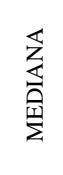 & 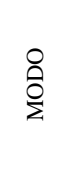 & 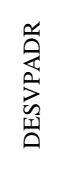 & 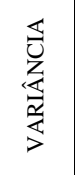 & $\sum_{\substack{3 \\
\Sigma}}^{\circ}$ & $\sum_{\substack{x \\
\sum}}^{0}$ & 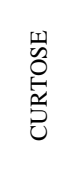 & 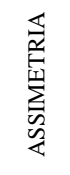 & 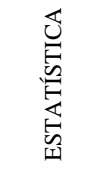 & 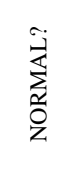 & 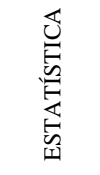 & 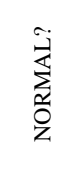 & 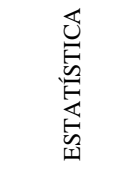 & 2 & $\frac{\tilde{z}}{\sum_{0}}$ & 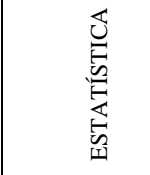 & $=$ & $\begin{array}{l}\text { 远 } \\
\text { zo } \\
\text { z }\end{array}$ & 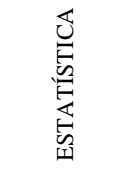 & a & 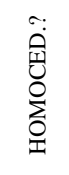 \\
\hline Variáveis com $n=600$ & & & & & & & & & & z crítico & $<1,96$ & z crítico & $<1,96$ & P crítico & $>0,05$ & & P crítico & $>0,05$ & & P crítico & $>0,05$ & \\
\hline & & & & & & & & & & raiz & 0,200 & raiz & 0,100 & & & & & & & & & \\
\hline CONCCO1XCONCCE1 & 0,56 & 0,15 & 0,00 & 3,27 & 10,71 & $-7,42$ & 8,58 & 0,87 & 0,66 & 4,37 & NÃO & 6,64 & NÃO & 0,90 & 0,000 & NÃO & 0,23 & 0,000 & NÃO & 1,47 & 0,090 & SIM \\
\hline $\mathrm{CONCCO3}$ & 0,05 & 0,44 & 0,44 & 1,15 & 1,32 & $-2,56$ & 1,44 & $-0,43$ & $-0,53$ & $-2,13$ & NÃO & $-5,32$ & NÃO & 0,88 & 0,000 & NÃO & 0,18 & 0,000 & NÃO & 2,05 & 0,006 & NÃO \\
\hline CONCCE3 & 0,01 & 0,03 & 1,03 & 1,20 & 1,43 & $-2,97$ & 1,03 & $-0,03$ & $-0,96$ & $-0,14$ & SIM & $-9,59$ & NÃO & 0,81 & 0,000 & NÃO & 0,26 & 0,000 & NÃO & 3,47 & 0,000 & NÃO \\
\hline CONCCO3XCONCCE3 & 0,11 & 0,05 & 0,46 & 1,47 & 2,18 & $-4,28$ & 7,58 & 5,86 & 0,61 & 29,30 & NÃO & 6,08 & NÃO & 0,87 & 0,000 & NÃO & 0,158 & 0,000 & NÃO & 1,66 & 0,039 & NÃO \\
\hline CONCCO4 & $-0,01$ & 0,66 & 0,66 & 1,42 & 2,01 & $-2,34$ & 1,66 & $-1,13$ & $-0,42$ & $-5,63$ & NÃO & $-4,25$ & NÃO & 0,85 & 0,000 & NÃO & 0,230 & 0,000 & NÃO & 1,05 & 0,399 & SIM \\
\hline CONCCE4 & $-0,01$ & 0,38 & 1,38 & 1,40 & 1,95 & $-2,62$ & 1,38 & $-0,83$ & $-0,63$ & $-4,16$ & NÃO & $-6,29$ & NÃO & 0,83 & 0,000 & NÃO & 0,227 & 0,000 & NÃO & 3,69 & 0,000 & NÃO \\
\hline CONCCO4XCONCCE4 & 0,89 & 0,83 & 2,30 & 2,11 & 4,46 & $-4,35$ & 6,12 & 1,10 & 0,45 & 5,52 & NÃO & 4,47 & NÃO & 0,92 & 0,000 & NÃO & 0,166 & 0,000 & NÃO & 2,83 & 0,000 & NÃO \\
\hline
\end{tabular}




\begin{tabular}{|c|c|c|c|c|c|c|c|c|c|c|c|c|c|c|c|c|c|c|c|c|c|c|}
\hline & & & & & & & & & & \multirow{2}{*}{\multicolumn{2}{|c|}{$\begin{array}{c}\text { TESTE Z } \\
\text { CURTOSE } \\
\text { curt/raiz(24/n) }\end{array}$}} & \multirow{2}{*}{\multicolumn{2}{|c|}{$\begin{array}{c}\text { TESTE Z } \\
\text { ASSIMETRIA } \\
\text { ass/raiz(6/n) }\end{array}$}} & \multirow{2}{*}{\multicolumn{3}{|c|}{$\begin{array}{c}\text { TESTE SHAPIRO-WILK } \\
\text { H0=VARSEGUE } \\
\text { D.NORMAL } \\
\end{array}$}} & \multirow{2}{*}{\multicolumn{3}{|c|}{ 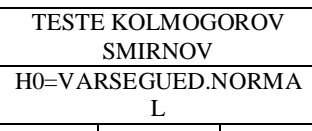 }} & \multicolumn{3}{|c|}{ TESTE LEVENE } \\
\hline & \multicolumn{9}{|c|}{ ESTATÍSTICAS DESCRITIVAS } & & & & & & & & & & & $\mathrm{h} 0=\mathrm{N}$ & ÃO TEM & DIF. \\
\hline VARIÁVEL & 吾 & 忞 & 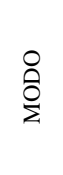 & 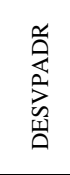 & 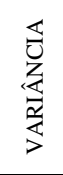 & 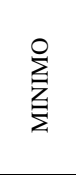 & $\sum_{\substack{x \\
\vdots}}^{0}$ & $\begin{array}{l}\text { W } \\
0 \\
0 \\
0 \\
\text { 岂 }\end{array}$ & 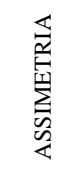 & 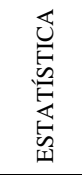 & 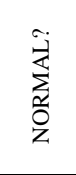 & 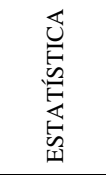 & 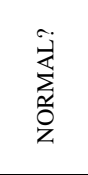 & 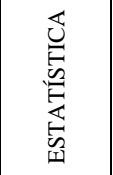 & 2 & 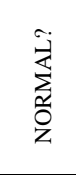 & 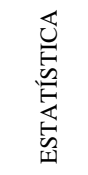 & 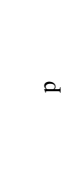 & 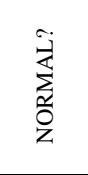 & 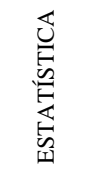 & 2 & 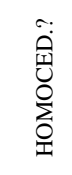 \\
\hline Variáveis com $n=412$ & & & & & & & & & & $\begin{array}{c}z \\
\text { crítico } \\
\end{array}$ & $<1,96$ & z crítico & $<1,96$ & P crítico & $\begin{array}{c}> \\
0,05 \\
\end{array}$ & & $\begin{array}{c}P \\
\text { crítico }\end{array}$ & $>0,05$ & & $\begin{array}{c}P \\
\text { crítico }\end{array}$ & $<0$ & \\
\hline & & & & & & & & & & raiz & 0,241 & raiz & 0,121 & & & & & & & & & \\
\hline AFDAT1 & 4,05 & 4,00 & 5,00 & 1,10 & 1,22 & 1,00 & 5,00 & 0,04 & $-0,92$ & 0,15 & SIM & $-7,64$ & NÃO & 0,79 & 0,000 & NÃO & 0,29 & 0,000 & NÃO & 22,58 & 0,000 & NÃO \\
\hline AFDAT2 & 3,62 & 4,00 & 5,00 & 1,25 & 1,56 & 1,00 & 5,00 & $-0,77$ & $-0,46$ & $-3,20$ & NÃO & $-3,84$ & NÃO & 0,86 & 0,000 & NÃO & 0,21 & 0,000 & NÃO & 17,10 & 0,000 & NÃO \\
\hline AFDAT3 & 4,12 & 5,00 & 5,00 & 1,16 & 1,34 & 1,00 & 5,00 & 0,27 & $-1,13$ & 1,13 & SIM & $-9,40$ & NÃO & 0,75 & 0,000 & NÃO & 0,32 & 0,000 & NÃO & 18,22 & 0,000 & NÃO \\
\hline MEDAFDAT & 3,93 & 4,00 & 5,00 & 0,97 & 0,93 & 1,00 & 5,00 & $-0,31$ & $-0,68$ & $-1,27$ & SIM & $-5,62$ & NÃO & 0,91 & 0,000 & NÃO & 0,14 & 0,000 & NÃO & Dep. & Dep. & \\
\hline AFDNS1 & 3,69 & 4,00 & 3,00 & 1,02 & 1,04 & 1,00 & 5,00 & $-0,21$ & $-0,43$ & $-0,85$ & SIM & $-3,54$ & NÃO & 0,88 & 0,000 & NÃO & 0,19 & 0,000 & NÃO & 1,93 & 0,030 & NÃO \\
\hline AFDNS2 & 3,51 & 3,00 & 3,00 & 1,02 & 1,05 & 1,00 & 5,00 & $-0,20$ & $-0,29$ & $-0,81$ & SIM & $-2,37$ & NÃO & 0,89 & 0,000 & NÃO & 0,20 & 0,000 & NÃO & 1,21 & 0,272 & SIM \\
\hline AFDNS3 & 3,49 & 3,00 & 3,00 & 1,16 & 1,35 & 1,00 & 5,00 & $-0,59$ & $-0,37$ & $-2,43$ & NÃO & $-3,06$ & NÃO & 0,89 & 0,000 & NÃO & 0,17 & 0,000 & NÃO & 1,09 & 0,369 & SIM \\
\hline MEDAFDNS & 3,56 & 3,67 & 3,00 & 0,79 & 0,62 & 1,33 & 5,00 & $-0,05$ & $-0,14$ & $-0,19$ & SIM & $-1,15$ & SIM & 0,97 & 0,000 & NÃO & 0,11 & 0,000 & NÃO & 1,02 & 0,431 & SIM \\
\hline AFDCP1 & 3,11 & 3,00 & 3,00 & 1,35 & 1,82 & 1,00 & 5,00 & $-1,05$ & $-0,03$ & $-4,36$ & NÃO & $-0,25$ & SIM & 0,89 & 0,000 & NÃO & 0,19 & 0,000 & NÃO & 4,46 & 0,000 & NÃO \\
\hline AFDCP2 & 3,41 & 3,00 & 5,00 & 1,35 & 1,82 & 1,00 & 5,00 & $-1,07$ & $-0,27$ & $-4,45$ & NÃO & $-2,26$ & NÃO & 0,87 & 0,000 & NÃO & 0,19 & 0,000 & NÃO & 3,21 & 0,000 & NÃO \\
\hline AFDCP3 & 3,44 & 3,00 & 5,00 & 1,30 & 1,69 & 1,00 & 5,00 & $-0,92$ & $-0,35$ & $-3,79$ & NÃO & $-2,92$ & NÃO & 0,88 & 0,000 & NÃO & 0,17 & 0,000 & NÃO & 2,12 & 0,015 & NÃO \\
\hline MEDAFDCP & 3,32 & 3,33 & 3,00 & 1,09 & 1,19 & 1,00 & 5,00 & $-0,72$ & $-0,17$ & $-2,98$ & NÃO & $-1,39$ & SIM & 0,96 & 0,000 & NÃO & 0,09 & 0,000 & NÃO & 4,02 & 0,000 & NÃO \\
\hline AFDIT1 & 3,36 & 3,00 & 3,00 & 1,24 & 1,55 & 1,00 & 5,00 & $-0,81$ & $-0,30$ & $-3,37$ & NÃO & $-2,47$ & NÃO & 0,90 & 0,000 & NÃO & 0,16 & 0,000 & NÃO & 1,51 & 0,118 & SIM \\
\hline AFDIT2 & 3,41 & 3,00 & 5,00 & 1,36 & 1,86 & 1,00 & 5,00 & $-1,07$ & $-0,31$ & $-4,42$ & NÃO & $-2,53$ & NÃO & 0,87 & 0,000 & NÃO & 0,19 & 0,000 & NÃO & 1,77 & 0,051 & SIM \\
\hline AFDIT3 & 2,61 & 3,00 & 1,00 & 1,47 & 2,17 & 1,00 & 5,00 & $-1,18$ & 0,40 & $-4,89$ & NÃO & 3,29 & NÃO & 0,85 & 0,000 & NÃO & 0,20 & 0,000 & NÃO & 8,37 & 0,000 & NÃO \\
\hline MEDAFDIT & 3,13 & 3,00 & 3,00 & 1,08 & 1,17 & 1,00 & 5,00 & $-0,76$ & $-0,07$ & $-3,16$ & NÃO & $-0,54$ & SIM & 0,97 & 0,000 & NÃO & 0,08 & 0,000 & NÃO & 3,14 & 0,000 & NÃO \\
\hline САFСBO1 & 0,00 & 0,54 & 0,46 & 1,21 & 1,46 & $-2,46$ & 1,54 & $-0,50$ & $-0,51$ & $-2,08$ & NÃO & $-4,20$ & NÃO & 0,89 & 0,000 & NÃO & 0,19 & 0,000 & NÃO & 1,38 & 0,172 & SIM \\
\hline CAFCBE1 & 0,00 & 0,44 & 0,56 & 1,26 & 1,58 & $-2,56$ & 1,44 & $-0,69$ & $-0,46$ & $-2,85$ & NÃO & $-3,79$ & NÃO & 0,87 & 0,000 & NÃO & 0,19 & 0,000 & NÃO & 5,52 & 0,000 & NÃO \\
\hline
\end{tabular}




\begin{tabular}{|c|c|c|c|c|c|c|c|c|c|c|c|c|c|c|c|c|c|c|c|c|c|c|}
\hline & & & & & & & & & & \multirow{2}{*}{\multicolumn{2}{|c|}{$\frac{\text { TESTE Z CURT }}{\text { curt/raiz(24/n) }}$}} & \multirow{2}{*}{\multicolumn{2}{|c|}{$\frac{\text { TESTE Z ASSIM }}{\text { ass/raiz(6/n) }}$}} & \multirow{2}{*}{\multicolumn{3}{|c|}{$\begin{array}{c}\text { TESTE SHAPIRO-WILK } \\
\text { H0=VAR NORMAL }\end{array}$}} & \multirow{2}{*}{\multicolumn{3}{|c|}{$\begin{array}{c}\text { TESTE KOLM-SMIRNOV } \\
\text { H0=VARNORMAL }\end{array}$}} & \multirow{2}{*}{\multicolumn{3}{|c|}{$\begin{array}{c}\text { TESTE LEVENE } \\
\text { h0=NÃO TEM DIF. }\end{array}$}} \\
\hline & \multicolumn{9}{|c|}{ ESTATÍSTICAS DESCRITIVAS } & & & & & & & & & & & & & \\
\hline VARIÁVEL & 空 & 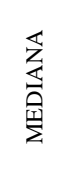 & 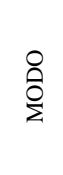 & 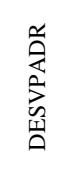 & 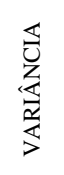 & 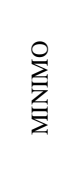 & $\sum_{\substack{x \\
\sum}}^{0}$ & $\begin{array}{l}\text { W } \\
0 \\
0 \\
0 \\
\tilde{J} \\
0\end{array}$ & 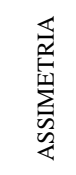 & 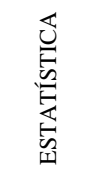 & 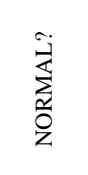 & 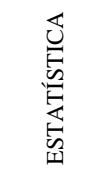 & $\begin{array}{l}\underset{j}{j} \\
\sum_{z} \\
z\end{array}$ & 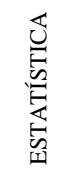 & $=$ & $\begin{array}{l}\hat{j} \\
\sum_{z} \\
\text { z }\end{array}$ & 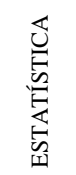 & $=$ & $\begin{array}{l}\stackrel{j}{j} \\
\sum_{\text {jo }} \\
z\end{array}$ & 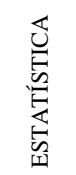 & $a$ & 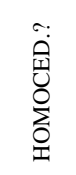 \\
\hline Variáveis com $n=412$ & & & & & & & & & & \multicolumn{2}{|c|}{ zcrítico $<1,96$} & \multicolumn{2}{|c|}{ z crítico $<1,96$} & \multicolumn{3}{|c|}{ P crítico $>0,05$} & \multicolumn{3}{|c|}{ P crítico $>0,05$} & \multicolumn{3}{|c|}{ P crítico $<0,05$} \\
\hline & & & & & & & & & & raiz & 0,241 & raiz & 0,121 & & & & & & & & & \\
\hline CONCBO1XCONBE1 & 0,33 & 0,26 & 0,26 & 1,56 & 2,44 & $-3,94$ & 6,29 & 2,74 & 0,21 & 11,36 & NÃO & 1,70 & SIM & 0,92 & 0,000 & NÃO & 0,16 & 0,000 & NÃO & 2,83 & 0,001 & NÃO \\
\hline CAFCBO2 & 0,00 & $\overline{0,20}$ & 0,80 & 0,96 & 0,93 & $-3,20$ & 0,80 & 1,25 & $-1,21$ & 5,16 & NÃO & $-10,02$ & NÃO & 0,78 & 0,000 & NÃO & 0,28 & 0,000 & NÃO & 3,10 & 0,000 & NÃO \\
\hline CAFCBE2 & 0,00 & 0,81 & 0,81 & 1,05 & 1,09 & $-3,19$ & 0,81 & 0,59 & $-1,15$ & 2,45 & NÃO & $-9,51$ & NÃO & 0,76 & 0,000 & NÃO & 0,32 & 0,000 & NÃO & 9,80 & 0,000 & NÃO \\
\hline CONCBO2XCONBE2 & 0,40 & 0,23 & 0,65 & 1,25 & 1,57 & $-2,60$ & 10,18 & 24,08 & 3,67 & 99,77 & NÃO & 30,45 & NÃO & 0,66 & 0,000 & NÃO & 0,30 & 0,000 & NÃO & 13,67 & 0,000 & NÃO \\
\hline САFСВОЗ & 0,00 & 0,21 & 1,21 & 1,22 & 1,49 & $-1,21$ & 2,79 & $-0,37$ & 0,74 & $-1,51$ & SIM & 6,11 & NÃO & 0,84 & 0,000 & NÃO & 0,22 & 0,000 & NÃO & 1,59 & 0,093 & SIM \\
\hline CAFCBE3 & 0,00 & 0,00 & 1,00 & 1,11 & 1,23 & $-3,00$ & 1,00 & $-0,12$ & $-0,83$ & $-0,50$ & SIM & $-6,90$ & NÃO & 0,81 & 0,000 & NÃO & 0,27 & 0,000 & NÃO & 1,63 & 0,082 & SIM \\
\hline CONCBO3XCONBE3 & 0,15 & 0,01 & 1,22 & 1,32 & 1,75 & $-5,56$ & 3,63 & 2,23 & 0,14 & 9,26 & NÃO & 1,14 & SIM & 0,92 & 0,000 & NÃO & 0,15 & 0,000 & NÃO & 1,28 & 0,225 & SIM \\
\hline CAFCNO1 & 0,00 & 0,08 & 0,08 & 1,30 & 1,68 & $-2,08$ & 1,92 & $-0,96$ & $-0,04$ & $-3,99$ & NÃO & $-0,37$ & SIM & 0,90 & 0,000 & NÃO & 0,16 & 0,000 & NÃO & 2,04 & 0,020 & NÃO \\
\hline CAFCNE1 & 0,00 & 0,33 & 1,33 & 1,31 & 1,71 & $-2,67$ & 1,33 & $-0,72$ & $-0,60$ & $-3,00$ & NÃO & $-4,94$ & NÃO & 0,84 & 0,000 & NÃO & 0,23 & 0,000 & NÃO & 2,89 & 0,001 & NÃO \\
\hline $\begin{array}{l}\text { CONCNO1XCONCNE } \\
1\end{array}$ & 0,74 & 0,13 & 0,05 & 1,76 & 3,09 & $-3,22$ & 5,56 & 0,99 & 0,62 & 4,08 & NÃO & 5,15 & NÃO & 0,93 & 0,000 & NÃO & 0,15 & 0,000 & NÃO & 2,29 & 0,008 & NÃO \\
\hline $\mathrm{CAFCNO2}$ & 0,00 & 0,20 & 1,20 & 1,13 & 1,28 & $-2,80$ & 1,20 & 0,08 & $-0,80$ & 0,33 & SIM & $-6,61$ & NÃO & 0,85 & 0,000 & NÃO & 0,20 & 0,000 & NÃO & 1,63 & 0,081 & SIM \\
\hline CAFCNE2 & 0,00 & 0,63 & 0,63 & 1,19 & 1,42 & $-2,63$ & 1,37 & $-0,68$ & $-0,36$ & $-2,82$ & NÃO & $-2,94$ & NÃO & 0,85 & 0,000 & NÃO & 0,22 & 0,000 & NÃO & 4,19 & 0,000 & NÃO \\
\hline $\begin{array}{l}\text { CONCNO2XCONCNE } \\
2\end{array}$ & 0,48 & 0,27 & 1,65 & 1,48 & 2,19 & $-3,85$ & 7,36 & 5,82 & 1,14 & 24,12 & NÃO & 9,46 & NÃO & 0,87 & 0,000 & NÃO & 0,20 & 0,000 & NÃO & 4,84 & 0,000 & NÃO \\
\hline CAFCCO1 & 0,00 & 0,44 & $0, \overline{44}$ & 1,21 & 1,47 & $-2,44$ & 1,56 & $-0,68$ & $-0,34$ & $-2,81$ & NÃO & $-2,83$ & NÃO & 0,89 & 0,000 & NÃO & 0,16 & 0,000 & NÃO & 0,52 & 0,904 & SIM \\
\hline CAFCCE1 & 0,00 & 0,32 & 1,32 & 1,18 & 1,39 & $-2,68$ & 1,32 & $-0,55$ & $-0,51$ & $-2,28$ & NÃO & $-4,20$ & NÃO & 0,86 & 0,000 & NÃO & 0,20 & 0,000 & NÃO & 2,56 & 0,003 & NÃO \\
\hline CONCC01XCONCCO1 & 0,38 & 0,30 & 0,30 & 1,53 & 2,34 & $-4,19$ & 6,54 & 2,90 & 0,17 & 12,00 & NÃO & 1,41 & SIM & 0,92 & 0,000 & NÃO & 0,14 & 0,000 & NÃO & 3,03 & 0,000 & NÃO \\
\hline CAFCCO2 & 0,00 & 0,11 & 0,11 & 1,30 & 1,69 & $-1,89$ & 2,11 & $-0,98$ & 0,10 & $-4,08$ & NÃO & 0,80 & SIM & 0,90 & 0,000 & NÃO & 0,16 & 0,000 & NÃO & 2,62 & 0,002 & NÃO \\
\hline CAFCCE2 & 0,00 & 0,17 & 0,17 & 1,42 & 2,03 & $-2,17$ & 1,83 & $-1,21$ & $-0,18$ & $-5,00$ & NÃO & $-1,47$ & SIM & 0,88 & 0,000 & NÃO & 0,15 & 0,000 & NÃO & 5,79 & 0,000 & NÃO \\
\hline CONCC02XCONCCO2 & 0,74 & 0,15 & $0, \overline{0}$ & 1,91 & 3,66 & $-4,56$ & 4,10 & $-0,08$ & 0,17 & $-0,32$ & SIM & 1,40 & SIM & 0,92 & 0,000 & NÃO & 0,20 & 0,000 & NÃO & 4,58 & 0,000 & NÃO \\
\hline
\end{tabular}


APENDICE N2 - Correlações entre variáveis explicativas para amostra alunos geral na IEM PU 1 
APÊNDICE O - Estatísticas descritivas e testes de normalidade para variáveis participantes das etapas de modelagem na IEM PU2 
APENDICE 01 - Estatísticas descritivas e testes de normalidade uni variada - IEM PU 2 - tratamento T2 e T3 - amostra alunos geral

\begin{tabular}{|c|c|c|c|c|c|c|c|c|c|c|c|c|c|c|c|c|c|c|c|c|c|c|}
\hline & & & & & & & & & & \multirow{2}{*}{\multicolumn{2}{|c|}{ TESTE Z CURTOSE }} & \multicolumn{2}{|c|}{$\begin{array}{c}\text { TESTE Z } \\
\text { ASSIMETRIA } \\
\end{array}$} & \multicolumn{3}{|c|}{$\begin{array}{c}\text { TESTE SHAPIRO-WILK } \\
\text { H0= VAR SEGUE DISTR }\end{array}$} & \multicolumn{3}{|c|}{$\begin{array}{l}\text { TESTE KOLMOGOROV } \\
\text { SMIRNOV - Lilliefors }\end{array}$} & \multicolumn{3}{|c|}{ TESTE LEVENE } \\
\hline & \multicolumn{9}{|c|}{ ESTATÍSTICAS DESCRITIVAS } & & & \multicolumn{2}{|c|}{ ass/raiz(6/n) } & \multicolumn{3}{|c|}{$\begin{array}{c}\mathrm{H} 0=\text { VAR SEGUE DISTR } \\
\text { NORMAL }\end{array}$} & \multicolumn{3}{|c|}{$\begin{array}{c}\mathrm{H} 0=\text { VAR SEGUE DISTR. } \\
\text { NORMAL }\end{array}$} & \multicolumn{3}{|c|}{$\begin{array}{c}\text { h0=NÃO EXISTIR } \\
\text { DIFERENÇAS }\end{array}$} \\
\hline VARIÁVEL & $\begin{array}{l}\overleftrightarrow{\Xi} \\
\stackrel{1}{\Sigma}\end{array}$ & 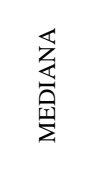 & $\stackrel{\circ}{\stackrel{0}{\Sigma}}$ & 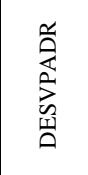 & 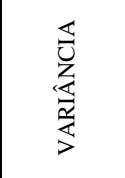 & $\underset{\sum}{\sum_{i}^{\prime}}$ & 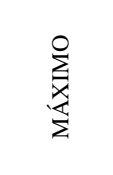 & 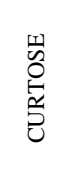 & 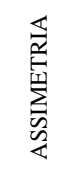 & 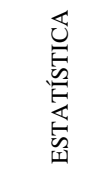 & 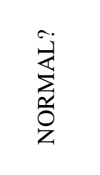 & 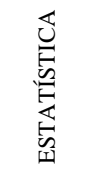 & $\begin{array}{l}\dot{\vec{t}} \\
\sum_{\tilde{z}} \\
\dot{z}\end{array}$ & 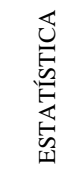 & $a$ & 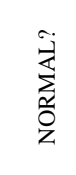 & 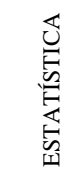 & 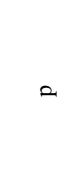 & 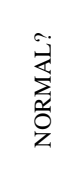 & 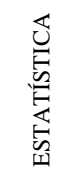 & 2 & 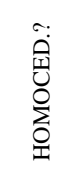 \\
\hline $\begin{array}{c}\text { Variáveis com } \\
\quad n=357\end{array}$ & & & & & & & & & & \multicolumn{2}{|c|}{$\begin{array}{c}\text { z crítico } \\
<1,96\end{array}$} & \multicolumn{2}{|c|}{$\begin{array}{c}\text { z crítico } \\
<1,96\end{array}$} & \multicolumn{3}{|c|}{ P crítico $>0,05$} & \multicolumn{3}{|c|}{ Pcrítico $>0,05$} & \multicolumn{3}{|c|}{ P crítico $>0,05$} \\
\hline & & & & & & & & & & raiz & 0,259 & raiz & 0,130 & & & & & & & & & \\
\hline GENERO & 0,46 & 0,00 & 0,00 & 0,50 & 0,25 & 0,00 & 1,00 & 1,99 & 0,15 & $-7,67$ & NÃO & 1,18 & SIM & 0,63 & 0,000 & NÃO & 0,36 & 0,000 & NÃO & 12,06 & 0,000 & NÃO \\
\hline IDADE & 15,67 & 15,67 & 15,00 & 1,00 & 0,99 & $\begin{array}{c}13,0 \\
0\end{array}$ & 20,00 & 1,51 & 0,85 & 5,82 & NÃO & 6,57 & NÃO & 0,87 & 0,000 & NÃO & 0,25 & 0,000 & NÃO & 2,36 & 0,030 & NÃO \\
\hline DISTANCIA & $\begin{array}{c}12161, \\
21\end{array}$ & $\begin{array}{c}10622, \\
06 \\
\end{array}$ & $\begin{array}{c}12206, \\
94\end{array}$ & $\begin{array}{c}10085, \\
66\end{array}$ & \begin{tabular}{|c|}
10172046 \\
3,56 \\
\end{tabular} & $\begin{array}{c}55,3 \\
7 \\
\end{array}$ & 43615,91 & 0,00 & 0,89 & 0,02 & SIM & 6,87 & NÃO & 0,91 & 0,000 & NÃO & 0,12 & 0,000 & NÃO & 2,40 & 0,028 & NÃO \\
\hline RENDA & $\begin{array}{c}5069,3 \\
7\end{array}$ & $\begin{array}{c}3767,1 \\
4\end{array}$ & $\begin{array}{c}3432,8 \\
9\end{array}$ & \begin{tabular}{|c|}
3535,5 \\
1
\end{tabular} & \begin{tabular}{|c|}
12499810, \\
01 \\
\end{tabular} & $\begin{array}{c}187, \\
39\end{array}$ & 19824,31 & 1,33 & 1,11 & 5,15 & NÃO & 8,58 & NÃO & 0,90 & 0,000 & NÃO & 0,15 & 0,000 & NÃO & 3,82 & 0,001 & NÃO \\
\hline DENSIDADE & $\begin{array}{c}9294,2 \\
5\end{array}$ & $\begin{array}{c}3734,3 \\
7\end{array}$ & $\begin{array}{c}37343, \\
\quad 67 \\
\end{array}$ & $\begin{array}{c}11962, \\
56\end{array}$ & \begin{tabular}{|c|}
14310295 \\
2,81 \\
\end{tabular} & 4,89 & 68434,98 & 2,45 & 1,68 & 9,45 & NÃO & 12,96 & NÃO & 0,75 & 0,000 & NÃO & 0,22 & 0,000 & NÃO & 2,73 & 0,013 & NÃO \\
\hline DISPAUTO & 0,98 & 1,00 & 1,00 & 0,13 & 0,02 & 0,00 & 1,00 & $\begin{array}{c}55,3 \\
1\end{array}$ & $-7,55$ & 213,30 & NÃO & $-58,23$ & NÃO & 0,11 & 0,000 & NÃO & 0,54 & 0,000 & NÃO & 3,23 & 0,004 & NÃO \\
\hline MODOIDA & 5,75 & 5,00 & 5,00 & 2,33 & 5,44 & 1,00 & 9,00 & 0,41 & $-0,02$ & $-1,60$ & SIM & $-0,16$ & SIM & 0,78 & 0,000 & NÃO & 0,32 & 0,000 & NÃO & Dep & Dep & \\
\hline MODOVOLTA & 5,28 & 5,00 & 5,00 & 2,29 & 5,24 & 0,00 & 9,00 & 0,21 & $-0,07$ & 0,81 & SIM & $-0,52$ & SIM & 0,78 & 0,000 & NÃO & 0,32 & 0,000 & NÃO & 26,05 & 0,000 & NÃO \\
\hline HABON & 0,26 & 0,22 & 0,00 & 0,26 & 0,07 & 0,00 & 1,00 & 1,09 & 1,22 & 4,20 & NÃO & 9,38 & NÃO & 0,85 & 0,000 & NÃO & 0,16 & 0,000 & NÃO & 0,97 & 0,445 & SIM \\
\hline HABAP & 0,31 & 0,33 & 0,00 & 0,24 & 0,06 & 0,00 & 1,00 & 0,14 & 0,57 & 0,54 & SIM & 4,42 & NÃO & 0,93 & 0,000 & NÃO & 0,11 & 0,000 & NÃO & 1,63 & 0,137 & SIM \\
\hline HABAC & 0,05 & 0,00 & 0,00 & 0,13 & 0,02 & 0,00 & 1,00 & $\begin{array}{c}28,2 \\
1\end{array}$ & 4,69 & 108,78 & NÃO & 36,21 & NÃO & 0,43 & 0,000 & NÃO & 0,40 & 0,000 & NÃO & 1,72 & 0,115 & SIM \\
\hline HABBC & 0,08 & 0,00 & 0,00 & 0,17 & 0,03 & 0,00 & 2,00 & $\begin{array}{c}46,6 \\
9\end{array}$ & 5,39 & 180,08 & NÃO & 41,54 & NÃO & 0,49 & 0,000 & NÃO & 0,33 & 0,000 & NÃO & 4,17 & 0,000 & NÃO \\
\hline HABAF & 0,27 & 0,14 & 0,00 & 0,32 & 0,11 & 0,00 & 3,00 & $\begin{array}{c}13,1 \\
6\end{array}$ & 2,38 & 50,76 & NÃO & 18,39 & NÃO & 0,77 & 0,000 & NÃO & 0,20 & 0,000 & NÃO & 5,13 & 0,000 & NÃO \\
\hline
\end{tabular}




\begin{tabular}{|c|c|c|c|c|c|c|c|c|c|c|c|c|c|c|c|c|c|c|c|c|c|c|}
\hline & & & & & & & & & & \multirow{2}{*}{\multicolumn{2}{|c|}{$\begin{array}{c}\text { TESTE Z } \\
\text { CURTOSE } \\
\text { curt/raiz(24/n) }\end{array}$}} & \multirow{2}{*}{\multicolumn{2}{|c|}{$\begin{array}{c}\text { TESTE Z } \\
\text { ASSIMETRIA } \\
\text { ass/raiz(6/n) } \\
\end{array}$}} & \multirow{2}{*}{\multicolumn{3}{|c|}{$\begin{array}{c}\text { TESTE SHAPIRO-WILK } \\
\text { H0= VAR SEGUE DISTR. } \\
\text { NORMAL }\end{array}$}} & \multirow{2}{*}{\multicolumn{3}{|c|}{$\begin{array}{c}\text { TESTE KOLMOGOROV } \\
\text { SMIRNOV } \\
\text { H0= VAR SEGUE DISTR. } \\
\text { NORMAL } \\
\end{array}$}} & \multirow{2}{*}{\multicolumn{3}{|c|}{$\begin{array}{c}\text { TESTE LEVENE } \\
\text { h0=NÃO EXISTIR } \\
\text { DIFERENÇAS } \\
\end{array}$}} \\
\hline & \multicolumn{9}{|c|}{ ESTATÍSTICAS DESCRITIVAS } & & & & & & & & & & & & & \\
\hline VARIÁVEL & 空 & 莸 & ஜ̊ & 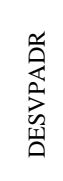 & 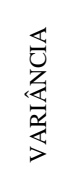 & $\sum_{i=}^{0}$ & 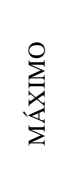 & 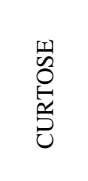 & 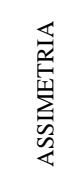 & 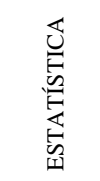 & 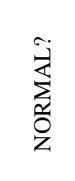 & 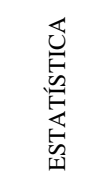 & 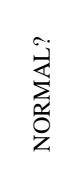 & 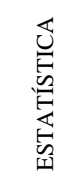 & $=$ & 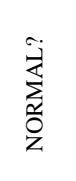 & 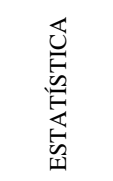 & $=$ & 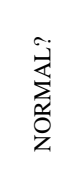 & 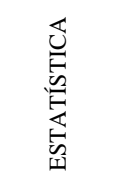 & 2 & 苜 \\
\hline $\begin{array}{c}\begin{array}{c}\text { Variáveis com } \\
n=255\end{array} \\
\end{array}$ & & & & & & & & & & z crítico & $<1,96$ & z crítico & $<1,96$ & $\begin{array}{c}P \\
\text { crítico } \\
\end{array}$ & $>0,05$ & & P crítico & $>0,05$ & & P crítico & $>0,05$ & \\
\hline & & & & & & & & & & raiz & 0,307 & raiz & 0,153 & & & & & & & & & \\
\hline HABVF & 0,02 & 0,00 & 0,00 & 0,22 & 0,05 & 0,00 & 4,00 & 327,94 & 17,78 & 1264,79 & NÃO & 137,11 & NÃO & 0,07 & 0,000 & NÃO & 0,46 & 0,000 & NÃO & 1,27 & 0,271 & SIM \\
\hline HABMT & 0,05 & 0,00 & 0,00 & 0,29 & 0,08 & 0,00 & 5,00 & 253,77 & 14,91 & 978,74 & NÃO & 115,01 & NÃO & 0,15 & 0,000 & NÃO & 0,43 & 0,000 & NÃO & 2,81 & 0,011 & NÃO \\
\hline CPAP & 2,15 & 1,00 & 1,00 & 1,51 & 2,28 & 1,00 & 5,00 & $-0,65$ & 0,95 & $-2,51$ & NÃO & 7,37 & NÃO & 0,73 & 0,000 & NÃO & 0,32 & 0,000 & NÃO & 1,68 & 0,124 & SIM \\
\hline CPON & 3,81 & 4,00 & 5,00 & 1,43 & 2,06 & 1,00 & 5,00 & $-0,57$ & $-0,92$ & $-2,20$ & NÃO & $-7,10$ & NÃO & 0,77 & 0,000 & NÃO & 0,27 & 0,000 & NÃO & 1,21 & 0,301 & SIM \\
\hline CPAF & 2,93 & 3,00 & 3,00 & 1,38 & 1,90 & 1,00 & 5,00 & $-1,13$ & 0,08 & $-4,38$ & NÃO & 0,62 & SIM & 0,89 & 0,000 & NÃO & 0,15 & 0,000 & NÃO & 1,44 & 0,199 & SIM \\
\hline CPAC & 1,64 & 1,00 & 1,00 & 0,96 & 0,93 & 1,00 & 5,00 & 2,60 & 1,72 & 10,03 & NÃO & 13,28 & NÃO & 0,70 & 0,000 & NÃO & 0,33 & 0,000 & NÃO & 2,87 & 0,010 & NÃO \\
\hline СРВC & 1,37 & 1,00 & 1,00 & 0,93 & 0,86 & 1,00 & 5,00 & 6,56 & 2,71 & 25,29 & NÃO & 20,90 & NÃO & 0,46 & 0,000 & NÃO & 0,44 & 0,000 & NÃO & 5,87 & 0,000 & NÃO \\
\hline CPTE & 1,46 & 1,00 & 1,00 & 1,08 & 1,18 & 1,00 & 5,00 & 4,49 & 2,41 & 17,31 & NÃO & 18,61 & NÃO & 0,47 & 0,000 & NÃO & 0,44 & 0,000 & NÃO & 1,67 & 0,127 & SIM \\
\hline CPMT & 1,33 & 1,00 & 1,00 & 0,83 & 0,68 & 1,00 & 5,00 & 7,55 & 2,83 & 29,13 & NÃO & 21,86 & NÃO & 0,45 & 0,000 & NÃO & 0,45 & 0,000 & NÃO & 2,84 & 0,010 & NÃO \\
\hline
\end{tabular}




\begin{tabular}{|c|c|c|c|c|c|c|c|c|c|c|c|c|c|c|c|c|c|c|c|c|c|c|}
\hline & & & & & & & & & & \multicolumn{2}{|c|}{$\begin{array}{c}\text { TESTE Z } \\
\text { CURTOSE }\end{array}$} & \multicolumn{2}{|c|}{$\begin{array}{c}\text { TESTE Z } \\
\text { ASSIMETRIA } \\
\end{array}$} & \multirow{2}{*}{\multicolumn{3}{|c|}{$\begin{array}{c}\text { TESTE SHAPIRO-WILK } \\
\text { H0= VAR SEGUE DISTR. } \\
\text { NORMAL } \\
\end{array}$}} & \multirow{2}{*}{\multicolumn{3}{|c|}{$\begin{array}{c}\text { TESTE KOLMOGOROV } \\
\text { SMIRNOV } \\
\text { H0= VAR SEGUE DISTR. } \\
\text { NORMAL } \\
\end{array}$}} & \multirow{2}{*}{\multicolumn{3}{|c|}{$\begin{array}{c}\text { TESTE LEVENE } \\
\text { h0=NÃO EXISTIR } \\
\text { DIFERENÇAS }\end{array}$}} \\
\hline & \multicolumn{9}{|c|}{ ESTATÍSTICAS DESCRITIVAS } & $\begin{array}{l}\text { curt/rai } \\
\mathrm{z}(24 / \mathrm{n}) \\
\end{array}$ & & $\begin{array}{c}\text { ass/raiz } \\
(6 / n) \\
\end{array}$ & & & & & & & & & & \\
\hline VARIÁVEL & 恧 & 㚆 & ஜ & 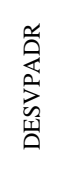 & 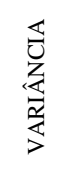 & $\sum_{\sum}^{\infty}$ & $\sum_{\substack{x \\
x}}^{0}$ & 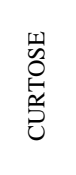 & 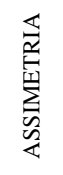 & 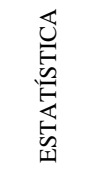 & 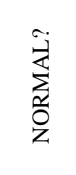 & 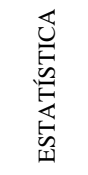 & 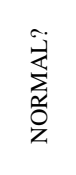 & 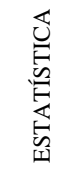 & $=$ & 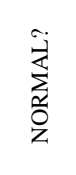 & 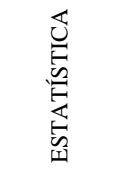 & $=$ & 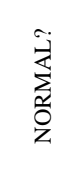 & 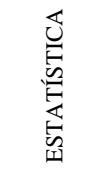 & 2 & 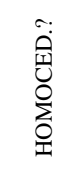 \\
\hline $\begin{array}{c}\begin{array}{c}\text { Variáveis com } \\
n=255\end{array} \\
\end{array}$ & & & & & & & & & & $\begin{array}{c}z \\
\text { crítico } \\
\end{array}$ & $<1,96$ & $\begin{array}{c}z \\
\text { crítico } \\
\end{array}$ & $<1,96$ & $\begin{array}{c}P \\
\text { crítico }\end{array}$ & $>0,05$ & & P crítico & $>0,05$ & & P crítico & $>0,05$ & \\
\hline & & & & & & & & & & raiz & 0,307 & raiz & 0,153 & & & & & & & & & \\
\hline APDAT1 & 2,35 & 2,00 & 1,00 & 1,50 & 2,26 & 1,00 & 5,00 & $-1,06$ & 0,65 & $-3,45$ & NÃO & 4,22 & NÃO & 0,79 & 0,000 & NÃO & 0,28 & 0,000 & NÃO & 12,84 & 0,000 & NÃO \\
\hline APDAT2 & 2,40 & 2,00 & 1,00 & 1,43 & 2,05 & 1,00 & 5,00 & $-1,08$ & 0,53 & $-3,51$ & NÃO & 3,48 & NÃO & 0,83 & 0,000 & NÃO & 0,25 & 0,000 & NÃO & 19,22 & 0,000 & NÃO \\
\hline APDAT3 & 2,28 & 2,00 & 1,00 & 1,44 & 2,09 & 1,00 & 5,00 & $-0,98$ & 0,66 & $-3,19$ & NÃO & 4,33 & NÃO & 0,80 & 0,000 & NÃO & 0,29 & 0,000 & NÃO & 13,23 & 0,000 & NÃO \\
\hline MEDAPDAT & 2,34 & 2,33 & 1,00 & 1,25 & 1,57 & 1,00 & 5,00 & $-0,88$ & 0,54 & $-2,88$ & NÃO & 3,51 & NÃO & 0,89 & 0,000 & NÃO & 0,16 & 0,000 & NÃO & Dep & Dep & \\
\hline APDNS1 & 2,70 & 3,00 & 3,00 & 1,21 & 1,46 & 1,00 & 5,00 & $-0,84$ & 0,17 & $-2,73$ & NÃO & 1,09 & SIM & 0,91 & 0,000 & NÃO & 0,17 & 0,000 & NÃO & 1,05 & 0,401 & SIM \\
\hline APDNS2 & 2,82 & 3,00 & 3,00 & 1,13 & 1,28 & 1,00 & 5,00 & $-0,59$ & 0,03 & $-1,92$ & NÃO & 0,21 & SIM & 0,91 & 0,000 & NÃO & 0,21 & 0,000 & NÃO & 2,15 & 0,011 & NÃO \\
\hline APDNS3 & 3,05 & 3,00 & 3,00 & 1,19 & 1,43 & 1,00 & 5,00 & $-0,77$ & $-0,06$ & $-2,52$ & NÃO & $-0,38$ & SIM & 0,91 & 0,000 & NÃO & 0,17 & 0,000 & NÃO & 0,59 & 0,872 & SIM \\
\hline MEDAPDNS & 2,86 & 3,00 & 2,67 & 0,83 & 0,68 & 1,00 & 5,00 & $-0,03$ & 0,12 & $-0,09$ & SIM & 0,78 & SIM & 0,98 & 0,001 & NÃO & 0,08 & 0,000 & NÃO & 1,19 & 0,286 & SIM \\
\hline APDCP1 & 2,97 & 3,00 & 1,00 & 1,60 & 2,56 & 1,00 & 5,00 & $-1,53$ & 0,02 & $-4,98$ & NÃO & 0,11 & SIM & 0,83 & 0,000 & NÃO & 0,20 & 0,000 & NÃO & 2,48 & 0,003 & NÃO \\
\hline APDCP2 & 2,24 & 1,00 & 1,00 & 1,51 & 2,29 & 1,00 & 5,00 & $-1,01$ & 0,74 & $-3,30$ & NÃO & 4,82 & NÃO & 0,76 & 0,000 & NÃO & 0,33 & 0,000 & NÃO & 6,06 & 0,000 & NÃO \\
\hline APCP3 & 2,43 & 2,00 & 1,00 & 1,46 & 2,13 & 1,00 & 5,00 & $-1,15$ & 0,50 & $-3,74$ & NÃO & 3,23 & NÃO & 0,82 & 0,000 & NÃO & 0,26 & 0,000 & NÃO & 3,83 & 0,000 & NÃO \\
\hline MDAPDCP & 2,55 & 2,33 & 1,00 & 1,22 & 1,49 & 1,00 & 5,00 & $-0,79$ & 0,43 & $-2,56$ & NÃO & 2,78 & NÃO & 0,93 & 0,000 & NÃO & 0,11 & 0,000 & NÃO & 1,65 & 0,068 & SIM \\
\hline APDIT1 & 2,43 & 2,00 & 1,00 & 1,31 & 1,71 & 1,00 & 5,00 & $-0,84$ & 0,53 & $-2,75$ & NÃO & 3,44 & NÃO & 0,87 & 0,000 & NÃO & 0,19 & 0,000 & NÃO & 1,04 & 0,415 & SIM \\
\hline APDIT2 & 2,18 & 1,00 & 1,00 & 1,42 & 2,02 & 1,00 & 5,00 & $-0,78$ & 0,78 & $-2,54$ & NÃO & 5,11 & NÃO & 0,77 & 0,000 & NÃO & 0,31 & 0,000 & NÃO & 4,99 & 0,000 & NÃO \\
\hline APDIT3 & 1,90 & 1,00 & 1,00 & 1,39 & 1,94 & 1,00 & 5,00 & 0,16 & 1,28 & 0,53 & SIM & 8,36 & NÃO & 0,67 & 0,000 & NÃO & 0,38 & 0,000 & NÃO & 9,03 & 0,000 & NÃO \\
\hline MEDAPDIT & 2,17 & 2,00 & 1,00 & 1,12 & 1,26 & 1,00 & 5,00 & $-0,27$ & 0,83 & $-0,87$ & SIM & 5,41 & NÃO & 0,89 & 0,000 & NÃO & 0,17 & 0,000 & NÃO & 1,68 & 0,061 & SIM \\
\hline
\end{tabular}




\begin{tabular}{|c|c|c|c|c|c|c|c|c|c|c|c|c|c|c|c|c|c|c|c|c|c|c|}
\hline & & & & & & & & & & \multicolumn{2}{|c|}{$\begin{array}{c}\text { TESTE Z } \\
\text { CURTOSE } \\
\end{array}$} & \multicolumn{2}{|c|}{$\begin{array}{c}\text { TESTE Z } \\
\text { ASSIMETRIA } \\
\end{array}$} & \multirow{2}{*}{\multicolumn{3}{|c|}{$\begin{array}{c}\text { TESTE SHAPIRO-WILK } \\
\text { H0= VAR SEGUE DISTR. } \\
\text { NORMAL }\end{array}$}} & \multirow{2}{*}{\multicolumn{3}{|c|}{$\begin{array}{c}\text { TESTE KOLMOGOROV } \\
\text { SMIRNOV } \\
\text { H0= VAR SEGUE DISTR. } \\
\text { NORMAL }\end{array}$}} & \multirow{2}{*}{\multicolumn{3}{|c|}{$\begin{array}{c}\text { TESTE LEVENE } \\
\text { h0=NÃO EXISTIR } \\
\text { DIFERENÇAS }\end{array}$}} \\
\hline & \multicolumn{9}{|c|}{ ESTATÍSTICAS DESCRITIVAS } & $\begin{array}{c}\text { curt/raiz( } \\
24 / \mathrm{n}) \\
\end{array}$ & & $\begin{array}{c}\text { ass/raiz } \\
(6 / \mathrm{n})\end{array}$ & & & & & & & & & & \\
\hline VARIÁVEL & 吾 & $\begin{array}{l}\overleftrightarrow{z} \\
\text { 帘 } \\
\text { 丞 }\end{array}$ & ڤి & 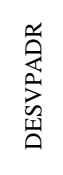 & 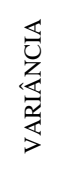 & $\sum_{\substack{\xi \\
\sum}}^{0}$ & 离 & 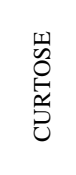 & 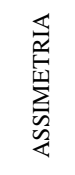 & 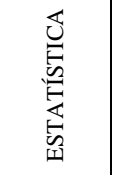 & 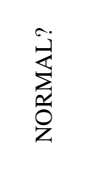 & 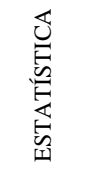 & 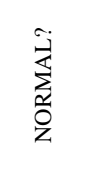 & 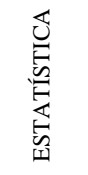 & $\approx$ & $\begin{array}{l}\hat{\vec{z}} \\
\sum_{0} \\
\dot{z}\end{array}$ & 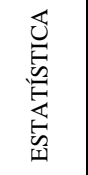 & $=$ & 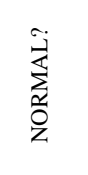 & 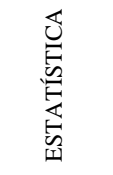 & 2 & 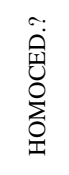 \\
\hline $\begin{array}{c}\begin{array}{c}\text { Variáveis com } \\
n=255\end{array} \\
\end{array}$ & & & & & & & & & & z crítico & $<1,96$ & $\begin{array}{c}z \\
\text { crítico } \\
\end{array}$ & $<1,96$ & $\begin{array}{c}P \\
\text { crítico } \\
\end{array}$ & $>0,05$ & & $\begin{array}{c}P \\
\text { crítico } \\
\end{array}$ & $>0,05$ & & P crítico & $>0,05$ & \\
\hline & & & & & & & & & & raiz & 0,307 & raiz & 0,153 & & & & & & & & & \\
\hline САРCBO1 & 0,00 & 0,23 & 0,23 & 1,15 & 1,32 & $-2,77$ & 1,23 & 0,05 & $-0,86$ & 0,16 & SIM & $-5,62$ & NÃO & 0,85 & 0,000 & NÃO & 0,24 & 0,000 & NÃO & 2,24 & 0,007 & NÃO \\
\hline CAPCBE1 & 0,00 & $-0,17$ & $-0,17$ & 1,41 & 2,00 & $-2,17$ & 1,83 & $-1,15$ & $-0,16$ & $-3,76$ & NÃO & $-1,04$ & SIM & 0,87 & 0,000 & NÃO & 0,16 & 0,000 & NÃO & 3,55 & 0,000 & NÃO \\
\hline $\begin{array}{c}\text { CAPCBO1XCAP } \\
\text { CBE1 }\end{array}$ & 0,64 & 0,19 & 2,24 & 1,62 & 2,62 & $-3,24$ & 6,03 & 2,89 & 1,09 & 9,42 & NÃO & 7,13 & NÃO & 0,87 & 0,000 & NÃO & 0,21 & 0,000 & NÃO & 3,65 & 0,000 & NÃO \\
\hline САРCBO2 & 0,00 & $-0,06$ & $-1,06$ & 1,15 & 1,32 & $-1,06$ & 2,94 & 0,12 & 0,97 & 0,39 & SIM & 6,35 & NÃO & 0,82 & 0,000 & NÃO & 0,23 & 0,000 & NÃO & 0,96 & 0,493 & SIM \\
\hline CAPCBE2 & 0,00 & 0,00 & 1,69 & 1,57 & 2,47 & $-2,31$ & 1,69 & $-1,43$ & $-0,31$ & $-4,65$ & NÃO & $-2,04$ & NÃO & 0,83 & 0,000 & NÃO & 0,22 & 0,000 & NÃO & 3,54 & 0,000 & NÃO \\
\hline $\begin{array}{c}\text { CAPCBO2XCAP } \\
\text { CBE2 }\end{array}$ & $-0,01$ & $-0,04$ & $-1,78$ & 1,84 & 3,40 & $-6,81$ & 4,97 & 2,15 & $-0,56$ & 7,01 & NÃO & $-3,67$ & NÃO & 0,93 & 0,000 & NÃO & 0,14 & 0,000 & NÃO & 1,57 & 0,087 & SIM \\
\hline САРCBO3 & 0,00 & 0,18 & 0,18 & 1,23 & 1,52 & $-1,82$ & 2,18 & $-0,77$ & 0,14 & $-2,51$ & NÃO & 0,93 & SIM & 0,90 & 0,000 & NÃO & 0,18 & 0,000 & NÃO & 2,01 & 0,018 & NÃO \\
\hline CAPCBE3 & 0,00 & 0,10 & 0,10 & 1,38 & 1,90 & $-1,90$ & 2,10 & $-1,13$ & 0,06 & $-3,67$ & NÃO & 0,39 & SIM & 0,89 & 0,000 & NÃO & 0,16 & 0,000 & NÃO & 2,24 & 0,007 & NÃO \\
\hline $\begin{array}{c}\text { CAPCBO3XCAP } \\
\text { CBE3 } \\
\end{array}$ & 0,53 & 0,12 & 0,02 & 1,78 & 3,18 & $-4,14$ & 4,57 & 0,79 & 0,03 & 2,56 & NÃO & 0,22 & SIM & 0,91 & 0,000 & NÃO & 0,19 & 0,000 & NÃO & 3,58 & 0,000 & NÃO \\
\hline CAPCNO1 & 0,00 & $-0,32$ & $-1,32$ & 1,24 & 1,53 & $-1,32$ & 2,68 & $-0,60$ & 0,62 & $-1,95$ & SIM & 4,03 & NÃO & 0,86 & 0,000 & NÃO & 0,19 & 0,000 & NÃO & 0,87 & 0,588 & SIM \\
\hline CAPCNE1 & 0,00 & $-0,34$ & $-1,34$ & 1,42 & 2,00 & $-1,34$ & 2,66 & $-1,03$ & 0,57 & $-3,35$ & NÃO & 3,70 & NÃO & 0,82 & 0,000 & NÃO & 0,27 & 0,000 & NÃO & 2,64 & 0,001 & NÃO \\
\hline $\begin{array}{c}\text { CAPCNO1XCAP } \\
\text { CNE1 }\end{array}$ & 0,59 & 0,45 & 1,76 & 1,76 & 3,08 & $-3,59$ & 7,14 & 1,65 & 0,34 & 5,39 & NÃO & 2,21 & NÃO & 0,93 & 0,000 & NÃO & 0,15 & 0,000 & NÃO & 0,74 & 0,735 & SIM \\
\hline CAPCNO2 & 0,00 & 0,15 & 0,15 & 1,16 & 1,35 & $-1,85$ & 2,15 & $-0,71$ & $-0,02$ & $-2,31$ & NÃO & $-0,11$ & SIM & 0,91 & 0,000 & NÃO & 0,20 & 0,000 & NÃO & 1,19 & 0,287 & SIM \\
\hline CAPCNE2 & 0,00 & $-0,34$ & $-1,34$ & 1,31 & 1,71 & $-1,34$ & 2,66 & $-0,69$ & 0,57 & $-2,24$ & NÃO & 3,74 & NÃO & 0,84 & 0,000 & NÃO & 0,23 & 0,000 & NÃO & 1,13 & 0,330 & SIM \\
\hline $\begin{array}{l}\text { CAPCNO2XCAP } \\
\text { CNE2 }\end{array}$ & 0,67 & 0,29 & 0,10 & 1,56 & 2,42 & $-4,91$ & 5,72 & 2,62 & 0,71 & 8,53 & NÃO & 4,63 & NÃO & 0,91 & 0,000 & NÃO & 0,16 & 0,000 & NÃO & 3,33 & 0,000 & NÃO \\
\hline CAPCCO1 & 0,00 & 0,31 & 1,31 & 1,30 & 1,69 & $-2,69$ & 1,31 & $-0,62$ & $-0,69$ & $-2,04$ & NÃO & $-4,47$ & NÃO & 0,85 & 0,000 & NÃO & 0,21 & 0,000 & NÃO & 0,97 & 0,482 & SIM \\
\hline
\end{tabular}




\begin{tabular}{|c|c|c|c|c|c|c|c|c|c|c|c|c|c|c|c|c|c|c|c|c|c|c|}
\hline & & & & & & & & & & \multicolumn{2}{|c|}{$\begin{array}{c}\text { TESTE Z } \\
\text { CURTOSE }\end{array}$} & \multicolumn{2}{|c|}{$\begin{array}{c}\text { TESTE Z } \\
\text { ASSIMETRIA }\end{array}$} & \multicolumn{3}{|c|}{ TESTE SHAPIRO-WILK } & \multicolumn{3}{|c|}{$\begin{array}{c}\text { TESTE KOLMOGOROV } \\
\text { SMIRNOV } \\
\end{array}$} & \multicolumn{3}{|c|}{ TESTE LEVENE } \\
\hline & \multicolumn{9}{|c|}{ ESTATÍSTICAS DESCRITIVAS } & \multicolumn{2}{|c|}{ curt/raiz(24/n) } & \multicolumn{2}{|c|}{ ass/raiz(6/n) } & \multicolumn{3}{|c|}{$\begin{array}{c}\mathrm{H} 0=\text { VAR SEGUE DISTR. } \\
\text { NORMAL }\end{array}$} & \multicolumn{3}{|c|}{$\begin{array}{c}\mathrm{H} 0=\text { VAR SEGUE DISTR. } \\
\text { NORMAL }\end{array}$} & \multicolumn{3}{|c|}{$\begin{array}{c}\text { h0=NÃO EXISTIR } \\
\text { DIFERENÇAS }\end{array}$} \\
\hline VARIÁVEL & 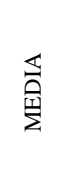 & 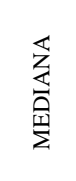 & $\begin{array}{l}\text { O̊ } \\
\stackrel{0}{\Sigma}\end{array}$ & 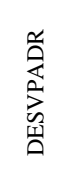 & 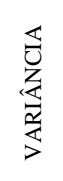 & 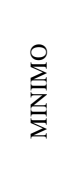 & 齐 & $\begin{array}{l}\text { w } \\
0 \\
0 \\
0 \\
\tilde{D} \\
0\end{array}$ & 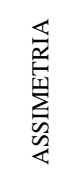 & 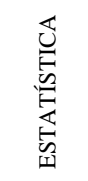 & 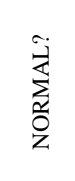 & 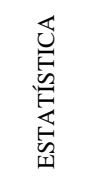 & 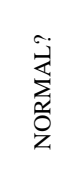 & 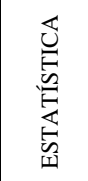 & $=$ & 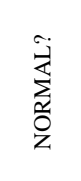 & 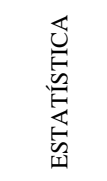 & D & 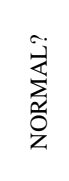 & 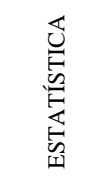 & 2 & 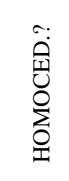 \\
\hline \multirow[t]{2}{*}{$\begin{array}{c}\text { Variáveis com } \\
n=255\end{array}$} & & & & & & & & & & $\begin{array}{c}z \\
\text { crítico } \\
\end{array}$ & $<1,96$ & $\begin{array}{c}z \\
\text { crítico } \\
\end{array}$ & $<1,96$ & $\begin{array}{c}P \\
\text { crítico } \\
\end{array}$ & $>0,05$ & & P crítico & $>0,05$ & & P crítico & $\begin{array}{l}> \\
0,05 \\
\end{array}$ & \\
\hline & & & & & & & & & & raiz & 0,307 & raiz & 0,153 & & & & & & & & & \\
\hline CAPCCE1 & 0,00 & $-0,11$ & 1,89 & 1,61 & 2,61 & $-2,11$ & 1,89 & $-1,55$ & $-0,14$ & $-5,04$ & NÃO & $-0,93$ & SIM & 0,83 & 0,000 & NÃO & 0,19 & 0,000 & NÃO & 7,51 & $\begin{array}{c}0,00 \\
0\end{array}$ & NÃO \\
\hline $\begin{array}{c}\text { CAPCCO1XCAP } \\
\text { CCE1 }\end{array}$ & 0,08 & $-0,04$ & 2,46 & 2,09 & 4,37 & $-5,08$ & 5,69 & 0,38 & 0,14 & 1,24 & SIM & 0,90 & SIM & 0,97 & 0,000 & NÃO & 0,10 & 0,000 & NÃO & 2,39 & $\begin{array}{c}0,00 \\
4\end{array}$ & NÃO \\
\hline CAPCCO2 & 0,00 & 0,09 & 1,09 & 1,34 & 1,80 & $-1,91$ & 2,09 & $-1,18$ & $-0,10$ & $-3,86$ & NÃO & $-0,66$ & SIM & 0,89 & 0,000 & NÃO & 0,17 & 0,000 & NÃO & 2,72 & $\begin{array}{c}0,00 \\
1\end{array}$ & NÃO \\
\hline CAPCCE2 & 0,00 & $-0,14$ & 1,86 & 1,49 & 2,23 & $-2,14$ & 1,86 & $-1,37$ & $-0,12$ & $-4,46$ & NÃO & $-0,80$ & SIM & 0,86 & 0,000 & NÃO & 0,17 & 0,000 & NÃO & 1,21 & $\begin{array}{c}0,27 \\
2\end{array}$ & SIM \\
\hline $\begin{array}{l}\text { CAPCCO2XCAP } \\
\text { CCE2 }\end{array}$ & 0,31 & $-0,01$ & $-0,01$ & 2,10 & 4,42 & $-4,48$ & 4,08 & $-0,22$ & 0,00 & $-0,73$ & SIM & 0,01 & SIM & 0,94 & 0,000 & NÃO & 0,16 & 0,000 & NÃO & 2,36 & $\begin{array}{c}0,00 \\
4\end{array}$ & NÃO \\
\hline
\end{tabular}




\begin{tabular}{|c|c|c|c|c|c|c|c|c|c|c|c|c|c|c|c|c|c|c|c|c|c|c|}
\hline & & & & & & & & & & \multirow{2}{*}{\multicolumn{2}{|c|}{$\begin{array}{c}\text { TESTE Z } \\
\text { CURTOSE } \\
\text { curt/raiz(24/n) }\end{array}$}} & \multirow{2}{*}{\multicolumn{2}{|c|}{$\begin{array}{c}\text { TESTE Z } \\
\text { ASSIMETRIA } \\
\text { ass/raiz(6/n) }\end{array}$}} & \multirow{2}{*}{\multicolumn{3}{|c|}{\begin{tabular}{|c} 
TESTE SHAPIRO-WILK \\
H0= VAR SEGUE DISTR. \\
NORMAL \\
\end{tabular}}} & \multirow{2}{*}{\multicolumn{3}{|c|}{$\begin{array}{c}\text { TESTE KOLMOGOROV } \\
\text { SMIRNOV } \\
\text { H0= VAR SEGUE DISTR. } \\
\text { NORMAL } \\
\end{array}$}} & \multirow{2}{*}{\multicolumn{3}{|c|}{$\begin{array}{c}\text { TESTE LEVENE } \\
\text { h0=NÃO EXISTIR } \\
\text { DIFERENÇAS } \\
\end{array}$}} \\
\hline & \multicolumn{9}{|c|}{ ESTATÍSTICAS DESCRITIVAS } & & & & & & & & & & & & & \\
\hline VARIÁVEL & $\begin{array}{l}\mathbb{1} \\
\text { 至 }\end{array}$ & 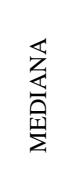 & $\stackrel{\circ}{0_{\Sigma}}$ & 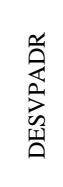 & 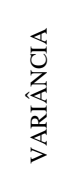 & $\sum_{i}^{0}$ & $\sum_{\substack{x \\
\sum}}^{0}$ & \begin{tabular}{l} 
w \\
0 \\
0 \\
\multicolumn{2}{|c|}{} \\
0
\end{tabular} & 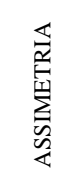 & 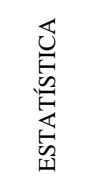 & 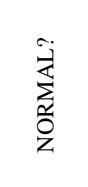 & 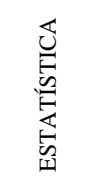 & 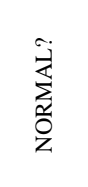 & 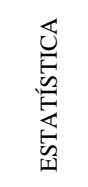 & $=$ & 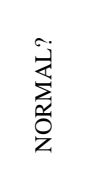 & 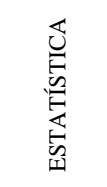 & $=$ & 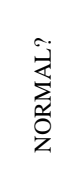 & 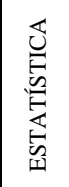 & 2 & 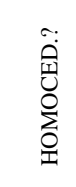 \\
\hline $\begin{array}{l}\text { Variáveis com } \\
\quad n=290\end{array}$ & & & & & & & & & & $\begin{array}{c}z \\
\text { crítico }\end{array}$ & $<1,96$ & $\begin{array}{c}z \\
\text { crítico }\end{array}$ & $<1,96$ & $\begin{array}{c}P \\
\text { crítico }\end{array}$ & $>0,05$ & & P crítico & $>0,05$ & & $\begin{array}{c}P \\
\text { críti } \\
\text { co }\end{array}$ & $\overrightarrow{0,05}$ & \\
\hline & & & & & & & & & & raiz & 0,288 & raiz & 0,144 & & & & & & & & & \\
\hline ONDAT1 & 3,21 & 3,00 & 3,00 & 1,22 & 1,49 & 1,00 & 5,00 & $-0,69$ & $-0,18$ & $-2,40$ & NÃO & $-1,23$ & SIM & 0,90 & 0,000 & NÃO & 0,20 & 0,000 & NÃO & 7,28 & 0,000 & NÃO \\
\hline ONDAT2 & 3,46 & 3,00 & 3,00 & 1,20 & 1,44 & 1,00 & 5,00 & $-0,56$ & $-0,35$ & $-1,93$ & SIM & $-2,45$ & NÃO & 0,89 & 0,000 & NÃO & 0,18 & 0,000 & NÃO & 7,82 & 0,000 & NÃO \\
\hline ONDAT3 & 3,42 & 3,00 & 3,00 & 1,22 & 1,48 & 1,00 & 5,00 & $-0,67$ & $-0,31$ & $-2,32$ & NÃO & $-2,17$ & NÃO & 0,89 & 0,000 & NÃO & 0,18 & 0,000 & NÃO & 6,44 & 0,000 & NÃO \\
\hline MEDONDAT & 3,36 & 3,33 & 3,00 & 0,97 & 0,94 & 1,00 & 5,00 & $-0,06$ & $-0,31$ & $-0,20$ & SIM & $-2,13$ & NÃO & 0,96 & 0,000 & NÃO & 0,13 & 0,000 & NÃO & Dep & Dep & \\
\hline ONDNS1 & 3,30 & 3,00 & 3,00 & 1,10 & 1,20 & 1,00 & 5,00 & $-0,21$ & $-0,18$ & $-0,75$ & SIM & $-1,28$ & SIM & 0,88 & 0,000 & NÃO & 0,24 & 0,000 & NÃO & 2,12 & 0,009 & NÃO \\
\hline ONDNS2 & 3,26 & 3,00 & 3,00 & 1,02 & 1,04 & 1,00 & 5,00 & 0,01 & $-0,25$ & 0,02 & SIM & $-1,72$ & SIM & 0,89 & 0,000 & NÃO & 0,23 & 0,000 & NÃO & 2,15 & 0,008 & NÃO \\
\hline ONDNS3 & 3,24 & 3,00 & 3,00 & 1,11 & 1,24 & 1,00 & 5,00 & $-0,37$ & $-0,19$ & $-1,30$ & SIM & $-1,30$ & SIM & 0,90 & 0,000 & NÃO & 0,21 & 0,000 & NÃO & 1,03 & 0,422 & SIM \\
\hline MEDONDNS & 3,27 & 3,00 & 3,00 & 0,78 & 0,61 & 1,00 & 5,00 & 0,75 & $-0,19$ & 2,60 & NÃO & $-1,35$ & SIM & 0,95 & 0,000 & NÃO & 0,19 & 0,000 & NÃO & 2,30 & 0,004 & NÃO \\
\hline ONDCP1 & 3,45 & 3,00 & 3,00 & 1,25 & 1,56 & 1,00 & 5,00 & $-0,72$ & $-0,35$ & $-2,50$ & NÃO & $-2,43$ & NÃO & 0,88 & 0,000 & NÃO & 0,18 & 0,000 & NÃO & 1,19 & 0,279 & SIM \\
\hline ONDCP2 & 3,54 & 3,54 & 3,00 & 1,21 & 1,46 & 1,00 & 5,00 & $-0,65$ & $-0,39$ & $-2,25$ & NÃO & $-2,73$ & NÃO & 0,89 & 0,000 & NÃO & 0,18 & 0,000 & NÃO & 3,87 & 0,000 & NÃO \\
\hline ONDCP3 & 3,66 & 4,00 & 5,00 & 1,29 & 1,67 & 1,00 & 5,00 & $-0,71$ & $-0,60$ & $-2,46$ & NÃO & $-4,17$ & NÃO & 0,86 & 0,000 & NÃO & 0,21 & 0,000 & NÃO & 4,43 & 0,000 & NÃO \\
\hline MEDONDCP & 3,55 & 3,67 & 3,00 & 0,97 & 0,93 & 1,00 & 5,00 & $-0,38$ & $-0,34$ & $-1,31$ & SIM & $-2,39$ & NÃO & 0,96 & 0,000 & NÃO & 0,10 & 0,000 & NÃO & 1,76 & 0,040 & NÃO \\
\hline ONDIT1 & 3,42 & 3,71 & 4,00 & 1,18 & 1,39 & 1,00 & 5,00 & $-0,43$ & $-0,50$ & $-1,50$ & SIM & $-3,51$ & NÃO & 0,89 & 0,000 & NÃO & 0,19 & 0,000 & NÃO & 2,66 & 0,001 & NÃO \\
\hline ONDIT2 & 3,60 & 4,00 & 5,00 & 1,28 & 1,64 & 1,00 & 5,00 & $-0,67$ & $-0,53$ & $-2,33$ & NÃO & $-3,65$ & NÃO & 0,86 & 0,000 & NÃO & 0,20 & 0,000 & NÃO & 4,83 & 0,000 & NÃO \\
\hline ONDIT3 & 3,82 & 4,00 & 5,00 & 1,29 & 1,65 & 1,00 & 5,00 & $-0,53$ & $-0,77$ & $-1,83$ & SIM & $-5,33$ & NÃO & 0,82 & 0,000 & NÃO & 0,26 & 0,000 & NÃO & 8,60 & 0,000 & NÃO \\
\hline MEDONDIT & 3,61 & 3,67 & 3,00 & 0,98 & 0,97 & 1,00 & 5,00 & $-0,20$ & $-0,54$ & $-0,68$ & SIM & $-3,74$ & NÃO & 0,95 & 0,000 & NÃO & 0,10 & 0,000 & NÃO & 3,84 & 0,000 & NÃO \\
\hline CONCBO1 & 0,00 & 0,28 & 0,28 & 1,08 & 1,17 & $-2,72$ & 1,28 & $-0,07$ & $-0,69$ & $-0,26$ & SIM & $-4,77$ & NÃO & 0,87 & 0,000 & NÃO & 0,23 & 0,000 & NÃO & 1,44 & 0,127 & SIM \\
\hline CONCBE1 & 0,00 & 1,02 & 1,02 & 1,22 & 1,48 & $-2,98$ & 1,02 & $-0,32$ & $-0,89$ & $-1,10$ & SIM & $-6,20$ & NÃO & 0,79 & 0,000 & NÃO & 0,30 & 0,000 & NÃO & 9,83 & 0,000 & NÃO \\
\hline
\end{tabular}




\begin{tabular}{|c|c|c|c|c|c|c|c|c|c|c|c|c|c|c|c|c|c|c|c|c|c|c|}
\hline \multirow[b]{3}{*}{ VARIÁVEL } & \multicolumn{9}{|c|}{ ESTATÍSTICAS DESCRITIVAS } & \multirow{2}{*}{\multicolumn{2}{|c|}{$\begin{array}{c}\text { TESTE Z } \\
\text { CURTOSE } \\
\text { curt/raiz(24/n) }\end{array}$}} & \multirow{2}{*}{\multicolumn{2}{|c|}{$\begin{array}{c}\text { TESTE Z } \\
\text { ASSIMETRIA } \\
\text { ass/raiz(6/n) }\end{array}$}} & \multirow{2}{*}{\multicolumn{3}{|c|}{$\begin{array}{c}\text { TESTE SHAPIRO-WILK } \\
\text { H0= VAR SEGUE DISTR. } \\
\text { NORMAL }\end{array}$}} & \multirow{2}{*}{\multicolumn{3}{|c|}{$\begin{array}{c}\text { TESTE KOLMOGOROV } \\
\text { SMIRNOV } \\
\text { H0= VAR SEGUE DISTR. } \\
\text { NORMAL } \\
\end{array}$}} & \multirow{2}{*}{\multicolumn{3}{|c|}{$\begin{array}{c}\text { TESTE LEVENE } \\
\text { h0=NÃO EXISTIR } \\
\text { DIFERENÇAS }\end{array}$}} \\
\hline & \multirow[b]{2}{*}{ 空 } & \multirow[b]{2}{*}{ 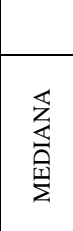 } & \multirow[b]{2}{*}{$\begin{array}{l}\circ \\
\overbrace{\Sigma}^{\circ}\end{array}$} & \multirow[b]{2}{*}{ 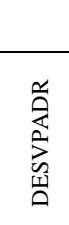 } & \multirow[b]{2}{*}{ 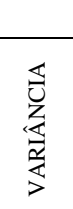 } & & & & & & & & & & & & & & & & & \\
\hline & & & & & & $\sum_{i}^{\circ}$ & $\underset{\substack{\infty \\
\vdots}}{\substack{x \\
\Sigma}}$ & $\begin{array}{l}\text { w } \\
0 \\
0 \\
0 \\
0 \\
0\end{array}$ & 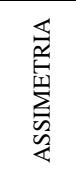 & 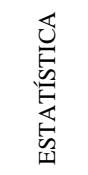 & 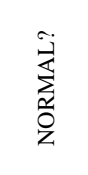 & 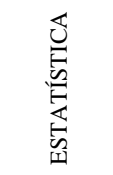 & 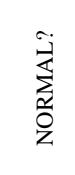 & 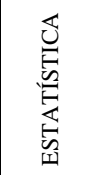 & $=$ & 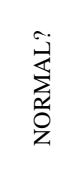 & 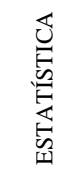 & $=$ & 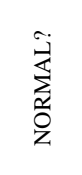 & 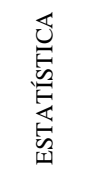 & $a$ & 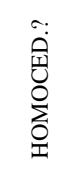 \\
\hline Variáveis com $n=255$ & & & & & & & & & & $\begin{array}{c}z \\
\text { crítico }\end{array}$ & $<1,96$ & z crítico & $<1,96$ & $\begin{array}{c}P \\
\text { crítico }\end{array}$ & $>0,05$ & & $\begin{array}{c}P \\
\text { crítico }\end{array}$ & $>0,05$ & & $\begin{array}{c}P \\
\text { crítico }\end{array}$ & $>0,05$ & \\
\hline & & & & & & & & & & raiz & 0,307 & raiz & 0,153 & & & & & & & & & \\
\hline CONCBO1XCONCBE1 & 0,52 & 0,29 & 0,29 & 1,40 & 1,97 & $-2,76$ & 8,10 & 7,24 & 1,80 & 25,15 & NÃO & 12,52 & NÃO & 0,85 & 0,000 & NÃO & 0,18 & 0,000 & NÃO & 2,06 & 0,012 & NÃO \\
\hline CONCBO2 & 0,00 & 0,48 & 0,48 & 1,20 & 1,43 & $-1,52$ & 2,48 & $-0,73$ & 0,30 & $-2,53$ & NÃO & 2,10 & NÃO & 0,89 & 0,000 & NÃO & 0,18 & 0,000 & NÃO & 2,28 & 0,005 & NÃO \\
\hline CONCBE2 & 0,00 & $-0,44$ & $-0,44$ & 1,24 & 1,54 & $-2,44$ & 1,56 & $-0,78$ & $-0,29$ & $-2,73$ & NÃO & $-2,04$ & NÃO & 0,88 & 0,000 & NÃO & 0,18 & 0,000 & NÃO & 5,29 & 0,000 & NÃO \\
\hline CONCBO2XCONCBE2 & 0,02 & $-0,21$ & $-0,21$ & 1,58 & 2,48 & $-6,05$ & 3,85 & 1,22 & 0,06 & 4,24 & NÃO & 0,45 & SIM & 0,94 & 0,000 & NÃO & 0,16 & 0,000 & NÃO & 5,17 & 0,000 & NÃO \\
\hline CONCBO3 & 0,00 & $-0,01$ & $-0,01$ & 1,13 & 1,27 & $-2,01$ & 1,99 & $-0,37$ & $-0,01$ & $-1,30$ & SIM & $-0,09$ & SIM & 0,89 & 0,000 & NÃO & 0,23 & 0,000 & NÃO & 1,15 & 0,312 & SIM \\
\hline CONCBE3 & 0,00 & 0,31 & 1,31 & 1,22 & 1,48 & $-2,69$ & 1,31 & $-0,60$ & $-0,56$ & $-2,07$ & NÃO & $-3,88$ & NÃO & 0,86 & 0,000 & NÃO & 0,20 & 0,000 & NÃO & 4,73 & 0,000 & NÃO \\
\hline CONCBO3XCONCBE3 & $-0,02$ & 0,00 & 0,01 & 1,47 & 2,15 & $-5,33$ & 5,41 & 3,66 & $-0,52$ & 12,71 & NÃO & $-3,62$ & NÃO & 0,86 & 0,000 & NÃO & 0,23 & 0,000 & NÃO & 3,55 & 0,000 & NÃO \\
\hline СONCBO4 & 0,00 & 0,32 & $-0,68$ & 1,11 & 1,23 & $-2,68$ & 1,32 & $-0,33$ & $-0,51$ & $-1,14$ & SIM & $-3,53$ & NÃO & 0,88 & 0,000 & NÃO & 0,17 & 0,000 & NÃO & 2,44 & 0,002 & NÃO \\
\hline CONCBE4 & 0,00 & $-0,39$ & $-0,39$ & 1,32 & 1,75 & $-2,39$ & 1,61 & $-0,95$ & $-0,30$ & $-3,31$ & NÃO & $-2,07$ & NÃO & 0,88 & 0,000 & NÃO & 0,18 & 0,000 & NÃO & 3,30 & 0,000 & NÃO \\
\hline CONCBO4XCONCBE4 & 0,24 & 0,26 & 0,26 & 1,67 & 2,80 & $-4,31$ & 6,40 & 2,69 & 0,41 & 9,36 & NÃO & 2,87 & NÃO & 0,92 & 0,000 & NÃO & 0,14 & 0,000 & NÃO & 2,44 & 0,002 & NÃO \\
\hline CONCNO1 & 0,00 & $-0,39$ & $-0,39$ & 1,09 & 1,19 & $-2,39$ & 1,61 & $-0,37$ & $-0,25$ & $-1,30$ & SIM & $-1,75$ & SIM & 0,90 & 0,000 & NÃO & 0,20 & 0,000 & NÃO & 2,14 & 0,009 & NÃO \\
\hline CONCNE1 & 0,00 & $-0,33$ & $-0,33$ & 1,19 & 1,41 & $-2,33$ & 1,67 & $-0,56$ & $-0,25$ & $-1,93$ & SIM & $-1,71$ & SIM & 0,89 & 0,000 & NÃO & 0,21 & 0,000 & NÃO & 4,37 & 0,000 & NÃO \\
\hline CONCNO1XCONCNE1 & 0,56 & 0,13 & 0,13 & 1,45 & 2,11 & $-3,99$ & 5,55 & 2,99 & 1,02 & 10,40 & NÃO & 7,09 & NÃO & 0,88 & 0,000 & NÃO & 0,19 & 0,000 & NÃO & 6,36 & 0,000 & NÃO \\
\hline CONCNO2 & 0,00 & $-0,30$ & $-0,30$ & 1,05 & 1,11 & $-2,30$ & 1,70 & $-0,06$ & $-0,31$ & $-0,20$ & SIM & $-2,18$ & NÃO & 0,89 & 0,000 & NÃO & 0,23 & 0,000 & NÃO & 1,50 & 0,104 & SIM \\
\hline CONCNE2 & 0,00 & $-0,33$ & $-0,33$ & 1,20 & 1,44 & $-2,33$ & 1,67 & $-0,58$ & $-0,24$ & $-2,02$ & NÃO & $-1,68$ & SIM & 0,89 & 0,000 & NÃO & 0,21 & 0,000 & NÃO & 2,47 & 0,002 & NÃO \\
\hline
\end{tabular}




\begin{tabular}{|c|c|c|c|c|c|c|c|c|c|c|c|c|c|c|c|c|c|c|c|c|c|c|}
\hline & & & & & & & & & & \multirow{2}{*}{\multicolumn{2}{|c|}{$\begin{array}{c}\text { TESTE Z } \\
\text { CURTOSE } \\
\text { curt/raiz(24/n) }\end{array}$}} & \multirow{2}{*}{\multicolumn{2}{|c|}{$\begin{array}{c}\text { TESTE Z } \\
\text { ASSIMETRIA } \\
\text { ass/raiz(6/n) } \\
\end{array}$}} & \multirow{2}{*}{\multicolumn{3}{|c|}{$\begin{array}{c}\text { TESTE SHAPIRO-WILK } \\
\text { H0= VAR SEGUE DISTR. } \\
\text { NORMAL }\end{array}$}} & \multirow{2}{*}{\multicolumn{3}{|c|}{$\begin{array}{c}\text { TESTE KOLMOGOROV } \\
\text { SMIRNOV } \\
\text { H0= VAR SEGUE DISTR. } \\
\text { NORMAL }\end{array}$}} & \multirow{2}{*}{\multicolumn{3}{|c|}{$\begin{array}{c}\text { TESTE LEVENE } \\
\text { h0=NÃO EXISTIR } \\
\text { DIFERENÇAS }\end{array}$}} \\
\hline & \multicolumn{9}{|c|}{ ESTATÍSTICAS DESCRITIVAS } & & & & & & & & & & & & & \\
\hline VARIÁVEL & 兘 & 䒺 & $\begin{array}{l}\text { O } \\
\overbrace{\Sigma}\end{array}$ & 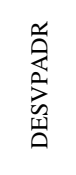 & 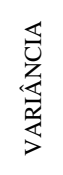 & $\sum_{i}^{0}$ & 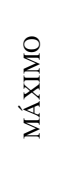 & $\begin{array}{l}\text { w } \\
0 \\
0 \\
0 \\
\tilde{5} \\
0\end{array}$ & 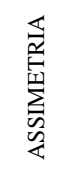 & 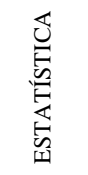 & 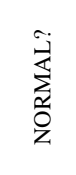 & 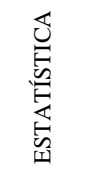 & 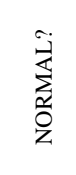 & 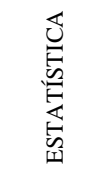 & $=$ & 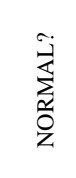 & 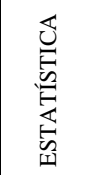 & $=$ & 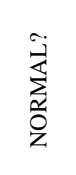 & 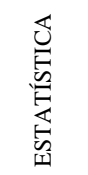 & 2 & 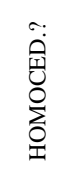 \\
\hline $\begin{array}{c}\text { Variáveis com } \\
n=255\end{array}$ & & & & & & & & & & $\begin{array}{c}z \\
\text { crítico } \\
\end{array}$ & $<1,96$ & $\begin{array}{c}z \\
\text { crítico } \\
\end{array}$ & $<1,96$ & P crítico & $>0,05$ & & $\begin{array}{c}P \\
\text { crítico } \\
\end{array}$ & $>0,05$ & & $\begin{array}{c}P \\
\text { crítico } \\
\end{array}$ & $>0,05$ & \\
\hline & & & & & & & & & & raiz & 0,307 & raiz & 0,153 & & & & & & & & & \\
\hline $\begin{array}{c}\text { CONCNO2X } \\
\text { CONCNE2 }\end{array}$ & 0,48 & 0,10 & 0,10 & 1,44 & 2,08 & $-3,95$ & 5,36 & 3,23 & 0,89 & 11,24 & NÃO & 6,22 & NÃO & 0,86 & 0,000 & NÃO & 0,19 & 0,000 & NÃO & 3,71 & 0,000 & NÃO \\
\hline CONCCO1 & 0,00 & 0,02 & 0,02 & 1,27 & 1,61 & $-1,98$ & 2,02 & $-0,94$ & 0,06 & $-3,25$ & NÃO & 0,39 & SIM & 0,91 & 0,000 & NÃO & 0,16 & 0,000 & NÃO & 1,53 & 0,094 & SIM \\
\hline CONCCE1 & 0,00 & $-0,09$ & $-0,09$ & 1,29 & 1,66 & $-2,09$ & 1,91 & $-0,88$ & $-0,06$ & $-3,06$ & NÃO & $-0,40$ & SIM & 0,89 & 0,000 & NÃO & 0,19 & 0,000 & NÃO & 3,23 & 0,000 & NÃO \\
\hline $\begin{array}{c}\text { CONCCO1X } \\
\text { CONCCE1 }\end{array}$ & 0,33 & 0,00 & 0,00 & 1,89 & 3,57 & $-4,24$ & 4,14 & 0,64 & $-0,02$ & 2,22 & NÃO & $-0,15$ & SIM & 0,89 & 0,000 & NÃO & 0,22 & 0,000 & NÃO & 2,24 & 0,006 & NÃO \\
\hline $\mathrm{CONCCO3}$ & 0,00 & $-0,29$ & $-0,29$ & 1,13 & 1,27 & $-2,29$ & 1,71 & $-0,47$ & $-0,22$ & $-1,64$ & SIM & $-1,54$ & SIM & 0,90 & 0,000 & NÃO & 0,19 & 0,000 & NÃO & 1,16 & 0,302 & SIM \\
\hline CONCCE3 & 0,00 & 0,34 & 1,34 & 1,26 & 1,60 & $-2,66$ & 1,34 & $-0,77$ & $-0,51$ & $-2,67$ & NÃO & $-3,58$ & NÃO & 0,86 & 0,000 & NÃO & 0,22 & 0,000 & NÃO & 4,88 & 0,000 & NÃO \\
\hline $\begin{array}{c}\text { CONCCO3X } \\
\text { CONCCE3 }\end{array}$ & 0,20 & 0,19 & 0,19 & 1,60 & 2,57 & $-4,53$ & 6,10 & 3,07 & 0,48 & 10,66 & NÃO & 3,32 & NÃO & 0,92 & 0,000 & NÃO & 0,16 & 0,000 & NÃO & 2,98 & 0,000 & NÃO \\
\hline $\mathrm{CONCCO4}$ & 0,00 & $-0,33$ & $-0,33$ & 1,29 & 1,67 & $-2,33$ & 1,67 & $-0,89$ & $-0,32$ & $-3,09$ & NÃO & $-2,22$ & NÃO & 0,90 & 0,000 & NÃO & 0,16 & 0,000 & NÃO & 1,79 & 0,036 & NÃO \\
\hline CONCCE4 & 0,00 & $-0,34$ & $-0,34$ & 1,34 & 1,79 & $-2,34$ & 1,66 & $-0,97$ & $-0,27$ & $-3,39$ & NÃO & $-1,88$ & SIM & 0,88 & 0,000 & NÃO & 0,17 & 0,000 & NÃO & 2,56 & 0,001 & NÃO \\
\hline $\begin{array}{c}\text { CONCCO4X } \\
\text { CONCCE4 }\end{array}$ & 0,57 & 0,44 & 0,11 & 1,87 & 3,49 & $-3,91$ & 5,44 & 0,89 & 0,10 & 3,09 & NÃO & 0,66 & SIM & 0,94 & 0,000 & NÃO & 0,14 & 0,000 & NÃO & 1,99 & 0,017 & NÃO \\
\hline
\end{tabular}




\begin{tabular}{|c|c|c|c|c|c|c|c|c|c|c|c|c|c|c|c|c|c|c|c|c|c|c|}
\hline & & & & & & & & & & \multirow{2}{*}{\multicolumn{2}{|c|}{$\begin{array}{c}\text { TESTE Z } \\
\text { CURTOSE } \\
\text { curt/raiz(24/n) }\end{array}$}} & \multirow{2}{*}{\multicolumn{2}{|c|}{$\begin{array}{c}\text { TESTE Z } \\
\text { ASSIMETRIA } \\
\text { ass/raiz(6/n) }\end{array}$}} & \multirow{2}{*}{\multicolumn{3}{|c|}{$\begin{array}{c}\text { TESTE SHAPIRO-WILK } \\
\text { H0= VAR SEGUE DISTR. } \\
\text { NORMAL }\end{array}$}} & \multirow{2}{*}{\multicolumn{3}{|c|}{$\begin{array}{c}\text { TESTE KOLMOGOROV } \\
\text { SMIRNOV } \\
\text { H0= VAR SEGUE DISTR. } \\
\text { NORMAL } \\
\end{array}$}} & \multirow{2}{*}{\multicolumn{3}{|c|}{$\begin{array}{c}\text { TESTE LEVENE } \\
\text { h0=NÃO EXISTIR } \\
\text { DIFERENÇAS }\end{array}$}} \\
\hline & \multicolumn{9}{|c|}{ ESTATÍSTICAS DESCRITIVAS } & & & & & & & & & & & & & \\
\hline VARIÁVEL & 离 & 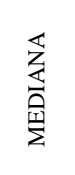 & @̊ & 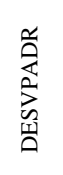 & 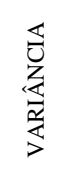 & $\sum_{\sum}^{\circ}$ & 齐 & 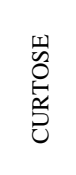 & 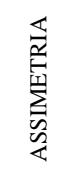 & 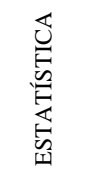 & 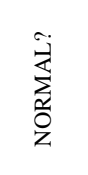 & 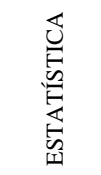 & 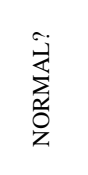 & 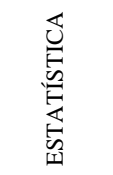 & 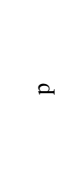 & 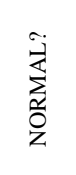 & 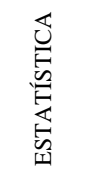 & $=$ & 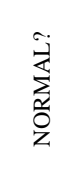 & 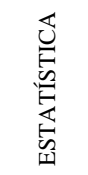 & 2 & 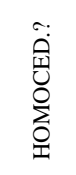 \\
\hline $\begin{array}{c}\begin{array}{l}\text { Variáveis com } \\
n=242\end{array} \\
\end{array}$ & & & & & & & & & & $\begin{array}{c}z \\
\text { crítico } \\
\end{array}$ & $<1,96$ & z crítico & $<1,96$ & P crítico & $>0,05$ & & $\begin{array}{c}P \\
\text { crítico } \\
\end{array}$ & $>0,05$ & & $\begin{array}{c}P \\
\text { crítico } \\
\end{array}$ & $>0,05$ & \\
\hline & & & & & & & & & & raiz & 0,315 & raiz & 0,157 & & & & & & & & & \\
\hline AFDAT1 & 3,58 & 4,00 & 5,00 & 1,35 & 1,82 & 1,00 & 5,00 & $-0,83$ & $-0,56$ & $-2,63$ & NÃO & $-3,53$ & NÃO & 0,85 & 0,000 & NÃO & 0,21 & 0,000 & NÃO & 13,74 & 0,000 & NÃO \\
\hline AFDAT2 & 3,34 & 3,00 & 5,00 & 1,41 & 1,99 & 1,00 & 5,00 & $-1,16$ & $-0,28$ & $-3,68$ & NÃO & $-1,77$ & SIM & 0,87 & 0,000 & NÃO & 0,19 & 0,000 & NÃO & 16,39 & 0,000 & NÃO \\
\hline AFDAT3 & 3,76 & 4,00 & 5,00 & 1,31 & 1,73 & 1,00 & 5,00 & $-0,55$ & $-0,75$ & $-1,75$ & SIM & $-4,73$ & NÃO & 0,83 & 0,000 & NÃO & 0,24 & 0,000 & NÃO & 18,92 & 0,000 & NÃO \\
\hline MEDAFDAT & 3,56 & 3,67 & 5,00 & 1,16 & 1,34 & 1,00 & 5,00 & $-0,59$ & $-0,46$ & $-1,88$ & SIM & $-2,91$ & NÃO & 0,92 & 0,000 & NÃO & 0,12 & 0,000 & NÃO & Dep & Dep & \\
\hline AFDNS1 & 3,46 & 3,00 & 3,00 & 1,19 & 1,42 & 1,00 & 5,00 & $-0,61$ & $-0,37$ & $-1,93$ & SIM & $-2,34$ & NÃO & 0,89 & 0,000 & NÃO & 0,16 & 0,000 & NÃO & 1,18 & 0,301 & SIM \\
\hline AFDNS2 & 3,28 & 3,00 & 3,00 & 1,10 & 1,21 & 1,00 & 5,00 & $-0,34$ & $-0,26$ & $-1,09$ & SIM & $-1,66$ & SIM & 0,90 & 0,000 & NÃO & 0,20 & 0,000 & NÃO & 2,67 & 0,002 & NÃO \\
\hline AFDNS3 & 3,29 & 3,00 & 3,00 & 1,18 & 1,38 & 1,00 & 5,00 & $-0,61$ & $-0,15$ & $-1,95$ & SIM & $-0,98$ & SIM & 0,90 & 0,000 & NÃO & 0,21 & 0,000 & NÃO & 1,80 & 0,049 & SIM \\
\hline MEDAFDNS & 3,34 & 3,33 & 3,00 & 0,89 & 0,79 & 1,00 & 5,00 & 0,10 & $-0,19$ & 0,31 & SIM & $-1,23$ & SIM & 0,97 & 0,000 & NÃO & 0,11 & 0,000 & NÃO & 1,57 & 0,102 & SIM \\
\hline AFDCP1 & 3,15 & 3,00 & 3,00 & 1,34 & 1,80 & 1,00 & 5,00 & $-1,01$ & $-0,16$ & $-3,19$ & NÃO & $-1,03$ & SIM & 0,89 & 0,000 & NÃO & 0,17 & 0,000 & NÃO & 3,56 & 0,000 & NÃO \\
\hline AFDCP2 & 3,10 & 3,00 & 3,00 & 1,40 & 1,97 & 1,00 & 5,00 & $-1,18$ & $-0,07$ & $-3,74$ & NÃO & $-0,44$ & SIM & 0,88 & 0,000 & NÃO & 0,15 & 0,000 & NÃO & 4,01 & 0,000 & NÃO \\
\hline AFDCP3 & 3,25 & 3,00 & 3,00 & 1,39 & 1,93 & 1,00 & 5,00 & $-1,09$ & $-0,23$ & $-3,47$ & NÃO & $-1,47$ & SIM & 0,88 & 0,000 & NÃO & 0,16 & 0,000 & NÃO & 4,69 & 0,000 & NÃO \\
\hline MEDAFDCP & 3,17 & 3,00 & 3,00 & 1,12 & 1,26 & 1,00 & 5,00 & $-0,66$ & $-0,13$ & $-2,08$ & NÃO & $-0,84$ & SIM & 0,96 & 0,000 & NÃO & 0,11 & 0,000 & NÃO & 4,61 & 0,000 & NÃO \\
\hline AFDIT1 & 3,27 & 3,00 & 3,00 & 1,37 & 1,87 & 1,00 & 5,00 & $-1,04$ & $-0,30$ & $-3,30$ & NÃO & $-1,88$ & SIM & 0,88 & 0,000 & NÃO & 0,15 & 0,000 & NÃO & 1,67 & 0,074 & SIM \\
\hline AFDIT2 & 3,27 & 3,00 & 3,00 & 1,38 & 1,90 & 1,00 & 5,00 & $-1,07$ & $-0,27$ & $-3,38$ & NÃO & $-1,73$ & SIM & 0,88 & 0,000 & NÃO & 0,15 & 0,000 & NÃO & 3,46 & 0,000 & NÃO \\
\hline AFDIT3 & 2,75 & 3,00 & 1,00 & 1,61 & 2,58 & 1,00 & 5,00 & $-1,49$ & 0,27 & $-4,72$ & NÃO & 1,74 & SIM & 0,82 & 0,000 & NÃO & 0,21 & 0,000 & NÃO & 7,19 & 0,000 & NÃO \\
\hline MEDAFDIT & 3,09 & 3,00 & 3,00 & 1,17 & 1,36 & 1,00 & 5,00 & $-0,89$ & $-0,01$ & $-2,82$ & NÃO & $-0,07$ & SIM & 0,96 & 0,000 & NÃO & 0,09 & 0,000 & NÃO & 2,39 & 0,006 & NÃO \\
\hline САFСВО1 & 0,00 & $-0,35$ & $-0,35$ & 1,22 & 1,49 & $-2,35$ & 1,65 & $-0,69$ & $-0,30$ & $-2,18$ & NÃO & $-1,92$ & SIM & 0,90 & 0,000 & NÃO & 0,18 & 0,000 & NÃO & 3,35 & 0,000 & NÃO \\
\hline CAFCBE1 & 0,00 & $-0,29$ & $-0,29$ & 1,25 & 1,56 & $-2,29$ & 1,71 & $-0,77$ & $-0,22$ & $-2,45$ & NÃO & $-1,38$ & SIM & 0,89 & 0,000 & NÃO & 0,18 & 0,000 & NÃO & 4,50 & 0,000 & NÃO \\
\hline
\end{tabular}




\begin{tabular}{|c|c|c|c|c|c|c|c|c|c|c|c|c|c|c|c|c|c|c|c|c|c|c|}
\hline & & & & & & & & & & \multirow{2}{*}{\multicolumn{2}{|c|}{$\begin{array}{c}\text { TESTE Z } \\
\text { CURTOSE } \\
\text { curt/raiz(24/n) }\end{array}$}} & \multirow{2}{*}{\multicolumn{2}{|c|}{$\begin{array}{c}\text { TESTE Z } \\
\text { ASSIMETRIA } \\
\text { ass/raiz(6/n) }\end{array}$}} & \multirow{2}{*}{\multicolumn{3}{|c|}{$\begin{array}{c}\text { TESTE SHAPIRO-WILK } \\
\text { H0= VAR SEGUE DISTR. } \\
\text { NORMAL }\end{array}$}} & \multirow{2}{*}{\multicolumn{3}{|c|}{\begin{tabular}{|c|} 
TESTE KOLMOGOROV \\
SMIRNOV \\
H0= VAR SEGUE DISTR. \\
NORMAL \\
\end{tabular}}} & \multirow{2}{*}{\multicolumn{3}{|c|}{$\begin{array}{c}\text { TESTE LEVENE } \\
\text { h0=NÃO EXISTIR } \\
\text { DIFERENÇAS } \\
\end{array}$}} \\
\hline & \multicolumn{9}{|c|}{ ESTATÍSTICAS DESCRITIVAS } & & & & & & & & & & & & & \\
\hline VARIÁVEL & 坴 & 㚆 & ஜ̊ & 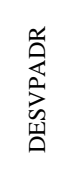 & 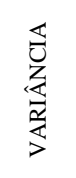 & 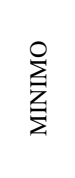 & 离 & $\begin{array}{l}\text { W } \\
0 \\
0 \\
0 \\
0 \\
0 \\
0\end{array}$ & 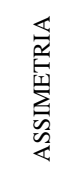 & 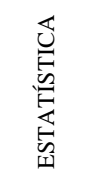 & 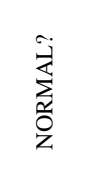 & 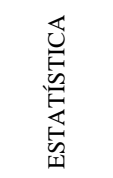 & 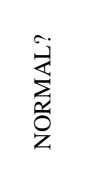 & 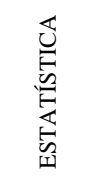 & 2 & 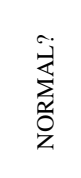 & 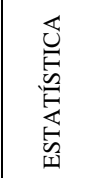 & $=$ & 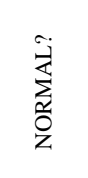 & 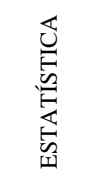 & $a$ & 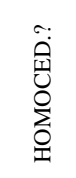 \\
\hline $\begin{array}{c}\text { Variáveis com } \\
n=255\end{array}$ & & & & & & & & & & $\begin{array}{c}z \\
\text { crítico } \\
\end{array}$ & $<1,96$ & z crítico & $<1,96$ & $\begin{array}{c}P \\
\text { crítico } \\
\end{array}$ & $>0,05$ & & $\begin{array}{c}P \\
\text { crítico } \\
\end{array}$ & $>0,05$ & & $\begin{array}{c}P \\
\text { crítico } \\
\end{array}$ & $>0,05$ & \\
\hline & & & & & & & & & & raiz & 0,307 & raiz & 0,153 & & & & & & & & & \\
\hline $\begin{array}{c}\text { CAFCBO1X } \\
\text { CACBE1 }\end{array}$ & 0,24 & 0,10 & 0,10 & 1,70 & 2,90 & $-4,02$ & 5,39 & 1,33 & 0,29 & 4,23 & NÃO & 1,84 & SIM & 0,93 & 0,000 & NÃO & 0,17 & 0,000 & NÃO & 4,66 & 0,000 & NÃO \\
\hline САFCBO2 & 0,00 & 0,17 & 1,17 & 1,09 & 1,20 & $-2,83$ & 1,17 & $-0,06$ & $-0,73$ & $-0,18$ & SIM & $-4,64$ & NÃO & 0,86 & 0,000 & NÃO & 0,20 & 0,000 & NÃO & 2,10 & 0,018 & NÃO \\
\hline CAFCBE2 & 0,00 & 0,29 & 1,29 & 1,27 & 1,62 & $-2,71$ & 1,29 & $-0,71$ & $-0,59$ & $-2,24$ & NÃO & $-3,76$ & NÃO & 0,84 & 0,000 & NÃO & 0,24 & 0,000 & NÃO & 6,27 & 0,000 & NÃO \\
\hline $\begin{array}{c}\text { CAFCBO2X } \\
\text { CACBE2 }\end{array}$ & 0,60 & 0,33 & 1,50 & 1,57 & 2,47 & $-3,64$ & 7,68 & 7,51 & 1,75 & 23,86 & NÃO & 11,12 & NÃO & 0,82 & 0,000 & NÃO & 0,20 & 0,000 & NÃO & 11,85 & 0,000 & NÃO \\
\hline САFСВОЗ & 0,00 & $-0,28$ & $-1,28$ & 1,26 & 1,58 & $-1,28$ & 2,72 & $-0,64$ & 0,64 & $-2,02$ & NÃO & 4,09 & NÃO & 0,85 & 0,000 & NÃO & 0,21 & 0,000 & NÃO & 1,41 & 0,161 & SIM \\
\hline CAFCBE3 & 0,00 & 0,41 & 1,41 & 1,28 & 1,65 & $-2,59$ & 1,41 & $-0,74$ & $-0,52$ & $-2,36$ & NÃO & $-3,29$ & NÃO & 0,87 & 0,000 & NÃO & 0,19 & 0,000 & NÃO & 3,57 & 0,000 & NÃO \\
\hline $\begin{array}{c}\text { CAFCBO3X } \\
\text { CACBE3 }\end{array}$ & $-0,16$ & $-0,40$ & $-1,81$ & 1,65 & 2,73 & $-7,03$ & 3,85 & 1,77 & 0,30 & 5,64 & NÃO & 1,93 & SIM & 0,92 & 0,000 & NÃO & 0,13 & 0,000 & NÃO & 2,92 & 0,001 & NÃO \\
\hline CAFCNO1 & 0,00 & $-0,15$ & $-0,15$ & 1,37 & 1,86 & $-2,15$ & 1,85 & $-1,10$ & $-0,24$ & $-3,49$ & NÃO & $-1,52$ & SIM & 0,89 & 0,000 & NÃO & 0,17 & 0,000 & NÃO & 1,44 & 0,147 & SIM \\
\hline CAFCNE1 & 0,00 & 0,50 & 1,50 & 1,43 & 2,05 & $-2,50$ & 1,50 & $-1,12$ & $-0,43$ & $-3,56$ & NÃO & $-2,74$ & NÃO & 0,84 & 0,000 & NÃO & 0,23 & 0,000 & NÃO & 4,34 & 0,000 & NÃO \\
\hline $\begin{array}{c}\text { CAFCNO1X } \\
\text { CACNE1 }\end{array}$ & 0,85 & 0,42 & 2,76 & 2,04 & 4,17 & $-4,63$ & 5,39 & 0,41 & 0,27 & 1,32 & SIM & 1,71 & SIM & 0,95 & 0,000 & NÃO & 0,13 & 0,000 & NÃO & 4,25 & 0,000 & NÃO \\
\hline CAFCNO2 & 0,00 & 0,51 & 1,51 & 1,36 & 1,85 & $-2,49$ & 1,51 & $-0,77$ & $-0,60$ & $-2,44$ & NÃO & $-3,84$ & NÃO & 0,86 & 0,000 & NÃO & 0,21 & 0,000 & NÃO & 2,52 & 0,004 & NÃO \\
\hline CAFCNE2 & 0,00 & $-0,30$ & $-0,30$ & 1,23 & 1,50 & $-2,30$ & 1,70 & $-0,65$ & $-0,19$ & $-2,06$ & NÃO & $-1,20$ & SIM & 0,88 & 0,000 & NÃO & 0,21 & 0,000 & NÃO & 2,33 & 0,008 & NÃO \\
\hline $\begin{array}{c}\text { CAFCNO2X } \\
\text { CACNE2 }\end{array}$ & 0,66 & 0,15 & 2,56 & 1,72 & 2,96 & $-4,23$ & 5,74 & 2,08 & 0,89 & 6,61 & NÃO & 5,66 & NÃO & 0,89 & 0,000 & NÃO & 0,17 & 0,000 & NÃO & 8,77 & 0,000 & NÃO \\
\hline CAFCCO1 & 0,00 & $-0,29$ & $-0,29$ & 1,19 & 1,42 & $-2,29$ & 1,71 & $-0,73$ & $-0,18$ & $-2,31$ & NÃO & $-1,13$ & SIM & 0,91 & 0,000 & NÃO & 0,17 & 0,000 & NÃO & 0,98 & 0,468 & SIM \\
\hline CAFCCE1 & 0,00 & $-0,20$ & $-0,20$ & 1,32 & 1,74 & $-2,20$ & 1,80 & $-0,93$ & $-0,20$ & $-2,95$ & NÃO & $-1,27$ & SIM & 0,89 & 0,000 & NÃO & 0,18 & 0,000 & NÃO & 2,46 & 0,005 & NÃO \\
\hline $\begin{array}{c}\text { CAFCCO1X } \\
\text { CACCE1 }\end{array}$ & 0,33 & 0,06 & 0,06 & 1,68 & 2,83 & $-4,12$ & 5,04 & 1,51 & 0,43 & 4,78 & NÃO & 2,74 & NÃO & 0,91 & 0,000 & NÃO & 0,19 & 0,000 & NÃO & 5,07 & 0,000 & NÃO \\
\hline CAFCCO2 & 0,00 & 0,24 & 0,24 & 1,26 & 1,58 & $-1,76$ & 2,24 & $-0,88$ & 0,21 & $-2,79$ & NÃO & 1,32 & SIM & 0,91 & 0,000 & NÃO & 0,16 & 0,000 & NÃO & 1,07 & 0,390 & SIM \\
\hline CAFCCE2 & 0,00 & 0,11 & 0,11 & 1,43 & 2,06 & $-1,89$ & 2,11 & $-1,22$ & 0,12 & $-3,88$ & NÃO & 0,77 & SIM & 0,88 & 0,000 & NÃO & 0,15 & 0,000 & NÃO & 3,51 & 0,000 & NÃO \\
\hline $\begin{array}{c}\text { CAFCCO2X } \\
\text { CACCE2 }\end{array}$ & 0,61 & 0,25 & 0,03 & 1,92 & 3,70 & $-4,23$ & 4,73 & 0,61 & $-0,07$ & 1,93 & SIM & $-0,41$ & SIM & 0,93 & 0,000 & NÃO & 0,16 & 0,000 & NÃO & 4,38 & 0,000 & NÃO \\
\hline
\end{tabular}


APENDICE 02 - Correlações entre variáveis explicativas para amostra "alunos geral" na IEM PU 2 
APÊNDICE P - Gráficos CURE para modelagens de crenças para o modo Automóvel da Família na IEM PU1 
APÊNDICE P - Modelos dos Construtos x crenças salientes para o modo Automóvel da Família na IEM PU1 (Modelagem por MLG no "R")

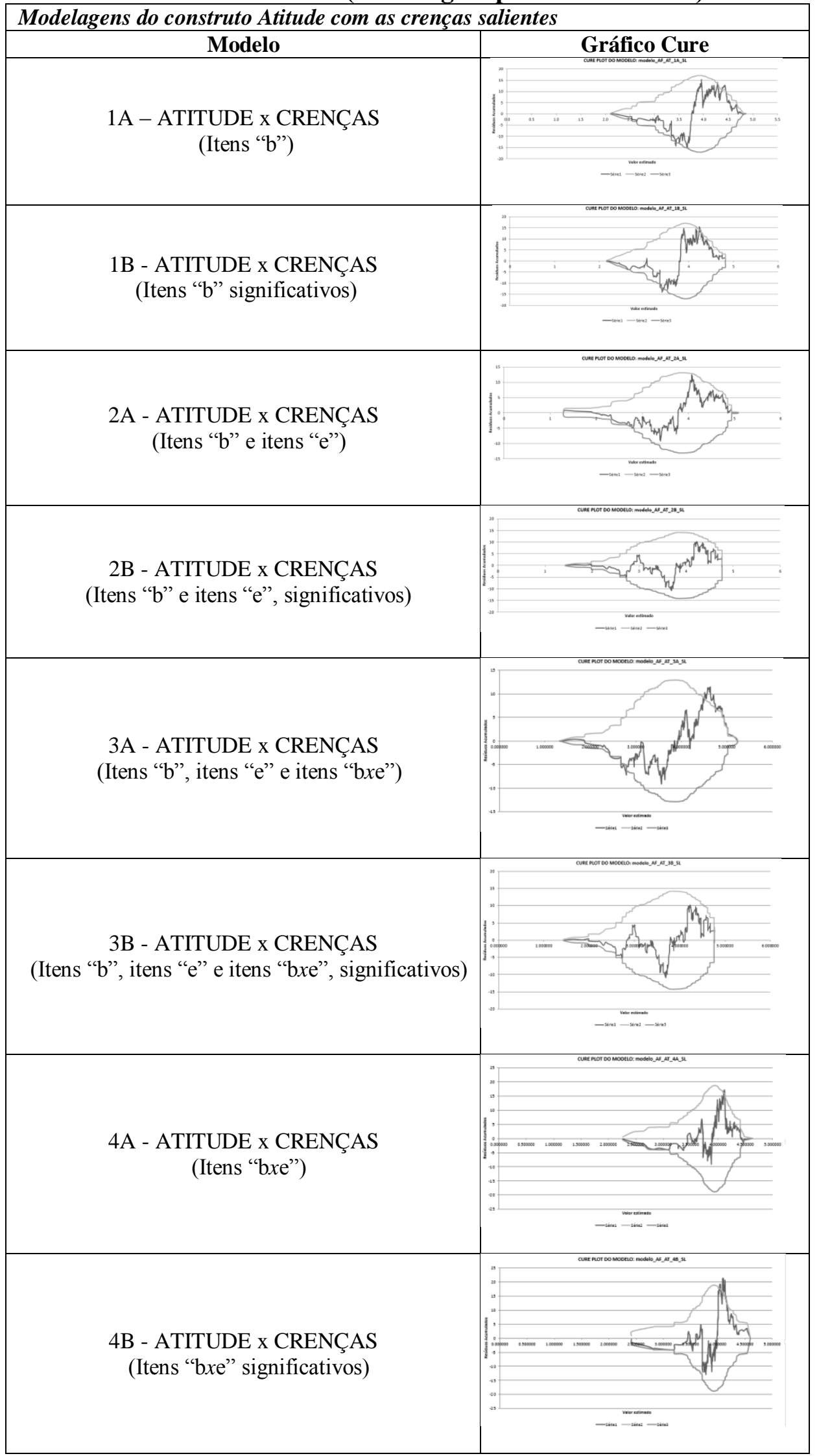




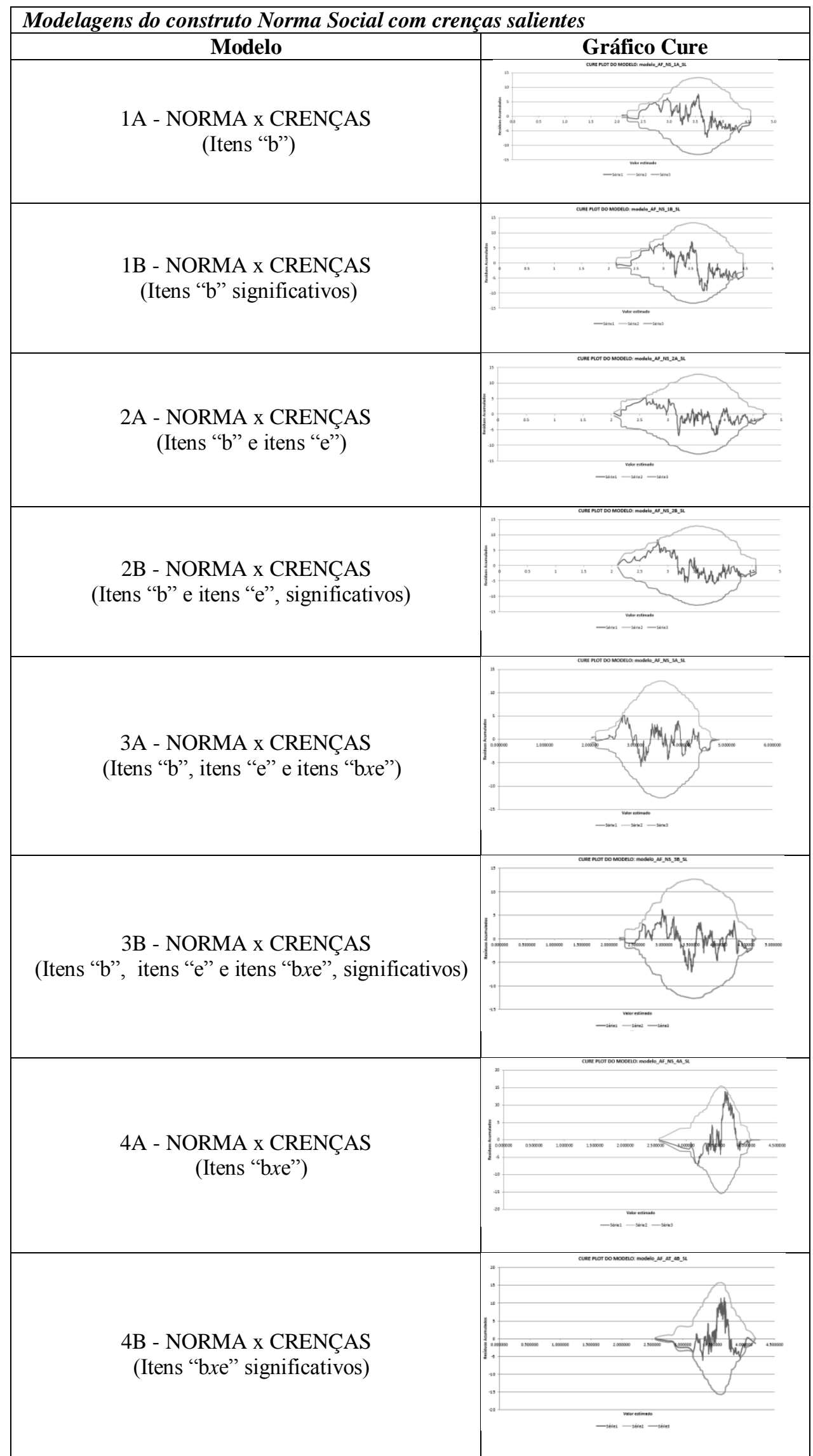




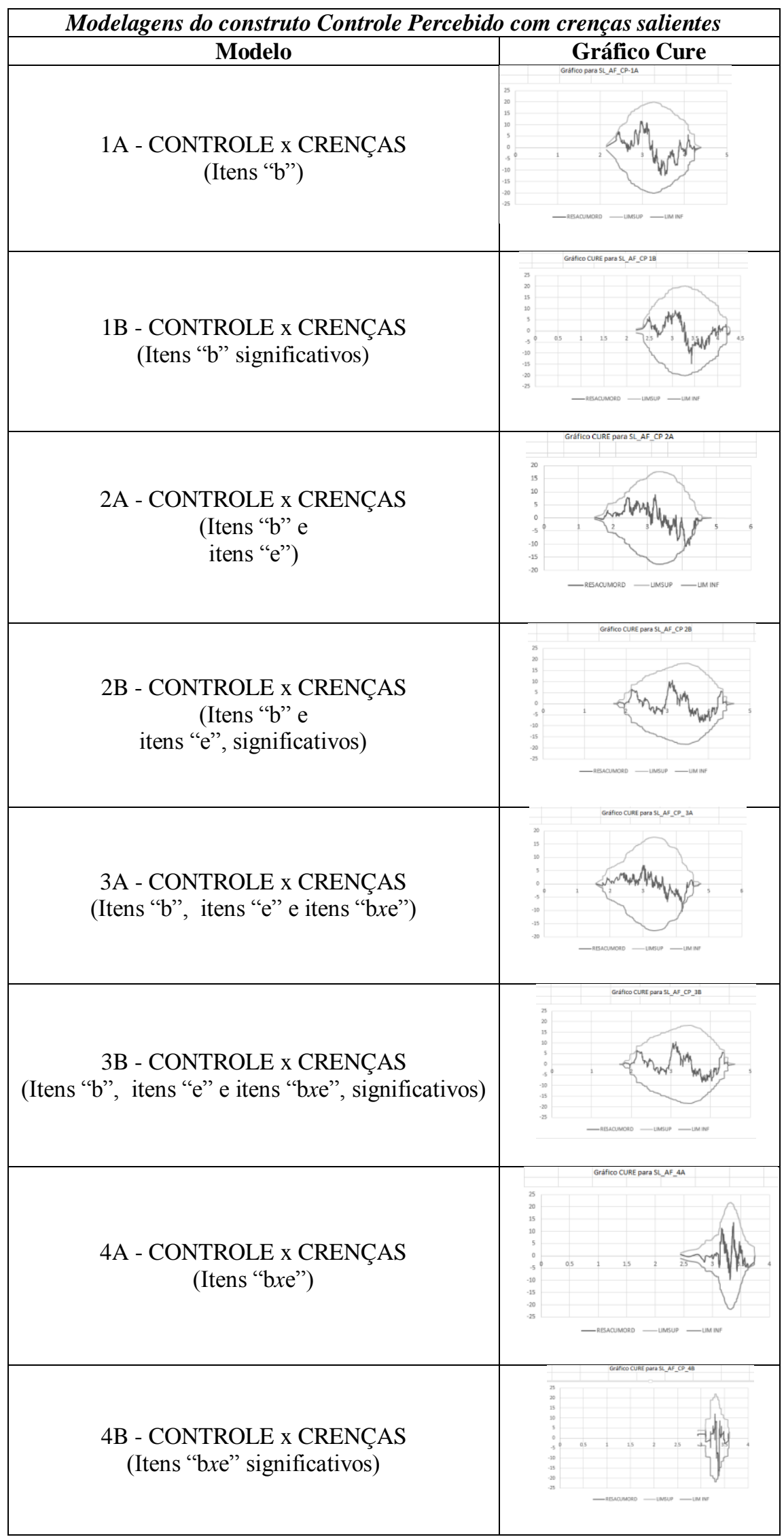




\begin{tabular}{|c|}
\hline Modelagens do construto Intenção com crenças salientes \\
\hline Modelo \\
\hline \\
1A - INTENÇÃO x CRENÇAS \\
(Itens "b")
\end{tabular}


APÊNDICE Q - Gráficos CURE para modelagens de crenças para o modo Ônibus na IEM PU1 
APÊNDICE Q - Modelos dos Construtos x crenças salientes para o modo Ônibus na IEM PU1 (Modelagem por MLG no "R")

\begin{tabular}{c}
\hline Modelagens do construto Atitude com as crenças salientes \\
\hline Modelo \\
\hline 1A - ATITUDE x CRENÇAS \\
(Itens "b")
\end{tabular}




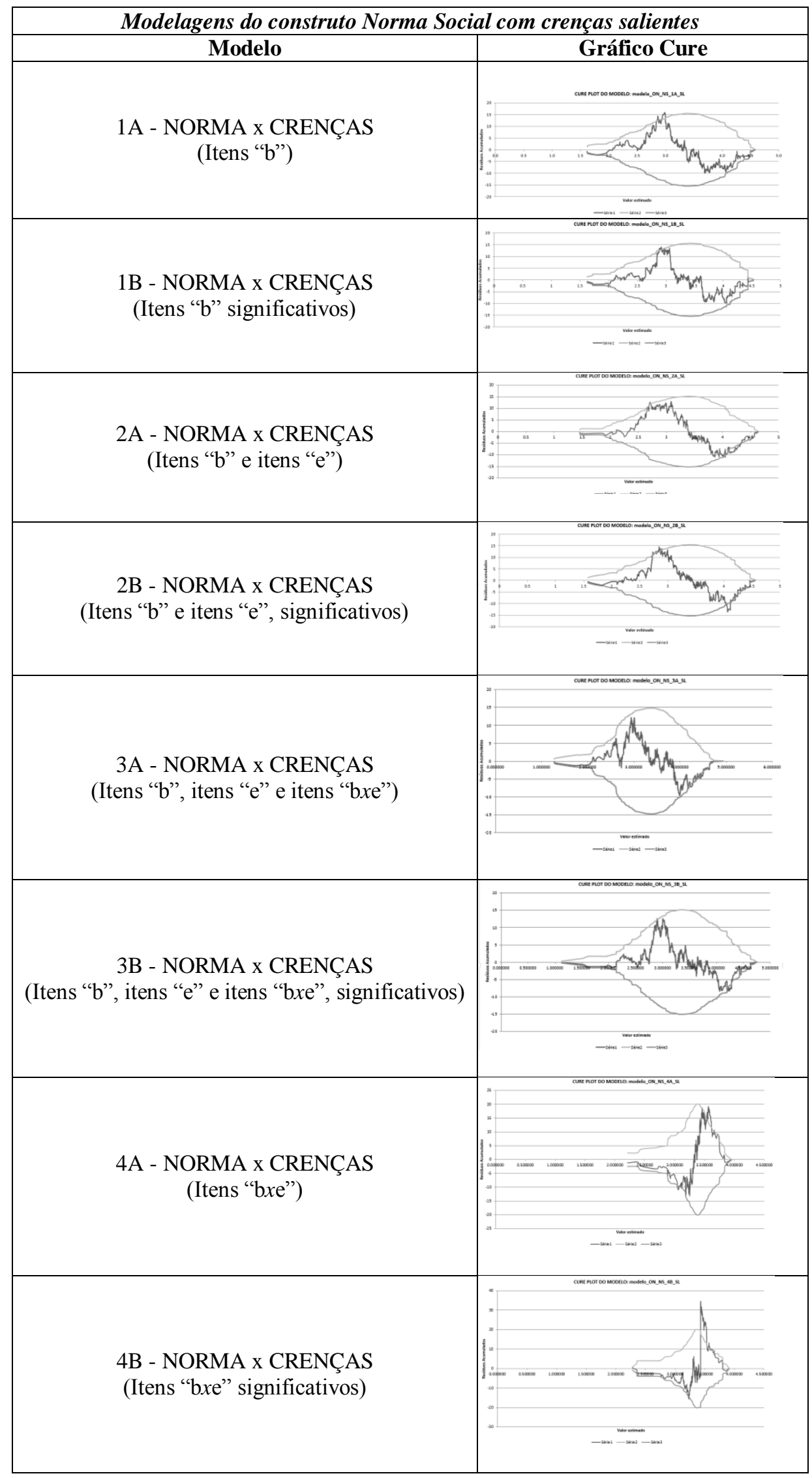




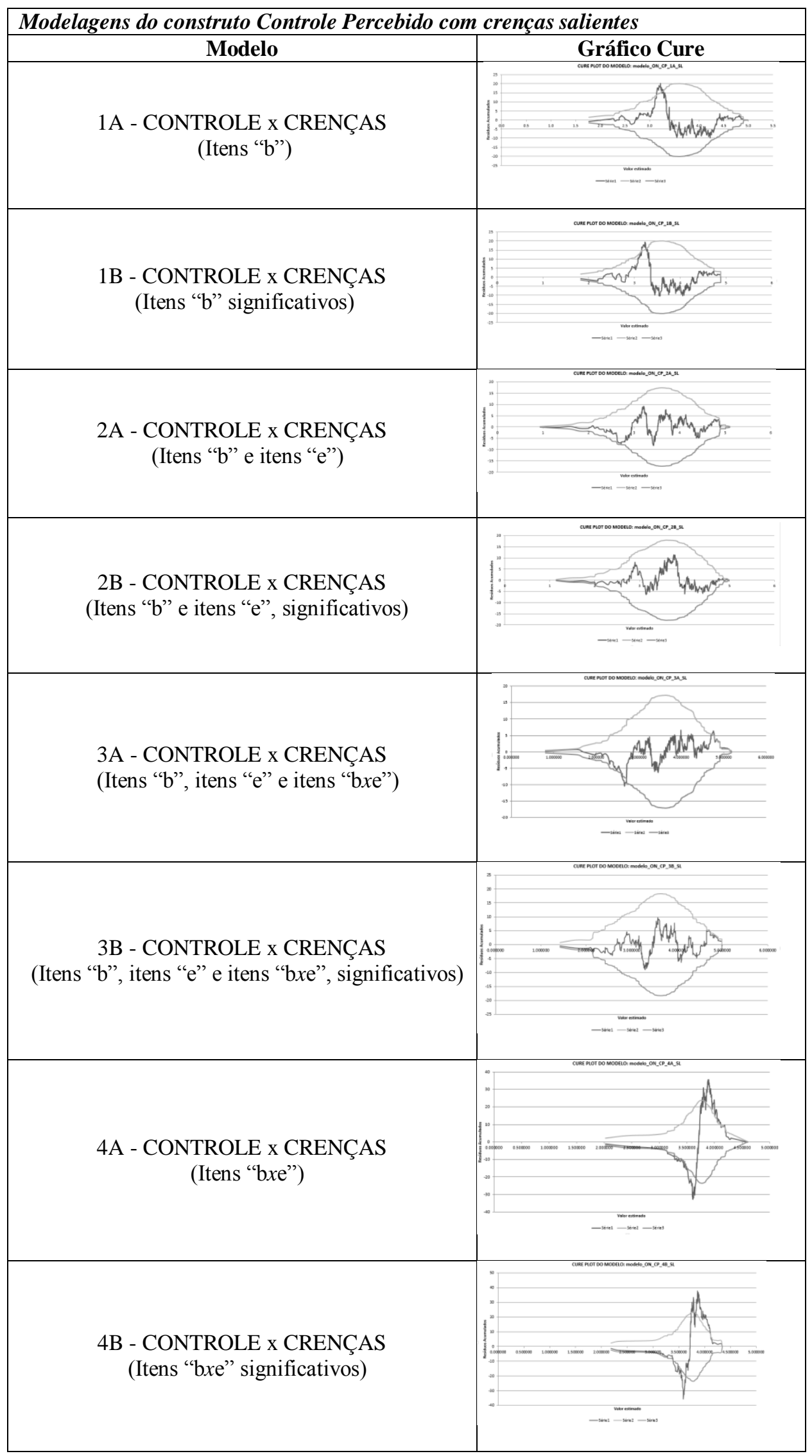




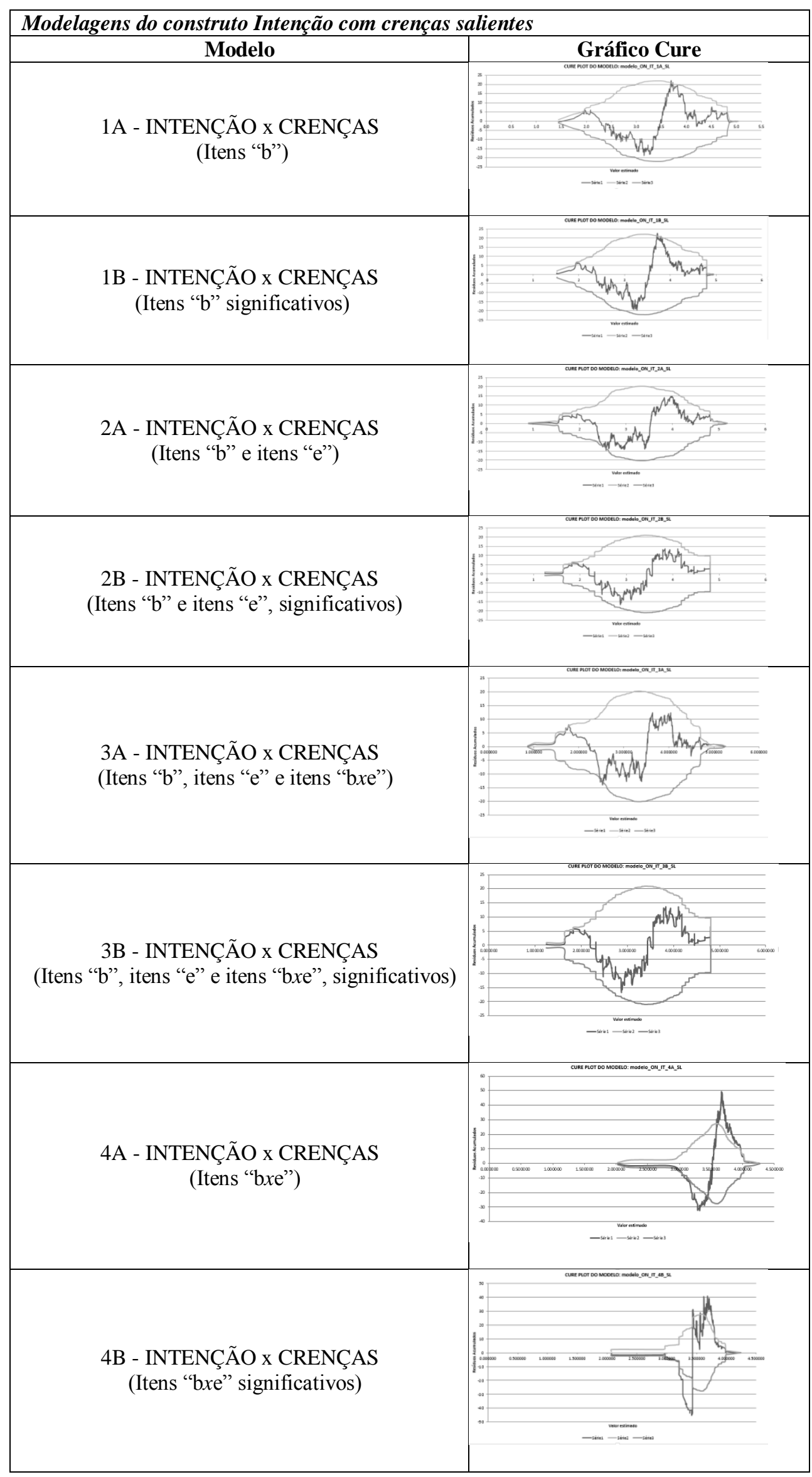


APÊNDICE R - Gráficos CURE para modelagens da Intenção na IEM PU1 
APÊNDICE R - Modelos da Intenção para o modo Automóvel da Família na IEM PU1 (Modelagem por MLG no "R")

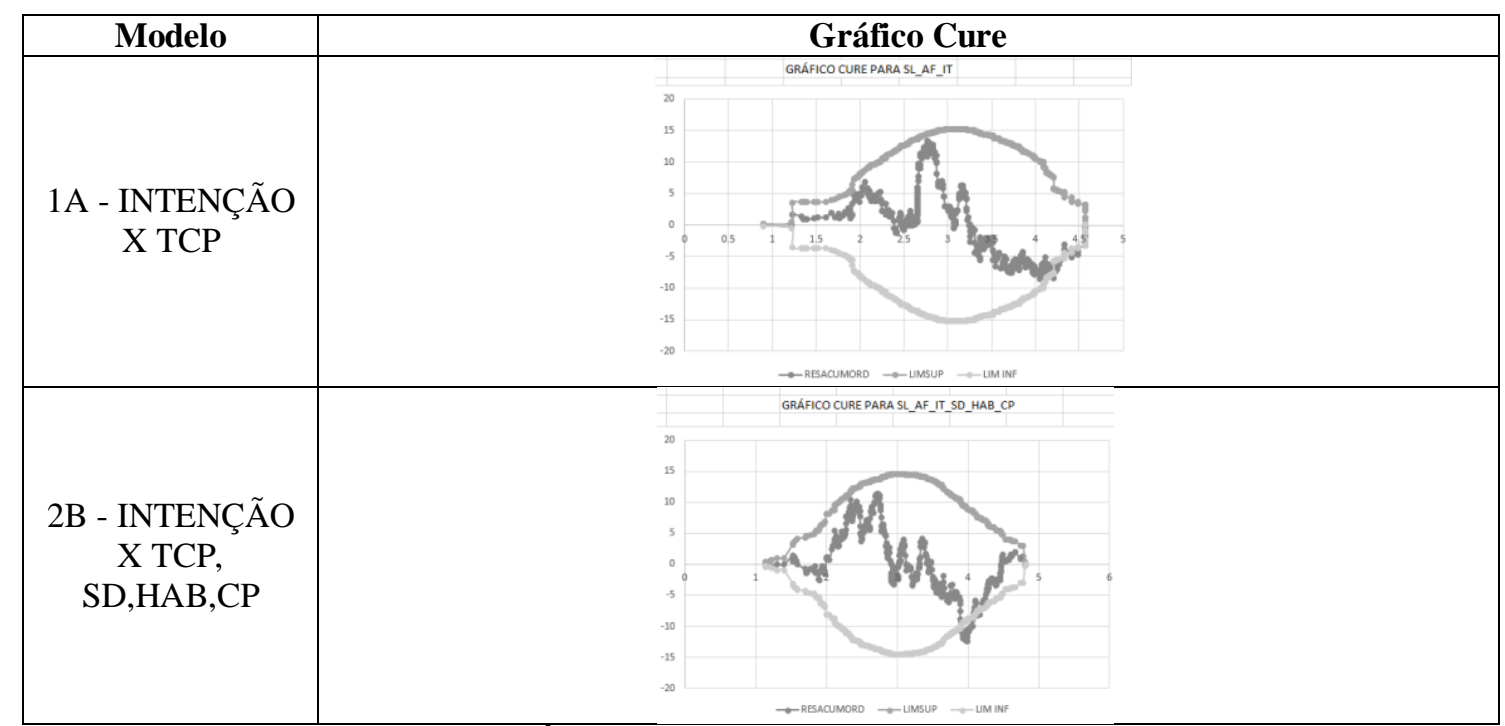

Modelos da Intenção para o modo Ônibus na IEM PU1 (Modelagem por MLG no "R")

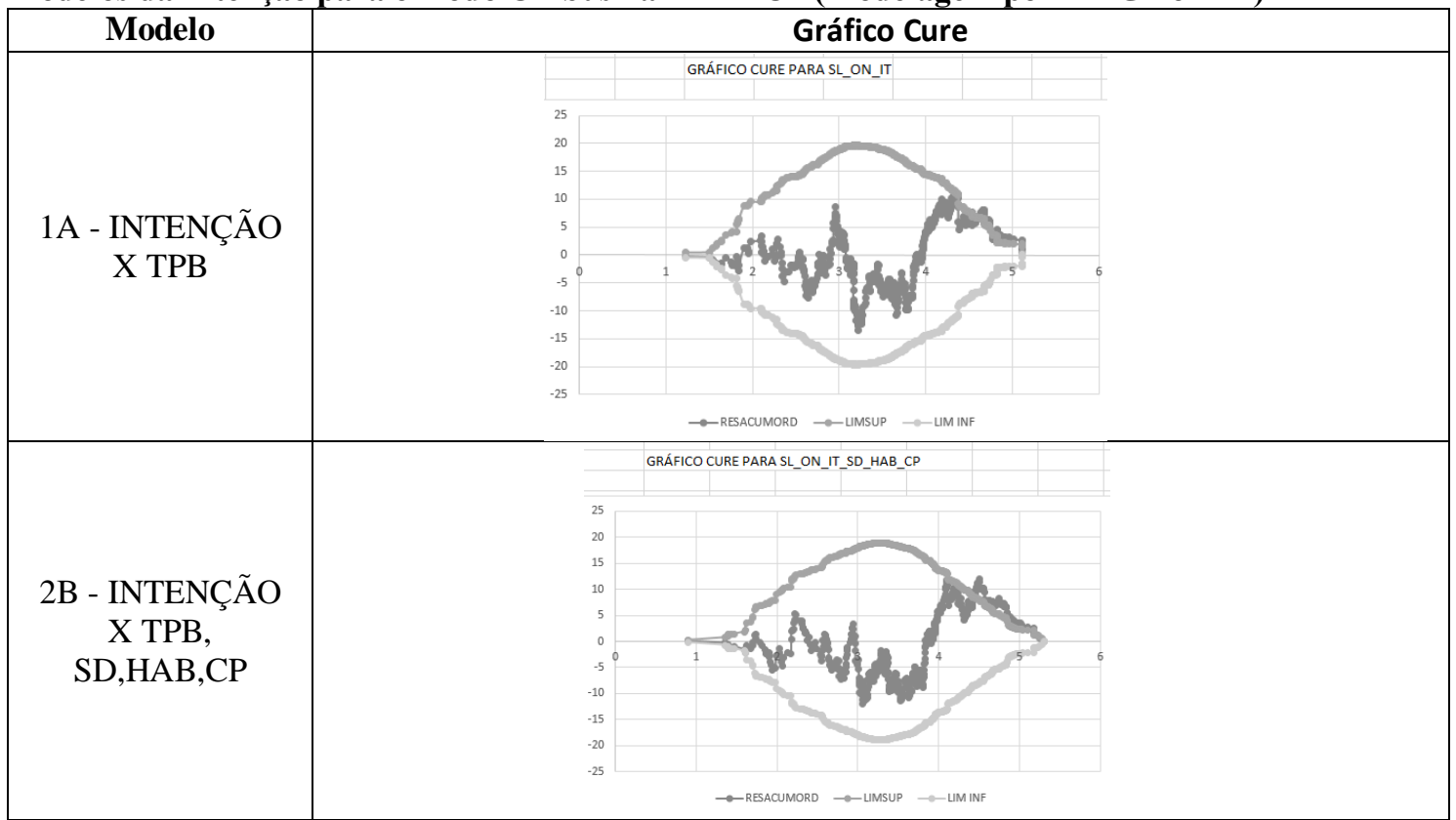


APÊNDICE S - Gráficos de resíduos para modelagens da Intenção na IEM PU2 
APÊNDICE S - Modelos da Intenção para o modo Automóvel da Família na IEM PU2 (Modelagem por MLG no "R")

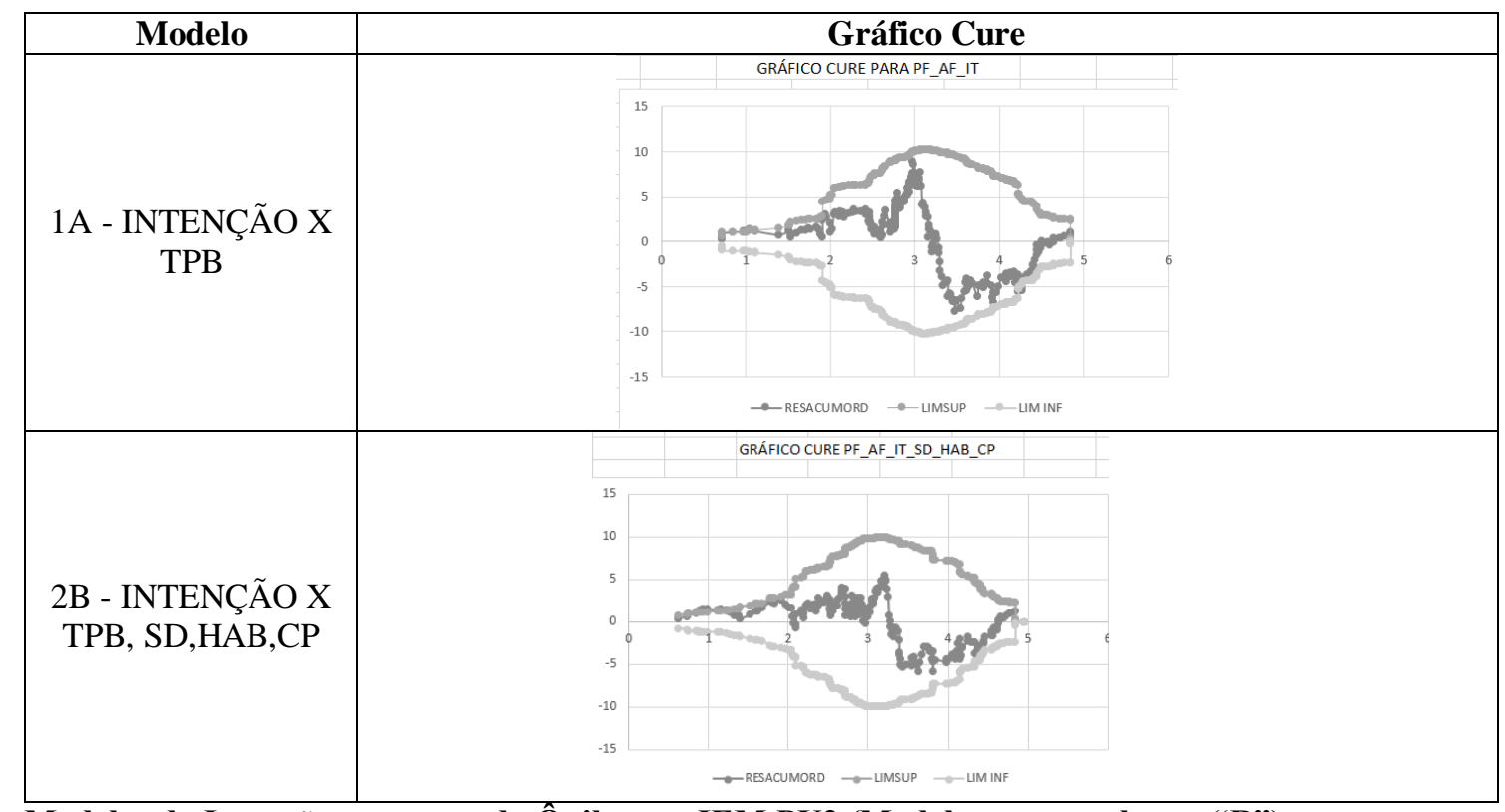

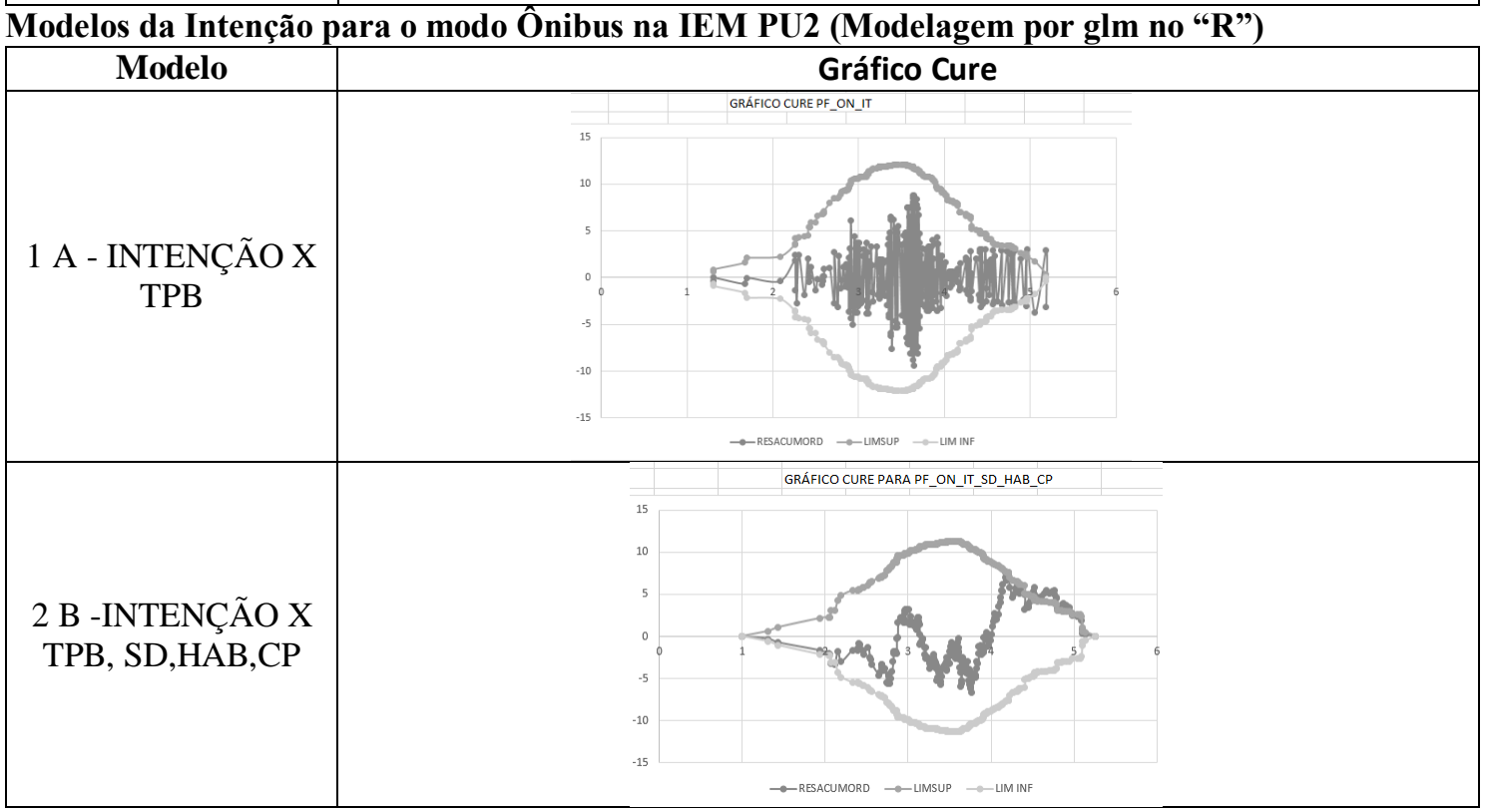

